\title{
Magnetoestratigrafía y parámetros magnéticos en sedimentos del Cenozoico tardío
}

\section{del sector Tandil-Balcarce-Mar del Plata}

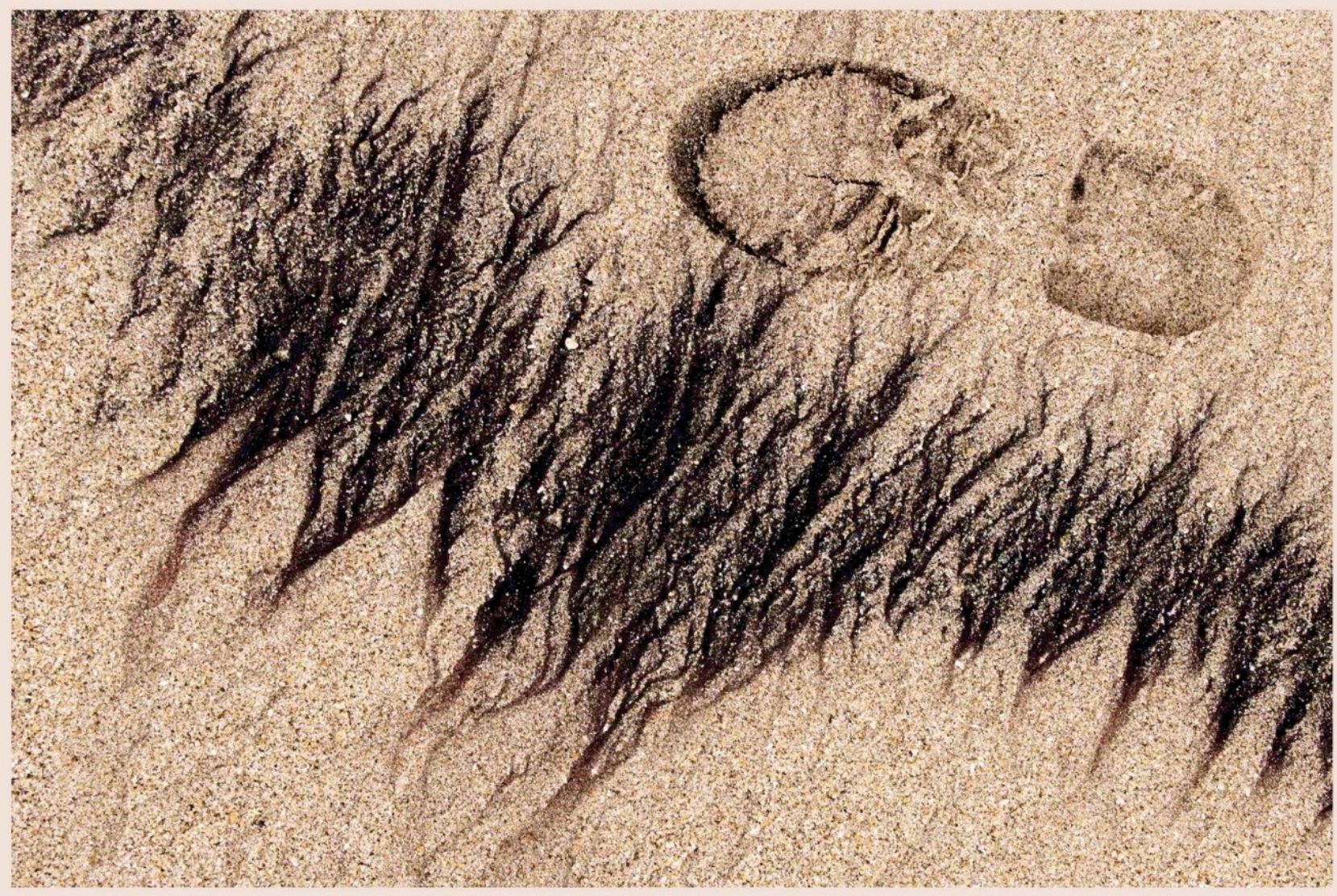

Lic. Mauro L. Gómez Samus

Director: PhD. Juan Carlos Bidegain

Co-Director: Dr. Martín A. Hurtado

Universidad Nacional de La Plata Facultad de Ciencias Naturales y Museo

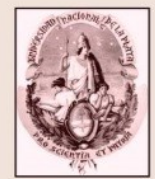





\section{A mis papás}



Subordinarse sin fin alguno a los hechos cientificos nunca es tan perjudicial como rechazarlos sin fundamentos. El primero de los casos hace surgir la imitación, útil para ciertos objetivos. El segundo produce una mentira que tiene varias y desagradables consecuencias. El primer caso vacía la atmósfera moral, la petrifica. El segundo la extermina.

Kandinsky, sobre lo espiritual en el arte. 



\section{RESUMEN}

Las sucesiones sedimentarias continentales del Cenozoico tardío contienen importante información acerca de las condiciones ambientales, así como de la evolución biológica.

El objetivo general de la presente investigación es contribuir al conocimiento cronológico, estratigráfico y sedimentológico de los depósitos del Cenozoico tardío de las Sierras de Tandil, Sierras de Balcarce y en los alrededores de Santa Clara del Mar, al norte de Mar del Plata, provincia de Buenos Aires.

El abordaje de la problemática de investigación se realizó fundamentalmente desde el Paleomagnetismo y el Magnetismo de Rocas; además, se utilizaron las técnicas convencionales de Geología, tales como análisis granulométricos, mineralógicos y químicos.

La implementación de técnicas de paleomagnetismo permitió definir zonas de magnetopolaridad en los sedimentos. Para ello se tuvieron en cuenta los antecedentes geológicos y paleontológicos, la litología y los hallazgos fosilíferos. El conjunto de datos obtenidos posibilitó el establecimiento de crones y subcrones de magnetopolaridad que se refirieron a la Escala de Inversiones Geomagnéticas. Se proponen edades mínimas y máximas para cada unidad y se elaboró una propuesta de equivalencias y correlaciones con unidades lito, alo y bioestratigráficas designadas por diversos autores a nivel regional.

Por otra parte, los parámetros de magnetismo de rocas brindan información adicional que sirve de soporte al análisis paleomagnético y al ajuste magnetoestratigráfico. Además, ofrecen la posibilidad de realizar interpretaciones referidas a las tasas de depositación, a los paleoclimas y a los paleoambientes sedimentarios. A través del análisis de estos parámetros se pudo determinar que la composición magnética dominante corresponde a especies ferrimagnéticas, tales como magnetita-titanomagnetita-maghemita. La contribución de especies antiferromagnéticas, si bien está presente, se incrementa en los niveles hidromórficos y en los paleosuelos del sector costero.

Mediante las relaciones interparamétricas se determinó que el tamaño de grano de los minerales magnéticos sería dominantemente Dominio Simple y Dominio Pseudo Simple, con cantidades variables de partículas Superparamagnéticas y Multidominio. La mayor contribución de granos magnéticos finos (Dominio Simple) se determinó en paleosuelos y suelos actuales; asimismo en paleosuelos del sector serrano y en los suelos actuales se obtuvo un incremento de partículas ultrafinas (Superparamagnéticas). 
Se obtuvieron dos comportamientos diferentes de la susceptibilidad en relación con los procesos de pedogénesis. En suelos actuales y en la mayoría de los paleosuelos del sector de Sierras de Tandil los valores de susceptibilidad se incrementaron respecto al material parental; en cambio en los paleosuelos del sector costero y de Sierras de Balcarce los valores de susceptibilidad disminuyeron en los paleosuelos. Dichos comportamientos estarían en función del tiempo de permanencia del agua durante la pedogénesis. En suelos hidromórficos, con períodos anaeróbicos relativamente prolongados, se generarían procesos que conducen a la pérdida de magnetita litogenética, mediante la oxidación secundaria. En suelos con alternancia de ciclos húmedos y secos, de corta duración y predominio de condiciones aeróbicas, se produciría la neoformación de partículas de magnetita (y/o maghemita), así como la conservación de la magnetita litogenética.

La Magnetoestratigrafía obtenida permite asignar las sucesiones estudiadas a los crones Brunhes, Matuyama, Gauss y Gilbert. El Cron Brunhes $(<0,781 \mathrm{Ma})$ es el mejor representado, y se determinó en todos los perfiles analizados. Es posible afirmar que prácticamente todas las unidades del sector costero al norte de Mar del Plata se depositaron durante este cron de Polaridad Magnética. El cron de polaridad inversa de Matuyama (0,781-2,581 Ma) estaría representado en los sedimentos del sector de Sierras de Balcarce y en la base de los acantilados marinos del barrio Felix Camet (Mar del Plata). Las edades de magnetopolaridad más antiguas corresponden a unidades sedimentarias del sector de Sierras de Tandil, donde se determinaron los crones Gauss (2,581 - 3,596 Ma) y Gilbert (3,596 - 6,033 Ma).

Las sucesiones sedimentarias del sector serrano se destacan por abarcar lapsos temporales mayores, que irían desde el Plioceno (o incluso Mioceno) hasta el Pleistoceno Tardío-Holoceno, presentando hiatus significativos. En el sector costero, a pesar de que los espesores fueron semejantes a los del sector serrano, se determinaron edades más jóvenes, que irían desde el Pleistoceno inferior y medio hasta el PleistocenoTardío-Holoceno. 


\begin{abstract}
The sedimentary continental successions of late Cenozoic in Argentina, contain relevant information referring to the environmental conditions as to the biological evolution of the past.

The aim of this research is to contribute to a better knowledge of the chronology, stratigraphy and sedimentology of the sedimentary deposits of Tandil Hills, Balcarce Hills and of the surrounding area of Santa Clara del Mar, north of Mar del Plata city, province of Buenos Aires, Argentina.

The approach to the problem was mainly performed by using paleomagnetic and rock magnetic techniques. Furthermore, conventional geological techniques such as particle size, mineralogical and chemical analysis were used.
\end{abstract}

The use of paleomagnetic techniques allowed us to define the magnetic polarity zonation as to assigne chrons and subchrons of magnetic polarity to the sedimentary sequences; taking into account, in any case, the lithology, the fossil remains, and the geological and paleontological contributions carried out in the area. The data thus obtained gave rise to the possibility of establishing a minimum and maximum age for each unit, as to propose equivalencies and correlations with litho, alo and bioestratigraphic units designated by several authors.

On the other hand, the rock magnetic parameters provide additional useful information for the paleomagnetic analysis and the stratigraphic interpretation. In addition, they offer the possibility of interpretations relating to the rates of deposition, paleoclimate and sedimentary paleoenvironments. By the analysis and interpretation of the behavioral of parameters, it was possible to determine that the dominant magnetic composition are the ferromagnetic magnetites, titanomagnetites and maghemites. Although the contribution of antiferromagnetic minerals is always present, it increases in hydromorphic levels and paleosols of the coastal sector.

Through the interparametric ratios it was possible to establish that the magnetic grain size would correspond mainly to Single Domain and Pseudo Single Domain, with varying amounts of Superparamagnetic and Multidomain particles. The greatest presence of fine magnetic grains (Single Domain) was determined in all of the (paleo)soils while in paleosols of the hills and in recent soils increases the ultrafine particles (Superparamagnetic).

Two different behaviors of magnetic susceptibility were detected. In recent soils and paleosols of Tandil Hills the magnetic susceptibility values increases in relation to the parent material ones; 
conversely, susceptibility values are lower in the paleosols than in the parent material of coastal sector and in Balcarce hills. The latter, would be assigned to the time of permanence of the water during the pedogenesis. Longer periods give rise to hydromorphic horizons that under anaerobic conditions favors the loss or alteration of the litogenetic magnetite, by secondary oxidation. The type and behavior of iron oxides change noteworthy in soils developed below alternates wet and dry cycles, of short duration, and aerobic conditions. In such cases, the conservation of lithogenetic magnetite is more frequent and new particles (of magnetite or maghemite) can be formed.

The obtained Magnetostratigraphy allows to assign the studied successions to the Brunhes, Matuyama, Gauss, and Gilbert chrons. Brunhes chron $(<0.781 \mathrm{Ma})$ was determined in all analyzed profiles. It is possible to say that virtually all units in the coastal sector North of Mar del Plata were deposited during this chron of magnetic polarity. The Matuyama chron $(0.781-2.581 \mathrm{Ma})$ is recorded in Balcarce Hills and at the base of the sea cliffs in the Felix Camet neighborhood (Mar del Plata). The oldest ages correspond to the sedimentary units of Tandil Hills area, where Gauss (2,581 - 3,596 Ma) and Gilbert (3.596 - 6.033 Ma) chrons seem to be represented.

The sedimentary sequences in the hill range of Tandil cover a greater time intervals than those of the coastal area. The former seems to represent a time spanning the Pliocene (or even late Miocene) until the Pleistocene and recent Holocene. The coastal area, although showing sedimentary sequence with similar thickness than those of the hills, were deposited in younger times, spanning the lower-middle Pleistocene to the late Pleistocene and Holocene. 


\section{INDICE}

CAPÍTULO 2. GENERALIDADES

2.1 Comportamiento magnético de los materiales $\quad 5$

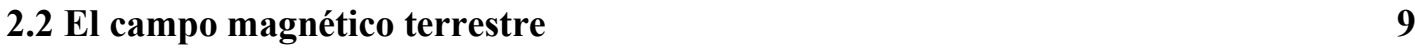

2.3 Registro del campo magnético terrestre en las rocas 11

$\begin{array}{ll}\text { 2.4 Magnetoestratigrafía } & 13\end{array}$

$\begin{array}{ll}2.5 \text { Magnetismos de rocas } & 13\end{array}$

$\begin{array}{lr}\text { 2.6 Figuras del Capítulo 2 } & 21\end{array}$

$\begin{array}{ll}\text { 2.7 Tablas del Capítulo 2 } & 35\end{array}$

CAPÍTULO 3. ANTECEDENTES GEOLÓGICOS Y ESTRATIGRÁFICOS 37

$\begin{array}{lc}\text { 3.1 Características generales del área } & 38\end{array}$

$\begin{array}{ll}3.1 .1 \text { Geomorfología } & \mathbf{3 8}\end{array}$

$\begin{array}{ll}3.1 .2 \text { Clima } & \mathbf{4 0}\end{array}$

3.1.3 Vegetación $4 \mathbf{4 1}$

$\begin{array}{ll}\text { 3.1.4 Suelos } & 41\end{array}$

3.2 Estratigrafía general de la provincia geológica de Tandilia 42

3.3 Estratigrafía de los depósitos continentales del Cenozoico tardío 43

3.3.1 Bioestratigrafía $\quad 45$

3.3.2 Magnetoestratigrafía $\quad 46$

3.3.3 Registro de las glaciaciones en América del Sur $\quad 46$

$\begin{array}{ll}\text { 3.3.4 Magnetismo ambiental } & \mathbf{4 7}\end{array}$

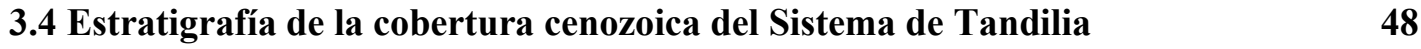


$\begin{array}{ll}3.4 .1 \text { Sector serrano } & \mathbf{4 8}\end{array}$

3.4.2 Sector costero $\quad \mathbf{5 3}$

$\begin{array}{ll}3.5 & \text { Figuras del capítulo } 3 \\ & 61\end{array}$

$\begin{array}{lr}\text { 3.6 Tablas del capítulo } 3 & 69\end{array}$

CAPÍTULO 4. TÉCNICAS Y HERRAMIENTAS

$\begin{array}{ll}\text { 4.1 Secciones estratigráficas } & 73\end{array}$

4.2 Perfiles paleomagnéticos, medición y procesado $\quad 74$

$\begin{array}{ll}\text { 4.3 Medición de parámetros magnéticos } & 77\end{array}$

4.4 Análisis químico $\quad 79$

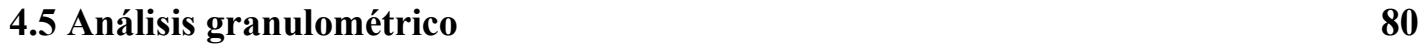

4.6 Análisis mineralógico $\quad 82$

$\begin{array}{ll}\text { 4.7 Figuras del capítulo } 4 & 85\end{array}$

4.8 Tabla del capítulo $4 \quad 91$

$\begin{array}{ll}\text { CAPÍTULO 5. SECCIONES ESTRATIGRÁFICAS } & 93\end{array}$

$\begin{array}{lc}\text { 5.1 Sector Sierras de Tandil } & 93\end{array}$

5.1.1 Sección estratigráfica Villa Cacique (PVC) 93

5.1.2 Sección estratigráfica María Ignacia (PMI) $\quad 97$

5.1.3 Sección estratigráfica Calle Fangio (PCF) 99

5.1.4 Sección estratigráfica Circuito Turístico (PCT) 101

$\begin{array}{ll}\text { 5.2 Sector Sierras de Balcarce } & 101\end{array}$

5.2.1 Sección estratigráfica San Manuel (PSM) 102

5.2.2 Sección estratigráfica Ramos Otero (PRO) 103

5.2.3 Sección estratigráfica Sierra Bachicha (PSB) $\quad 104$

5.2.4 Sección estratigráfica Cerro Quebracho (PCQ) $\quad 106$ 
$\begin{array}{lr}\text { 5.3 Sector costero al norte de Mar del Plata } & 107\end{array}$

$\begin{array}{ll}\text { 5.3.1 Sección estratigráfica GADA (PGA) } & \mathbf{1 0 7}\end{array}$

5.3.1 Sección estratigráfica Playa Dorada (PPD) $\quad \mathbf{1 0 9}$

5.3.2 Sección estratigráfica El Casal (PEC) $\quad \mathbf{1 1 1}$

5.3.4 Sección estratigráfica Santa Elena (PSE) 113

$\begin{array}{ll}\text { 5.4 Perfiles de suelos actuales } & 114\end{array}$

$\begin{array}{lr}\text { 5.4.1 Suelo actual en la sección PVC } & \mathbf{1 1 4}\end{array}$

5.4.2 Suelo actual en la sección PMI $\quad \mathbf{1 1 5}$

5.4.3 Suelo actual en la sección PCF $\quad \mathbf{1 1 6}$

$\begin{array}{ll}\text { 5.4.4 Suelo actual en la sección PCT } & \mathbf{1 1 7}\end{array}$

$\begin{array}{lr}\text { 5.4.5 Suelo actual en la sección PRO } & \mathbf{1 1 8}\end{array}$

$\begin{array}{lr}5.5 \text { Consideraciones de importancia } & 119\end{array}$

5.5.1 Correlación preliminar en el sector Sierras de Tandil $\mathbf{1 1 9}$

$\begin{array}{ll}\text { 5.5.2 Correlación preliminar en el sector Sierras de Balcarce } & \mathbf{1 2 1}\end{array}$

5.5.3 Correlación preliminar en el sector Costero al norte de Mar del Plata $\quad \mathbf{1 2 3}$

5.5.4 Correlación preliminar en el sector Tandil-Balcarce-Mar del Plata $\quad \mathbf{1 2 5}$

$\begin{array}{lr}5.6 \text { Figuras del capítulo } 5 & 127\end{array}$

$\begin{array}{ll}5.7 \text { Tablas del capítulo 5 } & 201\end{array}$

CAPÍTULO 6. ANÁLISIS GRANULOMÉTRICO Y MINERALOGÍA 205

$\begin{array}{ll}\text { 6.1 Análisis granulométrico } & 205\end{array}$

6.1.1 Análisis granulométrico en el sector serrano $\quad \mathbf{2 0 5}$

6.1.2 Análisis granulométrico en el sector costero al norte de Mar del Plata $\quad \mathbf{2 0 8}$

$\begin{array}{lr}\text { 6.2 Mineralogía } & 209\end{array}$

6.2.1 Observaciones en microscopio de luz transmitida $\quad 209$

$\begin{array}{ll}\text { 6.2.2 Difracción de Rayos X } & \mathbf{2 1 1}\end{array}$ 
$\begin{array}{lr}6.3 \text { Figuras del capítulo } 6 & 213\end{array}$

$\begin{array}{lr}\text { 6.4 Tablas del capítulo } 6 & 225\end{array}$

CAPÍTULO 7. ANÁLISIS QUÍMICO 229

$\begin{array}{ll}\text { 7.1 Análisis químico en el sector Sierras de Tandil } & 229\end{array}$

7.1.1 Química sección Villa Cacique (PVC) 229

7.1.2 Química sección María Ignacia (PMI) 230

7.1.3 Química sección Calle Fangio (PCF) 231

7.1.4 Química sección Circuito Turistico (PCT) 232

7.2 Análisis químico en el sector Sierras de Balcarce 232

7.2.1 Química sección San Manuel (PSM) 202

7.2.2 Química sección Ramos Otero (PRO) 233

7.2.3 Química sección Sierra Bachicha (PSB) 233

7.2.4 Química sección Cerro Quebracho (PCQ) 235

7.3. Análisis químico en el sector costero al norte de Mar del Plata 235

7.3.1 Química sección GADA (PGA) $\mathbf{2 3 5}$

7.3.2 Química sección Playa Dorada (PPD) 236

$\begin{array}{ll}\text { 7.3.3 Química sección El Casal (PEC) } & \mathbf{2 3 7}\end{array}$

$\begin{array}{ll}\text { 7.3.4 Química sección Santa Elena (PSE) } & \mathbf{2 3 7}\end{array}$

7.4 Caracterización química de las unidades litoestratigráficas del sector serrano 238

7.5 Caracterización química de las asociaciones de unidades del

$\begin{array}{lr}\text { sector costero al norte de Mar del Plata } & 238\end{array}$

$\begin{array}{lr}\text { 7.6 Consideraciones de importancia } & 239\end{array}$

$\begin{array}{ll}7.7 \text { Figuras del capítulo } 7 & 241\end{array}$

$\begin{array}{lc}\text { 7.8 Tablas del capítulo } 7 & 253\end{array}$ 
8.1 Perfiles paleomagnéticos en el sector Sierras de Tandil 255

8.1.1 Perfiles paleomagnéticos en la sección Villa Cacique (PVC) 255

8.1.2 Perfil paleomagnético en la sección María Ignacia (PMI) 259

8.1.3 Perfiles paleomagnéticos en la sección Calle Fangio (PCF) 261

8.1.4 Perfil paleomagnético en la sección Circuito Turístico (PCT) 263

$\begin{array}{ll}\text { 8.2 Perfiles paleomagnéticos en el sector Sierras de Balcarce } & 263\end{array}$

8.2.1 Perfiles paleomagnéticos en la sección San Manuel (PSM) $\quad 263$

8.2.2 Perfil paleomagnético en la sección Ramos Otero (PRO) $\mathbf{2 6 5}$

8.2.3 Perfiles paleomagnéticos en la sección Sierra Bachicha (PSB) 266

8.2.4 Perfil paleomagnético en la sección Cerro Quebracho (PCQ) 268

8.3 Perfiles paleomagnéticos en el sector costero al norte de Mar del Plata $\quad 269$

8.3.1 Perfiles paleomagnéticos en la sección GADA (PGA) $\mathbf{2 6 9}$

8.3.2 Perfil paleomagnético en la sección Playa Dorada (PPD) $\mathbf{2 7 0}$

8.3.3 Perfil paleomagnético en la sección El Casal (PEC) 271

8.3.4 Perfil paleomagnético en la sección Santa Elena (PSE) 273

$\begin{array}{lr}\text { 8.4 Consideraciones de importancia } & 274\end{array}$

8.4.1 Magnetoestratigrafía en el sector Sierras de Tandil $\mathbf{2 7 4}$

8.4.2 Magnetoestratigrafía en el sector Sierras de Balcarce $\mathbf{2 7 5}$

8.4.3 Magnetoestratigrafía en el sector costero al norte de Mar del Plata $\quad 276$

8.4.4. Magnetoestratigrafía en el sector Tandil-Balcarce-Mar del Plata $\quad 277$

$\begin{array}{lr}\text { 8.6 Figuras del capítulo } 8 & 283\end{array}$

$\begin{array}{lr}\text { 8.7 Tablas del capítulo } & 321\end{array}$ 
CAPÍTULO 9. PARÁMETROS MAGNÉTICOS Y MAGNETISMO DE ROCAS

9.1 Descripción de los parámetros magnéticos

9.1.1 Parámetros magnéticos en el sector Sierras de Tandil

326

9.1.2 Parámetros magnéticos en el sector Sierras de Balcarce

331

9.1.3 Parámetros magnéticos en el sector costero al norte de Mar del Plata

9.2 Caracterización magnética de los sedimentos del Cenozoico tardío

del sector Tandil-Balcarce-Mar del Plata

9.2.1 Mineralogía magnética

9.2.2 Tamaño de grano magnético

9.2.3 Ciclos de histéresis

9.2.4 Relación entre los parámetros magnéticos y el contenido de Hierro

9.2.5 Caracterización magnética de las unidades litoestratigráficas

del sector serrano

9.2.6 Caracterización magnética de las asociaciones de unidades

del sector costero

350

9.5 Consideraciones de importancia

352

9.6 Figuras del capítulo 9

359

9.7 Tabla del capítulo 9

385

\section{CAPÍTULO 10. AMBIENTES, EDADES, EQUIVALENCIAS Y CORRELACIONES DE LOS SEDIMENTOS DEL CENOZOICO TARDÍO DEL SECTOR TANDIL-BALCARCE-MAR DEL PLATA}


$\begin{array}{ll}\text { BIBLIOGRAFÍA } & 407\end{array}$

$\begin{array}{ll}\text { 13.1 Artículos citados en el texto } & 407\end{array}$

13.2 Difusión de los resultados 429 



\section{CAPÍTULO 1. INTRODUCCIÓN}

El presente trabajo de tesis se presenta como parte de los requisitos para optar al grado académico de Doctor en Ciencias Naturales, de la Universidad Nacional de la Plata. El mismo contiene los resultados obtenidos en investigaciones llevadas a cabo en el Laboratorio de Entrenamiento Multidisciplinario para la Investigación Tecnológica (LEMIT) durante el período comprendido entre abril del año 2011 y febrero del 2016, bajo la dirección del Doctor Juan Carlos Bidegain y la co-dirección del Doctor Martín Adolfo Hurtado.

Buena parte de los resultados obtenidos fueron publicados en revistas, congresos y jornadas de la especialidad, tanto en el ámbito nacional como internacional. El listado de los mismos se detalla en el apartado "Difusión de los resultados” del Capítulo 13.

El objetivo general de la presente investigación es contribuir al conocimiento cronológico, estratigráfico y sedimentológico de los depósitos del Cenozoico tardío del sector Tandil-Balcarce-Mar del Plata.

El abordaje de la problemática estratigráfica y de asignación de edad de los depósitos estudiados se realizó fundamentalmente desde el Paleomagnetismo y el Magnetismo de Rocas, esto sustentado en una minuciosa labor de campo. Además se utilizaron técnicas convencionales de Geología tales como análisis granulométricos, mineralógicos y químicos.

Toda la labor de muestreo se sustentó en el análisis de campo, que posibilitó la realización de paneles y columnas sedimentarias. Se analizaron un total de 12 secciones estratigráficas; 4 en el sector de Sierras de Tandil, 4 en el sector de Sierras de Balcarce y 4 en el sector costero al norte de Mar del Plata.

Las técnicas de paleomagnetismo fueron utilizadas a los fines de identificar zonas de distinta polaridad magnética en las sucesiones sedimentarias. Éstas, que pueden ser de polaridad normal o inversa, son referidas a Crones y Sub-Crones de la Escala Internacional de Inversiones del Campo Magnético Terrestre, a fin de establecer la edad de los sedimentos. La utilización de técnicas paleomagnéticas con fines cronológicos se conoce como Magnetoestratigrafía. Esto es posible debido a que las partículas magnéticas tienen la particularidad de orientarse y re-orientarse entre partículas no magnéticas durante y luego de la depositación. Con la compactación y la cementación del material, dichas partículas quedan bloqueadas en la dirección del campo magnético terrestre. Buen número de trabajos científicos en distintas regiones loéssicas del mundo (China, Europa, Rusia, Alaska, Argentina) confirman la existencia de 
registros paleomagnéticos de polaridad normal e inversa que han sido referidos a crones y subcrones de magnetopolaridad (Kukla et al., 1988; Maher y Thompson, 1991; Chlachula et al., 1997; Bidegain, 1991, entre otros). Los estudios magnetoestratigráficos en sedimentos neógeno-cuaternarios de la Argentina comenzaron en la década del 80. Las principales contribuciones se refieren a la provincia de Buenos Aires (Nabel y Valencio, 1981; Valencio y Orgeira, 1983; Orgeira y Valencio, 1984; Bobbio et al., 1986; Orgeira, 1988, 1990; Ruocco, 1990; Bidegain, 1991, 1998; Nabel et al., 1993; entre otros). Posteriormente, fueron publicados numerosos trabajos, cuyos resultados contribuyen a construir el campo gnoseológico, metodológico y técnico de la disciplina.

Las técnicas de magnetismo de rocas, que involucran el análisis de parámetros magnéticos de los minerales, brindan información adicional que sirven de soporte al análisis paleomagnético y al ajuste de la magnetoestratigráfica. La metodología se aplica por primera vez en la región y las herramientas, novedosas, son de utilidad en la interpretación de distintos procesos naturales. Actualmente se utilizan en la diferenciación del comportamiento magnético de los minerales de las rocas y sedimentos detríticos, de los suelos y de las partículas atmosféricas de origen natural, o producidas por la actividad humana. El análisis y posterior interpretación de los distintos comportamientos de los parámetros utilizados permite realizar inferencias respecto de los procesos depositacionales y post-depositacionales, que se vinculan a las tasas de depositación, a paleoclimas y paleoambientes, así como las variaciones que presentan a lo largo del tiempo. Por otra parte, las técnicas magnéticas permiten diferenciar los minerales de hierro de los sedimentos a partir del carácter para-, anti- o ferri-magnético de los mismos. El hierro es un elemento muy abundante en la corteza terrestre y en los sedimentos puede formar parte de los silicatos, óxidos e hidróxidos, tener buena forma cristalina o ser amorfo, ser estable o metaestable. La investigación mediante aplicación de técnicas de magnetismo de rocas en sedimentos del Cuaternario de Argentina se ha referido a la diferenciación del par loess/paleosuelo y los parámetros magnéticos se han utilizado en interpretaciones paleoambientales y paleoclimáticas (Vásquez et al., 1998; Orgeira et al., 1998; Bidegain et al., 2001, 2005, 2007, 2009; entre otros).

En el próximo capítulo se presentarán los conceptos básicos de las disciplinas involucradas en la presente investigación. Se exponen conceptos referidos al comportamiento magnético de los materiales, a las características del campo magnético terrestre, al paleomagnetismo y la magnetoestratigrafía, como así también a los parámetros de magnetismo de rocas, haciendo hincapié en los determinados en este trabajo.

En el Capítulo 3 se sintetiza el estado del conocimiento en cuanto al medio, principalmente físico, del área de estudio. Esto comprende geomorfología, clima, vegetación, suelos y estratigrafía. 
En el Capítulo 4 se indican las técnicas y herramientas utilizadas en el trabajo de gabinete, de campo y laboratorio.

El análisis y la exposición de los resultados obtenidos se efectúan en los capítulos 5 a 9. La integración y discusión de los resultados obtenidos se realiza en forma incremental a medida que avanzan los capítulos.

El Capítulo 5 se refiere a los resultados obtenidos en el trabajo de campo; de cada sección estratigráfica se presenta el contexto geomorfológico, la descripción detallada de cada una de las unidades litológicas, los paneles y las columnas sedimentarias. Hacia el final del capítulo se realiza una correlación tentativa entre las distintas unidades $\mathrm{y}$, en la medida de lo posible, las asignaciones a unidades litoestratigráficas designadas por otros autores.

En el Capítulo 6 se exponen los resultados de los análisis granulométricos y mineralógicos efectuados en muestras de sedimentos del área de estudio.

El Capítulo 7 corresponde al análisis químico; este incluyó la determinación de pérdida por calcinación, carbonato de calcio y hierro total.

El Capítulo 8 brinda la información sobre el análisis paleomagnético y magnetoestratigráfico. En la primera parte se analizan los resultados de cada sección estratigráfica, hacia el final del capítulo, se realiza la correlación magnetoestratigráfica entre las distintas secciones y se establecen edades mínimas y máximas para cada unidad.

En el Capítulo 9 se exponen los resultados de los parámetros magnéticos. En la primera parte se presentan y analizan los resultados de cada sección estratigráfica. Luego se realiza un análisis en conjunto y se establece la composición magnética dominante y el tamaño de grano magnético. También se presenta un análisis de los parámetros magnéticos y se los relaciona con el contenido de hierro total.

En los capítulos 10 y 11 se exponen los principales aportes al conocimiento generados en este trabajo de tesis.

En el capítulo 10 se expone para cada unidad estratigráfica determinada el probable ambiente de depositación, así como los procesos postdepositacionales que la afectaron; se indican las edades mínimas y máximas atribuidas, $\mathrm{y}$ se proponen equivalencias y correlaciones con unidades lito, alo y bioestratigráficas designadas por distintos autores, especialmente en el marco de la provincia Geológica de Tandilia. 
Finalmente, en el capítulo 11 se presentan las conclusiones generales, destacando los aportes originales del presente trabajo de tesis. 


\section{CAPITULO 2.GENERALIDADES}

En este capítulo se exponen conceptos referidos al comportamiento magnético de los materiales, a las características del campo magnético terrestre, al paleomagnetismo y la magnetoestratigrafía, como así también a los parámetros de magnetismo de rocas y el magnetismo paleoambiental. Debido a que se trata de conceptos básicos, aceptados ampliamente por la comunidad científica y constituyen los fundamentos teóricos (paradigma) de la disciplina, se ha evitado, a fin de simplificar la lectura, la mención excesiva de citas bibliográficas. El capítulo se basa principalmente en los libros de texto de los siguientes autores: Valencio (1980), Tarling (1983), Butler (1992), Opdyke y Channel (1996), Walden et al. (1999), Evans y Heller (2003), Tauxe $(2002,2010)$ y Gubbins y Herrero-Barbera (2007).

\subsection{Comportamiento magnético de los materiales.}

Todas las sustancias naturales poseen propiedades magnéticas, cuyo origen se encuentra fundamentalmente en los átomos que las constituyen. El momento magnético de un átomo, desde un punto de vista clásico, se origina a partir de dos tipos de movimientos de sus electrones: el movimiento de spin alrededor de su propio eje y el movimiento orbital alrededor del núcleo del átomo.

Puesto que el electrón produce un campo magnético con su movimiento orbital se lo puede considerar equivalente a un imán, y sus propiedades magnéticas se pueden expresar en función del momento magnético. De modo similar es posible hablar del momento magnético del movimiento de spin. El momento magnético de un átomo resulta de ambos momentos magnéticos (orbital y de spin) de todos los electrones que lo componen. Los electrones están ordenados alrededor del núcleo en capas y subcapas sucesivas. Cada subcapa puede albergar un número limitado de electrones, y ese número, cuando la subcapa está llena, es par. Varios tipos de comportamiento pueden reconocerse en función de la configuración electrónica de las sustancias.

En los átomos que tienen sus subcapas completas, los spines de los electrones se distribuyen en forma antiparalela. De este modo, los momentos magnéticos debidos al spin se equilibran y anulan perfectamente unos con otros. Por lo tanto el momento magnético del átomo es cero. Cuando una sustancia de esta clase se coloca en un campo magnético inductor, la dirección de los momentos magnéticos orbitales cambia ligeramente, orientándose, en sentido contrario al campo magnético aplicado. A causa de este cambio, la sustancia en cuestión adquiere una magnetización inducida $(\mathrm{M})$ de sentido 
opuesto al campo magnético aplicado (H) (Fig. 2.1); este fenómeno es conocido como diamagnetismo. Los minerales con comportamiento diamagnético más comunes son: cuarzo $\left(\mathrm{SiO}_{2}\right)$, calcita $\left(\mathrm{CaCO}_{3}\right)$, plagioclasas $\left(\mathrm{NaAl}_{3} \mathrm{O}_{8}-\mathrm{CaAl}_{2} \mathrm{Si}_{2} \mathrm{O}_{8}\right)$ y feldespatos potásicos $\left(\mathrm{KAl}_{2} \mathrm{Si}_{2} \mathrm{O}_{8}\right)$.

En otras substancias las subcapas electrónicas están incompletas de tal modo que los momentos magnéticos debidos al movimiento de spin no se contrarrestan por completo, y el átomo posee un momento magnético neto. Normalmente, sin embargo, los átomos poseen cierta energía térmica y están constantemente vibrando y girando al azar. A causa de esta agitación térmica, los momentos magnéticos de los átomos también se orientan al azar. Por lo tanto el cuerpo no tiene, en conjunto, momento magnético resultante en una dirección determinada. Cuando tal sustancia se coloca en un campo magnético $(\mathrm{H})$, los momentos magnéticos de los átomos tienden a orientarse en la dirección del campo, pero a esta tendencia se opone la agitación térmica de los mismos átomos, y la orientación no es perfecta. De ahí que la sustancia en cuestión adquiera una magnetización (M) muy débil en el sentido de H (Fig. 2.1). Este fenómeno es el paramagnetismo. Los minerales paramagnéticos más comunes son: piroxenos $\left[(\mathrm{Mg}, \mathrm{Fe}) \mathrm{SiO}_{3}\right]$, biotita $\left[\mathrm{K}(\mathrm{Mg}, \mathrm{Fe})_{3} \mathrm{AlSi}_{3} \mathrm{O}_{10}(\mathrm{OH})_{2}\right]$ y anfíboles $\left[\mathrm{Ca}_{2}(\mathrm{Mg}, \mathrm{Fe})_{5} \mathrm{Si}_{8} \mathrm{O}_{22}(\mathrm{OH})_{2}\right]$.

El ferromagnetismo es sólo posible cuando los átomos se influyen unos a otros forzándose a orientar sus momentos magnéticos en forma paralela. Esto se denomina interacción autoalineadora y se produce en sustancias que poseen sus átomos muy cercanos y regularmente espaciados, normalmente compuestos de metales de transición tales como Fe, Co, Ni. En estas sustancias los momentos magnéticos se alinean espontáneamente, con ordenamientos que pueden tener diferentes configuraciones (Fig. 2.2). En un cristal, la magnetización espontánea normalmente se produce en una dirección particular con respecto a los ejes cristalográficos y constituye la dirección de fácil magnetización.

En el caso de los metales, todos los electrones desapareados se acoplan paralelamente, resultando en una fuerte magnetización (Fig. 2.2a), este es el caso de los materiales ferromagnéticos en sentido estricto, como por ejemplo hierro metálico $(\alpha \mathrm{Fe})$, híquel $(\mathrm{Ni})$, cobalto $(\mathrm{Co})$ y cromo $(\mathrm{Cr})$. En los óxidos de estos metales, alternan celdas magnetizadas en dirección opuesta, de modo que sus momentos magnéticos se cancelan unos a otros (Fig. 2.2b). Si, en cambio, los momentos magnéticos de las subceldas son desiguales existirá una magnetización espontánea neta (Fig. 2.2c), este es el comportamiento de los minerales ferrimagnéticos, como magnetita $\left(\mathrm{Fe}_{3} \mathrm{O}_{4}\right)$, titanomagnetita $\left(\mathrm{Fe}_{3} \mathrm{O}_{4}-\mathrm{Fe}_{2} \mathrm{TiO}_{4}\right)$, maghemita $\left(\gamma \mathrm{Fe}_{2} \mathrm{O}_{3}\right)$, pirrotita $\left(\mathrm{Fe}_{7} \mathrm{~S}_{8}\right)$ y greigita $\left(\mathrm{Fe}_{3} \mathrm{~S}_{4}\right)$, entre otros. Cuando el arreglo no es perfectamente antiparalelo, existirá una pequeña magnetización espontánea remanente (Fig. 2.2d), esto sucede en los minerales antiferromagnéticos imperfectos como por ejemplo hematita $\left(\alpha \mathrm{Fe}_{2} \mathrm{O}_{3}\right)$ y goethita $(\alpha \mathrm{FeOOH})$. 
Las sustancias ferromagnéticas (en sentido amplio) se diferencian de las diamagnéticas y las paramagnéticas no sólo en la intensidad de magnetización, sino en la perdurabilidad de la misma. Al hacer desaparecer el campo inductor, los cuerpos diamagnéticos y paramagnéticos pierden por completo su magnetización, en tanto que un cuerpo ferromagnético (en sentido amplio) la retiene en gran parte. El magnetismo que queda en un cuerpo ferromagnético después de cesar la acción del campo que lo ha inducido se llama magnetización remanente (MR).

Además de los arreglos atómicos ya mencionados, dentro de las sustancias ferromagnéticas (en sentido amplio) pueden ser identificados otros tipos de organizaciones denominados dominios magnéticos. Un dominio es una región dentro del cristal, en la que los momentos magnéticos de los átomos están orientados en una misma dirección, aunque esta dirección difiere de la de los dominios vecinos (Fig. 2.3a). Los límites entre dominios constituyen las paredes de dominios o paredes de Bloch, en las cuales los momentos magnéticos rotan progresivamente desde la dirección de un dominio a la dirección del dominio vecino (Fig. 2.3a). Los dominios magnéticos permiten a la partícula obtener un estado de energía magnética total mínima. La energía magnética total de una sustancia es la suma de, entre otras, la energía de anisotropía, la energía magneto-estática y la energía de la pared de dominio.

La energía magneto-cristalina o de anisotropía es la energía que en un cristal ferromagnético (en sentido amplio) produce una magnetización que se orienta preferentemente a lo largo de los ejes cristalográficos de fácil magnetización.

Una partícula homogéneamente magnetizada actúa como un pequeño dipolo y crea un campo magnético externo importante (Fig. 2.3b). La energía magnetoestática es la energía potencial magnética de un material ferromagnético debida al campo magnético externo generado. La energía requerida para mantener este campo puede ser sustancial para partículas relativamente grandes. De este modo, cuando se produce la división en dominios, la energía magnetoestática y el campo magnético externo de una partícula magnetizada se reducen significativamente (Fig. 2.3c).

Cuando más de dos dominios están presentes, la energía magneto-estática es igual a 0 (cero) debido a la aparición de los denominados dominios de cierre, con ángulos de los límites triangulares con la magnetización igual a $45^{\circ}$; no hay campo magnético externo asociado (Fig. 2.4 a y b).

Esta auto-subdivisión en numerosos dominios no continúa indefinidamente debido a que la región de transición entre dominios requiere energía para generarse y mantenerse (energía de pared de dominio). De este modo, existe un número de dominios de equilibrio que se alcanzarán para un tamaño dado de 
partícula. Dicha configuración de dominios en equilibrio se alcanza cuando la suma de las energías magneto-estrictivas, magneto-estáticas y de las paredes de Bloch alcanza un mínimo.

La posición de las paredes de dominio en una partícula es determinada por defectos cristalinos e irregularidades de la superficie de la misma y corresponden a posiciones de mínima energía.

Partículas minerales que contienen sólo un dominio se denominan partículas dominio simple (DS); mientras que partículas que contienen muchos dominios son llamadas multidominio (MD). Las partículas MD tienden a ser fácilmente magnetizadas y su remanencia puede ser fácilmente alterada. En las partículas DS la remanencia es más "difícil" de cambiar, por lo que las mismas son apropiadas para obtener los registros del campo magnético terrestre del pasado geológico.

Entre las partículas DS y partículas MD, existe una configuración intermedia denominada dominio pseudo simple (DPS). La transición entre partículas DS y MD es gradual, de modo que partículas con pocos dominios tienen propiedades magnéticas intermedias entre partículas DS y MD.

Finalmente, puede distinguirse un cuarto comportamiento magnético denominado superparamagnetismo (SP). Cuando las partículas son muy pequeñas $(<0,03$ micrómetros) también son partículas dominio simple, aunque muestran propiedades únicas debido al tamaño. Estas partículas poseen vibraciones térmicas a temperatura ambiente con energías del mismo orden de magnitud que su energía magnética. Por lo tanto, no guardan la memoria o remanencia magnética ya que los tiempos de relajación son mucho más cortos que los tiempos necesarios para medir la remanencia. Actúan como partículas paramagnéticas, aunque debido a que adquieren magnetizaciones muy fuertes se denominan superparamagnéticas. En partículas ligeramente mayores a SP, el tiempo de relajación es tal que el descenso de la remanencia puede ser medido, originando el fenómeno de viscosidad magnética. Estas partículas se denominan dominio simple viscoso (DSV). Ligeramente por encima, existen granos DS que tienen tiempos de relajación tan largos que la remanencia es totalmente estable (Fig. 2.5).

La mayoría de los minerales de interés en magnetismo de rocas son óxidos de hierro y titanio que forman parte de un sistema ternario cuyos miembros finales son $\mathrm{FeO}-\mathrm{Fe}_{2} \mathrm{O}_{3}-\mathrm{TiO}_{2}$ (Fig. 2.6). Los principales minerales que corresponden a la señal magnética se ubican en el sector del diagrama comprendido entre magnetita-ulvoespinela-ilmenita-hematita. Estas cuatro especies minerales corresponden a los miembros finales de dos series de soluciones sólidas: la serie de ulvoespinela $\left(\mathrm{Fe}_{2} \mathrm{TiO}_{4}\right)$-magnetita $\left(\mathrm{Fe}_{3} \mathrm{O}_{4}\right)$, denominada serie de las titanomagnetitas y la serie ilmenita $\left(\mathrm{FeTiO}_{3}\right)$ hematita $\left(\mathrm{Fe}_{2} \mathrm{O}_{3}\right)$, denominada serie de las ilmenohematitas o titanohematitas. 
En la serie de las titanomagnetitas, de forma cristalina cúbica, el $\mathrm{Fe}^{+3}$ de la magnetita es reemplazado por $\mathrm{Fe}^{+2} \mathrm{y} \mathrm{Ti}^{+4}$. El Ti no posee electrones desapareados, por lo que no presenta momento magnético alguno. Esto conduce a un suave descenso de la magnetización espontánea a medida que la cantidad de Ti sustituido se incrementa y significa que el miembro correspondiente a ulvospinela es antiferromagnético. La oxidación de titano-magnetita genera productos no estequiométricos y metaestables a temperatura ambiente. Cuando el proceso se produce a bajas temperaturas se denomina maghemitización, puesto que el miembro final de oxidación es la maghemita.

En la serie de las titanohematitas, de forma cristalina romboédrica, el Fe es reemplazado por Ti. Por cada $\mathrm{Ti}^{+4}$ adicionado, uno de los remanentes de $\mathrm{Fe}^{+3}$ es convertido en $\mathrm{Fe}^{+2}$. Ambos miembros finales, ilmenita y hematita, son antiferromagnéticos, mientras que composiciones ricas en Ti en la serie, son paramagnéticas.

\subsection{El campo magnético terrestre.}

El campo magnético terrestre (CMT) en la actualidad es un 99\% de origen interno, es decir que se origina en la Tierra. El 1\% restante tiene origen fuera del planeta (viento solar, radiaciones, ionización). El 95\% del campo total se puede describir como un dipolo, cuyos polos geomagnéticos se ubican actualmente $80^{\circ} \mathrm{S}$ y $108^{\circ} \mathrm{E}$ (polo sur) y $80^{\circ} \mathrm{N}$ y $72^{\circ} \mathrm{E}$ (polo norte), es decir que el eje entre ambos polos del CMT se encuentra apartado unos $11,5^{\circ}$ respecto al eje de rotación de la Tierra (Fig. 2.7a).

El CMT posee tres componentes principales: declinación, inclinación e intensidad. En la figura 2.7b están representados los ángulos y las componentes con las cuales se define el CMT para un punto de observación (O) en el Hemisferio Sur. La declinación (D) se define como el ángulo que forma la componente horizontal del CMT con norte geográfico o meridiano local. Su rango de variación va de $0^{\circ}$ a $360^{\circ}$. La inclinación (I) es la medida de la desviación vertical con respecto al plano horizontal y puede variar entre $0^{\circ}$ y $90^{\circ}$. I adquiere un valor de cero grados en el Ecuador y va aumentando, aunque en sentidos opuestos, hacia los polos (Fig. 2.7a). Por convención, el valor de inclinación en el Hemisferio sur es precedido por un signo menos (-). Por último, la intensidad magnética $(\mathrm{J})$ corresponde a la magnitud del vector y su unidad de medición es el Tesla (T). J del CMT en superficie puede variar entre 25 a $65 \times 10^{-9} \mathrm{~T}$ (25.000 a $65.000 \mathrm{nT})$.

La teoría aceptada sobre el origen del CMT es la del geodínamo autoexitado, propuesta por Joseph Larmor en 1919 y ampliada en las década del 40 y 50 por numerosos investigadores, entre ellos Walter Elsasser y Edward Bullard. Esta teoría se basa en que la parte externa del núcleo de la Tierra se 
compone dominantemente de hierro en estado fluido, con alta conductividad eléctrica y en movimiento en estado de convección turbulenta originada por el calor residual, el calentamiento radioactivo y la diferenciación geoquímica. Además, a medida que la Tierra se enfría, a consecuencia de la energía térmica y gravitacional que dispone, los constituyentes más pesados van hacia el centro; consecuentemente el efecto sería el de una dínamo magneto-hidrodinámica que se retroalimenta y genera el CMT. Glatzmair y Robertz (1995) y paralelamente Kageyama y Sato (1995) validaron el modelo del geodínamo autoexitado a través de simulaciones numéricas auto-consistentes. Las ecuaciones que describen el modelo magnetohidrodinámico fueron resueltas usando un método espectral que trata a todos los términos lineales de forma implícita y a los no lineales de forma explícita.

Se ha observado que la posición de los polos geomagnéticos, así como la intensidad del campo, experimentan variaciones a lo largo del tiempo. Se determinaron distintos tipos de variaciones. Las variaciones seculares se manifiestan lenta y progresivamente a través de los años y se originan por la parte no dipolar del campo. Ambos polos experimentan movimiento en forma no solidaria. Existe un registro histórico de algo más de 400 años de variaciones seculares, las mediciones más antiguas corresponden a William Gilbert, en el año 1600. Se estima que las variaciones seculares, promediando 10.000 años de posiciones de los polos geomagnéticos es igual a cero y el polo magnético sería coincidente con la posición del eje de rotación de la Tierra. Hasta el momento no se han registrado apartamientos respecto al eje mayores a $20^{\circ}$. Otro tipo de variaciones del CMT corresponden a inversiones de la posición de sus polos. Las inversiones de magnetopolaridad sugieren lapsos durante el cual el polo geomagnético sur se encontraba en el hemisferio sur (Polaridad Inversa), así como en el hemisferio norte (Polaridad Normal). El patrón de inversiones geomagnéticas es aperiódico y la cantidad de inversiones ha variado en el tiempo (e.g. Lowrie y Kent, 2004). La última gran inversión del CMT registrada (Brunhes-Matutama) sucedió hace 780.000 años. Existen discrepancias en cuanto a la duración del proceso de inversión magnética. Hyodo et al. (2006), Yang et al. (2010), entre otros, indican que el proceso completo llevaría más de 10.000 años. Laj et al. (1987) indicaron una duración entre 2.000 y 4.000 años. Clement (2004), por su parte indicó, que el proceso variaría con la latitud, entre 2.000 (bajas latitudes) y 10.000 años (altas latitudes). Para Valet et al., (2012) no podría ser mayor a 1.000 años. Otros investigadores proponen duraciones aún menores (Camps et al., 1999; Coe et al., 1995; Bogue y Glen, 2010). Recientemente Sagnotti et al. $(2014,2016)$ estudiaron la transición Brunhes-Matuyama en sucesiones lacustres del centro de Italia y consideraron que el proceso de inversión habría ocurrido extremadamente rápido, a un ritmo algo menor a $2^{\circ}$ por año, con una duración de sólo 13 años. 


\subsection{Registro del campo magnético terrestre en las rocas.}

El Paleomagnetismo consiste fundamentalmente en el estudio del campo magnético en el pasado geológico, esto es posible debido a que los minerales ferrimagnéticos y en menor medida los antiferromagnéticos imperfectos son capaces de adquirir remanencia magnética posibilitando conocer la posición del polo geomagnético en el pasado. El Magnetismo Remanente Natural (MRN) es el que se encuentra contenido en la roca antes de que la misma sea tratada en laboratorio. El MRN se puede definir como la suma de magnetizaciones que la roca ha almacenado a lo largo de su historia geológica. Estas magnetizaciones dependen del campo geomagnético, de los procesos de formación de la roca y su historia posterior. El MRN está compuesto típicamente por más de una componente y corresponde a la suma de magnetizaciones de la roca. El magnetismo que se adquiere durante la formación de la roca se denomina magnetización primaria, y el magnetismo adquirido con posterioridad a su formación, magnetización secundaria y puede ocultar la magnetización primaria.

Las principales formas en que una roca adquiere magnetización son la Magnetización Termoremanente, la Magnetización Remanente Detrítica, y la Magnetización Remanente Química.

La Magnetización Termorremanente (MTR) se da principalmente en rocas con altas temperaturas de formación. Las resultantes magnéticas de los momentos magnéticos de los minerales ferromagnéticos se orientan paralelamente al CMT cuando la roca, en su proceso de enfriamiento, pasa por la temperatura de Bloqueo (cercana a la temperatura de Curie, $573{ }^{\circ} \mathrm{C}$ para Magnetita, $675^{\circ} \mathrm{C}$ para la hematita). Este tipo de magnetización se da principalmente en rocas ígneas y metamórficas de alta temperatura.

La Magnetización Remanente Detrítica (MRD) es adquirida durante la depositación y litificación de los sedimentos que componen rocas sedimentarias, si éstos contienen minerales ferromagnéticos (en sentido amplio). Los clastos ferromagnéticos (en sentido amplio) de una roca sedimentaria, originados principalmente de rocas ígneas, poseen una magnetización previa, esto posibilita su alineación en forma paralela al CMT. El alineamiento de dichas partículas comienza mientras descienden en una columna de fluido, y finaliza cuando el movimiento de las partículas se ve restringido (Fig. 2.8). La MRD está sujeta a parámetros físicos como la intensidad del campo magnético terrestre, la gravedad y la viscosidad y el tipo de flujo depositacional, pero también depende de las condiciones ambientales, como la dirección de la corriente del fluido, el $\mathrm{pH}$, la salinidad, la bioturbación, el empaquetamiento y la circulación de agua poral, así como la tasa de sedimentación y la compactación. El tamaño, la forma y la magnitud de la magnetización previa de las partículas también influyen en la adquisición de la MRD. Las partículas sedimentarias finas son más propensas a adquirir MRD ya que pueden ser orientadas con mayor facilidad. Suele considerarse que las partículas de diámetros mayores a $50 \mu \mathrm{m}$ contribuyen escasamente a la MRD. 
Las partículas con formas elongadas tienden a depositarse horizontalmente, generando errores en la Inclinación Magnética (Fig. 2.8). Así mismo, dichas partículas pueden verse afectadas por la dirección de las corrientes, dando errores en la Declinación Magnética.

La Magnetización Remanente Química (MRQ) responde a los cambios o alteraciones químicas que ocurren por debajo de la temperatura de bloqueo. La MRQ se origina a partir de la neoformación de minerales ferromagnéticos a partir de la alteración u oxidación de minerales que contenían hierro en su composición, o bien a través de la precipitación de soluciones ricas en hierro. En un comienzo, los minerales ferromagnéticos neoformados suelen ser de tamaño pequeño, superparamagnéticos (SP), sin capacidad de adquirir magnetismo remanente (Fig. 2.5), pero al ir aumentando su volumen pueden convertirse en dominio simple (DS). La neoformación de minerales ferromagnéticos también puede ser de origen biológico, a través de actividad bacterial.

Otro tipo de magnetización remanente es la Magnetización Remanente Viscosa (MRV), que es un tipo de magnetización secundaria, adquirida con posterioridad a la formación de la roca, mediante la exposición gradual a campos magnéticos pequeños en el tiempo. La MRV forma parte de la MRN, y puede ocultar las direcciones de magnetización primaria.

Como se ha dicho, las rocas, además de su magnetización remanente primaria, pueden adquirir durante su vida geológica otras magnetizaciones remanentes (secundarias) que se suman a la primaria de modo que la MRN es la resultante de la suma vectorial de todas ellas. En el tratamiento de las muestras paleomagnéticas es imprescindible aislar la magnetización primaria o magnetización remanente característica (MRC) de las magnetizaciones secundarias. Esto se consigue a través de técnicas de laboratorio basadas en las distintas propiedades de las magnetizaciones remanentes naturales. Las magnetizaciones secundarias normalmente son del tipo isotérmico y viscoso y afectan a los dominios magnéticos con fuerzas coercitivas bajas. Estas magnetizaciones son relativamente fáciles de destruir en laboratorio mediante técnicas de desmagnetización adecuadas. Las técnicas más habituales de desmagnetización ("lavado magnético"), corresponden a tratamiento térmico, es decir calentando en varios pasos la muestra a temperaturas crecientes; el "lavado magnético" por campos magnéticos alternos linealmente decrecientes (CMA), cuya ventaja reside en que no afecta la composición original de la muestra; o bien mediante la eliminación de óxidos de hierro secundarios mediante el tratamiento con ácido clorhídrico. Para el presente trabajo de tesis se ha utilizado la desmagnetización por campos alternos, que será explicada con mayor detalle en el capítulo próximo. 


\subsection{Magnetoestratigrafía}

La magnetoestratigrafía se refiere a la correlación y datación de sucesiones de rocas por medio de las direcciones de magnetopolaridad de éstas.

Un conjunto continuo de rocas con una misma polaridad magnética constituye lo que llamamos magnetozona. Las magnetozonas pueden ser de utilidad para contribuir a la construcción de la Escala de Inversiones Geomagnéticas, o bien, ser referida a dicha escala con el objetivo de conocer la edad de la sucesión de rocas estudiadas.

La Escala de Inversiones Geomagnéticas, a la cual referimos las magnetozonas determinadas, es construida a partir de aportes de investigadores en todo el mundo a través de la correlación entre edades radiométricas y la polaridad magnética de las rocas. Dicha escala posee una construcción jerárquica, donde la unidad principal es el Cron, cuya duración va de $1 \times 10^{6}$ a $1 \times 10^{7}$ años. Un cron, puede a su vez contener Subcrones, de menor duración (entre $1 \times 10^{5}$ y $1 \times 10^{6}$ años), o bien formar parte de un Supercron, de más de $1 \times 10^{7}$ años. Asimismo existen intervalos de una polaridad determinada de corta duración, conocidos informalmente con el nombre de "eventos", que pueden tener varios orígenes: excursiones magnéticas, variaciones de la intensidad del campo magnético o inversiones de muy corta duración.

La Escala de Inversiones Geomagnéticas recibió numerosas correcciones y ajustes en las últimas décadas. En este trabajo es utilizada la última actualización hasta el momento realizada, denominada GTS2012, correspondiente a Oggs (2012) que fue publicada en "The Geologic Time Scale" (Grandstein et al., 2012).

En la figura 2.9 se muestra la Escala de Inversiones Geomagnéticas para los últimos $6 \mathrm{Ma}$, que comprende parte del período Neógeno y todo el período Cuaternario.

\subsection{Magnetismo de Rocas}

En el presente trabajo los parámetros de magnetismo de rocas son utilizados en primera instancia como soporte de la investigación magnetoestratigráfica. Los mismos son indicadores de la presencia, concentración y tamaño de grano de los minerales magnéticos, algunos de los cuales poseen la capacidad de retener las direcciones de magnetización del pasado geológico. Asimismo, debido a que los minerales magnético se encuentran presentes en casi todos los materiales naturales, son sensibles a transformaciones fisicoquímicas y pueden ser detectados y caracterizados aún en muy bajas concentraciones a través de la información que brindan los parámetros magnéticos, es posible hacer inferencias paleoambientales y 
paleoclimáticas. Como se ha dicho, los parámetros magnéticos son sensibles a las variaciones cualitativas y cuantitativas de ciertos minerales portadores de hierro, así como al tamaño de grano de los mismos. Estas variaciones están relacionadas con diferentes procesos depositacionales y post-depositacionales, en tanto, es posible vincular los parámetros magnéticos con el régimen de humedad, con los ciclos de humedecimiento y secado, con el tiempo de exposición atmosférica y el grado de desarrollo pedogenético, así como con las tasas de acumulación y fuentes de aporte de sedimentos. Las condiciones ambientales, actuales o pasadas, tales como la temperatura, la precipitación, dirección y velocidad del viento, entre otras, influyen en los procesos de transporte, depositación y transformación de los minerales, pudiendo de este modo modificar la concentración, tamaño y tipo de minerales magnéticos presentes en los distintos medios naturales. Incluso, puede ocurrir la destrucción de determinados minerales magnéticos y/o la neoformación de otros.

Este tipo de estudios se engloba actualmente dentro de una disciplina relativamente reciente denominada Magnetismo Ambiental.

Los principales parámetros magnéticos utilizados en esta tesis son los obtenidos a partir de la suscetibilidad magnética [volumétrica $(\kappa)$ y másica $(\chi)$ ], la magnetización remanente anhistérica (MRA) y la magnetización remanente isotérmica (MRI). Las principales características de los mismos son descriptas someramente a continuación. En el capítulo 4 se ampliará la información en virtud de las técnicas que se emplean para su medición.

Cuando una sustancia es sometida a la influencia de un campo magnético directo $\mathrm{H}$, se induce una magnetización en la misma. La susceptibilidad magnética $(\kappa)$ es la relación entre el momento magnético inducido y el campo magnético directo inductor. Si el campo magnético H aplicado es lo suficientemente pequeño, no mayor de $\sim 80 \mathrm{~A} / \mathrm{m}$, y asumiendo que no hay anisotropía en el medio, es posible establecer la siguiente relación lineal, $\kappa=\mathrm{M} / \mathrm{H}$. Siendo $\kappa$, una cantidad escalar, adimensional y M, la magnetización inducida por unidad de volumen de muestra.

La susceptibilidad magnética se corresponde a la facilidad de los materiales para magnetizarse bajo la presencia de un campo magnético externo. Depende de los minerales magnéticos presentes, de su concentración y de características tales como el tamaño y la forma del grano.

Todas las fracciones minerales poseen susceptibilidad magnética, sin embargo, los registros más elevados se obtienen en los minerales ferrimagnéticos, secundariamente los antiferromagnéticos imperfectos y por último en los paramagnéticos; los minerales diamagnéticos brindan valores de susceptibilidad bajos y negativos. En la tabla 2.1 se muestran valores de susceptibilidad magnética para 
distintos tipos de materiales y en la tabla 2.2 se indican, entre otros, los valores de susceptibilidad magnética para magnetita, hematita y goethita.

A través de la medición de la susceptibilidad magnética a frecuencias de distinta magnitud (e.g. 470 y $4.700 \mathrm{~Hz}$ ), un mismo material puede responder en forma diferencial, según la presencia de minerales magnéticos ultrafinos $(<0,03 \mu \mathrm{m})$, de esta manera es posible detectar y cuantificar minerales de dominio superparamagnético (SP).

La medición de la susceptibilidad magnética en campos $\mathrm{H}$ pequeños es una forma no destructiva de medición, ya que bajo estas condiciones de campo aplicado, los procesos de magnetización son reversibles, es decir que al remover el campo magnético los momentos magnéticos de la partícula vuelven a su posición de equilibrio.

Sin embargo, cuando un campo directo de elevada intensidad es aplicado a una muestra de granos magnéticos orientados aleatoriamente y sin magnetizar, ésta adquirirá una magnetización remanente. La aplicación de campos sucesivamente más intensos incrementará la magnetización remanente. Este proceso de adquisición de magnetización es irreversible. Cabe destacar que sólo ciertos tipos de minerales, como algunos óxidos y sulfuros de hierro son capaces de adquirir remanencia magnética. Tanto los minerales paramagnéticos, así como los diamagnéticos, son incapaces de adquirir magnetización remanente.

La magnetización remanente anhistérica (MRA) es la magnetización remanente que adquiere una muestra cuando es sometida a un campo magnético directo y continuo (DC) y débil $\left(\mathrm{H}_{0}\right)$ sobreimpuesto a un campo magnético alterno (CMA) más intenso. El efecto del campo $\mathrm{H}_{0}$ (del orden del campo magnético terrestre) es superpuesto al del CMA mientras éste decrece lentamente desde su valor máximo predeterminado hasta cero. En este intervalo el CMA relaja el sistema a la vez que $\mathrm{H}_{0}$ induce una magnetización. La relajación de los granos magnéticos constituyentes depende de su distribución de coercitividades y del intervalo mapeado. Todas las partículas con coercitividad remanente igual o menor al campo máximo aplicado serán magnetizadas en la dirección del campo $\mathrm{H}_{0}$. El procedimiento se repite incrementando progresivamente el campo DC y midiendo la MRA luego de cada paso.

La intensidad de la MRA puede ser calculada a partir de la siguiente relación: $\mathrm{MRA}=\mathrm{H}_{0} / N\left(1+\mathrm{N}_{\mathrm{i}}\right)$, donde $N$ es el factor de desmagnetización, el cual está relacionado con la forma y el tamaño del grano magnético y $\kappa_{\mathrm{i}}$ a la susceptibilidad magnética intrínseca. Es posible calcular la susceptibilidad anhistérica ( $\kappa_{\mathrm{MRA}}$ ) en forma experimental, ya que ésta corresponde a la pendiente de los valores de MRA obtenidos a campos conocidos. 
Tanto la MRA como la $\kappa_{\text {MRA }}$ son dependientes de la interacción entre granos magnéticos. En este sentido, para una misma concentración, los valores que adquieren dichos parámetros son más elevados cuando los granos se encuentran dispersos, siendo las interacciones menos intensas. En relación a esto, tanto la MRA como la $\kappa_{\text {MRA }}$ ayudan en la discriminación de tamaños de grano magnéticos. Esto se debe a que son sensibles a la presencia de minerales ferrimagnéticos de dominio simple (DS) y granos pequeños de dominio pseudosimple (PSD) $(0,1-1 \mu \mathrm{m})$. En la figura 2.10 se muestra la dependencia entre la susceptibilidad anhistérica y diferentes tamaños de grano de magnetita.

Por otro lado, la adquisición de magnetización remanente isotérmica (MRI) constituye otra forma en que los materiales pueden adquirir una magnetización remanente. A diferencia de la MRA, el proceso es realizado sin la presencia de un campo alterno (CMA). La inducción magnética se realiza por medio de un campo directo $\mathrm{H}$, al igual que la MRA, aunque mucho más intenso. Generalmente, en el proceso de adquisición de MRI el campo $H$ alcanza valores máximos de 1-2,5 T, el cual es 6 órdenes de magnitud mayor que el $\mathrm{H}_{0}$ en la adquisición de MRA. Consecuentemente, este tipo de procesos induce MR más intensas, y cambios más difíciles de revertir o eliminar que en los procesos anhistéricos.

Las curvas de adquisición de magnetización remanente muestran la forma en la cual la MRI es adquirida a temperatura ambiente. En la figura 2.11 se observa la curva de adquisición de MRI de una muestra extraída en la sección estratigráfica de María Ignacia (Capítulo 5). A medida de que las partículas adquieren MR, los momentos magnéticos son progresivamente orientados en la dirección del campo aplicado. En granos MD, los mecanismos involucrados en la magnetización consisten en traslaciones de las paredes de los dominios, las cuales son reversibles a campos de menor intensidad e irreversibles cuando se aplican campos más intensos, debido a que la pared de dominio puede "saltar" sobre una energía de barrera. Además de traslaciones, pueden ocurrir rotaciones de los momentos magnéticos de los dominios, cuando un campo es aplicado en una dirección perpendicular a la pared del dominio. En el caso de partículas DS, los mecanismos involucrados en la magnetización de los mismos son rotaciones de los momentos magnéticos en la dirección del campo aplicado.

Una vez que la muestra ha sido saturada y medida la magnetización remanente isotérmica de saturación (MRIS) (Fig. 2.11), es posible realizar estudios adicionales aplicando campos $\mathrm{H}$ inversos (backfield), es decir campos orientados en sentido opuesto a la dirección original del campo saturante. En la figura 2.11 la línea roja corresponde a la curva de backfield. En dichas mediciones, al igual que en el proceso de adquisición, el campo inverso es incrementado sucesivamente en etapas desde valores relativamente pequeños $(-20 \mathrm{mT})$ hasta $\mathrm{H} \sim-300 \mathrm{mT}$. El efecto de estos campos inversos es reorientar parcialmente (en sentido opuesto) las magnetizaciones de algunas poblaciones de granos magnéticos, observándose una disminución de la MRI. A partir de este tipo de mediciones es posible definir dos 
parámetros de interés, en particular, la coercitividad de la remanencia $\left(\mathrm{H}_{\mathrm{cr}}\right)$ y el coeficiente S. Como se muestra en la figura $2.11 \mathrm{H}_{\mathrm{cr}}$ corresponde al campo $\mathrm{H}$ inverso necesario para reducir la MRIS a cero (0). Diferentes minerales ferromagnéticos pueden distinguirse a partir de este parámetro puesto que cada mineral posee valores característicos de $\mathrm{H}_{\mathrm{cr}}$ (Tabla 2.2).

El coeficiente S, se define como el cociente entre la MRI para un campo inverso de $300 \mathrm{mT}$ (MRI. 300) y la MRIS, es decir, $\mathrm{S}_{-300}=\mathrm{MRI}_{-300}$ /MRIS. Este parámetro está relacionado con la contribución de materiales magnéticamente duros (antiferromagnéticos, por ej.: goethita, hematita) y magnéticamente blandos (ferrimagnéticos, por ej.: magnetita). Si estos últimos son los dominantes, entonces $\mathrm{S}_{-300}$ adquiere un valor muy cercano a 1.

Este tipo de mediciones es útil a los fines de discriminar minerales magnéticos presentes en las muestras en estudio. Así, minerales ferrimagnéticos, tales como magnetita y maghemita, alcanzan la saturación cuando se aplican campos directos del orden de $300 \mathrm{mT}$, mientras que minerales antiferromagnéticos imperfectos tales como hematita o goethita requieren campos superiores a 2,5 $\mathrm{T}$ para adquirir saturación. La curva de aquisición de MRI es fuertemente dependiente del tamaño de grano en el caso de magnetita, ya que la intensidad de MRIS es progresivamente menor desde los granos más finos $(<5 \mu \mathrm{m})$ a los más gruesos $(150-250 \mu \mathrm{m})$, mientras que la hematita muestra menor dependencia de la MRIS con el tamaño de grano (Fig. 2.12).

Los parámetros magnéticos obtenidos de la susceptibilidad magnética, magnetización remanente isotérmica y la magnetización remanente anhistérica pueden usarse en conjunto por medio de cocientes o diagramas bivariantes a fin de realizar inferencias para la identificación de la mineralogía magnética, o bien el tamaño de grano de los minerales magnéticos. Los cocientes que involucran dos parámetros dependientes de la concentración eliminan los efectos de ésta y son importantes indicadores de tamaño de grano magnético, en particular para magnetita. Existen gráficos de uso corriente que son utilizados para la identificación de la mineralogía magnética, como por ejemplo el diagrama elaborado por Peters y Dekker (2003) (Fig 2.13a). Si la mineralogía dominante corresponde a magnetita, es posible inferir su tamaño de grano a través de diagramas, como por ejemplo el de King et al. (1982) (Fig. 2.13b).

La histéresis magnética es una propiedad de todos los materiales ferromagnéticos (en sentido amplio). Es la causante de que la magnetización de dichos materiales dependa de su historia magnética, es decir, de la exposición a un campo magnético externo.

Como se observa en la figura 2.14, para la obtención de un ciclo de histéresis completo, la magnetización (M) de una muestra es medida en función de un campo externo (H) que se aplica 
continuamente desde cero (a) hasta un valor máximo positivo (b), luego regresa a cero (c), y sigue hasta un valor máximo negativo (d), finalmente vuelve hasta el máximo positivo (b). Cabe destacar que a diferencia de la MRI, M es medida simultáneamente a la aplicación de H.

Al aplicarse un campo de intensidad suficiente, la muestra adquiere su magnetización de saturación (Ms) y una vez saturada no puede aumentar por más que se incremente el campo. Al sustraer el campo tendrá una magnetización remanente (Mrs). El campo magnético necesario para que Ms regrese a cero se conoce como coercitividad $\left(\mathrm{H}_{\mathrm{c}}\right)$. Para regresar al punto en el que la muestra tiene remanencia cero después de remover el campo (regresar al origen), se necesita un campo magnético negativo grande denominado coercitividad remanente $\left(\mathrm{H}_{\mathrm{cr}}\right)$.

Como se observó en la figura 2.1 si el ciclo de histéresis es aplicado a sustancias paramagnéticas el incremento de la magnetización (M) será lineal respecto del campo aplicado $(\mathrm{H})$.

La forma de la curva, así como los parámetros del ciclo de histéresis $\left(\mathrm{M}_{\mathrm{s}}, \mathrm{M}_{\mathrm{r}}, \mathrm{H}_{\mathrm{c}} \mathrm{y} \mathrm{H}_{\mathrm{cr}}\right)$, dependen de los minerales magnéticos presentes y de su distribución de tamaños.

La histéresis magnética se utiliza para estimar la distribución de estados de dominio magnético, que se encuentran en función de la mineralogía y la forma de la partícula.

El cociente $\mathrm{M}_{\mathrm{rs}} / \mathrm{M}_{\mathrm{s}}$, es empleado para la identificación de minerales SP y el cociente $\mathrm{H}_{\mathrm{cr}} / \mathrm{H}_{\mathrm{c}}$ para la identificación de minerales MD. Juntos, estos cocientes son particularmente útiles para la elaboración del diagrama de Day (Day et al., 1977). Este se utiliza para estimar la distribución de estados de dominio magnético. Originalmente se elaboró considerando Ti-magnetitas de tamaños y composición específicas, sin granos superparamagnéticos (SP). Dunlop (2002), realizó algunas modificaciones al diagrama, en particular con la adición de un campo para los granos superparamagnéticos (SP), con adaptaciones específicas para sedimentos, suelos y rocas, de acuerdo a una compilación de datos de muestras naturales. No obstante, este gráfico cuando se analizan muestras naturales puede otorgar resultados ambiguos, esto puede deberse a mezcla de minerales magnéticos con coercitividades marcadamente diferentes o bien a una amplia distribución de tamaños de grano de un mismo mineral (Dunlop y Carter-Stiglitz, 2006; Kumari et al., 2015; entre otros).

Los estudios que incluyen análisis de propiedades magnéticas de diferentes sedimentos, principalmente sucesiones de loess-paleosuelos de edad cuaternaria, han sido de utilidad en la reconstrucción de variaciones climáticas en diferentes regiones del mundo. Las sucesiones de loesspaleosuelos han sido intensamente estudiadas en el Plateau de China (Kukla et al., 1988; Maher y Thompson, 1991; Banerjee y Hunt, 1993; entre otros), donde el patrón de comportamiento de los 
parámetros magnéticos plantea máximos de susceptibilidad en los niveles pedogenizados y mínimos en los niveles correspondientes al material parental. Si bien en otras regiones del mundo este patrón fue confirmado, existen otras regiones de Europa, Alaska y Argentina que presentan un panorama más complejo (Chlachula et al., 1997; Orgeira et al., 1998; Bidegain et al., 2005; entre otros), de modo que este patrón y su asociación con los cambios climáticos no puede ser considerado universal. 


\subsection{Figuras del Capítulo 2}

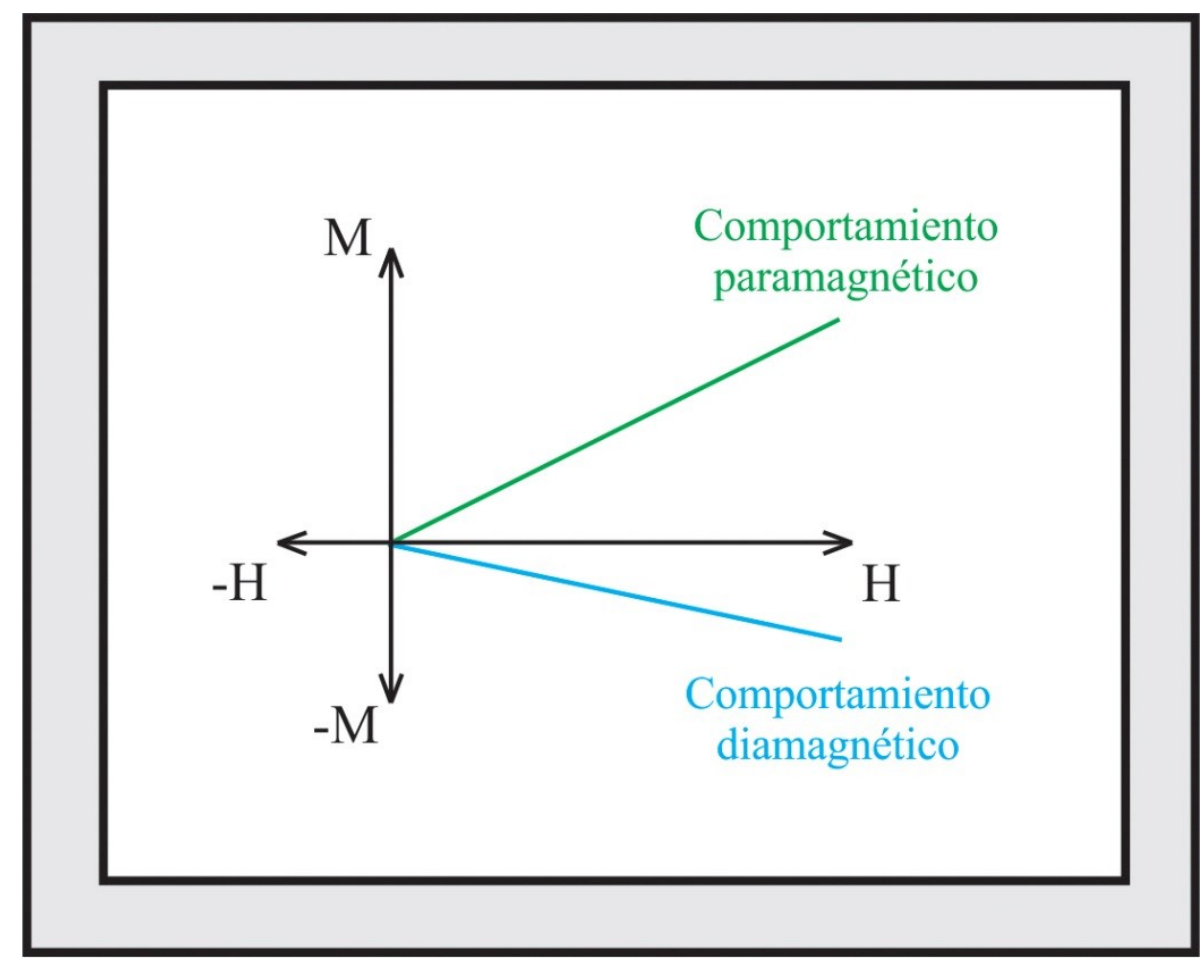

Figura 2.1. Campo magnético aplicado (H) vs. Magnetización inducida (M). Comportamiento de materiales diamagnéticos y paramagnéticos. Tomado de Walden et al., 1999. 


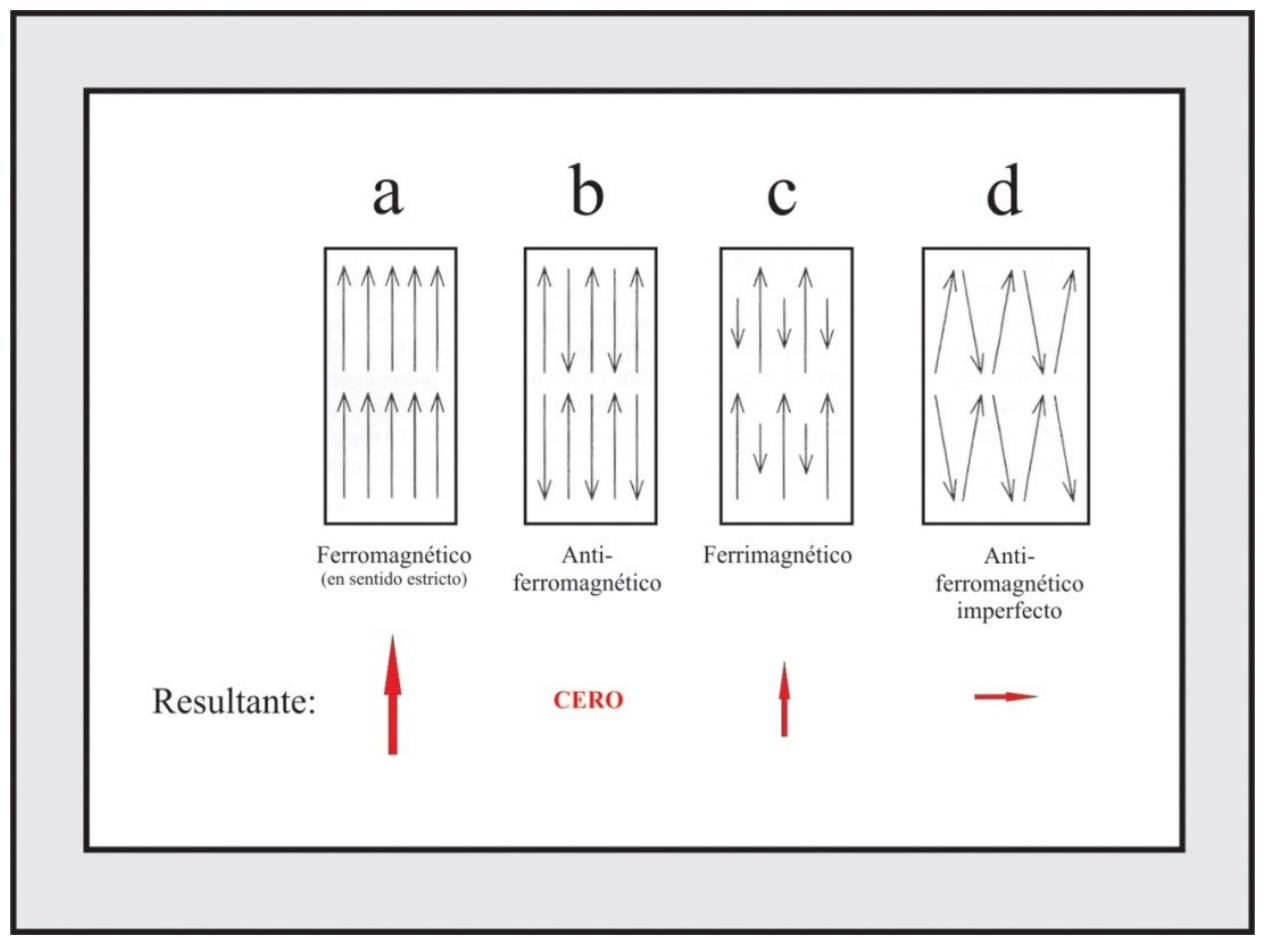

Figura 2.2. Representación esquemática de la distribución de los vectores de magnetización en sustancias ferromagnéticas (en sentido amplio) y resultante de la magnetización espontanea (modificado de McElhinny, 1973). a) Comportamiento ferromagnético (en sentido estricto); b) Comportamiento antiferromagnético; c) Comportamiento ferrimagnético; d) Comportamiento antiferromagnético imperfecto. 


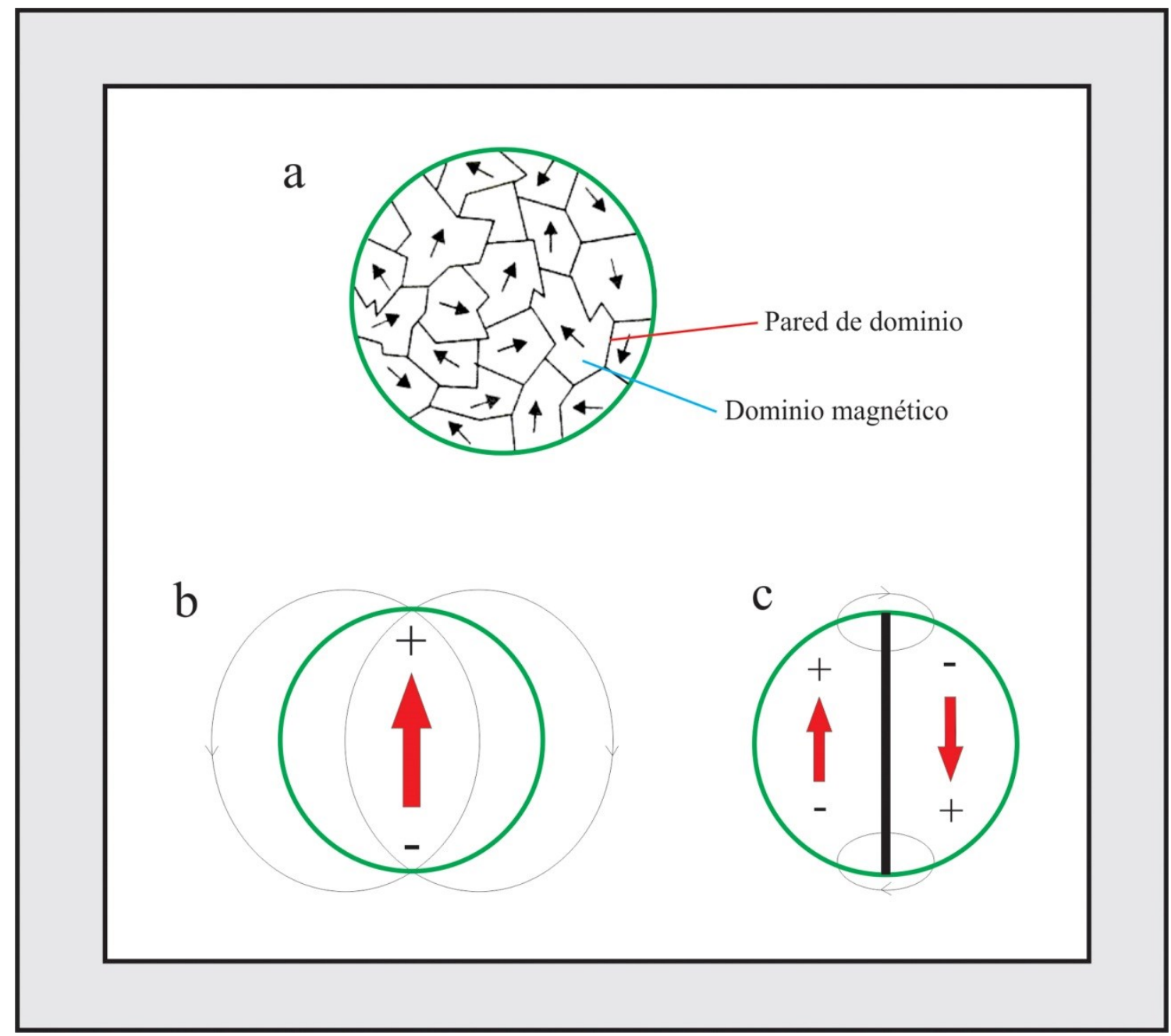

Figura 2.3. Esquema de la configuración de dominios magnéticos (modificado de Dankers, 1978). a) Partícula multidominio; b) Partícula dominio simple; c) Partícula subdividida en dos dominios. 


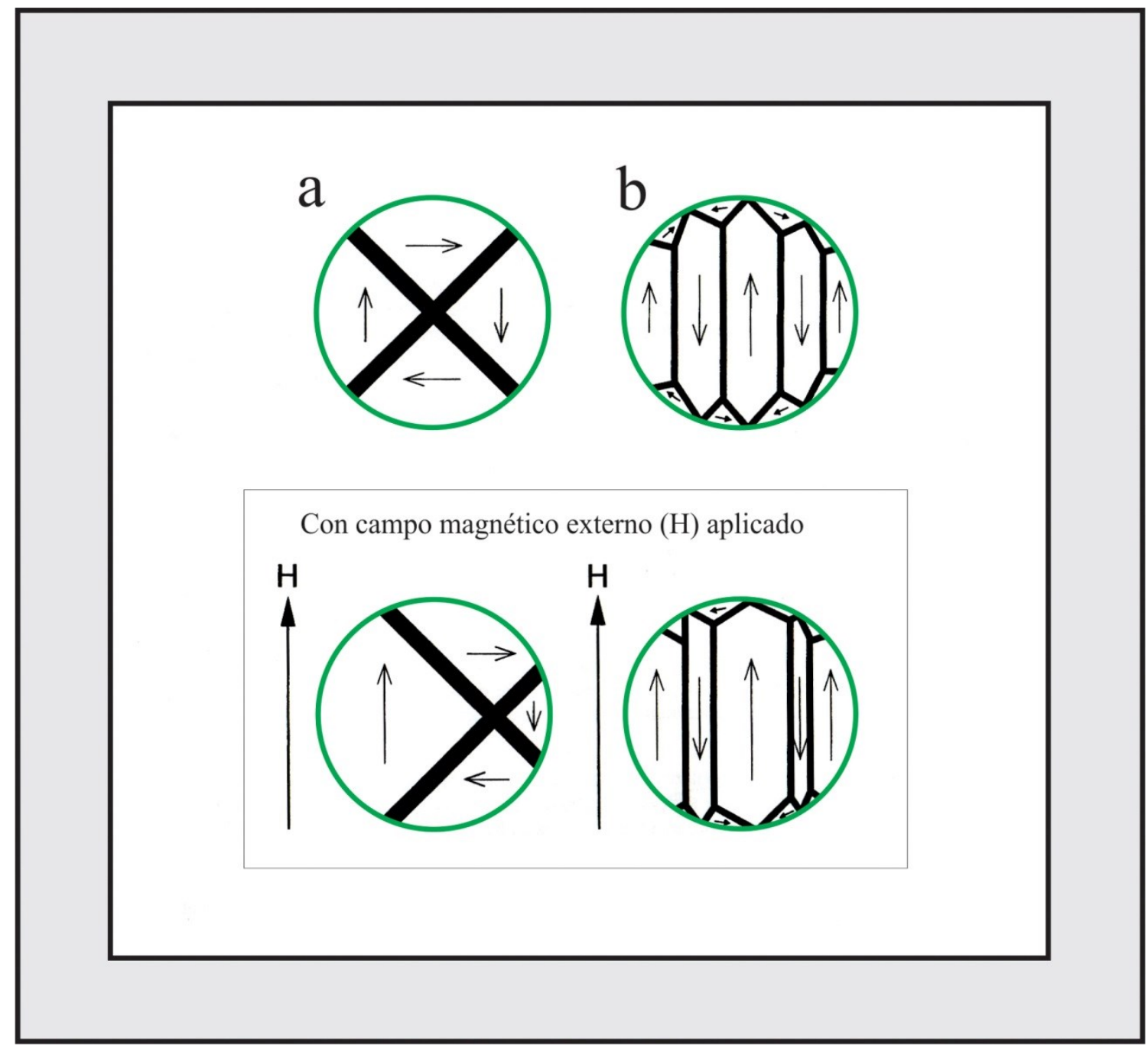

Figura 2.4. Esquema de la configuración de dominios magnéticos (modificado de Dankers, 1978). Arriba, sin aplicación de campo magnético externo; abajo, con aplicación de campo magnético externo; a) partícula con cuatro dominios; c) partícula multidominio. 


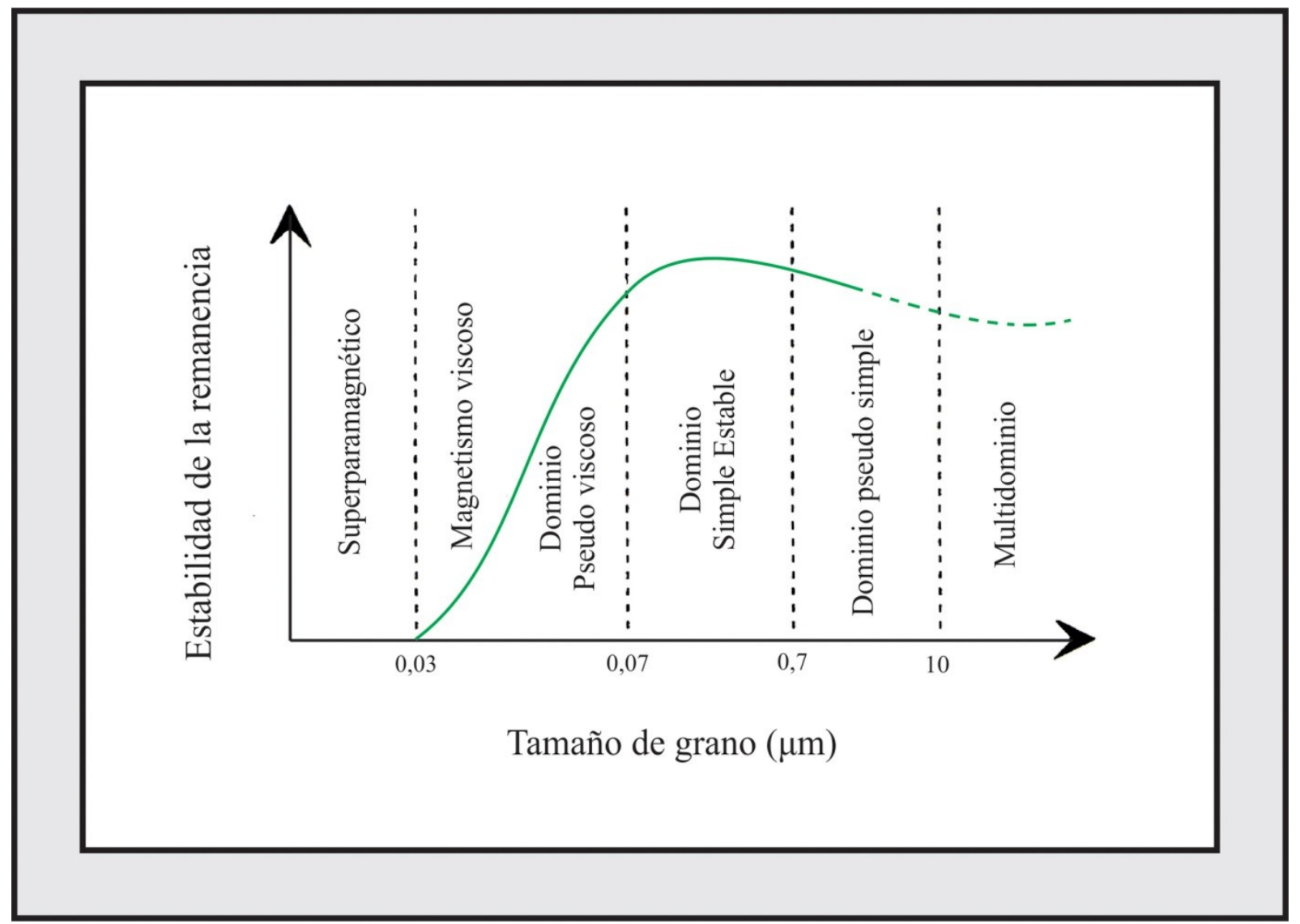

Figura 2.5. Estabilidad de la remanencia en función del tamaño de grano (en micrométros) para minerales ferromagnéticos. Tomado de Walden et al. (1999). 


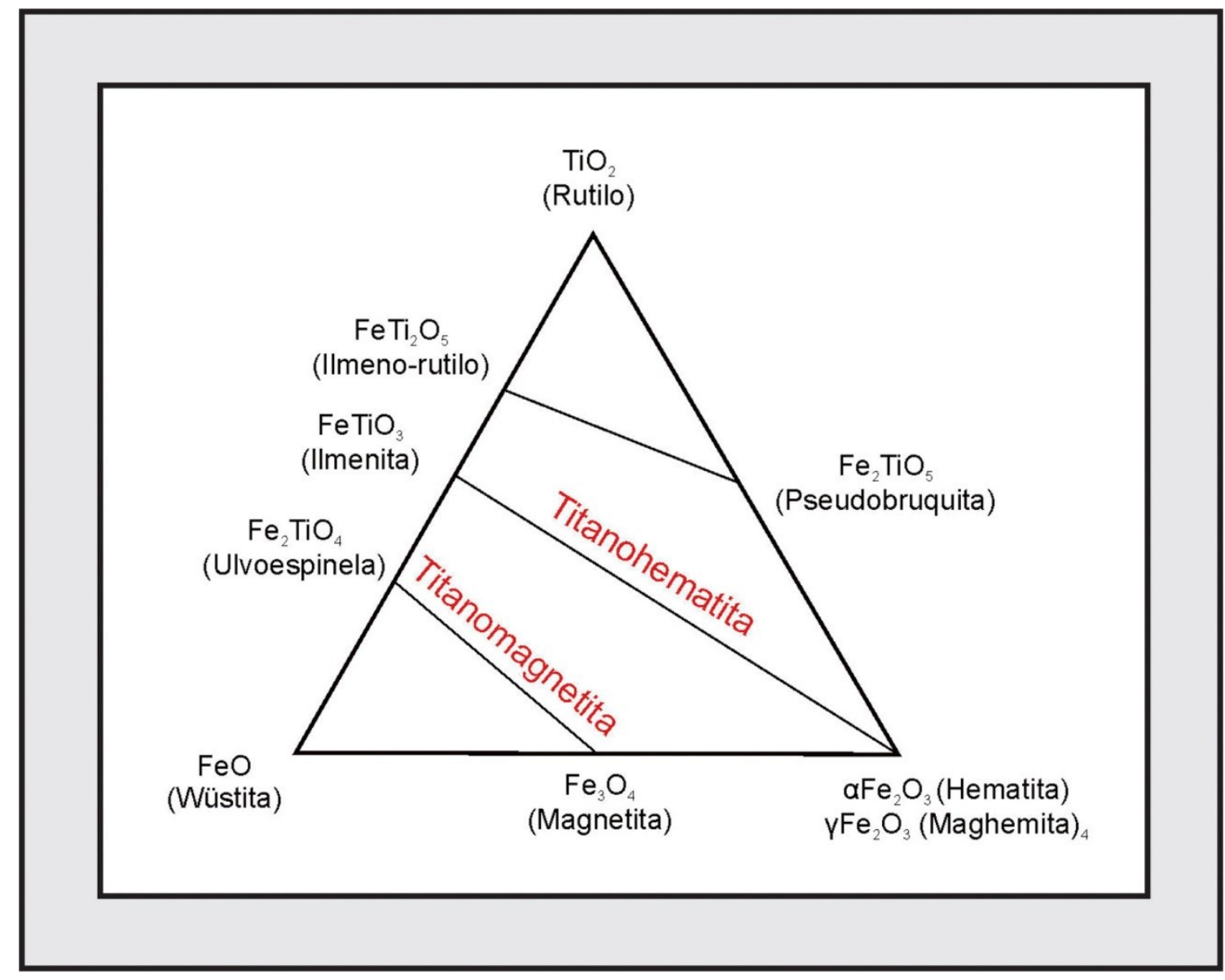

Figura 2.6. Diagrama ternario de composición de los óxidos de hierro-titanio más comunes. Modificado de Valencio (1980). 


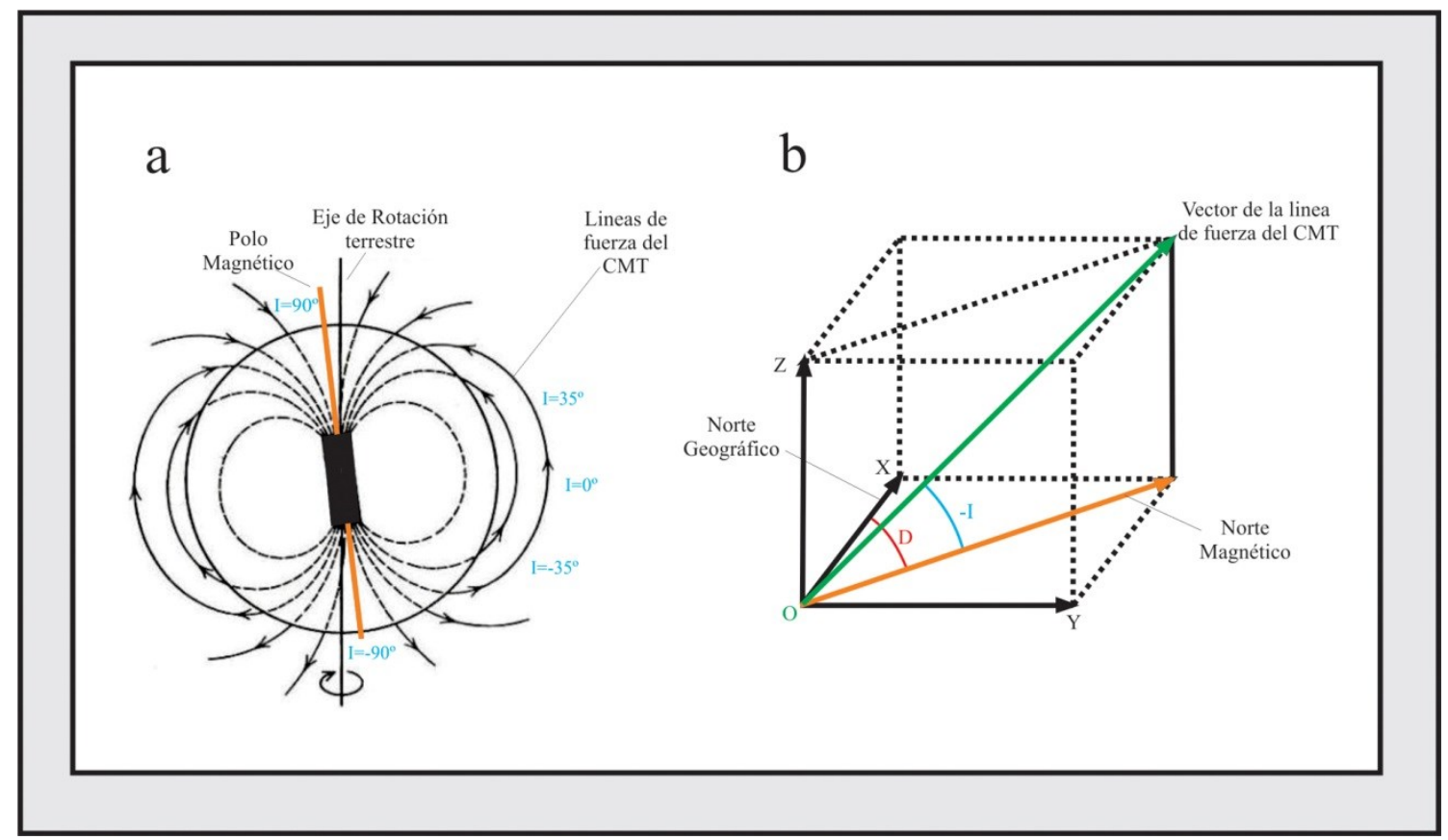

Figura 2.7. Representación del campo magnético terrestre (CMT) para el hemisferio sur. a) Líneas de fuerza del CMT y apartamiento de los polos geomagnéticos respecto al eje de rotación de la Tierra; b) Componentes del CMT. Modificado de Valencio (1980). 


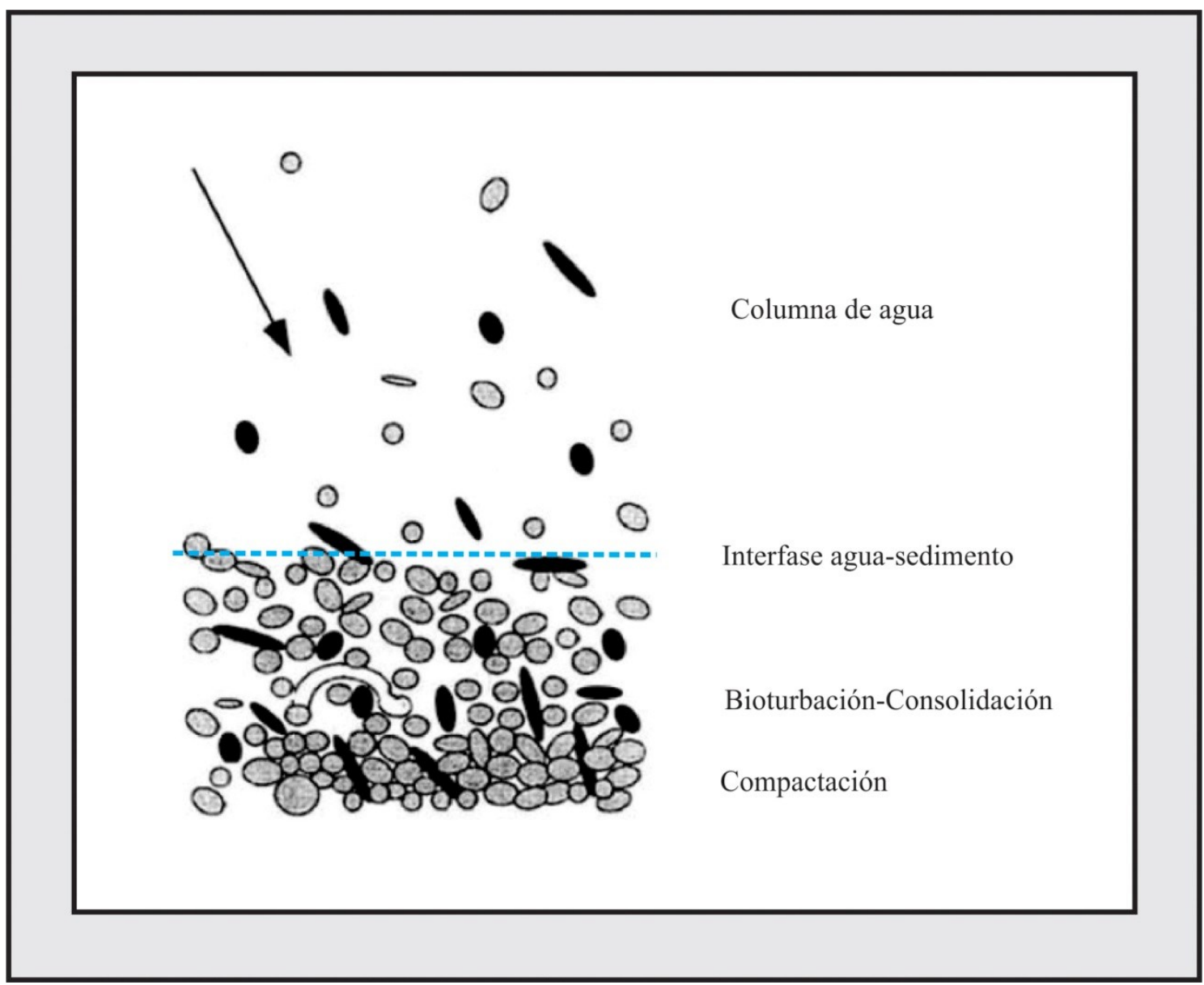

Figura 2.8. Magnetización Remanente Detrítica (MRD). Esquema de alineación de partículas magnéticas. Tomado de Evans y Heller (2003). 


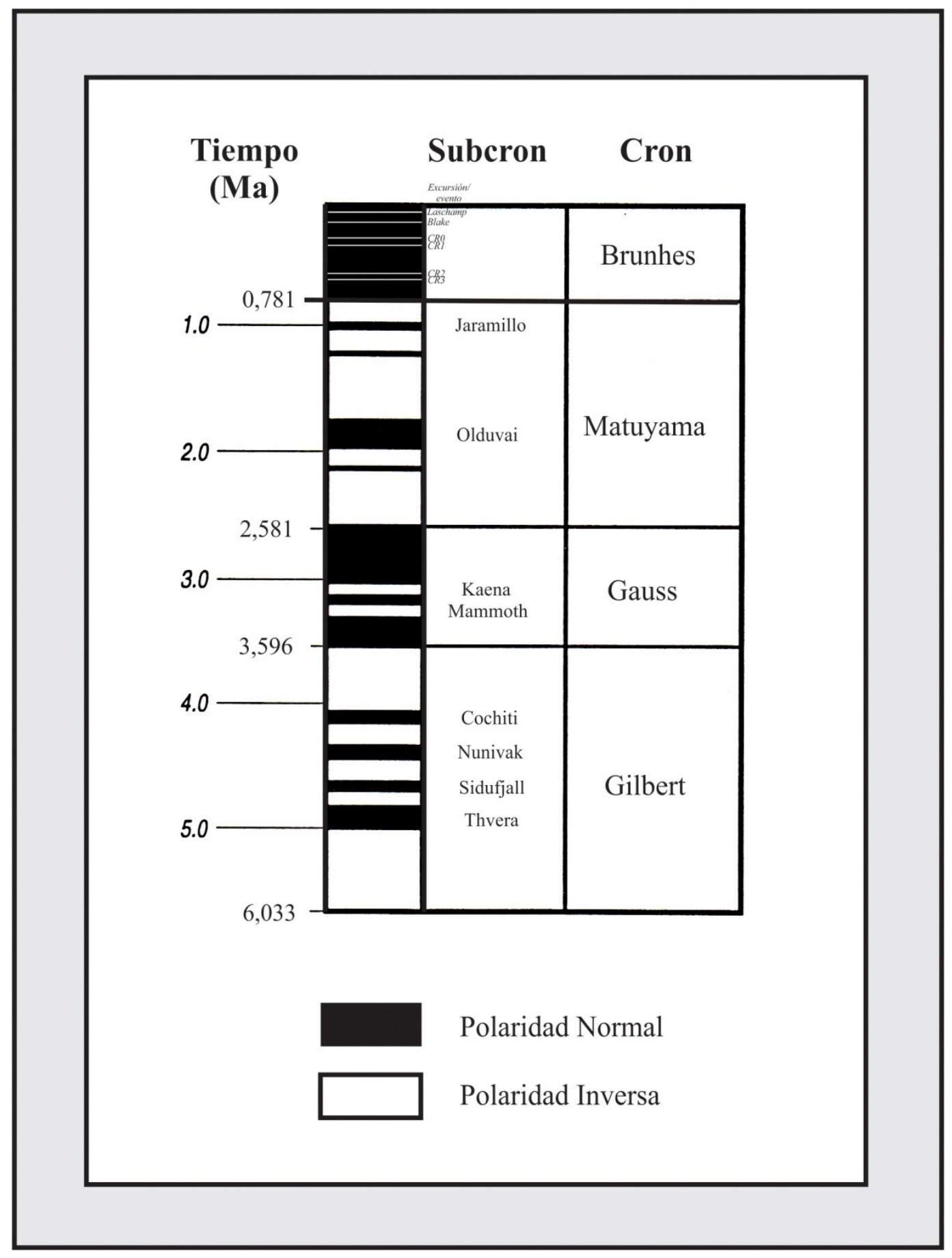

Figura 2.9. Escala de inversiones magnéticas simplificada para los últimos 5,7 Ma. Modificado de Stratton Noller et al. (2000) y Gradstein et al. (2012) 


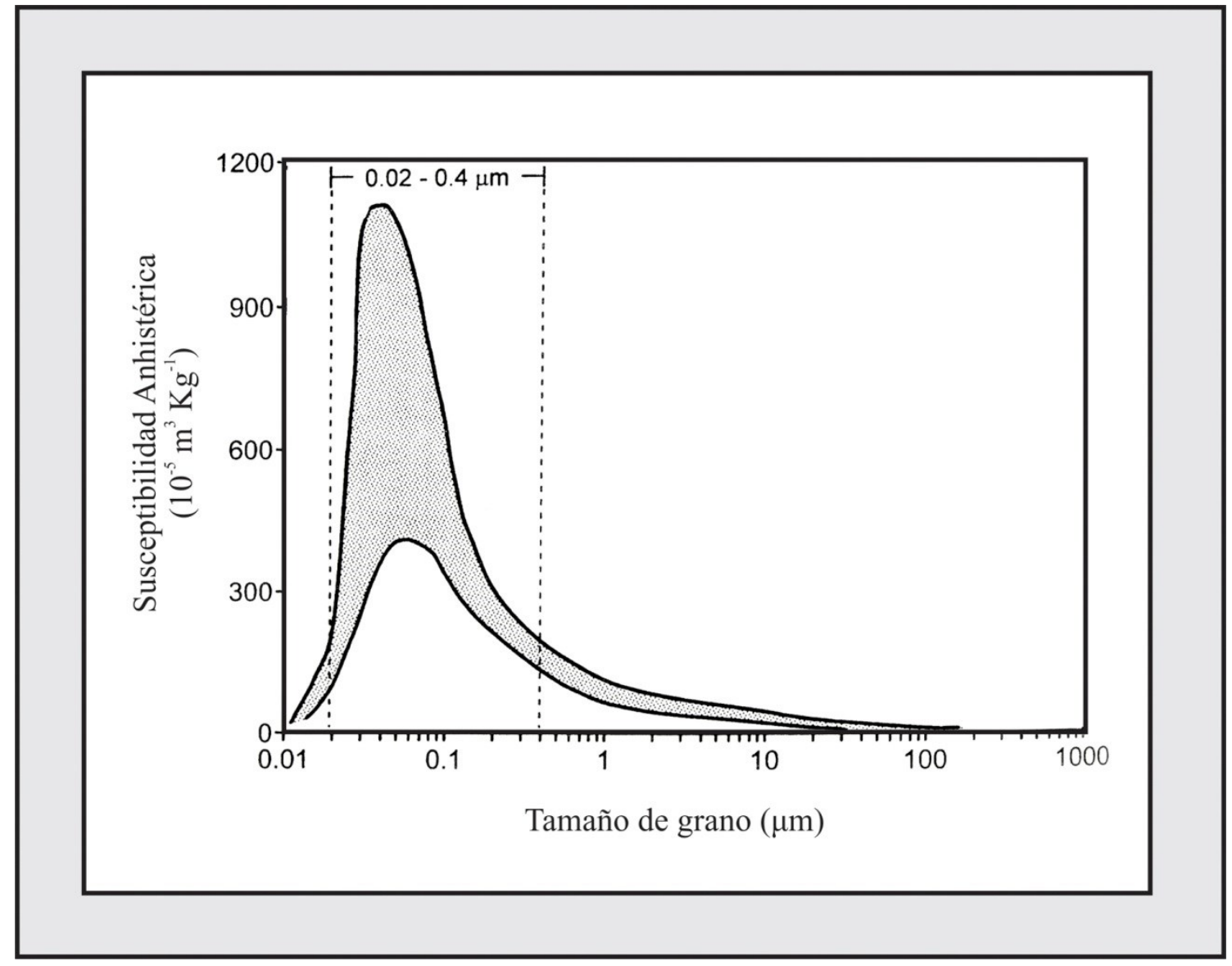

Figura 2.10. Dependencia de la susceptibilidad magnética anhistérica con el tamaño de grano de la magnetita en micrómetros. Modificado de Maher (1988). 


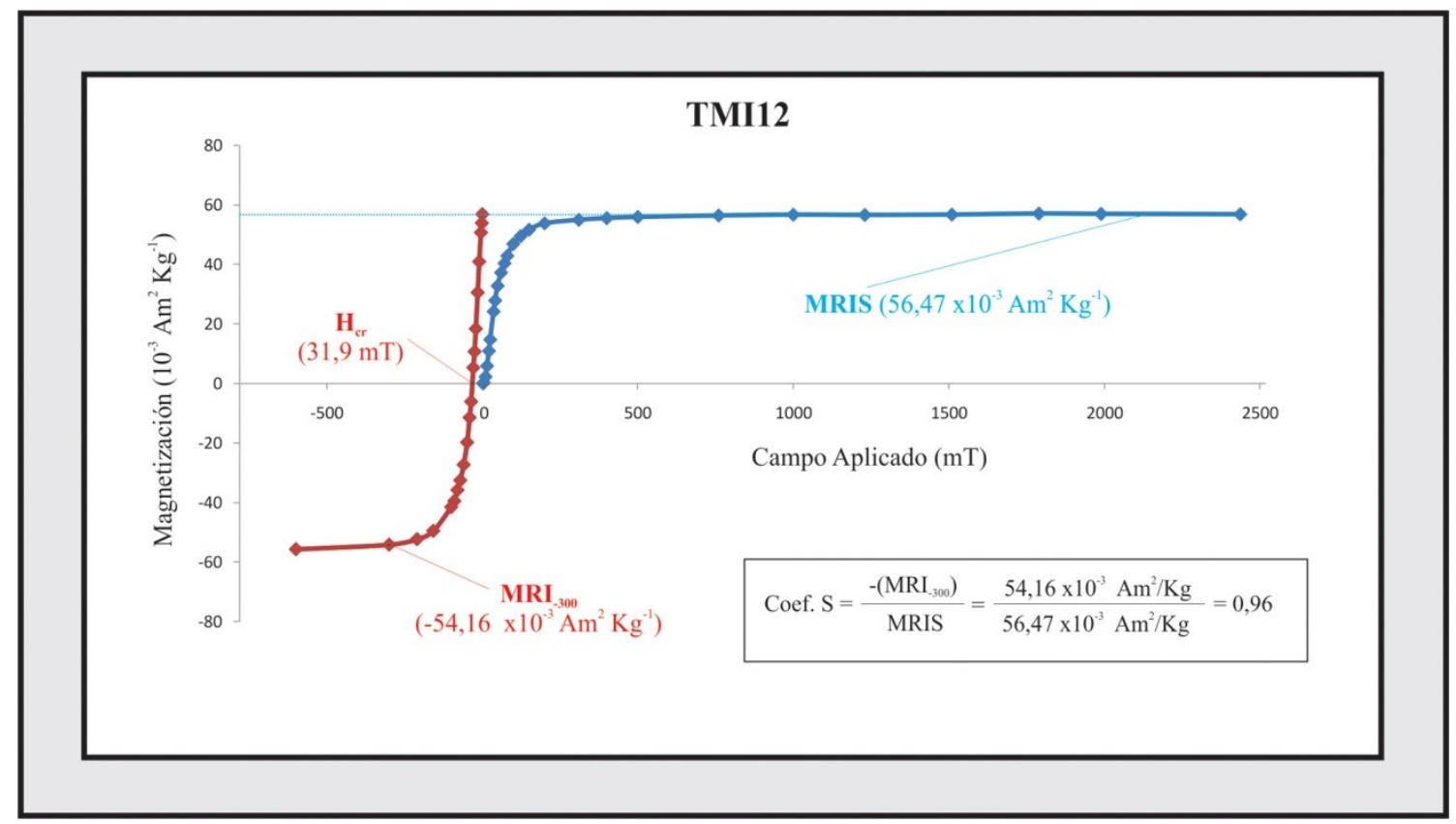

Figura 2.11. Ejemplo de curva de adquisición de la magnetización remanente isotérmica (MRI) para una muestra de sedimento del partido de Tandil, provincia de Buenos Aires. 


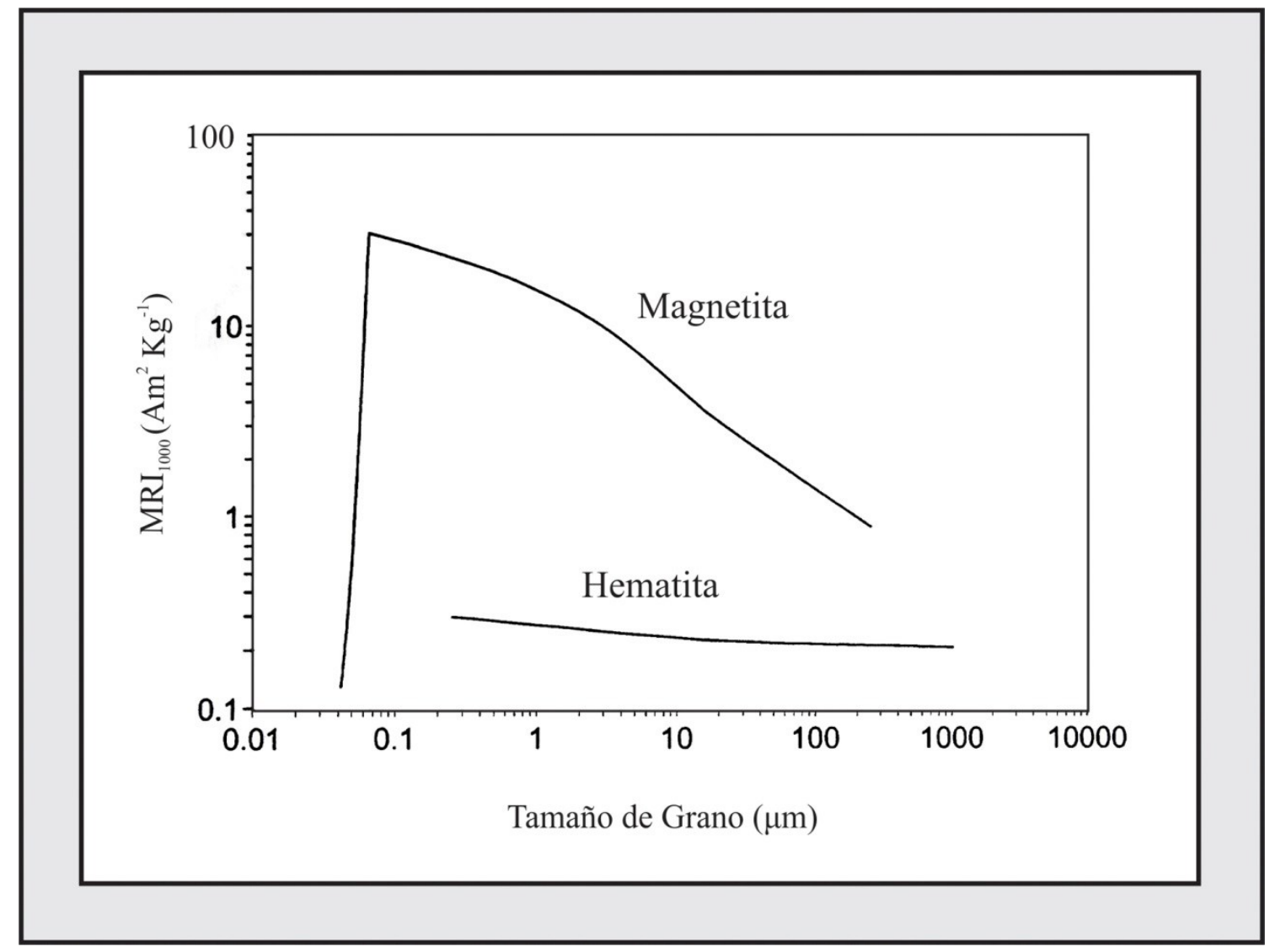

Figura 2.12. Variación de la MRIS ( $\mathrm{MRI}_{1000 \mathrm{mT}}$ ) con el tamaño de grano para magnetita y hematita. Modificada de Thompson and Oldfiel (1986). 


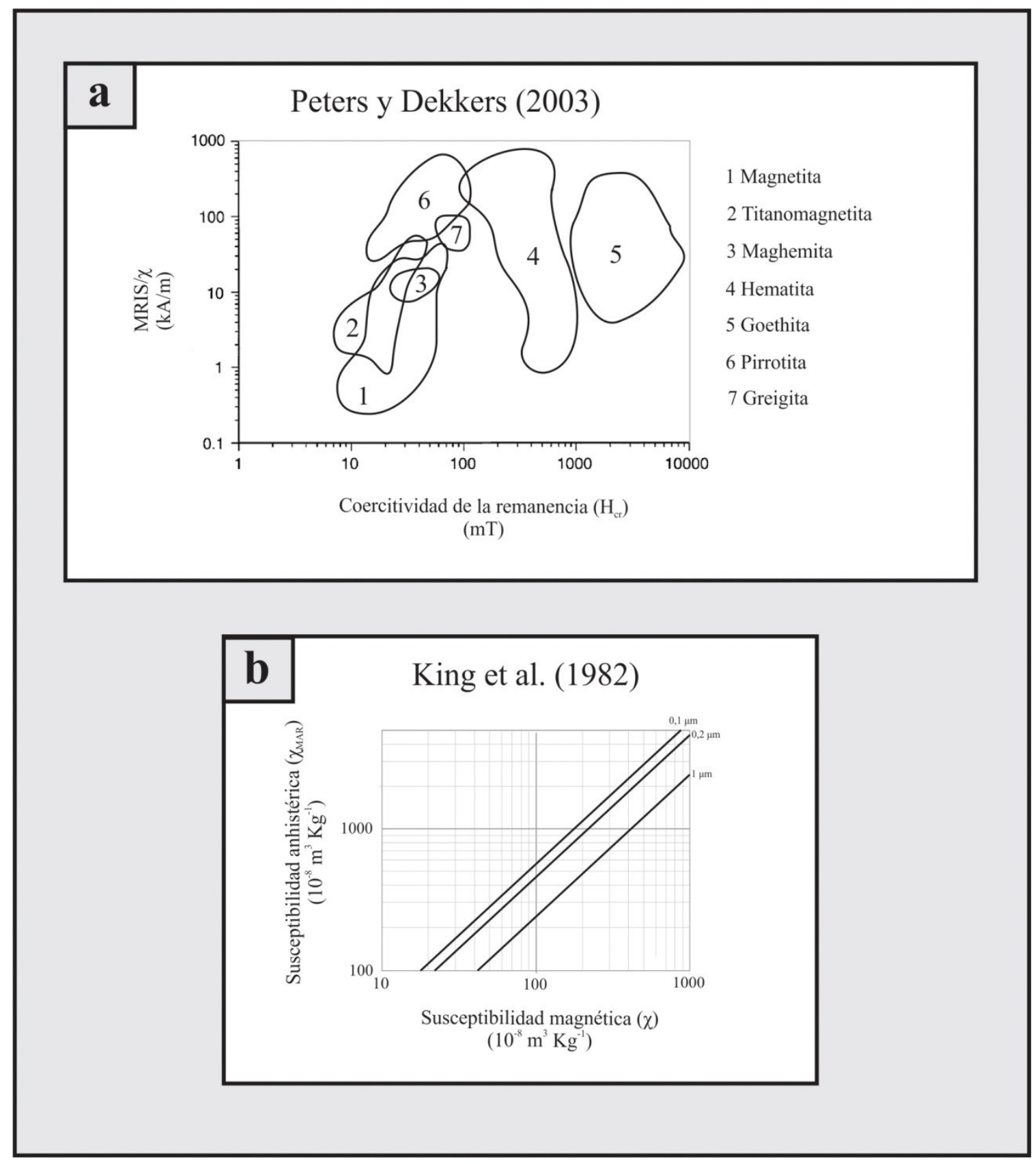

Figura 2.13. Gráficos para estimación de composición y tamaño de grano de los minerales magnéticos. a) Gráfico de Petters y Dekker (2003) para determinación de la composición magnética; b) Gráfico de King et al. (1982) para estimación de tamaño de grano magnético. 


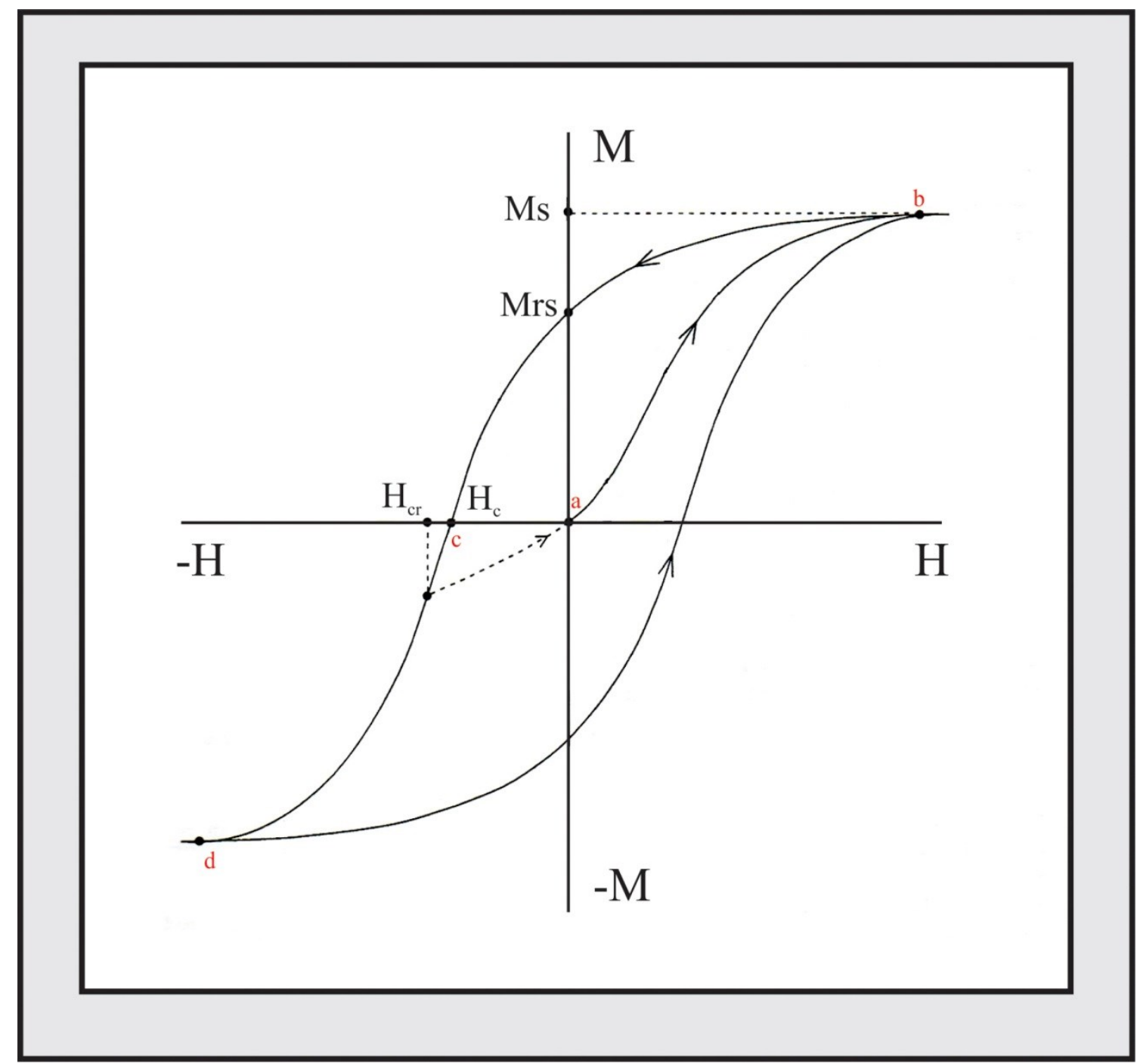

Figura 2.14. Ejemplo de ciclo de histéresis de una sustancia ferromagnética. Tomada de Walden et al. (1999) 


\subsection{Tablas del Capítulo 2}

\begin{tabular}{|c|c|c|c|}
\hline Tipo de Material & Comportamiento & $\mathbf{1 0} \mathbf{- 8}^{\mathbf{3}} \mathbf{K g}^{\mathbf{- 1}}$ & Ejemplo \\
\hline Ferromagnético & Suceptibilidad alta positiva & $\begin{array}{c}27.600 .000 \mathrm{a} \\
6.885 .000\end{array}$ & Hierro puro, niquel, cromo \\
\hline $\begin{array}{c}\text { Ferrimagnético } \\
\text { Antiferromagnético } \\
\text { imperfecto }\end{array}$ & $\begin{array}{r}\text { Suceptibilidad alta positiva } \\
\text { positiva }\end{array}$ & 111.600 a 5.000 & $\begin{array}{c}\text { Magnetita, maghemita, } \\
\text { pirrotita, greigita }\end{array}$ \\
\hline $\begin{array}{c}\text { Paramagnético } \\
\text { Diamagnético }\end{array}$ & Susceptibilidad baja positiva & 169 a 31 & Hematita, goethita \\
\hline Susceptibilidad baja negativa & $-0,5 \mathrm{a} \mathrm{-2}$ & $\begin{array}{c}\text { Biotita, olivina, piroxeno, } \\
\text { anfibol, illita, smectita }\end{array}$ \\
\hline
\end{tabular}

Tabla 2.1. Susceptibilidad magnética para distintos tipos de material. Modificado de Walden et al. (1999).

\begin{tabular}{|c|c|c|c|}
\hline Mineral & $\begin{array}{c}\text { Susceptibilidad } \\
\text { magnética } \\
10^{-8} \mathrm{~m}^{3} / \mathrm{Kg}\end{array}$ & $\begin{array}{c}\text { Magnetización remanente } \\
\text { de saturación } \\
10^{-3} \mathrm{Am}^{2} / \mathrm{Kg}\end{array}$ & $\begin{array}{c}\text { Coercitividad de la } \\
\text { remanencia } \\
\mathrm{mT}\end{array}$ \\
\hline Magnetita & $52.000-67.000$ & $1.000-10.000$ & $15-33$ \\
\hline Hematita & 40 & 200 & 700 \\
\hline Goethita & 70 & 22.200 & 268 \\
\hline
\end{tabular}

Tabla 2.2. Propiedades magnéticas de óxidos de hierro presentes en sedimentos. Los datos corresponden a trabajos de diversos autores (Maher, 1998; Thompson y Oldfidls, 1986; Heider et al., 1994) 


\section{CAPÍTULO 3. ANTECEDENTES GEOLÓGICOS Y ESTRATIGRÁFICOS}

Los materiales en estudio corresponden a los sedimentos del Neógeno-Cuaternario que cubren parcialmente la Provincia Geológica de Tandilia (también conocida como Sistema de Tandilia, o bien, desde un punto de vista geográfico Sierras Septentrionales de la provincia de Buenos Aires). La misma, junto al Sistema de Ventania, al sur, y la llanura interserrana, entre ambas, conforman el llamado Positivo Bonaerense (Yrigoyen, 1975), que es limitado al noroeste por el Hemigraben (o lineamiento) de Vallimanca. Los límites norte y sur, son respectivamente la Cuenca del tectónica del Salado y la Cuenca tectónica del Colorado. En la figura 3.1 se muestra el mapa topográfico de la provincia de Buenos Aires y sus elementos morfoestructurales.

Según Ramos (1999) el Sistema de Tandilia limita mediante un sistema de fallas normales con la Cuenca tectónica del Salado al noreste y al sureste con la Cuenca tectónica de Claromecó (Fig. 3.2).

Teruggi y Kilmurray (1975) definieron a la Provincia Geológica de Tandilia como un conjunto de montañas en bloque, formada por relieves discontinuos de sierras y cerros alineados en sentido NO-SE que sobresalen entre 50 y 250 metros por encima del llano circundante. El área con presencia de exposiciones rocosas abarca una extensión aproximada de $350 \mathrm{Km}$, desde Olavarría a Mar del Plata, con una anchura máxima en su parte central de $60 \mathrm{Km}$. Sin embargo, el extremo más austral de Tandilia ha sido identificado a partir de evidencias geofísicas a $57 \mathrm{Km}$ al sudeste de Punta Mogotes en la plataforma continental argentina (Kostadinoff, 1985). Como se muestra en la figura 3.2, la extensión del Basamento Precámbrico indicaría el área total de la Provincia Geológica de Tandilia, esto incluiría su continuidad en la plataforma continental (Dalla Salda et al., 2005).

El carácter discontinuo de los afloramientos rocosos ha permitido la división del cordón en distintos grupos menores de sierras que de NO a SE son: Sierras de Olavarría, Sierras de Azul, Sierras de Tandil y Sierras de Lobería, Balcarce y de Mar del Plata (Fig. 3.3). Las mayores elevaciones se encuentran en las Sierras de Tandil (Sierra La Juanita) con aproximadamente 524 m.s.n.m. 


\subsection{Características generales del área}

\subsubsection{Geomorfología}

El cordón serrano de Tandilia exhibe un perfil transversal asimétrico (Nágera, 1932, 1940), esto se debería a la disposición de los bloques que componen el basamento, con una inclinación de cinco grados hacia el sur y sudoeste (Teruggi y Kilmurray, 1975). La margen SO (costa de Claraz) presenta una suave pendiente cubierta por sedimentos del Cenozoico tardío. En cambio, la margen NE (costa de Heusser), presenta paredes subverticales que según Teruggi y Kilmurray (1975) corresponderían a una escarpa de falla muy desbastada por la erosión.

Nágera (1940) y posteriormente Teruggi y Kilmurray (1975), destacaron que la morfología del relieve de Tandilia se encuentra controlada por la litología de las rocas aflorantes. Las formas redondeadas se presentan allí donde aflora el basamento ígneo-metamórfico (e.g. Sierras de Tandil) y las formas tabulares y mesetiformes corresponden a afloramientos de cuarcitas (e.g. Sierras de Balcarce).

El sistema de Tandilia queda enmarcado dentro del dominio geomorfológico denominado Cordón serrano Septentrional (Frenguelli, 1950). Internamente pueden diferenciarse tres unidades geomorfológicas principales: sector serrano, piedemonte y llanura (Sala, 1975). Según el autor, el sector serrano está caracterizado por la presencia de sierras, cerros aislados y valles, estos últimos relacionados a la existencia de bloques elevados por fallas directas. La topografía es abrupta con pendientes más pronunciadas. Comprende la zona de cabeceras de los cursos fluviales, con drenaje superficial de tipo consecuente, que sigue la pendiente regional en forma integrada y bien definida. El diseño fluvial es de tipo dendrítico, con regímenes transitorios, efímeros y con divisorias bien delimitadas. El sector de piedemonte se localiza en forma continua al serrano y se conforma de abanicos aluviales coalescentes, por lo que las pendientes son más suaves. En esta zona los cursos de agua son divergentes, con divisorias poco definidas. Por último, el sector de llanura se caracteriza por poseer pendientes bajas. Los cursos de la vertiente NE, nacidos en las Sierras de Olavarría, Sierras de Azul, Sierras de Tandil y norte de las Sierras de Balcarce desarrollan, en la Pampa Deprimida (Frenguelli, 1950; INTA, 1970, 1989), cursos abortivos y numerosas cuencas endorreicas y arreicas, que conforman la denominada Zona de Derrames (Dangavs, 2005a). Los cursos de la misma vertiente, pero que nacen hacia el sur del sector central de las Sierras de Balcarce, forman arroyos que logran desembocar en la costa atlántica, entre Mar Chiquita y Mar del Plata. De forma similar, los cursos de la vertiente SO, que nacen en las Sierras de Tandil y en las Sierras de Lobería, Balcarce y Mar del Plata, desembocan en la costa atlántica, entre Mar del Plata y Necochea. 
Martínez (2001) dividió el paisaje de la vertiente norte, entre las Sierras de Balcarce y Mar del Plata hasta la costa atlántica y la albufera de Mar Chiquita, en tres dominios geomorfológicos: Sierras, Franja Eólica Periserrana y Planicie Fluvio-Eólica (Fig. 3.4). El dominio de Sierras o Relieve serrano incluye al sector de roca desnuda, donde predomina la meteorización física de las laderas convexas (Cumbres Planas), en ocasiones cubiertas por depósitos eólicos del Pleistoceno tardío, y un sector escarpado (Frente serrano), de laderas cóncavas, con formación de "aleros" por erosión. Predominan los procesos de remosión en masa, con caídas y desprendimientos de bloques en la zona alta, en tanto que en la baja ocurre la depósitacion de coluvios y aluvios. La Franja Eólica Periserrana, es dominada por depósitos loéssicos del Pleistoceno tardío-Holoceno que se disponen en lomas elongadas a subcirculares, de hasta $60 \mathrm{~m}$ de altura, que se adosan a los frentes serranos. Según el autor, aquí los arroyos presentan nacientes puntuales, efímeras entre las lomadas y se van integrando anárquicamente hasta conformar una red de drenaje definida, con diseño dendrítico en la Planicie Fluvio-Eólica. Esta última, se corresponde con la Pampa Deprimida y constituye un complejo relieve de llanura, con pendientes promedio de $0,11 \%$, que se caracteriza por una superposición de geoformas de origen eólico y fluvial. Las geoformas más conspicuas corresponden a una asociación de paleodunas parabólicas, longitudinales, cubetas de deflación (actualmente lagunas) y dunas de limo asociadas.

Aún es discutido el origen del relieve de Tandilia. Para Teruggi y Kilmurray (1975) los bloques habrían terminado de definir su actual disposición como consecuencia de reactivaciones de los sistemas de fracturas, en relación a los distintos pulsos tectónicos de la orogenia andina durante el Cenozoico tardío. Rolleri (1975) destacó que se trata de un paisaje longevo y propuso una edad mesozoica. Más recientemente Rabassa et al. $(1995,1998)$ y Demoulin et al. (2005) propusieron que el paisaje de Tandilia debía estudiarse desde una perspectiva gondwánica y analizaron el relieve utilizando como marco de correlación la historia geomorfológica de Sudáfrica, considerando que podría tratarse de un paisaje relicto, originado durante el Mesozoico. En el marco de esta propuesta, mencionaron tres superficies de erosión regional. La superficie más antigua puede observarse en las sierras de mayor altitud (Sierra La Juanita, Sierra Alta de Vela y Cerro La Blanca). Esta superficie afecta a granitos proterozoicos a una altura variable entre 450 y 500 m.s.n.m. y fue interpretada como previa al desmembramiento de Gondwana Occidental, en el Jurásico tardío - Cretácico temprano. La segunda superficie de erosión se encontraría en la zona de Balcarce y Mar del Plata a una altura de 200 - 250 m.s.n.m. y en la zona de Tandil a una altura de 300 - 350 m.s.n.m. Según los autores, la segunda superficie de erosión se habría desarrollado durante un periodo de 100 Ma de estabilidad, desde el Cretácico temprano hasta el Oligoceno tardío, que siguió al desmembramiento de Gondwana. La reactivación de la subsidencia y levantamiento de los cordones ubicados en el centro-oeste de Argentina durante el Mioceno temprano, resultado del incremento en la tasa de convergencia de las placas de Nazca y Sudamericana habría puesto fin a la evolución de la segunda 
superficie. La tercera superficie de erosión, de edad Mioceno medio, estaría vinculada a la profundización de las redes de drenaje y sería el sustrato de la cubierta sedimentaria cenozoica, representada por la llanura de loess pampeano y los depósitos desarrollados al pie de las sierras. En este esquema (Demoulin et al., 2005), se propone que las sierras corresponden a relictos de un paisaje mesozoico y que las exposiciones rocosas serían consecuencia de procesos de subsidencia en las cuencas que rodean al Positivo Bonaerense, es decir en las cuencas del Salado y del Colorado.

\subsubsection{Clima}

En cuanto a las características meteorológicas de la zona, el clima de la región es de tipo húmedo a subhumedo, mesotermal, con nula o pequeña deficiencia de agua. La temperatura media anual para Tandil (calculada para en el período 1949-1986) es de $13,6^{\circ} \mathrm{C}$, con una media máxima para el mes de enero de $20,8^{\circ} \mathrm{C}$ y una media mínima para el mes de julio de $8,1^{\circ} \mathrm{C}$ (Ruiz de Galarreta, 2006). En Mar del Plata los registros de temperatura son similares, con una media anual, para el período 1961-1990, de $13,8^{\circ} \mathrm{C}$, y una media máxima en el mes de enero de $19,7^{\circ} \mathrm{C}$ y una media mínima para el mes de julio de $8,2^{\circ} \mathrm{C}$.

Según los datos expuestos por Ruiz de Galarreta et al. (2007), la precipitación media anual para Tandil (registrada para el período 1900-2000) es de $838 \mathrm{~mm}$. Donde el mes más lluvioso corresponde a marzo, representando el 12\% de la precipitación anual $(99 \mathrm{~mm})$. El verano, comprendido en los meses de diciembre-enero-febrero, presenta el mayor volumen de precipitaciones, que equivale al $29 \%$ del total anual $(243 \mathrm{~mm})$. En contrapartida, el período invernal, que comprende los meses de junio-julio-agosto, presenta el menor volumen de precipitaciones, con $134 \mathrm{~mm}$ que corresponden al 16\% de la precipitación anual. Por otro lado, los autores mencionados determinaron que la evapotranspiración potencial para Tandil es de $712 \mathrm{~mm} /$ año y la evapotranspiración real de $694 \mathrm{~mm}$. Con un déficit hídrico de $18 \mathrm{~mm}$ en época estival. Desde mayo a noviembre el exceso hídrico sería de $144 \mathrm{~mm}$. El almacenaje de agua útil fue establecido en $150 \mathrm{~mm}$. No hay variaciones significativas para Mar del Plata y Balcarce, donde para el período 1941-1960 las precipitaciones medias anuales calculadas fueron de 849 y $840 \mathrm{~mm}$ y la evapotranspiración potencial determinada fue de 674 y $723 \mathrm{~mm}$ respectivamente (Cionchi, 1997). 


\subsubsection{Vegetación}

Las sierras septentrionales de la provincia de Buenos Aires se encuentran enmarcadas en la Provincia Fitogeográfica Pampeana, que pertenece al Dominio Chaqueño, donde la vegetación dominante es la estepa de gramíneas, formada principalmente por matas de Stipa (Cabrera, 1976). En el ambiente serrano, perdura la vegetación autóctona, evidenciándose un predominio de especies herbáceas, principalmente gramíneas, entre la que se destaca Cortaderia dioica. El estrato arbustivo está representado por Baccharis tandilensis y Colletia paradoxa. Las superficies rocosas suelen estar cubiertas por líquenes y briófitas. En aquellas zonas rocosas donde el agua subterránea es surgente son muy abundantes los helechos, especialmente Rumohra sp.

\subsubsection{Suelos}

Los suelos que se desarrollan en torno a las sierras septentrionales, en la denominada Subregión de Sierras y piedemonte de Tandilia (INTA, 1970, 1989), corresponden, en líneas generales, según la clasificación norteamericana de suelos (Soil Survey Staff, 2010), al orden Molisol y dado que régimen de humedad es predominantemente údico en toda la región, el suborden de los mismo correspondería a Udol. En el sector serrano no se desarrollan suelos allí donde las alturas alcanzan valores máximos, aflora la roca desnuda y los flancos muy empinados no ofrecen superficies apropiadas para la retención de los materiales que allí se depositan o que resultan de la meteorización de la roca. En cambio, donde las pendientes se hacen gradualmente más suaves es característica la pedregosidad en superficie y la presencia de un delgado manto de sedimentos limosos, donde se desarrollan suelos muy poco profundos (Hapludoles líticos) (Hurtado et al., 2005). Los sectores rocosos ocupan áreas muy reducidas respecto a los piedemontes serranos. La zona pedemontana, que comprende los flancos, las zonas de lomadas y pequeños sectores de llanura, están constituidos por un manto de material loessoide, de un espesor que puede superar los dos metros y que normalmente se apoya sobre una costra calcárea, que suele aflorar en la parte alta de las ondulaciones (Hurtado et al., 2005). En este sector predominan Argiudoles típicos y Paleoudoles petrocálcicos (Godagnone et al., 2002). Los Argiudoles típicos de la región son suelos profundos, con horizontes bien diferenciados, bien drenados y de $\mathrm{pH}$ neutro en todo el perfil. Con un horizonte "A" de alrededor de $25 \mathrm{~cm}$ de espesor, textura franca, estructura granular y bien provistos de materia orgánica (hasta 5\% y, ocasionalmente, más). Sigue un horizonte "B" de textura franco-arcillosa y estructura prismática, de aproximadamente unos $40 \mathrm{~cm}$ de espesor que pasa gradualmente al horizonte "C" (muy poco pedogenizado) (Hurtado et al., 2005). Los Paleoudoles petrocálcicos tienen morfología y otras características similares a los anteriores, pero están limitados por la costra calcárea, que se encuentra 
generalmente entre 50 y $100 \mathrm{~cm}$ de profundidad, aunque existen sitios donde el suelo consiste solamente en un horizonte "A" apoyado sobre la costra calcárea (Hurtado et al., 2005). Los fenómenos de hidromorfismo y halomorfismo en la región serrana de Tandilia son escasos y sólo existen en zonas de relieve cóncavo, entre lomadas. En las zonas distales, correspondientes a las subregiones Pampa deprimida y Pampa interserrana (INTA, 1989), las condiciones de alta saturación hídrica (régimen ácuico) se hacen más frecuentes.

\subsection{Estratigrafía general de la provincia geológica de Tandilia}

La provincia geológica de Tandilia, junto a la Isla Martín García, situada en el estuario del Rio de la Plata, posee los únicos afloramientos del basamento (Complejo Buenos Aires), de edad paleoproterozoica (2100 -2200 Ma) (Cingolani, 2005, 2010). El basamento se continúa en el subsuelo de una amplia región, correspondiente a la llanura Chaco-paranaense $\left(1.000 .000 \mathrm{Km}^{2}\right)$. Dichas rocas son las más antiguas de Argentina y constituyen la expresión más austral del cratón del Rio de la Plata (Almeida, 1971). Es de carácter ígneo-metamórfico, compuesto por gneises, migmatitas, anfibolitas y plutones graníticos, a los cuales se agregan esquistos, mármoles, metavulcanitas, y diques básicos y ácidos (Cingolani, 2005).

Posteriormente se originaron depósitos de plataforma marina somera de edad neoproterozoica, de composición carbonática y silicoclástica, denominados Grupo Sierras Bayas (formaciones Villa Mónica, Cerro Largo y Loma Negra) y Formación Cerro Negro (Iñiguez Rodriguez, 1999). Los mismos afloran mayormente en el extremo NO y a lo largo del flanco sur del sistema serrano.

Hacia el SE del sistema de Tandilia, se apoyan sobre el basamento las rocas que componen la Formación Balcarce (Dalla Salda e Iñiguez Rodriguez, 1979), compuesta por ortocuarcitas del paleozoico inferior, estratificadas y con intercalaciones de pelitas (Teruggi y Kilmurray, 1975). La máxima potencia de esta formación se encuentra en el extremo sudoriental de las Sierras (Punta Mogotes, con más de 400 $\mathrm{m})$.

Finalmente, mediante una importante discordancia y hiatus, las rocas mencionadas son cubiertas parcialmente por el complejo sedimentario del Cenozoico tardío, que constituye el objeto de estudio del presente trabajo. 


\subsection{Estratigrafía de los depósitos continentales del Cenozoico tardío}

El estudio de los depósitos del Cenozoico de la provincia Buenos Aires comenzó en el siglo XIX (D'Orbigny, 1842; Darwin, 1846; Doering, 1874, 1882; Ameghino, 1881, 1889, 1898) y continuó, casi sin interrupciones, hasta el presente.

La sedimentación cenozoica tardía continental en la provincia de Buenos Aires se habría iniciado con la prefase del tercer movimiento de la orogenia andina, cuyo primer efecto sería el inicio de la regresión del mar paranense (Pascual et al., 1965). Posteriormente Zárate (2005) indicó que dicha sedimentación habría comenzado en el Mioceno (ca. 12-11 Ma).

Los depósitos conforman sucesiones muy homogéneas desde el punto de vista textural y mineralógico, sólo varían en su coloración y contenido fosilífero (Teruggi, 1957). Se componen principalmente de limos arenosos y limos arcillosos de colores castaños y constituyen el llamado Plateau de "loess" de Argentina, donde la procedencia sería principalmente del oeste y sudoeste, es decir de la cordillera de los Andes, y se habrían desarrollado singenéticamente con el levantamiento de la misma como sedimentos transportados por medios eólicos y fluviales (Teruggi, 1957) y que fueron redistribuidos durante los cambios climáticos episódicos y cíclicos (Zárate, 2003). Por otro lado, Zárate y Blasi (1991, 1993 ) propusieron que las partículas que componen el loess pampeano fueron primero transportadas desde el piedemonte andino y la Patagonia septentrional por los sistemas de los ríos Colorado y Negro y depositadas en sus respectivas planicies aluviales. Luego los sedimentos fueron removilizados por el viento. Asímismo, Zárate y Rabassa (2005) consideraron que en el norte de la Provincia de Buenos Aires, la dinámica de la cuenca del Paraná y las Sierras Pampeanas, constituirían áreas de aporte secundario.

Teruggi (1957) indicó que la mineralogía corresponde a plagioclasas, cuarzo, ortoclasa, vidrio volcánico, feldespatos alterados, fragmentos de rocas volcánicas y ópalo orgánico. Los minerales pesados corresponden a óxidos de hierro (magnetita, ilmenita y minerales del grupo de las limonitas), anfíboles y piroxenos. Teruggi y Andreis (1971) observaron que los minerales inestables de la fracción arena y limo grueso presentaban escasos signos de meteorización. Por otro lado, González Bonorino (1965) reconoció, a partir de muestras extraídas por perforaciones en el área metropolitana de Buenos Aires y alrededores, dos zonas con características mineralógicas distintivas. La zona superior se caracteriza por abundancia de illita y plagioclasa, en tanto la zona inferior se distingue por la abundancia de cuarzo y montmorillonita, con escaso o nulo vidrio volcánico. El autor propuso que las diferencias se deben a un cambio de área de aporte y consideró a la zona cuarzo-montmorillonítica como Preensenadense. 
Diversos autores (Teruggi 1957; Gallet et al., 1998; Zárate y Blasi, 1991; entre otros) destacaron que los depósitos loéssicos de Argentina se distinguen de los de Europa y China por presentar vidrio volcánico, abundante plagioclasa en detrimento del cuarzo y textura más gruesa

Para referirse en sentido amplio y de manera informal al conjunto de depósitos del Cenozoico tardío continental es frecuentemente utilizado el término "pampeano" o "sedimentos pampeanos". La adjetivación "pampeano" fue empleado por primera vez por D'Orbigny (1842). El término fue utilizado desde entonces con sentido litoestratigráfico, cronológico, o bien como una mezcla entre ambos.

En cuanto a la estratigrafía, los esquemas pioneros fueron realizados por Ameghino $(1889,1908)$ sobre la base del grado evolutivo de las asociaciones de vertebrados fósiles. Posteriormente, han surgido numerosas propuestas. Algunas tuvieron valor exclusivamente local y no trascendieron. Otras, por el contrario, siguen siendo utilizadas hoy en día. La existencia de abundantes esquemas estratigráficos dio lugar a una gran proliferación de nombres y designaciones, que constituyen un caos nomenclatural, generando una gran dificultad a la hora de efectuar análisis de antecedentes (Zárate, 2005; Blasi et al., 2009), y por sobre todo, correlaciones estratigráficas.

Regionalmente, Zárate (2005), teniendo en cuenta las dificultades expuestas anteriormente, propuso un esquema abarcativo para toda la sedimentación continental del Cenozoico tardío de la región. El autor individualizó cuatro intervalos estratigráficos separados por discordancias que denominó: Subciclo Mioceno tardío (12-11 a 7-6? Ma), Subciclo Mioceno tardío-Plioceno (7-6? a 3,2 Ma), Subciclo Plioceno-Pleistoceno tardío (3,2 a 0,040-0,030 Ma) y Subciclo Pleistoceno tardío - Holoceno (0,0400,030 Ma hasta el presente). En la tabla 3.1 se sintetizan las principales características de los subciclos de sedimentación. Las discordancias que separan algunos de estos intervalos estratigráficos fueron vinculadas por Folguera Telichevsky (2011) a la tectónica andina, a fuerzas originadas en la dorsal centro-oceánica atlántica y a los acomodamientos isostáticos. No se descarta la importancia de los controles sedimentarios dados por las fluctuaciones climáticas.

Cabe destacar que debido a la escasa disponibilidad de métodos de datación viables, dadas las características de los sedimentos y el intervalo cronológico que abarcan, la asignación temporal de las distintas unidades sedimentarios de la región en estudio constituye un problema de importancia. Las dataciones por ${ }^{14} \mathrm{C}$, realizadas en valvas calcáreas, materia orgánica y colágeno en restos óseos, han sido muy difundidas. El alcance temporal del método (aproximadamente $40 \mathrm{Ka}$ ) lo restringe sólo a los depósitos más modernos. Un problema semejante corresponde a las dataciones por vías luminiscentes (termoluminiscencia, TL y luminiscencia ópticamente estimulada, OSL) las cuales superan rara vez los $400 \mathrm{Ka}$. Dataciones por TL y OSL fueron empleadas con buenos resultados hasta edades de $100 \mathrm{Ka}$. 
Superado ese intervalo los resultados suelen ser ambiguos. Esto puede deberse entre otras cosas, a la presencia de agregados de arcilla o clastos pelíticos tamaño arena (Lang, 1994). Amén de que se trata de depósitos sedimentarios, ha sido posible obtener edades numéricas confiables a partir de técnicas radiométricas como el método ${ }^{40} \mathrm{Ar}-{ }^{39} \mathrm{Ar}$, aplicado a sedimentos recristalizados a partir de fusión parcial generada por impactos de meteoritos o asteroides (Schultz et al., 1998), estos materiales se conocen actualmente con el nombre de escorias o vidrios de impacto (Fig. 3.5) y aunque carecen de amplia distribución areal y temporal, fueron hallados y datados en varias ocasiones (Schultz et al., 1998, 2004, 2006, 2008; Zárate et al., 2007)

\subsubsection{Bioestratigrafía}

Los sedimentos del Cenozoico tardío poseen una gran riqueza en contenido fósil, especialmente en restos óseos de mamíferos. Pascual et al. (1965, 1966), Marshall y Pascual (1978) y Marshall (1985) realizaron una revisión exhaustiva de la fauna fósil contenida en dichos sedimentos y basándose en los esquemas de Ameghino $(1889,1908)$, propusieron una serie de edades mamífero teniendo en cuenta el grado evolutivo de los taxa, el cambio de asociaciones faunísticas a lo largo del tiempo y en la primera y/o última aparición de ciertos grupos. Las edades mamífero tomaron en la provincia de Buenos Aires los siguientes nombres: Montehermosense, Chapalmalense, Uquiense, Ensenadense, Lujanense (Marshall, 1985). Posteriormente Cione y Tonni (1995) reemplazaron el término "Uquiense" por "Marplatense" y lo subdividieron en Barrancalobense, Vorohuense, Sanandresense y agregaron "Bonaerense" entre Ensenadense y Lujanene, restringiendo la edad de este último. Además dichos autores, basándose en que la asignación del grado evolutivo de los taxa es interpretativa, propusieron reemplazar el uso de las edades-mamífero por unidades bioestratigráficas, cronoestratigráficas, geocronológicas, tales como biozona y piso (o edad). Los nombres otorgados a las edades mamífero fueron reutilizados en este nuevo esquema (Fig 3.6).

Si bien en la actualidad las unidades bioestratigráficas del Cenozoico tardío de la Provincia de Buenos Aires están bajo una intensa revisión, ya que muchas de ellas fueron definidas sobre la base de fósiles de dudosa precedencia y ubicación estratigráfica incierta, la interacción con la magneto y la cronoestratigrafía ha permitido elaborar un marco estratigráfico bastante completo. En la Tabla 3.2 se muestran los intervalos cronológicos considerados para los Pisos (Edades) para la provincia de Buenos Aires, algunos de ellos son aún discutidos. 


\subsubsection{Magnetoestratigrafía}

Los estudios magnetoestratigráficos en sedimentos loessoides de la República Argentina comenzaron en la década del 80 y continúan hasta la actualidad. Los mismos marcaron un gran avance en cuanto al conocimiento de la edad de dichos sedimentos. Asimismo son de gran ayuda, junto a otros métodos de datación, para otorgar un marco cronológico a las unidades bioestratigráficas del Cenozoico tardío del área pampeana (Fig. 3.6).

Las principales contribuciones se refieren a sedimentos de la provincia de Buenos Aires. Entre ellos cabe mencionar los trabajos de Nabel y Valencio, 1981; Bobbio et al, 1986; Orgeira, 1987, 1988, 1990; Ruocco, 1989; Bidegain, 1991, 1998; Nabel et al., 1993, entre otros. Posteriormente, fueron publicados numerosos aportes, cuyos resultados contribuyen a construir el campo gnoseológico, metodológico y técnico de la disciplina.

En la provincia geológica de Tandilia, los estudios magnetoestratigráficos realizados hasta el presente se centraron en los afloramientos neogeno-cuaternarios expuestos en los acantilados marinos, entre Necochea y Santa Clara del Mar (Orgeira y Valencio, 1984; Orgeira, 1987, 1988, 1990; Ruocco, 1989, 1990; Heil et al., 2002; Bidegain et al., 2005b; Soibenson et al., 2009, 2010; Bidegain y Rico, 2012; Rico y Bidegain, 2013a, 2013b; Rico et al., 2014a, 2014b).

Las edades más antiguas asignadas a los sedimentos expuestos en el sector costero de Tandilia corresponden a los crones Gilbert superior (3,596 - 4,187 Ma) (Orgeira y Valencio, 1984) y Gauss (2,5813,596 Ma) (Orgeira y Valencio, 1984; Orgeira, 1987; Ruocco, 1989; Bidegain y Rico, 2012; Rico et al., 2014a), determinados en sucesiones expuestas entre el sur de Mar del Plata y Miramar. En la mayoría de los trabajos mencionados se han determinado los crones Matuyama $(0,781-2,581 \mathrm{Ma})$, incluyendo los subcrones Olduvai $(1,778-1,945 \mathrm{Ma})$ y Jaramillo $(0,988-1,073 \mathrm{Ma})$, y Brunhes $(<0,78 \mathrm{Ma})$.

\subsubsection{Registro de las glaciaciones en América del Sur}

Las oscilaciones del clima ejercen un importante control en los procesos depositacionales; esto fundamentalmente en relación a los ascensos y descensos en el nivel del mar, producto de ciclos glacieustáticos.

Rabassa et al. (2005) realizaron un esquema cronológico de las glaciaciones para América del Sur. Esta labor fue posible dada la excelente preservación de antiguas morrenas y otros depósitos glacigénicos en la Patagonia, vinculado esto a las condiciones predominantemente secas en la Patagonia 
extra-andina desde el Mioceno tardío hasta el presente. Asimismo los depósitos glacigénicos cuentan con intercalaciones de rocas volcánicas de flujo, que permitieron realizar dataciones numéricas de los depósitos. En el artículo mencionado, utilizando la información paleomagnética disponible se correlacionan las unidades loéssicas pampeanas con las glaciaciones patagónicas.

La glaciación patagónica más antigua reconocida por los autores se habría desarrollado entre $c a .7$ y $5 \mathrm{Ma}$ (Mioceno final-Plioceno inicial), e indicaron que habrían ocurrido un mínimo de ocho glaciaciones durante el Plioceno medio-tardío. El máximo avance glaciar (o Gran Glaciaciación Patagónica según los autores) habría tenido lugar entre 1,168 y 1,016 Ma. Posteriormente, 14-16 épocas geoclimáticas frías, con sus correspondientes equivalentes cálidos, habrían sucedido. Según los autores el Ultimo Máximo Glacial inició hacia $25 \mathrm{Ka}$ y finaliza hacia $16 \mathrm{Ka}$. Finalmente, habrían tenido lugar dos nuevos re-avances glaciarios (o fases estacionarias) durante el Tardiglacial $(15-10 \mathrm{Ka})$.

Durante los eventos glaciales se habrían producido cambios climáticos y ambientales, que tuvieron gran influencia en el desarrollo del paisaje y en los ecosistemas patagónicos y pampeanos en los últimos 5 millones de años. Las sucesiones de loess/paleosuelos se desarrollan en la Región Pampeana, en función de dichas oscilaciones. Asimismo, el modelo de reemplazo de las faunas terrestres pampeanas, así como el poblamiento de América, también se relacionaría a este esquema.

\subsubsection{Magnetismo ambiental}

Los estudios de magnetismo ambiental y magnetismo de rocas en sucesiones loéssicas de Argentina comenzaron en la década del 90. Registros de susceptibilidad magnética obtenidos en sedimentos del Cenozoico tardío en el norte y sudoeste de la provincia de Buenos Aires evidenciaron un patrón de comportamiento diferente al observado en sucesiones de loess-paleosuelo en China y Siberia. Mientras que en China los valores más elevados de susceptibilidad se registraron en horizontes pedogenizados (Maher y Thompson, 1999), en sucesiones pedo-sedimentarias expuestas en diversas

localidades del norte de la provincia de Buenos Aires se obtuvieron valores de susceptibilidad más bajos en los paleosuelos que en material parental (Nabel et al., 1993; Orgeira et al., 1998, 2001, 2002; Bidegain et al., 1996, 2001, 2005a, 2007, 2009, 2012).

Hacia el sur, ya sea en los acantilados del sector costero de la Provincia Geológica de Tandilia (Heil et al., 2002, Rico y Bidegain, 2011; Bidegain y Rico, 2012; Rico y Bidegain, 2013), así como en sedimentos fluviales del arroyo Tapalqué (Olavarría) (Orgeira et al, 2001, 2002), el patrón de 
susceptibilidad magnética obtenido en sedimentos plio-pleistocenos es semejante al obtenido en el norte de la provincia de Buenos Aires.

Hacia el centro (Bartel, 2009) y sur de la provincia de Buenos Aires (Bartel, 2009; Bartel et al., 2011) y en la provincia de La Pampa (Bartel, 2009; Bartel et al., 2011) se han determinado comportamientos con características afines a las registradas en el plateau de loess de China, con aumento de la susceptibilidad magnética en el solum. Orgeira y Compagnucci $(2006,2010)$ y Orgeira et al. (2011) relacionaron los cambios en el patrón de comportamiento de la susceptibilidad magnética con umbrales determinados en función de la precipitación media anual y la evapotranspiración potencial.

Bidegain et al. (1996, 2004) y Bidegain y Rico (2004), encontraron en sedimentos expuestos en canteras cercanas a la ciudad de La Plata una relación directa entre la susceptibilidad magnética y el contenido de hierro ferroso $\left(\mathrm{Fe}^{++}\right)$. Los valores más altos de ambos parámetros fueron determinados en materiales parentales, con escasos signos de pedogénesis; los valores intermedios en paleosuelos; y los más bajos en niveles de colores gley, con rasgos hidromórficos. En este sentido relacionaron la disminución de la señal magnética con el proceso de oxidación del hierro en los horizontes de paleosuelos, lo que habría dado lugar a la formación de oxihidróxidos paramagnéticos $(\mathrm{FeOOH})$.

\subsection{Estratigrafia de la cobertura cenozoica del Sistema de Tandilia}

\subsubsection{Sector serrano}

A través de perforaciones Tapia (1937) estudió la cubierta sedimentaria neógeno-cuaternaria de la Provincia Geológica de Tandilia en valles intermontanos cercanos a la localidad de Balcarce, indicando que su espesor alcanzaría los 165,55 m, disminuyendo, incluso hasta desaparecer, en las laderas de las sierras.

Rabassa (1971, 1973) y Teruggi et al. (1973) realizaron análisis granulométricos y mineralógicos en sucesiones del Cenozoico tardío del Sistema de Tandilia y propusieron orígenes mixtos: coluvialfluvial, eólico-coluvial-fluvial y eólico-coluvial, con desarrollo de paleosuelos. Además determinaron que, si bien la procedencia de los minerales es principalmente alóctona, estos depósitos contienen materiales autóctonos, provenientes de las sierras. 
En cuanto a la estratigrafía, Tapia (1937) mencionó la existencia de arcillas pardas y areniscas arcillosas que atribuyó al Plioceno, en el subsuelo de valles intermontanos en la región de las sierras de Balcarce, y las vinculó al "araucanense". El autor además determinó que la base de esos depósitos corresponde a un conglomerado (conglomerado basal) compuesto de fragmentos de ortocuarcitas, aplitas y basamento cristalino, con matriz de arcillas pardas. La edad de los depósitos mencionados fue fundamentada sobre la base de un fragmento de un roedor (Ctenomis Chapalmalensis) extraído a una profundidad de $45 \mathrm{~m}$ durante una perforación, sin embargo no descartó una edad más joven (Ensenadense). Según el autor, el límite superior de estos depósitos correspondería a un nivel calcáreo, hallado a una profundidad máxima de 16,40 m. Por encima de esta unidad, en discordancia erosiva reconoció una unidad compuesta por arenas finas a muy finas de origen eólico, color pardo amarillento, con bajo contenido de "calcáreos" y abundantes impresiones radiculares y tallos de herbáceas a la que denominó "Médano Invasor". Además realizó un análisis microscópico, en el que destacó que la arena está constituida dominantemente por granos de cuarzo pequeños, de contorno redondeado y a veces teñidos de óxidos de hierro. El contenido de vidrio volcánico es una característica predominante y lo acompañan granos de zircón, apatita y hornblenda en proporciones muy variables, así como plagioclasas y finas láminas de biotita. El autor mencionado observó además que el "Médano Invasor" se dispone en forma de lomadas que tienen alturas sobre el llano colindante de hasta $80 \mathrm{~m}$. En cuanto a la edad, el autor asignó a estos sedimentos al Pleistoceno en base al hallazgo de fauna fósil, correspondiente al Lujanense. Los depósitos del llamado "Médano Invasor" son de gran importancia dada su amplia distribución areal, ya que abarcan gran parte de la provincia de Buenos Aires y han sido estudiados y redefinidos por otros autores en diversos sitios de la región pampeana. Se corresponderían con las denominaciones Formación La Postrera (Fidalgo et al., 1973, 1986, 1990; Dangavs, 2005b), Formación Las Ánimas (Rabassa, 1971, 1973), entre otras.

Tapia (1937) además reconoció para la región otras unidades a las que asignó los siguientes nombres: "Rodados Ascendidos”, "Depósitos Lacustres” y "Depósitos Aluviales”.

Los "Rodados Ascendidos" se encuentran en las cumbres planas de las sierras formadas por ortocuarcitas. Según el autor corresponderían a acumulaciones fluviales que cubren una vieja superficie de erosión, que se encuentra actualmente a 250, 300 o más m.s.n.m. Teruggi et al. (1962) y Martínez (2001) interpretaron a los "Rodados Ascendidos" como un fenómeno de meteorización "in situ" de cuarcitas.

En cuanto a los "Depósitos Lacustres" y "Depósitos Aluviales", los primeros corresponden a arcillas grises, verdosas y amarillentas que atribuyó al Lujanense y serían contemporáneos al "Médano Invasor". En tanto, los "Depósitos Aluviales" pertenecen a las áreas fluviales, y corresponderían al Platense, de edad Holocena. 
En la región de Tandil, Rabassa $(1971,1973)$ realizó el primer esquema litoestratigráfico para el Cenozoico tardío de la región serrana de Tandilia. El esquema propuesto por el autor muestra cinco unidades litoestratigráficas. Las Formaciones Barker, Vela y Las Ánimas ocupan las áreas interfluviales (Tabla 3.3), las áreas fluviales están representadas por los sedimentos aluviales de edad reciente que se apoyan en discordancia erosiva sobre la Formación Tandileufú, que se apoya en discordancia sobre la Formación Vela.

En los trabajos antes citados se describe a la Formación Barker como una limolita castaño rojiza, arcillosa, sin estratificación aparente, muy compacta y que se desgrana en pequeños paralelepípedos que podrían corresponder a horizontes "B" de paleosuelos. En general carece de carbonato de calcio en su masa, a excepción de "muñecos de tosca" algunos de grandes dimensiones, formados por una tosca rosada muy dura. El autor atribuyó el color rojizo de la Formación Barker a la presencia de impregnaciones ferruginosas diseminadas en la masa de la sedimentita y a su homogeneidad en cuanto a estructura y granulometría. Para el autor, la génesis de la misma sería probablemente eólica. A la Formación Vela la describió como limos areno arcillosos a limos arcillo arenosos, a veces arenosos o con lentes de arcilla. Son de color castaño claro, con variaciones locales en el tono, de acuerdo al contenido de carbonatos. El autor consideró que los depósitos fueron originados por sedimentación eólica, pero con indicios importantes de acción hídrica. La unidad se habría desarrollado como un manto, generalmente de poco espesor, que cubre en discordancia erosiva casi totalmente los afloramientos de la Formación Barker o rocas más antiguas. Sobre la Formación Vela se desarrolló una antigua superficie topográfica, sobre la cual se asienta el relleno loéssico de las llanuras interserranas actuales. La antigua superficie topográfica mencionada corresponde a una costra calcárea de extensión regional, denominada Paleosuperficie Tandil (Teruggi et al., 1973), la misma, aunque se presenta generalmente en el sector cuspidal de la Formación Vela, puede sin embargo estar sobre unidades más antiguas, como la Formación Barker, el Basamento cristalino o sobre antiguos depósitos de remoción en masa (Fig. 3.7). Rabassa (1973) destacó que el manto de tosca constituye en muchos lugares el piso de los cauces de gran parte de los arroyos del área. Tanto la Formación Barker como Vela presentan desarrollo local de niveles de conglomerados, propios de zonas de piedemonte. En discordancia erosiva sobre la costra calcárea regional, tiene lugar la sedimentación de limos arenosos de origen predominantemente eólico pertenecientes a la Formación Las Ánimas, que como fue dicho, serían equivalentes al "Médano Invasor" y a la Formación La Postrera. Gentile y Ribot (2001) reconocieron un nivel de cenizas volcánicas en esta unidad, en un perfil situado en la ciudad de Tandil, y la compararon con otros niveles de cenizas hallados en la costa atlántica (Camet Norte) y en sedimentos aflorantes en el arroyo Tapalqué (Olavarría). De forma simultánea al desarrollo de los depósitos basales de la Formación Las Ánimas, se habrían generado los depósitos fluviales de la Formación Tandileufú (Rabassa, 1971, 1973), que comienzan con arenas gruesas que pasan a limos arcillosos en la parte 
superior. La sedimentación fluvial continuó, dando lugar a la formación del aluvio de edad reciente, integrado por limos grises, más o menos arenosos (Rabassa, 1971, 1973).

Rabassa (1973) realizó la caracterización mineralógica de las unidades por vía óptica y por difracción de rayos-X y determinó que la Formación Barker es rica en montmorillonita, pobre en illita, prácticamente carece de vidrio volcánico, donde es llamativa la abundancia de litoclastos de origen volcánico. La Formación Vela es rica en illita, pobre en montmorillonita y el vidrio volcánico es un componente muy importante, siendo los fragmentos incoloros mucho más abundantes que los de color castaño. La Formación Las Ánimas contiene abundante vidrio volcánico incoloro, escaso vidrio castaño y la relación montmorillonita-illita es variable. La mineralogía de la Formación Tandileufú es similar a la de la Formación Las Ánimas, aunque presenta abundancia de litoclastos de origen metamórfico hacia la base. Se carece de datos mineralógicos para el "Aluvio actual". En la Tabla 3.4 se muestra el contenido mineralógico porcentual promedio de las fracciones arena fina y muy fina, correspondientes a las formaciones Barker, Vela, Las Ánimas y Tandileufú. Los datos utilizados para construir la tabla 3.4 fueron tomados de Rabassa (1973).

En cuanto a la edad de las unidades, Rabassa $(1971,1973)$ le asignó una edad Pleistoceno tardíoHoloceno a la Formación Las Ánimas en función de su contenido fósil; asimismo, Fidalgo (1990), subdividió a la Formación La Postrera (que sería equivalente a Formación Las Ánimas) en tres miembros (I, II, III). Según el autor La Postrera I se habría depositado entre los 50.000 y 12.000 años AP en condiciones frías y áridas, La Postrera II entre los 12.000 y 7.000 años AP bajo condiciones templadashúmedas y La Postrera III entre los 7.000 años AP y la actualidad. Zárate y Blasi (1991) subdividieron el manto eólico en cuatro unidades aloestratigráficas e indicaron que la unidad más antigua se habría depositado entre 20-18 Ka; la siguiente durante el límite Pleistoceno-Holoceno; la tercera hace $c a .4500$ años y la más reciente durante la pequeña edad del hielo. Posteriormente Martínez (2001) y Dangavs (2005b) plantean esquemas similares.

Rabassa (1973) asignó la Formación Vela al Pleistoceno medio; sin embargo, Gasparini et al. (2012) mencionaron fósiles del Piso Lujanense en los niveles superiores.

En relación con la ubicación temporal de la Formación Barker, su edad es hasta ahora incierta. No se conocen hallazgos fosilíferos ni dataciones por otras vías. Rabassa (1973) le asignó con dudas una edad Plioceno - Pleistoceno inferior. Folguera y Zárate (2009) y Folguera Telichevsky (2011) propusieron para la Formación Barker una edad Mioceno tardío-Plioceno temprano en base a correlaciones con unidades litoestratigráficas presentes en el Sistema de Ventania y en la provincia de La Pampa. Por otra parte, Zárate y Mehl (2010) correlacionaron esta unidad con afloramientos de limolitas castaño rojizas, de 
aspecto macizo, ubicadas en las cabeceras del arroyo Azul así como en excavaciones en la localidad de Olavarría y proponen una edad Pliocena. Poiré et al. (2005) propuso designar los sedimentos aflorantes expuestos en excavaciones en la localidad de Olavarría bajo el nombre de "formación El Polvorín", sin embargo en Folguera Telichevsky (2011) son denominados como Formación Barker, siguiendo el esquema de Rabassa (1971, 1973). Recientemente en dichos sedimentos De los Reyes et al. (2013), Zurita et al. (2014) y Zamorano et al. (2015) citaron la presencia de vertebrados fósiles asignados a la Piso Chapalmalalense y Gómez Samus et al., (2014) registraron en la parte media y basal direcciones magnéticas de polaridad normal que atribuyeron al cron Gauss $(2,581-3,596 \mathrm{Ma})$.

Por otra parte, en forma paralela a los trabajos de Rabassa (1971, 1973), Teruggi et al. (1973) estudiaron los sedimentos del Cenozoico tardío expuestos en una excavación realizada en el faldeo SO de Sierra Bachicha (Balcarce). Este es el primer trabajo en Argentina que abordó el estudio de paleosuelos. Para ello realizaron ensayos granulométricos, mineralógicos y químicos. Los autores reconocieron en este perfil dos paleosuelos por debajo del suelo actual. La sucesión descripta por los autores consta de 7 niveles que se disponen en discordancia sobre el basamento cristalino. El nivel 1 corresponde a una mezcla de derrubios de falda con gravas y arenas fluviales, además de materiales eólicos. Según los autores, este depósito coluvio-fluvial fue cubierto por materiales loessoides posteriormente pedogenizados (nivel 2), que corresponderían a un período de cierta aridez, aunque es posible que ésta no haya sido muy marcada. El nivel 3 se compone de psefitas coluviales y fluviales intercaladas entre sedimentos arenosos y loessoides, que atribuyeron a una cierta actividad hídrica vinculada a un período de cierta humedad, que pasa paulatinamente a mayor sequía. El cese de la sedimentación habría provocado el desarrollo de impregnaciones de $\mathrm{CaCO}_{3}$ y mantos de tosca, que interpretaron como un horizonte "B" calcimórfico, de considerable importancia regional que denominaron Paleosuperficie Tandil (Fig 3.7). El nivel 4, dominado por depósitos loéssicos, en parte arenosos, indicaría la continuación de condiciones de sequedad. Finalmente los niveles 5, 6 y 7 corresponderían a los depósitos más recientes. El nivel 5 se compone de materiales locales depositados bajo influencia hídrica y entremezclados con depósitos eólicos, que se encuentran conformando un paleosuelo. Sobre el nivel 5 se habría depositado un delgado espesor de sedimentos loessicos (nivel 6) que se hacen algo coluviales hacia arriba, donde se ha desarrollado el suelo actual (nivel 7).

Los autores correlacionaron tentativamente algunos de los niveles determinados con el esquema estratigráfico de Rabassa (1971) para las Sierras de Tandil. De esta manera vincularon los niveles 1 y 2 con la Formación Barker, el nivel 3 con la Formación Vela y el nivel 4 con la Formación Las Ánimas.

El análisis mineralógico realizado por Teruggi et al. (1973) indicó que el vidrio volcánico, salvo en muestras de niveles edafizados del sector superior ( 5 y 7), es el componente predominante. Donde, la 
muestra obtenida del nivel 2 registró un porcentaje de trizas vítreas que alcanzó el 64\% de la fracción liviana. En forma opuesta, Rabassa (1973) destacó la marcada escasez de vidrio volcánico en la Formación Barker, respecto de las unidades sobreyacentes. Asimismo, Teruggi et al. (1973) no hicieron mención del contenido de litoclastos volcánicos en el perfil de sierra Bachicha, componente descripto como muy abundante en la fracción arena fina y muy fina de la Formación Barker (Rabassa, 1973).

Por último, es de destacar un estudio relativamente reciente, que abarca el ordenamiento estratigráfico de depósitos de remoción en masa que bordean las sierras y serranías de Tandilia. El mismo fue llevado a cabo por Martínez (2001) en las sierras de Bachicha y La Brava (Sierras de Balcarce). El autor diferenció tres unidades litoestratigráficas constituidas por depósitos de ortoconglomerados, matrizsosten, que denominó Formación El Junco, Barraque y Bachicha. La primera de ellas, la más joven, fue correlacionada con la Formación Las Ánimas, en cambio, la segunda, que posee un encostramiento calcáreo en su tope, identificado con la Paleosuperficie Tandil, fue correlacionada con la Formación Vela y probablemente Barker. La unidad más antigua (Formación Bachicha) se podría corresponder, según el autor, a tectofacies vinculadas a un ascenso del sistema serrano. Si bien la correlacionó con dudas con la Formación Barker, no descartó edades más antiguas, considerando una posible depositación durante el Mesozoico.

\subsubsection{Sector costero}

\section{Sector costero al sur de Mar del Plata}

Uno de los primeros investigadores en estudiar las sucesiones sedimentarias aflorantes en el sector costero de la provincia de Buenos Aires fue Ameghino (1908), quien planteó las bases para el estudio de la sedimentación cenozoica de la región. El autor realizó esquemas estratigráficos basados principalmente en la fauna fósil (Tabla 3.5). Más tarde Frenguelli (1921) estudió el área de acantilados desde Miramar a Mar del Plata y modificó ligeramente el esquema de Ameghino, adicionando conceptos tectónicos y litoestratigráficos. Posteriormente Kraglievich $(1952,1953$, 1959) realizó un esquema estratigráfico y propuso, en la última actualización (1959), las siguientes unidades litoestratigráficas (Tabla 3.5): Formación Chapadmalal, Barranca de Los Lobos, Vorohue, Miramar, Arroyo Seco, Santa Isabel y Lobería. Más tarde, Teruggi et al. (1974) analizaron los sedimentos de estas localidades tomando en cuenta las superficies de discontinuidad presentes (paleosuelos, costras calcáreas y discordancias). Siguiendo esta línea, Zárate (1989) en el marco de su tesis doctoral, consideró que el esquema de 
Kraglievich $(1952,1953,1959)$ no es válido, debido a que no hay diferenciación clara entre las unidades, ya que se establecen principalmente sobre la base de su contenido faunístico y no son mapeables a escala 1:25.000. Asimismo, el autor apeló a que el alto grado de homogeneidad litológica, mineralógica y textural de los depósitos del Cenozoico tardío expuestos en los acantilados marinos entre Miramar y Mar del Plata, imposibilitan un adecuado ordenamiento litoestratigráfico. Debido a esto, el autor efectuó una propuesta aloestratigráfica (Tabla 3.5), esto consiste en la división de la sección en unidades limitadas por discontinuidades. Las superficies de erosión (paleocanales) y las de no depositación (paleosuelos y niveles de costras calcáreas) presentan una gran extensión lateral que las hace identificables a lo largo de todo el acantilado. Por tal motivo, consideró que el uso de discontinuidades como límite de unidades es muy apropiado y es a la vez el que más contribuye a esclarecer el panorama estratigráfico, además de cumplir con el requisito de mapeabilidad a escala 1:25.000, tal como que exige el Código de Nomenclatura Estratigráfico Argentino (1992). Recientemente Beilinson (2009, 2011) estudió los depósitos del PlioPleistoceno (Aloformación Punta San Andrés) sobre la base de análisis faciales y arquitecturales. La autora identificó tres sistemas depositacionales: sistema fluvial anabranching, sistema fluvial entrelazado confinado y sistema fluvial entrelazado no confinado.

A pesar de la contribución de Zárate (1989), el esquema de Kraglievich (1952, 1953, 1959) aún goza de una notable vigencia. El mismo fue utilizado por numerosos autores con posterioridad a 1989.

\section{Sector costero al norte de Mar del Plata}

Las sucesiones sedimentarias expuestas en los acantilados costeros al norte de Mar del Plata han recibido menor atención en comparación con las presentes al sur de dicha ciudad. Uno de los primeros antecedentes corresponde a Ameghino (1908), quien utilizando como patrón el esquema que él mismo definió al sur de Mar del Plata, señaló que hacia el norte de dicha ciudad, las barrancas están constituidas por el Pampeano inferior (Ensenadense) y la parte inferior del Pampeano superior (Bonaerense). El autor mencionó la presencia de una "capa verdosa" entre ambas unidades que estaría representando la transgresión Belgranense, entonces atribuida al plioceno (hoy en día la denominación transgresión Belgranense hace referencia a los sedimentos marinos depositados durante el estadío isotópico 5e, hace ca. $130 \mathrm{Ka}$ ) (e.g. Schnack et al., 2005). Ameghino (1908) señaló que en los acantilados entre Mar del Plata y Miramar las sucesiones presentan sedimentos más antiguos (Chapadmalense), que se van hundiendo progesivamente hacia el sur, bajo depósitos más modernos. Al norte de Mar del Plata, las sucesiones comienzan con depósitos más jóvenes (Ensenadense). 
Kraglievich (1952) realizó la primera definición de unidades litoestratigráficas en los sedimentos aflorantes al norte de Mar del Plata en base a asociaciones faunísticas y discontinuidades físicas, y las correlacionó con el esquema que definió al sur de dicha ciudad. El autor interpretó que la parte superior de la sucesión sería equivalente a las formaciones Arroyo seco y Santa Isabel. Asimismo reconoció las formaciones Vorohué y San Andrés. Posteriormente, Tonni et al., (1992) consideraron errónea dicha correlación, ya que las unidades poseen fósiles de edad mamífero Ensenadense y correlacionaron algunos de estos afloramientos con la Formación Miramar (Kraglievich, 1952, 1953).

Tricart (1973) describió los sedimentos más jóvenes de la sucesión en un perfil ubicado en las cercanías de Santa Clara del Mar, donde reconoció dos eventos eólicos (E1 y E3) separados por un paleosuelo truncado de edad Platense. Los depósitos eólicos se apoyan sobre una costra calcárea, que denominó superficie Finipampeana, desarrollada sobre la parte superior del "pampiano", que representaría un sistema de explanadas (glacis) fosilizado por el loess inferior (E3), asociado a clima árido. El paleosuelo representaría un período de estabilidad, separando por épocas de intensa acción eólica. Martínez (2001) indicó que la superficie Finipampeana sería equivalente a la Paleosuperficie Tandil de Teruggi et al. (1973).

Fasano et al. (1984) estudiaron depósitos lacustres expuestos en la localidad de Camet Norte (Partido de Mar Chiquita) y los correlacionaron con el Lujanense (Frenguelli, 1950) y con las formaciones Santa Isabel y Cobo (Kraglievich, 1953). Interpretaron además, en coincidencia con Rovereto y Kraglievich (en Frenguelli y Outes, 1924), que los sedimentos lujanenses no constituirían una sedimentación post-bonaerense, sino que corresponderían a una variación facial del Bonaerense. Fasano et al. (1984) denominaron esta unidad como Facies Camet Norte de la Formación Santa Clara de Schnack et al. (1982). Intercalado con los sedimentos lacustres fue hallado un nivel cinerítico de $15 \mathrm{~cm}$ de espesor, posteriormente datado $\left({ }^{14} \mathrm{C}\right.$ ) en $21.000 \pm 15.000$ AP (Bigazzi et al., 1995). A partir de una nueva datación ${ }^{14} \mathrm{C}$ realizada por Pardiñas et al. (1998) en materia orgánica de excrementos, atribuidos a un herbívoro, se obtuvo una edad de $24.550 \pm 600$ AP. Poco después, Corbella et al. (2000) propusieron denominar al nivel tobáceco como Miembro Cineritas Camet de la Formación Lujan (Fidalgo et al., 1973) y lo describieron textural, química, mineralógica y paleomagnéticamente. Asimismo realizaron dos dataciones vía ${ }^{40} \mathrm{Ar}^{39} \mathrm{Ar}$ cuyos resultados fueron 20,9 $\pm 2,5$ y 20,9 $\pm 2,6 \mathrm{Ka}$. En cuanto a las características magnetoestratigráficas, los autores hallaron direcciones medias de polaridad magnética que se apartan del campo geomagnético de la región $\left(\mathrm{D}=83,0^{\circ} ; \mathrm{I}=-34,9^{\circ}\right)$ y asociaron estos datos, teniendo en cuenta las dataciones obtenidas, a una excursión del campo magnético sucedida durante el cron Brunhes $(<0,781 \mathrm{Ma})$, posiblemente el evento Mono Lake, datado en $25 \mathrm{Ka}$. Los autores además realizaron determinaciones de susceptibilidad 
magnética y obtuvieron valores de este parámetro mucho más bajos que en los sedimentos loessicos infra y suprayacentes.

Schnack et al. (1982) estudiaron los sedimentos ubicados al sur de Mar Chiquita y definieron la Formación Santa Clara. Los autores indicaron que dichos sedimentos están constituidos por limos de coloraciones amarillentas a rojizas, con abundante contenido de carbonato de calcio dispuesto en nódulos, tabiques, muñecos y bancos horizontales. Los autores le asignaron una edad mamífero Lujanense (en sentido de Pascual et al., 1965). Posteriormente, Fasano (1991) extendió la Formación Santa Clara al subsuelo y diferenció dos miembros (inferior y superior), cuyo perfil tipo se encuentra en las proximidades del arroyo Santa Elena (Santa Clara del Mar). El autor indicó que el Miembro Superior está constituido por limos con arenas muy finas, de tonalidades castaño amarillento claro a rojizo; presenta concreciones de tosca discontinua en tabiques verticales o costras horizontales; en el techo de la unidad se presenta un paleosuelo decapitado con cutanes de arcilla, pátinas de manganeso y estructura prismática. En la localidad de Mar de Cobo, el autor exhumó una asociación restos de vertebrados de edad mamífero Lujanense (Pascual et al., 1965) y correlacionó el Miembro Superior de la Formación Santa Clara con el Bonaerense (Frenguelli 1950, 1957) y la Formación Arroyo Seco (Kraglievich, 1952). Fasano (1991) indicó que en la localidad tipo, el Miembro Inferior sólo aflora entre 1 y 2 m por encima del nivel del mar y lo definió sobre la base de perforaciones. Está integrado por limos arcillosos a limos arenosos de color castaño amarillento claro de ambiente fundamentalmente fluvial, con un nivel de tosca muy compacto en su techo. Su potencia varía entre 4 y $7 \mathrm{~m}$. El autor halló restos de un Mesotherium cristatum y le asignó una edad mamífero Ensenadense. Finalmente correlacionaron el Miembro Inferior de la Formación Santa Clara con el Ensenadense (Ameghino, 1908; Frenguelli, 1950, 1957) y con la Formación Miramar (Kraglievich, 1952).

Bidegain et al. (2005b) brindaron un ajuste cronológico en las sucesiones ubicadas al norte de Mar del Plata a través de la realización de tres perfiles magnetoestratigráficos. En la base de las sucesiones de la desembocadura del Arroyo La Tapera y de Camet (partido de general Pueyrredon) hallaron un cambio de polaridad que asignaron al límite Brunhes-Matuyama (0,781 Ma), mientras que en la desembocadura del Arroyo Santa Elena (Santa Clara del Mar), al norte de los anteriores, obtuvieron sólo direcciones de polaridad normal por lo que consideraron que esos sedimentos son más jóvenes y que se depositaron durante el cron Brunhes $(<0,781 \mathrm{Ma})$. Los autores correlacionaron sus resultados con los obtenidos al sur de Mar del Plata (Orgeira y Valencio, 1984 y Ruocco, 1989) en la Formación Arroyo Seco (Kraglievich, 1952) y con los obtenidos en canteras cercanas a la ciudad de La Plata (Bidegain et al., 2001). Cabe destacar que los espesores de los acantilados son relativamente constantes en las tres localidades estudiadas, sin embargo el espesor de las unidades más modernas se incrementa hacia el norte. 
Posteriormente Prevosti et al. (2009) citaron para el sector basal de los acantilados cercanos al Arroyo Santa Elena la presencia de Theriodictis platensis y Protocyon $s p$, ambos correspondientes al Piso Ensenadense, que de acuerdo a la magnetoestratigrafía estarían en el cron Brunhes $(<0,781 \mathrm{Ma})$. Esto a su vez es consistente con lo establecido en diversas canteras de los alrededores de la ciudad de La Plata (Bidegain, 1991; Bidegain et al., 2007) en las que se determinó que a un paleosuelo con polaridad inversa (Matuyama) sobreyacen sedimentos loessoides de polaridad normal (Brunhes) en espesores variables (4 a 5 metros) que fueron asignados a la Formación Ensenada. Cabe consignar, por otra parte, que de estos mismos niveles fue exhumado un resto de un fósil asignado al Ensenadense (Mesotherium).

Martínez (2001), estudió las sucesiones sedimentarias al norte de Mar del Plata, tanto en el ámbito costero como en el interior continental y realizó un esquema estratigráfico abarcativo para los sedimentos que sobreyacen al Ensenadense de Ameghino (1908) o bien al miembro inferior de la Formación Santa Clara en el sentido de Fasano (1991). El autor designó una serie de unidades alo y edafoestratigráficas y realizó dataciones por termoluminiscencia (TL) y luminiscencia ópticamente estimulada (OSL). En la tabla 3.6 se muestran las unidades propuestas por Martínez (2001) donde el Geosuelo Compuesto Mar del Plata, corresponde a la unidad más antigua del esquema. El espesor máximo de dicho complejo paleopedogenético $(2,6 \mathrm{~m})$ fue descripto en una excavación que se ubicaba en el hipódromo de Mar del Plata, en las periferias de la ciudad. Se comprende de horizontes Bt, involucrando al menos tres paleosuelos. El autor consideró que el desarrollo del mismo sucedió durante el estadio isotópico 5e y correlacionó esta unidad con el Bonaerense de Ameghino (1908) y con la Formación Arroyo Seco (Kraglievich, 1952). Sobre el geosuelo Mar del Plata se apoyan en discordancia erosiva las aloformaciones El Hipódromo y Santa Clara, que según el autor son equivalentes, la primera fue definida en la excavación antes mencionada y la segunda en los acantilados costeros. En ambas predomina la fracción arena muy fina con cantidades variables de limo y arcilla, presentan estratificación cruzada y abundantes paleocanales rellenos por conglomerados de matriz arenosa. El autor identificó dos alomiembros (inferior y superior), cuya diferencia estriba en que los sedimentos del alomiembro superior son más friables y macizos. Consideró que los sedimentos descriptos se depositaron bajo condiciones frías y secas. En el techo de ambos alomiembros identificó paleosuelos que aludirían a eventos interestadiales. Al paleosuelo que corona el alomiembro inferior lo denominó Geosuelo El Hipódromo mientras que al del tope del alomiembro superior lo llamó Geosuelo Los Padres, este último presenta abundante carbonato de calcio que identificó como la paleosuperficie Tandil (Teruggi et al., 1973) y la superficie Finipampeana (Tricart, 1973). Por otra parte, en el alomiembro superior el autor registró un nivel de cenizas, cuyos valores de susceptibilidad magnética fueron más el elevados que en material hospedante (Bidegain et al., 2005a) y se considera más antiguo que el descripto para Camet Norte (con valores de susceptibilidad bajos). Las dataciones realizadas corresponden a la Aloformación El Hipódromo, donde Martínez (2001) 
registró las siguientes edades: $160,0 \pm 17 ; 91,5 \pm 12,4 ; 57,0 \pm 8 ; 46,9 \pm 7,7 ; 44,0 \pm 6 \mathrm{Ka} ; 41,8 \pm 5,6$ y 33,9 \pm 5 . El autor correlacionó la Aloformación El Hipódromo con la Aloformación Santa Clara, con el Bonaerense (Ameghino, 1908; Frenguelli, 1957), la Formación Santa Clara (Schnack et al., 1982), el miembro superior de la Formación Santa Clara (Fasano, 1991), la Formación Vela (Rabassa, 1971; 1973) y con La Postrera I (Fidalgo, 1990). Además la Aloformación Santa Clara incluiría sedimentos más jóvenes, correlacionables con la Formación Tandileufú (Rabassa, 1973) y la Formación Santa Isabel (Kraglievich, 1952; 1953). Por encima el autor describió otra unidad, denominada Aloformación Médano Invasor en virtud de la equivalencia de estos sedimentos, de origen dominantemente eólicos, con los definidos por Tapia (1937) en el sector serrano. Martínez (2001) propuso dos alomiembros para esta unidad, separados por un paleosuelo que denominó Geosuelo El Coyunco, ubicado en el tope del alomiembro inferior. El alomiembro inferior posee muy escaso espesor $(10-20 \mathrm{~cm})$ y su distribución es saltuaria. En cambio, el alomiembro superior puede alcanzar hasta $2,50 \mathrm{~m}$, apoyándose en discordancia sobre el anterior o sobre sedimentos más antiguos (e.g. aloformación el Hipódromo). El alomiembro superior remata con otro paleosuelo, con rasgos de hidromorfismo y una costra calcárea en su base. Este paleosuelo correspondería a un horizonte B enterrado (2Btb) constituyente del suelo actual. Las edades numéricas registradas por el autor para la aloformación Médano Invasor son: 58,3 $\pm 11 ; 39,6 \pm 5,2 ; 39,0 \pm 5$ y 15,5 \pm 2 Ka. Finalmente, correlacionó la unidad con los sedimentos "post-pampeanos" (Ameghino, 1889; Frenguelli, 1957; Tricart, 1973), el "Medano Invasor” (Tapia, 1937), el Cordobense (Frenguelli, 1957), la Formación Las Ánimas (Rabassa, 1971, 1973), la Formación Lobería (Kraglievich, 1952), la Aloformación Arroyo Lobería (Zárate, 1989), la Formación La Postrera (Tonni y Fidalgo, 1978), el miembro La Postrera II (Fidalgo, 1990), el E3 (Tricart, 1973), los limos Nahuel Ruca (Schanack et al, 1982) y la Formación Nahuel Rucá (Fasano, 1991). En discordancia sobre la Aloformacion Médano Invasor, Martínez (2001) designó como Aloformación E1, basándose en la denominación de Tricart (1973), a un conjunto de sedimentos loéssicos que representarían un nuevo evento de depositación eólica. Esta unidad debido a su intensa pedogenesis no siempre puede ser distinguida y en general constituye el horizonte "A" del suelo actual, que se apoyan sobre un "B" truncado (2Btb), e indicó que el episodio de truncamiento tendría una edad de 4,54 $\pm 0,5 \mathrm{Ka}$ basándose en las dataciones efectudas por Zárate y Flegenheimer (1991) en Cerro La China (Olavarría). Esta edad sería coincidente con la regresión del máximo nivel del mar holoceno. Cuando la Aloformación E1 es individualizable, su espesor generalmente varía entre 15 y $50 \mathrm{~cm}$. En sectores de divisorias, pueden distinguirse dos alomiembros (inferior y superior) separados por una discordancia, en estos casos el perfil de suelo adquiere la siguiente sucesión de horizontes: A-AC-2Ab-3Btb. La edad obtenida en esta aloformación fue de 0,75 $\pm 0,09 \mathrm{Ka}$. En cuanto a las correlaciones, identificó el alomiembro inferior de la aloformación E1 con el E1 (Tricart, 1973), el Aimarense (Frenguelli, 1957), La Postrera III (Fidalgo, 1990) y la "unidad 3" de la Llanura Interserrana (Zárate y Blasi, 1991), asimismo correlacionó al 
Alomiembro superior con los sedimentos post-conquista del Piso Ariano (Doering, 1882), sugiriendo una posible vinculación con la "Pequeña edad del Hielo", ocurrida durante los siglos XVI y XIX. 
3.5. Figuras del capítulo 3 .

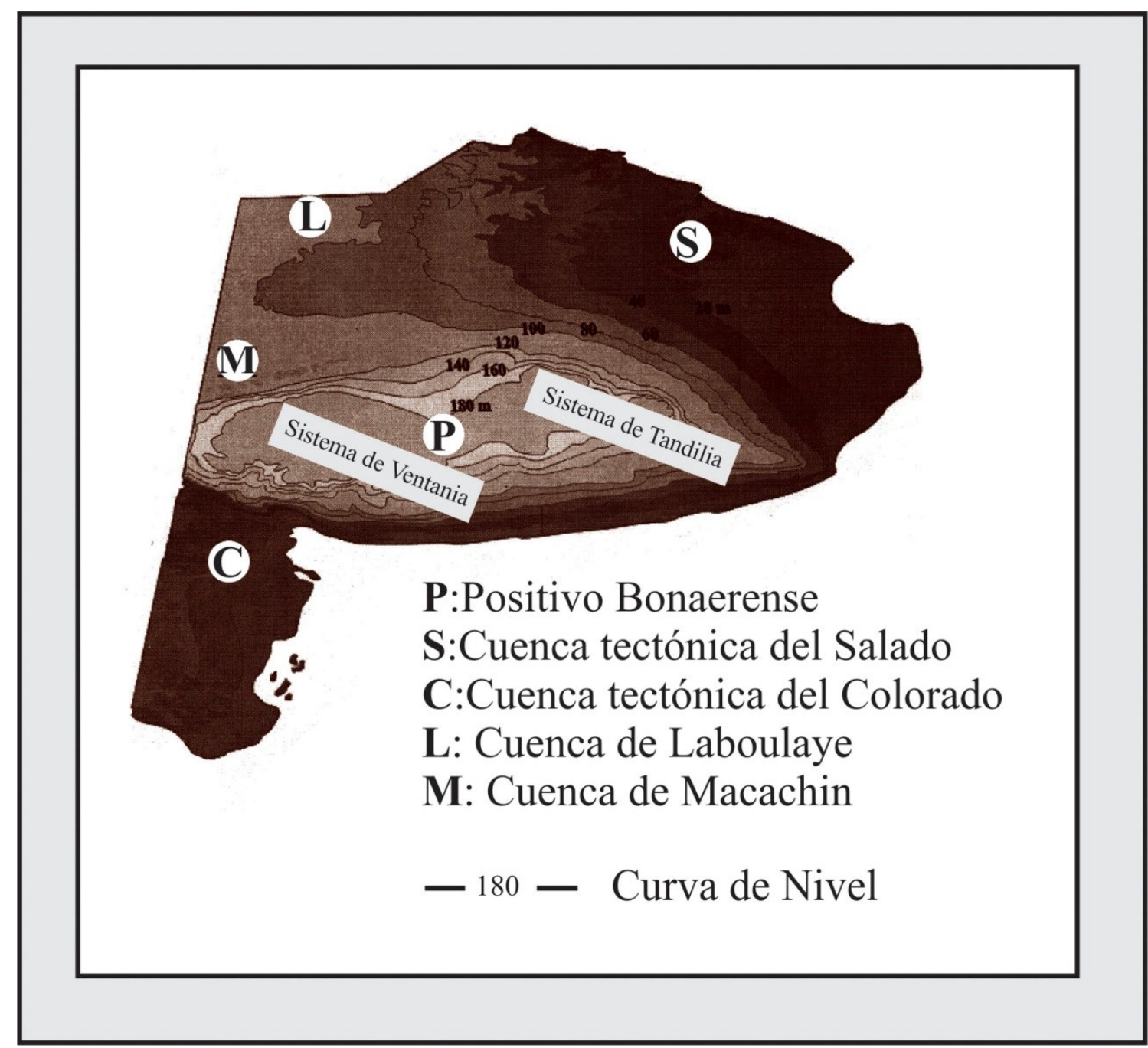

Figura 3.1. Mapa topográfico y elementos morfoestructurales de la provincia de Buenos Aires. Modificado de Zárate y Rabassa (2005). 


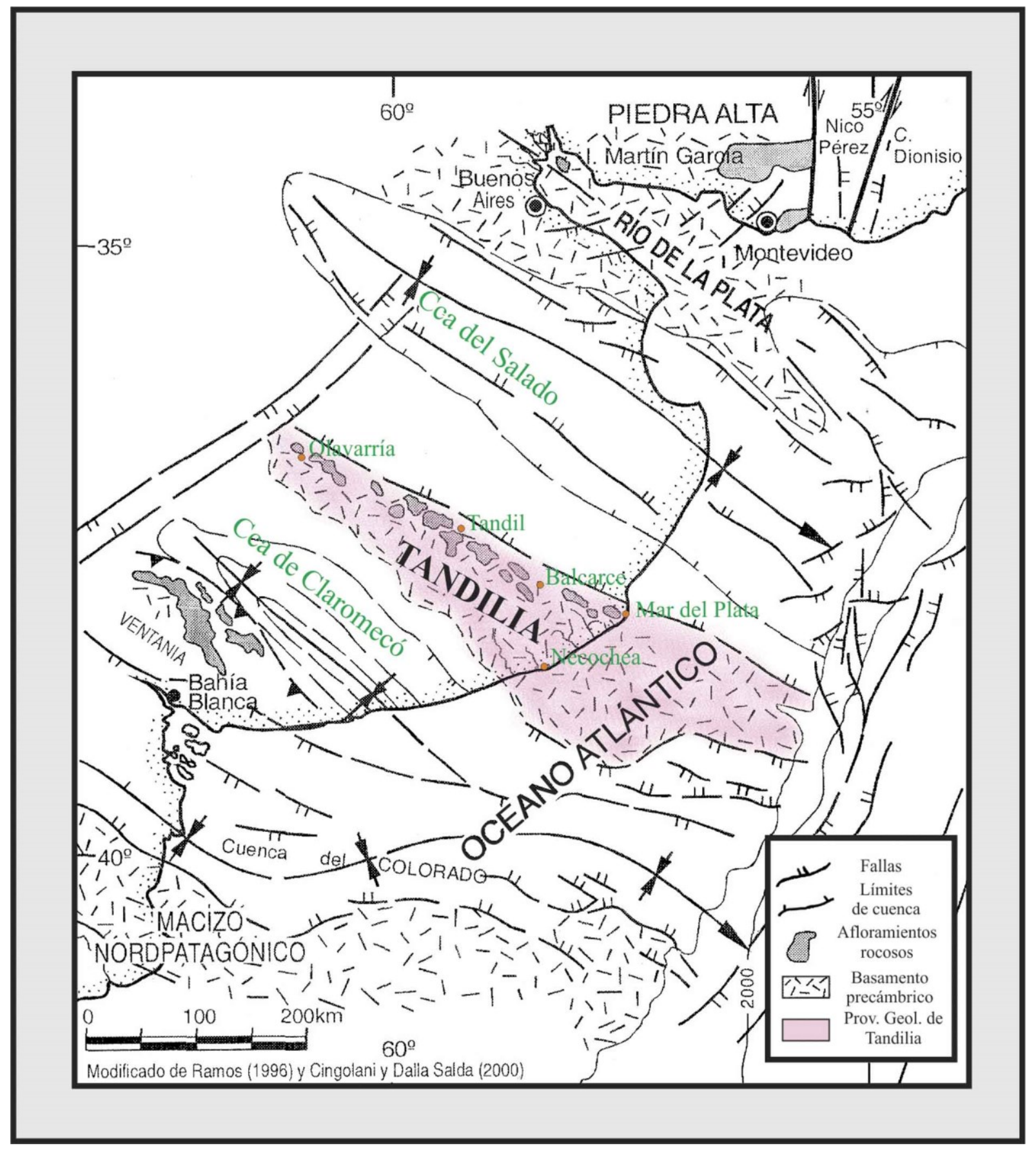

Figura 3.2. Distribución del afloramientos precámbricos y ubicación de la provincia geológica de Tandilia. Modificado de Dalla Salda et al. (2005). 


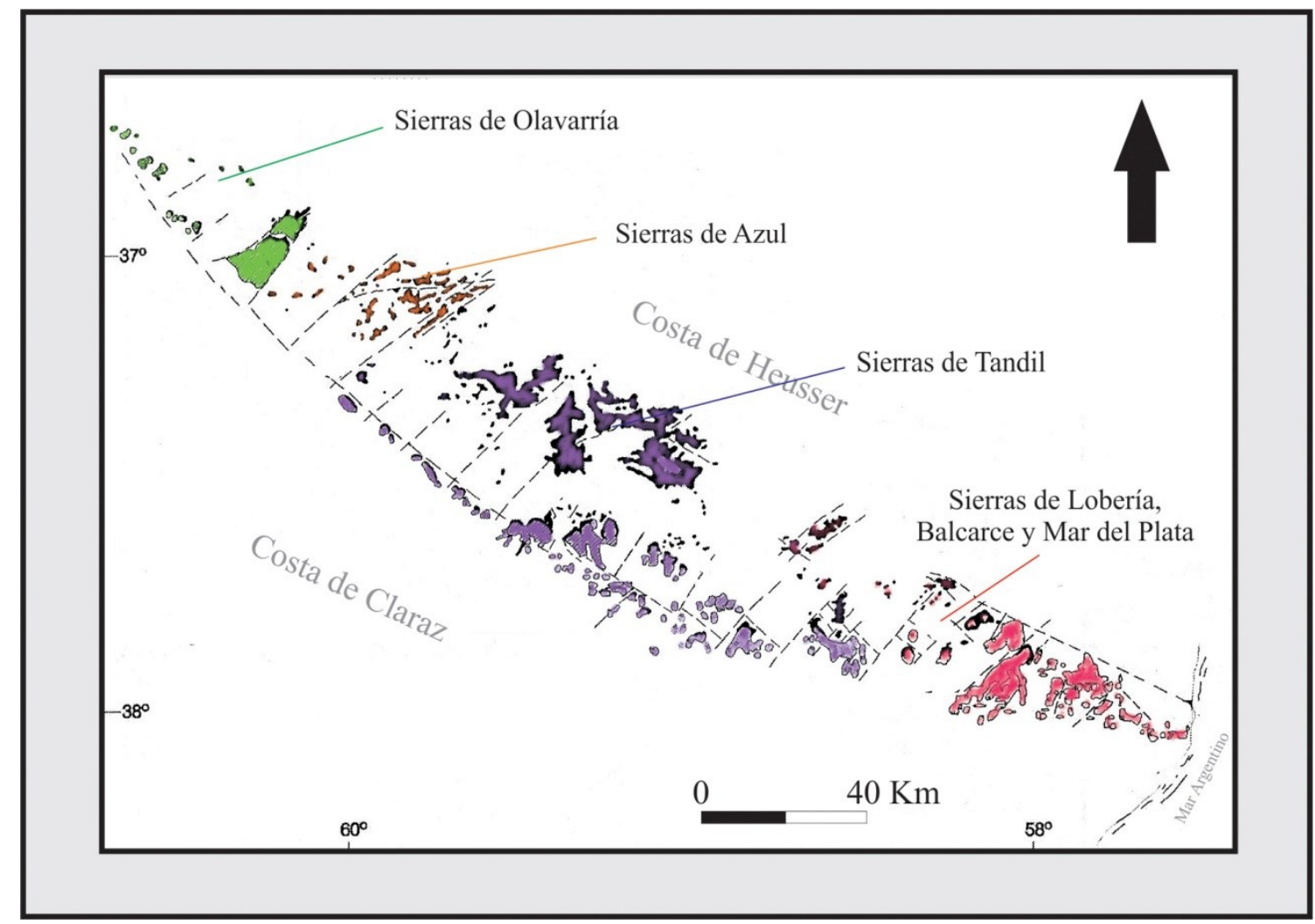

Figura 3.3. Distintos grupos de sierras menores del Sistema de Tandilia. Modificado de Ramos (1999). 


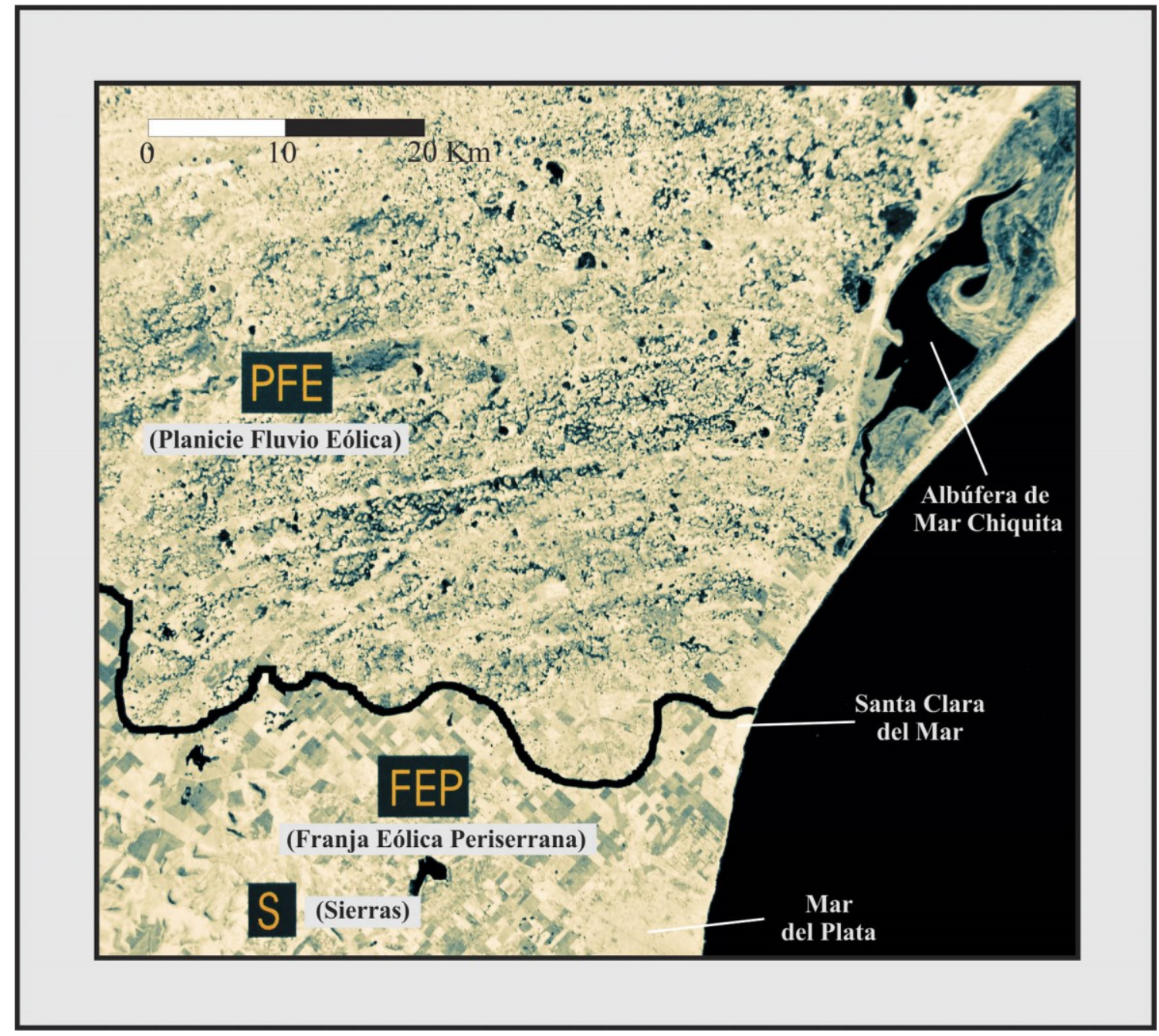

Figura 3.4. Dominios geomorfológicos en el sector sureste de Tandilia en el límite con la Pampa Deprimida (cuenca del Salado). Modificado de Martínez (2001). 


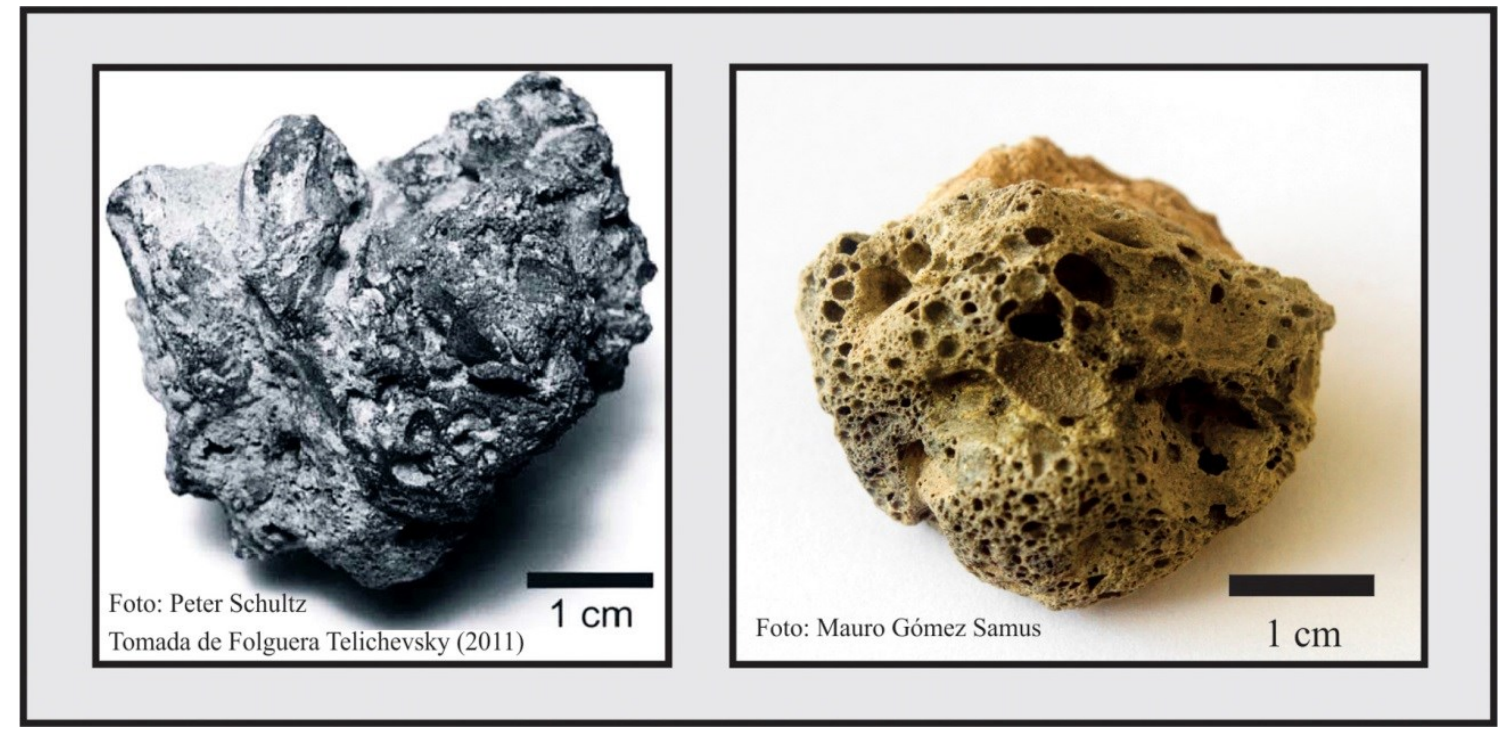

Figura 3.5. Fotografías de escorias o vidrios de impacto. 


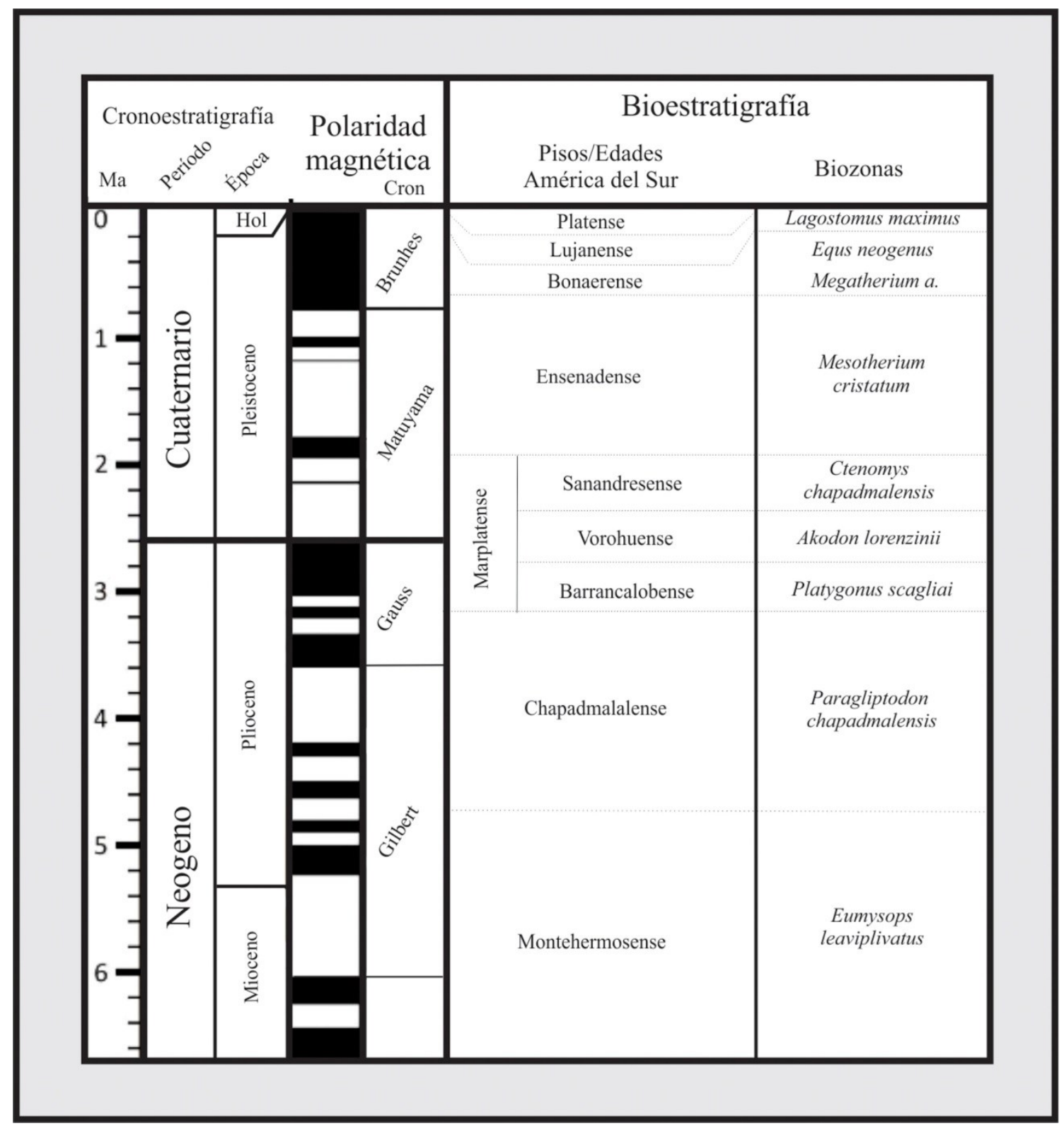

Figura 3.6. Pisos (Edades) para América del Sur, biozonas y marco temporal. Modificado de Cione y Tonni (2005) y Tomassini et al. (2013). 


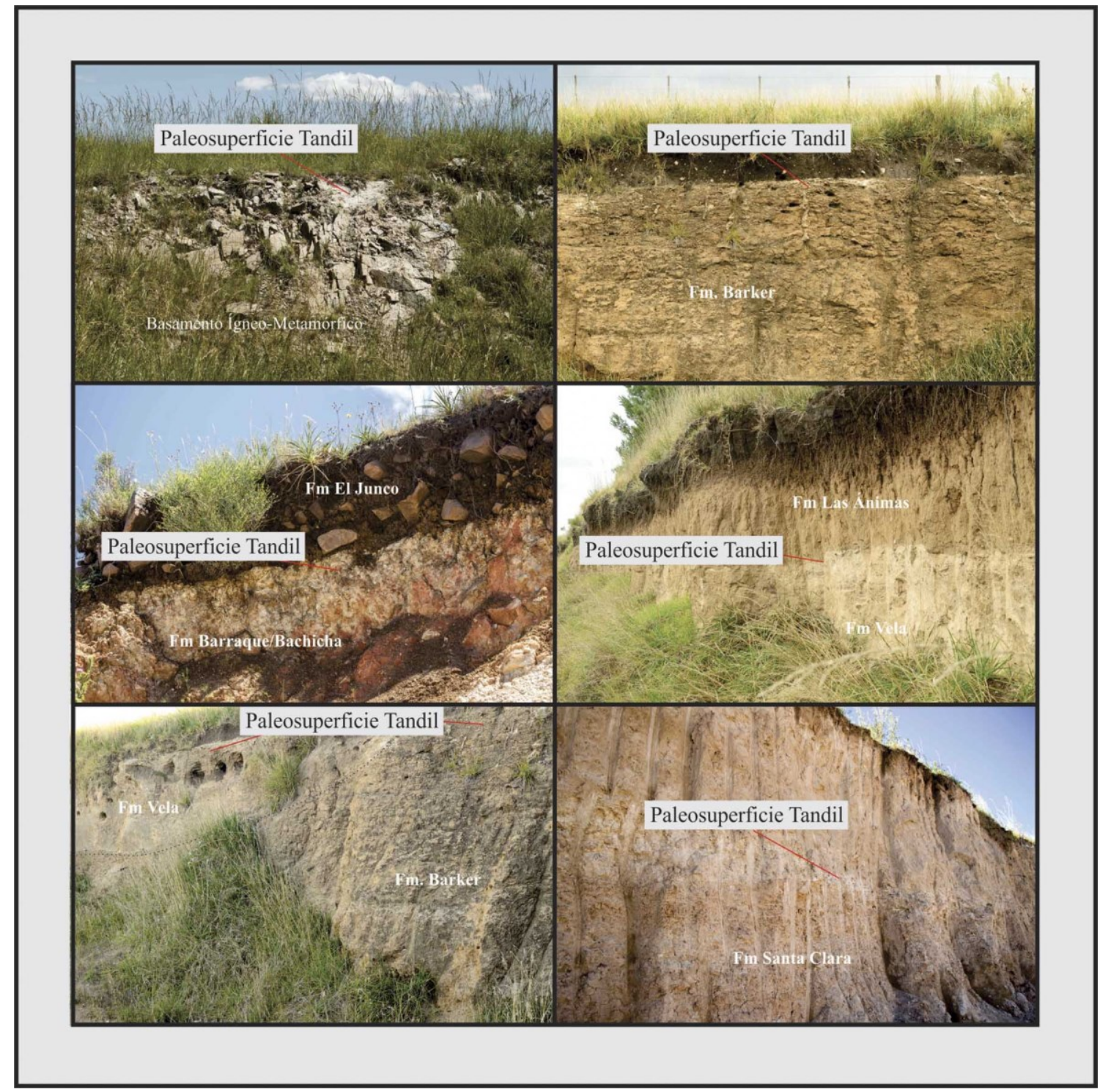

Figura 3.7. Fotografías de la costra calcárea regional (Paleosuperficie Tandil según Teruggi et al., 1973). Las fotografías fueron tomadas por el autor de la tesis. 


\subsection{Tablas del capítulo 3}

\begin{tabular}{|c|c|c|c|c|c|}
\hline $\begin{array}{c}\text { Ciclo } \\
\text { sedimentario }\end{array}$ & $\begin{array}{c}\text { Subciclo } \\
\text { sedimentario }\end{array}$ & $\begin{array}{c}\text { Edad } \\
\text { numérica } \\
\text { (Ma) }\end{array}$ & Piso (Edad) & Distribución areal & $\begin{array}{c}\text { Unidades estratigraficas } \\
\text { más nombradas }\end{array}$ \\
\hline \multirow{4}{*}{ Cenozoico tardío } & $\begin{array}{l}\text { Pleistoceno tardío - } \\
\text { Holoceno }\end{array}$ & $\begin{array}{c}0,040-0,030 \mathrm{Ma} \\
\text { hasta el } \\
\text { presente }\end{array}$ & $\begin{array}{l}\text { Platense } \\
\text { Lujanense }\end{array}$ & $\begin{array}{l}\text { en todas las unidades } \\
\text { morfoestructurales } \\
\text { bonaerenses }\end{array}$ & $\begin{array}{c}\text { Postpampeano: Ariano, } \\
\text { Aimarense, Lujanense, Platense, } \\
\text { Fm Luján, Fm La Postrera, } \\
\text { Médano Invasor, Fm Lobería } \\
\end{array}$ \\
\hline & $\begin{array}{c}\text { Plioceno - } \\
\text { Pleistoceno tardío }\end{array}$ & $\begin{array}{c}3,2 \text { a } 0,040- \\
0,030 \mathrm{Ma}\end{array}$ & $\begin{array}{l}\text { Bonaerense } \\
\text { Ensenadense } \\
\text { Marplatense }\end{array}$ & $\begin{array}{l}\text { Cuenca tectónica del Salado, } \\
\text { Tandilia, llanura interserrana }\end{array}$ & $\begin{array}{c}\text { Fm Pampeano, Fm Puelches, Fm } \\
\text { Arroyo Seco, Fm Miramar, Fm } \\
\text { Vorohué, Fm Barranca de los } \\
\text { Lobos } \\
\end{array}$ \\
\hline & $\begin{array}{l}\text { Mioceno tardío - } \\
\text { Plioceno }\end{array}$ & $7-6 ?$ a $3,2 \mathrm{Ma}$ & $\begin{array}{l}\text { Chapadmalalense } \\
\text { Montermosense } \\
\text { Huayqueriense }\end{array}$ & $\begin{array}{l}\text { Positivo bonaerense, Cuenca } \\
\text { tectónica del Colorado }\end{array}$ & $\begin{array}{c}\text { Araucano (araucanense), Fm } \\
\text { Chapadmalal, Fm Río Negro, Fn } \\
\text { Monte Hermoso }\end{array}$ \\
\hline & Mioceno tardío & $12-11$ a $7-6 ? \mathrm{Ma}$ & $\begin{array}{l}\text { Huayqueriense } \\
\text { Chasiquense }\end{array}$ & $\begin{array}{l}\text { Cuencas tectónicas del } \\
\text { Colorado y Macachin, } \\
\text { subsuelo del Positivo } \\
\text { Bonaerense }\end{array}$ & $\begin{array}{c}\text { Fm Epecuén, Fm Los Salitrales, } \\
\text { Fm Arroyo Chasico, Fm Cerro } \\
\text { Azul }\end{array}$ \\
\hline
\end{tabular}

Tabla 3.1. Subciclos de sedimentación para el Cenozoico tardío propuestos por Zárate (2005)

\begin{tabular}{|c|c|}
\hline PISO (EDAD) & INTERVALO \\
\hline Platense & $13-11 \mathrm{Ka}$ hasta el presente \\
\hline Lujanense & 130 a $13-11 \mathrm{Ka}$ \\
\hline Bonaerense & $400-500$ a $130 \mathrm{Ka}$ \\
\hline Ensenadense & $2-2,2 \mathrm{Ma}$ a $400-500 \mathrm{Ka}$ \\
\hline Marplatense & $3,2-3,3$ a $2-2,2 \mathrm{Ma}$ \\
\hline Chapadmalalense & $4,5-5$ a $3,2-3,3 \mathrm{Ma}$ \\
\hline Montehermosense & $6,8-5,3$ a $4,5-5 \mathrm{Ma}$ \\
\hline
\end{tabular}

Tabla 3.2. Intervalos cronológicos para los Pisos (Edades) de América del Sur. Las edades de los intervalos fueron tomadas de distintos autores (Cione y Tonni, 2005; Cione et al., 2007; Verzi y

Montalvo, 2008). 


\begin{tabular}{|c|c|c|}
\hline \multicolumn{2}{|c|}{ UNIDADES LITOESTRATIGRÁFICAS } & \multirow{2}{*}{ EDAD } \\
\hline Interfluvios & Áreas Fluviales & Holoceno \\
\hline Fm. Las Ánimas & Aluvio & Pleistoceno superior \\
\cline { 2 - 3 } & Fm. Tandileufú & Pleistoceno medio \\
\hline Fm. Vela & & $\begin{array}{c}\text { Plioceno - Pleistoceno } \\
\text { inferior? }\end{array}$ \\
\hline Fm. Barker & & \begin{tabular}{c} 
Hon \\
\hline
\end{tabular}
\end{tabular}

Tabla 3.3. Unidades litoestratigráficas y edades para la cubierta Cenozoica tardía del sector de Sierras de Tandil según Rabassa (1971, 1973).

\begin{tabular}{|c|c|c|c|c|c|c|c|c|}
\hline $\begin{array}{c}\text { UNIDADES } \\
\text { LITOESTRATIGRÁFICAS } \\
\text { (Rabassa, 1973) }\end{array}$ & \multicolumn{7}{|c|}{ MINERALOGÍA DE LA FRACCIÓN ARENA FINA Y MUY FINA (\%) } \\
(modificado de Rabassa, 1973) \\
\hline Barker & Q & FK & Pl & L & Vi & Vc & Op & P \\
\hline Vela & 14,45 & 3,95 & 11,32 & 62,68 & 2,71 & 1,13 & 2,13 & 1,61 \\
\hline Las Ánimas & 10,36 & 4,43 & 12,55 & 37,1 & 30,71 & 1,21 & 2,67 & 1,48 \\
\hline Tandileofú & 11,83 & 5,13 & 10,46 & 22,75 & 46,08 & 0,79 & 1,75 & 1,42 \\
\hline & 13,71 & 6,86 & 11,07 & 34,40 & 30,07 & 0,83 & 1,86 & 1,46 \\
\hline
\end{tabular}

Tabla 3.4. Mineralogía de la fracción arena fina y muy fina de las unidades litoestratigráficas del Cenozoico tardío del sector Sierras de Tandil. Valores tomados de Rabassa (1973). Q=Cuarzo; $\mathrm{FK}=$ Feldespato potásico; $\mathrm{Pl}=$ Plagioclasa $; \mathrm{Vi}=$ Vidrio incoloro; $\mathrm{Vc}=$ Vidrio castaño; $\mathrm{Op}=\mathrm{Opacos}$; $\mathrm{P}=$ Pesados translúcidos. 


\begin{tabular}{|c|c|c|c|c|c|c|}
\hline \multicolumn{2}{|c|}{ Ameghino (1908) } & $\begin{array}{c}\text { Kraglievich } \\
\text { (1952) }\end{array}$ & $\begin{array}{c}\text { Kraglievich } \\
\text { (1953) }\end{array}$ & $\begin{array}{c}\text { Kraglievich } \\
\text { (1959) }\end{array}$ & \multicolumn{2}{|c|}{ Zárate (1989) } \\
\hline $\begin{array}{c}\text { Post- } \\
\text { Pampeano }\end{array}$ & $\begin{array}{l}\text { Platense } \\
\text { Lujanense }\end{array}$ & Fm. Lobería & Fm. Lobería & Fm. Lobería & \multicolumn{2}{|c|}{ Aloformación $\mathrm{A}^{\circ}$ Lobería } \\
\hline \multirow{7}{*}{ Pampeano } & \multirow{2}{*}{$\begin{array}{l}\text { Bonaerense } \\
\text { Belgranense }\end{array}$} & \multirow[b]{2}{*}{ Fm. Arroyo Seco } & Fm. Santa Isabel & Fm. Santa Isabel & \multirow{6}{*}{$\begin{array}{c}\text { Aloformación } \\
\text { Punta San } \\
\text { Andrés }\end{array}$} & Alomiembro \\
\hline & & & Fm. Arroyo Seco & Fm. Arroyo Seco & & \\
\hline & $\begin{array}{l}\text { Ensenadense } \\
\text { cuspidal }\end{array}$ & Fm. Miramar & Fm. Miramar & Fm. Miramar & & $\begin{array}{l}\text { Alomiembro } \\
\text { Medio }\end{array}$ \\
\hline & \multirow{2}{*}{$\begin{array}{c}\text { Inter- } \\
\text { ensenadense }\end{array}$} & Fm. San Andrés & Fm. San Andrés & \multirow{2}{*}{ Fm. Vorohué } & & \multirow{3}{*}{$\begin{array}{l}\text { Alomiembro } \\
\text { Inferior }\end{array}$} \\
\hline & & Fm. Vorohué & Fm. Vorohué & & & \\
\hline & \multirow{2}{*}{$\begin{array}{l}\text { Ensenadense } \\
\text { Basal }\end{array}$} & Fm Barranca de & Fm Barranca de & Fm Barranca de & & \\
\hline & & los lobos & los lobos & los lobos & \multirow{2}{*}{\multicolumn{2}{|c|}{$\begin{array}{l}\text { Aloformación Punta } \\
\text { Martínez de Hoz }\end{array}$}} \\
\hline \multirow{3}{*}{ Araucano } & \multirow{3}{*}{$\begin{array}{l}\text { Chapad- } \\
\text { malense }\end{array}$} & \multirow{3}{*}{$\begin{array}{c}\text { Fm. } \\
\text { Chapadmalal }\end{array}$} & \multirow{3}{*}{ Fm. Chapadmalal } & \multirow{3}{*}{ Fm. Chapadmalal } & & \\
\hline & & & & & \multicolumn{2}{|c|}{$\begin{array}{c}\text { Aloformación Playa Los } \\
\text { Lobos }\end{array}$} \\
\hline & & & & & \multicolumn{2}{|c|}{$\begin{array}{l}\text { Aloformación Playa San } \\
\text { Carlos }\end{array}$} \\
\hline
\end{tabular}

Tabla 3.5. Esquemas estratigráficos para los sedimentos aflorantes en los acantilados entre Miramar y Mar del Plata según distintos autores. 


\begin{tabular}{|c|c|c|}
\hline Aloformación & Alomiembro & $\begin{array}{c}\text { Geosuelo/Hz } \\
\text { Pedológico }\end{array}$ \\
\hline \multirow{2}{*}{ E1 } & Superior & A-AC \\
\cline { 2 - 3 } & Inferior & $2 \mathrm{~A}$ \\
\hline \multirow{2}{*}{ Médano Invasor } & Superior & $2 \mathrm{Btb}$ \\
\cline { 2 - 3 } & Inferior & El Coyunco \\
\hline \multirow{2}{*}{ Santa Clara/El Hipódromo } & Superior & Los Padres \\
\cline { 2 - 3 } & Inferior & El Hipódromo \\
\hline \multicolumn{2}{|c|}{ Geosuelo Mar del Plata } \\
\hline \multicolumn{2}{|c|}{} \\
\hline
\end{tabular}

Tabla 3.6. Esquema aloestratigráfico para el Cenozoico superior del sector entre Mar del Plata y Mar Chiquita según Martínez (2001). 


\section{CAPITULO 4. TÉCNICAS Y HERRAMIENTAS}

El trabajo comenzó con una serie de recorridas exploratorias en el marco de la transecta planteada: Tandil - Balcarce - Mar del Plata. Durante esta etapa fueron identificados gran parte de afloramientos disponibles, algunos sirvieron para la realización de perfiles geológicos y tomar muestras paleomagnéticas en forma preliminar. El muestreo paleomagnético preliminar consistió en la adquisición de especímenes paleomagnéticos en distintos afloramientos y en distintas unidades litoestratigráficas. En esta etapa, la densidad de muestreo fue baja, con distancias verticales que en ocasiones superaron los $50 \mathrm{~cm}$. Esto tuvo como objeto conocer el comportamiento magnético general de los sedimentos del área de estudio. Esto se debió a que los valores magnéticos varían según la composición mineralógica y/o granulométrica de los materiales. Por ello, emprender muestreos de detalle sin conocer la aptitud de los mismos hubiera sido inadecuado. En posteriores salidas a los fines de efectuar las tareas de campo los muestreos fueron intensificados.

Se escogieron exposiciones sedimentarias artificiales (canteras y destapes al margen de rutas y caminos) y naturales (acantilados marinos). Teniendo en cuenta sus características, dispersión areal, posición topográfica y geomorfológica, así como su representatividad y sus particularidades, fueron seleccionados los afloramientos más apropiados para realizar los estudios propuestos en el marco del proyecto de Tesis.

Para facilitar la comparación entre los perfiles se delimitaron a su vez tres áreas, distinguibles por sus características geomorfológicas: Sector Sierras de Tandil, sector Sierras de Balcarce y sector costero al norte de Mar del Plata.

En la figura 4.1, se muestran los tres sectores que enmarcan los perfiles realizados, donde el sector Sierras de Tandil, ubicado en sector central del Sistema de Tandilia, se incluye dentro de los partidos de Tandil y Benito Juárez; el sector Sierras de Balcarce, al sureste del anterior, en los partidos de Balcarce y Lobería, y el sector costero abarca el sudoeste del Partido de Mar Chiquita y el noreste del Partido de General Pueyrredon.

\subsection{Secciones estratigráficas}

Previo a las labores de muestreo se delimitó el área de investigación y se la dividió en zonas a partir de características geológicas particulares. En cada una de esas zonas se escogieron los afloramientos 
más representativos de las unidades a ser investigadas desde el punto de vista paleomagnético y paleoambiental. El marco geológico se consideró de fundamental importancia en la investigación ya que provee una base adecuada para ajustar los muestreos y para que los mismos adquieran un grado de representatividad apropiado. Además, una correcta y minuciosa descripción de campo no sólo brinda el marco de referencia para las tareas de muestreo, sino que otorga también valiosísima información de base a la hora de interpretar los datos.

Como se indica en la figura 4.1, se han descripto y muestreado un total de 12 secciones estratigráficas. Su ubicación y altura sobre el nivel del mar se detalla en la tabla 4.1.

La metodología para el levantamiento de perfiles estratigráficos fue semejante en todos los casos. Incluyó la identificación de distintos niveles o capas, teniendo en cuenta la litología, la geometría, espesor, texturas, estructuras primarias y secundarias, su variación vertical y lateral, así como los contactos entre las distintas unidades. Además fue posible distinguir rasgos depositacionales (primarios) de otros de carácter postdepositacional (paleosuelos, entoscamientos y evidencias de bioturbación). En las secciones estratigráficas que presentaban exposición del suelo actual no disturbado por labores antrópicas, éste fue descripto según las recomendaciones de Schoeneberger et al. (2000) y clasificado tentativamente según Soil Survey Staff (2010).

Los datos obtenidos durante el trabajo de campo se emplearon para elaborar, en gabinete, paneles y columnas sedimentarias de cada uno de los afloramientos relevados, donde se incluyeron los datos de litología, espesores, estructuras, rasgos postdepositacionales, tipos de contactos, y demás datos descriptivos de relevancia.

Se recolectaron dos tipos de muestras; las "muestras paleomagnéticas", que se extrajeron orientadas y sin disturbar, y se destinaron a obtener los registros de polaridad magnética; y las muestras de sedimentos o "muestras totales", entre $1 / 2$ y $1 \mathrm{Kg}$ de material, una a cuatro muestras por capa, destinadas a la medición de parámetros magnéticos, análisis químico, textural y mineralógico.

\subsection{Perfiles paleomagnéticos, medición y procesado}

El muestreo paleomagnético se efectuó mediante un sacatestigos a pistón, denominado Swedish piston, diseñado originalmente por el Dr. Mörner y modificado posteriormente por el Dr. Bidegain (Fig 4.2a). El mismo está constituido por un tubo metálico no magnético (hidrobronce o acero austenítico) de sección cuadrada (18,5 mm de lado) y de hasta $30 \mathrm{~cm}$ longitud. En el interior del tubo es colocado un 
prisma macizo (vástago), de aluminio, de libre movimiento, cuya función es aislar el sedimento de un sistema de empuje con rosca de acero, ubicado en la parte posterior del tubo, necesario para expulsar el material.

Para la obtención de cada muestra paleomagnética, la superficie sedimentaria a ser muestreada debió ser emparejada y limpiada. El muestreador fue orientado con su eje máximo según el norte magnético mediante una brújula (Brunton o Declinatoria) y nivelado horizontalmente con nivel de burbuja (Fig 4.2b). Posteriormente el muestreador fue hincado en el sedimento con martillo o masa.

Finalmente el material recolectado por esta vía fue colocado en cubos de plástico de $8 \mathrm{~cm}^{3}$ (Fig 4.3a), al que se le imprimió una flecha con marcador indeleble indicando la dirección del norte magnético. Para fijar los granos y evitar el movimiento de los mismos durante el traslado y la medición, se adicionó adhesivo vinílico no magnético (plasticola) o silicato de sodio analítico.

Cuando fue posible, el muestreador fue hincado a una profundidad horizontal mayor a $3 \mathrm{~cm}$ a fin de evitar zonas disturbadas por exposición aérea y alcanzar zonas con mayor humedad, lo cual otorga coherencia al sedimento extraído.

Las muestras paleomagnéticas se extrajeron a una equidistancia vertical promedio de $20 \mathrm{~cm}$. En ocasiones el muestreo fue realizado a equidistancias inferiores para obtener mayor resolución. No obstante, algunos afloramientos presentaron sectores de difícil acceso, esto obligó a realizar la toma de muestras con un espaciamiento mayor, aunque, para obtener mayor control, se realizaron extracciones por duplicado, ya sea exactamente en el mismo lugar o bien distanciadas lateralmente, siguiendo la capa sedimentaria.

La dureza de los niveles calcáreos en ocasiones impide el muestreo por la vía descripta anteriormente. En tales casos se extrajeron bloques de calcreta mediante masa y cortafierro, orientados según el norte magnético que luego fueron cortados en laboratorio, en forma cilíndrica o cúbica, a fin de adecuar sus dimensiones a los equipos de medición (Fig 4.3b).

Todas las muestras paleomagnéticas fueron medidas en el Área de Paleomagnetismo del LEMIT mediante un magnetómetro rotativo Minispin de la empresa Molspin Ltd (Fig 4.4a). En una primera etapa se midieron las magnetizaciones remanentes naturales (MRN) de todas las muestras y luego se efectuó la desmagnetización por campos magnéticos alternos (CMA) linealmente decrecientes, mediante un desmagnetizador de la misma empresa (Fig 4.4b). 
El proceso de "lavado" magnético se realizó a partir de campos bajos de 2,5 militesla (mT) a los fines de evitar la destrucción de la muestra y hasta campos generalmente de $80 \mathrm{mT}$. En muestras con escasa resistencia al proceso de desmagnetización ("blandas"), el "lavado" magnético se efectuó hasta 40 $\mathrm{mT}$ de campo pico, así mismo, muestras con mayor resistencia a la desmagnetización (“duras"), fueron sometidas a campos de 100 y $120 \mathrm{mT}$ de campo pico.

El objetivo del lavado magnético es eliminar componentes secundarias, de origen químico, que se sobreponen a la componente detrítica. Los mecanismos de desmagnetización más habituales comprenden el lavado térmico y el lavado por campos alternos, siendo ambas técnicas de probada eficacia para materiales donde el portador principal de la remanencia corresponde a (titano)magnetita, como es el caso de los depósitos de loess de China (Heller y Liu, 1984; Heller y Evans, 1995; Spassov et al., 2001; entre otros), de Argentina (Orgeira y Valencio, 1984; Bidegain, 1991; Nabel et al., 1993; entre otros) y diversas regiones loéssicas del mundo. Se optó por la desmagnetización por campos alternos debido a que la técnica de muestreo, mediante el uso de material plástico y adhesivos vinilicos, no es adecuada para el tratamiento térmico.

Los datos obtenidos de la desmagnetización fueron procesados mediante el software SUPER IAPD2000 (Torsvik et al., 2000) y se construyeron para cada una de las muestras analizadas redes estereográficas, curvas de desmagnetización y diagramas ortogonales o de Zijderveld (Fig 4.5), todo ello para conocer el comportamiento de las muestras frente a la desmagnetización. Mediante el mismo software, utilizando la técnica de análisis de componentes principales de Kirschvink (1980) fueron determinadas las direcciones del Magnetismo Remanente Característico (MRC) y calculada la máxima desviación angular (MDA).

Las redes estereográficas (Fig 4.5a) exhiben las variaciones de la declinación (D) y la inclinación (I) durante cada paso de la desmagnetización, pero no suministran información acerca de las variaciones de la intensidad magnética (J). Asimismo las curvas de desmagnetización (Fig 4.5b) muestran únicamente las variaciones de J. En cambio, para observar las variaciones de D e I en función de J en un mismo gráfico, son utilizados los diagramas de Zijderveld (Fig 4.5c).

Las direcciones del MRC de cada muestra por su naturaleza sedimentaria se atribuyen al Magnetismo Remanente Detrítico (MRD). Las mismas fueron graficadas en función de las unidades sedimentarias determinadas en cada perfil. De esta manera fue posible en la mayoría de los casos establecer zonaciones de magnetopolaridad, que posteriormente se interpretaron según la escala de inversiones geomagnéticas (Gradstein et al., 2012). 
Las zonas de magnetopolaridad establecidas se nombraron teniendo en cuenta el nombre de la locación del perfil y anteponiendo la letra M (de magnetozona), por ejemplo M-VC1 corresponde a la magnetozona superior identificada en el Perfil Villa Cacique (PVC). De cada magnetozona se calculó la declinación (D) e inclinación (I) media, así como los parámetros estadísticos $\kappa$ (kappa) de concentración (o de precisión) y el semiángulo del cono de confianza para una probabilididad de 0,05 $\left(\alpha_{95}\right)$ (Fisher et al., 1987). Las magnetozonas pueden comprender distintas unidades (litológicas o litoestratigráficas), dado que los contactos entre éstas involucran discontinuidades, los análisis estadísticos se realizan teniendo en cuenta a cada unidad por separado; esto es a los fines de considerar las discontinuidades, que a nivel regional pueden desempeñar un rol fundamental en la definición de la columna magnetoestratigráfica.

\subsection{Medición de parámetros magnéticos}

Como se indicó, paralelamente al muestreo paleomagnético se tomaron, de cada capa, entre una y cuatro muestras de aproximadamente entre $1 / 2$ y $1 \mathrm{Kg}$ de sedimento, a las cuales nos referiremos como "muestras totales". Para el nombre de las mismas se antepuso la letra "T" (de Total) seguido por la abreviación del perfil y el número de muestra (e.g. TMI4, para la cuarta muestra de la sección estratigráfica de María Ignacia).

En el laboratorio, las muestras totales fueron utilizadas en primera instancia, de apoyo a las observaciones de campo. Para ello fueron descriptas macroscópicamente (incluyendo toma de color mediante comparación visual con Tabla Munsell y textura al tacto) y en ocasiones observadas bajo lupa binocular. Las muestras fueron secadas al aire y posteriormente se procedió al cuarteo y a la molienda de las mismas en mortero de Ágata o con rodillo de madera.

El sedimento molido fue dividido en distintas fracciones. Cada una de estas fue destinada a distintos análisis. Los parámetros magnéticos fueron medidos en casi todas las muestras totales y se determinó $\mathrm{Fe}_{2} \mathrm{O}_{3}$ y $\mathrm{CaCO}_{3}$. Paralelamente, un conjunto de muestras seleccionadas fue analizado desde el punto de vista granulométrico y mineralógico.

Los parámetros magnéticos, en su gran mayoría, fueron medidos en el Instituto de Física Arroyo Seco de la Universidad del Centro (IFAS-UNICEN-CONICET), Tandil. Se efectuaron mediciones de susceptibilidad magnética, magnetismo remanente anhistérico y magnetismo remanente isotermal. Por otra parte, en el Laboratorio Daniel Valencio de la Facultad de Ciencias Exactas de la UBA se obtuvieron ciclos de histéresis mediante la utilización de un Magnetómetro de Muestra Vibrante (VSM). 
Para la medición del magnetismo remanente anhistérico y el magnetismo remanente isotermal, así como de la susceptibilidad magnética de las "muestras totales" se destinaron entre 6 y 8 g de material, que fueron colocados en cajas cúbicas plásticas de $8 \mathrm{~cm}^{3}$. A este se le adicionó silicato de sodio analítico para fijar los granos. Para cada muestra se siguió el protocolo de la figura 4.6.

La medición de la susceptibilidad magnética se efectuó a temperatura ambiente y en todas las muestras recolectadas. Se utilizaron susceptibilímetros de marca Bartington (modelo MS2 y MS3) con sensor MS2B de dos frecuencias, donde primero se obtuvo la susceptibilidad en baja (470 hz) y luego en alta frecuencia $(4700 \mathrm{hz})$.

No todas las muestras medidas contaron exactamente con la misma cantidad de sedimento. Para poder efectuar comparaciones, los valores de susceptibilidad observados en el display del equipo fueron recalculados en función de la masa. La susceptibilidad magnética másica se simboliza $\chi$.

La $\chi$ es controlada por la concentración y la calidad de los minerales magnéticos, así como por el tamaño y la forma de los mismos. La presencia de minerales ultrafinos $(<0,03 \mu \mathrm{m})$ de dominio superparamagnético (SP) produce un incremento en la susceptibilidad en baja frecuencia $\left(\chi_{\mathrm{bf}}\right)$ respecto de la lectura en alta frecuencia $\left(\chi_{\mathrm{af}}\right)$, de esta manera es posible determinar la presencia de partículas SP a través de la susceptibilidad dependiente de la frecuencia en forma porcentual $\left[\chi_{\mathrm{df} \%}=100 \mathrm{x}\left(\chi_{\mathrm{bf}}-\chi_{\mathrm{af}}\right) / \chi_{\mathrm{bf}}\right]$ (Sandgren y Snowball, 2001; Evans y Heller, 2003). Cuando $\chi_{\mathrm{d} \mathrm{m} \%}<2 \%$ se considera que prácticamente no hay partículas SP, en cambio, si los valores son mayores a 6\% indican una significativa proporción de partículas SP (Dearing et al., 1996). Así mismo, según de Wall y Worm (2000), la $\chi_{\mathrm{df} \%}$ es afectada por el contenido de Ti en las titanomagnetitas, a partir de ello, dicha interpretación sería válida, si los minerales ferrimagnéticos presentes en la muestra son sólo magnetitas libres de Ti, o Ti-magnetitas de composición constante.

Las mediciones de magnetización remanente anhistérica fueron realizadas con un equipo pMRA, un Desmagnetizador por Campos Alternos Molspin Ltd. y un Magnetómetro Rotativo Minispin, de Molspin Ltd. El campo alterno fue fijado en $100 \mathrm{mT}$, con una tasa de decrecimiento de $17 \mu \mathrm{T}$ por ciclo.

La magnetización remanente anhistérica fue hallada a partir de un campo DC de $90 \mu \mathrm{T}$ (71,62

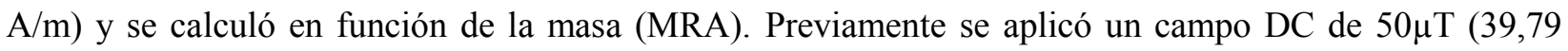
$\mathrm{A} / \mathrm{m}$ ), esto con el objeto de conocer la susceptibilidad anhistérica, que corresponde a la pendiente de la recta definida entre ambos valores, luego fue corregida en función de la masa $\left(\chi_{\text {MrA }}\right)$. 
Las mediciones de magnetización remanente isotérmica (MRI) fueron llevadas a cabo mediante un magnetizador de pulso (ASC cientific IM-10) y un Magnetómetro Rotativo Minispin, Molspin Ltd. Luego de la aplicación de cada pulso se midió la magnetización remanente en el magnetómetro.

En primera instancia se construyeron las curvas de adquisición de remanencia. En la mayoría de las muestras analizadas se alcanzaron valores de remanencia, muy próximos a su magnetización isotermal de saturación (MRIS) a campos cercanos a $300 \mathrm{mT}$. En este estudio, siguiendo a Sandgren y Snowball (2001), se consideró como MRIS a la remanencia adquirida mediante la aplicación de un campo de 1 T.

Una vez alcanzada la MRIS se procedió a aplicar campos magnéticos en sentido inverso (back field) a los fines de obtener el parámetro $\mathrm{H}_{\mathrm{cr}}$ y la $\mathrm{MRI}_{-300}$ necesaria para calcular el coeficiente $\mathrm{S}$.

Los parámetros obtenidos de la magnetización remanente isotérmica, la magnetización remanente anhistérica y la susceptibilidad magnética fueron utilizados en conjunto para el cálculo de cocientes. En este sentido fueron calculados los cocientes $\chi_{\mathrm{MRA}} / \chi_{\mathrm{bf}}, \chi_{\mathrm{MRA}} / \mathrm{MRIS}, \mathrm{MRA} / \mathrm{MRIS}$ y MRIS$/ \chi_{\mathrm{bf}}$, que permiten eliminar los efectos de concentración y son indicadores de tamaño de grano magnético, en particular de la magnetita (Evans y Heller, 2003; Blanchet et al., 2007, entre otros).

Para la realización de los ciclos de histéresis se utilizó entre 0,5 y 1 g de material seco al aire. El mismo fue colocado en porta-muestras especiales, cilíndricos, de $5 \mathrm{~mm}$ de diámetro. La fijación de los granos se realizó por compactación. El equipo utilizado corresponde a un magnetómetro de muestra vibrante (VSM) de marca Molspin, modelo Nuvo MK2.

\subsection{Análisis químico}

El análisis químico consistió fundamentalmente en la determinación de porcentajes de Hierro total, expresado como $\mathrm{Fe}_{2} \mathrm{O}_{3}$ y Carbonato de Calcio $\left(\mathrm{CaCO}_{3}\right)$.

El hierro (Fe), por ser un elemento de transición, influye en las características magnéticas de los materiales que lo contienen. El conocimiento del contenido (y el estado en que se encuentra) es útil para el análisis de los datos que se obtienen en paleomagnetismo y en magnetismo de rocas. Mediante la utilización de un espectrómetro para fluorescencia de rayos-X modelo SPECTRO IQ del LEMIT, fue posible la determinación y cuantificación de $\mathrm{Fe}_{2} \mathrm{O}_{3}$. A $5 \mathrm{~g}$ de cada muestra se le adicionó un ligante (Blinder BM-0002 Fluxana) en relación 5:1 en peso, a fin de impedir el movimiento de los granos durante el manejo de las muestras y posterior medición. De esta forma se confeccionaron pastillas de $32 \mathrm{~mm}$ de diámetro y de 3 a $5 \mathrm{~mm}$ de espesor mediante una prensa con presión de $15 \mathrm{Tn}$. 
Del mismo modo resulta importante la determinación química de carbonato de calcio, tan frecuente en los sedimentos plio-pleistocénos de la región objeto de estudio. $\mathrm{El} \mathrm{CaCO}_{3}$ se presenta generalmente bajo la forma de calcita y constituye en la mayoría de los casos un mineral secundario vinculado a procesos post-depositacionales. La calcita debido a su carácter diamagnético contribuye a la dilución de la señal de los parámetros dependientes de la concentración de los minerales magnéticos. En este sentido es útil conocer el contenido de $\mathrm{CaCO}_{3}$ a fin de normalizar dichos parámetros en función de su porcentaje [valor del parámetro x $\left.\left(1+\% \mathrm{CaCO}_{3} / 100\right)\right]$. Mediante técnicas termogravimétricas -basadas en la variación de la masa, tras el calentamiento de una sustancia a una temperatura dada- fue posible determinar el porcentaje de $\mathrm{CaCO}_{3}$. Las muestras fueron tratadas a $550^{\circ} \mathrm{C}$ durante 3 horas. La pérdida de masa fue calculada porcentualmente y corresponde a la materia orgánica y al agua de composición (PI550). Posteriormente las muestras fueron incineradas a $1000^{\circ} \mathrm{C}$ durante dos horas, descomponiéndose así el $\mathrm{CaCO}_{3}$. Por diferencia de masa se obtuvo el porcentaje de $\mathrm{CO}_{2}$ liberado, que es multiplicado por el factor 2,273 $\left(\mathrm{PM} \mathrm{CaCO}_{3} / \mathrm{PM} \mathrm{CO}_{2}\right)$ para estimar el $\% \mathrm{CaCO}_{3}$.

\subsection{Análisis granulométrico}

En primera instancia se realizó una determinación textural expeditiva durante el trabajo de campo, en forma táctil y visual. Este mismo procedimiento fue realizado nuevamente en el laboratorio, utilizando además lupa Binocular.

El análisis granulométrico fue realizado por un lado a los fines de constatar las observaciones de campo. Además, éste puede ser de utilidad a la hora de interpretar resultados paleomagnéticos y de parámetros de magnéticos, especialmente aquellos relacionados con el tamaño de grano magnético.

Un conjunto de muestras obtenidas de distintos perfiles fue analizado en el Instituto de Geomorfología y Suelos (IGS-UNLP) por personal de dicha institución, mediante el método del pipeteo (Galenhause, 1971), a intervalos granulométricos de un phi (escala UDDEN-WENTWORTH). El mismo se basa en la velocidad de caída de las partículas en un medio de densidad conocida (ley de Stokes), considerando que las mismas son esféricas y de una densidad promedio de $2,65 \mathrm{~g} / \mathrm{cm}^{3}$. Cada muestra fue desagregada en forma mecánica mediante rodillo de madera. A $20 \mathrm{~g}$ de material rodillado se lo desagregó químicamente en un vaso de precipitados con agua destilada, utilizando peróxido de hidrogeno $\left(\mathrm{H}_{2} \mathrm{O}_{2}\right)$ para eliminar los aglutinantes orgánicos; el ácido clorhídrico $(\mathrm{HCl})$ se utilizó para eliminar cementos carbonáticos. Una vez finalizada la etapa de desagregación, la fracción mayor a $62 \mu \mathrm{m}$ fue separada mediante tamizado (tamiz 230) en húmedo, secada a estufa y pesada, y pasada por una batería de tamices de mayor abertura. El sedimento que pasó por el tamiz 230 (limo y arcilla) fue colocado en una probeta, a 
la que se le agregó agua destilada (hasta $1000 \mathrm{~cm}^{3}$ ) y un dispersante (Hexametafosfato de Sodio). Luego el contenido de la probeta fue agitado durante un minuto. A lapsos determinados para cada intervalo granulométrico, a una profundidad dada según la fracción granulométrica $(20 \mathrm{~cm}$ para las más gruesas, 10 $\mathrm{cm}$ para las intermedias, $5 \mathrm{~cm}$ para las más finas) con control de la temperatura, se tomaron alícuotas de la suspensión mediante una pipeta de doble aforo. El contenido de la pipeta fue vertido en distintos crisoles y secado a estufa. Una vez seco, el sedimento fue pesado y se calculó el porcentaje representado por cada intervalo granulométrico. Con los datos de distribución granulométrica se confeccionaron histogramas y gráficos de frecuencia acumulada.

Complementariamente, un conjunto menor de muestras fue analizado en el LEMIT mediante el método del trasvasado (modificado de Smith, 1985) a intervalos de 2 phi (escala UDDENWENTWORTH). Este método permite obtener volúmenes considerables de cada fracción, las cuales pueden ser destinadas a distintos tipos de análisis. El autor diseñó este método con la finalidad de no alterar la mineralogía magnética de los sedimentos, esto se logra evitando el uso de reactivos como el $\mathrm{HCl}$ y el $\mathrm{H}_{2} \mathrm{O}_{2}$ que afectan a los óxidos de hierro. El empleo de esta técnica permitió reservar distintas fracciones granulométricas, las cuales serán destinadas a la medición de parámetros magnéticos. De manera análoga al método del pipeteo, esta técnica se fundamenta en la Ley de Stokes y supone que las partículas son esféricas y de una densidad promedio de $2,65 \mathrm{~g} / \mathrm{cm}^{3}$. Para la determinación, 40 gramos de material rodillado y seco al aire se colocaron en vasos de precipitado de $600 \mathrm{~cm}^{3}$. Para lograr una desagregación equivalente a la obtenida por el método del pipeteo a fin de comparar los resultados, se seleccionaron muestras que no evidenciaban materia orgánica (en base al color) ni carbonatos (reacción negativa al $\mathrm{HCl}$ ). Luego la desagregación de las partículas se realizó en medio ácueo mediante la utilización de un equipo de ultrasonido y pisón de goma. Como agente dispersante fue utilizado una solución diluida de $\mathrm{NH}_{4} \mathrm{OH}$. A cada vaso de precipitados se le agregó agua destilada hasta una altura de 10 $\mathrm{cm}$; luego se agitó enérgicamente durante un minuto. Luego de 8 minutos de reposo el material sobrenadante fue vertido en otro vaso de precipitados; esto permitió separar la fracción más fina que $6 \Phi$ $(15,6 \mu \mathrm{m})$. A los vasos con la fracción más fina que $6 \Phi$ se le agregó agua destilada hasta una altura de 10 cm, se agitó enérgicamente durante un minuto y se dejó reposar durante dos horas; luego el material sobrenadante fue vertido en otros vasos de precipitado; esta operación permitió separar la fracción arcilla. Las operaciones descriptas fueron en cada caso repetidas hasta dos veces, entre las mismas se realizó también tratamiento con ultrasonido y pisón de goma. El material de cada vaso de precipitados fue secado a estufa, luego pesado. El material más grueso que $6 \Phi$ fue tratado mediante una batería de tamices.

Ambos métodos se fundamentan en los mismos principios y se utilizó la misma escala granulométrica, en tanto se considera que los resultados pueden ser comparados. Dado que existieron 
diferencias en el pretratamiento, para corroborar la confiabilidad de los resultados la fracción arena de todas las muestras se observó mediante lupa binocular a fin de constatar la ausencia de agregados (pseudoparticulas), producto de una desagregación insuficiente.

Por otra parte, los porcentajes de arena, limo y arcilla determinados fueron utilizados para determinar las clases texturales mediante diagrama ternario. Cabe destacar que este diagrama fue diseñado para la escala granulométrica USDA, con límite arena/limo en $50 \mu \mathrm{m}$, y que los métodos utilizados corresponden a la escala UDDEN-WENTWORTH, con límite arena/limo en $62 \mu \mathrm{m}$. En este sentido Hurtado (com. pers.) me indicó que la variación en el porcentaje de arena es prácticamente despreciable en suelos y sedimentos del sector pampeano. Esta afirmación fue fundamentada sobre la base de las experiencias obtenidas en análisis granulométricos en el IGS-UNLP a lo largo de los años.

\subsection{Análisis mineralógico}

El análisis mineralógico fue realizado sobre el contenido de muestras totales mediante técnicas ópticas (mediante lupa binocular y microscopio de doble polarización de luz transmitida) en el Área de Mineralogía y Petrografía del LEMIT, y por difracción de rayos X (DRx) en el Centro de Investigaciones Geológicas (CIG-CONICET). Asimismo en algunas muestras fue determinado el porcentaje de expansión libre (Free Swell Test) con el fin de relacionar el resultado con el contenido de arcillas expandibles, fundamentalmente del grupo de la smectita.

El análisis óptico fue realizado sobre distintas fracciones granulométricas. Dichas fracciones fueron separadas mediante tamizado. Previo a ello, en algunos casos, las muestras fueron tratadas con $\mathrm{H}_{2} \mathrm{O}_{2}$ y $\mathrm{HCl}$, ultrasonido y pisón de goma. Además, el contenido magnético de muestras seleccionadas fue concentrado mediante un imán compuesto de una aleación de neodimio, hierro y boro.

Las fracciones más gruesas $(>0,125 \mathrm{~mm})$ fueron observadas en Lupa Binocular de Marca Leica, modelo DMS8APO con el objetivo principal de distinguir las características morfológicas de los cristales y agregados, así como una caracterización mineralógica expeditiva. Las fracciones $(0,088-0,125 \mathrm{~mm})$ y $(0,125-0,177 \mathrm{~mm})$, tanto el contenido mineralógico total como el separado magnético, fueron montadas en portamuestras de vidrio con Balsamo de Canadá y cubreobjetos y se observaron en un microscopio de la misma marca, modelo DM2500P a los fines de distinguir las características morfológicas entre los granos y realizar una caracterización mineralógica expeditiva. 
El análisis por DRx fue realizado sobre muestra total mediante un difractómetro de rayos X marca Philips con ánodo de Cobre, a fin de conocer las especies mineralógicas dominantes. El análisis de arcillas (natural, glicolado, calcinado) fue realizado en el mismo laboratorio, sin embargo sus resultados no serán expuestos dado que al momento de la medición el equipo no otorgaba resultados confiables (Poiré com pers).

Para el ensayo de expansión libre se tomó un volumen de sedimento de entre 20 y $30 \mathrm{ml}$, molido y tamizado; se lo vertió en una probeta de $100 \mathrm{ml}$ con aproximadamente $70 \mathrm{ml}$ de agua; al cabo de 24 horas se midió la diferencia de volumen y se calculó el porcentaje de expansión. Según ASTM standards anual books (1997) este ensayo que debe ser realizado con material pasante tamiz T40 (425 $\mu \mathrm{m})$, sin embargo, dado que el objetivo es relacionar los resultados con el tipo de arcilla, se procuró utilizar tamices de menor abertura. 


\subsection{Figuras del Capítulo 4}

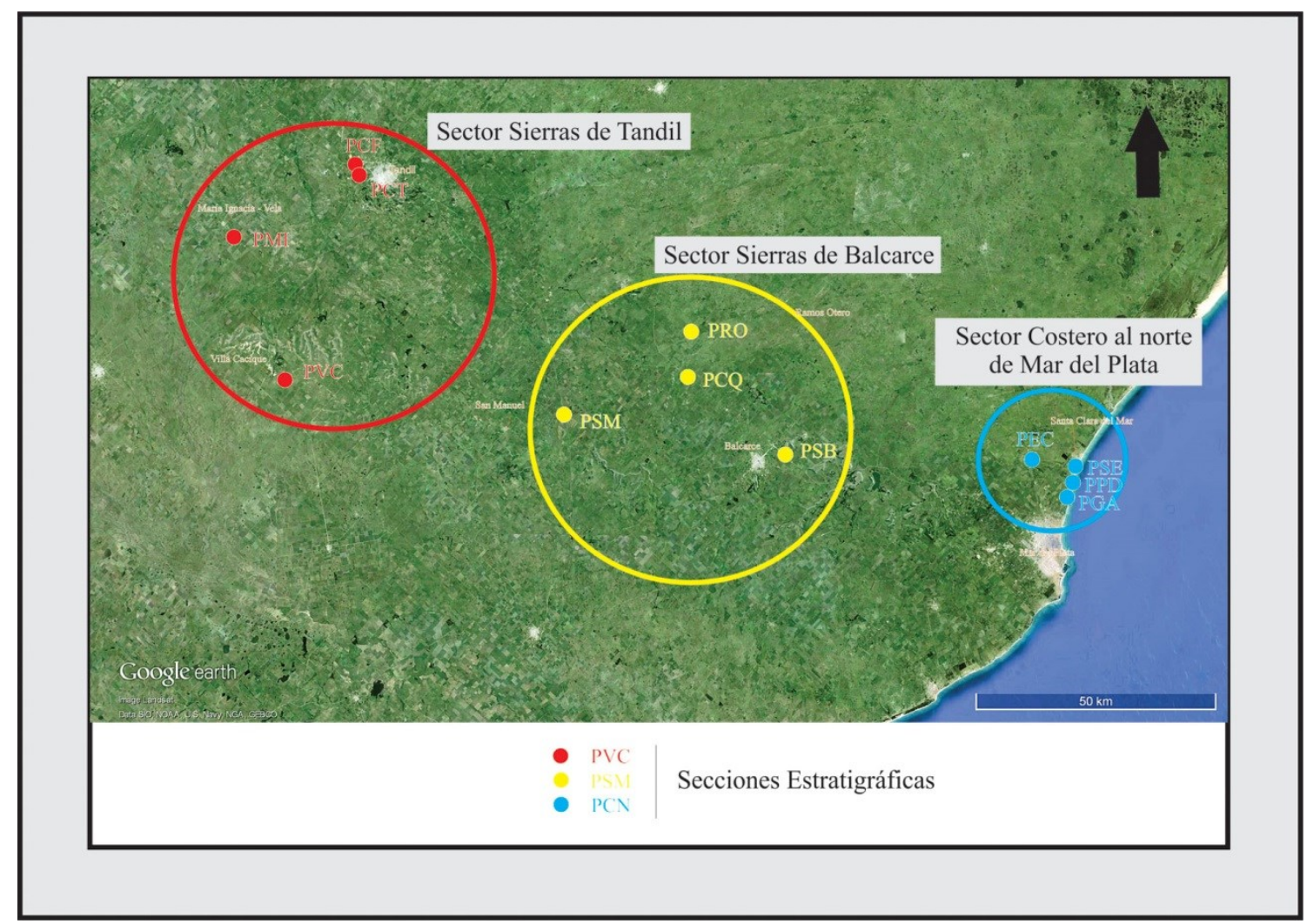

Figura 4.1. Sectores delimitados y ubicación de las secciones estratigráficas. Círculo rojo: sector Sierras de Tandil; círculo amarillo: sector Sierras de Balcarce; círculo celeste: sector costero al Norte de Mar del Plata. 


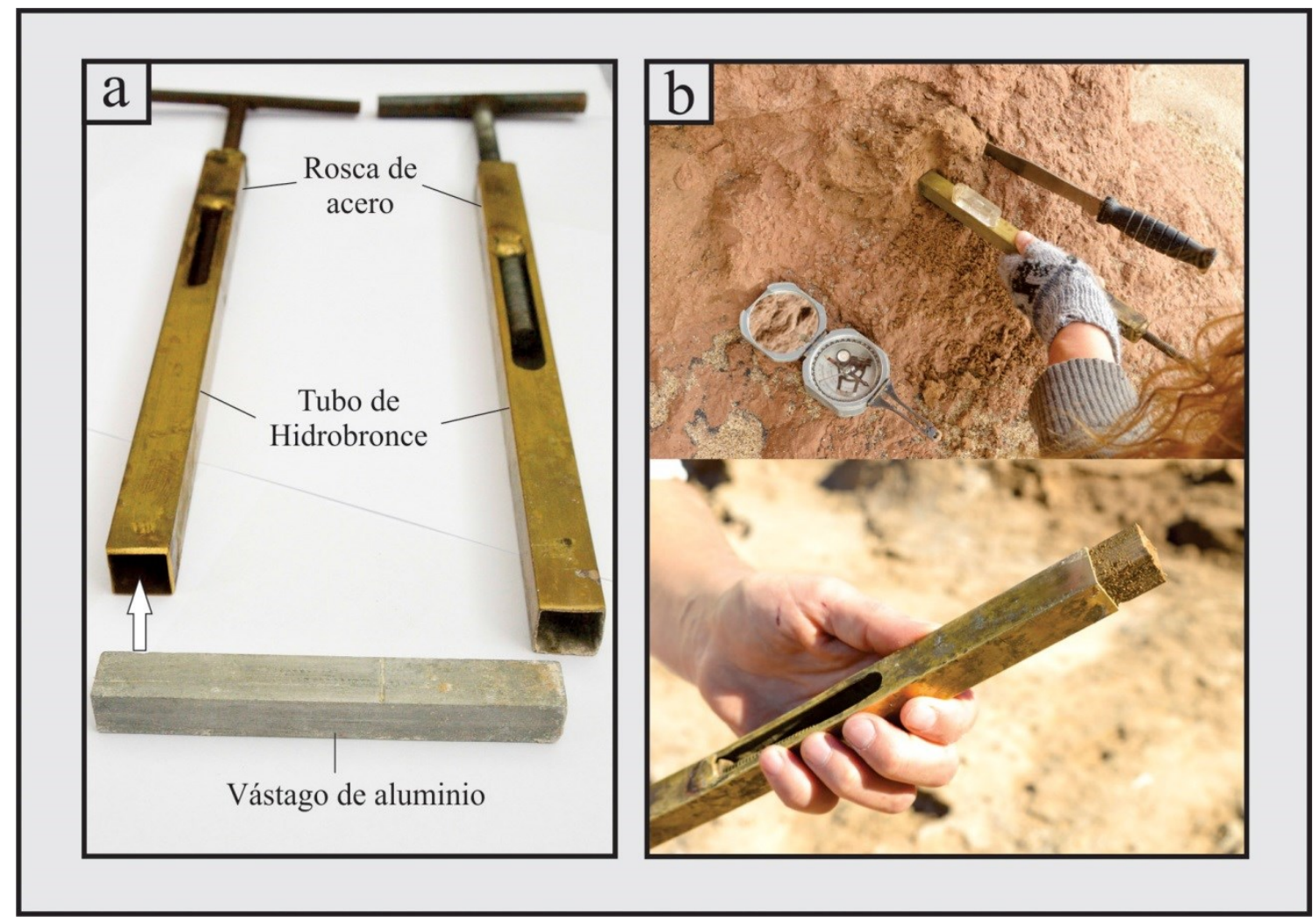

Figura 4.2. Muestreo paleomagnético. a) Muestreador de hidrobronce; b) Obtención de muestras orientadas de sedimento. 


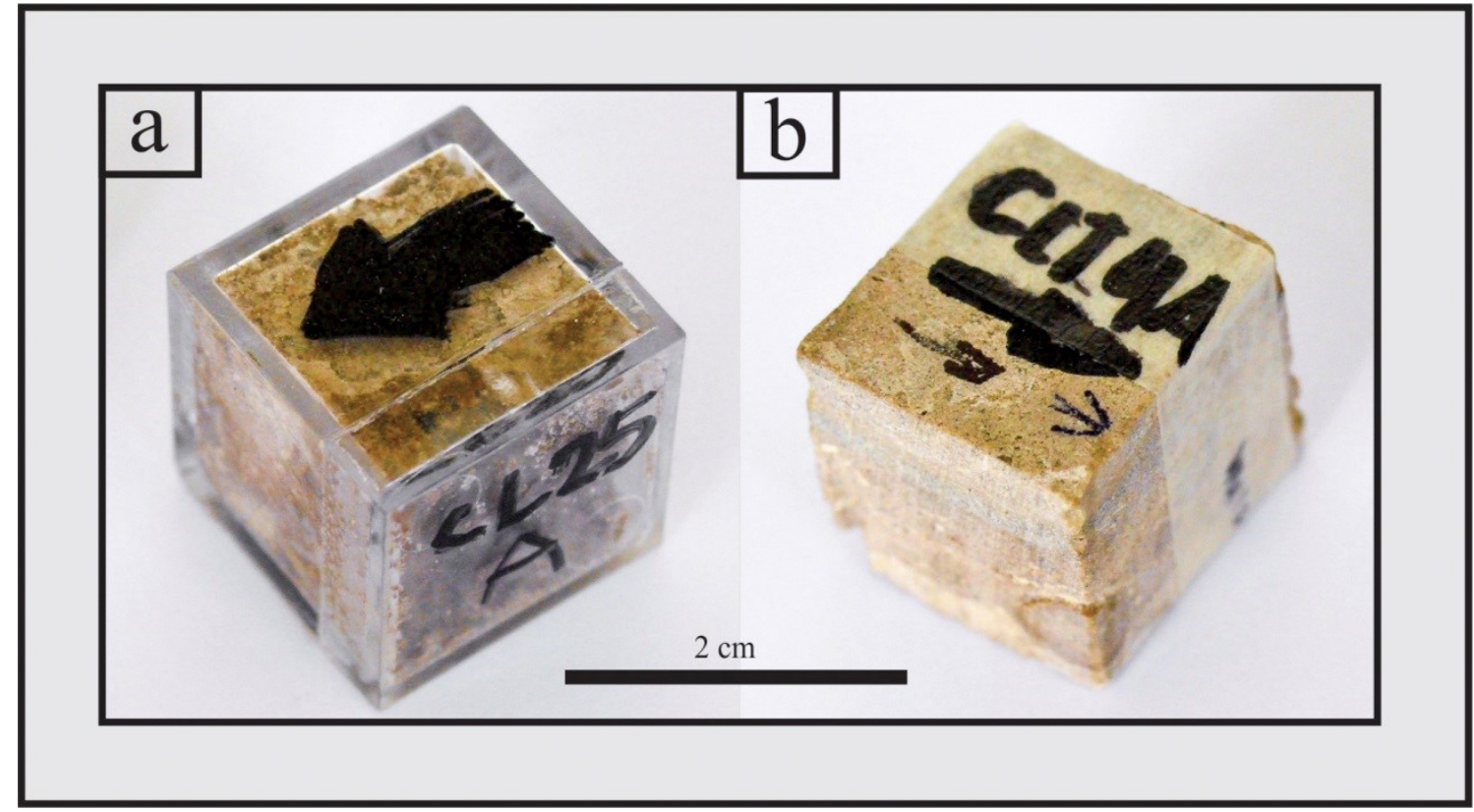

Figura 4.3. Muestras paleomagnéticas. a) Muestra de sedimento en cubo de plástico; b) Muestra de calcreta

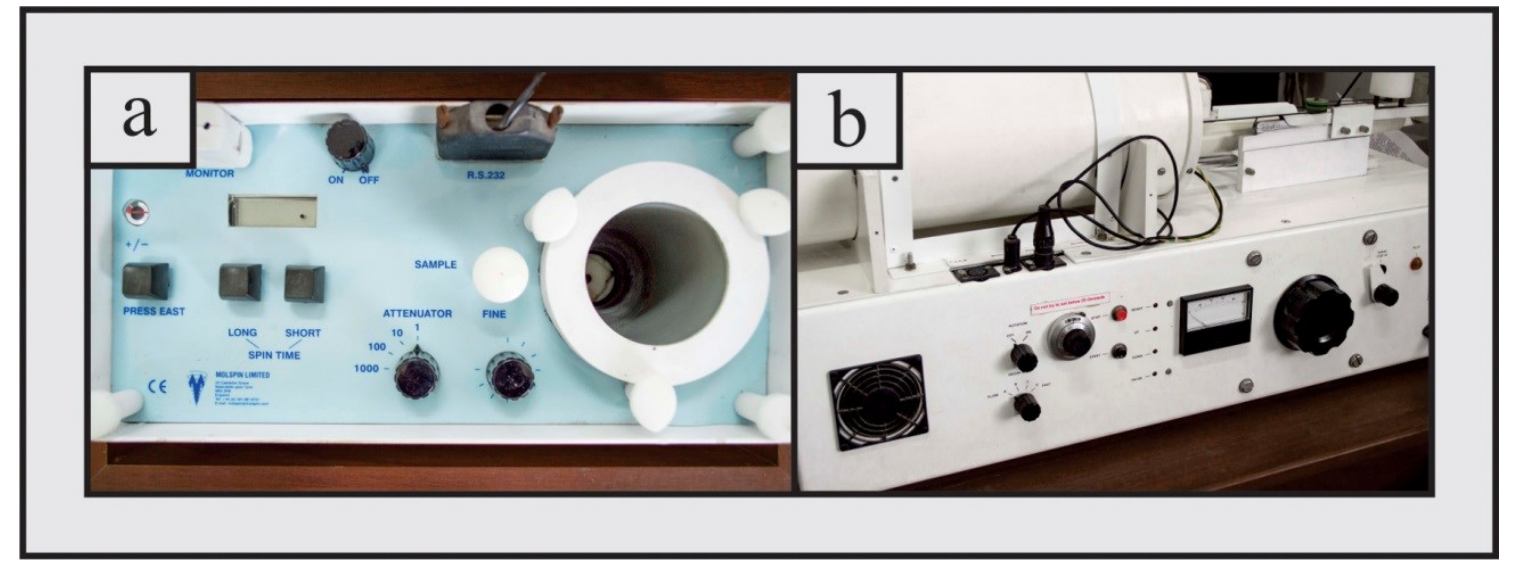

Figura 4.4. Equipos del Área de Paleomagnetismo del LEMIT utilizados. a) Magnetómetro rotativo Minispin Molspin Ltd ; b) desmagnetización por campos magnéticos alternos Molspin Ltd. 


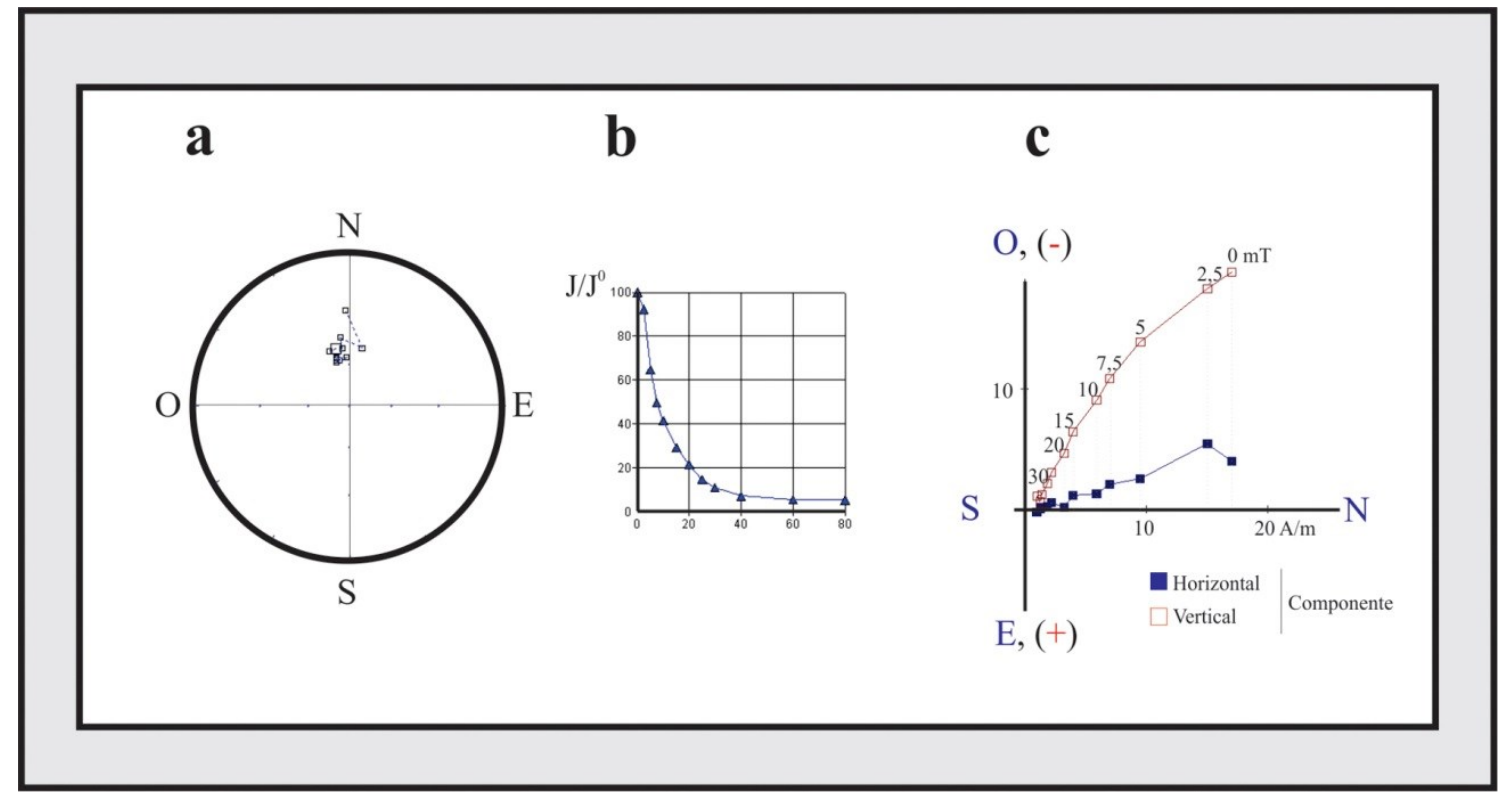

Figura 4.5. Gráficos para el análisis de muestras paleomagnéticas. a) Red estereográfica; b) Curva de desmagnetización; c) Diagrama ortogonal o de Zijderveld. 


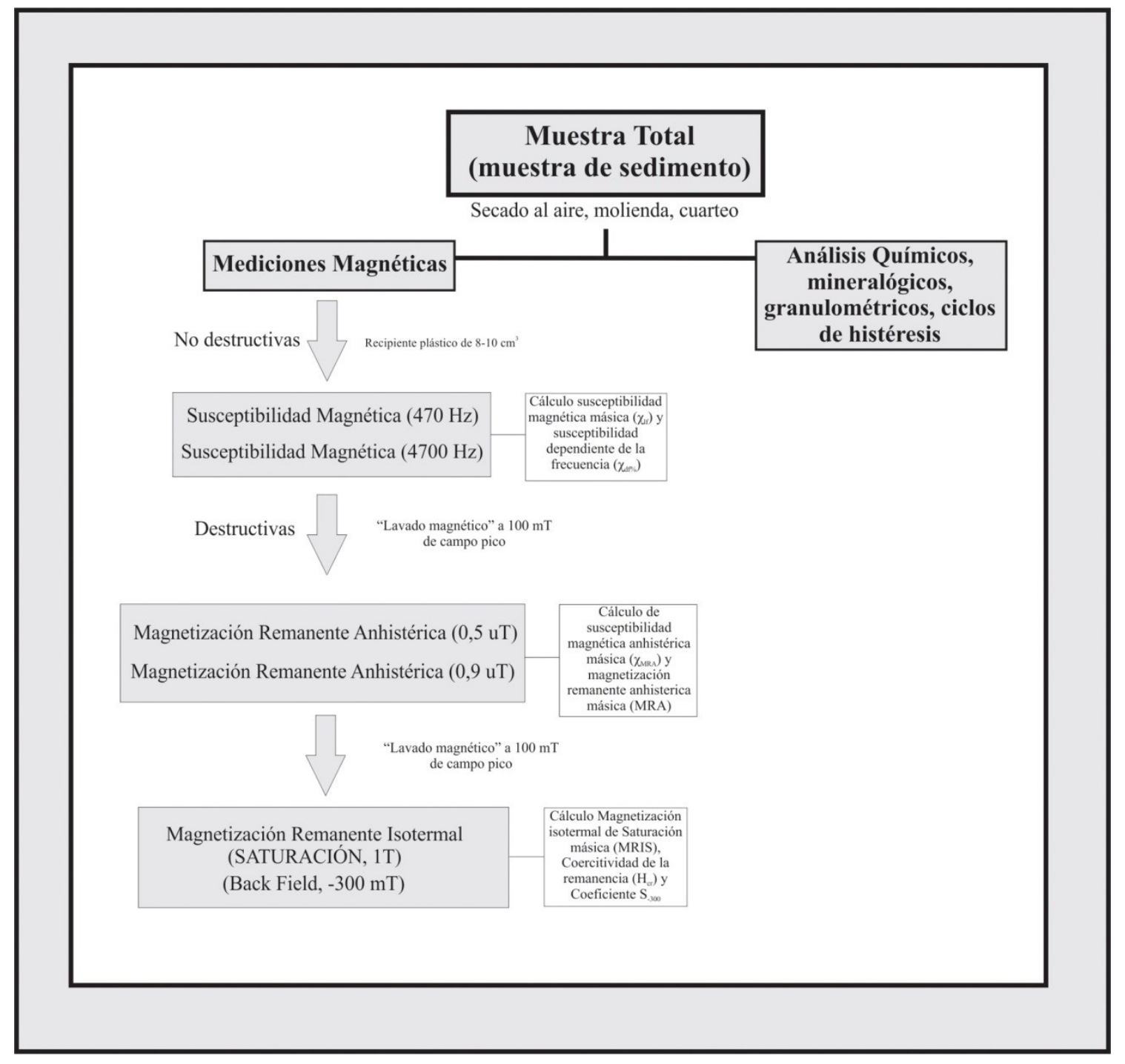

Figura 4.6. Protocolo de análisis de "muestras totales" 


\subsection{Tabla del Capítulo 4}

\begin{tabular}{|c|l|l|c|c|c|}
\hline SECTOR & \multicolumn{1}{|c|}{ PERFIL } & SIGLA & LATITUD & LONGITUD & ALTITUD (m) \\
\hline \multirow{4}{*}{$\begin{array}{c}\text { Sierras de } \\
\text { Tandil }\end{array}$} & Villa Cacique & PVC & $37^{\circ} 41^{\prime} 29.49^{\prime \prime} \mathrm{S}$ & $59^{\circ} 22^{\prime} 49,74^{\prime \prime} \mathrm{O}$ & 228 \\
\cline { 2 - 6 } & María Ignacia & PMI & $37^{\circ} 25^{\prime} 38,48^{\prime \prime} \mathrm{S}$ & $59^{\circ} 28^{\prime} 54,95^{\prime \prime} \mathrm{O}$ & 230 \\
\cline { 2 - 6 } & Calle Fangio & PCF & $37^{\circ} 17^{\prime} 37,56^{\prime \prime} \mathrm{S}$ & $59^{\circ} 11^{\prime} 42,82^{\prime \prime} \mathrm{O}$ & 206 \\
\cline { 2 - 6 } & Circuito Turistico & PCT & $37^{\circ} 25^{\prime} 38,48^{\prime \prime} \mathrm{S}$ & $59^{\circ} 28^{\prime} 54,95^{\prime \prime} \mathrm{O}$ & 209 \\
\hline \multirow{3}{*}{$\begin{array}{c}\text { Sierras de } \\
\text { Balcarce }\end{array}$} & San Manuel & PSM & $37^{\circ} 45^{\prime} 13,27^{\prime \prime} \mathrm{S}$ & $58^{\circ} 42^{\prime} 42,23^{\prime \prime} \mathrm{O}$ & 167 \\
\cline { 2 - 6 } & Ramos Otero & PRO & $37^{\circ} 35^{\prime} 37,96^{\prime \prime} \mathrm{S}$ & $58^{\circ} 29^{\prime} 59,40^{\prime \prime} \mathrm{O}$ & 126 \\
\cline { 2 - 6 } & Sierra Bachicha & PSB & $37^{\circ} 49^{\prime} 37,58^{\prime \prime} \mathrm{S}$ & $58^{\circ} 12^{\prime} 12,71^{\prime \prime} \mathrm{O}$ & 145 \\
\hline \multirow{2}{*}{$\begin{array}{c}\text { Sector } \\
\text { Costero } \\
\text { al norte de } \\
\text { Mar del Plata }\end{array}$} & Cerro Quebracho & PCQ & $37^{\circ} 37^{\prime} 36,72^{\prime \prime} \mathrm{S}$ & $58^{\circ} 37^{\prime} 21,10^{\prime \prime} \mathrm{O}$ & 212 \\
\cline { 2 - 6 } & GADA & PGA & $37^{\circ} 53^{\prime} 34,28^{\prime \prime} \mathrm{S}$ & $57^{\circ} 31^{\prime} 16,25^{\prime \prime} \mathrm{O}$ & 9 \\
\cline { 2 - 6 } & Slaya Dorada & PPD & $37^{\circ} 52^{\prime} 25,56^{\prime \prime} \mathrm{S}$ & $57^{\circ} 30^{\prime} 51,61^{\prime \prime} \mathrm{O}$ & 7 \\
\hline \multirow{2}{*}{} & Santa Elena & PSE & $37^{\circ} 50^{\prime} 32,01^{\prime \prime} \mathrm{S}$ & $57^{\circ} 36^{\prime} 43,86^{\prime \prime} \mathrm{O}$ & 20 \\
\hline \multirow{2}{*}{} & & $37^{\circ} 50^{\prime} 55,12^{\prime \prime} \mathrm{S}$ & $57^{\circ} 30^{\prime} 17,74^{\prime \prime} \mathrm{O}$ & 6 \\
\hline
\end{tabular}

Tabla 4.1. Nombre, sigla, ubicación y altitud de las secciones estratigráficas (perfiles) de los sectores Sierras de Tandil, Sierras de Balcarce y costero. 


\section{CAPITULO 5. SECCIONES ESTRATIGRÁFICAS}

Se describieron y muestrearon un total de 12 secciones estratigráficas, 4 en el sector Sierras de Tandil, 4 en el sector Sierras de Balcarce y 4 en el sector costero al norte de Mar del Plata. Las características principales de cada sección estratigráfica fueron representadas mediante paneles y columnas sedimentarias. Las rastras utilizadas en los paneles y columnas se indican en la figura 5.1.

\subsection{Sector Sierras de Tandil}

El sector Sierras de Tandil abarca el área central del Sistema de Tandilia, que incluye los partidos de Tandil y Benito Juárez. Esta zona se caracteriza por presentar afloramientos del Basamento ignéometamorfico (Complejo Buenos Aires) de edad paleoproterozoica, que constituyen las mayores elevaciones de la provincia geológica (e.g. Sierra La Juanita, 524 m.s.n.m). No obstante, hacia el SO afloran también rocas sedimentarias neoproterozoicas pertenecientes al Grupo Sierras Bayas y la Formación Cerro Negro, conformando serranías de menor altitud. Los sedimentos del Cenozoico tardío ocupan las áreas interserranas y conforman un relieve que alterna suaves lomadas y depresiones.

\subsubsection{Sección estratigráfica Villa Cacique (PVC)}

La sección de Villa Cacique (PVC) corresponde a un destape efectuado para la explotación de la Caliza Loma Negra por la Empresa Loma Negra S.A. (planta Barker), para la producción de cementos, en el poblado de Villa Cacique. Se localiza a los $37^{\circ} 41^{\prime} 29,49^{\prime \prime}$ S y 59 $22^{\prime} 49,74^{\prime \prime}$ O, a una altitud de 228 m.s.n.m., en el sector de cabeceras del Arroyo Diamante, cuyo nacimiento se encuentra en las sierras de la Juanita (524 m.s.n.m.), y forma parte de un sistema de cursos que desembocan en el Río Quequén Chico, y éste en el Quequén Grande. En la Fig. 5.2a, se indica el perfil PVC, que se sitúa a 6,9 Km al sudeste de la base del cerro Cuchilla de las Águilas y a 4,5 Km al sudoeste de la base del cerro La Juanita. En la figura 5.2b se puede observar que el perfil PVC se encuentra ubicado al noreste y noroeste de dos cerros menores, uno (al sudoeste), cuyo nombre se desconoce, posee una altitud de 283 m.s.n.m y dista 900 metros del perfil, el otro, cerro Toro, está ubicado $1,1 \mathrm{~km}$ al sudoeste el perfil y tiene una altitud de 334 m.s.n.m. 
En las mismas figuras se indican las transectas realizadas mediante Google Earth, para la realización de tres perfiles de elevación (Fig. 5.3). En los mismos se observa la posición topográfica del perfil PVC con respecto a los sistemas serranos que lo rodean. El perfil A-A' muestra la posición de PVC respecto del Cerro La Juanita (Fig. 5.3a), el perfil B-B' respecto al Cerro "sin nombre" (Fig. 5.3b) y el perfil C-C' respecto al Cerro Toro (Fig. 5.3c). Mediante Google Earth se extrajo información sobre las cotas donde domina la roca desnuda, los depósitos coluviales y el material loessoide. Por debajo de los 250 m.s.n.m. dominan los depósitos de material loessoide. Por encima de los 250 y hasta los 300 m.s.n.m. predominan los depósitos de remoción en masa. Por encima de los 300 m.s.n.m. dominan los afloramientos de rocas cuarciticas, parcialmente cubiertas de vegetación.

En la figura 5.4 se muestran fotografías de la cara sur de la cantera Loma Negra planta Barker, donde se ha realizado la descripción y el muestreo. El perfil expuesto PVC posee una potencia máxima de $20 \mathrm{~m}$. Se individualizaron 6 unidades litológicas, de techo a base U-VC1 - U-VC6, las mismas se indican en las fotografías. Las características generales, los contactos entre las capas y otros caracteres relevantes se indican en el panel de la Fig. 5.5, asimismo en la columna sedimentaria (Fig 5.6) se expone la granulometría dominante de cada unidad, así como las estructuras sedimentarias conspicuas.

\section{Unidades litológicas individualizadas en la sección PVC:}

Unidad U-VC1: Se observa en la fotografía de la figura 5.4(b1). El espesor varía entre 0,5 y 2,5 m. Se compone de limos arenosos, con escasos clastos carbonáticos de tamaño arena media gruesa, estos aumentan en proporción y tamaño hacia la base de la unidad, donde llegan a ser psefíticos. En los $25 \mathrm{~cm}$ superiores (Hz. A) se observan abundantes clastos psamíticos y psefíticos, angulosos, compuestos principalmente de cuarzo. En general no presenta estructura primaria identificable, no obstante es posible advertir una laminación tenue, sobre todo hacia la base. Esta unidad constituye el material parental del suelo actual, cuyo perfil es A-Bt-BC-C. El color del sedimento (Hz. C) es 7,5 YR 5/3 en seco y 7,5 YR $3 / 2$ en húmedo. El contacto con la unidad subyacente es neto, sinuoso, corresponde a una discordancia erosiva. El origen de esta unidad sería predominantemente eólico, aunque con indicios de acción hídrica encauzada en los sectores basales y probablemente coluviales hacia el tope.

Unidad U-VC2: En la figura 5.4(bI-II) se muestra una fotografía de la unidad U-VC2. Alcanza un espesor de entre 4 y 5 metros. Se compone de arenas limosas. Se destaca la presencia de acumulaciones psefíticas que conforman lentes (Fig. 5.7a), compuestas por clastos de carbonato, limolita, ortocuarcita

(de la Formación Cerro Negro) y escasos carbonatos micríticos (de la Formación Loma Negra). En el 
sector basal de la unidad se halla la acumulación psefítica más importante, que puede superar el metro de espesor (Fig 5.8), los clastos en general son angulosos, algunos llegan a estar subredondeados, sus tamaños pueden alcanzar los $30 \mathrm{~cm}$. La estructura más conspicua es la estratificación entrecruzada (Fig 5.7b), aunque también presenta estratificación paralela. El color del sedimento es 10 YR 6/3 en seco y 10 YR 3/3 en húmedo. El matiz grada a 7,5 YR. La luminosidad es variable debido a acumulaciones locales de carbonato de calcio, el cual es abundante en toda la unidad, la acumulación más importante conrresponde al tope de la unidad, donde se dispone en planchas horizontales. Algunos rasgos a destacar son la presencia de sectores pedogenizados (probablemtente horizontes $\mathrm{Bw}$ ) lateralmente discontinuos. Por otra parte, la unidad presenta abundantes crotovinas circulares de hasta $1 \mathrm{~m}$ de diámetro (Fig 5.7c) y abundantes restos óseos fragmentados y con escaso grado de conservación. La bioturbación es común, particularmente de anélidos, representada principalmente por el género Taenidium (Genise, com. pers.) como se indica en la Fig 5.7d, también son comunes las rizoconcreciones. Como se dijo, hacia el tope la unidad presenta una acumulación calcárea de importancia, cuando esta se encuentra cerca de la superficie se corresponde con el horizonte $2 \mathrm{Ckm}$ del suelo actual. Cabe destacar que hacia el sector medio de la unidad se halla otra acumulación calcárea con características similares a la anterior (Fig 5.9), aunque generalmente con menor grado de expresión y continuidad lateral. El contacto con las unidades subyacentes es neto, sinuoso y corresponde a una discordancia erosiva, con incisiones profundas. Se interpreta que la unidad es de origen dominantemente fluvial, con escasas facies de planicie de inundación donde se halla el género Taenidium.

Unidad U-VC3: Está representada de manera saltuaria. Debido a que fue muy erosionada sólo se observa allí donde las incisiones son menos profundas (Fig 5.4bII; Fig 5.9). No supera los dos metros de espesor. Se compone de limos arcillosos sin estructura primaria determinable. Evidencia rasgos pedogenéticos conspicuos, determinados por una estructura en bloques (sub)angulares pequeños, fuertes, con revestimientos de manganeso y marcas de raicillas, similares a los de la figura 5.10. Hacia la base de la unidad las manifestaciones pedogenéticas disminuyen. Desde un punto de vista paleopedológico se designan los $100 \mathrm{~cm}$ superiores de la unidad como paleosuelo S-VC1. El color de la unidad es 5 YR 7/4 en seco y 5 YR 4/4 en húmedo, el matiz tiende a 7,5 YR. Un rasgo a destacar es la presencia de nódulos o concreciones de carbonato de calcio, de gran tamaño, que en ocasiones alcanzan los $50 \mathrm{~cm}$ de diámetro (Fig 5.9). Se observaron además crotovinas elongadas de disposición diagonal (Fig 5.11a). El contacto con la unidad subyacente es neto y plano, no erosivo.

Unidad U-VC4: Subyace indistintamente a U-VC2 o U-VC3. Presenta hasta 6 metros de espesor. Se compone de limos y arenas muy finas, aumentando la proporción de arena hacia la base. La estratificación entrecruzada es común en toda la unidad (Fig 5.12). También se observa laminación 
paralela. Toda la unidad presenta rasgos pedogenéticos, se observan varios niveles de paleosuelos, discontinuos lateralmente. El paleosuelo de mayor desarrollo y continuidad lateral se halla en el tope, el mismo se designa como S-VC2. El mismo posee estructura prismática que rompe a bloques sub-angulares pequeños, fuertes, con revestimientos de arcilla y manganeso como los de la figura 5.10, marcas de raíces, rizoconcreciones y concreciones calcáreas de gran diámetro. Este paleosuelo posee abundantes crotovinas elongadas de disposición diagonal, que pueden cortarse entre sí (Fig 5.11b). Del interior de las mismas se han exhumado restos óseos de roedores correspondientes a Actenomys y Lagostomus (Lagostomopsis) (Verzi, Straccia, com. pers.) (Fig 5.13). El color es 7,5 YR 6/4 en seco, 7,5 YR 4/4 en húmedo, el matiz grada a 5 YR. El contacto con la unidad subyacente es neto y levemente sinuoso, no erosivo.

Unidad U-VC5: Hasta 6 metros de espesor. Son limos, arenas y gravas, en la base presenta abundantes clastos gruesos, incluyendo calizas micríticas, ortocuarcita y pelitas del Grupo Sierras Bayas y Formación Cerro Negro (Fig. 5.14a). El contenido de material grueso aumenta hacia la parte basal, aunque presenta lentes de conglomerados en todo el cuerpo de la unidad. Presenta estratificación entrecruzada. Hacia el tope presenta estructura pedogenética en bloques sub-angulares con revestimientos de arcilla y manganeso similares a los de la figura 5.10. Este sector se designa al paleosuelo S-VC3. El color es 7,5 YR 6/4 en seco y 7,5 YR 4/4 en húmedo, el matiz grada a 5 YR. La unidad posee importantes acumulaciones de carbonato de calcio, conformando concreciones muy duras, de hasta un metro de potencia y gran extensión lateral (Fig 5.15). El contacto con la unidad subyacente es neto y sinuoso, corresponde a una discordancia erosiva.

Las unidades U-VC3, U-VC4 y U-VC5 -sobre la base de los análisis realizados, que indican una gran similitud de los materiales- se consideran pertenecientes a una misma unidad litoestratigráfica. Cabe consignar que las estructuras primarias, como estratificación entrecruzada y laminación paralela subordinada, aunque difusas y a veces ocultas por los rasgos pedogenéticos, sugieren una depositación dominantemente fluvial. Por otro lado, si bien se distinguieron 3 niveles conspicuos de paleosuelos (SVC1; S-VC2 y S-VC3) se observan manifestaciones pedogenéticas prácticamente en toda la unidad litoestratigráfica, así como la presencia de paleosuelos de escasa extensión lateral.

Unidad U-VC6: Lateralmente posee una extensión que supera los 300 metros en el lugar de muestreo. Presenta entre 0,5 y $2 \mathrm{~m}$ de espesor. Se compone de conglomerados matriz sostén y clasto sostén (Fig. 5.4bIII). Los clastos (y bloques) pueden alcanzar los $50 \mathrm{~cm}$ de lado y son predominantemente de calizas micriticas de la Formación Loma Negra (Fig. 5.15b). El tamaño y concentración de los mismos suele aumentar hacia la base de la unidad. La matriz es arcillosa a arcillo limosa, con destacables características de arcillas expandibles (rasgos vérticos), como son estructura en bloques angulares 
cuneiformes y abundantes slickensides (Fig. 5.16). No se reconocieron estructuras primarias. En la matriz se presentan impresiones radiculares. El color de la matriz es 7,5 YR 6/4 en seco y 7,5 YR 5,5/4 en húmedo, grada hacia una coloración más rojiza (5 YR). Cabe resaltar que hacia la parte media y basal contiene abundante carbonato de calcio, ya sea disperso en la masa o conformando concreciones mamelonares. Se apoya mediante discordancia erosiva sobre la caliza Loma Negra. La unidad se vincula a un depósito de remoción en masa afectado por pedogénesis.

\subsubsection{Sección estratigráfica María Ignacia (PMI)}

La sección de María Ignacia (PMI) corresponde a un corte a la vera de la ruta RP80. Se ubica a 3 $\mathrm{Km}$ al sudeste del poblado de María Ignacia-Vela y a $13 \mathrm{Km}$ al noroeste de la intersección con la ruta RP74. Sus coordenadas son $37^{\circ} 25^{\prime} 38,48^{\prime \prime}$ S y $59^{\circ} 28^{\prime} 54,95^{\prime \prime}$ O, con una altitud de 230 m.s.n.m. Su ubicación corresponde al sector de cabeceras de la cuenca del Arroyo Chapaleofú, a 9 Km al Oeste de la Sierra Alta de Vela (aproximadamente 450 m.s.n.m). La ubicación del perfil PMI se observa en la figura 5.17, asimismo, en la figura 5.17a se indica la posición de la transecta A-A', utilizada para la construcción del perfil de elevación desde PMI hasta la sierra Alta de Vela (Fig 5.17b). La roca desnuda (Complejo Buenos Aires) aflora por encima de los 320 - 340 m.s.n.m. Entre los 320 y 250 m.s.n.m predominan los depósitos coluviales. Por debajo de los 250 m.s.n.m los depósitos son dominantemente loessoides.

En la figura 5.18 se muestran dos fotografías del corte de ruta que expone la sección estratigráfica PMI. La misma posee una potencia de $4,7 \mathrm{~m}$. Fueron individualizadas 5 unidades litológicas, de techo a base U-MI1 - U-MI5. Las figura 5.19 corresponde al panel, la 5.19 a la columna sedimentaria.

\section{Unidades litológicas individualizadas en el la sección PMI:}

Unidad U-MI1: Una fotografía de la unidad puede observase en la figura 5.21a. Su espesor varía entre 0,15 y $0,35 \mathrm{~m}$. Son limos arenosos con presencia de clastos angulosos de cuarzo de hasta $6 \mathrm{~mm}$ de diámetro (Fig. 5.21b). No es posible determinar estructuras primarias, esto debido a que se encuentra completamente pedogenizada conformando el horizonte Ak del suelo actual. El carbonato de calcio se presenta, ya sea en la masa o bien conformando pseudomicelios. Color 10 YR 3/2 en seco y 10 YR 2/1 en húmedo. El contacto con la unidad subyacente es neto y plano, discordante. Génesis eólica, aunque con participación coluvial. 
Unidad U-MI2: Alcanza un espesor de 1,60 metros. Comprende arenas limosas y limos arenosos con importantes acumulaciones de material psefítico conformando lentes (Fig. 5.22). Es frecuente la presencia de conglomerados hacia la base. La unidad presenta estratificación entrecruzada en artesa. Color 7,5 YR 7,5/3 en seco y 7,5 YR 6,5/3 en húmedo. Los elevados valores de luminosidad se deben a la abundante concentración de carbonato de calcio, generalmente pulverulento, ya sea disperso en la masa o conformando lentes, asimismo hacia el tope de la unidad se dispone en planchas horizontales muy duras (duricostra calcárea) y corresponde al horizonte petrocálcico del suelo actual (2Ckkm). El contacto con la unidad subyacente es neto, levemente sinuoso, corresponde a una discordancia erosiva. Se interpreta que la unidad es de origen fluvial.

Unidad U-MI3: El espesor promedio es de 0,70 m. Se compone de limos sin estructura primaria identificable. El color es 7,5 YR 6/4 en seco y 7,5 YR 4/4 en húmedo. El contacto con la unidad subyacente es neto y levemente sinuoso, no erosivo.

Unidad U-MI4: Su espesor varía entre 0,75 y 1,05 m. Predomina la fracción limo. Masivo o con difusa estratificación entrecruzada. En el tope se ha desarrollado un paleosuelo (S-MI1), limo arcilloso de espesor variable, con estructura en bloques subangulares pequeños, con abundantes pátinas negro azuladas y revestimientos de arcilla (Fig 5.23). Color 7,5 YR 6/4 en seco y 7,5 YR 4/4 en húmedo, tiende a 5 YR. . Hacia el sector medio se presenta un nivel calcáreo de hasta $10 \mathrm{~cm}$ de espesor, dispuesto en láminas de aproximadamente $4 \mathrm{~mm}$, con destacada continuidad lateral. El contacto con la unidad subyacente es neto y levemente sinuoso, no erosivo.

Unidad U-MI5: Su espesor es al menos de 1,20 m. Predominan los limos y limos arenosos. La estructura es difusa, probablemente estratificación entrecruzada. Hacia el tope, se identifica un paleosuelo (S-MI2), limo arcilloso, con estructura en bloques subangulares, pequeños, duros, y con pátinas negro azuladas. El tope se corresponde con un nivel calcáreo de $20 \mathrm{~cm}$ de potencia de gran extensión lateral; se compone de láminas horizontales de hasta $1 \mathrm{~cm}$. El color del sedimento es 7,5 YR 6/4 en seco y 7,5 YR 3/4 en húmedo. No se observa la base de esta unidad.

Las unidades U-MI3, U-MI4 y U-MI5 poseen características similares, por ello se consideran parte de una misma unidad litoestratigráfica. Estos depósitos se vinculan a un ambiente fluvial, empero la unidad U-MI3 podría corresponder a un depósito eólico (loess). Cabe destacar que si bien se destaca la presencia de dos paleosuelos, los rasgos pedogenéticos son comunes en las tres unidades. 


\subsubsection{Sección estratigráfica Calle Fangio (PCF)}

La sección estratigráfica PCF corresponde a un corte de camino ubicado en la Calle Fangio en la

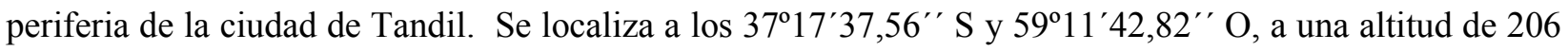
m.s.n.m. En la Figura 5.24a se indica la ubicación de PCF. El mismo se sitúa a $2 \mathrm{Km}$ al noroeste del Cerro Leones (aproximadamente 350 m.s.n.m). Asimismo, en la figura 5.24b se observan dos perfiles topográficos transversales. El perfil A-A', va desde Cerro Leones y pasa por PCF. Por debajo de los 225 m.s.n.m. predominan los depósitos sedimentarios loessoides, por encima de dicha altura afloran roca desnuda (Complejo Buenos Aires) y escasos depósitos coluviales. En el perfil B-B' se muestra que la sección se ubica en una loma (morfología erosiva). Las fotografías de la figura 5.24c muestran el descenso de la topografía hacia el noroeste (izquierda) y hacia el sudeste (derecha).

El perfil expuesto posee una potencia máxima de 4,2 $\mathrm{m}$. En el mismo fueron individualizadas 5 unidades litológicas, de techo a base U-CF1 - U-CF5. Las características generales, los contactos entre las capas y otros caracteres de relevancia se plasman en el panel de la figura 5.25, asimismo en la columna sedimentaria (Fig. 5.26) se expone la granulometría dominante de cada unidad, así como las estructuras sedimentarias conspicuas. Las distintas unidades se muestran en las fotografías de las figuras 5.27, 5.28 y 5.29 .

\section{Unidades litológicas individualizadas en la sección PCF:}

U-CF1: Presenta entre 2 y 0,10 metros de potencia. Se compone de arenas muy finas a limos gruesos bien seleccionados, con escasos clastos tamaño arena media y gruesa de cuarzo y carbonato. Hacia la base aumenta la proporción de clastos gruesos. Sin estructura primaria identificable (masivo), hacia la base presenta laminación difusa. Hacia el tope se desarrolla el suelo actual (A-Bw-BC-C). El color del horizonte $\mathrm{C}$ es 10 YR 6/4 en seco y 10 YR 3/4 en húmedo. El contacto con la unidad subyacente neto y sinuoso, corresponde a una discordancia erosiva, con incisiones profundas. El origen de la unidad se interpreta como predominante eólico, con evidencias de acción hídrica encauzada en la base.

U-CF2. Entre 2 y 0,30 metros de espesor. Se compone de arenas limosas con abundantes clastos tamaño arena gruesa y psefíticos. Es característica la presencia de lentes de rodados psefíticos. Presenta estratificación entrecruzada que grada lateralmente a laminar paralela. Color 7,5 YR 6/3 en seco y 7,5 YR 4/3 en húmedo. Presenta carbonato de calcio en toda la unidad, ya sea en forma pulverulenta en la masa o bien conformando pseudomiscelios. La mayor concentración de carbonatos corresponde al tope de la unidad, donde presenta una plancha de $15 \mathrm{~cm}$ de espesor, conformada por láminas de entre 0,2 y $1 \mathrm{~cm}$, su continuidad lateral sólo es interrumpida por las incisiones más profundas generadas por el contacto 
erosivo de la unidad suprayacente. Cuando la acumulación carbonática se encuentra cerca de la superficie se corresponde con el horizonte $2 \mathrm{Ckm}$ del suelo actual. Se han encontrado signos de bioturbación, el más conspicuo se observa en la figura 5.30, dicha estructura fue interpretada a priori como un paleohormiguero/termitero, sin embargo Genise (Com. Pers.) indicó que es más propicio vincularlo a la actividad de lombrices, las cuales forman boxworks, cuyos hallazgos en el registro sedimentario son muy frecuentes. El contacto con las unidades subyacentes es neto, sinuoso y corresponde a una discordancia erosiva. La unidad se vincula a génesis fluvial.

U-CF3. Hasta 1 metro de espesor. Se compone de limos arenosos. En general no se distingue estructura primaria, hacia la base presenta laminación paralela. Presenta estructura secundaria en bloques sub-angulares, con pátinas negro azuladas y escasos barnices de arcilla. Color 7,5 YR 5/4 en seco y 7,5 YR 3/4 en húmedo. Hacia el centro y base presenta carbonato de calcio dispuesto en finas láminas. En la cúspide de la loma donde se describe la sección estratigráfica, esta unidad se halla cerca de la superficie y se encuentra afectada por los carbonatos en planchas descriptos anteriormente. Son comunes las marcas de raíces. El contacto con la unidad subyacente es neto y plano, no erosivo.

U-CF4. Aproximadamente 1,2 metros de espesor. Se compone de limos arenosos. Presenta laminación oblicua difusa que se hace más notoria hacia el sector medio y base de la unidad. Presenta manifestaciones pedogenéticas, representadas por bloques subangulares con pátinas negro-azuladas y escasos barnices de arcilla. En el sector medio donde la pedogénesis es menos manifiesta. Color 7,5 YR 6/4 en seco y 7,5 YR 3,5/4 en húmedo. El matiz tiende a 5 YR. Hacia el tope de la unidad se presenta la mayor concentración de $\mathrm{CaCO}_{3}$, el cual se halla formado finas láminas discontinuas. El contacto con la unidad subyacente es neto y plano, no erosivo.

U-CF5. Al menos dos metros de potencia. Predomina la fracción limo. No fue posible identificar estructuras primarias. La estructura pedogenética en bloque angulares es común en toda la unidad, el sector inferior presenta estructura prismática que rompe a bloques angulares, con abundantes patinas negro-azuladas y barnices de arcilla; este sector se identifica como paleosuelo S-CF1. Hacia el tope del paleosuelo aumenta la concentración de $\mathrm{CaCO}_{3}$, el cual se dispone en finas láminas horizontales. Color 7,5 YR 6/4 (en seco) y 7,5 YR 3,5/4 en húmedo. El matiz tiende a 5 YR. No es posible observar la base de la unidad.

Las unidades litológicas U-CF3; U-CF4 y U-CF5 se consideran como una misma unidad litoestratigráfica. La génesis es probablemente fluvial. 


\subsubsection{Sección estratigráfica Circuito Turístico (PCT)}

La sección estratigráfica PCT corresponde a un destape en la RP30, en la periferia de la ciudad de Tandil. Se localiza a los $37^{\circ} 25^{\prime} 38,48^{\prime \prime}$ S y $59^{\circ} 28^{\prime} 54,95^{\prime \prime}$ O, a una altitud de 209 m.s.n.m. En la Figura 5.31 y 5.32 se muestra la ubicación de PCT. El mismo se sitúa a $2 \mathrm{Km}$ al oeste del Cerro La Movediza (aproximadamente 300 m.s.n.m.) y a 1,5 Km al este del Cerro Leones (aproximadamente 300 m.s.n.m.).

El perfil expuesto posee una potencia de $3 \mathrm{~m}$. Sólo se compone de una unidad (U-CT1) (Fig $5.32 \mathrm{~b}$ ), sin embargo, $150 \mathrm{~m}$ hacia el sur, en una posición topográfica más elevada, se distingue otra unidad por debajo (U-CT2) (Fig 5.32c), esta a su vez se apoya directamente sobre rocas ígneo-metamórficas del Complejo Buenos Aires, el cual aflora $50 \mathrm{~m}$ más hacia el sur (Fig. 5.32d). En el panel de la figura 5.33, construido en función de la transecta B-B', se muestran las unidades aflorantes y se interpreta su continuidad en el subsuelo.

La unidad U-CT1 en el sitio de muestreo posee al menos 2,5 metros de espesor. Se compone de arenas limosas bien seleccionadas. Sin estructura primaria identificable (masiva). Hacia los $60 \mathrm{~cm}$. Superiores se desarrolla el suelo actual, de escaso desarrollo (A-Bw-BC-C). El color del sedimento (Hz. C) es 7,5 YR 6/4 en seco y 7,5 YR 4/4 en húmedo. Si bien en el sitio de muestreo no se observa la base, hacia el sur, el contacto con U-CT2 es neto, levemente sinuoso y se interpreta como una discordancia erosiva. Se considera que la unidad U-CT1 es de origen eólico.

En la figura 5.34 se indica también el lugar de extracción de tres muestras totales. Otras dos muestras (TCT4 y TCT5) se extrajeron en la misma posición estratigráfica que las muestras TCT2 y TCT3 respectivamente, aunque distanciadas alrededor de $20 \mathrm{~m}$ hacia el suroeste.

\subsection{Sector Sierras de Balcarce}

El sector Sierras Balcarce incluye los partidos de Lobería y Balcarce. Esta zona se caracteriza por afloramientos del Basamento igneo-metamorfico (Complejo Buenos Aires) y de cuarcitas del Paleozoico inferior (Formación Balcarce). Los sedimentos del Cenozoico tardío ocupan las áreas interserranas, conformando un relieve que alterna suaves lomadas y depresiones. En la figura 5.35 se muestra la ubicación de las secciones estratigráficas estudiadas en el sector Sierras de Balcarce. 


\subsubsection{Sección estratigráfica San Manuel (PSM)}

La sección (PSM) corresponde a un corte de la ruta RP227, ubicado aproximadamente $22 \mathrm{Km}$ al sur del empalme con la ruta RN226 y a $12 \mathrm{Km}$, al este del poblado San Manuel. Sus coordenadas son $37^{\circ} 45^{\prime} 13,27^{\prime \prime}$ S y $58^{\circ} 42^{\prime} 42,23^{\prime \prime} \mathrm{O}$, con una altitud de 167 m.s.n.m.

En la figura 5.36a-b se muestran fotografías del corte de ruta que expone la sección estratigráfica PSM, cuyo espesor es de $3 \mathrm{~m}$. En la misma se individualizaron tres unidades litológicas principales, de techo a base U-SM1 a U-SM3 (Fig 5.36a-b). Las características generales, los contactos entre las capas y otros caracteres de relevancia se muestran en el panel de la figura 5.37. En la columna sedimentaria (Fig. 5.38) se exponen la granulometría dominante de cada unidad, así como las estructuras sedimentarias más conspicuas

\section{Unidades litológicas individualizadas en la sección PSM:}

U-SM1: Alcanza un espesor de 1,70 m. Se compone de arenas limosas, con escasos clastos psefíticos y de arena gruesa, compuestos generalmente de calcita, subordinadamente de cuarzo y arcilla. El material psefítico se incrementa hacia la base. Posee estratificación entrecruzada que grada lateralmente a laminar paralela, en ocasiones oculta por la estructura secundaria en bloques subangulares. Color 7,5 YR 6/4 en seco y 7,5 YR 4/4 en húmedo, el matiz tiende a 10 YR. Un rasgo distintivo es la presencia de carbonato de calcio, el cual es abundante en toda la unidad. Generalmente se halla disperso en la masa o bien conformando pseudomiscelios. La mayor concentración de carbonato se halla en el tope, donde se dispone en planchas horizontales y escasos tabiques verticales (que corresponden al horizonte $2 \mathrm{Ckkm}$ del suelo actual). La base de la unidad es neta y sinuosa, corresponde a una discordancia erosiva, con incisiones profunda. Se interpreta que los sedimentos de la unidad U-SM1 se depositaron mediante agente fluvial.

Cabe destacar que por encima de la unidad U-SM1 se apoyan mediante discordancia sedimentos disturbados por actividad antrópica, en general son de poco espesor $(20 \mathrm{~cm})$, y conforman el horizonte Ap del suelo actual. Lateralmente adquieren mayor espesor y presentan características de depósito eólico.

U-SM2: Esta unidad se halla estratigráficamente por debajo de la unidad descripta anteriormente, sin embargo, como se observa en la figura 5.36a-b, se dispone lateralmente a la misma. Posee un espesor máximo de dos metros. Se compone de limos gruesos y limos arenosos. Posee estratificación entrecruzada (Fig. 5.36c) y laminar paralela. Las evidencias pedogenéticas son escasas, manifestadas por la presencia de bloques subangulares con patinas negro-azuladas poco manifestadas y marcas de raíces. Color 7,5 YR 
7/4 en seco y 7,5 YR 4/4 en húmedo. Presenta en general escaso carbonato de calcio, disperso en la masa. Hacia el techo de la unidad se halla la mayor concentración de carbonato, dispuesto en planchas horizontales, y constituye el horizonte $2 \mathrm{Ckkm}$ del suelo actual. El contacto con la unidad subyacente es neto y plano, no erosivo.

U-SM3: Al menos un metro de espesor. Se compone principalmente de limos gruesos; en el tope de la unidad se halla un nivel de gravas, compuestos por fragmentos de roca y rodados de arcilita y limolíta (Fig. 5.36d). Presenta estructuras difusa, laminación paralela y estratificación entrecruzada. Presenta estructura secundaria en bloques subangulares con marcas de raíces. Color 7,5 YR 6/4 en seco y 7,5 YR 4/4 en húmedo. Ne se puede observar la base de la unidad.

Las unidades U-SM2 y U-SM3 poseen características similares y corresponden a una misma unidad litoestratigráfica, que se vincula con un ambiente fluvial.

\subsubsection{Sección estratigráfica Ramos Otero (PRO)}

La sección PRO corresponde a un corte de la ruta RP29, ubicado aproximadamente $13 \mathrm{Km}$ al norte del empalme con la ruta RN226, a $16 \mathrm{Km}$ al sudoeste de la localidad Ramos Otero y 60 metros al norte de la Capilla San Antonio. Sus coordenadas son $37^{\circ} 35^{\prime} 38,04^{\prime \prime}$ S y 58 29'56.12" O, con una altitud de 126 m.s.n.m.

En la figura 5.39 se muestra el perfil topográfico de una transecta en sentido N-S, cuyo punto central corresponde a la sección PRO. En la misma se observa que la sección se corresponde a una loma, de amplitud considerable.

En las fotografías de la figura 5.40 se observan las dos unidades individualizadas en la sección. Las características generales, los contactos entre las capas y otros caracteres de relevancia se muestran en el panel de la figura 5.41. En la columna sedimentaria (Fig. 5.42) se exponen la granulometría dominante de cada unidad, así como las estructuras sedimentarias más conspicuas.

\section{Unidades litológicas individualizadas en la sección PRO:}

U-RO1: Espesor promedio de 1,20 m. Se compone de limos arenosos con escasos clastos de calcita tamaño arena gruesa. No se distinguen estructuras primarias (masivo). La parte superior se 
encuentra modificada por el ciclo pedogenético actual (A-Bt-BC-C). El color en el sector menos afectado por pedogénesis (Hz. C) es 7,5 YR 5,5/4 en seco y 7,5 YR 3/4 en húmedo. El contacto con la unidad subyacente es neto y sinuoso, corresponde a una discordancia erosiva. Esta unidad se considera de origen eólico.

U-RO2: Al menos un metro de espesor. Se compone de limos arenosos y arenas limosas con clastos tamaño arena media, compuestos principalmente de carbonato de calcio. Presenta estratificación y laminación paralela. Color 10 YR 6/4 en seco y 10 YR 4/4 en húmedo. Cabe destacar que la luminosidad en seco varía entre 8 y 5 dependiendo de la concentración de carbonatos, el cual es abundante y se halla disperso en la masa o bien, conformando lentes acintados. El tope de la unidad presenta un marcado incremento de $\mathrm{CaCO}_{3}$. No se observa la base de la unidad. Se interpreta que la unidad fue depositada en ambiente dominantemente fluvial.

\subsubsection{Sección estratigráfica Sierra Bachicha (PSB)}

El perfil Sierra Bachicha (PSB) corresponde a un destape efectuado para la explotación de rocas

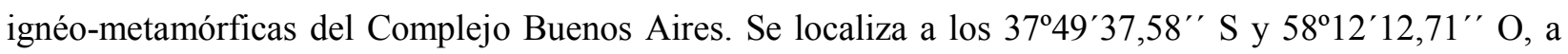
una altitud de 145 m.s.n.m. En el faldeo sur de la Sierra Bachicha (385 m.s.n.m.), y a 250 metros de la cima del cerro Punta Tota (160 m.s.n.m). En las figuras 5.43 y 5.44 se indica la ubicación de PSB. Además, en las mismas figuras se observan los perfiles de elevación de las transectas A-A' y B-B'. El perfil A-A' muestra la posición respecto de la Sierra Bachicha (Fig. 5.43) y el perfil B-B'respecto a Punta Tota (Fig. 5.44). Por debajo de los 160 m.s.n.m. afloran sedimentos loessoides y por encima los depósitos de remoción en masa. A partir de los 275 m.s.n.m. dominan los afloramientos de rocas cuarcíticas de la Formación Balcarce (Fig.5.43).

Las fotografías de las figuras 5.45 y 5.46 muestran el perfil expuesto (PSB) que en el momento del muestreo presentaba una potencia máxima de $10 \mathrm{~m}$. Como se indica en las mismas, fueron individualizadas 4 unidades. En panel de la sección se indica en la figura 5.47; la columna sedimentaria en la figura 5.48 . 


\section{Unidades litológicas individualizadas en la sección PSB:}

U-SB1: Entre 0,10 y 1,5 metros de espesor. Limos arenosos con escasos clastos tamaño arena gruesa de carbonato de calcio, estos aumentan en tamaño y proporción hacia la base. En general sin estructura (masiva) a tenuemente laminada hacia la base. Color 7,5 YR 5/3 en seco y 7,5 YR 3/4 en húmedo. Hacia la parte superior de la unidad se desarrolla el suelo actual, el mismo se encuentra decapitado y con marcada evidencia de removilización antrópica. El contacto con la unidad subyacente es neto y sinuoso, corresponde a una discordancia erosiva. Si bien se interpreta que el origen de la unidad es eólico, también presenta rasgos de acción hídrica encausada en la base.

U-SB2: Hasta 2,3 metros de espesor. Se compone de arenas limosas con clastos de rocas metamórficas y calcita, tamaño psamítico a psefítico, que aumentan en proporción hacia la base. Posee estratificación paralela y subordinadamente entrecruzada. Color 7,5 YR 7/3 en seco y 7,5 YR 5/3 en húmedo. El matiz tiende a 10 YR. Un rasgo característico de la unidad es la abundante proporción de carbonato de calcio, este se encuentra disperso en la masa o conformando pseudomiscelios. Hacia el tope de la unidad se incrementa la concentración de carbonatos, el cual se dispone en láminas de $2 \mathrm{~mm}$, conformando una plancha continua lateralmente. El contacto con la unidad subyacente es neto y sinuoso, se interpreta como una discordancia erosiva, con incisiones profundas. El depósito se considera de origen fluvial.

U-SB3: Hasta 3 metros de potencia. Se compone de una alternancia de capas limo arenosas y capas areno limosas. Son abundantes los clastos psefíticos de rocas metamórficas de hasta $30 \mathrm{~cm}$ de diámetro. Sin estructura a tenuemente laminada. Las capas de granulometría más fina presentan color 7,5 YR 6/4 en seco y 7,5 YR 3/4 en húmedo, las de más gruesa color 10 YR 6/3 en seco y 10 YR 4/3 en húmedo. Algunas capas presentan bloques subangulares con pátinas oscuras asociadas a marcas de raíces, esto indicaría procesos pedogenéticos incipientes. En el tope de la unidad distingue un paleosuelo (SSB1), franco arcilloso, color 7,5 YR 5/4 en seco y 7,5 YR 3/4 en húmedo, con estructura prismática que rompe a bloques subangulares pequeños, fuertes, con revestimientos de arcilla y manganeso. Son comunes en la unidad los nódulos calcáreos, de alrededor de $20 \mathrm{~cm}$. Se distinguen crotovinas circulares que alcanzan el metro de diámetro. El contacto con la unidad subyacente es neto, plano, no erosivo.

U-SB4: Al menos 4 metros de espesor. Se compone de una alternancia de capas subhorizontales limo arenosas y areno limosas. Son abundantes los clastos psefíticos de rocas metamórficas de hasta 30 $\mathrm{cm}$ de diámetro, dispersos en toda la unidad. En general no se distingue estructura (masiva), a veces tenuemente laminada. Las capas de granulometría más fina son de color 7,5 YR 6/4 en seco y 7,5 YR 4/4 en húmedo y las de más gruesa 10 YR 6/4 en seco y 10 YR 5/4. Algunas capas presentan bloques 
subangulares con pátinas negro-azuladas y marcas de raíces, que indican procesos pedogenéticos incipientes. En el tope de la unidad se halla un paleosuelo de escaso desarrollo (S-SB2), color 7,5 YR 5,5/4 en seco y 7,5 YR 4/4 en húmedo, con escasos revestimiento de arcilla y pátinas de manganeso. Se vincula este paleosuelo a una antigua superficie, con pendiente hacia el sur. La unidad presenta localmente acumulaciones de carbonatos, ya sea en la masa o en nódulos calcáreos. No se observa la base de la unidad.

Las unidades litológicas U-SB3 y U-SB4 corresponden a una misma unidad litoestratigráfica y se consideran como un depósito coluvial distal. El aspecto del depósito es loessoide y contiene clastos de rocas locales.

\subsubsection{Sección estratigráfica Cerro Quebracho (PCQ)}

Sus coordenadas son $37^{\circ} 37^{\prime} 36,7^{\prime \prime}$ S y $58^{\circ} 37^{\prime} 21.1^{\prime \prime}$ O, con una altitud de 212 m.s.n.m. Se ubica sobre la ruta 226, entre las ciudades de Tandil y Balcarce, en la ladera noroeste del Cerro Quebracho (aproximadamente 230 m.s.n.m.) (Fig. 5.49a). Los laboreos para la construcción de la ruta nacional 226 dejaron expuestas las rocas del basamento (Complejo Buenos Aires) (5.49b) y el espesor de sedimentos, de interés en esta investigación, es extremadamente reducido. Como se indica en el perfil de elevación de la Figura $5.49 \mathrm{c}$, la cobertura sedimentaria es prácticamente nula en la parte más elevada del terreno y aumenta en espesor hacia las laderas. En la figura 5.49d se muestran las unidades sedimentarias presentes en la sección PCQ. Las características más importantes de las mismas se representan en la columna sedimentaria de la figura 5.50 .

\section{Unidades litológicas individualizadas en la sección PCQ:}

U-CQ1: Hasta 1,20 metros de espesor. Son limos arenosos con clastos tamaño arena gruesa de cuarzo y escasos de tamaño psefítico de carbonatos. Color 7,5 YR 5,5/4 en seco y 7,5 YR 3/4 en húmedo. No se distingue estructura primaria. Hacia el tope de la unidad se desarrolla el suelo actual (A-Bw-BC-C). El contacto con la unidad subyacente es neto, sinuoso, corresponde a una discordancia erosiva. La génesis del depósito se vincula a ambiente eólico.

U-CQ2: Hasta un metro de espesor. Son arenas limosas con abundantes clastos psefíticos de basamento que decrecen en proporción hacia el tope. Posee laminación paralela. Color 10 YR 8/4 en seco y 10 YR 5/4 en húmedo. Presenta abundante carbonato de calcio, ya sea disperso en la masa como 
conformando planchas. La unidad se apoya mediante discordancia erosiva sobre el basamento cristalino. Génesis probablemente fluvial-coluvial.

\subsection{Sector costero al norte de Mar del Plata}

En esta zona se incluyen cuatro secciones estratigráficas de los partidos de Mar Chiquita y norte de General Pueyrredón. La ubicación de las secciones estudiadas se indica en la Figura 5.51. Este sector se caracteriza por poseer cotas más bajas que los anteriores $(<30$ m.s.n.m.) y constituye una zona de planicie. Desde el punto de vista geomorfológico la mayoría de las secciones estratigráficas se incluyen en la denominada Franja Eólica Periserrana; la sección PEC se halla en la Planicie Fluvio Eólica, cerca del límite con la Franja Eólica Periserrana (Fig. 3.4).

\subsubsection{Sección estratigráfica GADA (PGA)}

Sus coordenadas son $37^{\circ} 53^{\prime} 34,3^{\prime \prime}$ S y $57^{\circ} 31^{\prime} 16,25^{\prime \prime}$ O, con una altitud de 9 m.s.n.m. Se ubica en los acantilados marinos ubicados frente al destacamento del Grupo de Artillería Antiaérea (GADA), en el barrio Felix Camet del partido de General Pueyrredón, aproximadamente $7 \mathrm{Km}$ al norte de la Ciudad de Mar del Plata.

En la figura 5.52 se muestra una fotografía del acantilado marino correspondiente a la sección estratigráfica PGA, cuya altura fluctúa entre los 8 y $9 \mathrm{~m}$. Las características generales, los contactos entre las capas y otros caracteres de relevancia se plasman en el panel de la figura 5.53, asimismo en la columna sedimentaria (Fig 5.54) se expone la granulometría dominante de cada unidad, así como las estructuras sedimentarias conspicuas.

\section{Unidades litológicas individualizadas en la sección PGA:}

U-GA1. Lateralmente discontinua, en general no supera el metro de espesor. Son arenas muy finas a limos gruesos, con escasos clastos de arena mediana y gruesa. Hacia la base suele presentar clastos psefíticos redondeados, dominantemente de carbonato de calcio. En general no se distingue estructura primaria, a tenuemente laminada. Hacia el tope se desarrolla el suelo actual, el cual se encuentra en su parte superior muy disturbado por actividad antrópica, o bien con sus horizontes superiores erosionados. El color del sedimento (horizonte C) es 10 YR 5/3 en seco y 10 YR 3/4 en húmedo. El contacto con las unidades subyacentes es neto y levemente sinuoso, se interpreta como una discordancia erosiva. Se considera esta unidad como un depósito dominantemente eólico, aunque con evidencias de acción hídrica encauzada en la base. 
U-GA2. Posee un espesor promedio de dos metros. Son arenas muy finas, limosas, con clastos de arena media a muy gruesa y psefíticos que se incrementan en tamaño y proporción hacia la base. Presenta estratificación entrecruzada conspicua. Color 7,5 YR 6/4 en seco y 7,5YR 4/4 en húmedo. El matiz tiende a 10 YR. Un rasgo distintivo de la unidad es la abundante presencia de carbonato de calcio disperso en la masa. La mayor acumulación se da en el tope de la unidad, donde se dispone en planchas y tabiques (Fig. 5.55). La unidad presenta crotovinas circulares, de hasta un metro de diámetro. Se han observado abundantes restos óseos. El contacto con las unidades subyacentes es neto y sinuoso, se corresponde con una discordancia erosiva, con incisiones profundas que pueden llegar hasta la base del acantilado. El origen del depósito es dominantemente fluvial.

Cabe destacar que aproximadamente 100 metros al sur del sitio de muestreo se determinó otra unidad entre las unidades U-GA1 y U-GA2. La misma corresponde a arenas finas con estratificación entrecruzada y carbonato de calcio disperso en la masa; su posición en la sucesión estratigráfica se indica en la Fig. 5.56.

U-GA3. Entre 50 y $75 \mathrm{~cm}$ de espesor, lateralmente es discontinua. Está integrada por limos arcillosos a limos arenosos, en la base presenta intraclastos de arena mediana. Presenta laminación, aunque obliterada por la estructura pedogenética que afecta prácticamente toda la unidad, ésta es en bloques subangulares pequeños, fuertes, con revestimientos de arcilla. Color 7,5 YR 7/4 en seco y 7,5 YR $5 / 4$ en húmedo. El contacto con la unidad subyacente es neto, sinuoso y se interpreta como una discordancia erosiva. La unidad corresponde a un paleosuelo conspicuo (S-GA1) desarrollado sobre materiales de origen probable origen fluvial.

U-GA4. Hasta 3 metros de espesor. Sucesión de capas tabulares, limo arenosas con laminación paralela y en ocasiones entrecruzada. Estructura pedogenética en bloques subangulares débiles, con escasas pátinas negras. Hacia el tope de la unidad se observa un paleosuelo discontinuo lateralmente. Color 7,5 YR 7/4 en seco y 7,5 YR 4/4 en húmedo. La unidad presenta concreciones subesféricas de carbonato de calcio de hasta $50 \mathrm{~cm}$ de diámetro. Se han observado crotovinas circulares y restos óseos. El contacto con la unidad subyacente es neto y levemente sinuoso, concordante. Origen fluvial.

U-GA5. Durante la pleamar esta unidad está parcialmente cubierta de agua. La unidad posee una extensión lateral de alrededor de 1,5 Km. Posee hasta dos metros de espesor. Son limos arcillosos y arcillas limosas, sin estructura primaria identificable. La estructura secundaría es en bloques subangulares medios a pequeños, fuertes, con abundantes patinas negras y rojizas. Se destaca por su coloración amarillenta (2,5Y 7,5/2 en seco; 2,5Y 5/2 en húmedo, el matiz tiende a 5Y). Presenta escasas concreciones de Mn-Fe de hasta $2 \mathrm{~mm}$ de diámetro. Cabe destacar que la erosión marina actual generó hendiduras más 
profundas, especialmente donde presenta estructura en bloques pequeños. El contacto con la unidad subyacente es neto y plano, concordante. Se asocia esta unidad a un nivel paleolagunar/palustre vinculado probablemente a una planicie de inundación.

U-GA6. Hasta un metro de espesor. Arenas muy finas con abundantes clastos psefíticos de limolita, arcilita y carbonato de calcio. Puede ser interpretado también como un conglomerado matriz sostén. Presenta estratificación entrecruzada. Posee estructura secundaria en bloques subangulares medios, débiles, con marcas de raíces. Color 10 YR 8/2 en seco y 10 Y/R 4/3 en húmedo. Cabe destacar que en el tope de la unidad se observa una costra calcárea de hasta $25 \mathrm{~cm}$ de potencia y destacada continuidad lateral (Fig. 5.57). El contacto con la unidad subyacente es neto, plano, concordante. Se interpreta que el origen de la unidad es fluvial.

U-GA7. La mayor parte de esta unidad no suele aflorar, ya que se encuentra cubierta por arena de playa. Fue descubierta tras cavar. Posee al menos un metro de espesor. Son limos arenosos y limos arcillosos con escasos intraclastos peliticos tamaño arena y psefíticos. Presenta laminación paralela tenue. El sector medio-basal presenta estructura pedogenética en bloques subangulares duros, con barnices de arcilla y pátinas de Mn. Este nivel se identifica como paleosuelo S-GA2. El color de la unidad es 7,5 YR 8/3 en seco y 7,5 YR 5/3 en húmedo. El matiz grada a 10 YR. Durante la pleamar, esta unidad, al igual que la U-GA6 se encuentra bajo el nivel del mar.

Las unidades litológicas U-GA5 a U-GA7 se consideran una misma unidad litoestratigráfica cuyo origen seria dominantemente fluvial.

\subsubsection{Sección estratigráfica Playa Dorada (PPD)}

Sus coordenadas son $37^{\circ} 52^{\prime} 25,6^{\prime \prime} \mathrm{S}$ y $57^{\circ} 30^{\prime} 51,6^{\prime \prime} \mathrm{O}$, con una altitud de 7 m.s.n.m. Se ubica en los acantilados marinos del balneario Playa Dorada, partido de Mar Chiquita, aproximadamente 3,3 Km al sur de la Ciudad de Santa Clara del Mar.

En la fotografía de las figura 5.58 se muestra el sector del acantilado marino correspondiente a la sección estratigráfica PPD. El espesor del acantilado alcanza los $8 \mathrm{~m}$, en el mismo se identificaron seis unidades litológicas, de techo a base U-PD1 a U-PD6. El panel se presenta en la figura 5.59; la columna sedimentaria en la figura 5.60 . 


\section{Unidades litológicas individualizadas en el perfil Playa Dorada:}

U-PD1: Discontinua lateralmente, puede alcanzar un espesor de 1,50 m. Se compone de limos arenosos, con escasos clastos de arena gruesa. Sin estructura primaria identificable. Sobre esta unidad se desarrolla el suelo actual, el cual se encuentra disturbado por actividad antrópica, o bien con sus horizontes superiores erosionados. Color 10 YR 7/3 en seco y 10 YR 4/3 en húmedo, el matiz tiende a 7,5 YR. Como se muestra en las figuras 5.61a y 5.62, hacia la base de la unidad, se observaron acumulaciones de cenizas volcánicas. El contacto con la unidad subyacente es neto y levemente sinuoso (discordancia erosiva). Se considera esta unidad como un depósito dominantemente eólico.

U-PD2. Posee un espesor promedio de 1,20 metros. Son arenas limosas. Presenta clastos de arena gruesa, muy gruesa y psefíticos en la base. Presenta estratificación entrecruzada. Color 10 YR 6/3 en seco y 10YR 4/4 en húmedo. Cabe mencionar que la unidad presenta carbonato de calcio disperso en la masa o conformando finas planchas horizontales, relativamente continuas lateralmente. El contacto con la unidad subyacente es neto y levemente sinuoso, se considera como una discordancia erosiva. El origen del depósito sería dominantemente fluvial.

U-PD3. Posee un espesor promedio de dos metros. Son arenas muy finas limosas. Presenta abundantes clástos pelíticos y carbonaticos de arena gruesa y psefíticos. Presenta estratificación entrecruzada y planar hacia la base. Color 10 YR 6/4 en seco y 10YR 4/4 en húmedo, haciéndose más oscura hacia la base. El matiz tiende a 7,5 YR. Cabe destacar que la unidad presenta abundante carbonato de calcio disperso en la masa. La mayor acumulación de carbonato se halla en el paleosuelo que corona la unidad (S-PD1), donde se dispone en planchas y tabiques que le confieren un aspecto reticulado (Fig. 5.61a-b). El contacto con la unidad subyacente es neto, sinuoso, corresponde a una discordancia erosiva con incisiones profundas que pueden llegar hasta la base del acantilado. El relleno de dichas incisiones contiene abundantes clastos psefíticos de carbonatos. El origen del depósito se considera fluvial.

U-PD4. Unidad saltuaria. Posee un espesor promedio de $60 \mathrm{~cm}$. Predomina la arena muy fina, aunque se observan clastos de arena media y gruesa, también acumulaciones psefíticas (rodados de carbonato) en sectores basales. Presenta estratificación entrecruzada. Lateralmente la unidad presenta rasgos pedogenéticos conspicuos. Color 10 YR 6/4 en seco y 10YR 4/4 en húmedo. El matiz tiende a 7,5 YR. El contacto con la unidad subyacente es neto, sinuoso y corresponde a una discordancia erosiva con incisiones profundas. El origen del depósito se considera fluvial. 
U-PD5. Posee hasta 1,5 metros de espesor. Son arenas limosas con laminación paralela. Se destaca por su coloración amarillenta (2,5 Y 7/3 en seco, 2,5Y 5/3 en húmedo; el matiz tiende a 5Y). Cabe resaltar la presencia de signos de bioturbación. El sector medio presenta abundantes patinas rojizas. Posee concreciones de Mn-Fe y concreciones de carbonato de calcio. El contacto con la unidad subyacente es neto, plano, no erosivo. Se vincula a un ambiente de planicie de inundación.

U-PD6: Al menos dos metros de espesor. Se compone de arenas y limos. Presenta abundantes clastos psefíticos en toda la unidad, compuestos de limolita/arcilita y carbonato de calcio, la mayor concentración se halla hacia el centro de la unidad (Fig. 5.64a). Estructura planar paralela (Fig. 5.64b) y entrecruzada subordinada. Color 7,5 YR 7,5/4 en seco y 7,5 YR 5/4 en húmedo, hacia el techo el matiz pasa a 10 YR. Presenta pátinas negras y rojizas, concreciones de Mn-Fe y concreciones de carbonatos. No se observa la base de la unidad. La génesis vincula a ambiente fluvial.

Las unidades U-PD5 y U-PD6 corresponderían a una misma unidad litoestratigráfica cuyo origen sería fluvial.

\subsubsection{Sección estratigráfica El Casal (PEC)}

Los sedimentos expuestos en este sitio corresponden a una cantera ubicada a los $37^{\circ} 50^{\prime} 32,0^{\prime \prime}$ de latitud S y 57 36 $43,9^{\prime \prime}$ longitud O, con una altitud de 20 m.s.n.m. en el extremo noroeste del partido de General Pueyrredón, en la intersección entre la Autovía 2 y la calle de acceso a la Ciudad de Santa Clara del Mar, aproximadamente a $7 \mathrm{Km}$ al oeste de dicha ciudad.

En las fotografías de la figura 5.65 se muestra la cantera y se indican las unidades litológicas individualizadas. En la figura 5.66 se presenta el panel de la sección; en la figura 5.67 la columna sedimentaria.

\section{Unidades litológicas individualizadas en la sección PEC:}

Unidad U-EC1: Entre 100 y $10 \mathrm{~cm}$. de espesor. Son limos arenosos, con escasos clastos tamaño arena media. Sin estructura primaria identificable. Sobre esta unidad se desarrolla el suelo actual, en el sitio de muestreo se encuentra decapitado y con marcadas evidencias de removilización antrópica. Color 10 YR 5/3 en seco y 10 YR 3/3 en húmedo. El contacto con la unidad subyacente es neto y levemente sinuoso (discordancia erosiva). Se vincula a génesis eólica. 
Unidad U-EC2: Hasta 1,40 metros de espesor. Se compone de arenas limosas. Posee clastos de arena media y gruesa. Laminación entrecruzada difusa. Color 10 YR 7/3 en seco y 10 YR 4/3 en húmedo. Posee carbonato de calcio disperso en la masa, la mayor concentración se encuentra en el tope de la unidad, donde el carbonato se dispone en finas láminas horizontales. El contacto con la unidad subyacente es neto y sinuoso, correspondería a una discordancia erosiva. La unidad se vincula a depositación fluvial.

Unidad U-EC3: Hasta 1,80 m de espesor. Arcillo limosa. Corresponde a un nivel con abundantes signos de pedogénesis, manifestados por estructura prismática que rompe a bloques subangulares, presenta abundantes barnices de arcilla y marcas de raicillas. En general sin estructura primaria identificable. En los sectores donde la unidad es más potente, es posible observar los sedimentos de la base, con menor grado de pedogénesis, donde se observó estratificación entrecruzada y clastos tamaño psefíticos de carbonato. Color 7,5 YR 6/4 en seco y 7,5 YR 5/4 en húmedo. El contacto con la unidad subyacente es neto y sinuoso, corresponde a una discordancia erosiva. Se vincula a un depósito fluvial, un paleosuelo se desarrolló sobre el mismo (paleosuelo S-EC1).

Unidad U-EC4: Puede alcanzar los dos metros de espesor, aunque generalmente no supera el metro. Son sedimentos areno limosos, con abundante proporción de material psefítico que se incrementa hacia la base de la unidad. Posee estratificación entrecruzada, laminación paralela, además presenta estructuras que se vinculan a barras de canal. Color 10 YR 7/3 en seco y 10 YR 4/3 en húmedo. Cabe destacar que esta unidad posee carbonato de calcio disperso en la masa, la mayor concentración se encuentra en el tope de la unidad, donde el carbonato se dispone en láminas horizontales y tabiques verticales que se vinculan a grietas de desecación rellenas con carbonato, el aspecto es reticulado. Lateralmente esta acumulación calcárea puede reducirse en magnitud, incluso desaparecer, y el paleosuelo S-EC1 puede involucrar parte de la presente unidad. El contacto con la unidad subyacente neto y sinuoso y corresponde a una discordancia erosiva, con incisiones profundas (Fig. 5.68 ). El depósito se vincula a génesis fluvial.

Unidad U-EC5. Hasta 2,50 metros de espesor. En general arcillo limosa. Son sedimentos con abundantes rasgos pedogenéticos, como son estructura prismática que rompe a bloques subangulares con abundantes barnices de arcilla, pátinas negras, concreciones de manganeso y hierro, bioturbación. En el sector de muestreo se registraron dos pulsos de sedimentación afectados por pedogenesis, donde el paleosuelo superior se designa S-EC2 y el inferior S-EC3, cabe destacar que en otro sector de la cantera se observaron tres pulsos de sedimentación afectados por pedogénesis, a veces constituyendo suelos superpuestos, otras veces suelos soldados. En los sectores con menor grado de desarrollo pedogenético los sedimentos son limo arenosos, con estructura entrecruzada y laminación paralela, y presentan intraclastos psefíticos y psamíticos. Presenta crotovinas circulares pequeñas que se asocian a roedores (Fig. 5.69a), 
probablemente correspondientes a Ctenomys Kraglievichi (Verzi et al., 2004), y rizoconcreciones. En algunos sectores es posible observar la estratificación entrecruzada a pesar de la pedogénesis (Fig. 5.69ab). Color 10 YR 5/3 en seco y 10 YR 4/3 en húmedo. El contacto con la unidad subyacente es neto y sinuoso (discordancia erosiva). Se vincula esta unidad a depósitos fluviales afectados por pedogénesis.

Unidad U-EC6: Al menos 1,60 metros de espesor. Limos arenosos y arenas limosas con laminación oblicua y paralela. Estructura secundaria en bloques angulares con pátinas negras. Color 7,5 YR 5,5/4 en seco y 7,5 YR 3,5/4 en húmedo. Presenta escasas concreciones de manganeso y hierro pequeñas. En el tope de la unidad se observan concreciones subesféricas de carbonato de calcio que pueden superar los $10 \mathrm{~cm}$ de diámetro. No es posible observar la base de la unidad. Se considera dominantemente de origen fluvial.

\subsubsection{Sección estratigráfica Santa Elena (PSE)}

Los sedimentos expuestos en este sitio corresponden a los acantilados marinos cercanos a la desembocadora del Arroyo Santa Elena, en la Ciudad de Santa Clara del Mar. Las coordenadas son $37^{\circ} 50^{\prime} 55,1^{\prime \prime}$ de latitud S y $57^{\circ} 30^{\prime} 17,4^{\prime \prime}$ longitud $\mathrm{O}$, con una altitud de 6 m.s.n.m.

El afloramiento posee 3,30 metros de altura. En la figura 5.70a se muestra una fotografía del perfil estudiado y se indican las principales unidades individualizadas. Las mismas también se indican en el en Panel de la figura 5.71 y en la columna sedimentaria de la figura 5.72.

\section{Unidades litológicas individualizadas en la sección PSE:}

U-SE1: Menos de $25 \mathrm{~cm}$ de espesor. Limos arenosos sin estructura primaria identificable. Color 10 YR 4/3 en seco y 10 YR 2/3 en húmedo. Presenta marcadas evidencias de removilización y erosión. El contacto con la unidad subyacente es neto, ligeramente ondulado (discordancia erosiva).

U-SE2. Posee un espesor entre 80 y 130 centímetros. Son arenas limosas con clastos de arena media, y escasas acumulaciones psefíticas (rodados de carbonato) en la base. Presenta estratificación entrecruzada débil. Color 10 YR 7/3 en seco y 10YR 5/4 en húmedo. Presenta carbonato de calcio disperso en la masa. La base de la unidad es neta, levemente sinuosa, probablemente discordancia erosiva. El origen sería dominantemente fluvial. 
U-SE3. Posee un espesor máximo de 2 metros. Son arenas muy finas y finas, hacia la base presenta clastos psefíticos. Presenta estratificación entrecruzada. El color en el sector superior es 7,5 YR 5/4 en seco y 7,5 YR 3/4 en húmedo, en la base el color es 10 YR 6/4 en seco y 10 YR 4/4 en húmedo. Esta unidad se caracteriza por poseer abundantes restos bioclásticos (Fig. 5.70b) y granos de arena media y gruesa muy redondeados en el sector basal (Fig. 5.73), con características de depósito de playa. Presenta abundante carbonato de calcio disperso en la masa. El contacto con la unidad subyacente es neto y sinuoso, corresponde a una discordancia erosiva. Se interpreta esta unidad como un relleno de canal, cuya parte inferior correspondería a una ingresión marina y la parte superior a depósitos fluviales.

U-SE4. Posee un espesor promedio de dos metros. Son arenas muy finas. Hacia la base presenta abundantes clastos de arena gruesa, muy gruesa y psefíticos, generalmete de carbonato de calcio. Presenta estratificación entrecruzada. Color 10 YR 6/3 en seco y 10YR 4/4 en húmedo, haciéndose más clara hacia el sector central. Presenta carbonato de calcio disperso en la masa. La mayor acumulación de carbonato se halla en el paleosuelo que corona la unidad, donde se dispone en planchas y tabiques que le confieren un aspecto reticulado. El color del paleosuelo es 7,5 YR 5/4 en seco y 7,5 YR 3/4 en húmedo. El contacto con la unidad subyacente es neto, sinuoso, corresponde a una discordancia erosiva con incisiones profundas. El origen de esta unidad se considera fluvial.

U-SE5: Al menos 80 centímetros de espesor. Se compone de arenas y limos con estructura planar paralela difusa a masiva. Color 7,5 YR 6/4 en seco y 7,5 YR 4/4 en húmedo. Presenta concreciones de carbonatos. Probablemente fluvial.

\subsection{Perfiles de Suelos Actuales.}

En algunas secciones estratigráficas donde el perfil de suelo se encontraba poco o nada disturbado por acción antrópica el mismo fue descripto en detalle según las recomendaciones de Schoeneberger et al. (2000) y clasificado tentativamente según Soil Survey Staff (2010). Las secuencias de horizontes se indican también en figuras correspondientes a los paneles y columnas sedimentarias de las secciones estratigráficas estudiadas, así como en figuras que incluyen fotografías del sector superior de las secciones. 


\subsubsection{Suelo actual en la sección PVC}

A $\quad 0-20 \mathrm{~cm} ; 10 \mathrm{YR} \mathrm{3/2} \mathrm{en} \mathrm{seco,} 10$ YR 2/1 en húmedo; franco arcillo limoso, presenta fragmentos rocosos esféricos-angulares de hasta $2 \mathrm{~cm}$ de diámetro (menos del 1\%); granular fina a media; ligeramente duro; friable; no plástico; ligeramente adhesivo; raíces comunes; límite inferior abrupto y ondulado.

Bt 20-65 cm; 7,5 YR 4/3 en seco; 7,5 YR 3/2 en húmedo; arcilloso; prismas medios a gruesos, fuertes, que rompe a bloques subangulares medios y finos, fuertes; duro; firme, muy plástico; muy adhesivo; revestimientos arcillo-húmicos muy abundantes; revestimientos de arcillas comunes; raíces escasas; límite inferior gradual y ondulado.

BC $\quad 65-75 \mathrm{~cm} ; 7,5$ YR 5/4 en seco; 7,5 YR 3/4 en húmedo; franco arcilloso; bloques subangulares gruesos moderados; ligeramente duro; friable; ligeramente plástico, ligeramente adhesivo; revestimientos de arcilla escasos; límite inferior gradual y ondulado.

C 75-128 cm; 7,5 YR 5,5/4 en seco; 7,5 YR 3/4 en húmedo; franco; masivo; ligeramente duro; friable; límite inferior gradual y ondulado.

Ck 128-176 cm; 10 YR 7/3 en seco; 10 YR 4/4 en húmedo; franco; masivo; carbonatos dispersos en la masa y nódulos escasos; límite inferior muy abrupto y plano.

2Ckm 176-195+ cm. 10 YR 7/3 en seco, 10 YR 3/4 en húmedo; franco arenoso; bloques subangulares; costra calcárea en planchas gruesas.

Posición topográfica: Piedemonte. Ladera distal de loma amplia.

Pendiente: $2 \%$

Clase natural de drenaje: Bien Drenado

Clasificación Taxonómica: Argiudol típico 


\subsubsection{Suelo actual en la sección PMI.}

Ak 0-30 cm; 10 YR 2/1 en seco, 10 YR 1/1 en húmedo; franco limoso, presenta fragmentos rocosos esféricos-angulares de hasta $2 \mathrm{~cm}$ de diámetro (menos del 2\%); migajosa, fina, débil; ligeramente duro; friable; no plástico; no adhesivo; raíces abundantes; nódulos de carbonato finos comunes; límite inferior abrupto y plano.

2Ckkm 30-52 cm; 7,5 YR 8/2 en seco, 7,5 YR 6/3 en húmedo; franco limoso; costra calcárea en láminas muy gruesas, muy dura.

2Ckm 52-72 cm; 7,5 YR 7/4 en seco, 7,5 YR 5/4 en húmedo; franco arenoso; bloques subangulares a laminar; costra calcárea en planchas muy gruesas, dura.

2Ck 72-100+ cm; 7,5 YR 6/4 en seco y 7,5 YR 4/4 en húmedo; franco limoso; bloques subangulares; carbonato pulverulento muy abundante.

Posición topográfica: Piedemonte distal. Divisoria secundaria. Loma amplia (probable relicto de erosión).

Pendiente: $1-2 \%$

Clase natural de drenaje: Bien Drenado a Algo Excesivamente Drenado

Clasificación Taxonómica: Paleoudol petrocálcico

\subsubsection{Suelo actual en la sección PCF}

A1 0-18 cm; 10 YR 3/2 en seco, 10 YR 2/2 en húmedo; franco; granular, fina, débil; blando; friable; no plástico; no adhesivo; raíces abundantes; crotovinas; límite inferior claro y plano.

A2 18-30 cm; 10 YR 3/1,5 en seco, 10 YR 2/2 en húmedo; franco; granular, fina, débil; blando; friable; no plástico; no adhesivo; raíces moderadas; crotovinas; límite inferior claro y plano. 
Bw 30-80 cm; 10 YR 3/2,5 en seco; 7,5 YR 2/1,5 en húmedo; franco limoso; bloques subangulares medios, fuertes; duros; firmes, ligeramente plástico; ligeramente adhesivo; revestimientos arcillo-húmicos escasos; raíces escasas; límite inferior gradual y ondulado.

BC $\quad 80-108 \mathrm{~cm} ; 7,5$ YR 5/4 en seco; 7,5 YR 3/4 en húmedo; franco limoso; bloques subangulares gruesos, débiles; no plástico; no adhesivo; límite inferior gradual y ondulado.

C 108-127 cm; 7,5 YR 6/4 en seco; 7,5 YR 3/4 en húmedo; franco; masivo; ligeramente duro; friable; límite inferior gradual y ondulado.

Ck 127-169 cm; 7,5 YR 6/4 en seco; 7,5 YR 4/4 en húmedo; franco; masivo; carbonatos dispersos en la masa; límite inferior abrupto e irregular.

2Ckm 169-195+ cm. 7,5 YR 6/3 en seco, 7,5 YR 4/3 en húmedo; franco arenoso; bloques subangulares; costra calcárea en planchas gruesas; muy duro.

Posición topográfica: Piedemonte distal. Divisoria secundaria. Ladera de loma estrecha (relicto de erosión).

Pendiente: Pronunciada, 10\%

Clase natural de drenaje: Algo Excesivamente Drenado a Excesivamente Dreanado

Clasificación Taxonómica: Hapludol típico

\subsubsection{Suelo actual en la sección PCT}

Ap $\quad$ 0-18 cm; 10 YR 3/2 en seco, 10 YR 2/2 en húmedo; franco; granular, fina, débil; blando; friable; no plástico; no adhesivo; raíces abundantes; límite inferior claro y ondulado.

Bw 18-41 cm; 7,5 YR 6/3 en seco; 7,5 YR 4/3 en húmedo; franco; prismas medios, moderados; duro; firme, no plástico; no adhesivo; raíces escasas; límite inferior gradual y ondulado.

BC 41-62 cm; 7,5 YR 6/3 en seco; 7,5 YR 4/3 en húmedo; franco; bloques subangulares gruesos, débiles; no plástico; no adhesivo; límite inferior difuso y plano. 
C 62-126+ cm; 10 YR 6,5/4 en seco; 10 YR 4/4 en húmedo; franco; masivo; ligeramente duro; friable.

Posición topográfica: Piedemonte, con afloramiento rocoso cercano.

Pendiente: Pronunciada, $8 \%$

Clase natural de drenaje: Algo Excesivamente Drenado a Excesivamente Drenado

Clasificación Taxonómica: Hapludol típico

\subsubsection{Suelo actual en la sección PRO}

A $\quad 0-25 \mathrm{~cm} ; 10$ YR 3/2 en seco, 10 YR 1,5/2 en húmedo; franco arcillo limoso; granular, fina; duro; no plástico; no adhesivo; raíces abundantes; límite inferior abrupto y plano.

Bt 25-62 cm; 7,5 YR 5/4 en seco; 7,5 YR 2/3 en húmedo; arcilloso; prismas medios a gruesos, fuertes que rompe a bloques subangulares medios y finos, fuertes; duro; firme, plástico; adhesivo; barnices arcillo-húmicos abundantes; barnices de arcilla comunes; raíces escasa; límite inferior claro y ondulado.

BC $\quad 62-82 \mathrm{~cm} ; 7,5$ YR 5/4 en seco; 7,5 YR 3/4 en húmedo; franco arcilloso; bloques subangulares gruesos débiles; ligeramente duro; friable; ligeramente plástico, ligeramente adhesivo; barnices de arcilla escasos; límite inferior gradual y ondulado.

C 82-120 cm; 7,5 YR 5,5/4 en seco; 7,5 YR 3/4 en húmedo; franco limoso; masivo; friable; límite inferior; límite inferior abrupto y ondulado.

2Ckm 120-145 cm. 10 YR 7/4 en seco; 10 YR 5/4 en húmedo; franco limoso; bloques subangulares; costra calcárea en planchas gruesas; muy duro; límite inferior claro y ondulado,

2Ck 145-175 cm. 10 YR 5/4 en seco; 10 YR 3/4 en húmedo; franco limoso; bloques subangulares; carbonato de calcio en la masa, muy abundante; límite inferior claro y ondulado.

2Ckm 175-217 cm. 10 YR 6/4 en seco; 10 YR 5/4 en húmedo; franco limoso; bloques subangulares; costra calcárea en planchas medias; duro. 
Posición topográfica: Divisoria secundaria. Loma amplia.

Pendiente: $1 \%$

Clase natural de drenaje: Bien drenado

Clasificación Taxonómica: Argiudol típico

En la figura 5.74 se plantean esquemas geopedológicos simplificados en sentido de Zinck (2012) para sectores positivos del área serrana. Las situaciónes descriptas como "Loma" (estrecha y amplia), corresponden a geoformas de erosión, parcialmente cubiertas, hacia las laderas por depósitos más jóvenes (fluviales y eólicos); donde "loma estrecha" es coincidente con las secciones de calle Fangio y San Manuel y "loma amplia" con la sección María Ignacia. La situación de piedemonte, con afloramiento rocoso cercano, es coincidente con la sección Circuito Turístico y Cerro Quebracho.

\subsection{Consideraciones de importancia.}

El análisis y las descripciones de campo constituyen la base de la investigación y son de importancia fundamental para la realización de muestreos. Esta labor permitió individualizar en cada sección estratigráfica distintos cuerpos sedimentarios (unidades litológicas) con características morfológicas distintivas, separados por superficies de discontinuidad, ya sean concordantes o discordantes.

Se determinó que las sucesiones estudiadas son dominantemente fluviales; no obstante la influencia de depositación coluvial es importante en los sectores serranos. Sólo las unidades más recientes, afectadas por el ciclo pedogenético actual, presentan características de depósito eólico.

En el presente trabajo las unidades litológicas individualizadas son consideradas como cuerpos de menor jerarquía y que forman parte de cuerpos litológicos mayores (e.g. unidades litoestratigráficas). En este sentido, en la mayoría de los casos es posible vincular estas unidades a unidades lito o aloestratigráficas definidas por distintos autores. Asimismo, en base a las características distintivas de cada unidad o conjunto de unidades, es posible establecer un esquema tentativo de correlaciones entre los perfiles de cada sector estudiado, así como un esquema abarcativo que relaciona los sectores de Sierras de Tandil y Balcarce, y algunas de las unidades del sector costero al norte de Mar del Plata. 


\subsubsection{Correlación preliminar en el sector Sierras de Tandil}

En la figura 5.75 se muestran las columnas sedimentarias, se indican las unidades litoestratigráficas asignadas y las correlaciones realizadas en el sector Sierras de Tandil. Los sedimentos del tope de las secciones PVC, PCF, así como la unidad U-CT1, presentan características similares: corresponden a limos arenosos, sin estratificación primaria identificable, que se vinculan a depósitos eólicos (loess), aunque con indicios de acción hídrica encausada hacia la base. Hacia el tope de estos se desarrolla el suelo actual. En las secciones PVC y PCF se apoyan sobre una duricostra calcárea. De manera similar, en la sección PMI, por encima de una duricostra calcárea, se apoya un manto de $30 \mathrm{~cm}$ de espesor, limoso y sin estructura identificable, que se encuentra enteramente pedogenizado, conformando el horizonte Ak del suelo actual. En las distintas secciones estratigráficas estos depósitos son asignados a la Formación Las Ánimas (Rabassa, 1971, 1973) definida para las Sierras de Tandil, que sería equivalente al "Médano Invasor" (Tapia, 1937) para Sierras de Balcarce, a la Formación La Postrera (Fidalgo et al., 1986) de la cuenca del arroyo Tapalqué (Olavarría) y a la unidad litoestratigráfica 3 (Zárate y Mehl, 2010) de la cuenca del arroyo Azul.

Por debajo de la Formación Las Ánimas, fueron descriptos en las secciones PVC, PMI y PCF depósitos de arenas limosas, con estratificación entrecruzada conspicua y laminación paralela subordinada, con importantes acumulaciones psefíticas y abundante carbonato de calcio en la masa, cuya concentración más importante se halla en el tope de la unidad, donde se dispone en planchas horizontales y conforma una duricostra, que se vincula a la paleosuperficie Tandil (Teruggi et al., 1973). La base de esta unidad es erosiva, con incisiones profundas, indicando una importante reactivación fluvial. Estas unidades se asignan a la Formación Vela (Rabassa, 1971, 1973), que sería equivalente a la unidad litoestratigráfica 2 (Zárate y Mehl, 2010) de la cuenca del arroyo Azul.

Por debajo de la Formación Vela, en las secciones PVC, PMI y PCF se hallaron depósitos dominantemente limosos, con cantidades subordinadas de arena y arcilla, algunos niveles presentaron acumulaciones psefíticas, correspondientes a fragmentos de rocas y limolitas retransportadas. Su coloración es más rojiza que las unidades descriptas anteriormente. Presenta estructuras sedimentarias difusas, generalmente estratificación entrecruzada y laminación paralela, que son consistentes con ambiente fluvial; no obstante, en el perfil de María Ignacia se reconoció una capa de limos masivos, probablemente vinculados a ambiente eólico. Los rasgos pedogenéticos son prácticamente constantes en toda la unidad litoestratigráfica; no obstante se reconocieron niveles de paleosuelos conspicuos. La presencia de concreciones de carbonato de calcio es también común. Se asigna este conjunto de unidades a 
la Formación Barker (Rabassa, 1971, 1973), que sería equivalente a la unidad litoestratigráfica 1 (Zárate y Mehl, 2010) de la cuenca del arroyo Azul. Cabe resaltar que en la sección PVC fueron hallados hacia el techo de la Formación Barker restos óseos de roedores (Actenomys y Lagostomopsis). La importancia de éstos estriba en que corresponden a los primeros hallazgos con importancia bioestratigráfica para dicha unidad en su localidad tipo (localidad 51, Cantera Loma Negra de Barker; Rabassa, 1971, 1973) y para el sector de las Sierras de Tandil. Según el Dr. Diego Verzi y el Dr. Pablo Straccia (com. pers. escrita) los restos corresponderían a la edad-piso Chapalmalalense-Montehermosense, que se extendería entre los 3,2 y 6,8 Ma (Cione et al., 2007; Verzi y Montalvo, 2008). Actualmente el material se encuentra en proceso de descripción sistemática detallada a cargo del Paleontólogo Nicolás Chimento, quien por su parte confirmó las clasificaciones efectuadas por los Doctores Verzi y Straccia. Luego de esto, se prevé depositar e inventariar el material en el museo Histórico y de Ciencias Naturales Dr. Aurelio de Lusarreta, de la localidad de María Ignacia Vela, a $43 \mathrm{Km}$ de la sección de Villa Cacique.

En la sección PVC, por debajo de los sedimentos asignados a la Formación Barker y por encima de la Caliza Loma Negra, fue descripta la unidad U-VC6, que corresponde a un conglomerado, cuyos clastos y bloques se componen principalmente de carbonatos micriticos, con matriz rojiza, arcillosa, con abundantes rasgos vérticos (slickensides y agregados cuneiformes). No se conoce nombre formal para esta unidad, en tanto considero que constituye una nueva unidad litoestratigráfica que debe adicionarse a parte inferior del esquema de Rabassa (1971, 1973). Por el momento, no se propone un nombre formal a fin de evitar la incorporación de designaciones a la literatura geológica neógeno-cuaternaria de la región pampeana y para no contribuir a incrementar el caos nomenclatural existente. Cabe mencionar que en otros sectores de la provincia geológica de Tandilia, ya sea en las sierras de Balcarce (Tapia, 1937; Martínez, 2001) como en Olavarría (Poiré et al., 2013), existen referencias a depósitos conglomerádicos apoyados sobre rocas pre-mezosoicas (ver capítulo 3), las descripciones realizadas por los autores distan de las características aquí observadas. Si bien la composición de los clastos puede ser diferente debido a características locales de las rocas, la diferencia más marcada consiste en la composición de la matriz. Ninguno de los autores mencionados hace referencia al predominio de arcilla con conspicuos rasgos vérticos, lo cual es la característica más distintiva de esta unidad. No obstante no se descartan posibles correlaciones.

Lo dicho anteriormente se resume en la tabla 5.1, en la misma se indican las unidades litológicas correlacionadas, sus características más conspicuas y su asignación a unidades litoestratigráficas. 


\subsubsection{Correlación preliminar en el sector Sierras de Balcarce}

En la figura 5.75 se muestran las columnas sedimentarias, se indican las unidades litoestratigráficas asignadas y las correlaciones realizadas en el sector Sierras de Balcarce. Los sedimentos del tope de las secciones PRO, PSB, PCQ, así como la unidad cuspidal de la sección PSM (presente en forma lateral al sitio de muestreo), poseen características similares: corresponden a limos arenosos, sin estratificación primaria identificable, que se vincula a un depósito eólico (loess), aunque con indicios de acción hídrica encauzada hacia la base. En todas las secciones se apoyan sobre una duricostra calcárea y hacia el tope se desarrolla el suelo actual. Estas unidades son consistentes con las asignadas a la Formación Las Ánimas en el sector de Sierras de Tandil, que sería equivalente también al "Médano Invasor".

Por debajo, fueron descriptos depósitos de arenas limosas y limos arenosos, con estratificación entrecruzada y laminación paralela subordinada, con acumulaciones psefíticas y abundante carbonato de calcio en la masa, cuya concentración más importante se halla en el tope, donde se dispone en planchas horizontales y conforma una duricostra que se vincula a la paleosuperficie Tandil. En los perfiles donde se pudo observar la base (PSM, PSB, PCQ), ésta es erosiva, con incisiones profundas, y se relacionarían con una reactivación fluvial. Este conjunto es equivalente a las unidades asignadas a la Formación Vela en el sector de Sierras de Tandil.

Las unidades litológicas que se encuentran por debajo de la Formación Vela presentaron importantes diferencias en los distintos perfiles del sector de Sierras de Balcarce. En la sección PCQ, la Formación Vela se apoya directamente sobre el basamento cristalino, el cual presenta signos de meteorización. En las secciones PSB y PSM se hallaron por debajo de Vela conjuntos sedimentarios con aspecto loessoide, pero que a pesar de estar en la misma posición estratigráfica, presentaron diferencias, que hacen suponer que no serían equivalentes. En la sección PSM los sedimentos son predominantemente limos rojizos, con estratificación entrecruzada y se consideran equivalentes a la Formación Barker, en cambio, en la sección PSB, se trata de sedimentos limo arenosos, castaños, sin estructura primaria determinable o con laminación paralela difusa, con clastos de basamento diseminados y crotovinas circulares. Estos se consideran equivalentes a los niveles 2 y 1 de Teruggi et al. (1973). Cabe destacar que el análisis mineralógico expuesto en Teruggi et al. (1973) en dichas unidades indica importantes diferencias con los análisis mineralógicos de Rabassa (1973) en la Formación Barker, esto será tratado con mayor profundidad en el capítulo 6. Por otro lado es menester destacar que Tapia (1937), en una perforación realizada cerca de la ciudad de Balcarce, extrajo un fragmento de un roedor identificado como Ctenomys Chapadmalensis, el cual, según el esquema de Cione y Tonni (2005), corresponde a la biozona 
homónima, correspondiente al Piso Marplatense, más joven que los hallados en la Formación Barker en este trabajo de tesis. Por las mismas razones expuestas anteriormente no se asigna nombre formal a la unidad litoestratigráfica conformada por las unidades U-SB3 y U-SB4, se designa en este trabajo como U$\mathrm{SB} 3 / 4$.

Lo dicho anteriormente se resume en la tabla 5.2, en la misma se indican las unidades litológicas correlacionadas, sus características más conspicuas y su asignación a unidades litoestratigráficas.

\subsubsection{Correlación preliminar en el sector costero al norte de Mar del Plata}

En la figura 5.76 se muestran las columnas sedimentarias y se indican las unidades correlacionadas en el sector costero al norte de Mar del Plata. La existencia de varios esquemas estratigráficos, a menudo incompletos, generó dificultes a la hora de asignar las unidades descriptas a unidades lito y aloestratigráficas. Para referirnos a las unidades que se consideran equivalentes se definen cinco "asociaciones de unidades" (A1 - A5). Las mismas se indican en la tabla 5.3.

Los sedimentos del tope de las cuatro secciones estudiadas (U-GA1; U-PD1; U-EC1 y U-SE1) presentan rasgos similares, se trata de sedimentos limo arenosos, bien seleccionados, sin estructura primaria identificable que se interpretaron como un depósito dominantemente eólico; los mismos se designan como asociación A1, y se vincularía al "Médano Invasor" (Tapia, 1937), al par E1-E3 (Tricart, 1973), a la Aloformación Médano Invasor (Martínez, 2001), a la Formación La Postrera (Fidalgo et al., 1973, 1989) y a la Formación Las Ánimas (Rabassa, 1971, 1973). Cabe destacar que en la base de la unidad U-PD1 fue hallado un nivel de ceniza volcánica. Si bien existe en la zona mención a distintas acumulaciones cineríticas de distintas edades, dada la posición estratigráfica, éstas se consideran equivalentes a las Cineritas Camet, datadas en $21 \mathrm{Ka}$ (Corbella et al., 2000).

En las secciones PPD, PEC, PSE pero a un nivel inferior al de la asociación A1, y por encima de una costra calcárea reticulada, fueron determinadas las unidades U-PD2, U-EC2, U-SE2 y una unidad lateral al sitio del muestreo en GADA (PGA). Se comprobó que éstas presentan características litológicas y morfológicas similares. Se trata de arenas muy finas y limos gruesos, con estratificación entrecruzada difusa y acumulaciones de carbonatos de calcio dispuesto en finas laminas horizontales, sobre la base de lo expuesto se designa a estos sedimentos como asociación A2. La homologación de ésta a designaciones realizadas por otros autores es dificultosa, probablemente se corresponda al alomiembro inferior de la 
Aloformación Médano Invasor (Martínez, 2001). Asimismo, es posible que las acumulaciones calcáreas de esta unidad se vinculen en parte a lo que Tricart (1973) denominó superficie Finipampeana.

Por otro lado, es posible asociar las unidades U-GA2, U-PD3, U-EC4 y U-SE4, debido a que en todas las secciones, corresponden a depósitos limo arenosos a areno limosos, con estratificación entrecruzada conspicua e importantes acumulaciones psefíticas en la base con arreglo granodecreciente. Se apoyan sobre las unidades subyacentes mediante discordancia erosiva, con incisiones profundas, indicando reactivación de la red de drenaje. En el tope, éstas unidades, presentan una importante acumulación de carbonato de calcio que se dispone en planchas horizontales y tabiques verticales que le confieren un aspecto reticulado que recuerdan al "calcaire cloisonner" de D'Órbigny (1842), se vincula a la paleosuperficie Tandil (Teruggi, 1973) y probablemente a la superficie Finipampeana de Tricart (1973). Este conjunto de unidades se designa como A3 y se asocia al Bonaerense (Ameghino, 1908), a la Formación Santa Clara (Schnack et al., 1982), al miembro superior de la Formación Santa Clara (Fasano, 1990), a las Aloformaciones Santa Clara y El Hipódromo (Martínez, 2001) y a la Formación Buenos Aires (Bidegain et al., 2005).

Cabe destacar, que por debajo de A2, y por encima de A3, apoyado en discordancia de erosión, en la sección PSE fue hallado un nivel de arenas, con contenido bioclástico (U-SE3), que correspondería a una ingresión marina. En la misma posición estratigráfica, en la sección PEC, fue determinado un paleosuelo (S-EC1). Dada la posición estratigráfica, estos depósitos vinculados a clima húmedo, se podrían asignar al estadio isotópico 5 e $(c a .120 \mathrm{Ka})$. En este intervalo temporal el nivel del mar habría alcanzado el ultimo máximo y su registro es abundante en la costa atlántica bonaerense (Schanack et al., 2005). La presencia de este nivel es consistente con lo manifestado por Cione et al. (2002), quienes describieron sedimentos marinos que asignaron al "Belgranense" en la localidad de Santa Clara del Mar. Recientemente, en el año 2013, en la ciudad de La Plata se llevó a cabo el Simposio Multidisciplonario: El estadio Isotópico 3 en la Argentina y el sur de América del Sur, con el fin de promover la interacción entre los especialistas a los efectos de llevar una puesta al día del conocimiento sobre dicho estadio isotópico. En este marco resulta oportuno plantear como alternativa una vinculación con el estadio isotópico 3 (25 $60 \mathrm{Ka}$ ) para la depositación de la unidad litológica U-SE3 y la formación del paleosuelo S-EC1. No obstante cabe destacar que la mención en la literatura estratigráfica del MIS3 en la región es escasa y generalmente está ligada a discusiones de índole metodológico, vinculadas a edades radiocarbónicas en el límite de detección del método (Schnack et al., 2005; Tonni et al., 2010); asimismo cabe destacar que la línea de costa en dicho período habría estado más retirada que en la actualidad (Isla com. oral. Simposio Multidisciplonario: El estadio Isotópico 3 en la Argentina y el sur de América del Sur). 
Por debajo de A3 es frecuente hallar depósitos areno limosos con estratificación entrecruzada (UGA3, U-PD4, U-EC5), que suelen presentar conspicuos rasgos pedogenéticos, conformando horizontes Bt (S-GA1; S-EC2; S-EC3). Estas unidades se disponen en forma saltuaria debido a que han sido muy erosionadas. Se designan como asociación A4 y se vinculan al Geosol Mar del Plata (Martínez, 2001).

Otro conjunto de unidades con características distintivas, y que facilitan la correlación entre las secciones estratigráficas comprende los depósitos de la base de los perfiles, son las unidades designadas como U-GA4 a 7, U-PD5 y 6, U-EC6 y U-SE5. Si bien se trata de un conjunto heterogéneo y complejo, una característica distintiva es la de conformar estratos tabulares, compactos, con alternancia de niveles rojizos y amarillo grisáceos (gley). La granulometría es variada (arenas limosas, limos arenosos, limos arcillosos y depósitos psefíticos). La estructura dominante es laminar paralela y en parte entrecruzada difusa. Se considera que este conjunto sedimentario es de origen fluvial; se lo se designa como asociación A5. Se vincula al Ensenadense (Ameghino, 1908;), al miembro inferior de la Formación Santa Clara (Fasano, 1990) y a la Formación Ensenada (Bidegain et al., 2005). Cabe destacar que existen hallazgos fosilíferos en la base de los acantilados costeros estudiados (Prevosti et al., 2007) y en la base de la cantera El Casal (Soibenson et al., 2001), que fueron asociados al Piso Ensenadense, que según Cione et al. (2007) finalizaría ca. $450 \mathrm{Ka}$ (ver tabla capítulo 3). Asimismo, Bidegain et al. (2005) determinaron el límite Brunhes-Matuyama (0,78 Ma) en unidades correspondientes este nivel en la desembocadura del arroyo La Tapera y en los acantilados del Barrio Felix Camet.

\subsubsection{Correlación preliminar en el sector Tandil-Balcarce-Mar del Plata}

En base a la asignación a unidades litoestratigráficas en los sectores de Sierras de Tandil y Balcarce es posible relacionar ambos esquemas sedimentarios. Asimismo es posible vincular los sedimentos eólicos del tope de los perfiles del sector costero (A1) con la Formación Las Ánimas, determinada en los sectores señalados. De forma similar, las unidades de la asociación A3 presentaron características afines a la Formación Vela, entre otras, las estructuras sedimentarias, la abundancia de carbonatos y la discordancia erosiva, con incisiones profundas, que la separa de las unidades subyacentes. Las correlaciones entre los distintos sectores serán tratadas en profundidad más adelante, luego de analizar los datos paleomagnéticos (capítulo 8). 


\subsection{Figuras del capítulo 5}

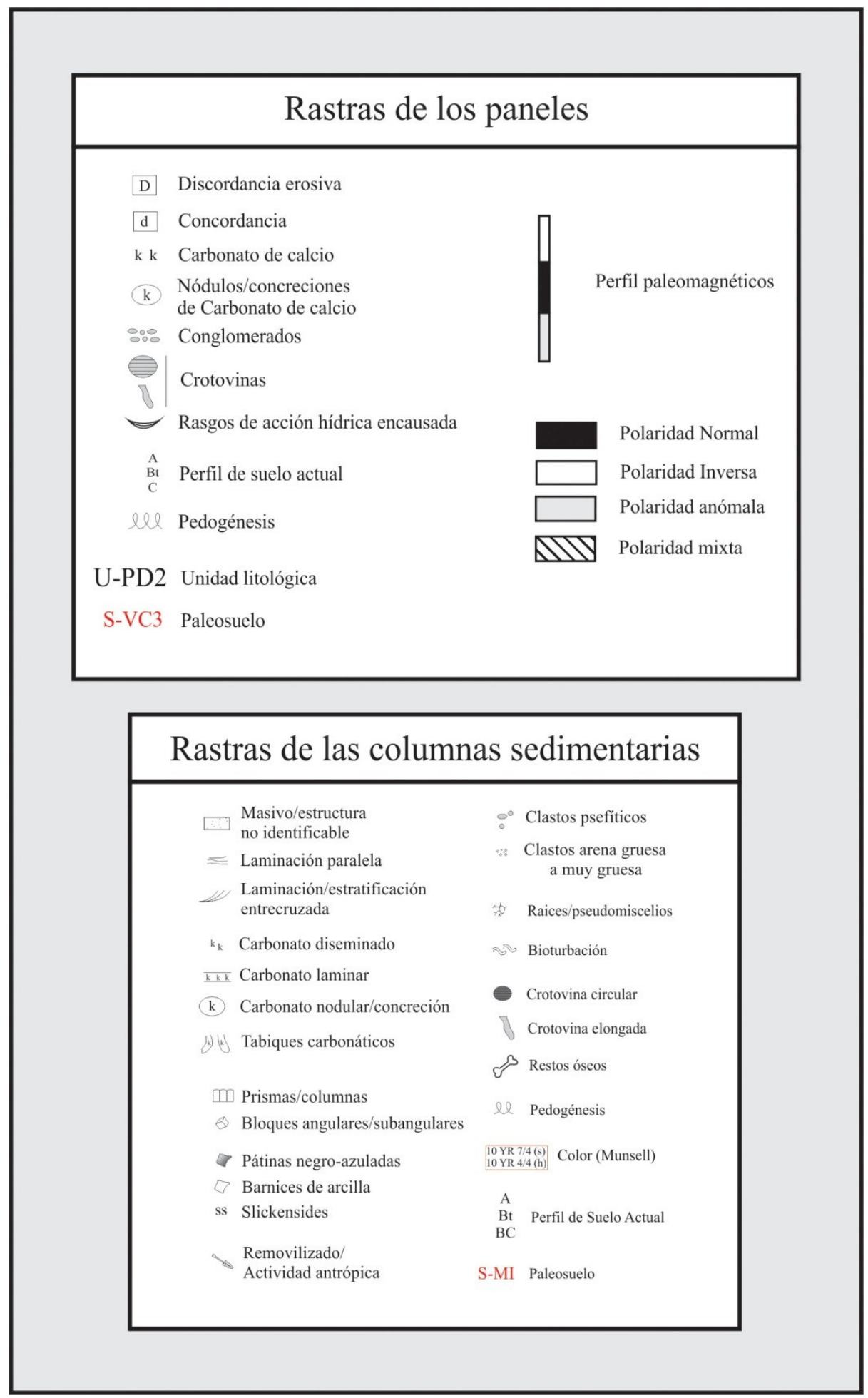

Figura 5.1. Rastras utilizadas en los paneles y columnas sedimentarias. 


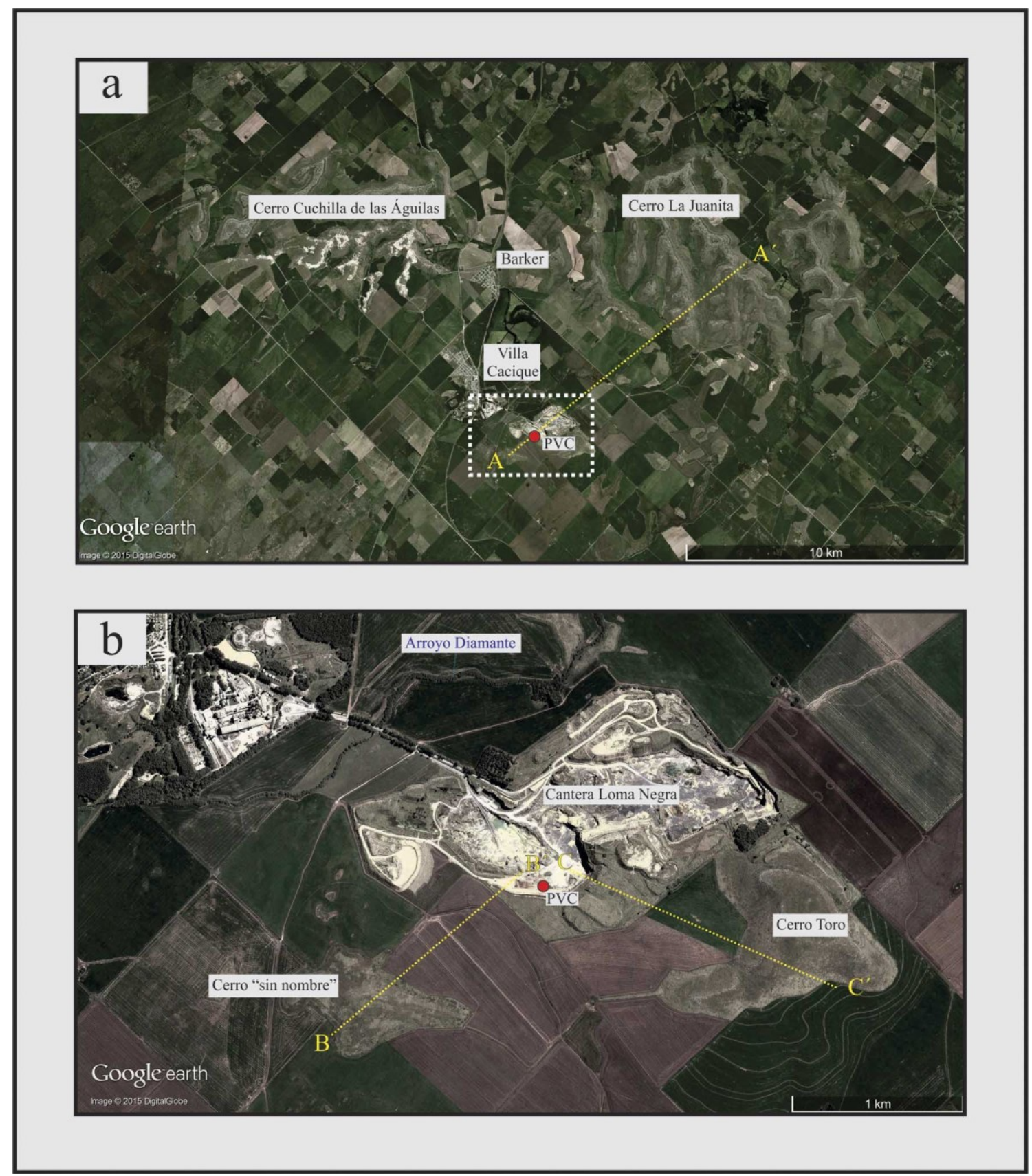

Figura 5.2. Ubicación de la sección estratigráfica de Villa Cacique (PVC). Las líneas amarillas indican las transectas utilizadas para realizar perfiles de elevación. a) Vista general y transecta A-A'; b) Vista de detalle y transectas B-B'y C-C'. 

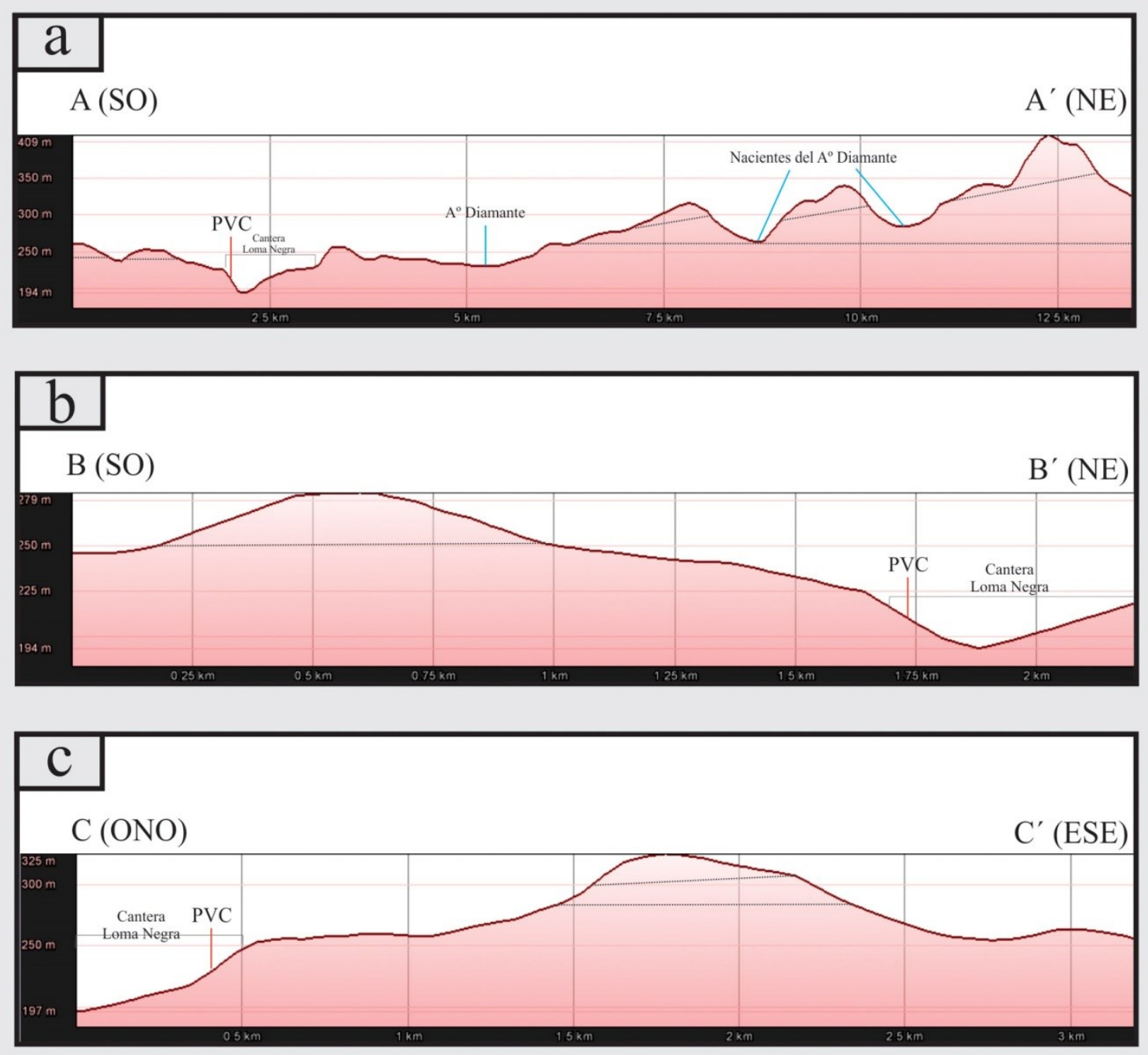

Figura 5.3. Perfiles de elevación de las transectas indicadas en la figura 5.2. a) Perfil de la transecta A-A';

b) Perfil de la transecta B-B'; c) Perfil de la transecta C-C'. 


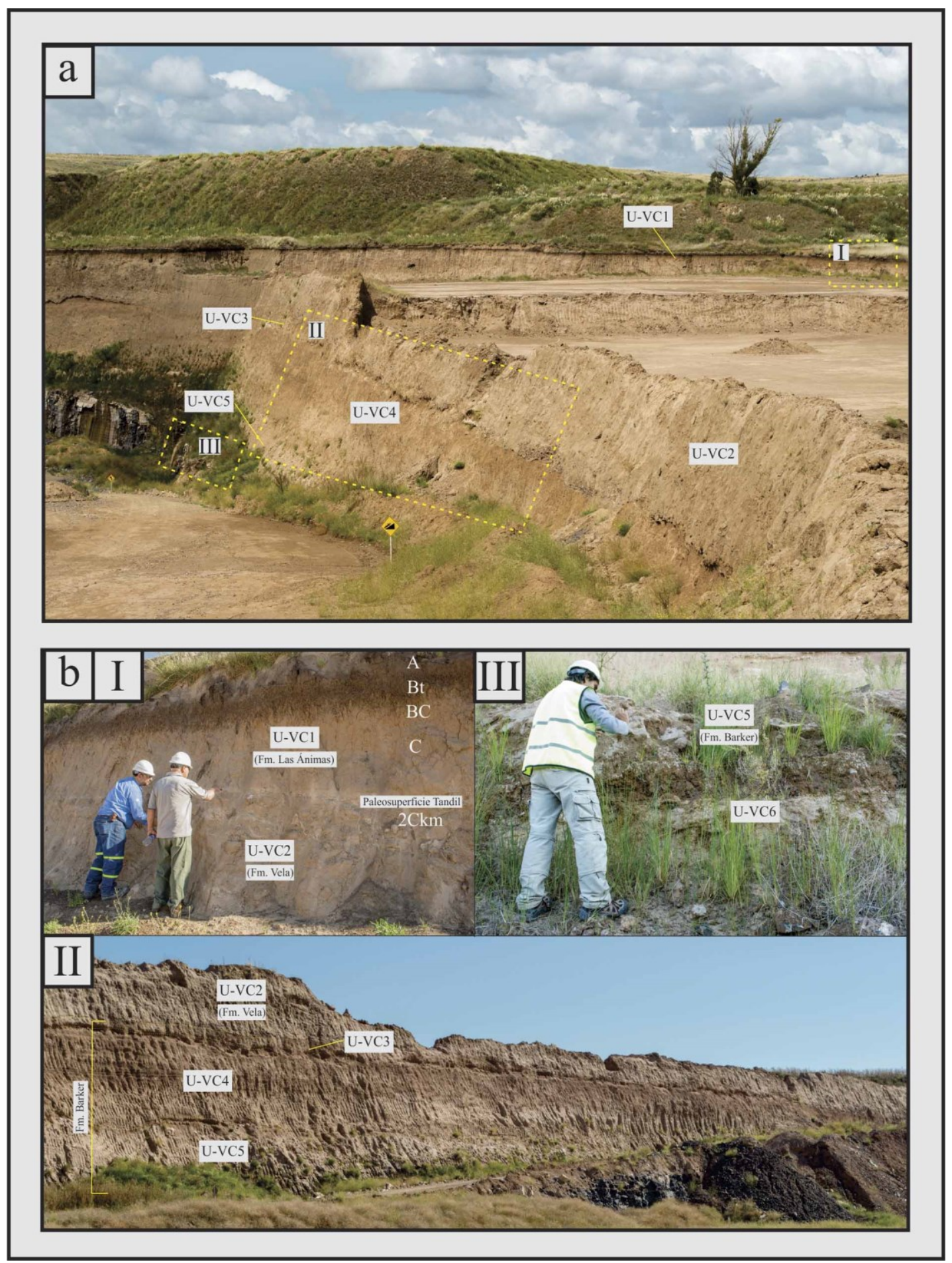

Figura 5.4. Fotografías de los sedimentos expuestos en la cara sur de la cantera Loma Negra (planta Barker). a) Vista general de los sedimentos; bI) Unidades U-VC1 y U-VC2; bII) Unidades U-VC2 a UVC5; bIII) Unidades U-VC5 y U-VC6 


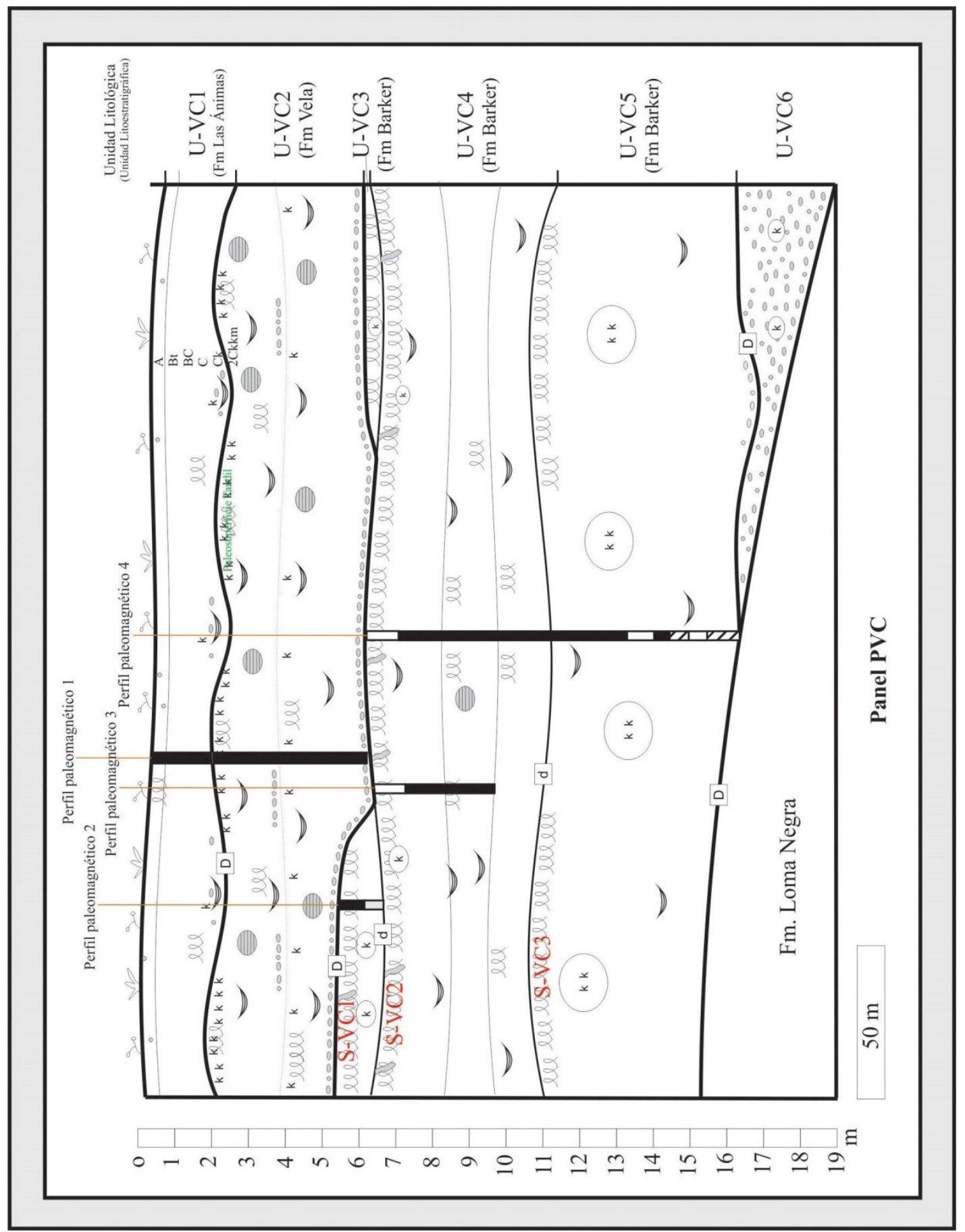

Figura 5.5. Panel esquemático de la sección de Villa Cacique (PVC). 


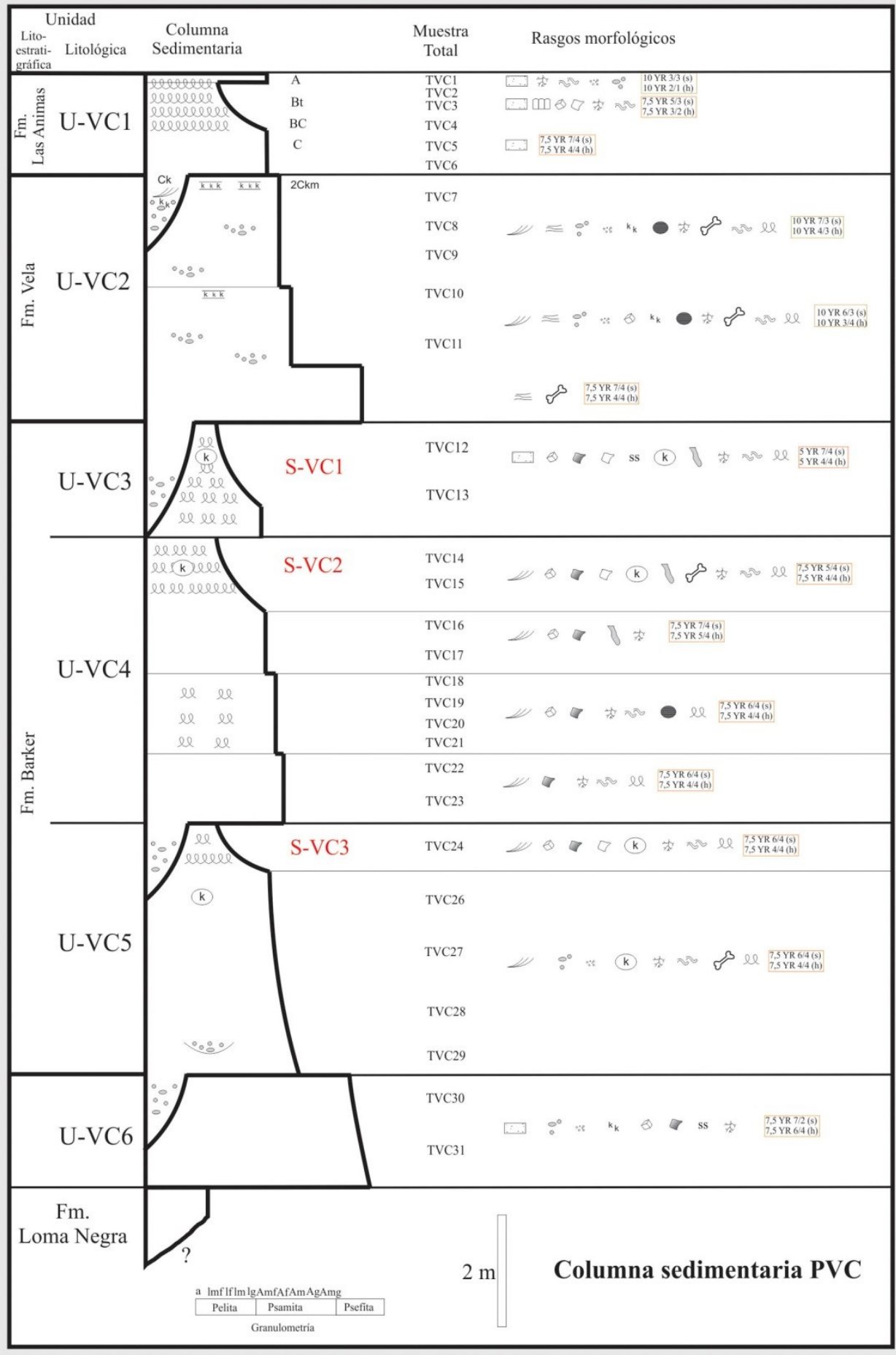

Figura 5.6. Columna sedimentaria de la sección de Villa Cacique (PVC). 


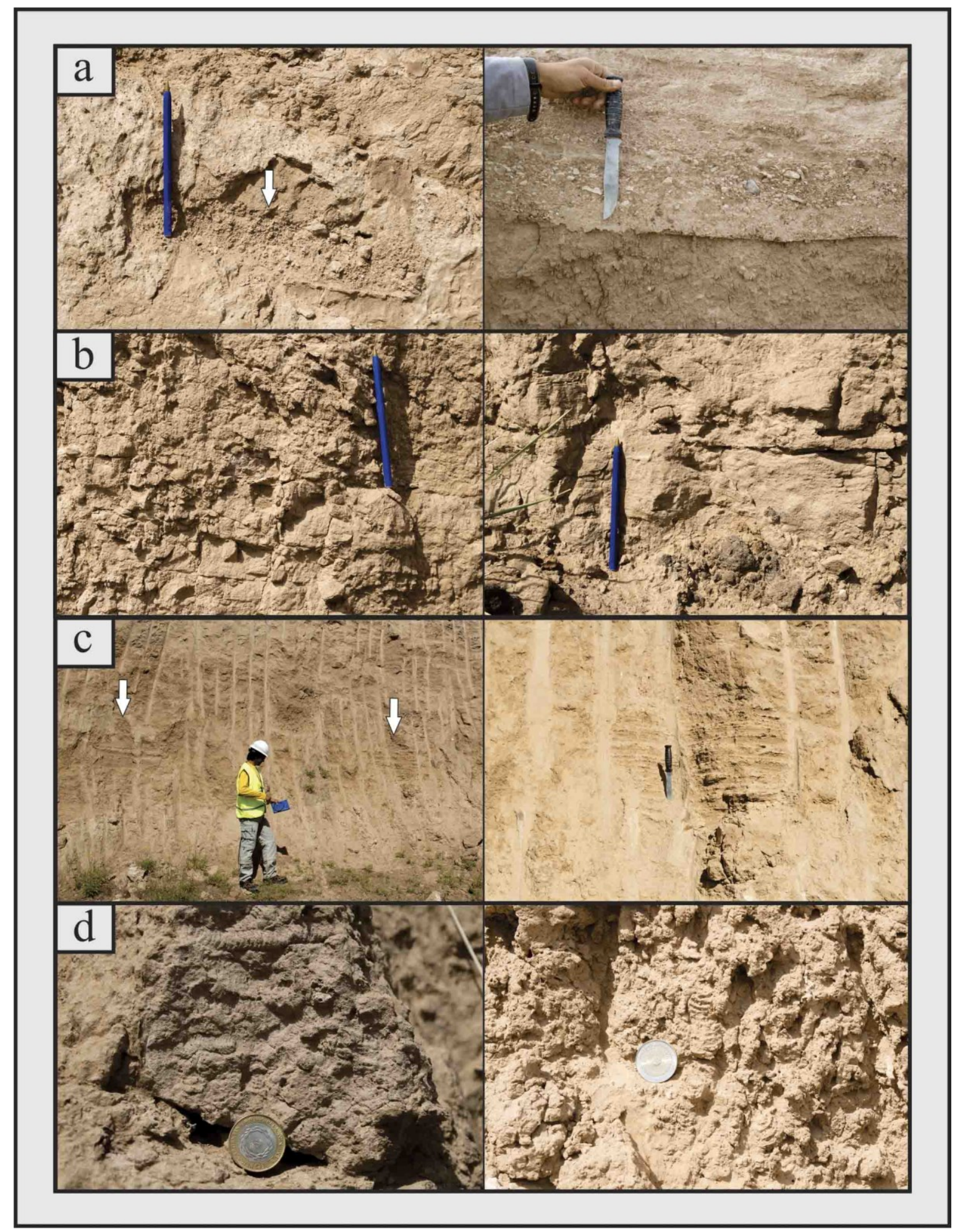

Figura 5.7. Rasgos morfológicos de la unidad U-VC2. a) Acumulaciones psefíticas; b) Estratificación entrecruzada; c) Crotovinas circulares; d) Bioturbación (Taenidium). 


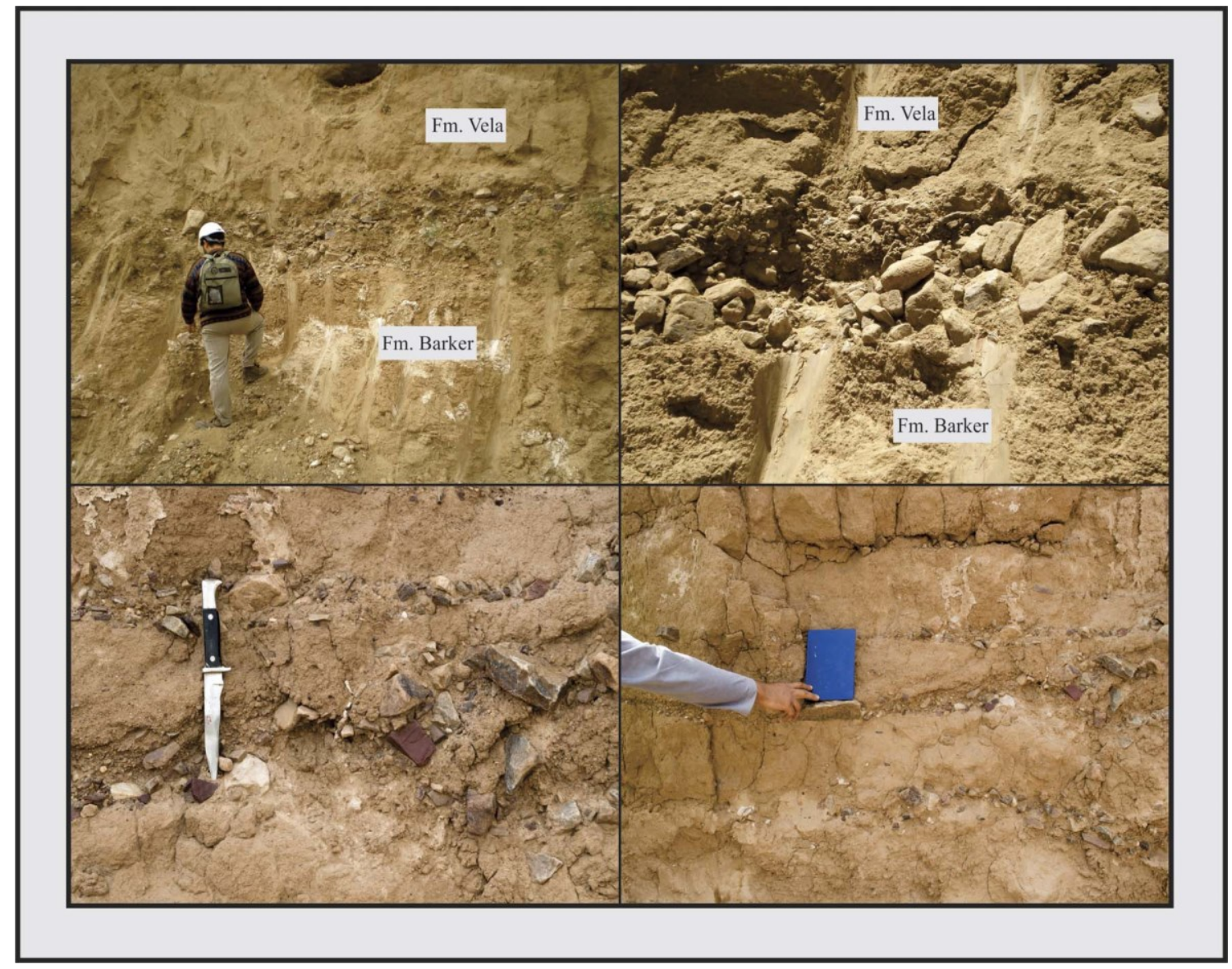

Figura 5.8. Distintas fotografías de la acumulación psefítica de la base de la unidad U-VC2. 


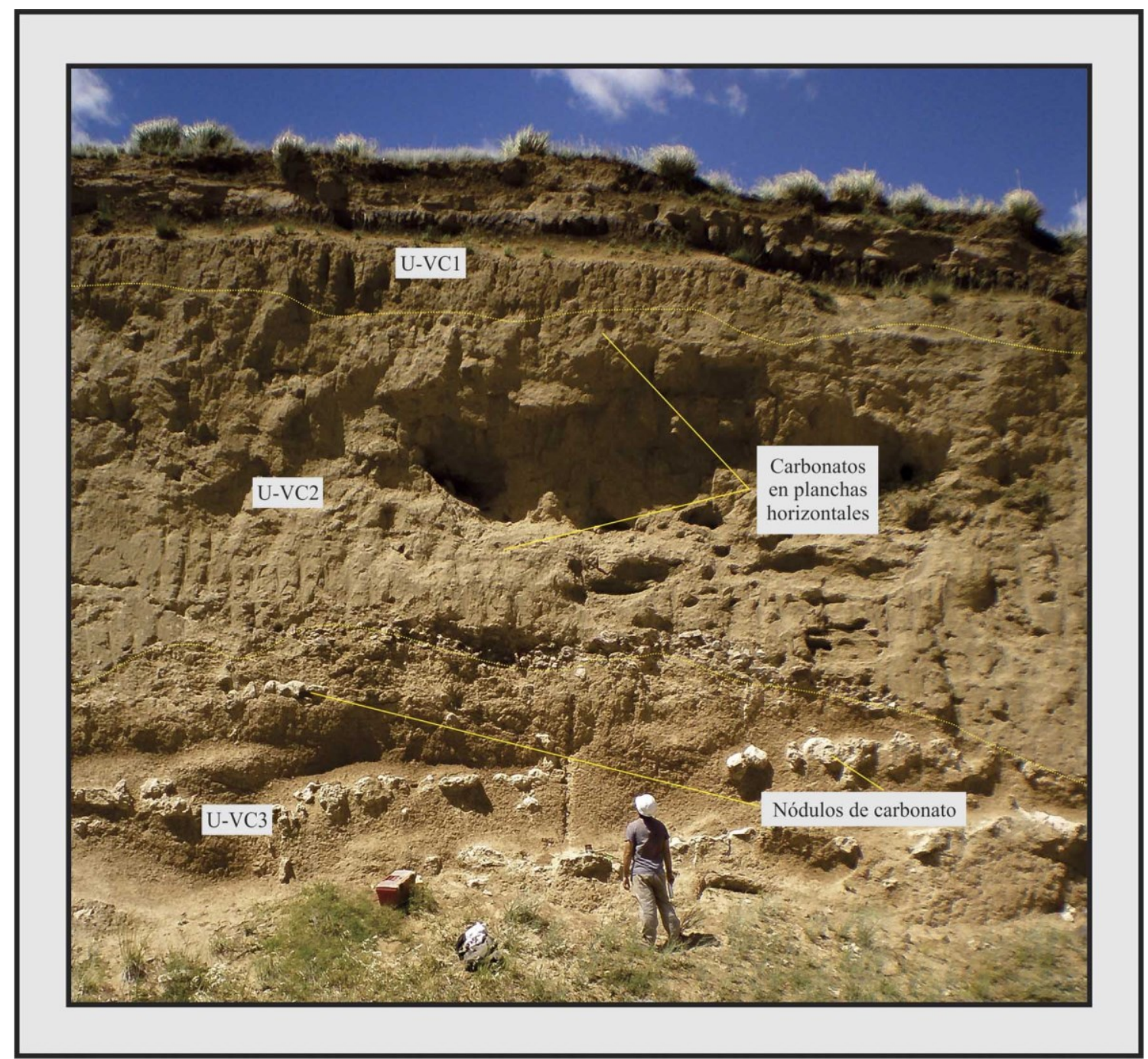

Figura 5.9. Fotografía donde se indican las unidades U-VC1, U-VC2 y U-VC3 y las acumulaciones calcáreas presentes. 


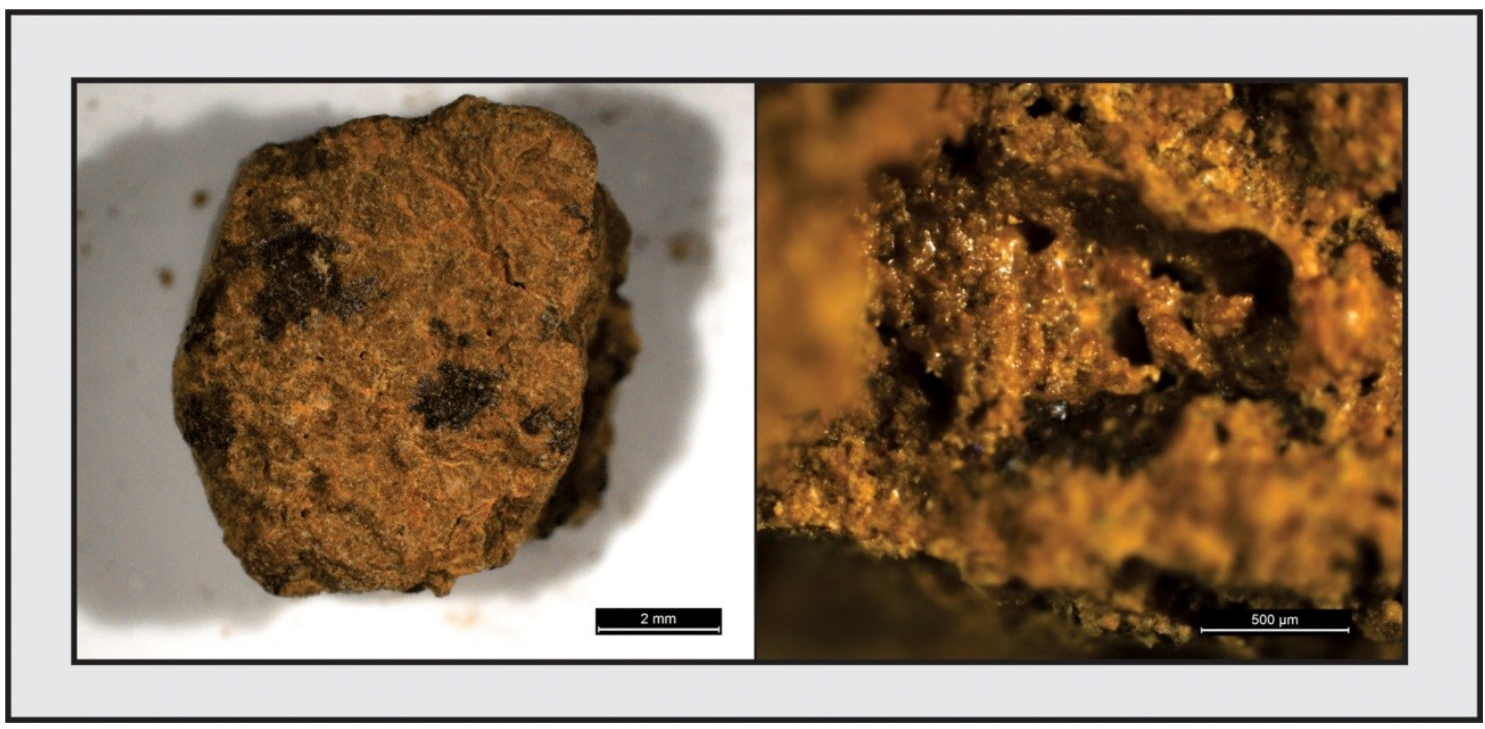

Figura 5.10. Bloques subangulares con revestimientos de manganeso y arcilla y marcas de raicillas.

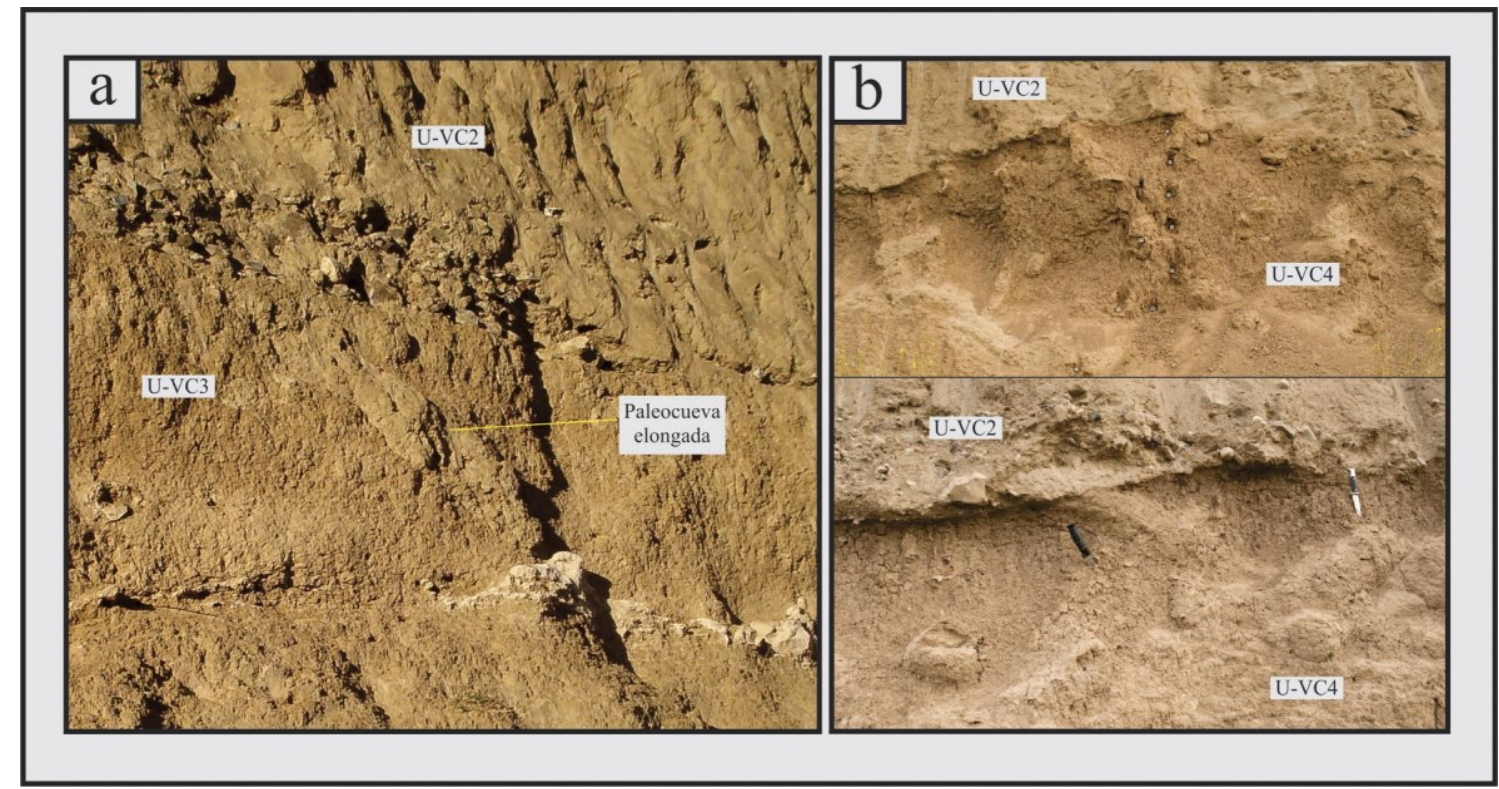

Figura 5.11. Crotovinas elongadas. a) de la unidad U-VC3; b) de la unidad U-VC4. 


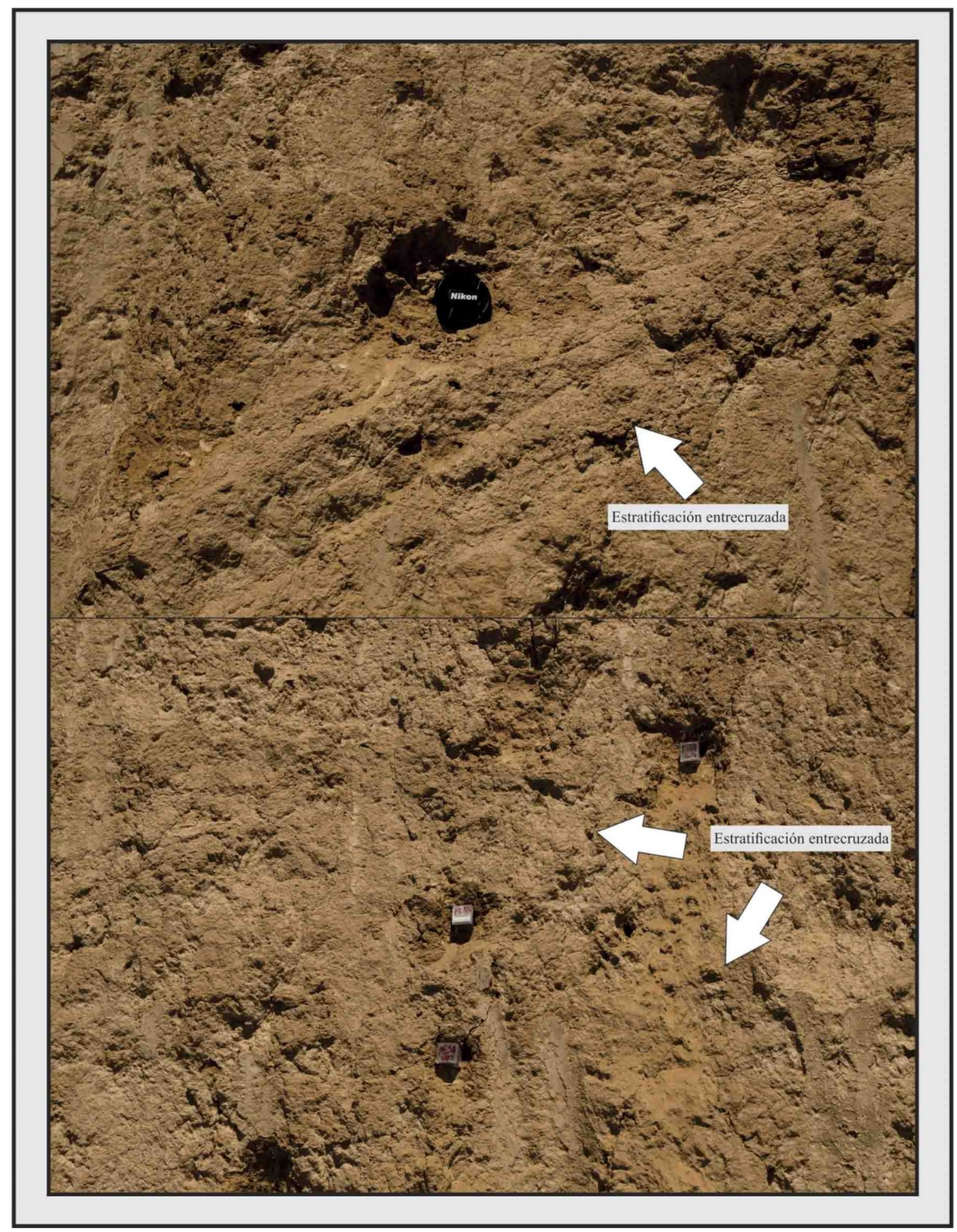

Figura 5.12. Estratificación entrecruzada en la unidad U-VC4. 


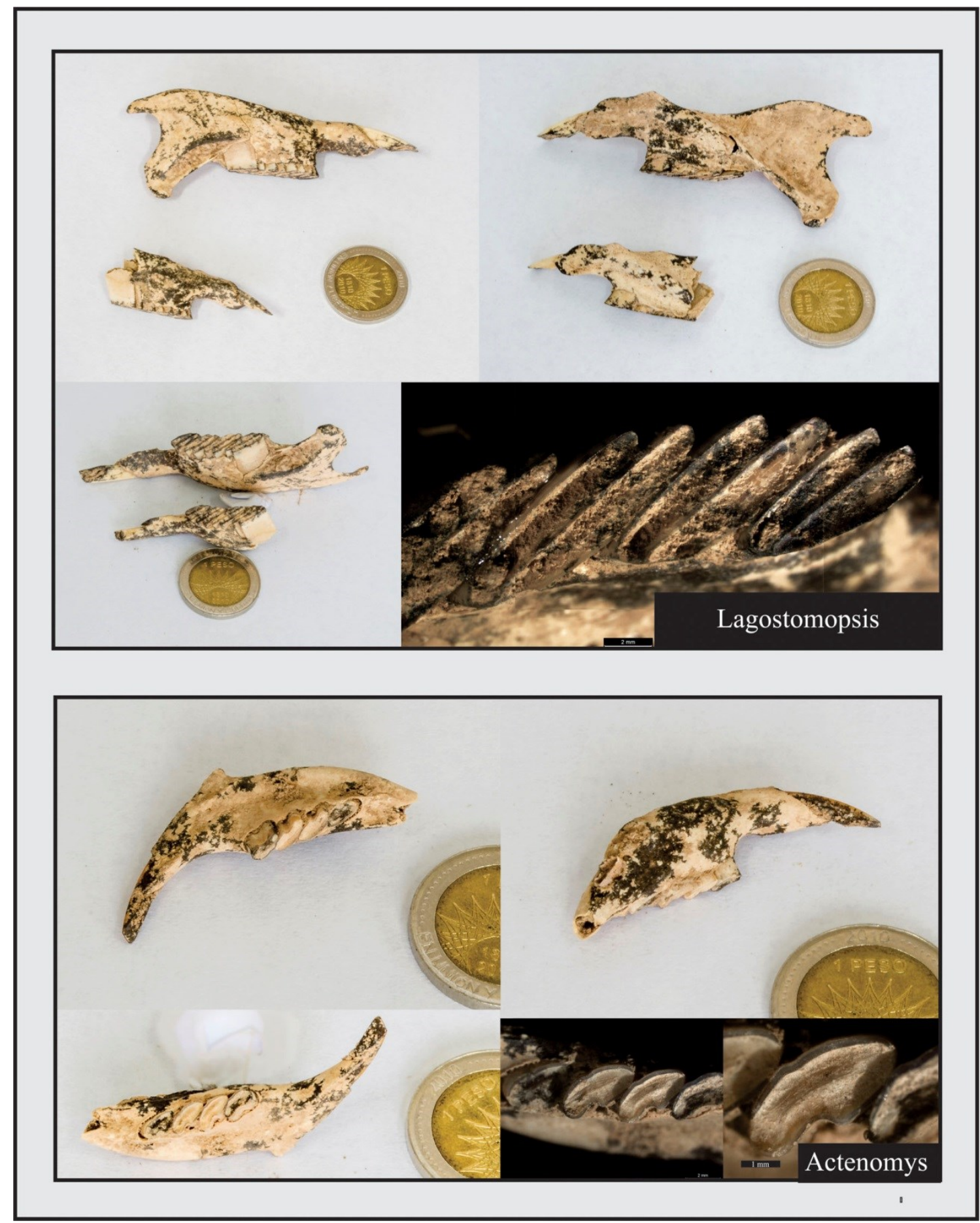

Figura 5.13. Restos fósiles de la unidad U-VC4. a) Lagostomus (Lagostomopsis); b) Actenomys 


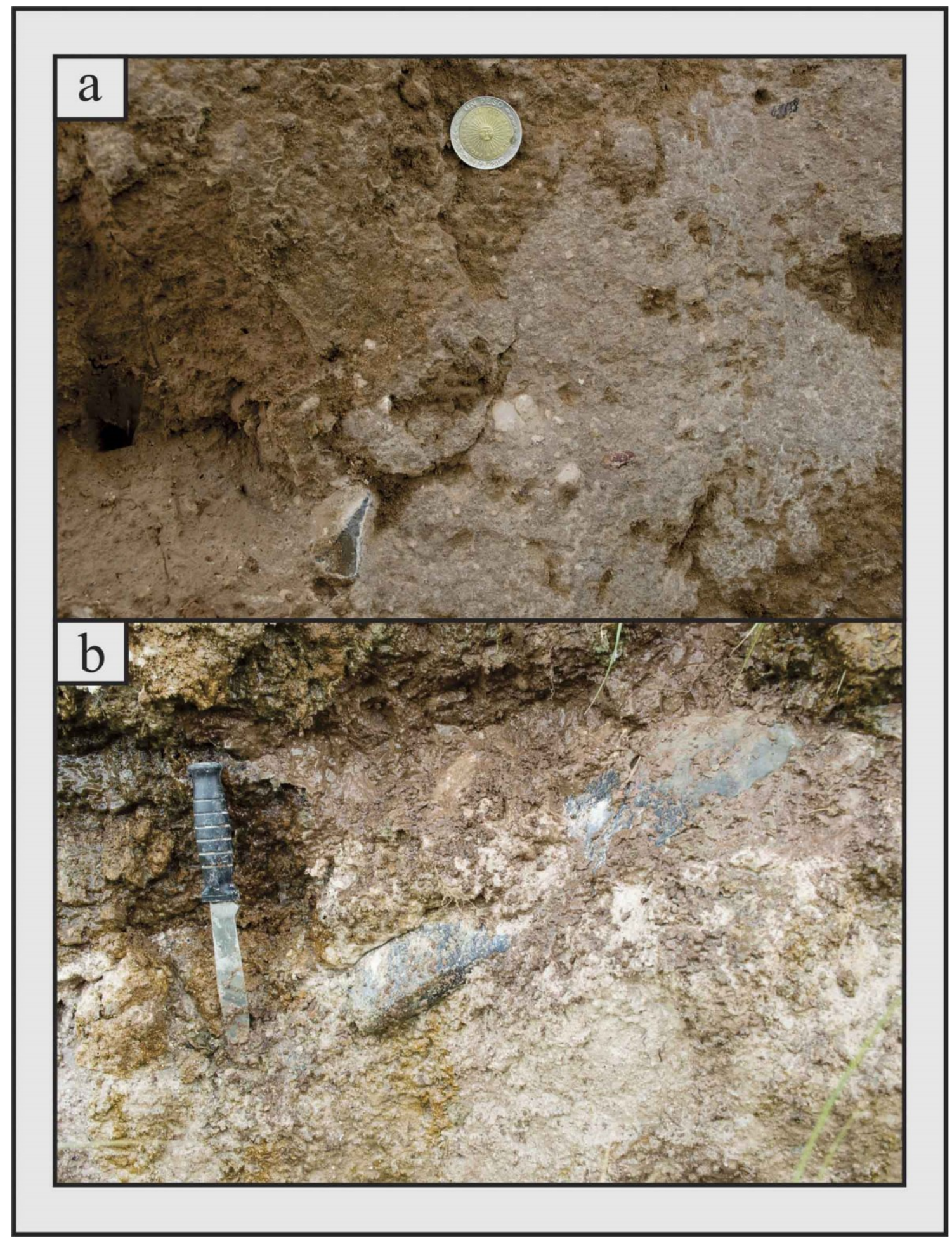

Figura 5.14. Clastos de roca. a) en la unidad U-VC5; b) en la unidad U-VC6. 


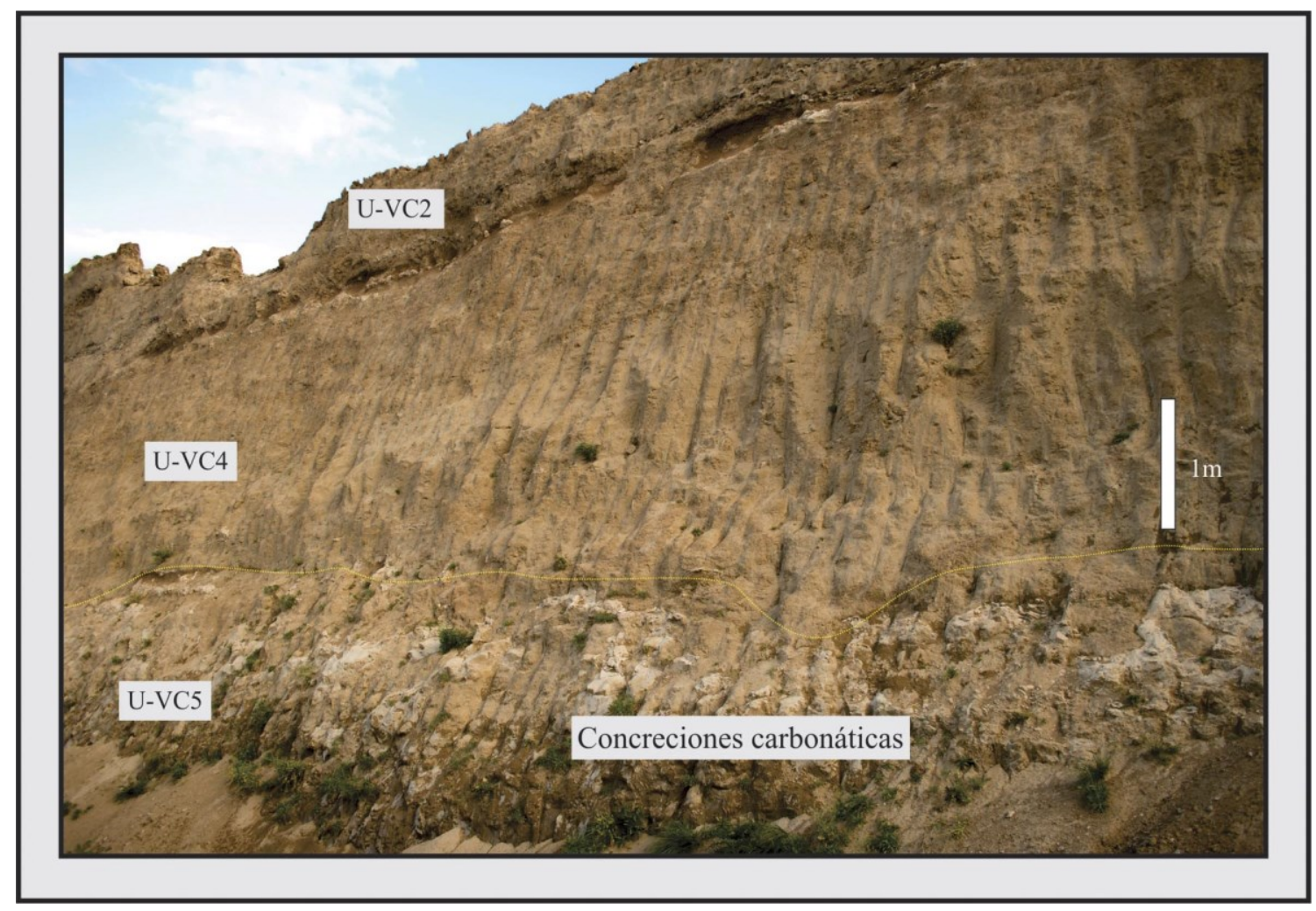

Figura 5.15. Fotografía donde se indican las unidades U-VC2, U-VC4 y U-VC5 y concreciones carbonáticas de la unidad U-VC5. 


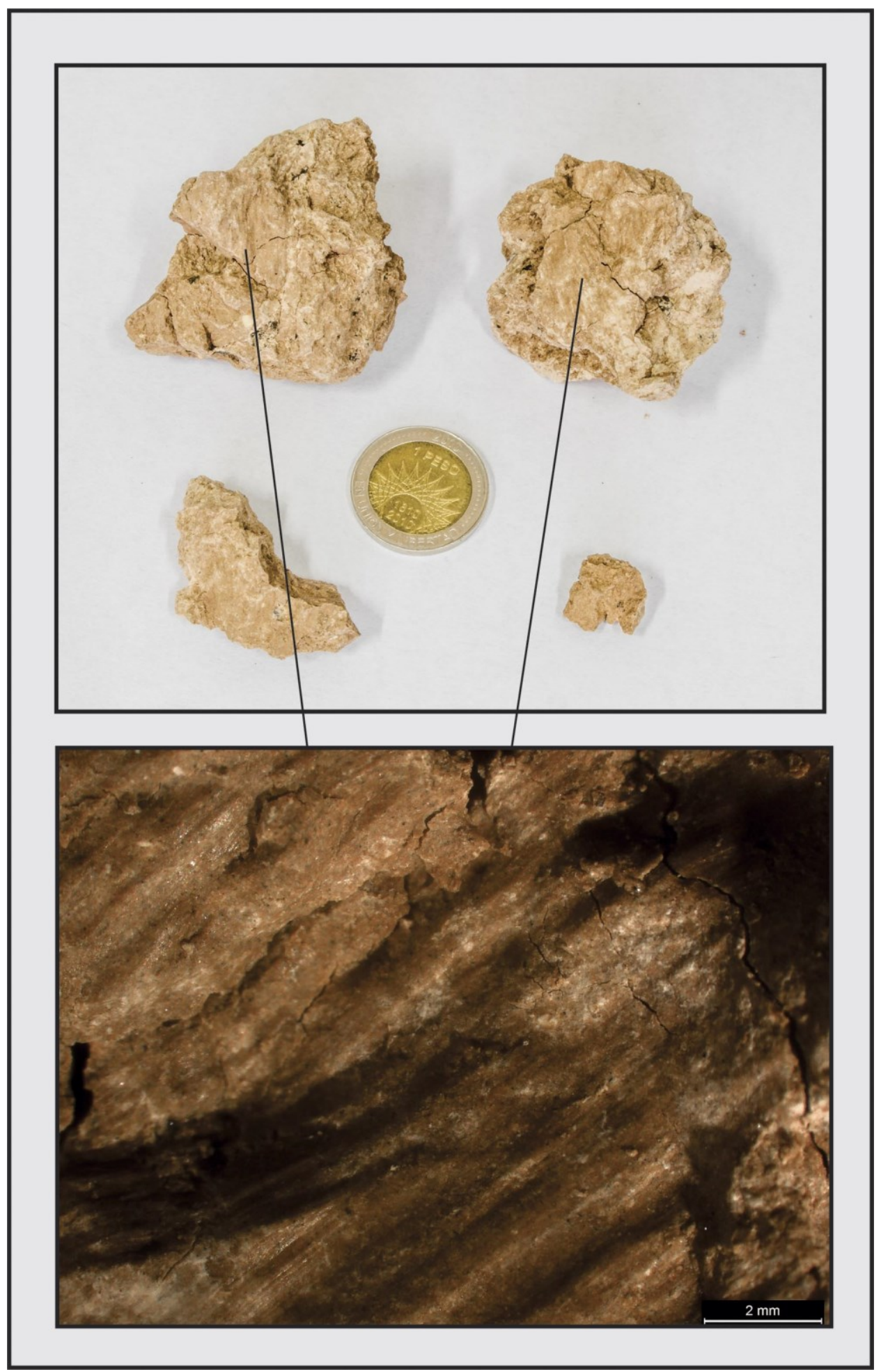

Figura 5.16. Slickensides de la matriz de la unidad U-VC6. 


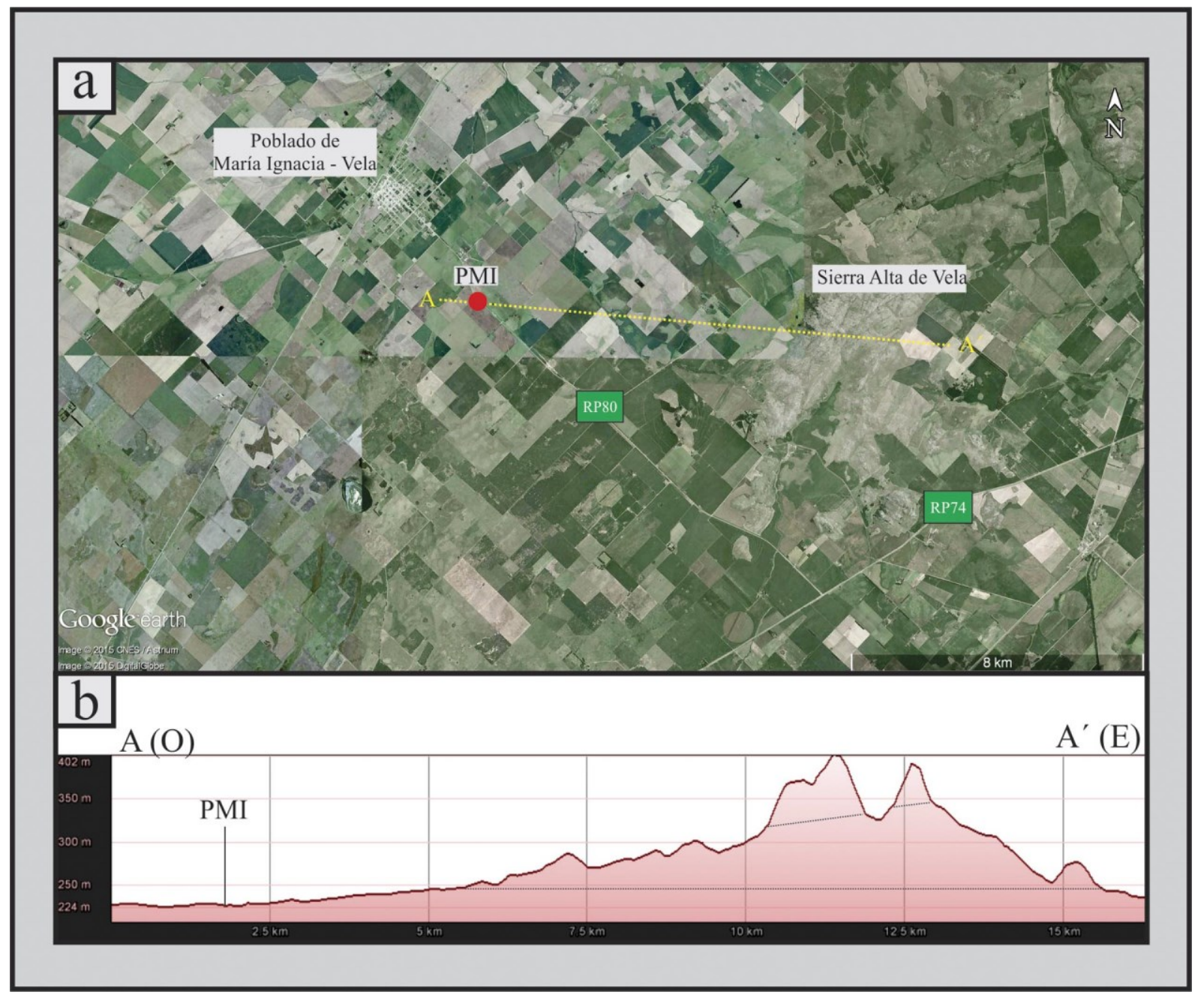

Figura 5.17. a) Ubicación de la sección estratigráfica de María Ignacia (PMI) y transecta A-A'; b) Perfil de elevación de la transecta A-A'. 


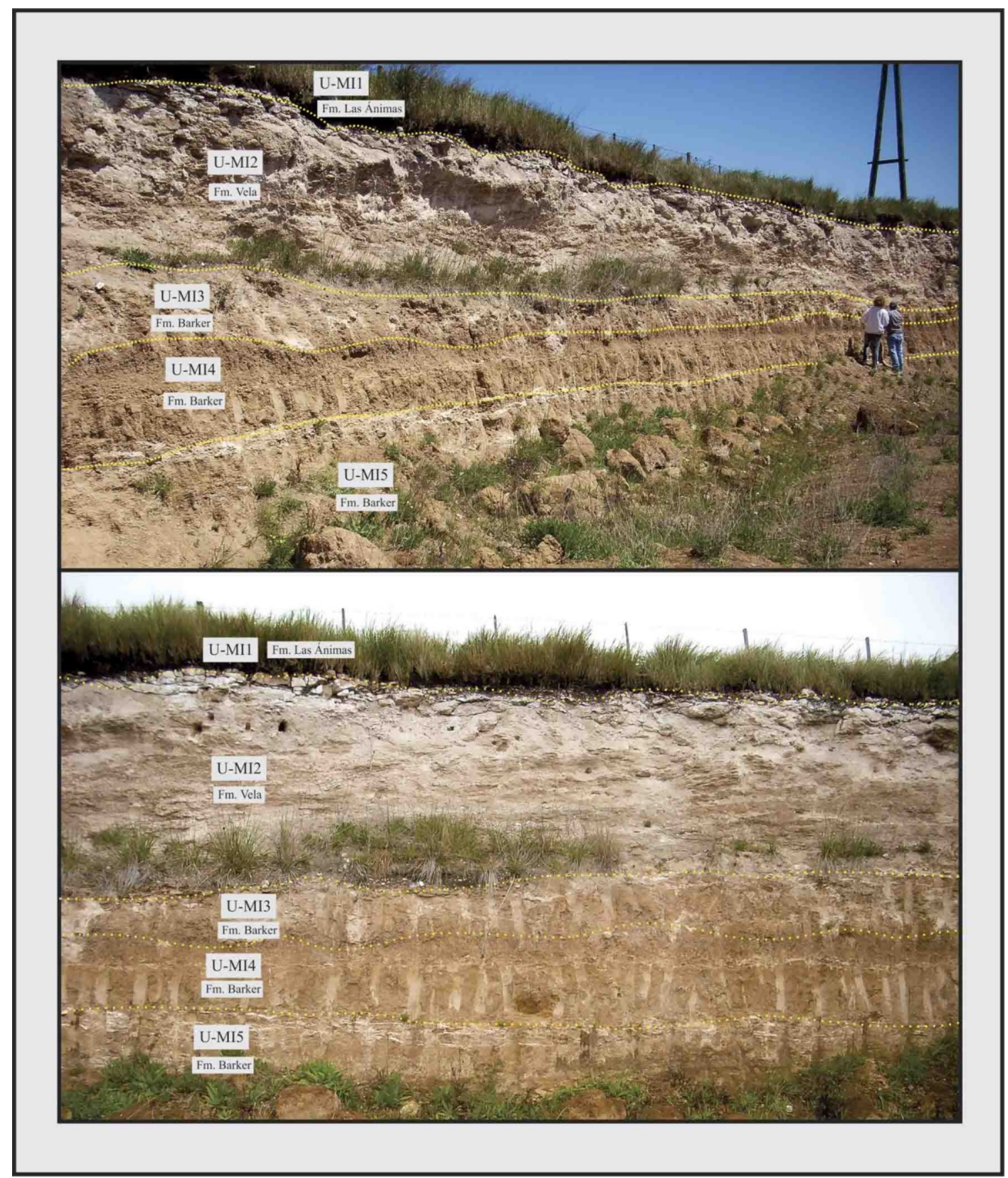

Figura 5.18. Fotografía de los sedimentos expuestos en la Ruta 80 (sección PMI) y unidades litológicas individualizadas. 


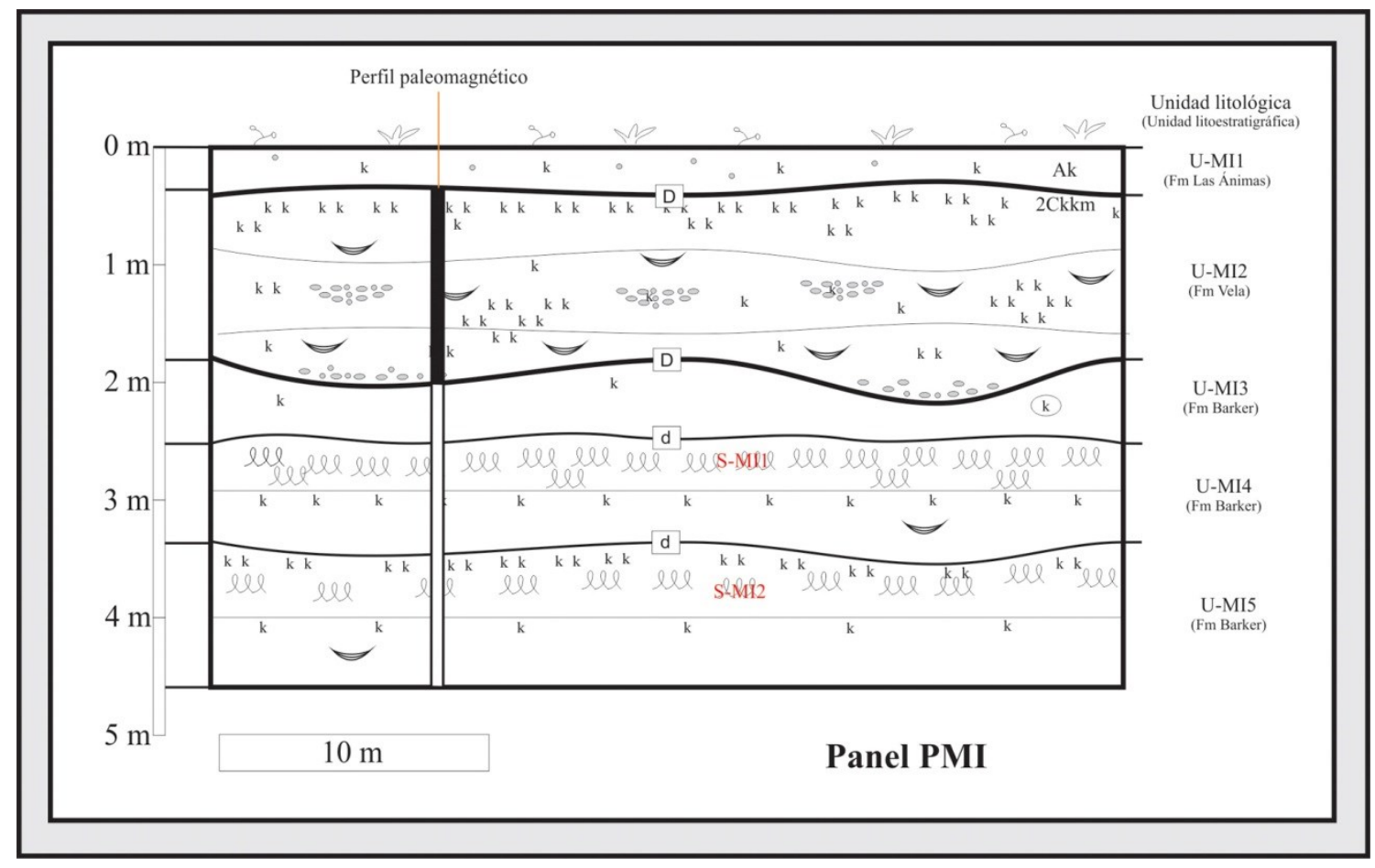

Figura 5.19. Panel esquemático de la sección de María Ignacia (PMI). 


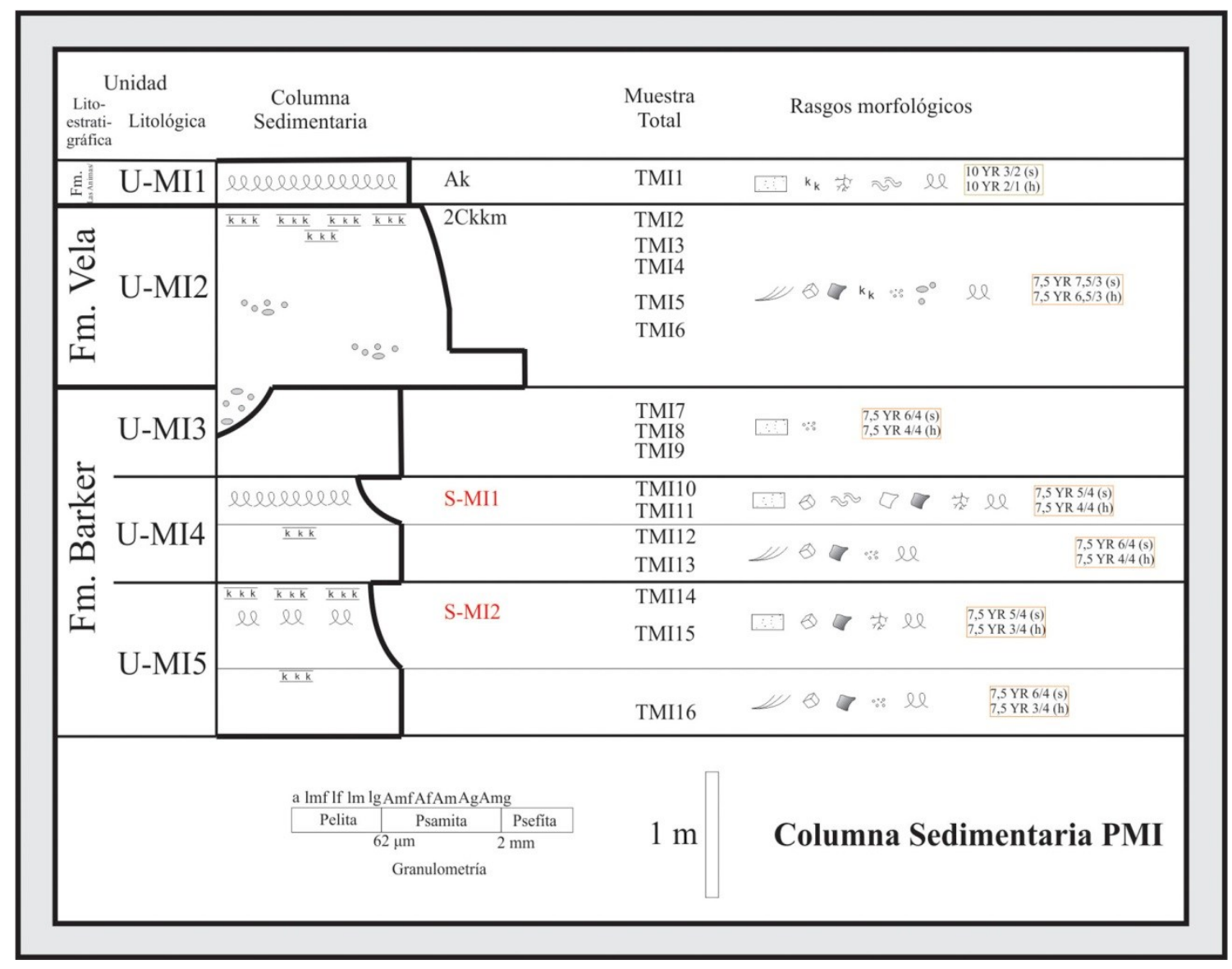

Figura 5.20. Columna sedimentaria de la sección de María Ignacia (PMI). 


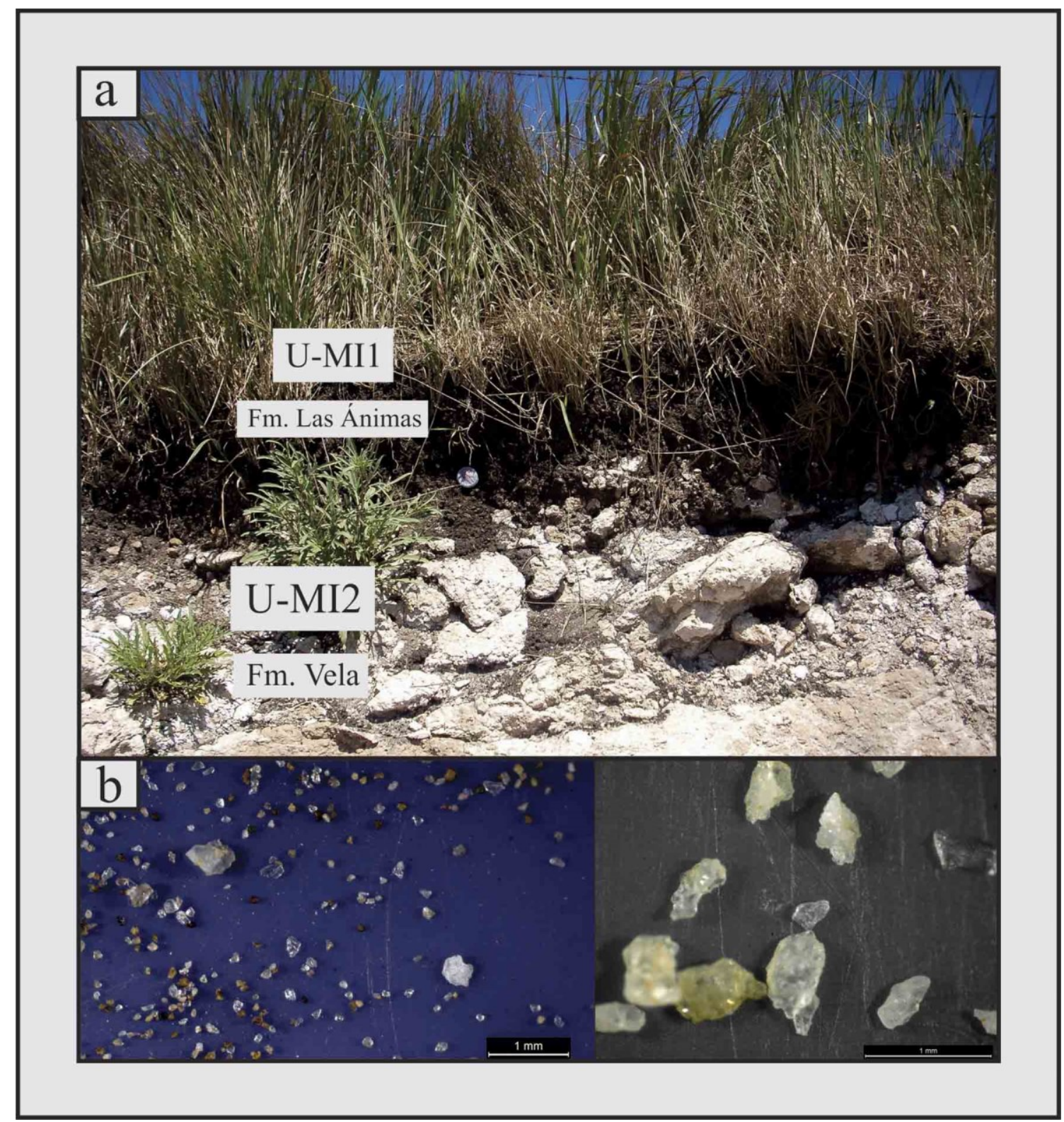

Figura 5.21. a) Fotografia de la parte superior de la sección; arriba unidad U-MI1 (horizonte Ak), abajo costra calcárea del tope de U-MI2; b) Intraclastos de cuarzo de la unidad U-MI1. 


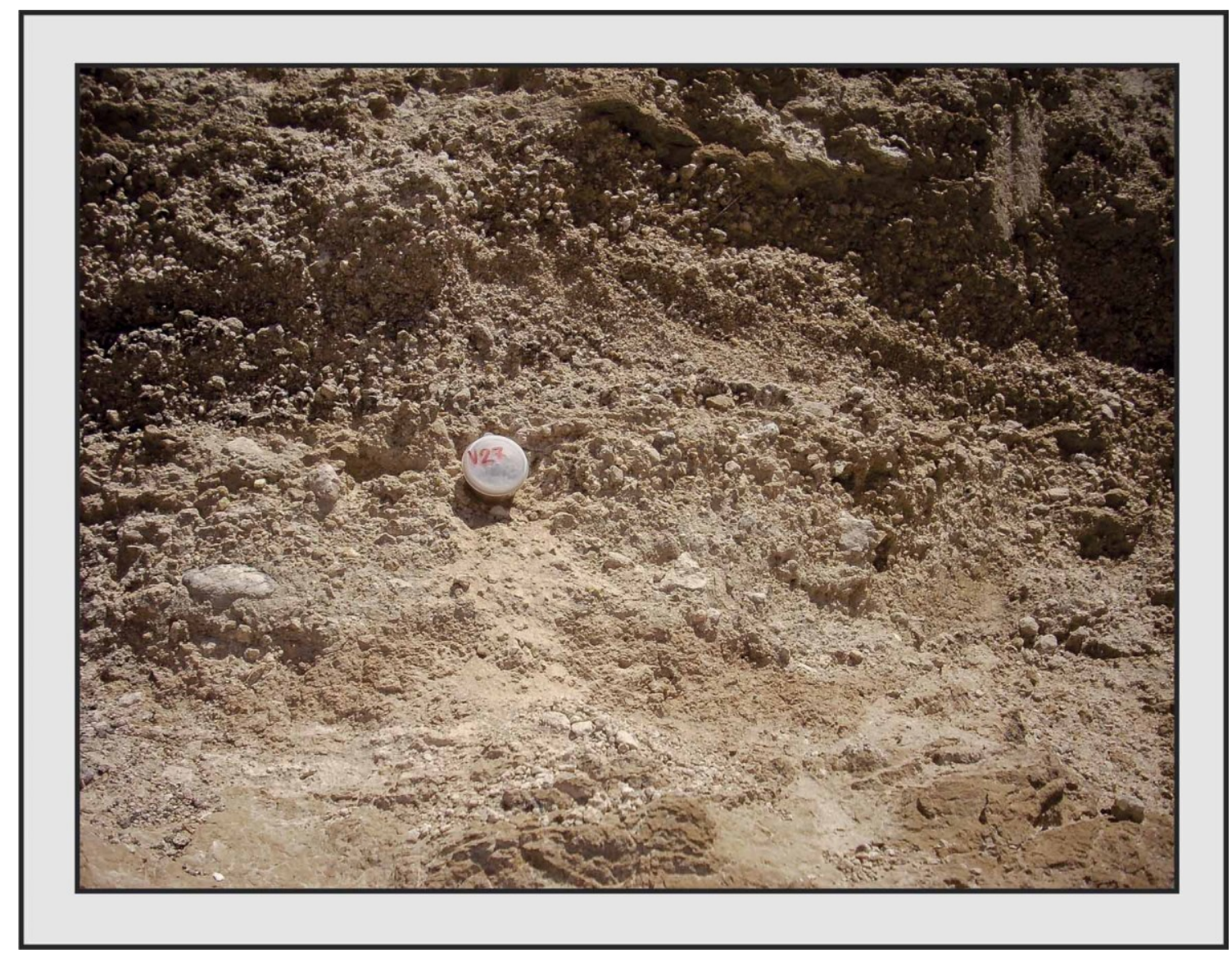

Figura 5.22. Acumulación psefítica en la unidad U-MI2. 


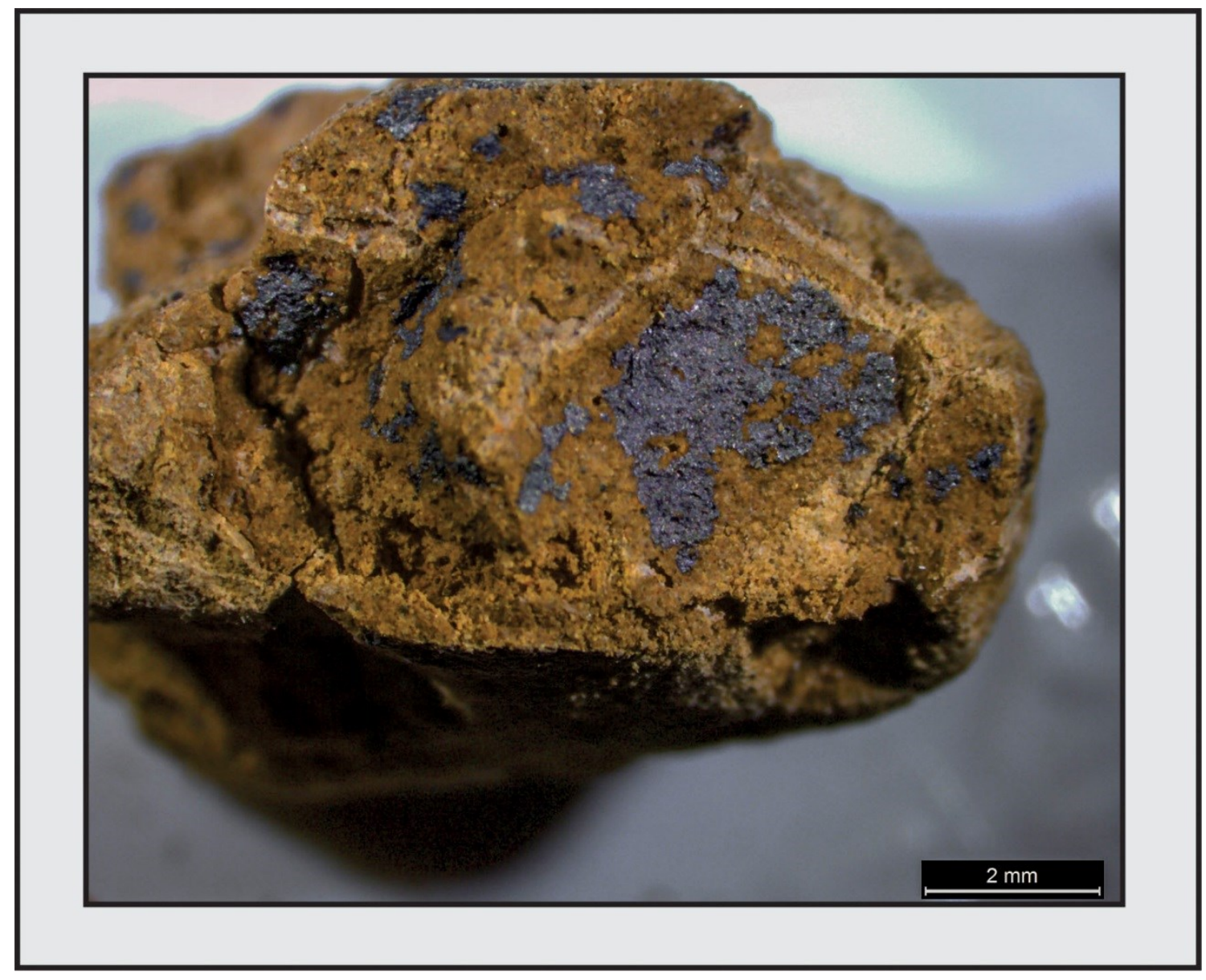

Figura 5.23. Bloque subangular del paleosuelo de la unidad U-MI4. 


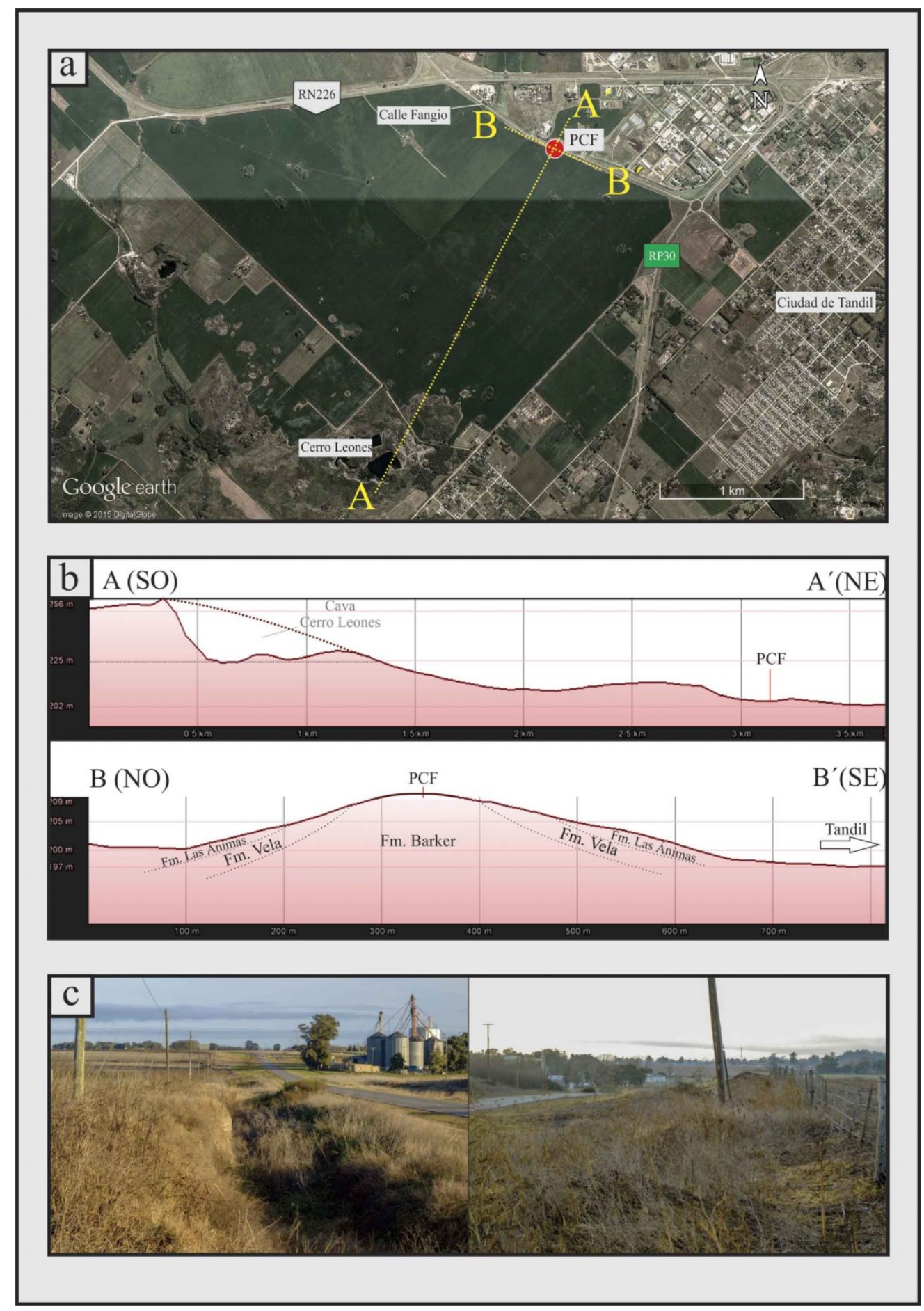

Figura 5.24. a) Ubicación de la sección estratigráfica Calle Fangio y transectas A-A'y B-B'; b) Perfiles de elevación de las transectas A-A' (arriba) y B-B'(abajo); c) fotografías desde la sección (loma), hacia el NO (foto de la izquierda) y hacia él SE (foto de la derecha). 


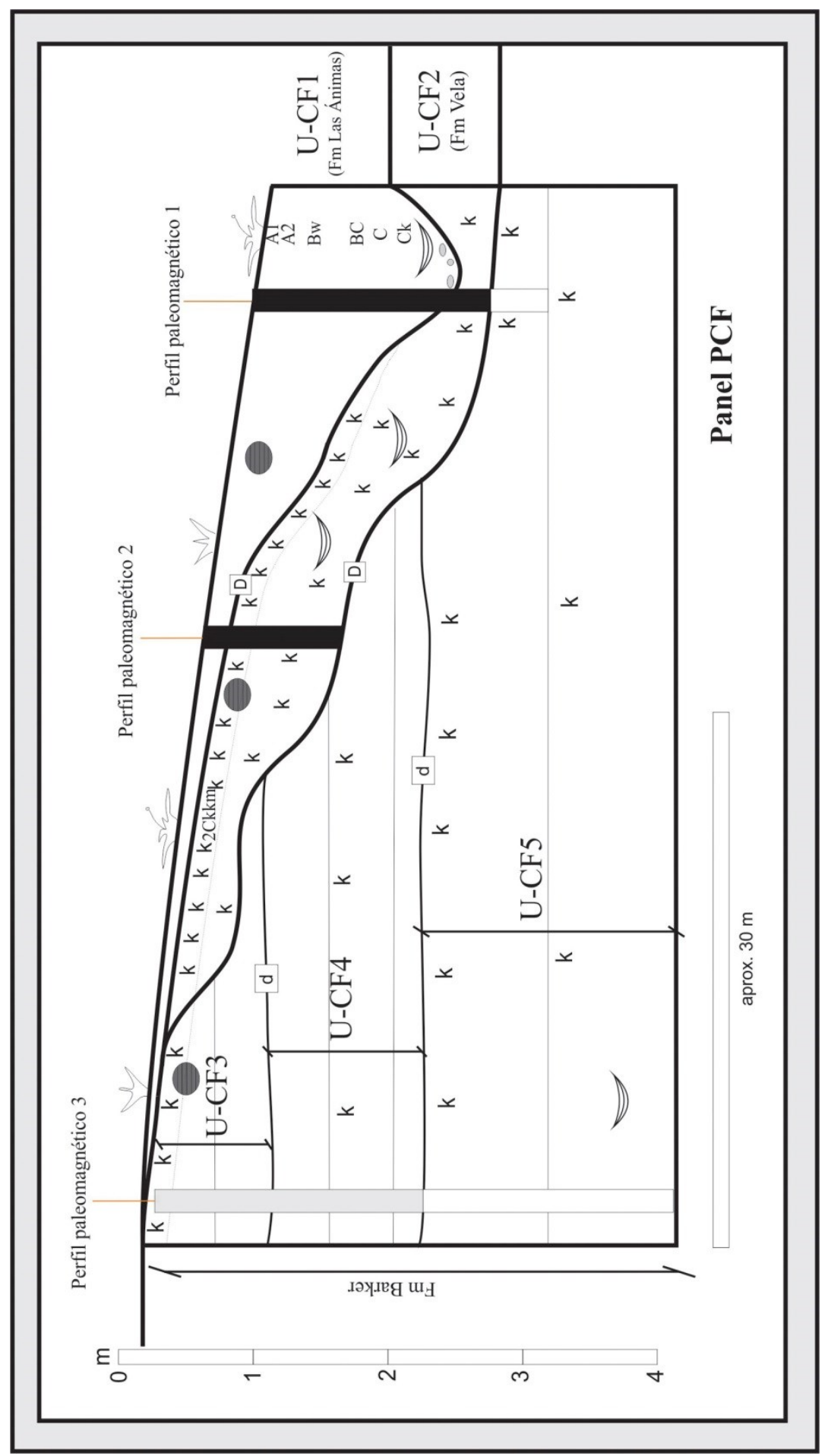

Figura 5.25. Panel esquemático de la sección de la calle Fangio (PCF). 


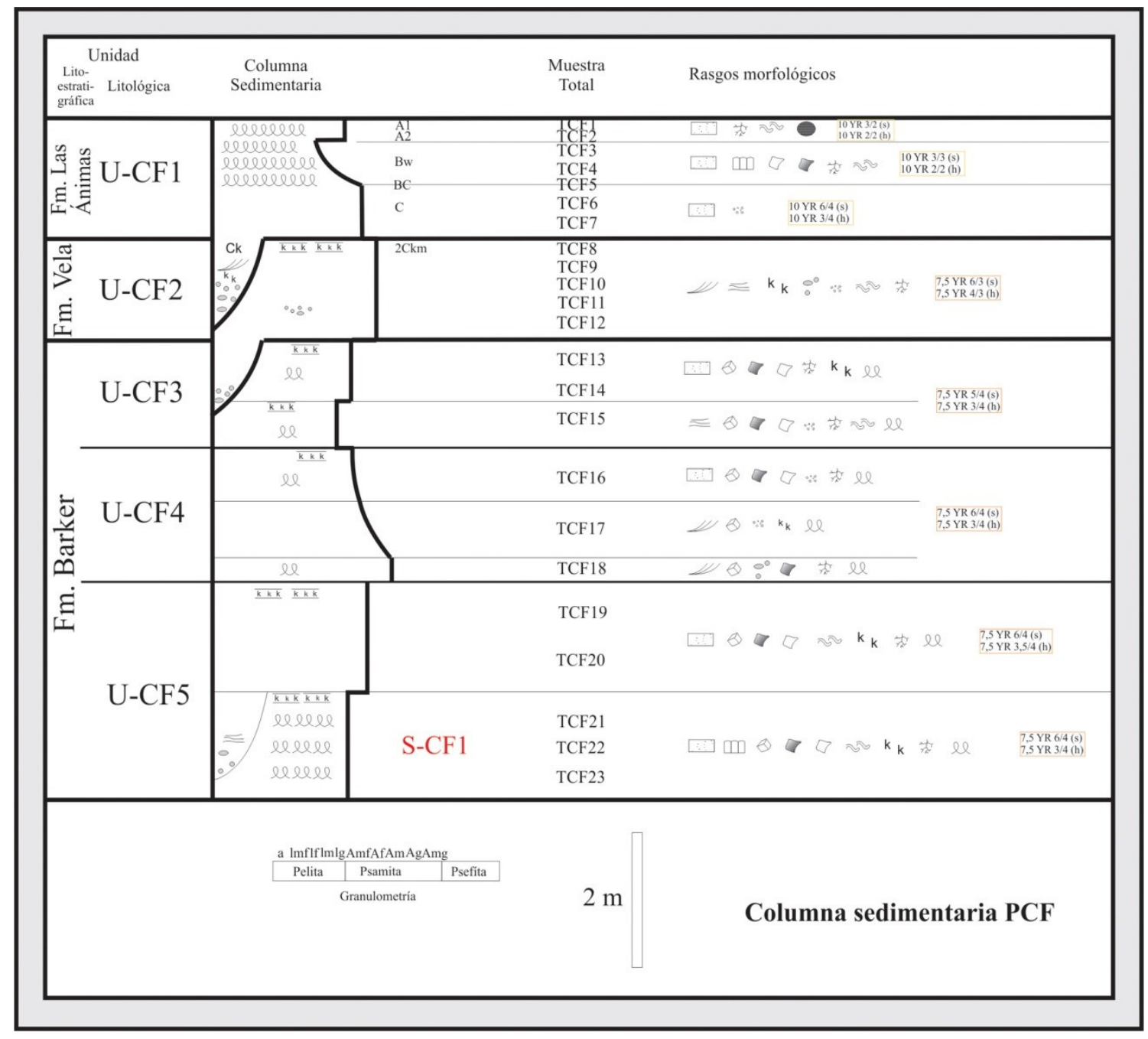

Figura 5.26. Columna sedimentaria de la sección de la calle Fangio (PCF). 


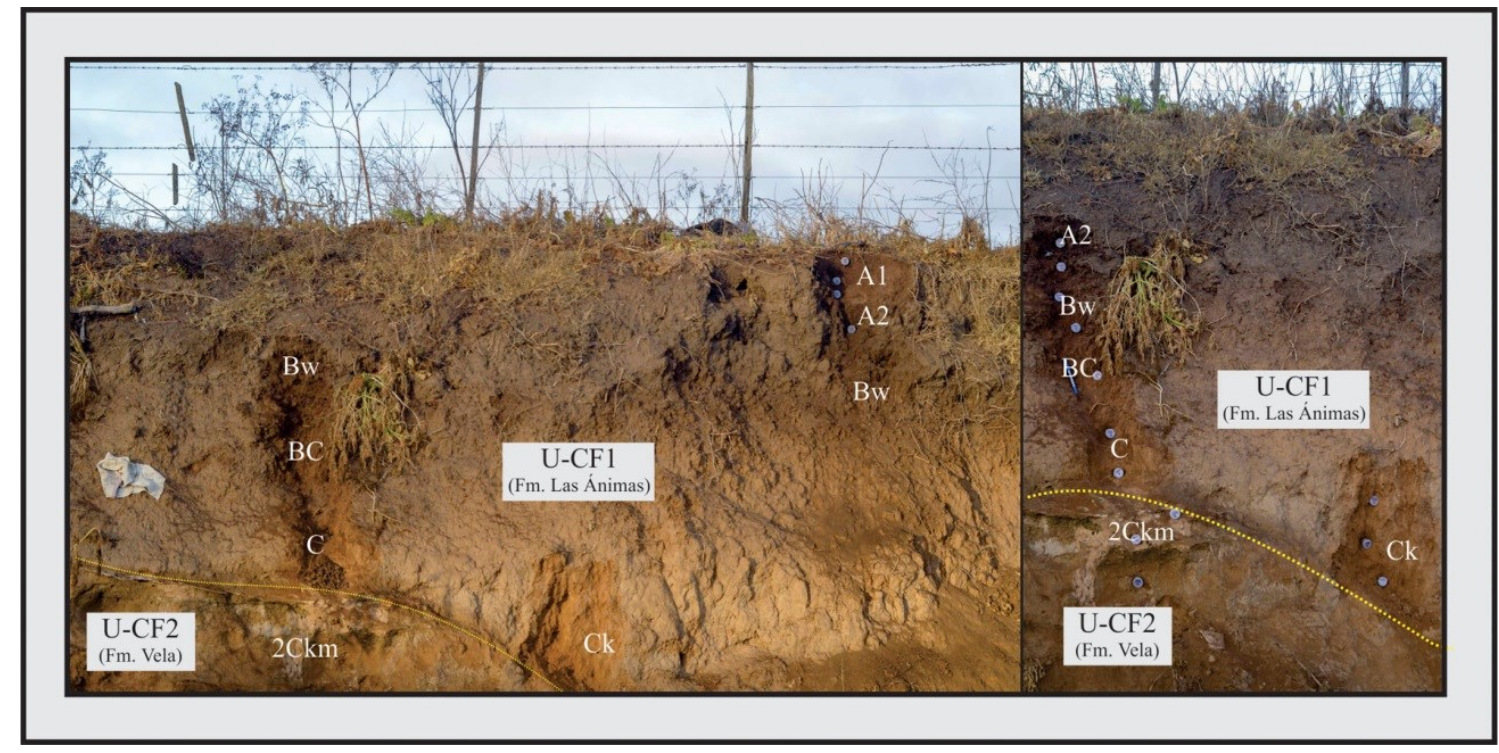

Figura 5.27. Fotografia de la unidad U-CF1, contacto con U-CF2 y horizontes del suelo actual.

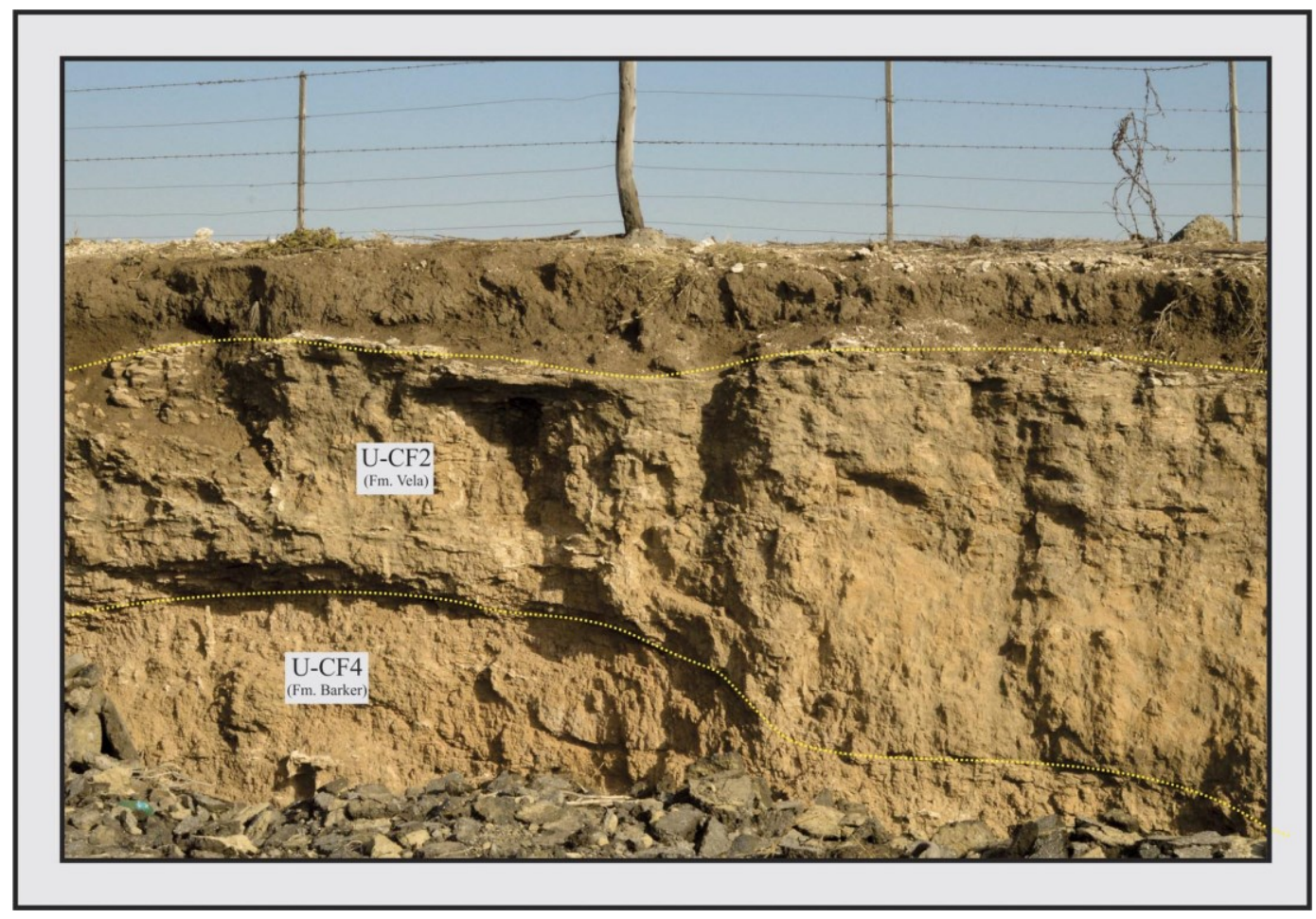

Figura 5.28. Fotografía de la unidad U-CF2 y contacto erosivo con la unida U-CF4. 


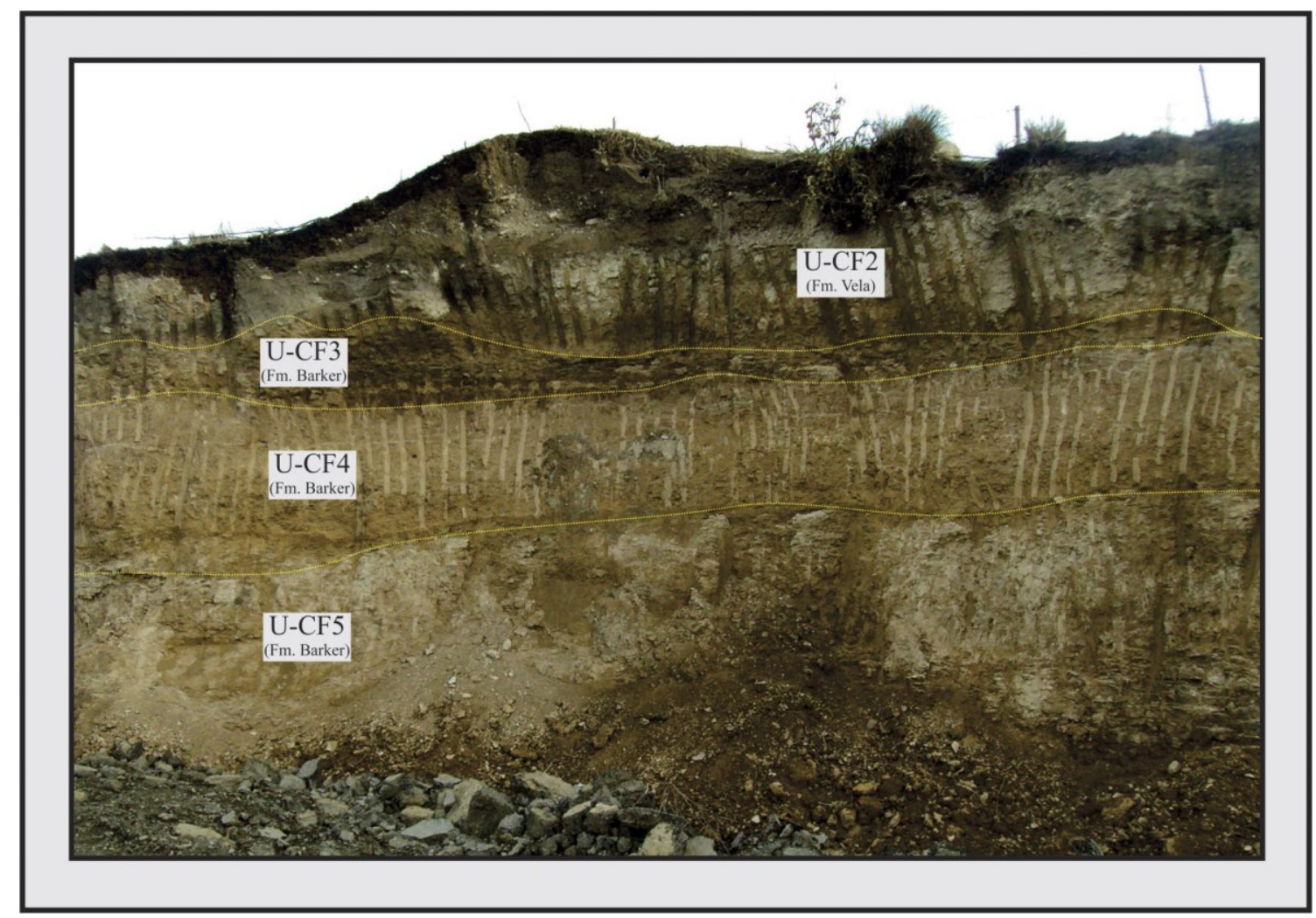

Figura 5.29. Fotografía de las unidades U-CF2, U-CF3, U-CF4 y U-CF5. 


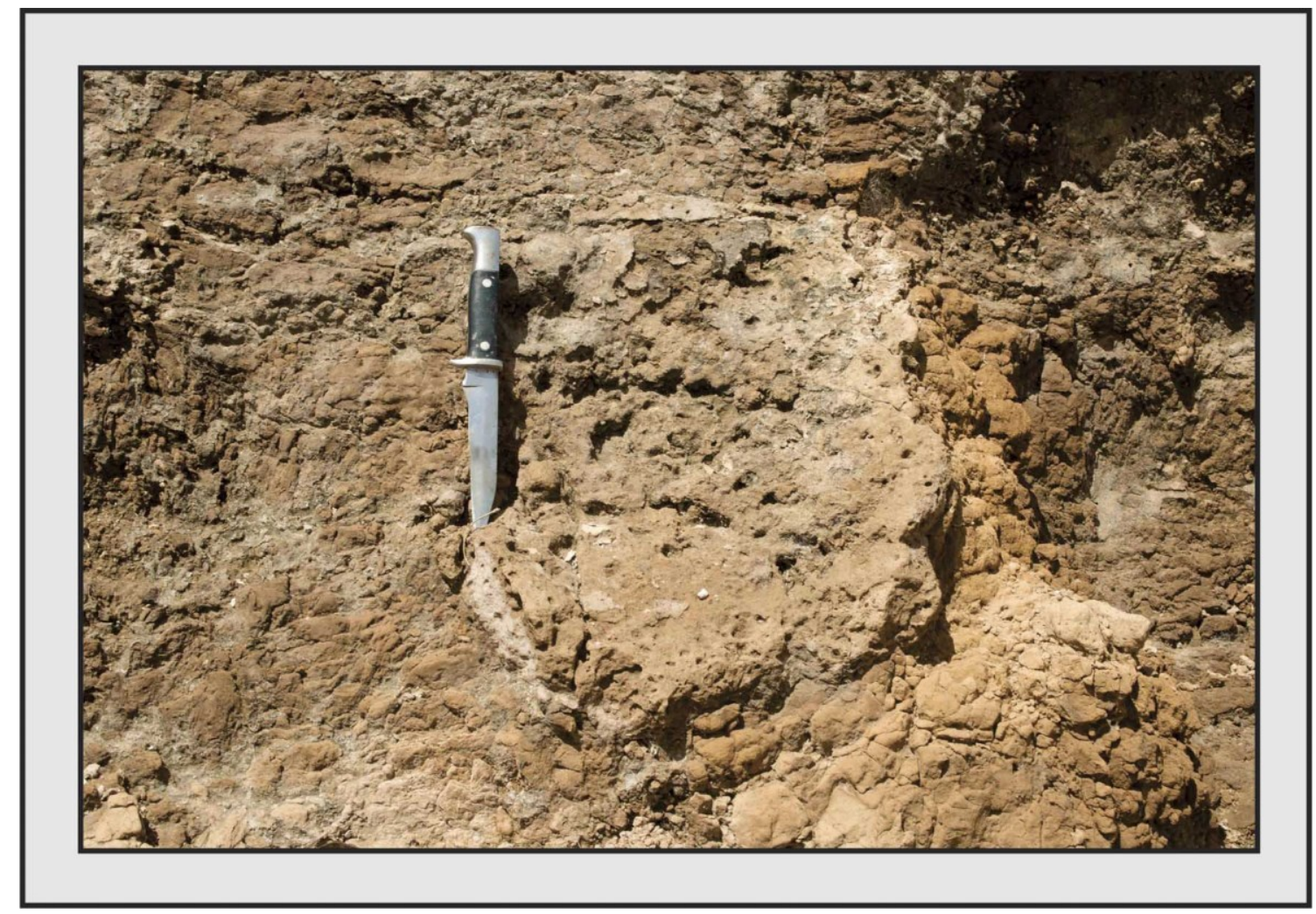

Figura 5.30. Estructura de bioturbación en la unidad U-CF2. 


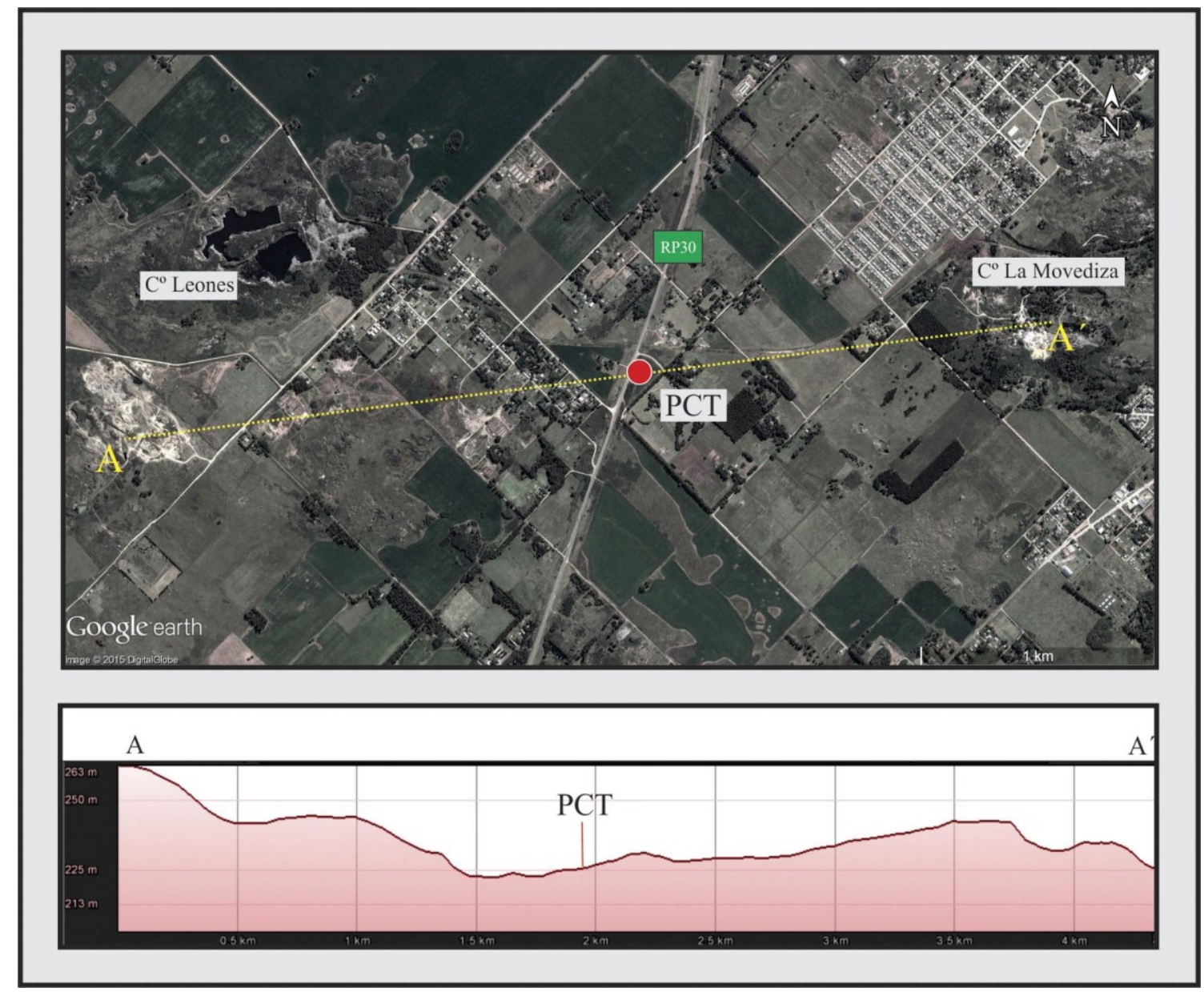

Figura 5.31. a) Ubicación de la sección estratigráfica Circuito Turístico (PCT) y transecta A-A’; b) Perfil de elevación de la transecta A-A'. 


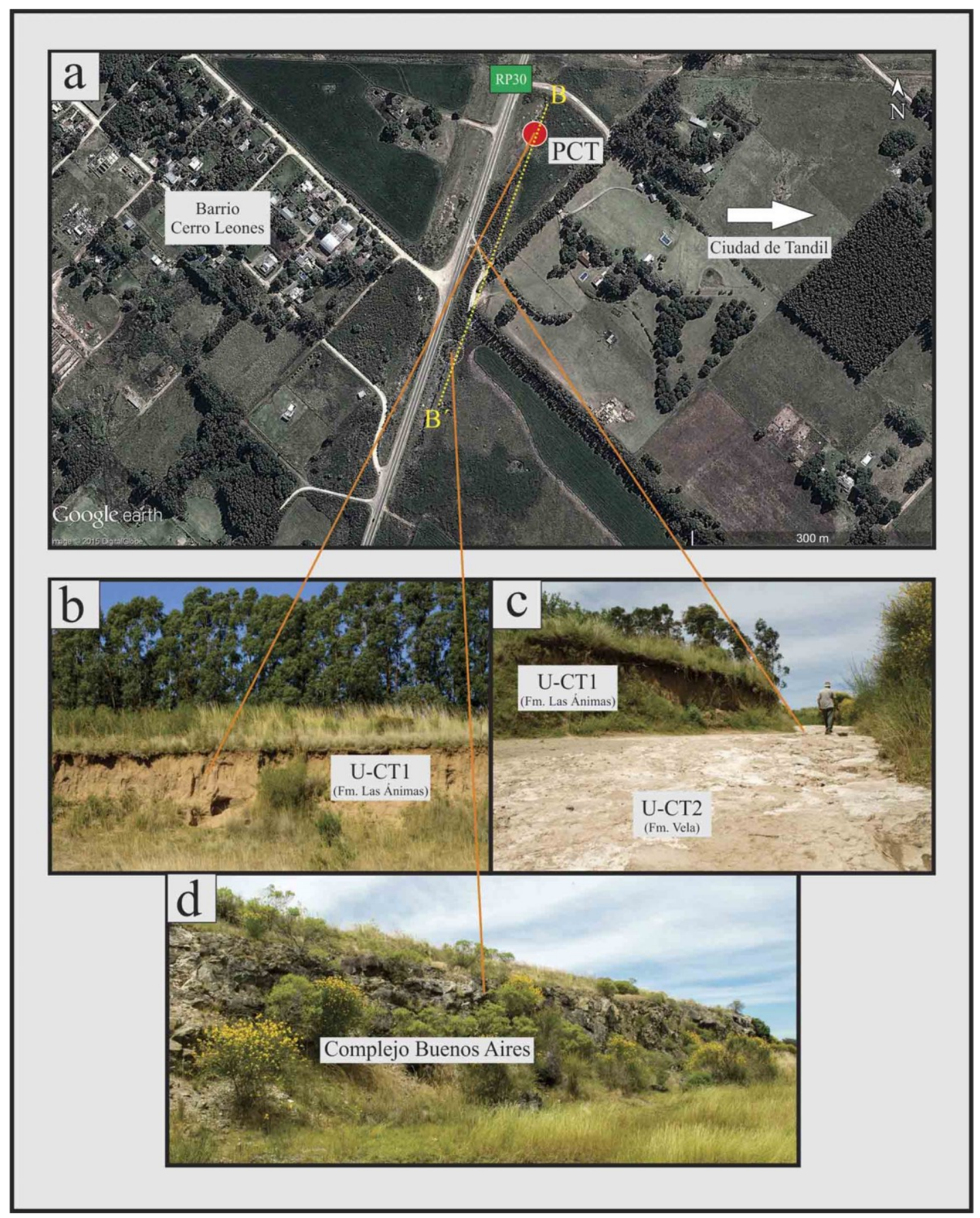

Figura 5.32. a) Detalles de la ubicación de la sección PCT y transecta B-B'; b) fotografía del sector muestreado (unidad U-CT1), extremo norte de la transecta; c) afloramiento de la unidad U-CT2, sector central de la transecta; d) fotografía de afloramiento rocoso (Complejo Buenos Aires) en el sector sur de la transecta. 


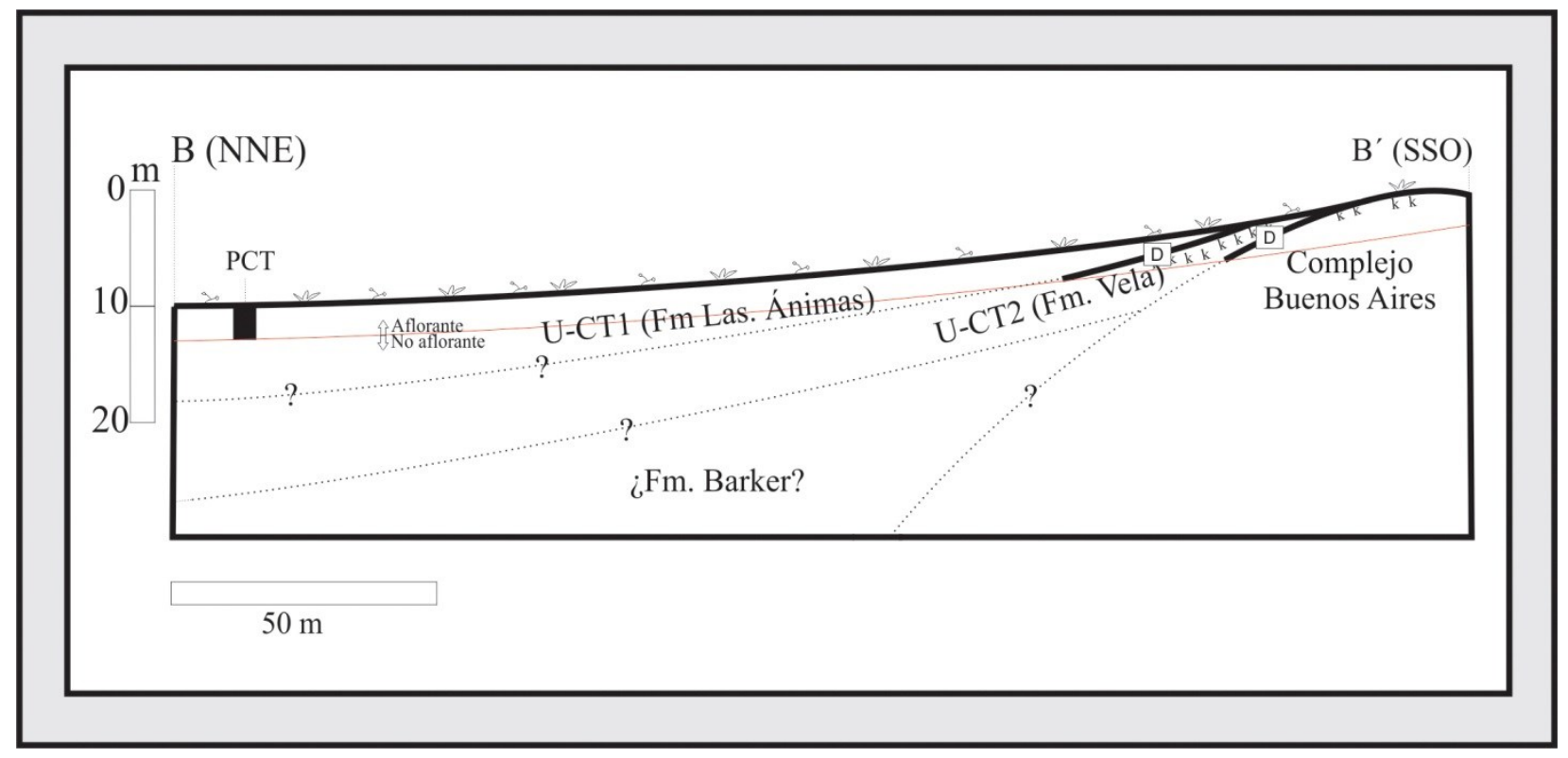

Figura 5.33. Panel esquemático de la sección PCT en base a la transecta B-B'. 


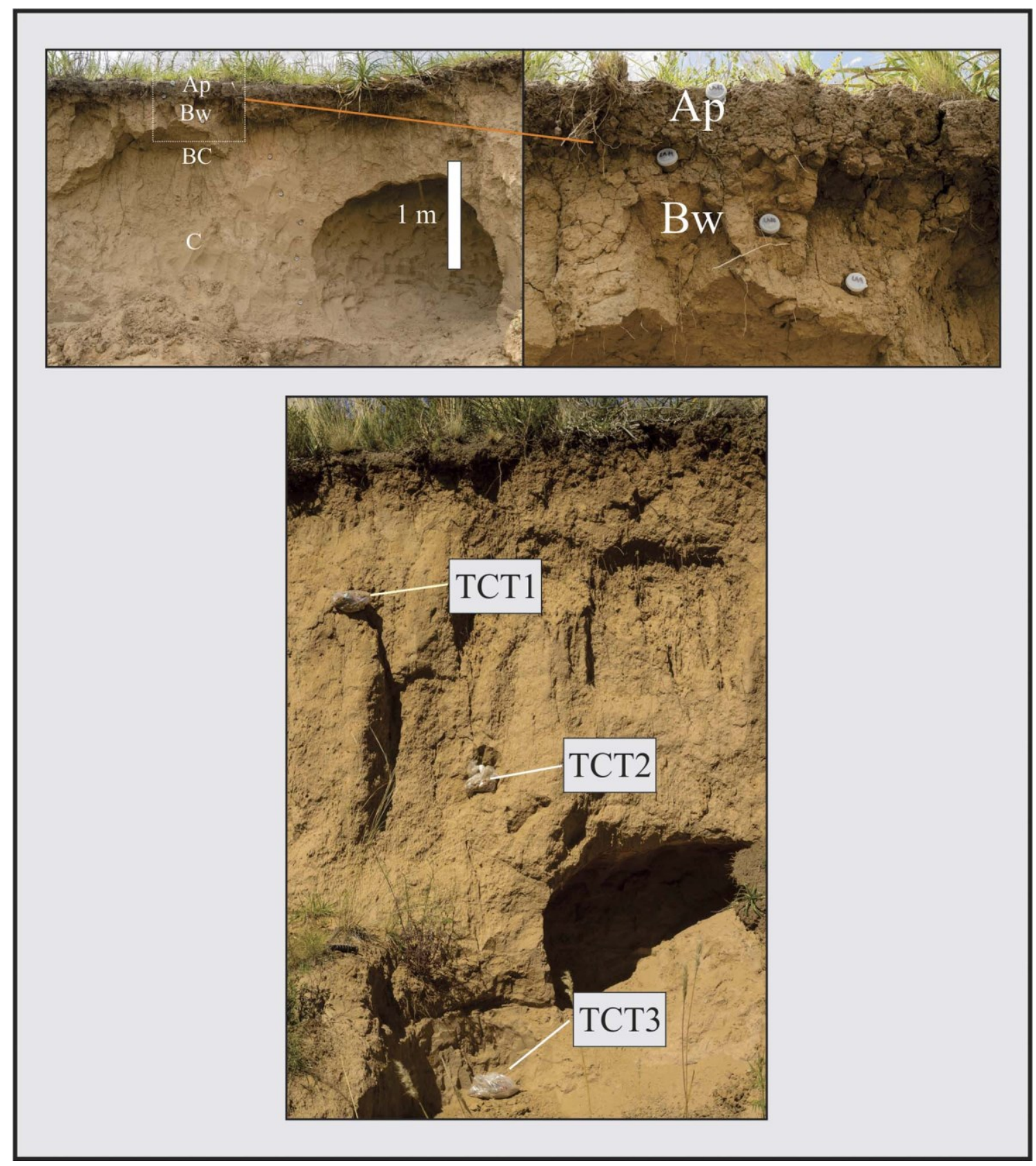

Figura 5.34. Fotografías de los sedimentos estudiados muestreados en la sección PCT. Arriba horizontes del suelo actual. Abajo ubicación de muestras totales. 


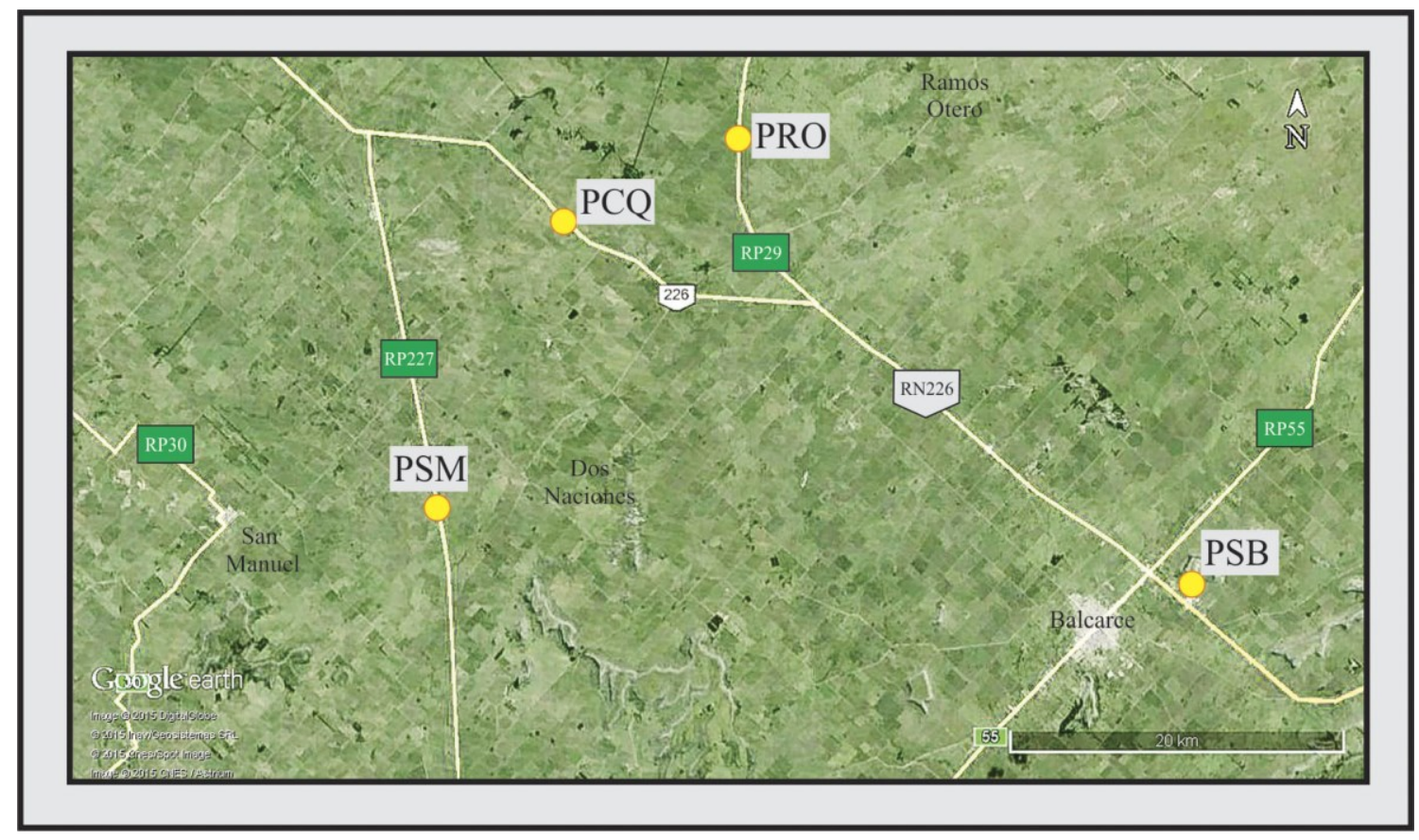

Figura 5.35. Ubicación de las secciones estratigráficas del sector Sierras de Balcarce. 


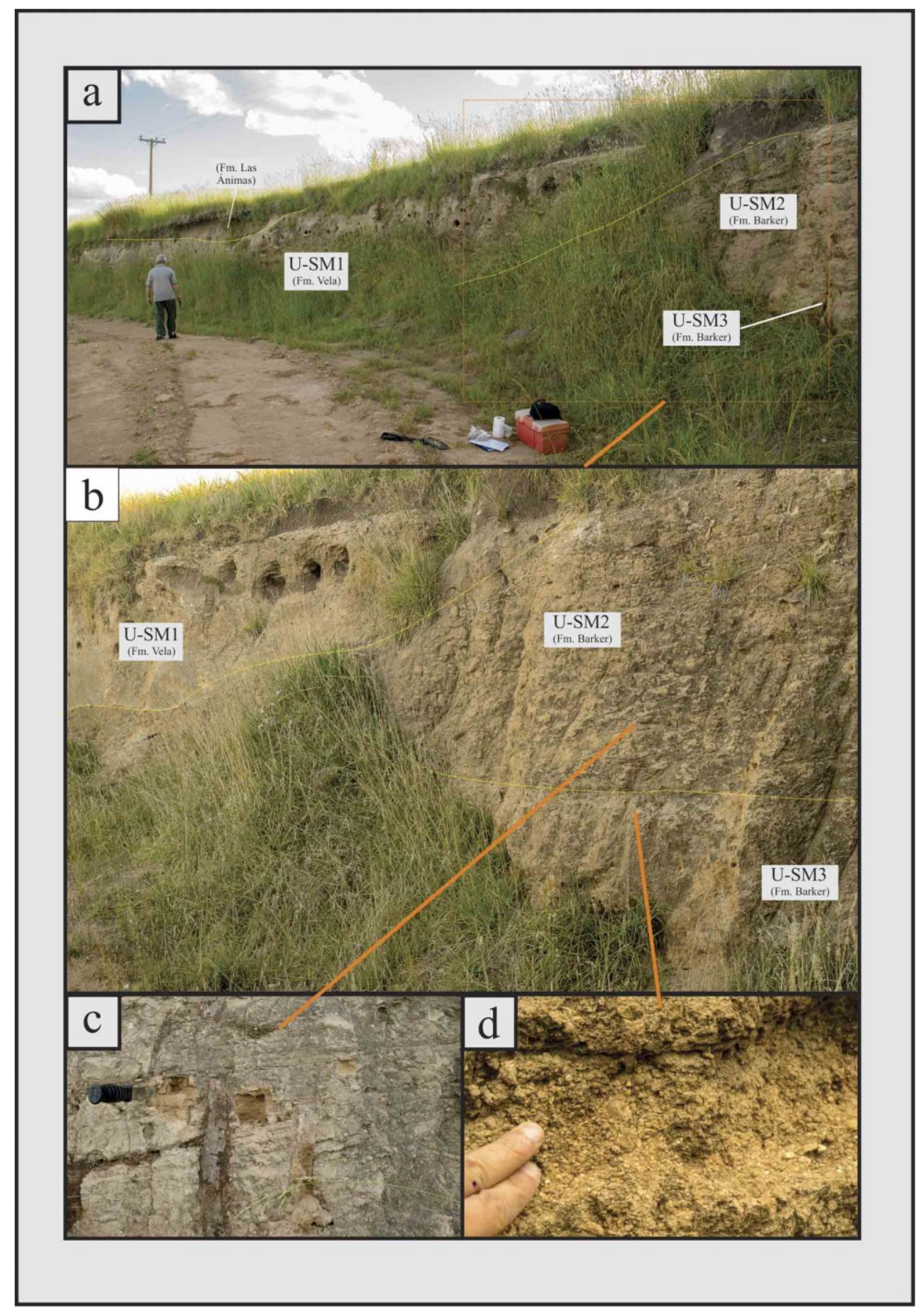

Figura 5.36. Sedimentos expuestos en la Ruta 227 cerca del poblado de San Manuel (Sección PSM). a) Foto general de la exposición; b) Detalle del contacto erosivo entre U-SM1 y U-SM2; c) Estratificación entrecruzada en la unidad U-SM2; d) Acumulación de grava en el tope de U-SM3. 


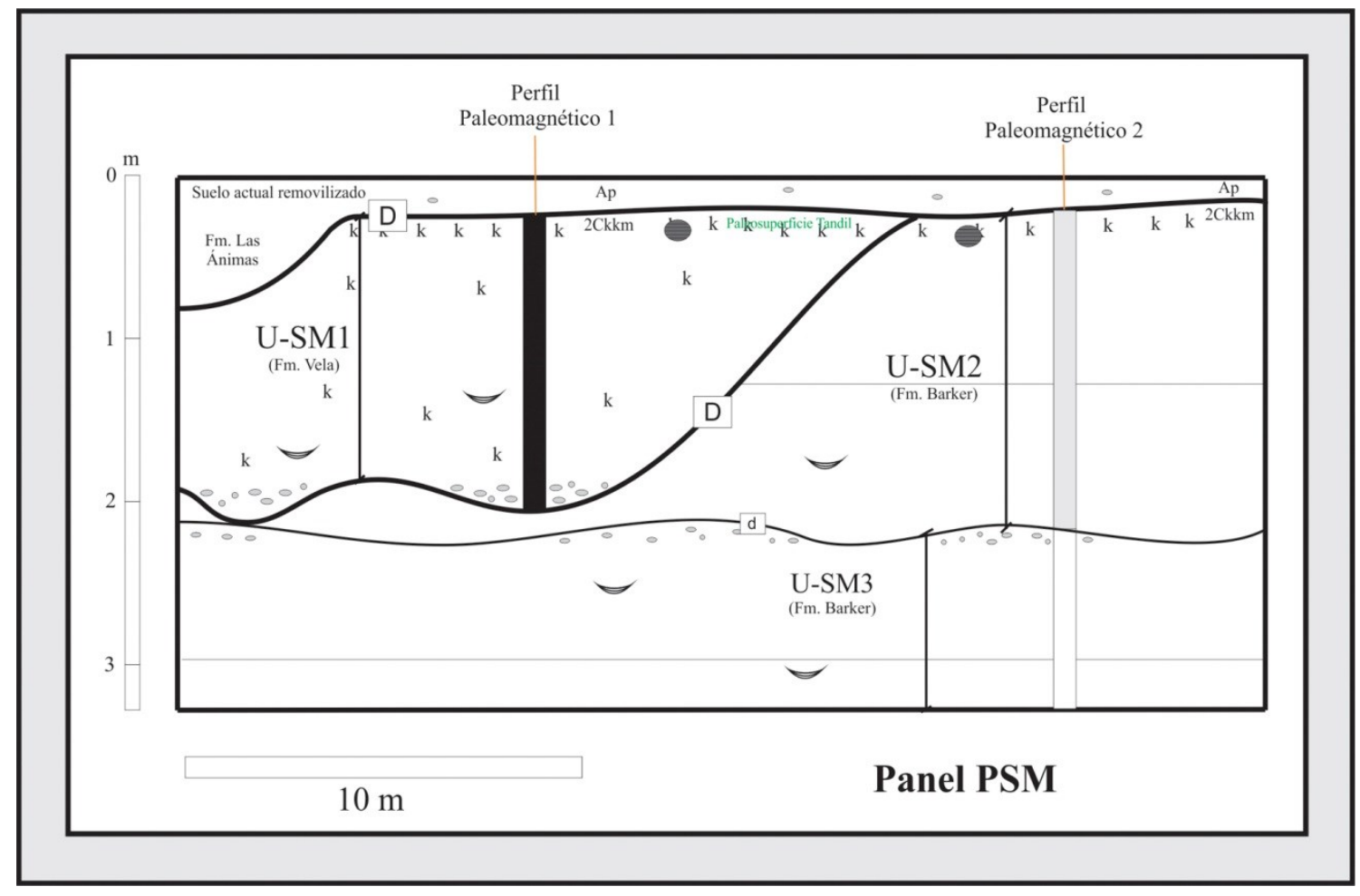

Figura 5.37. Panel esquemático de la sección de San Manuel (PSM). 


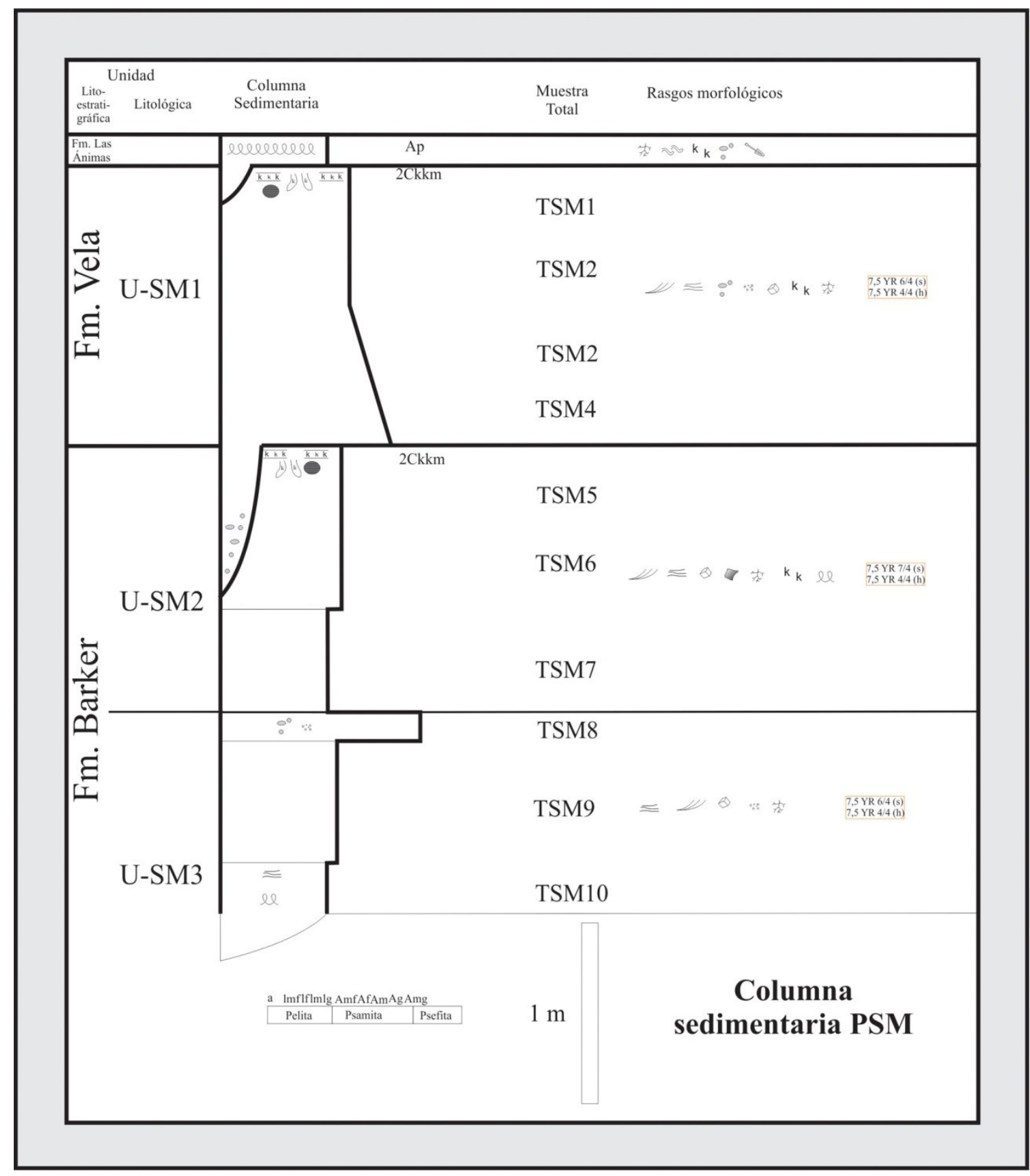

Figura 5.38. Columna sedimentaria de la sección de San Manuel (PSM). 


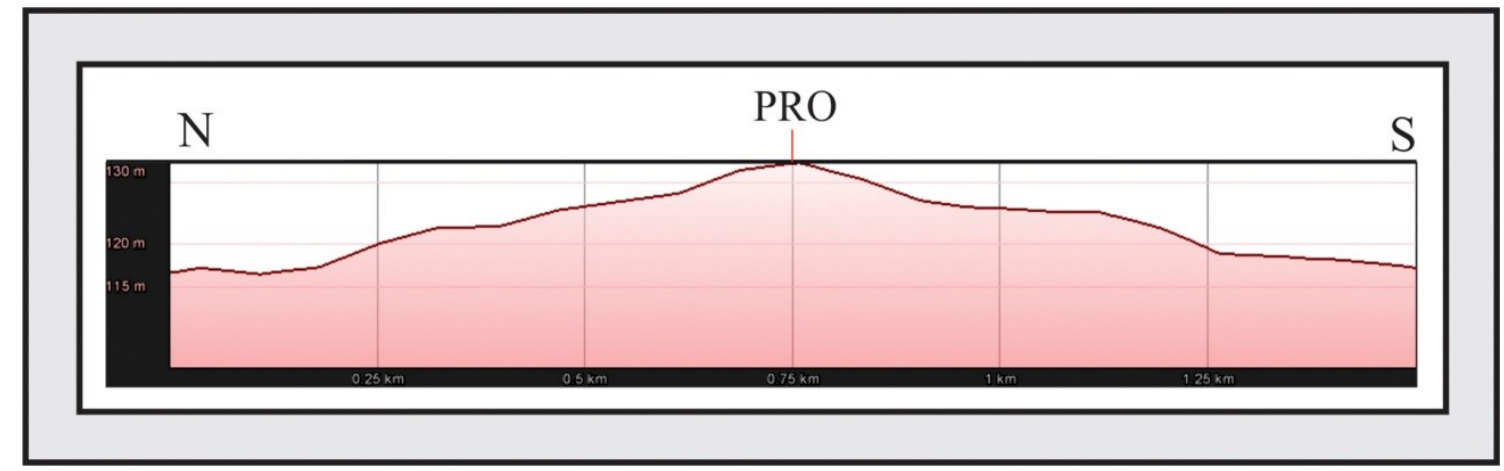

Figura 5.39. Perfil de elevación de una transecta de $1,5 \mathrm{Km}$ en sentido N-S cuyo centro corresponde a la sección de Ramos Otero (PRO). 


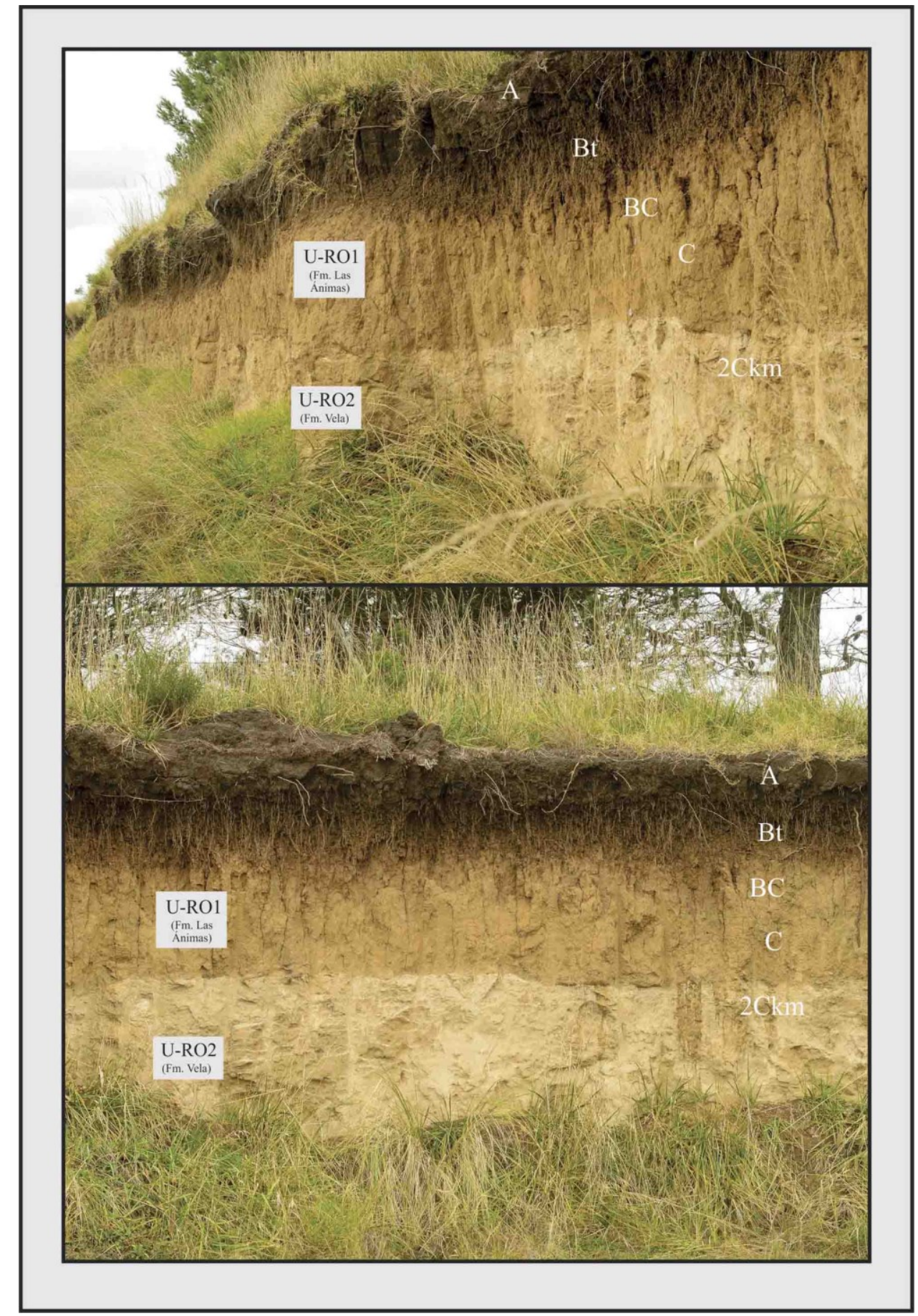

Figura 5.40. Fotografías de sedimentos expuestos en la Ruta 29 cerca del poblado de Ramos Otero (sección PRO). En las mismas se indican las unidades litológicas y los horizontes del suelo actual. 


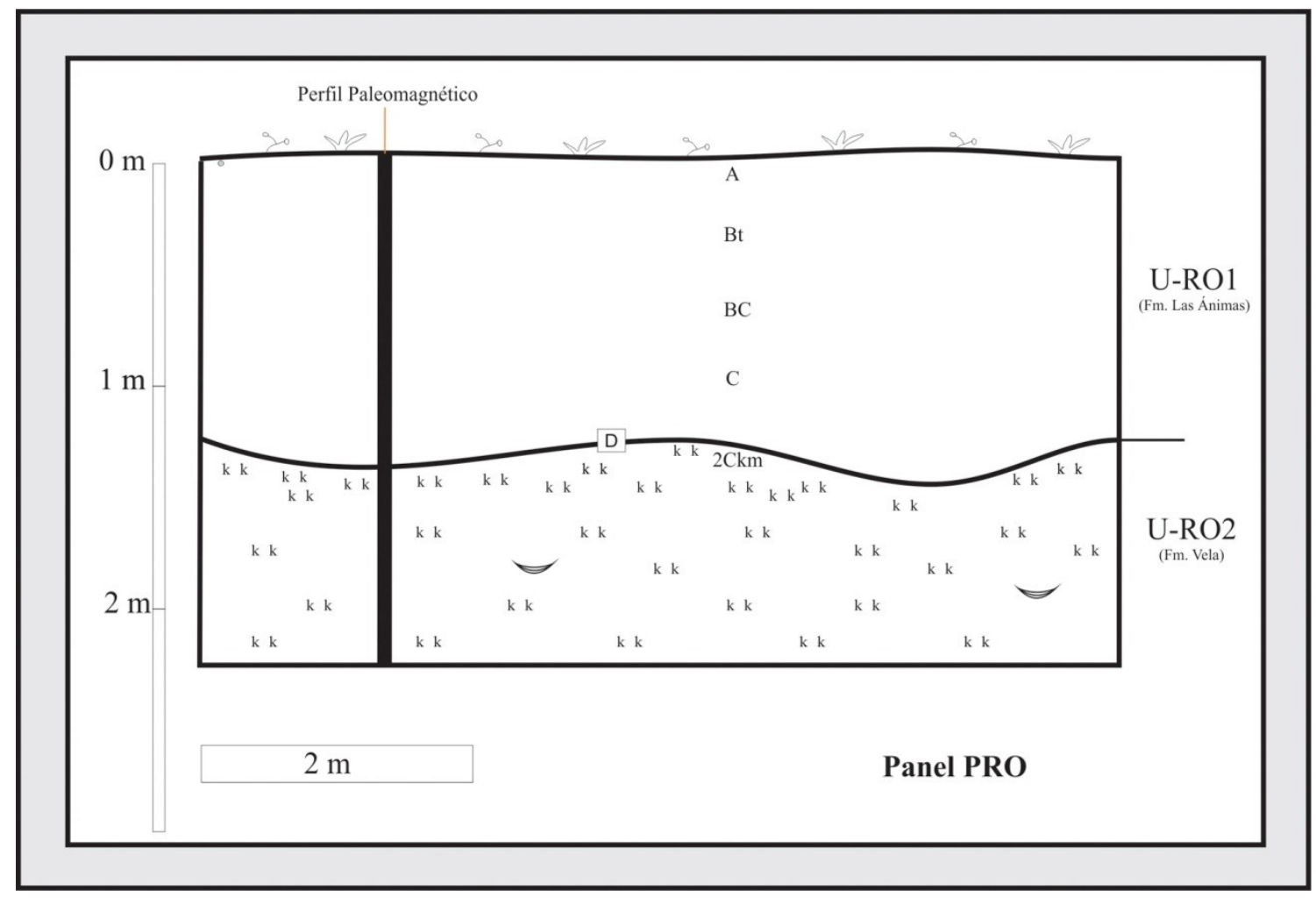

Figura 5.41. Panel esquemático de la sección PRO. 


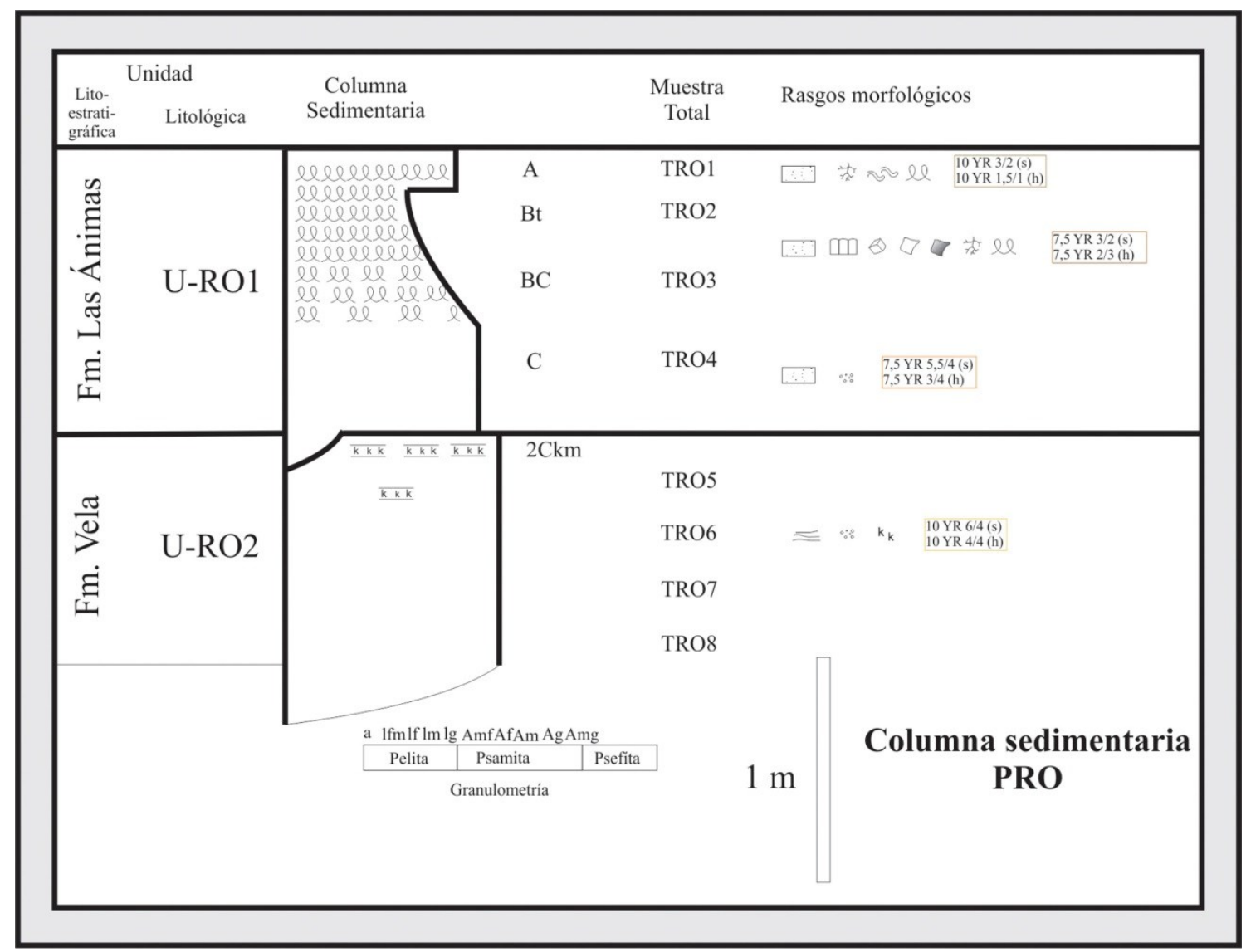

Figura 5.42. Columna sedimentaria de la sección PRO. 


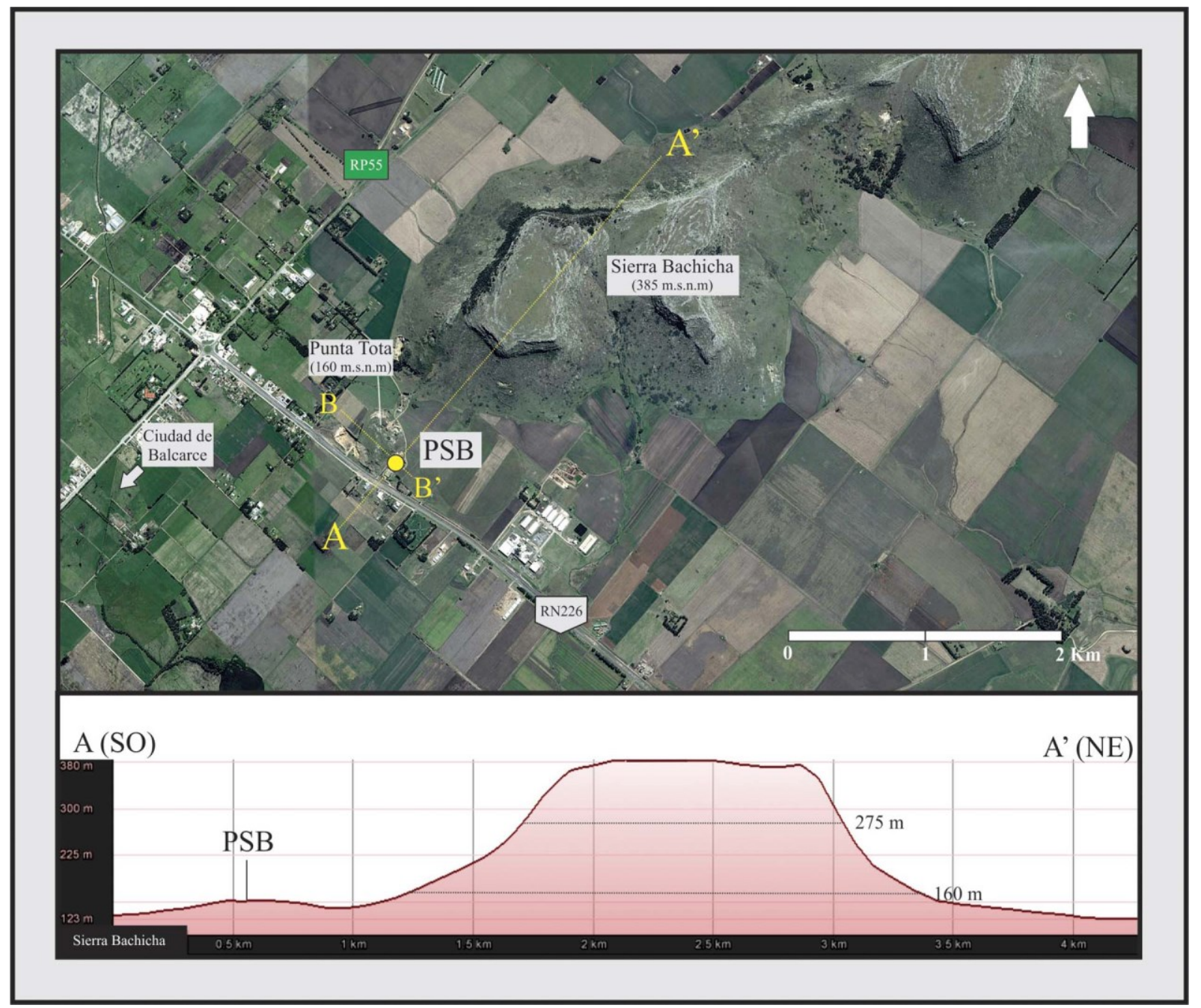

Figura 5.43. Ubicación de la sección estratigráfica de Sierra Bachicha y transectas A-A' y B-B'. Abajo se indica el perfil de elevación correspondiente a la transecta A-A'. 


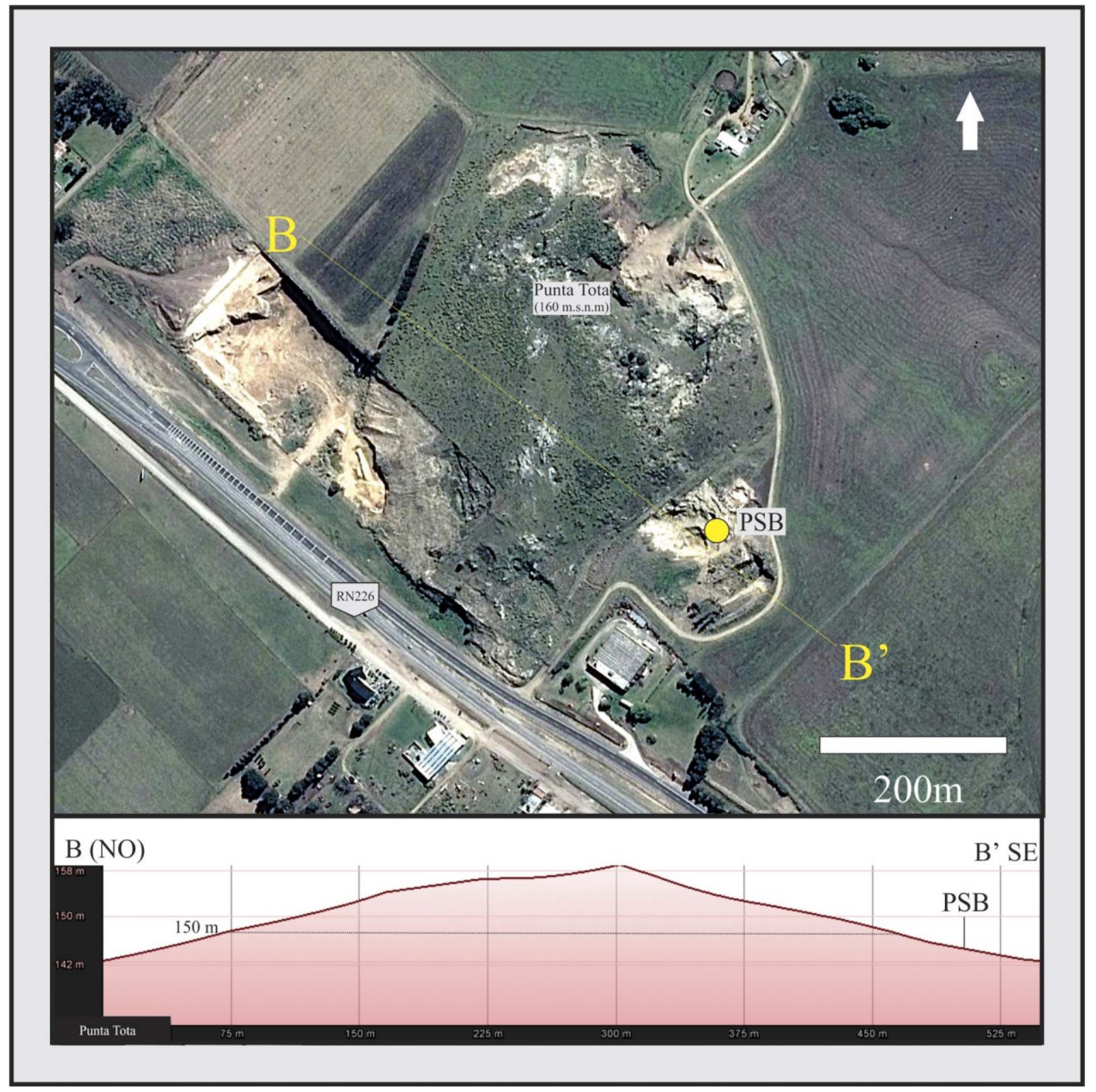

Figura 5.44. Detalle de la ubicación de la sección estratigráfica de Sierra Bachicha (PSB) y la transecta B$\mathrm{B}^{\prime}$. Abajo, perfil de elevación correspondiente a la transecta B-B'. 


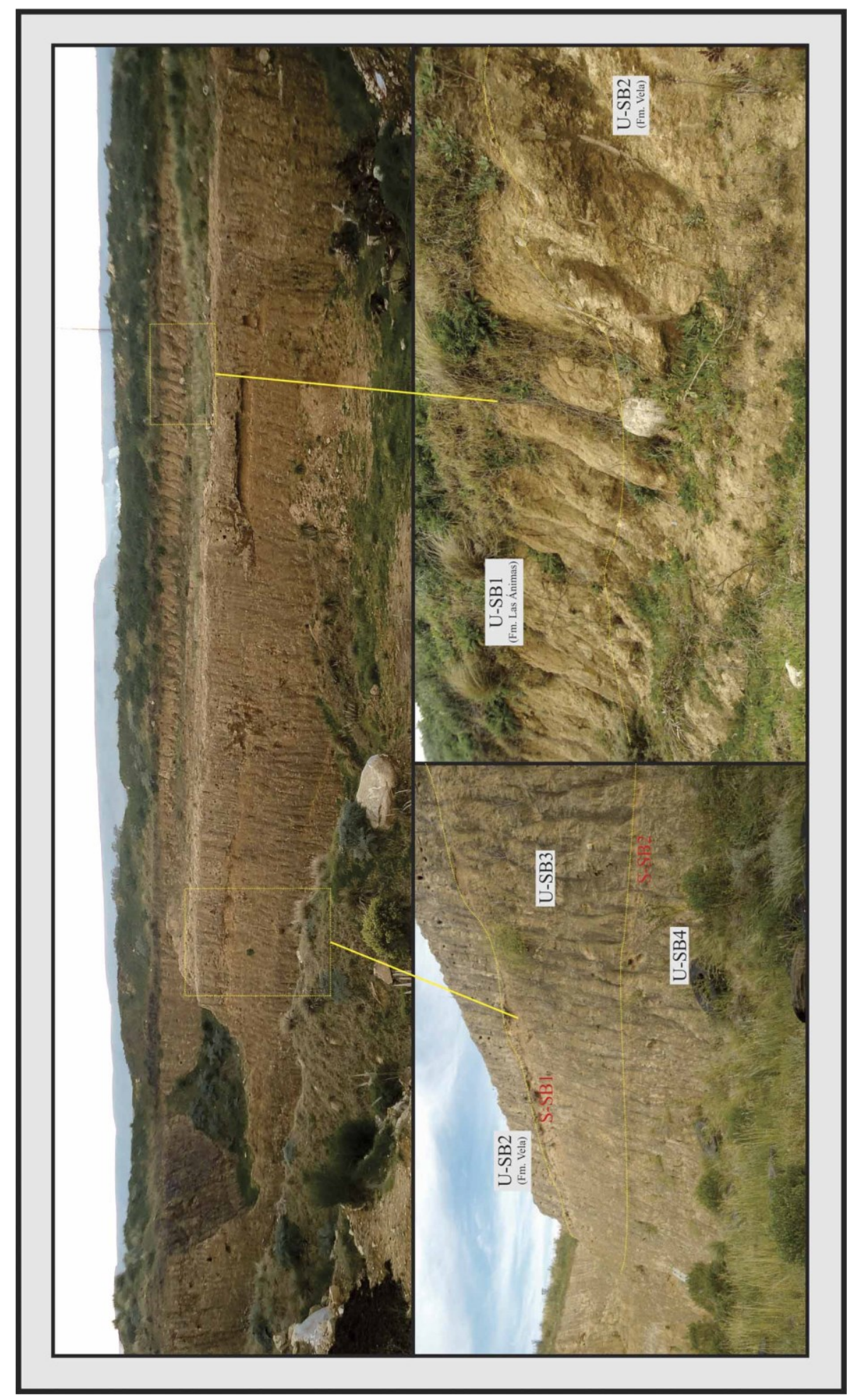

Figura 5.45. Fotografías los sedimentos expuestos en la cantera de Sierra Bachicha (PSB). 


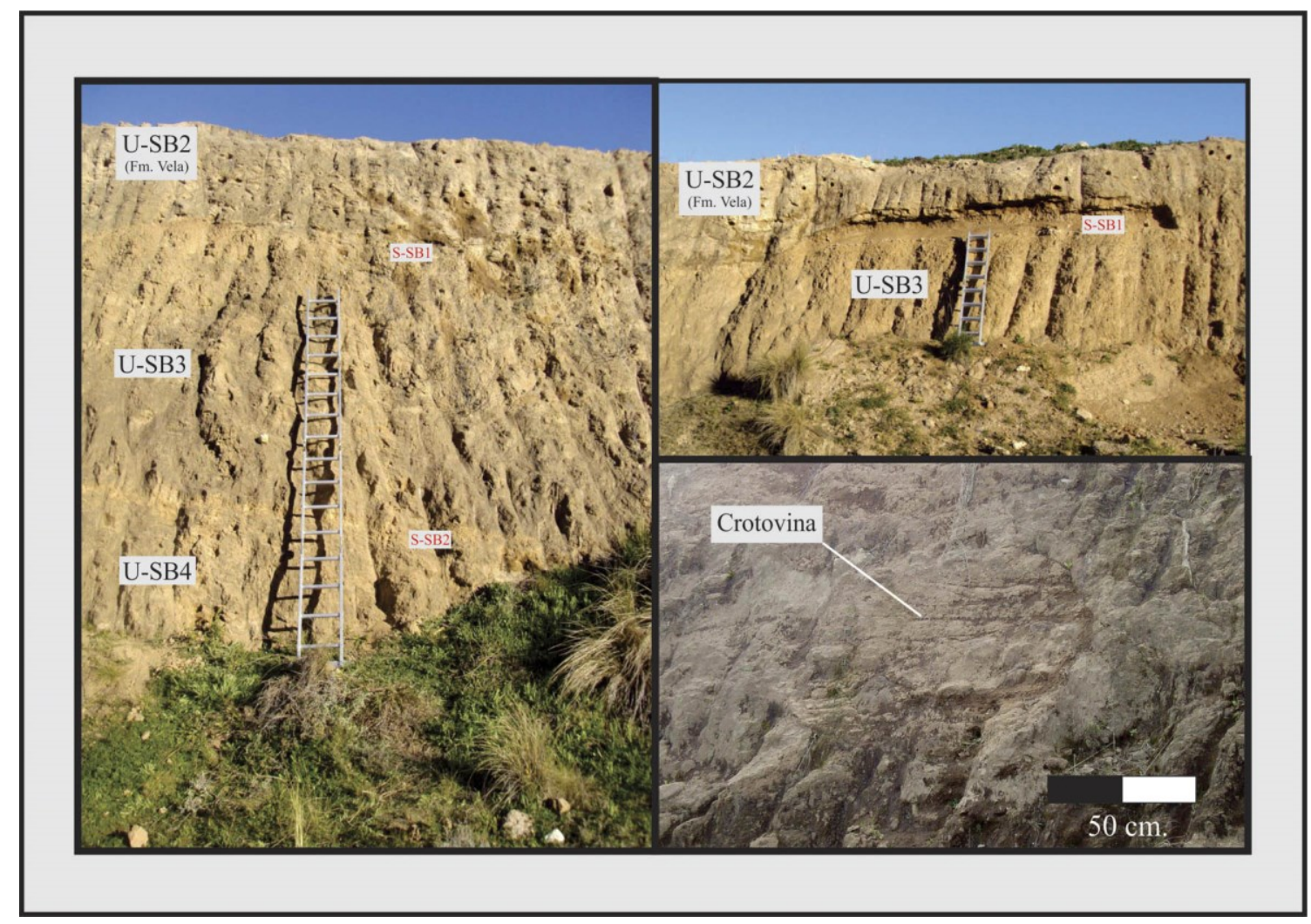

Figura 5.46. Detalles de los sedimentos expuestos en PSB. 


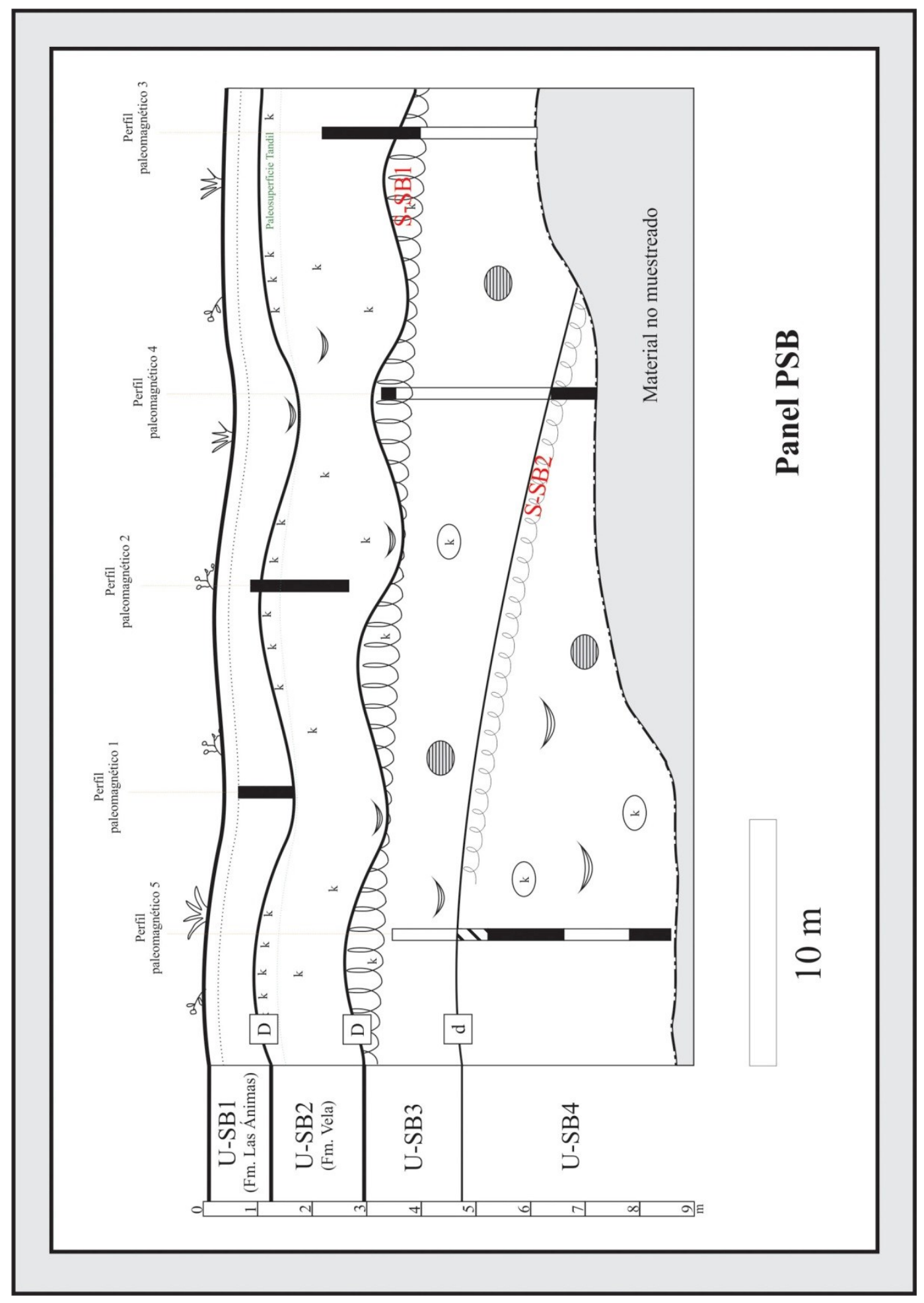

Figura 5.47. Panel esquemático de la sección de Sierra Bachicha (PSB). 


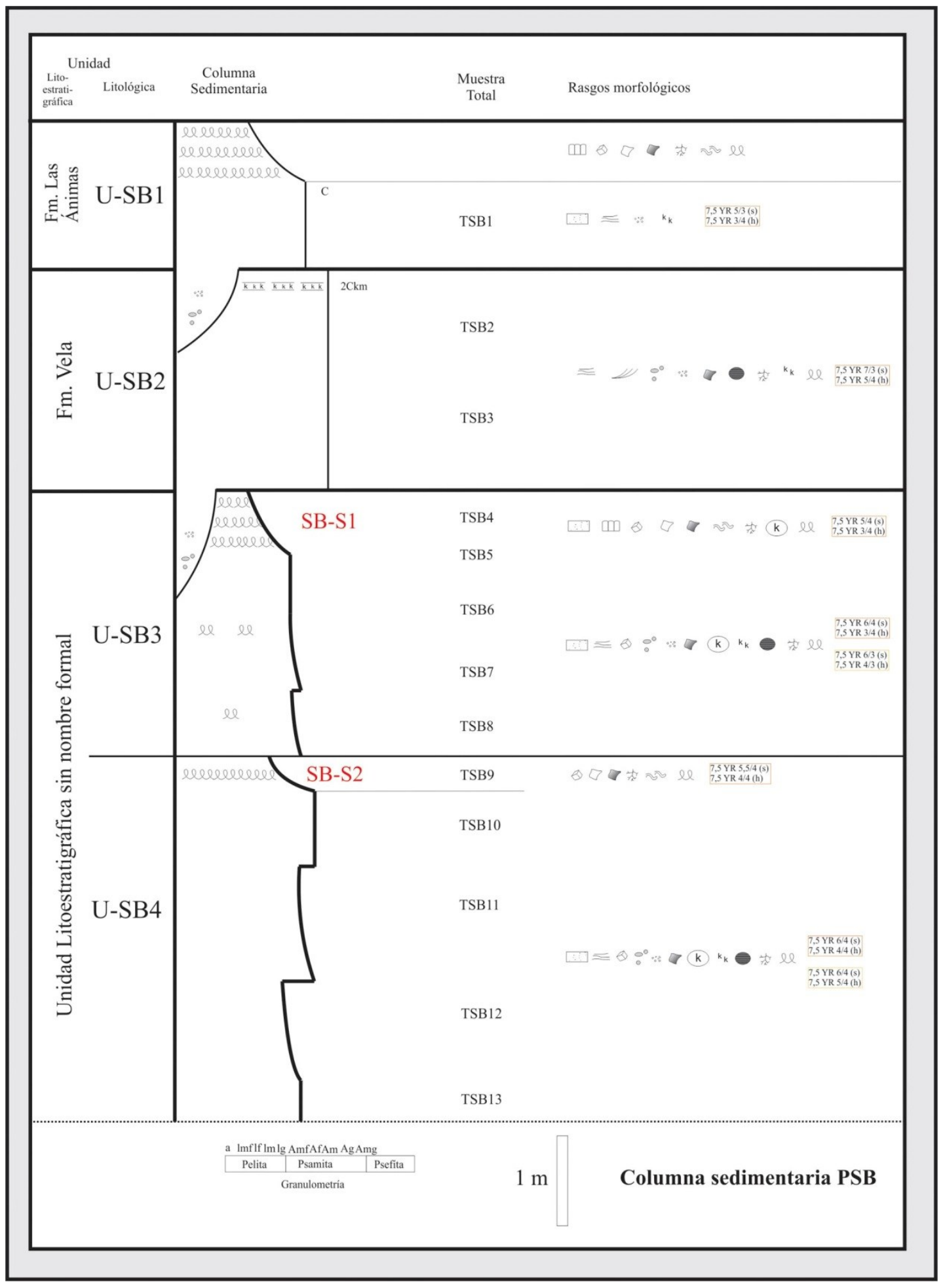

Figura 5.48. Columna sedimentaria de la sección de Sierra Bachicha (PSB). 


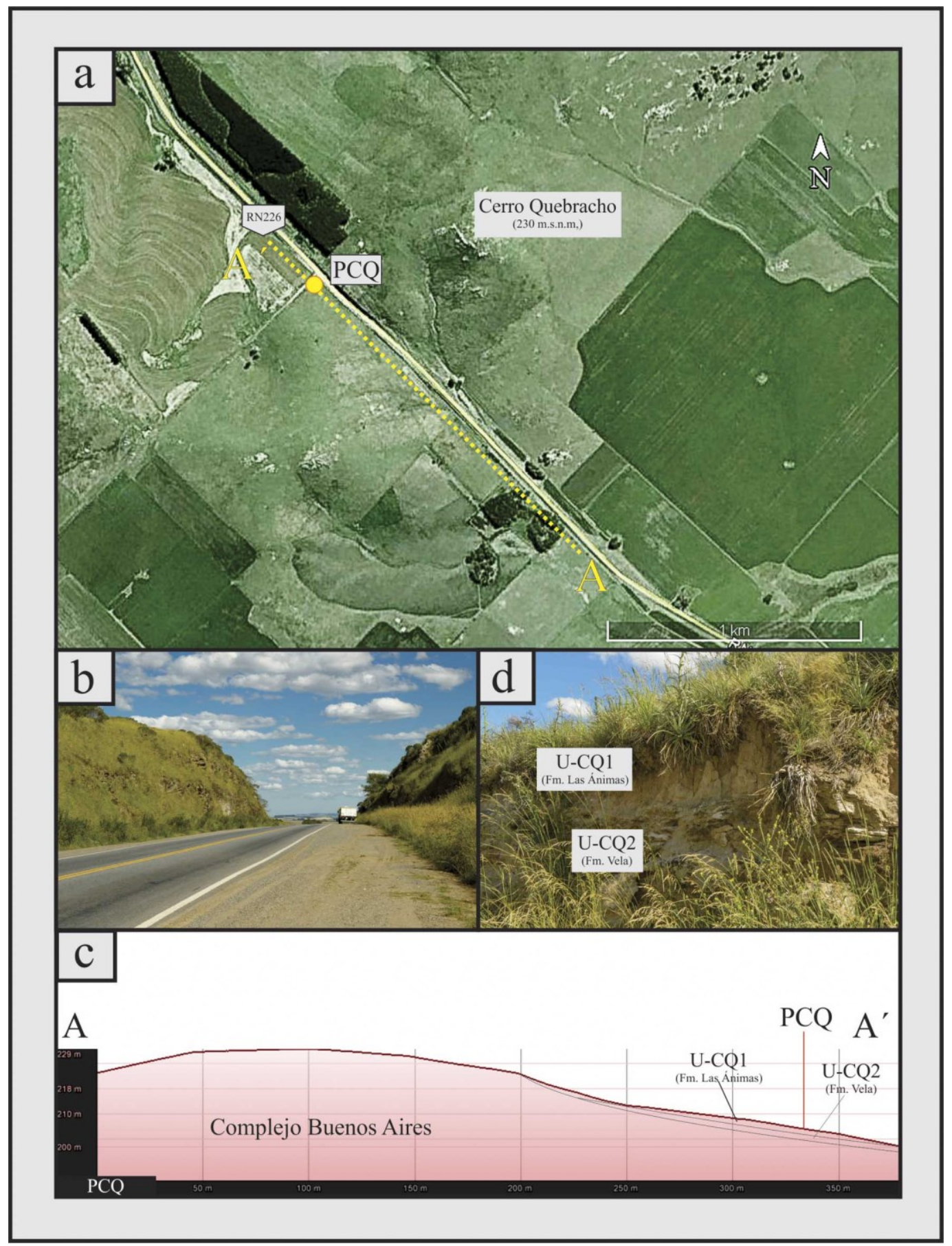

Figura 5.49. Imágenes de la sección de Cerro Quebracho (PCQ). a) Ubicación de la sección y transecta A-A'; b) Vista hacia el sudeste desde PCQ; c) Perfil de elevación correspondiente a la transecta A-A'; d) sedimentos analizados en la sección PCQ. 


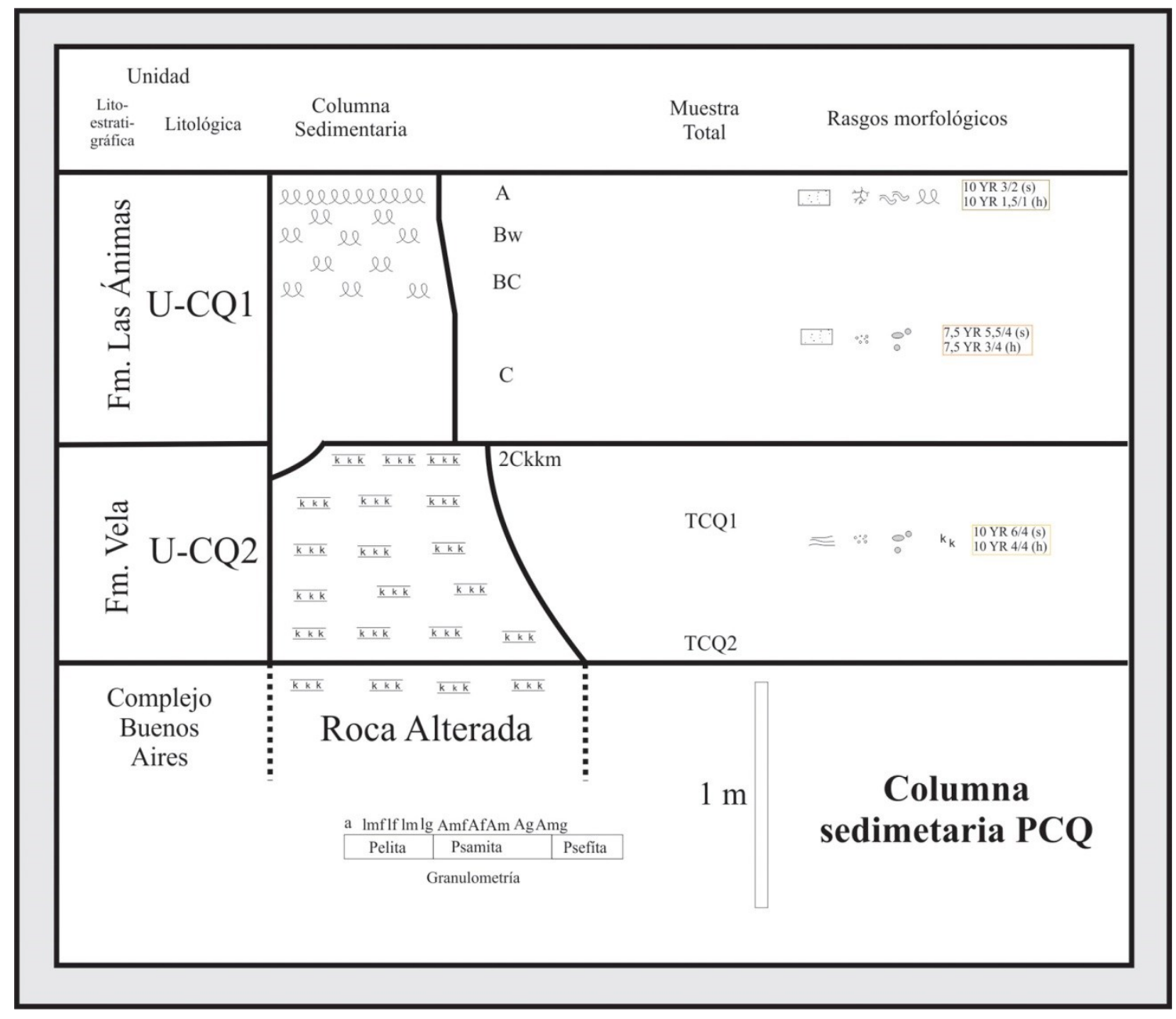

Figura 5.50. Columna sedimentaria de la sección de Cerro Quebracho (PCQ). 


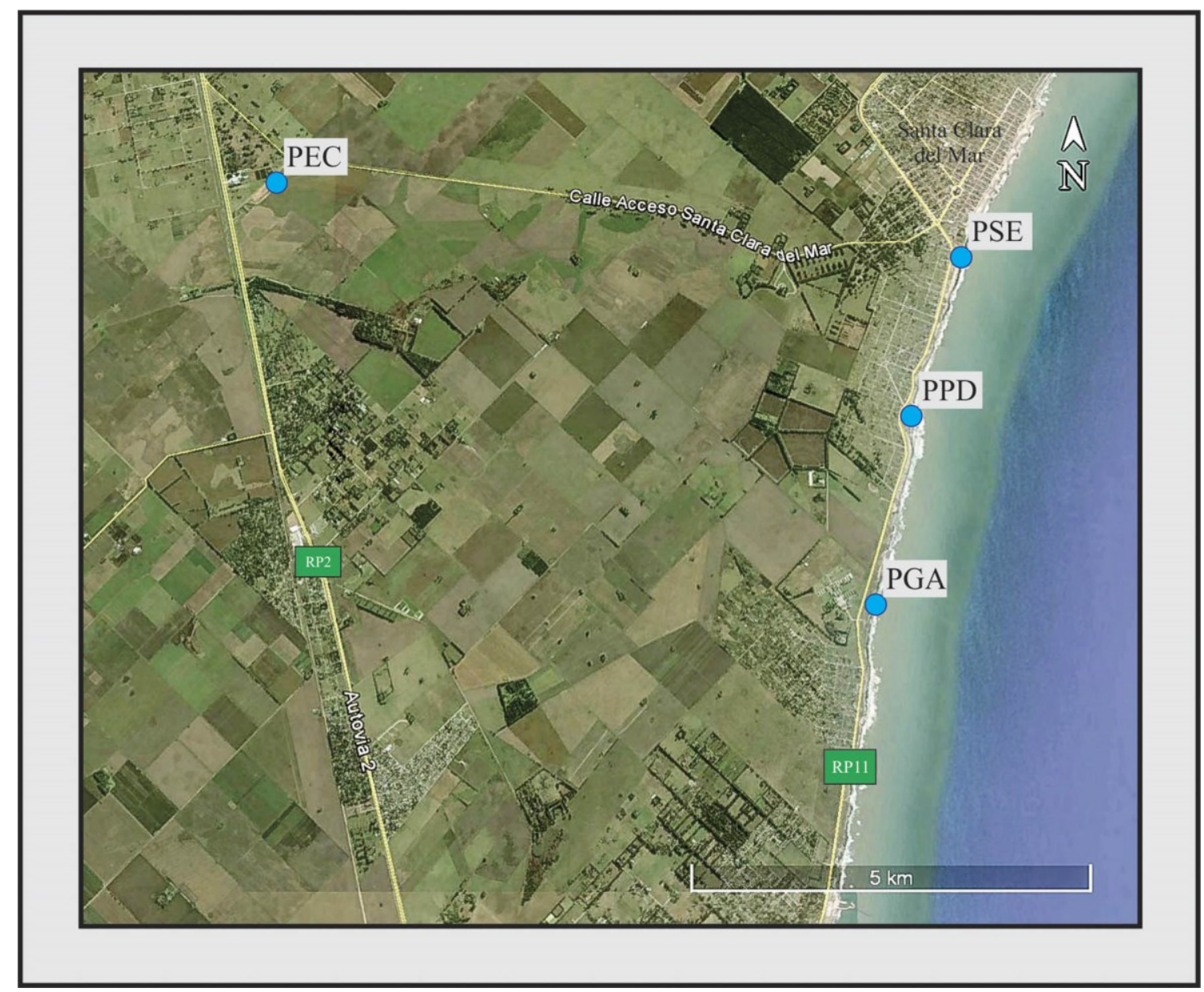

Figura 5.51. Ubicación de las secciones estratigráficas del sector costero al norte de Mar del Plata. 


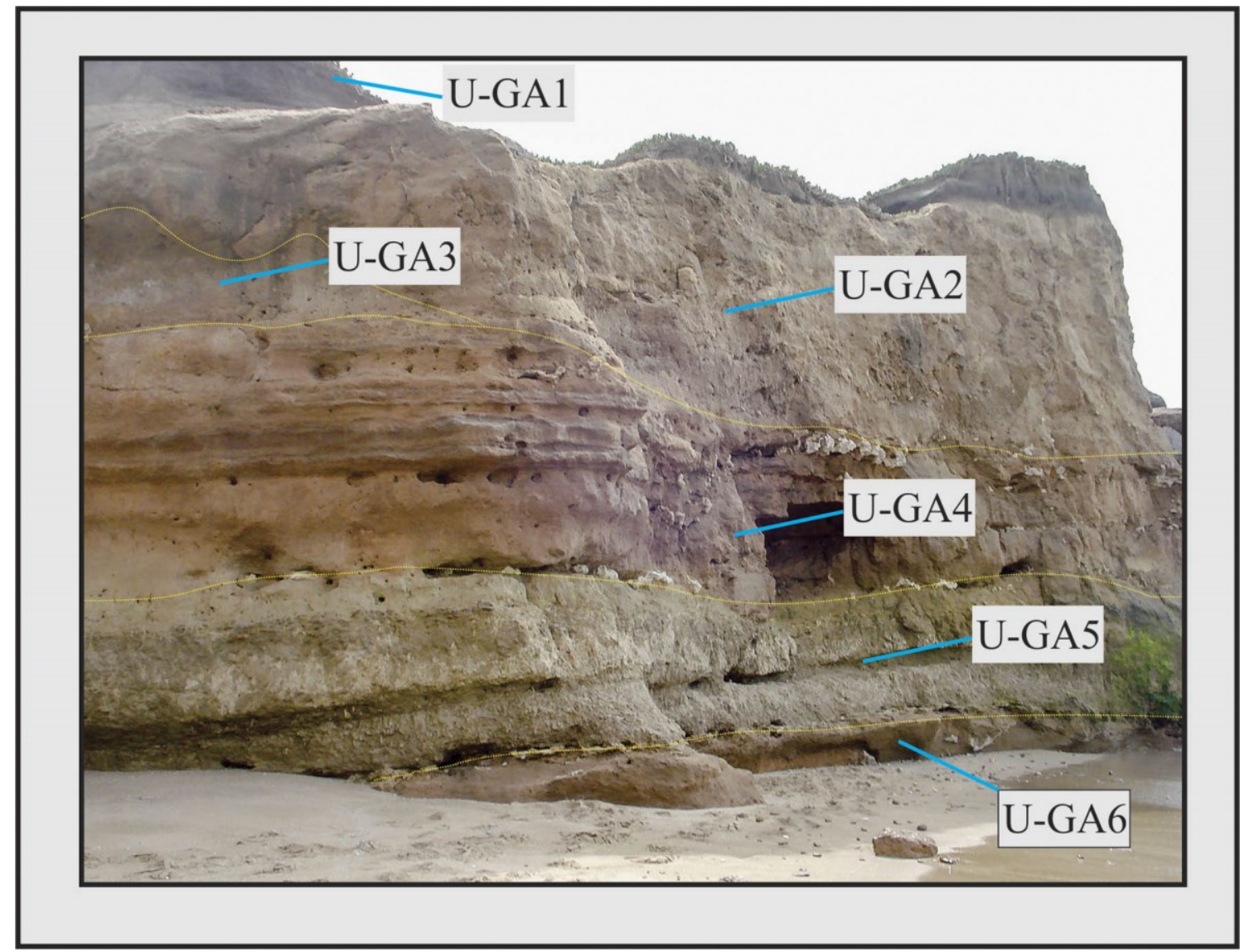

Figura 5.52. Fotografía del acantilado marino de la sección GADA (PGA) y unidades litológicas. 


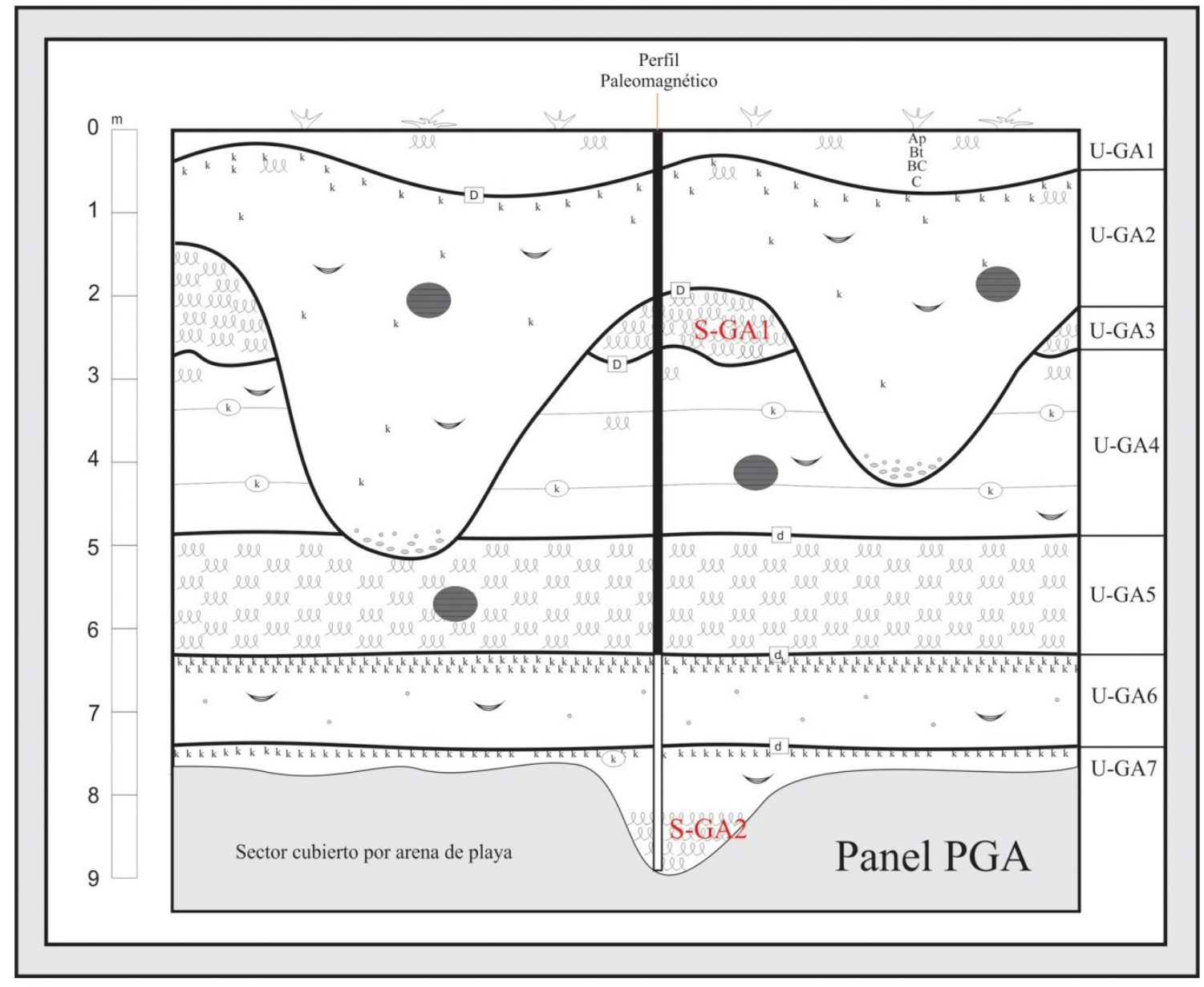

Figura 5.53. Panel esquemático de la sección GADA (PGA). 


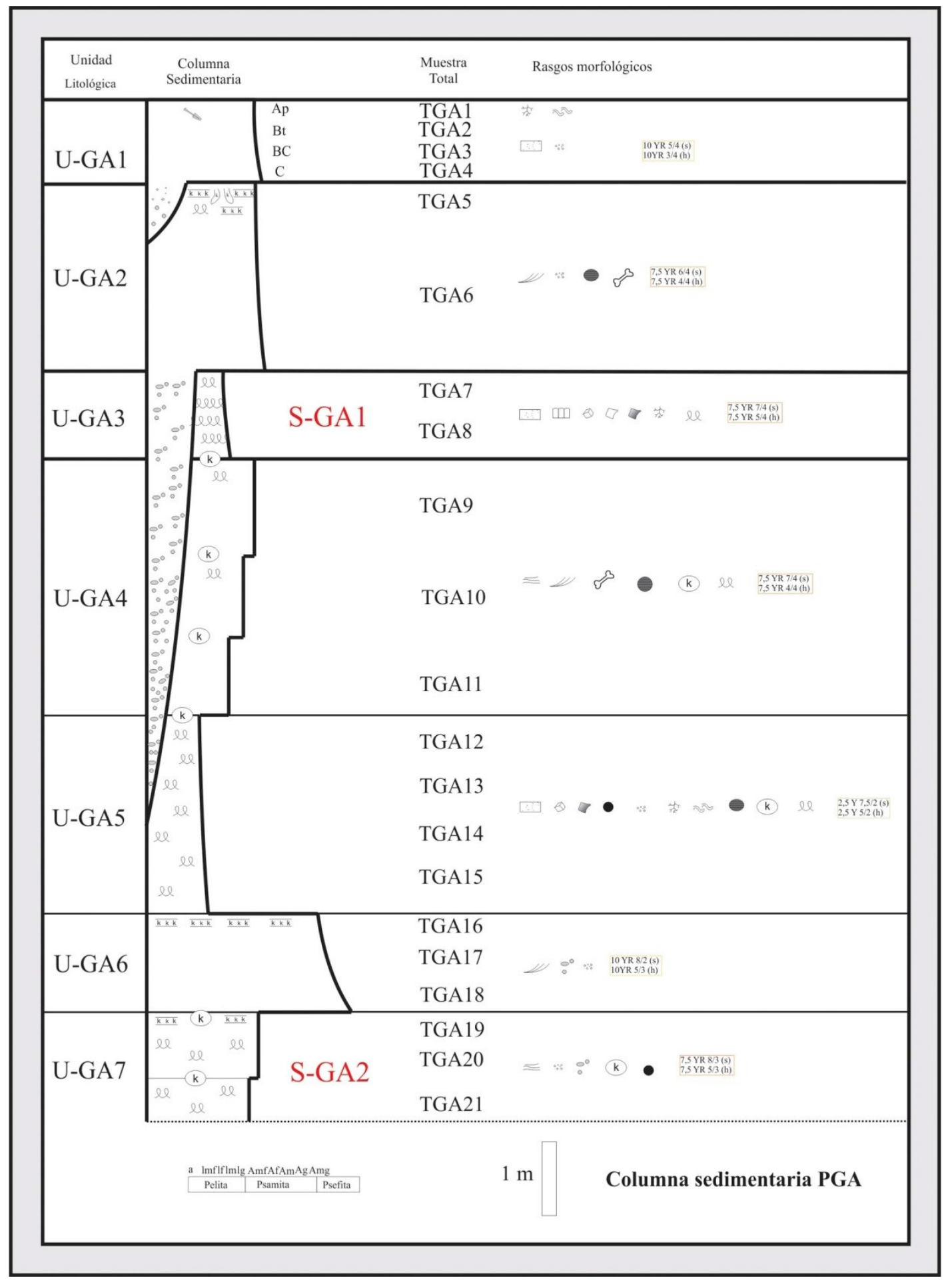

Figura 5.54. Columna sedimentaria de la sección GADA (PGA). 


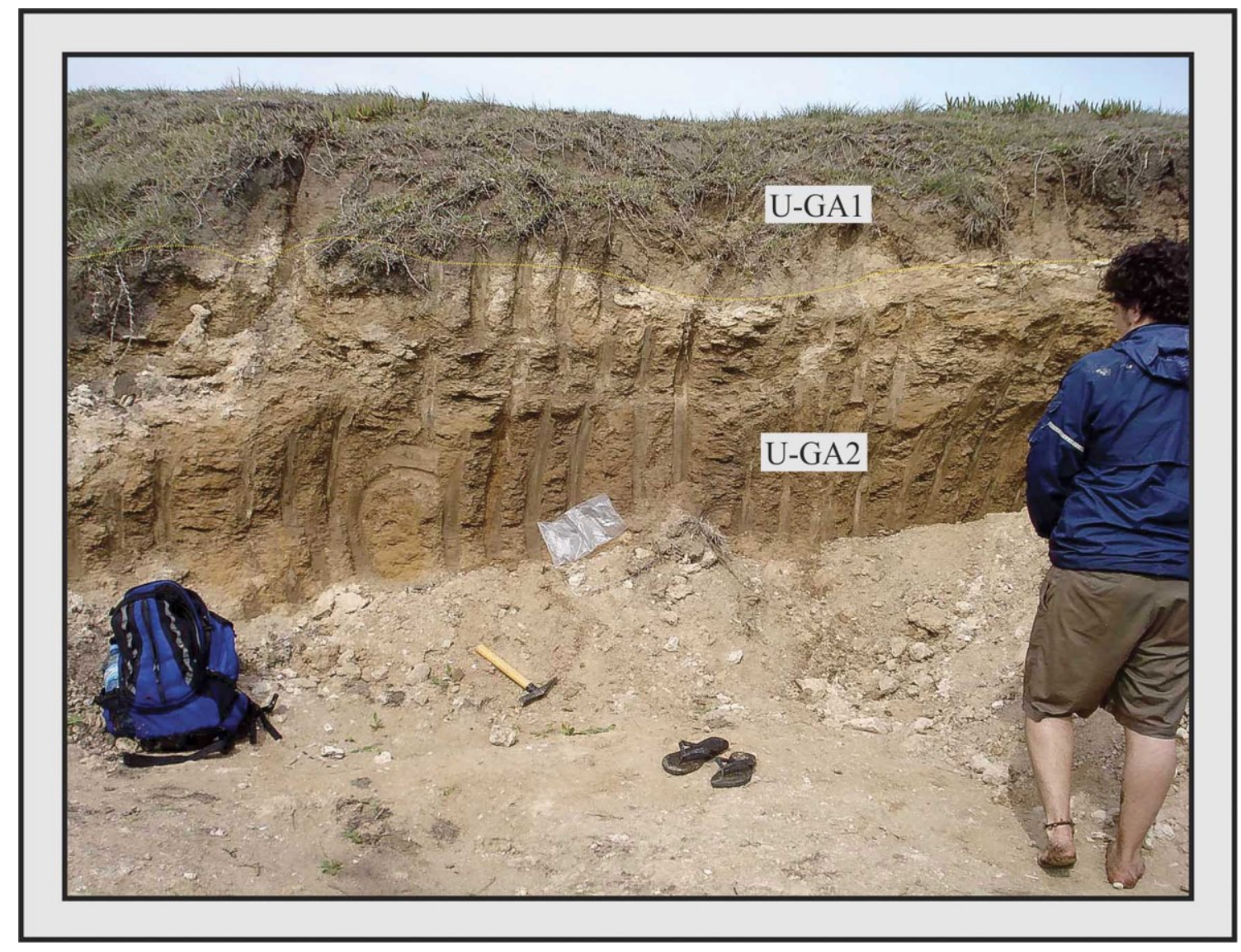

Figura 5.55. Unidades del tope de la sección PGA. 


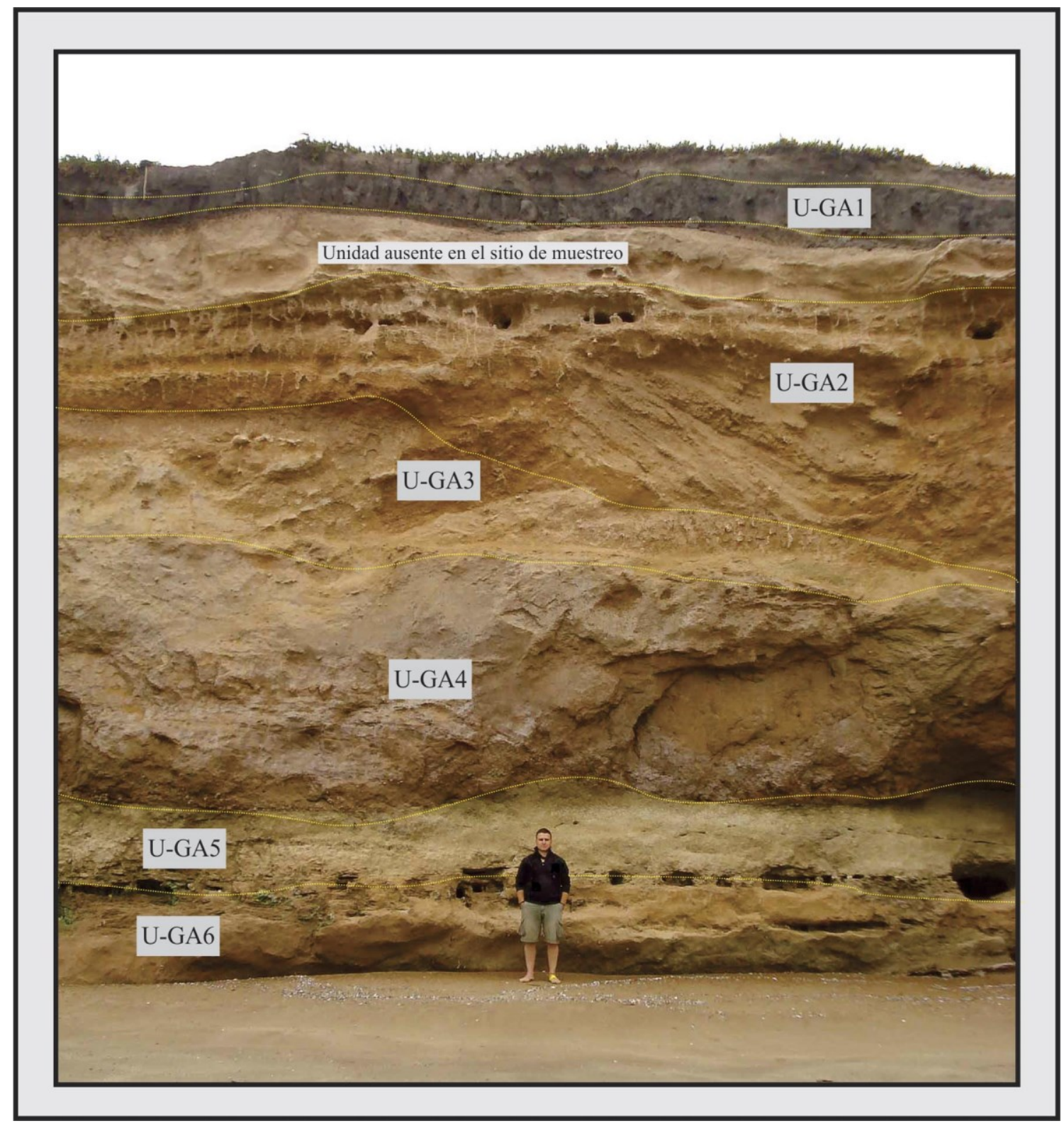

Figura 5.56. Acantilado marino 100 metros al sur del sitio de muestreo de la sección PGA. 


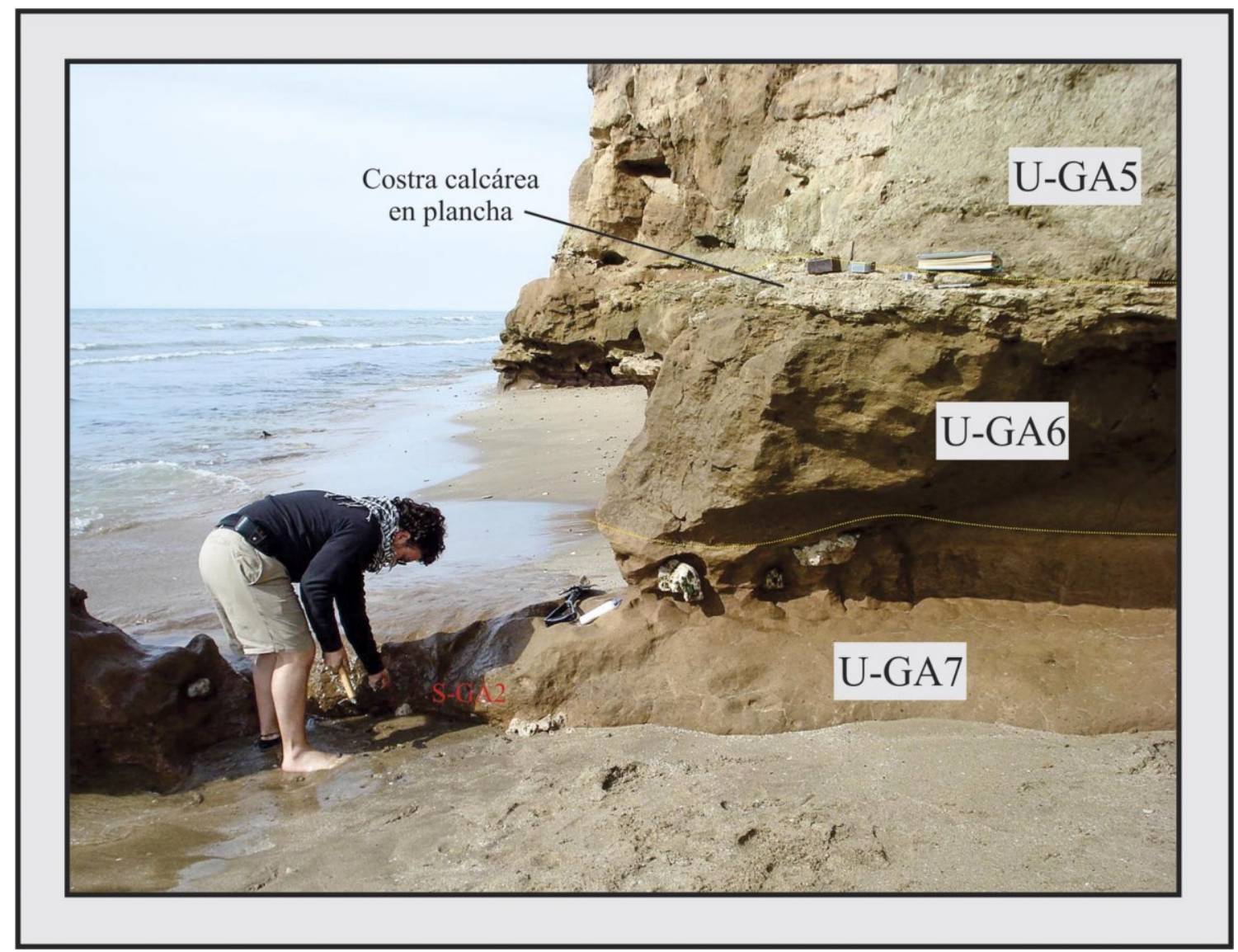

Figura 5.57. Unidades de la base de la sección PGA. 


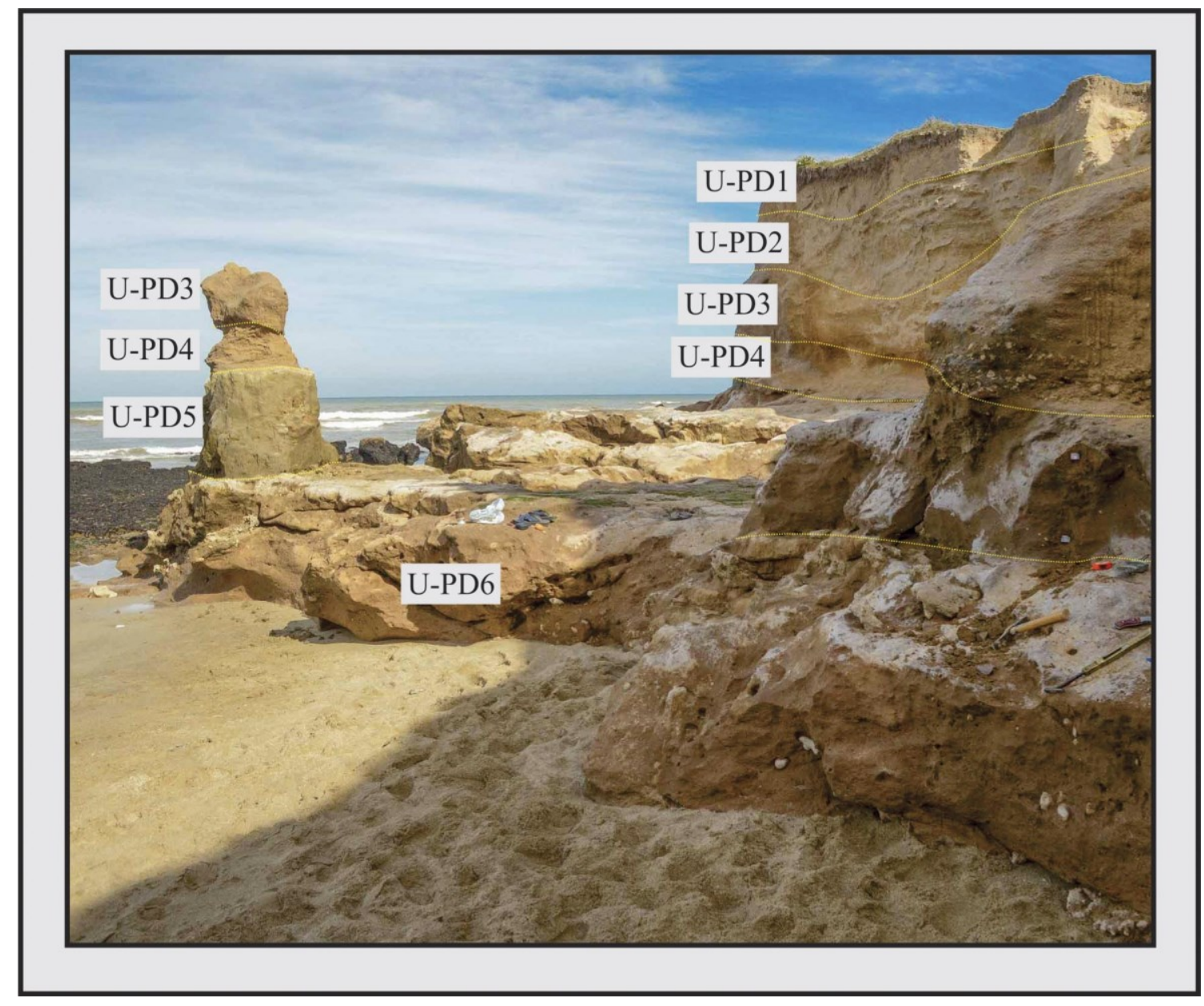

Figura 5.58. Fotografía del acantilado marino de la sección Playa Dorada (PPD). 


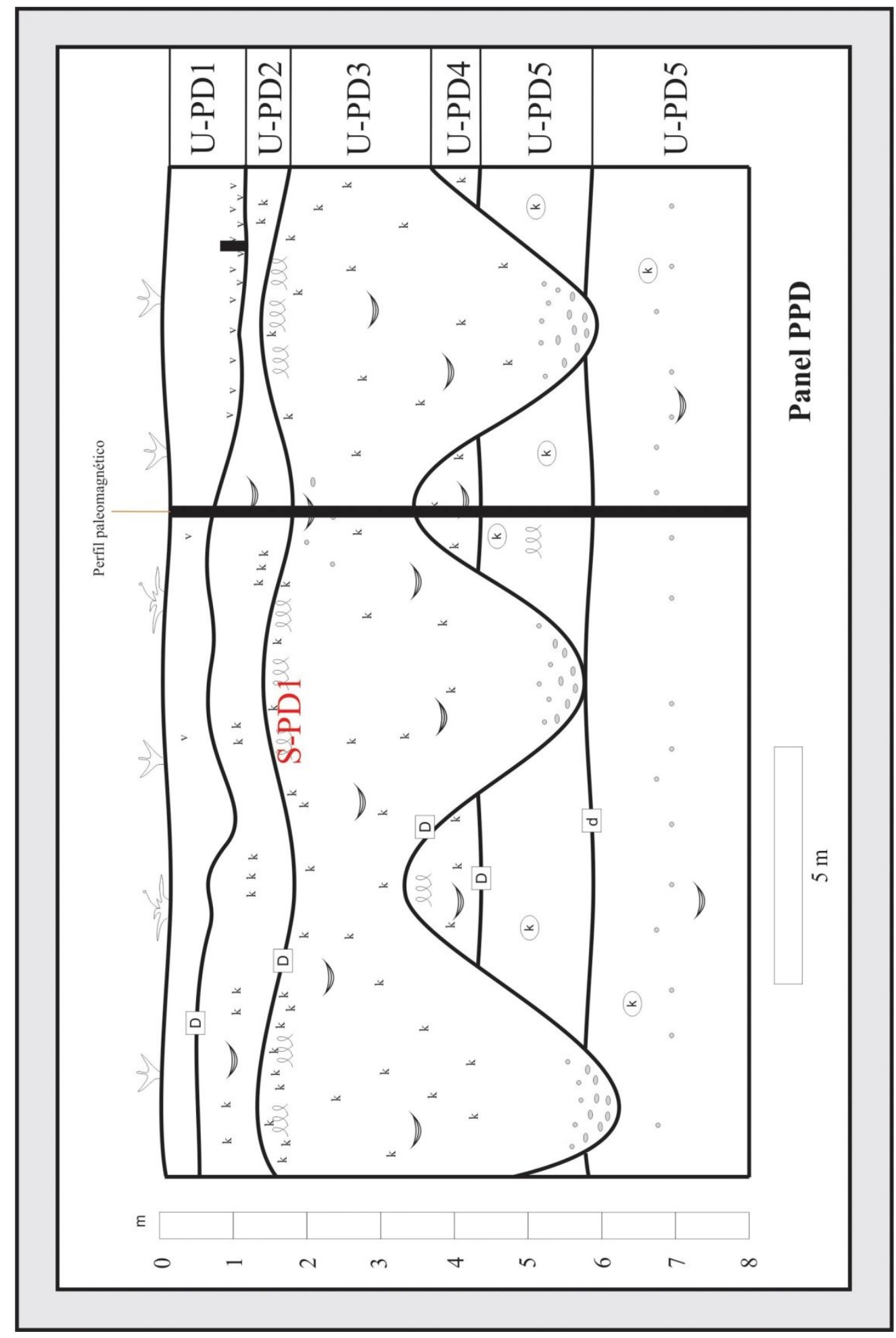

Figura 5.59. Panel esquemático de la sección Playa Dorada (PPD). 


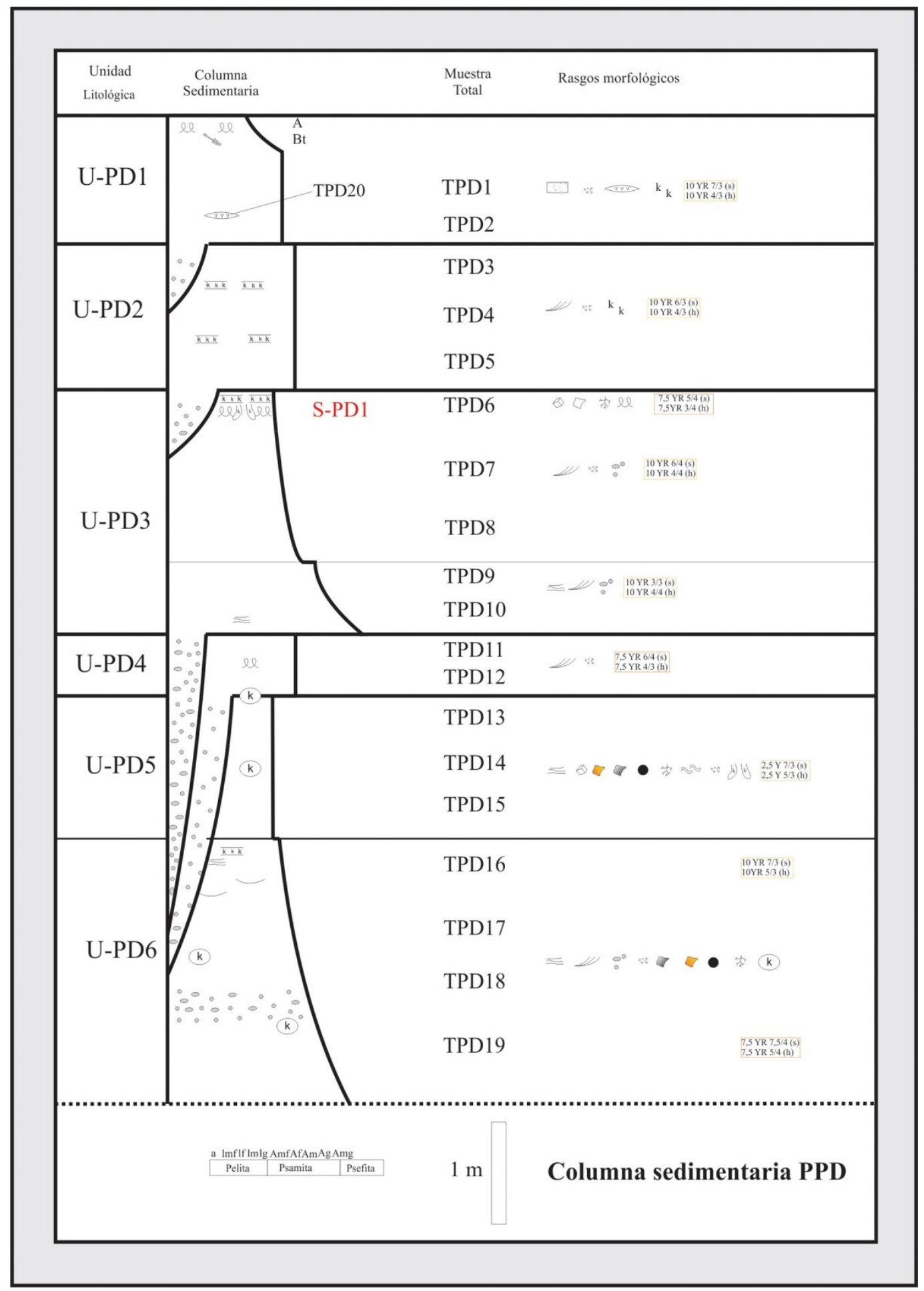

Figura 5.60. Columna sedimentaria de la sección Playa Dorada (PPD). 


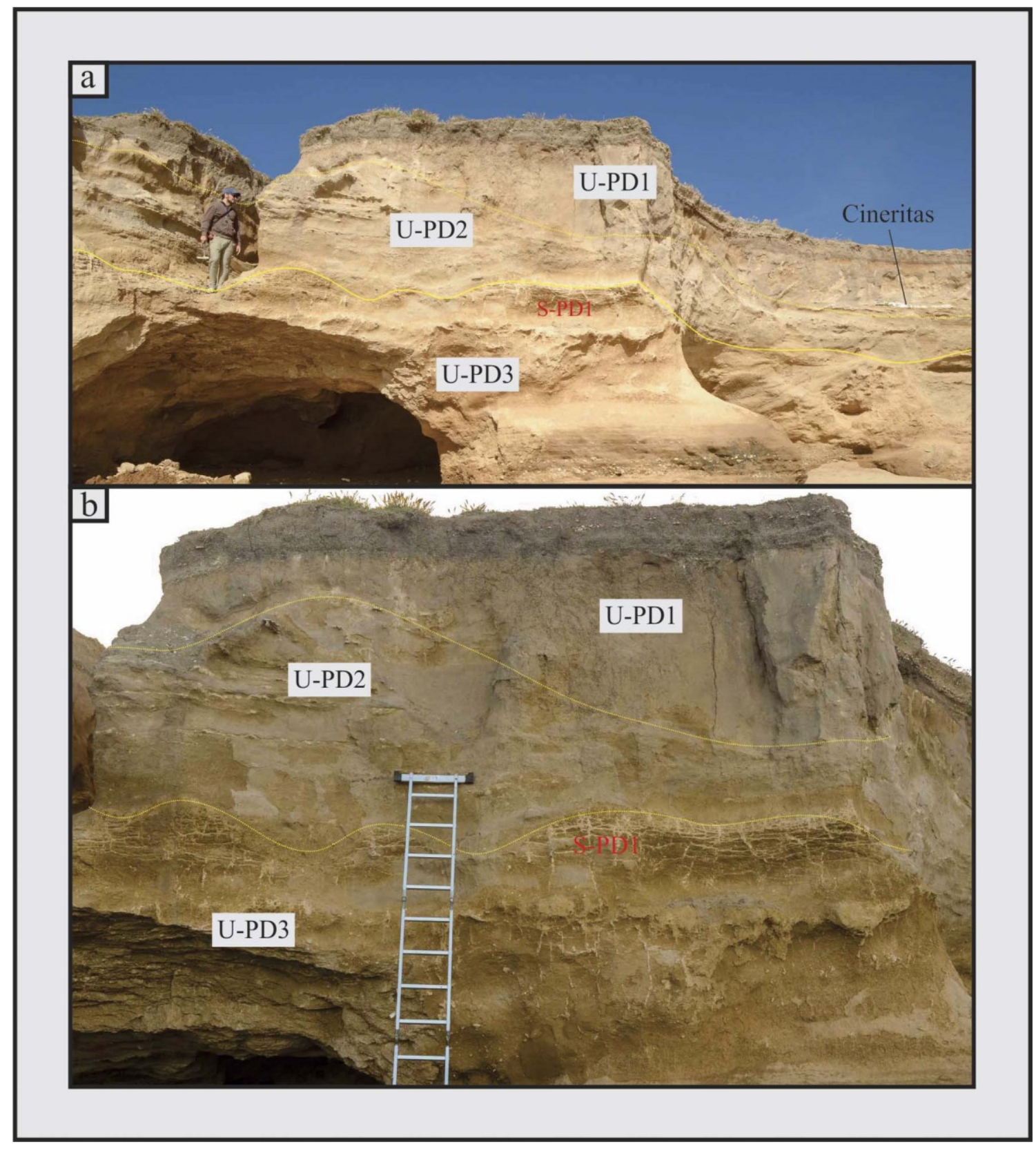

Figura 5.61. Unidades del tope de la sección PPD. En a) se indica (a la derecha) la posición del nivel de ceniza en la base de la unidad U-PD1; en b) se indica el paleosuelo con acumulación calcárea de aspecto reticulado. 


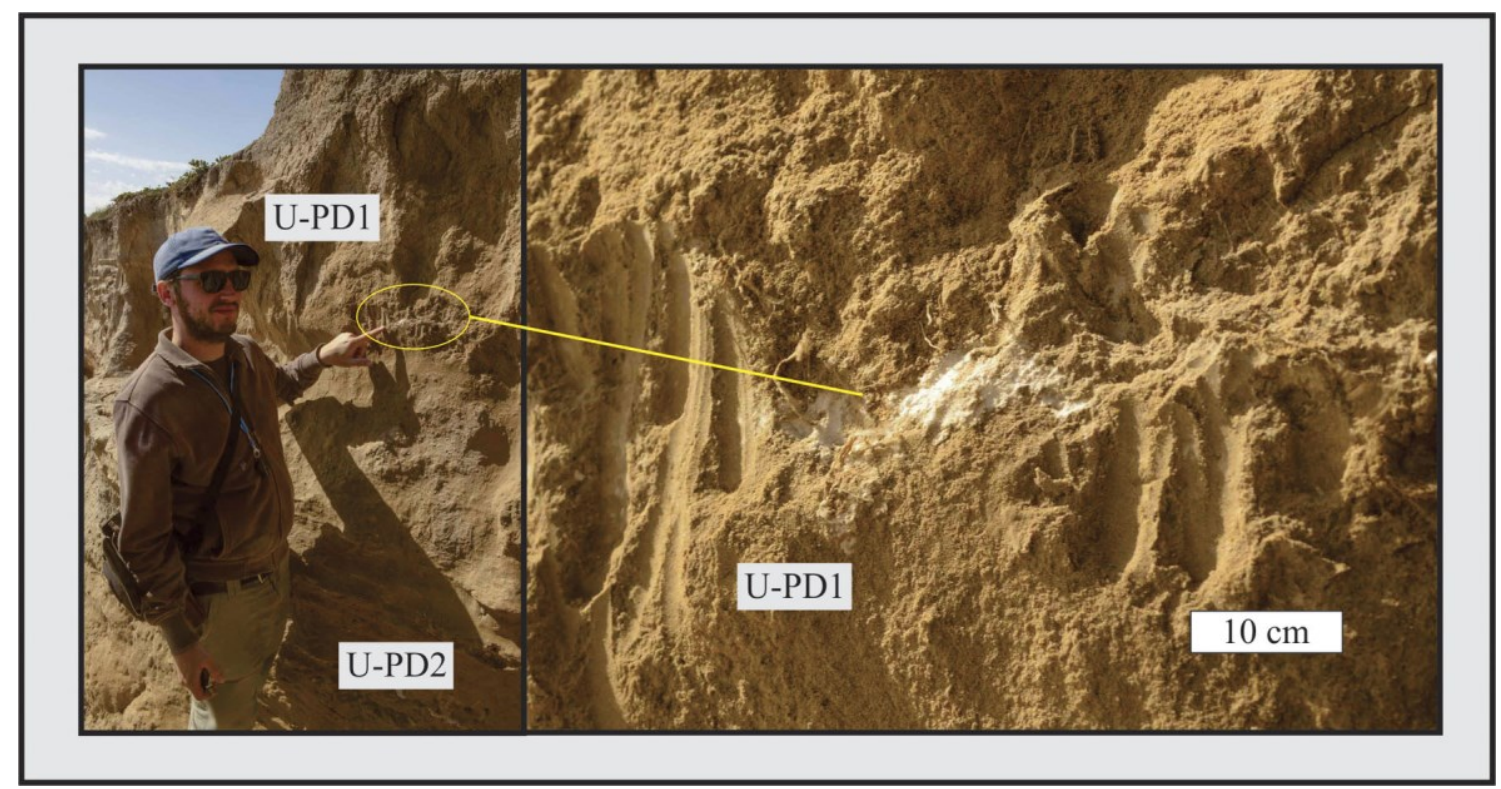

Figura 5.62. Ceniza removilizada en la unidad U-PD1.

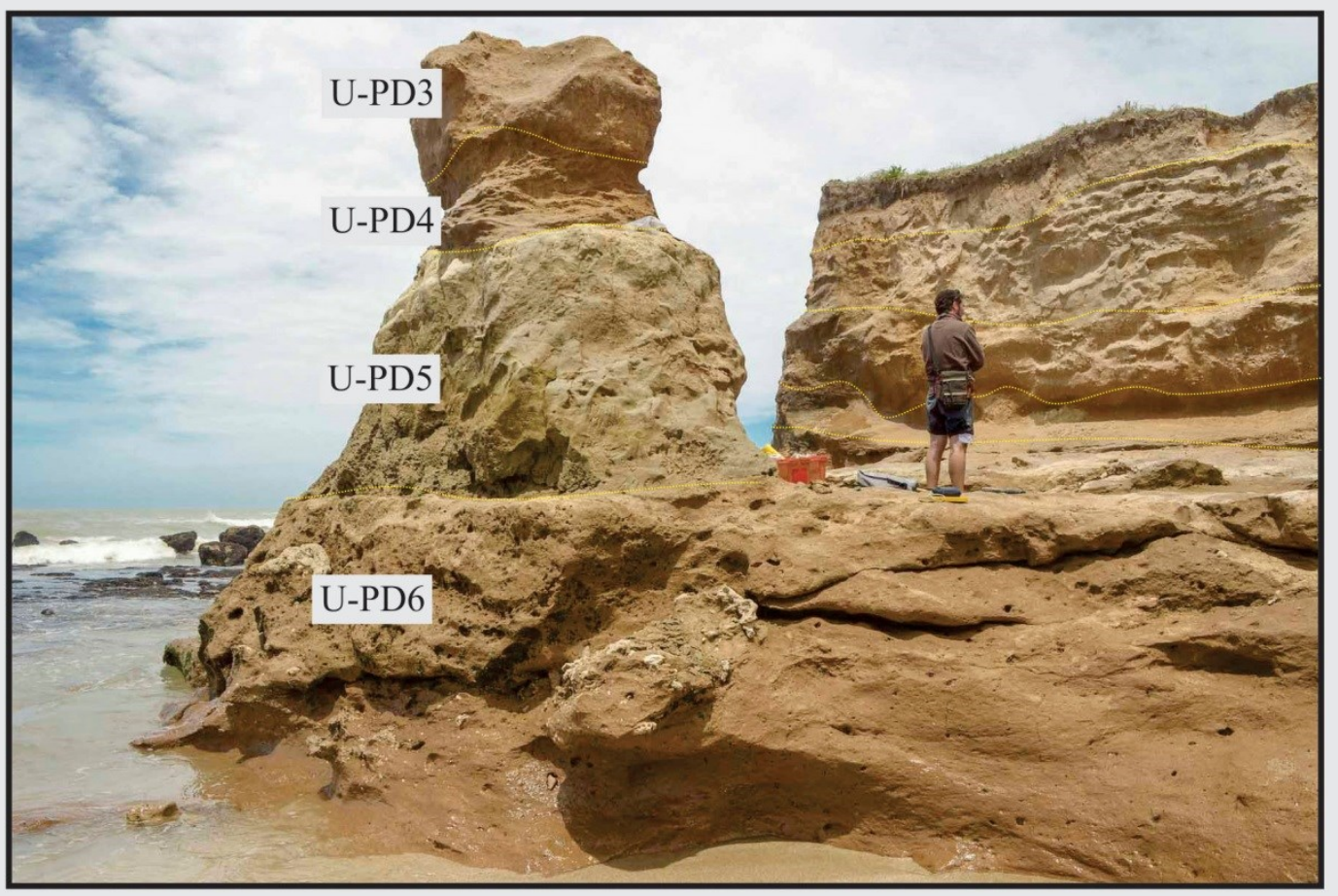

Figura 5.63. Fotografía del acantilado marino de la sección PPD y unidades litológicas basales. 


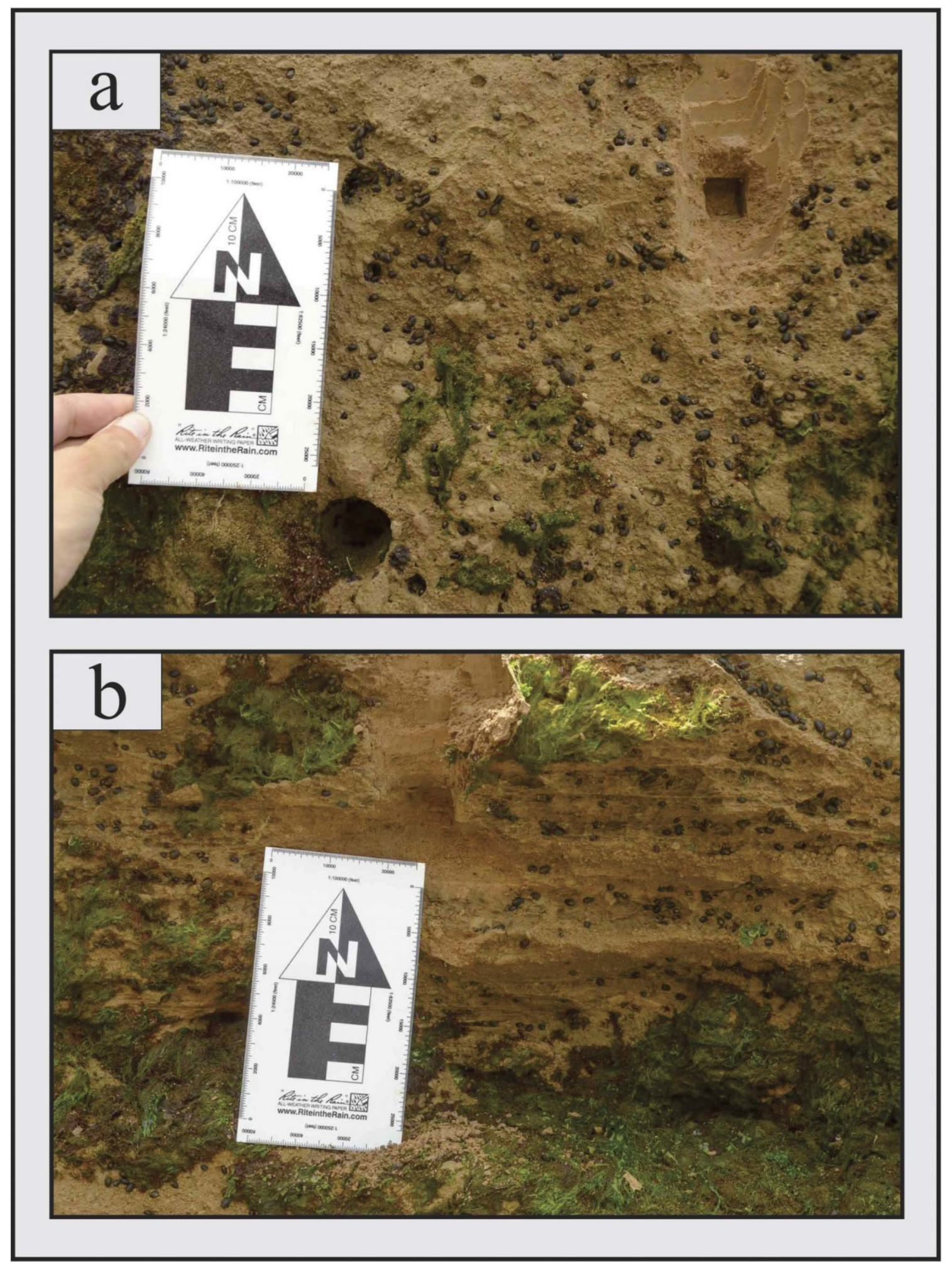

Figura 5.64. Unidad U-PD6. a) Intraclastos de limolita/arcillita; b) Laminación paralela. 


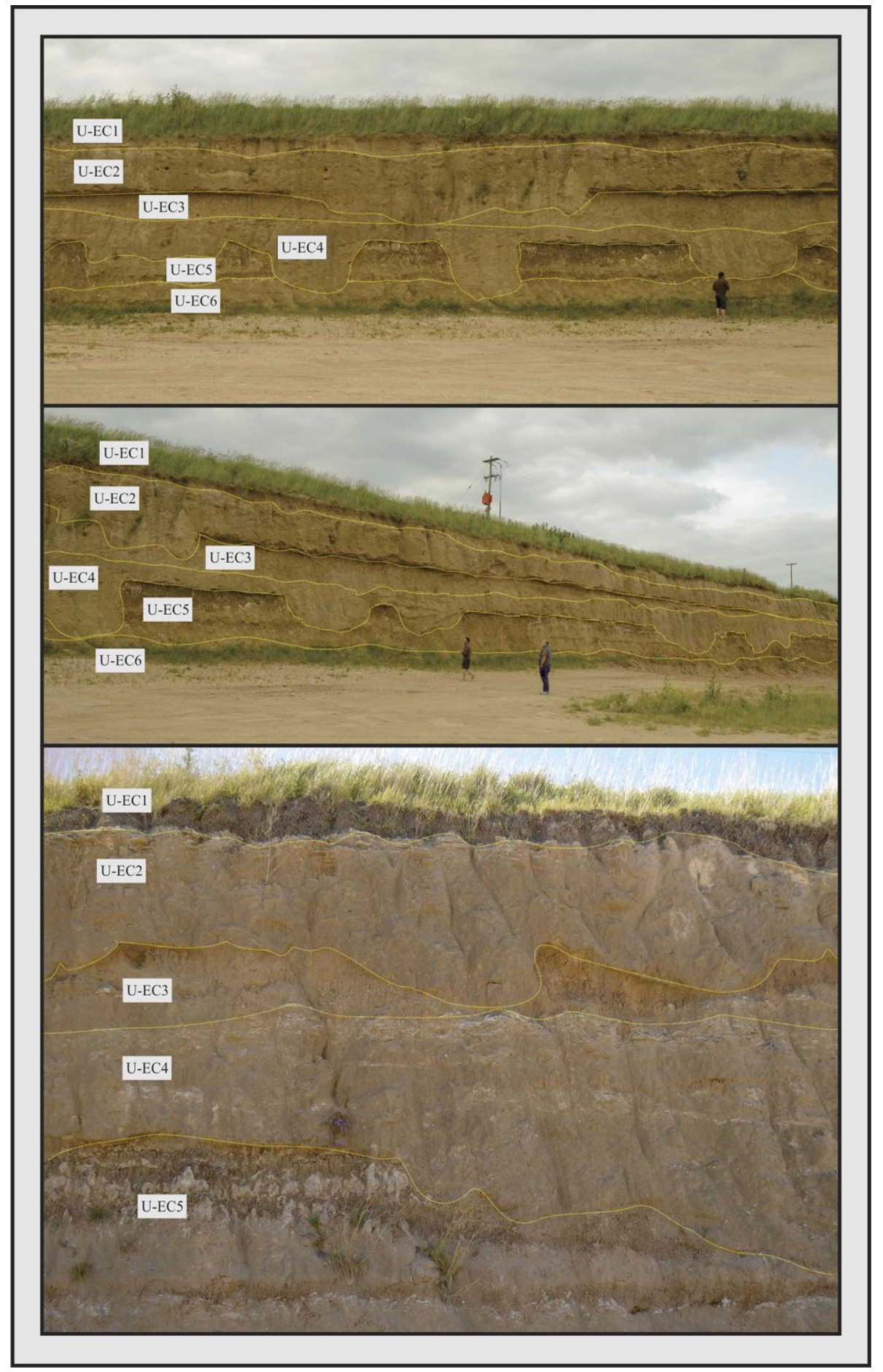

Figura 5.65. Sedimentos expuestos en la cantera de El Casal (PEC) y unidades litológicas. 


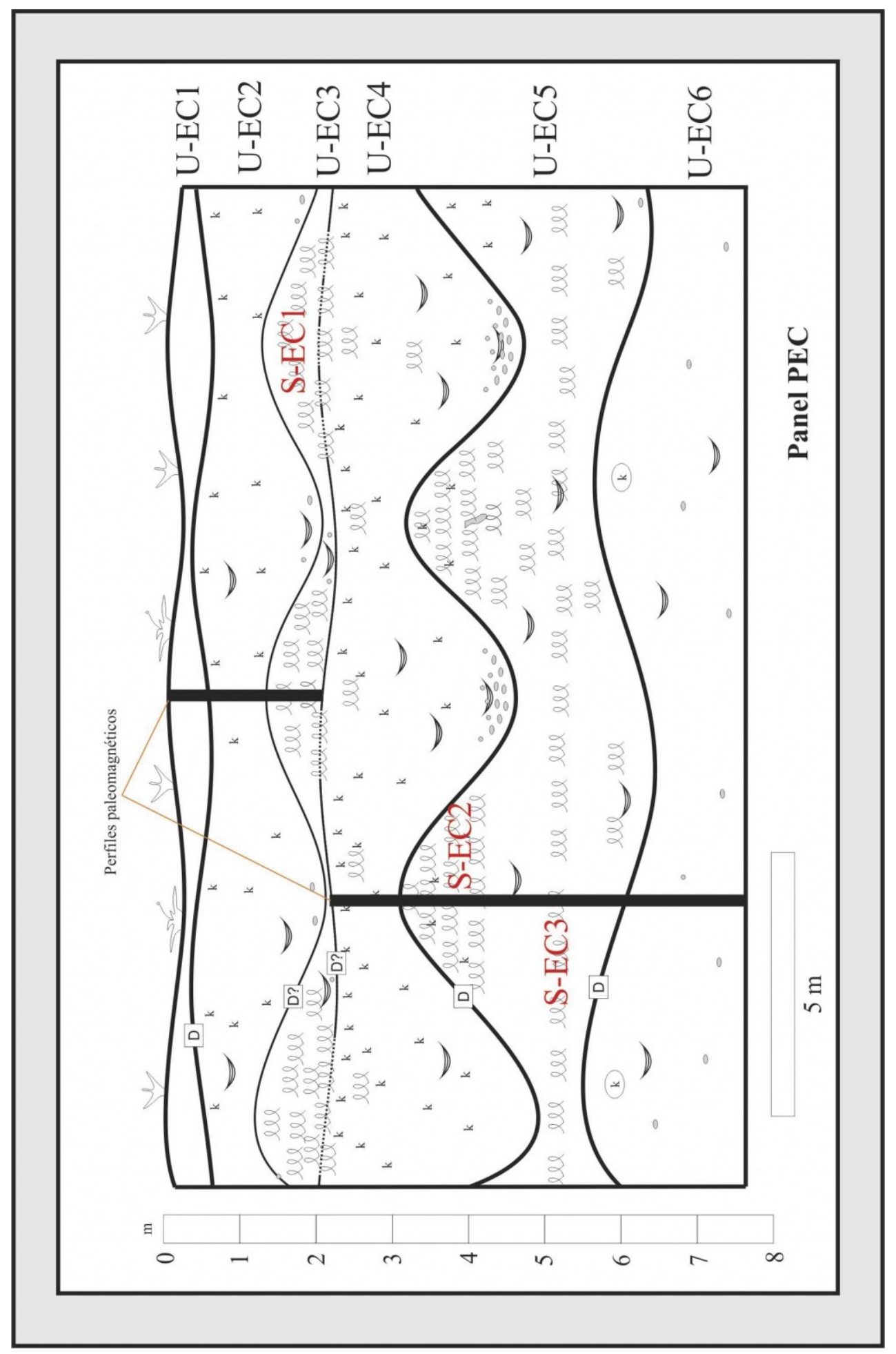

Figura 5.66. Panel esquemático de la sección El Casal (PEC). 


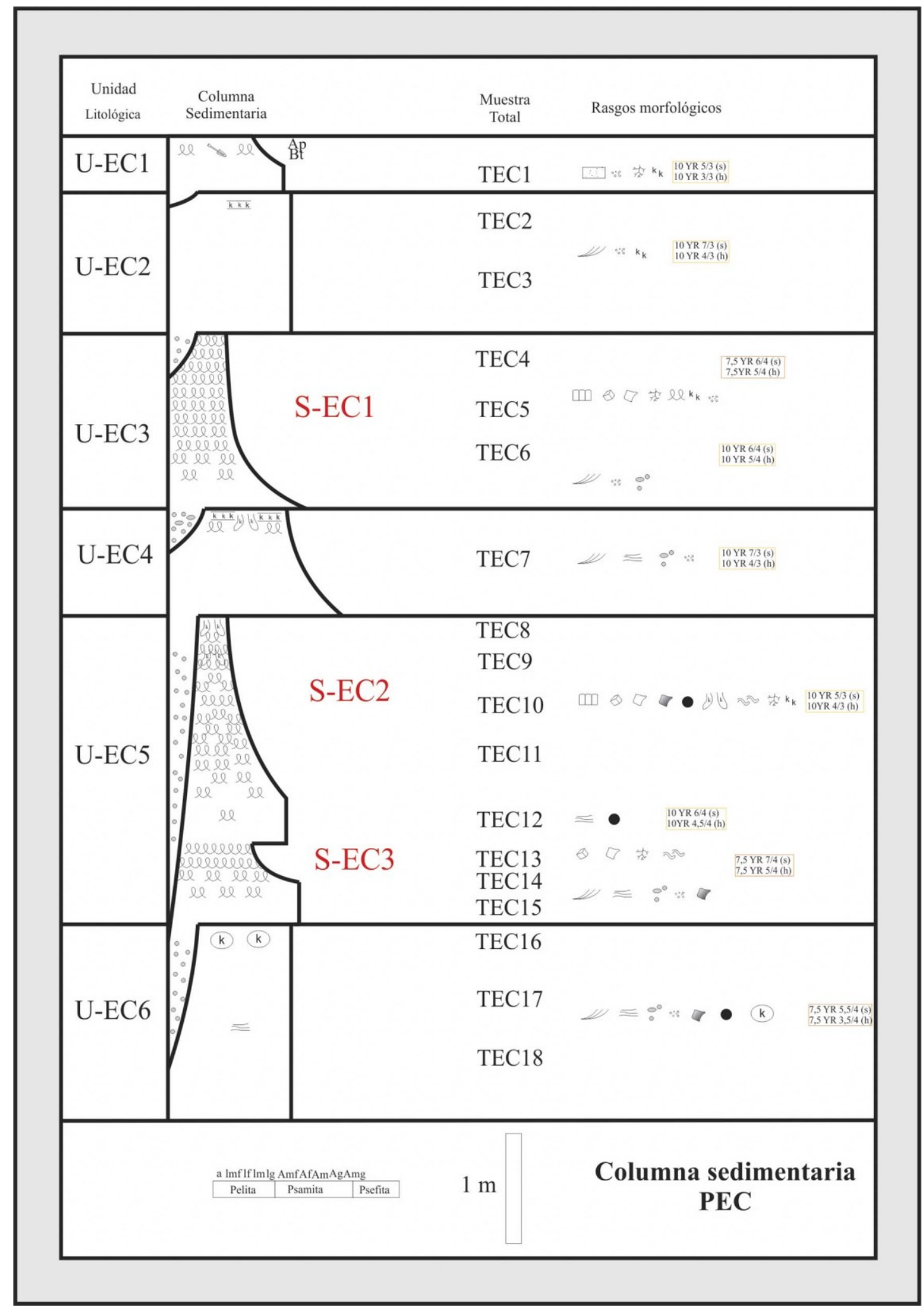

Figura 5.67. Columna sedimentaria de la sección El Casal (PEC). 


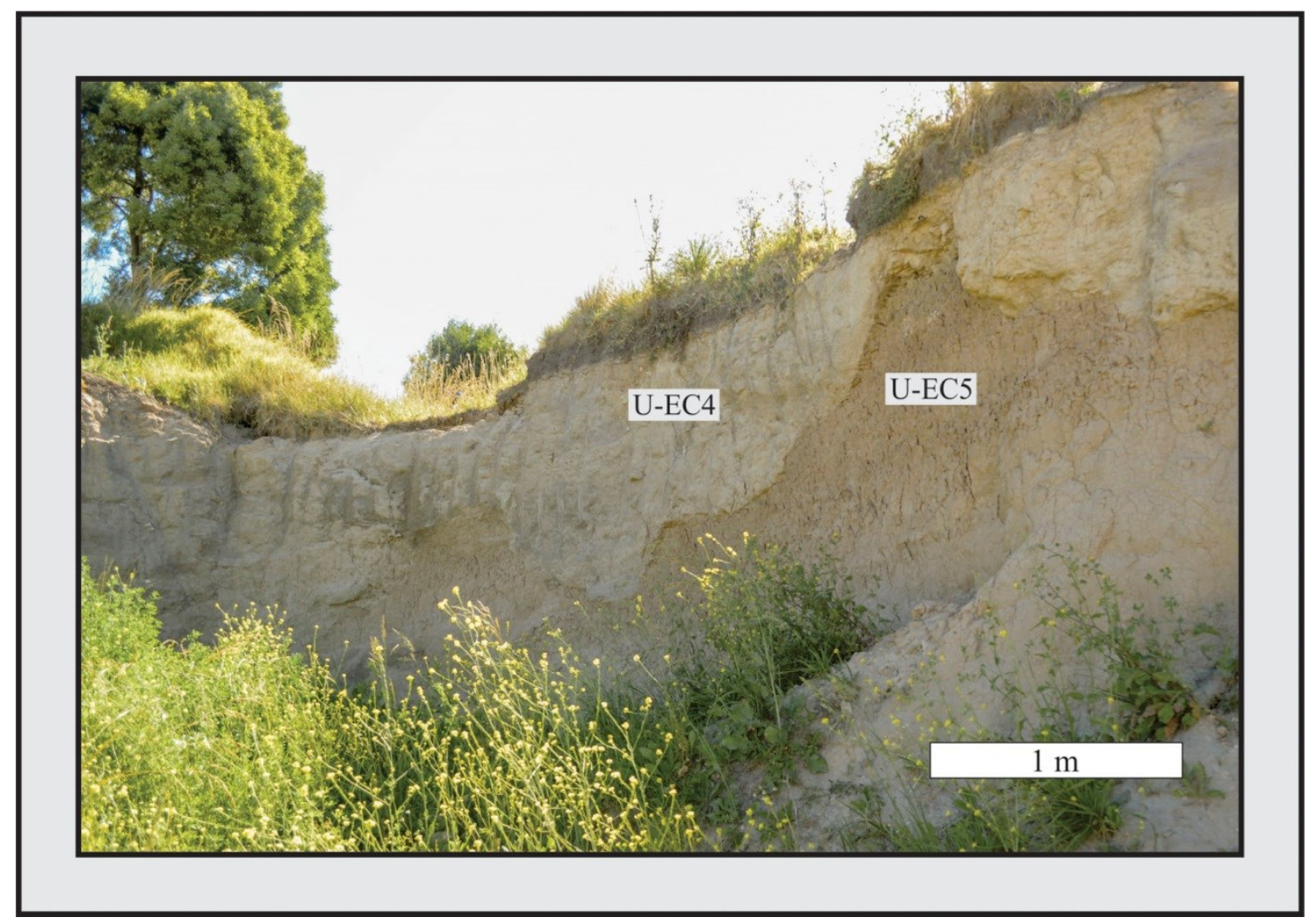

Figura 5.68. Discordancia erosiva entre la unidad U-EC4 y el paleosuelo de la unidad U-EC5. 


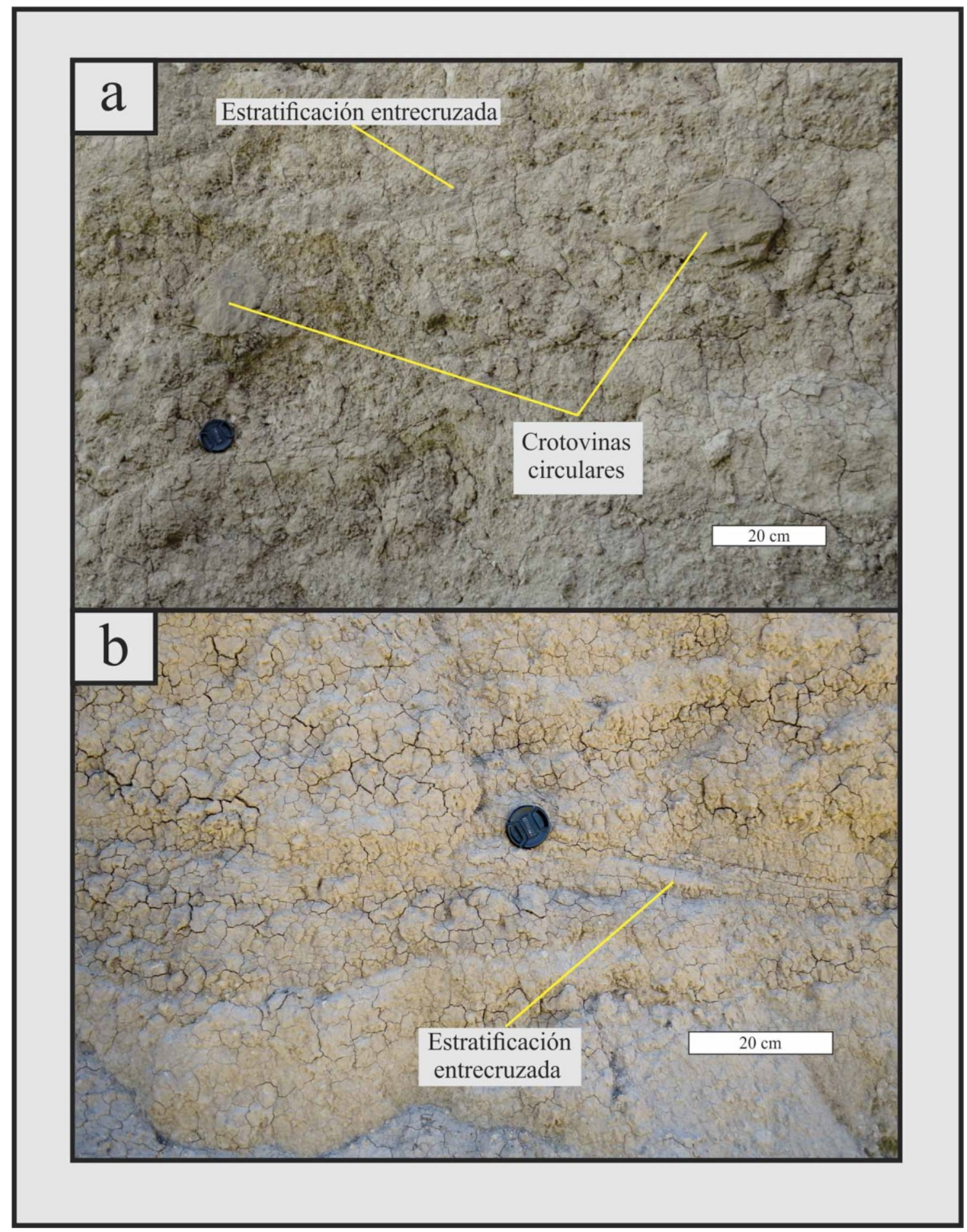

Figura 5.69. Paleosuelo de la unidad U-EC5. a) Crotovinas circulares y estratificación entrecruzada; b) Estratificación entrecruzada. 


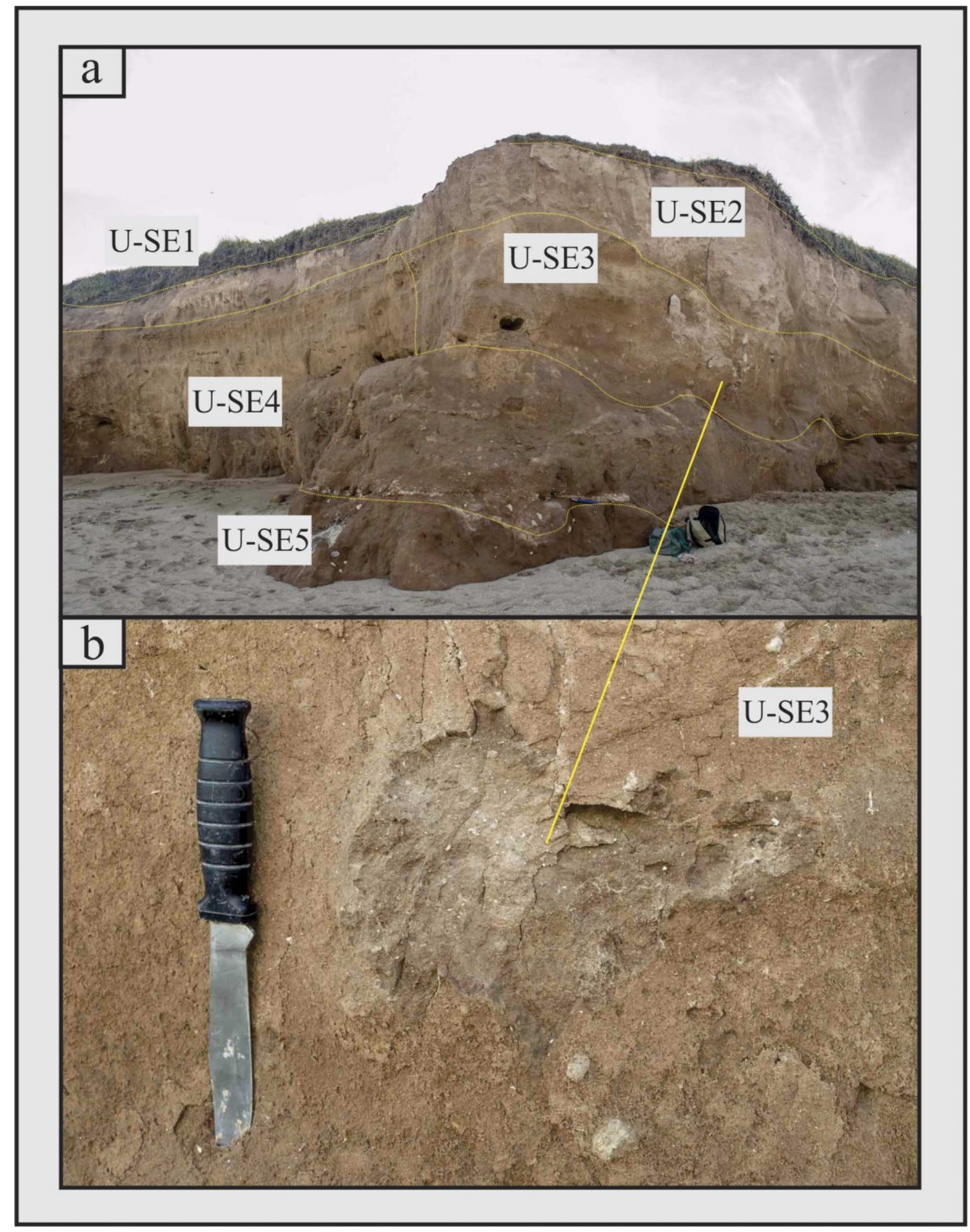

Figura 5.70. Acantilado marino de la sección Santa Elena (PSE). a) Fotografía del acantilado y unidades litológicas. b) Detalle de la unidad U-SE3. 


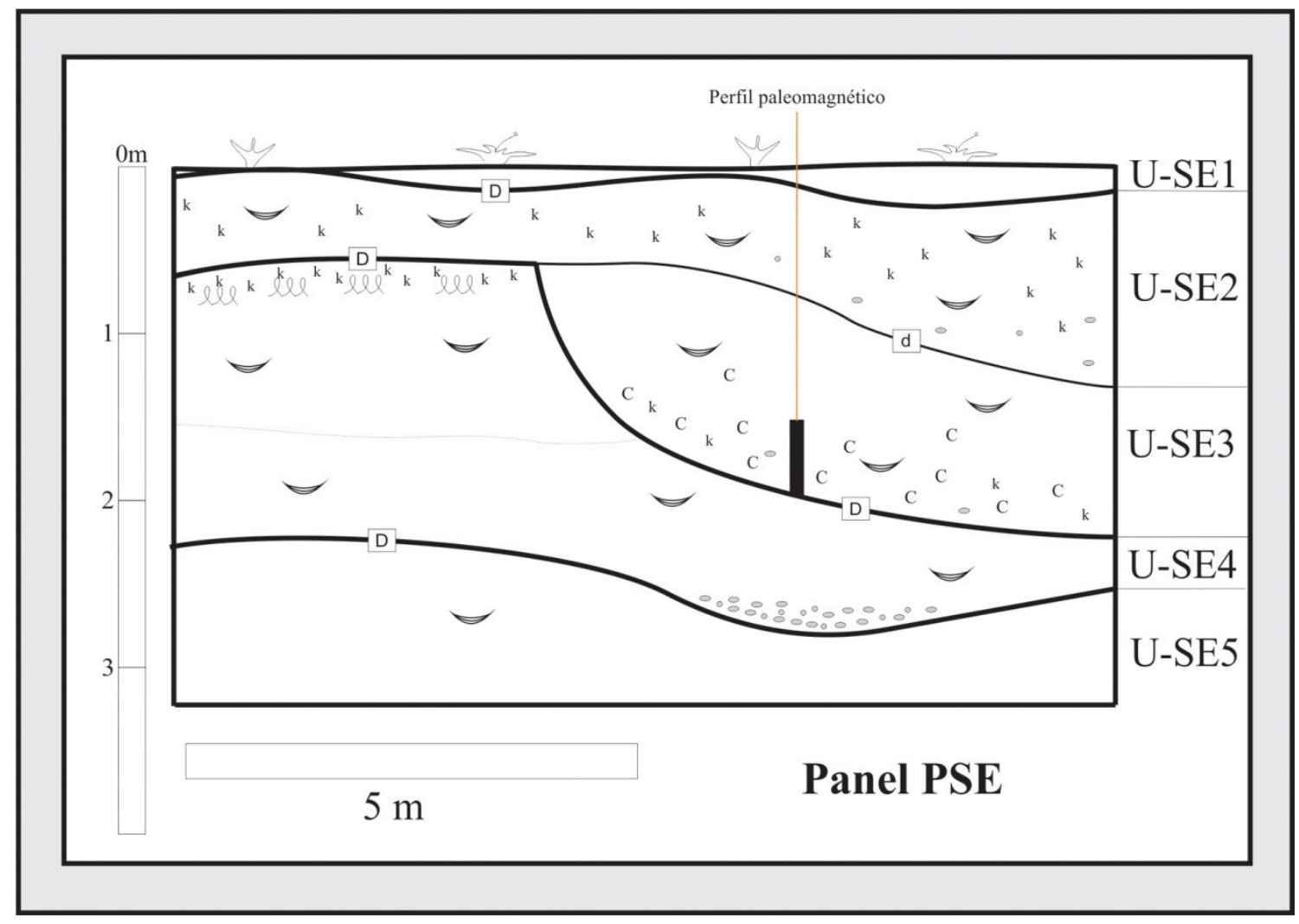

Figura 5.71. Panel esquemático de la sección Santa Elena (PSE). 


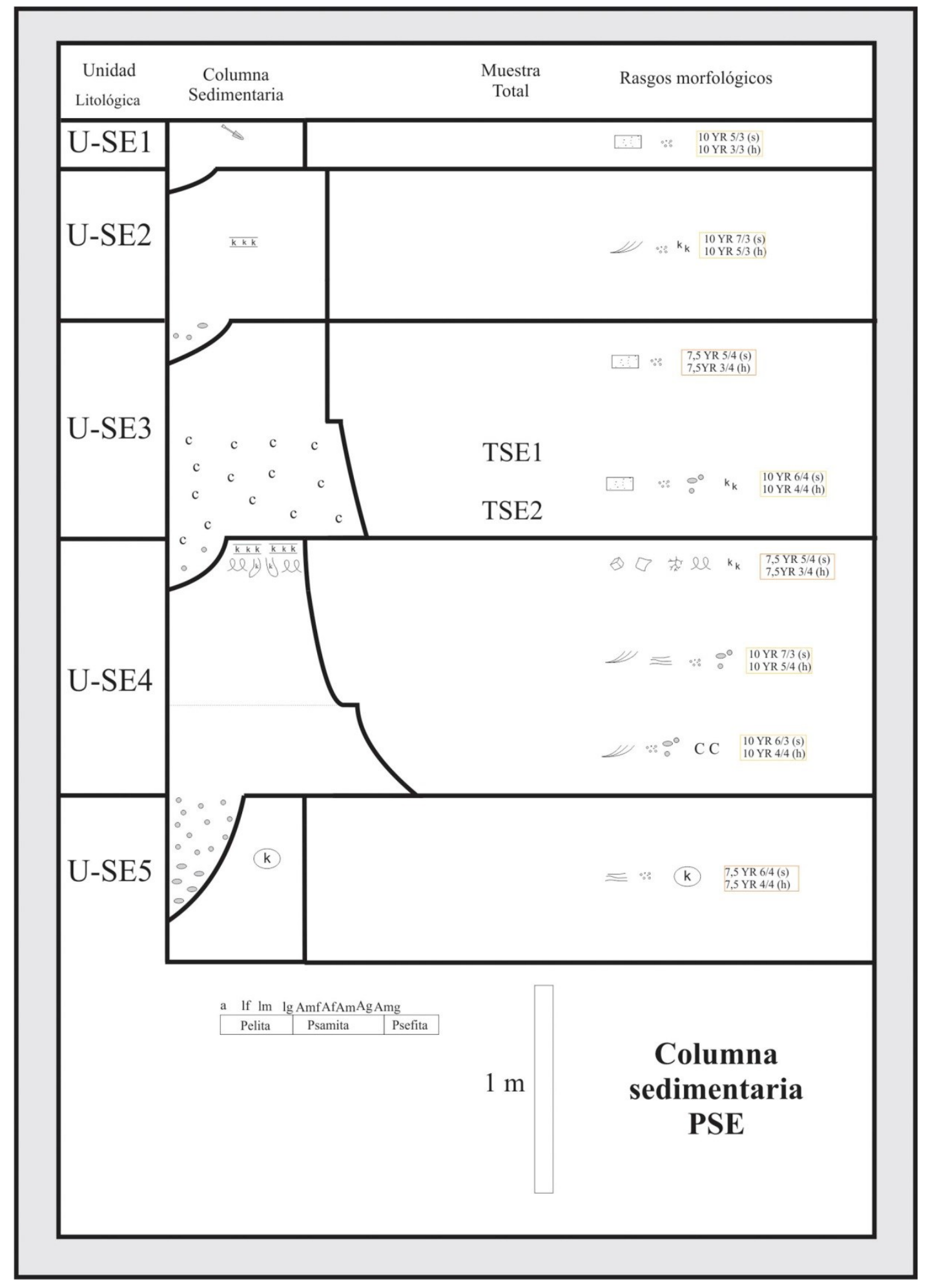

Figura 5.72. Columna sedimentaria de la sección Santa Elena (PSE). 


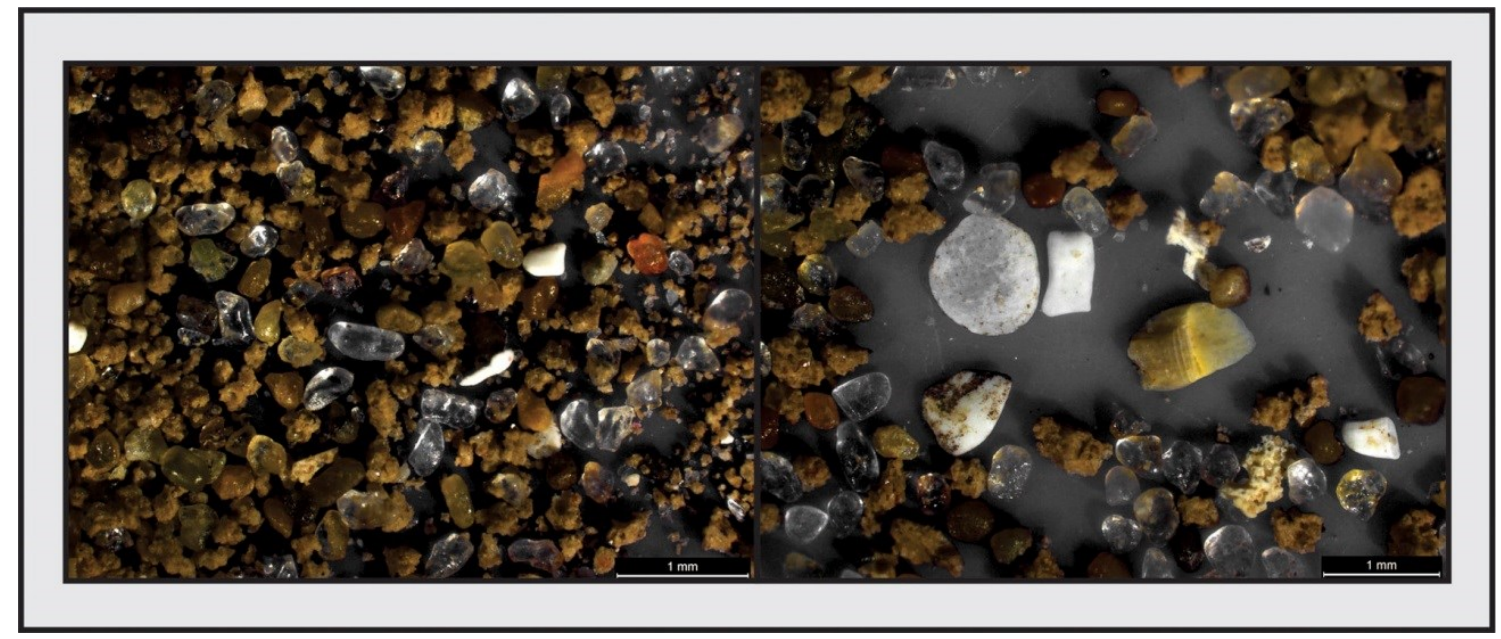

Figura 5.73. Clastos de arena muy redondeados y fragmentos de valvas de moluscos de la unidad U-SE3. 


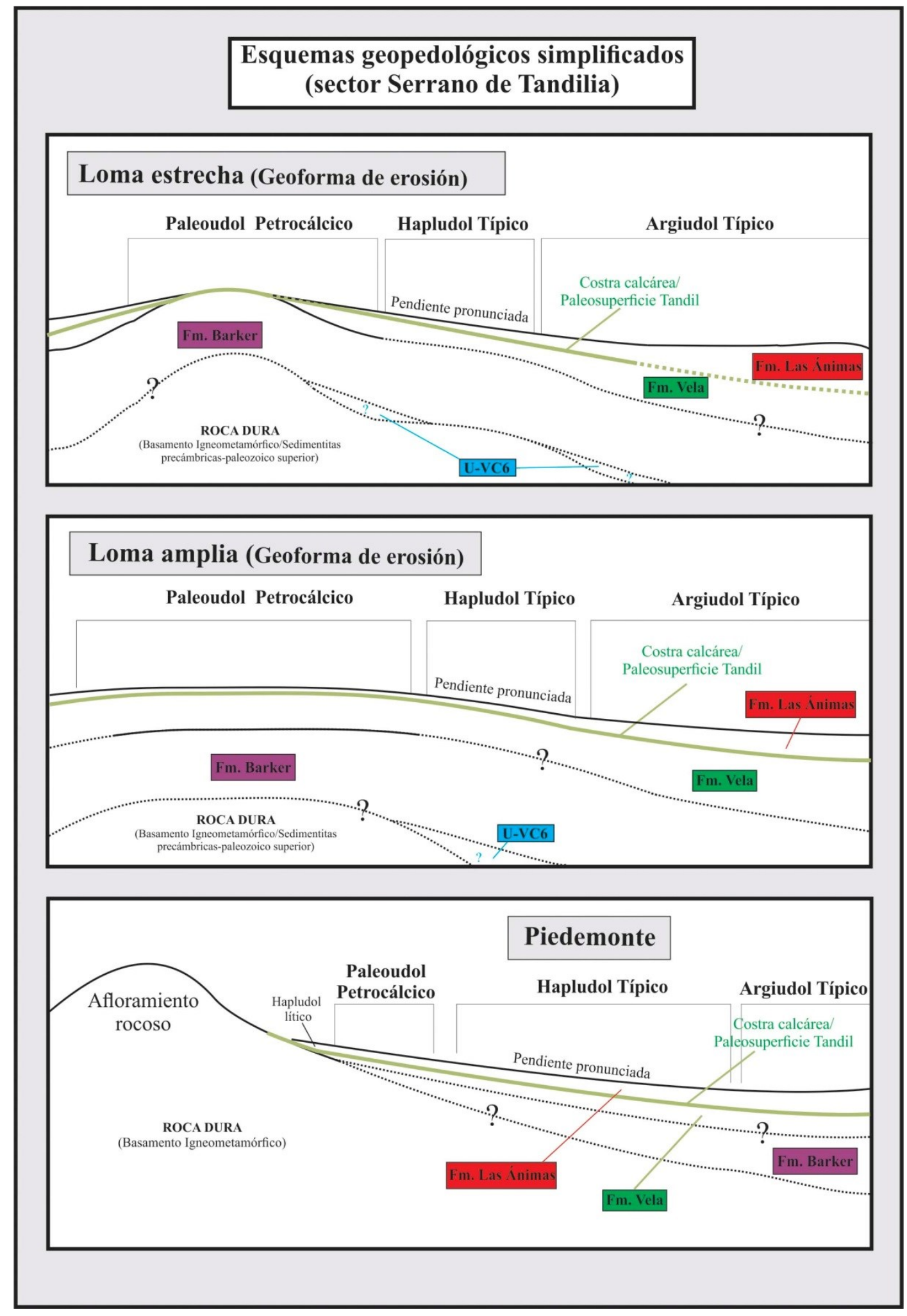

Figura 5.74. Esquemas geopedológicos simplificados para áreas positivas del sector serrano. 


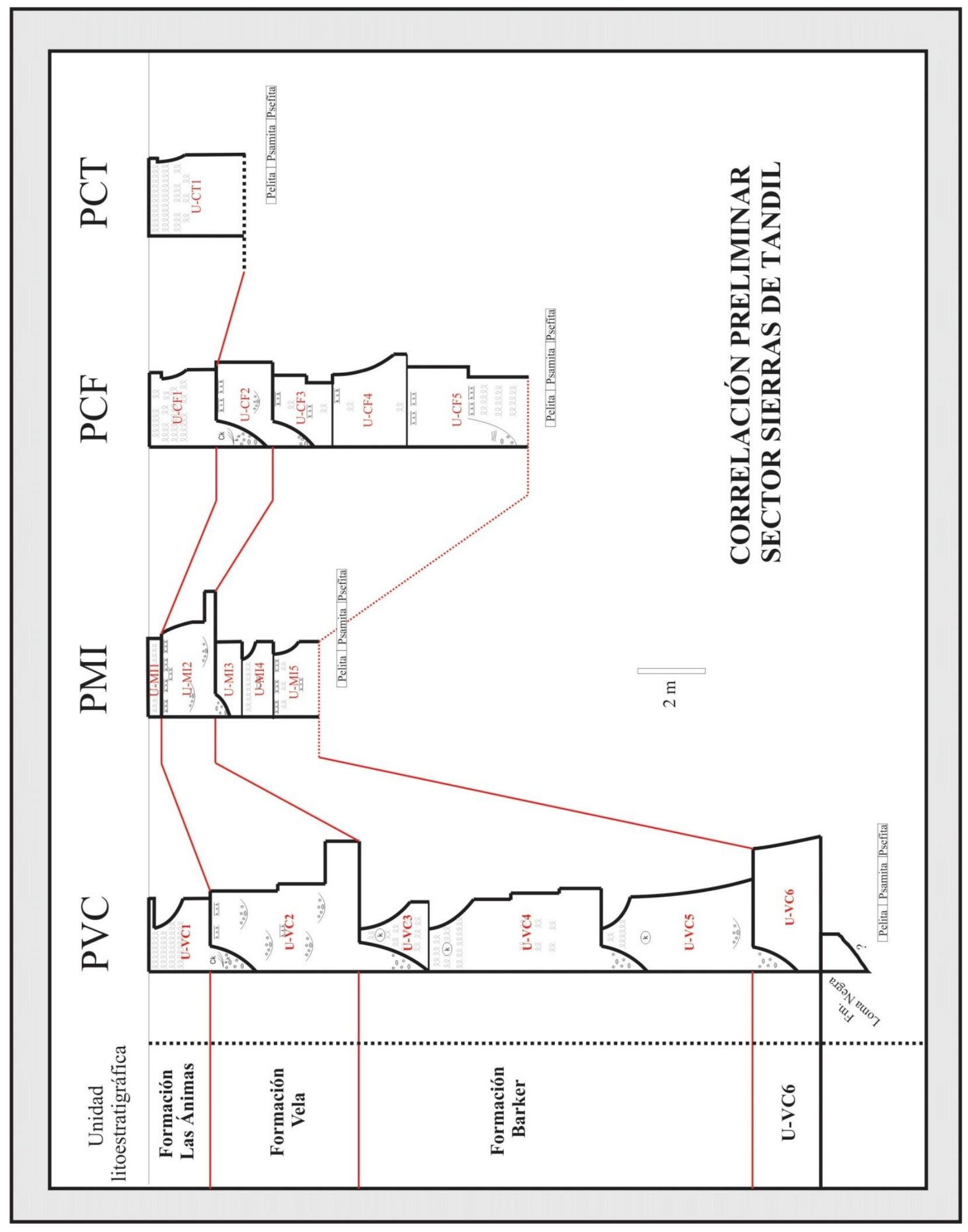

Figura 5.75. Correlación preliminar de las secciones estratigráficas del sector Sierras de Tandil. 


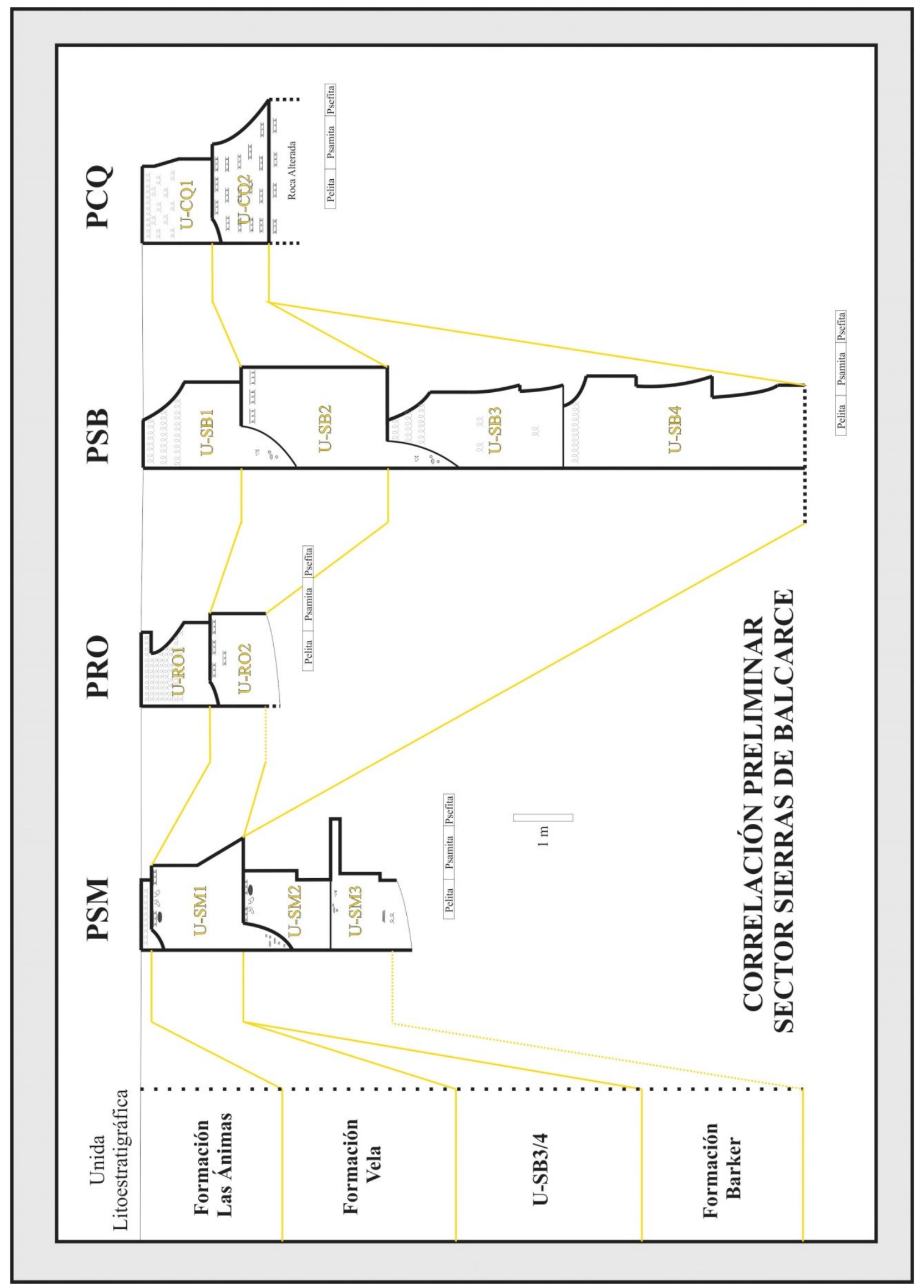

Figura 5.76. Correlación preliminar de las secciones estratigráficas del sector Sierras de Balcarce. 


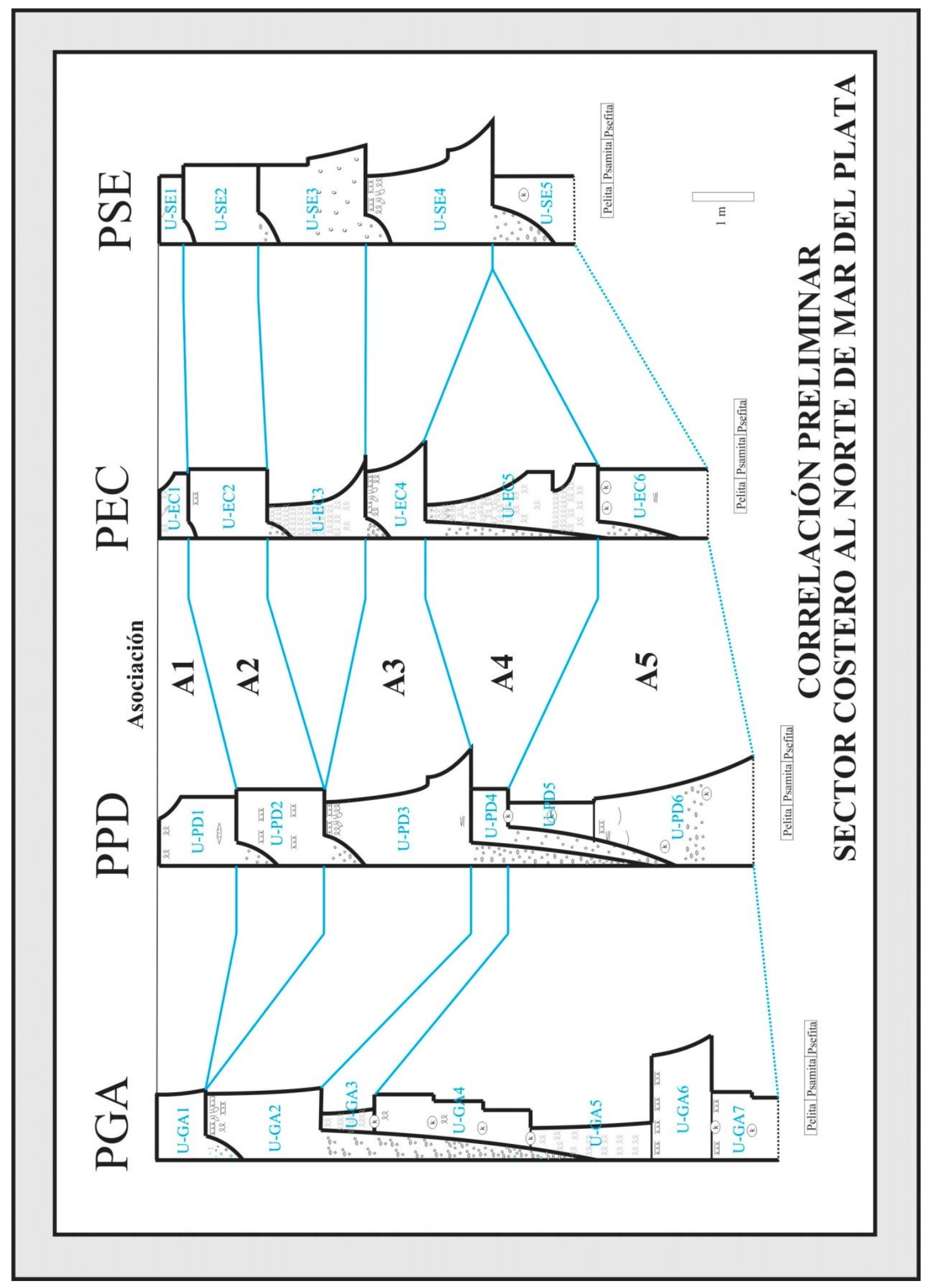

Figura 5.77. Correlación preliminar de las secciones estratigráficas del sector costero al norte de Mar del Plata. 


\subsection{Tablas del Capítulo 5}

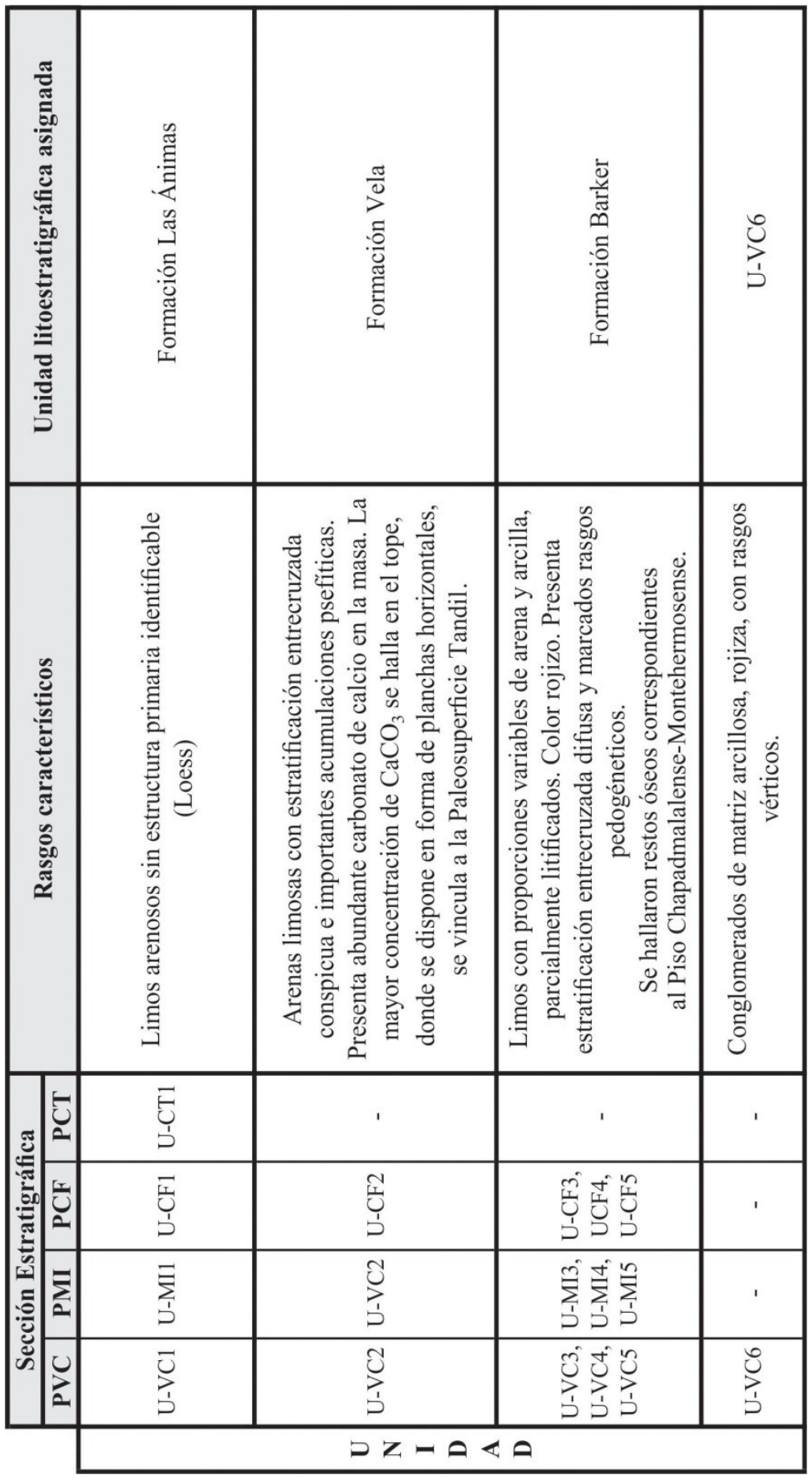

Tabla 5.1. Unidades litológicas correlacionadas del sector Sierras de Tandil, descripción y unidades litoestratigráficas. 


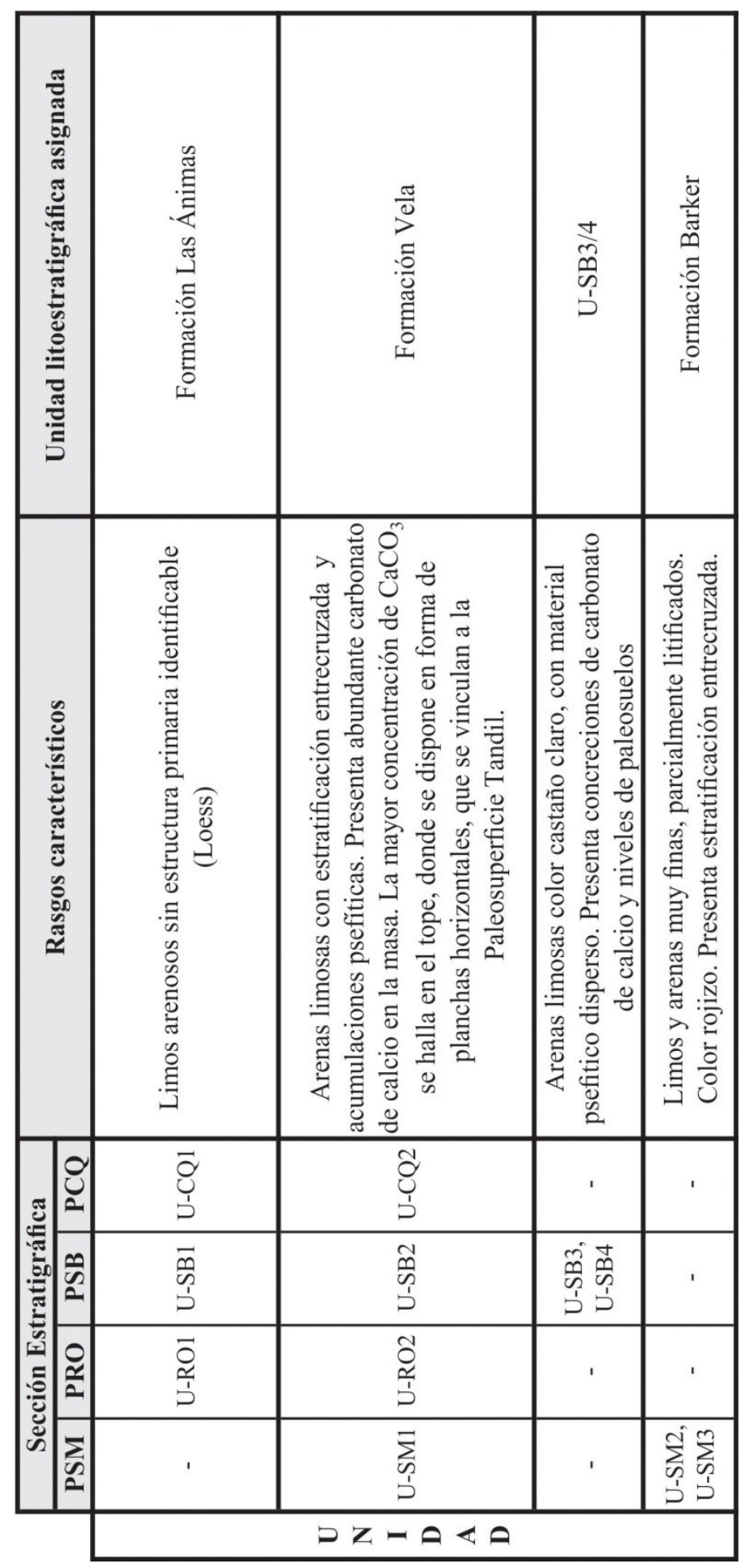

Tabla 5.2. Unidades litológicas correlacionadas del sector Sierras de Balcarce, descripción y unidades litoestratigráficas. 


\begin{tabular}{|c|c|c|c|c|c|}
\hline \multicolumn{4}{|c|}{ Sección Estratigráfica } & \multirow{2}{*}{ Rasgos característicos } & \multirow{2}{*}{$\begin{array}{c}\text { Asociación de } \\
\text { Unidades }\end{array}$} \\
\hline PGA & PPD & PEC & PSE & & \\
\hline U-GA1 & U-PD1 & U-EC1 & U-SE1 & $\begin{array}{l}\text { Limos arenosos sin estructura primaria identificable (Loess). } \\
\text { Hacia la base se halló un nivel de cenizas volcánicas } \\
\text { que puede ser asociado al de Camet Norte, datado en } 21 \mathrm{Ka} \text {. } \\
\text { Se correlaciona con la Fm. Las Ánimas del sector serrano. }\end{array}$ & A1 \\
\hline lateral & U-PD2 & U-EC2 & U-SE2 & $\begin{array}{l}\text { Arenas muy finas con estratificación entrecruzada difusa y } \\
\text { carbonatos dispuestos en finas láminas }\end{array}$ & A2 \\
\hline- & - & U-EC3 & U-SE3 & $\begin{array}{c}\text { U-EC3 son a sedimentos fuertemente pedogenizados; } \\
\text { U-SE3 son a depósitos de playa vinculados a una } \\
\text { ingresión marina. Estas unidades se vinculan dada la posición } \\
\text { estratigráfica y a que indicarían clima húmedo. } \\
\text { Corresponderían al MIS5 (117 -130 Ka). }\end{array}$ & - \\
\hline U-GA2 & U-PD3 & U-EC4 & U-SE4 & $\begin{array}{c}\text { Arenas con estratificación entrecruzada. Base erosiva con } \\
\text { abundantes depositos psefíticos. Tope con abundantes } \\
\text { carbonatos dispuestos en planchas y tabiques } \\
\text { (probablemente relacionados a la } \\
\text { paleosuperficie Tandil) } \\
\text { Se correlaciona con la Fm. Vela del sector serrano. }\end{array}$ & A3 \\
\hline U-GA3 & U-PD4 & U-EC5 & - & $\begin{array}{c}\text { Arenas limosas con estratificación entrecruzada; fuertemente } \\
\text { pedogenizadas (horizontes Bt) } \\
\text { (Geosol Mar del Plata) }\end{array}$ & A4 \\
\hline $\begin{array}{l}\text { U-GA4 } \\
\text { U-GA5 } \\
\text { U-GA6 } \\
\text { U-GA7 }\end{array}$ & $\begin{array}{l}\text { U-PD5 } \\
\text { U-PD6 }\end{array}$ & U-EC6 & U-SE5 & $\begin{array}{l}\text { Sucesion compleja de estratos tabulares compactos, de } \\
\text { granulometría y estructuras variadas. } \\
\text { Origen dominantemente fluvial. } \\
\text { Es caracteristica la alternancia de niveles rojizos y gley. } \\
\text { (Ensenadense) }\end{array}$ & A5 \\
\hline
\end{tabular}

Tabla 5.3. Unidades litológicas correlacionadas del sector costero al norte de Mar del Plata, descripción y asociaciones de unidades. 


\section{CAPITULO 6. ANÁLISIS GRANULOMÉTRICO Y MINERALOGÍA}

En este capítulo se exponen resultados de los análisis granulométricos y mineralógicos realizados en muestras extraídas de las secciones estratigráficas analizadas. Si bien se conoce abundante bibliografía acerca de la granulometría y la mineralogía de los sedimentos neógeno-cuaternarios de la región, en la presente investigación los mismos se efectúan en forma complementaria a los estudios paleomagnéticos y de magnetismo de rocas.

\subsection{Análisis granulométrico}

Los análisis granulométricos se efectuaron mediante distintas técnicas: Pipeteo (Robinson) y Método del Trasvasado (Smith, 1985). Todas las muestras del sector serrano (salvo la muestra de la unidad U-VC6) fueron analizadas mediante pipeteo, en cambio, las del sector costero, en su mayoría, se analizaron mediante trasvasado. Ambas técnicas se fundamentan en la ley de Stokes, especialmente para la separación de las fracciones más finas $(<62 \mu \mathrm{m})$, y en el tamizado en húmedo para las mayores a 62 $\mu \mathrm{m}$. En tanto, los resultados obtenidos por ambos métodos serían teóricamente comparables. Dado que existieron diferencias en el pretratamiento, para corroborar la confiabilidad de los resultados y poder efectuar comparaciones, la fracción arena de todas las muestras se observó mediante lupa binocular a fin de constatar la ausencia de agregados (pseudoparticulas) producto de una desagregación insuficiente. La fracción arena de todas las muestras analizadas por el método del trasvasado evidenciaron una presencia prácticamente nula de agregados. De forma similar, la mayoría de las muestras analizadas mediante pipeteo presentaron una cantidad despreciable de agregados, empero algunas muestras correspondientes a la Formación Barker, presentaron una abundante proporción de los mismos, generando una sobrestimación de la fracción arena. Dichas muestras no se utilizaron para la caraterización granulométrica.

\subsubsection{Análisis granulométrico en el sector serrano.}

En la tabla 6.1 y en la figura 6.1 se indican los porcentajes de las fracciones arena, limo y arcilla, la unidad litoestratigráfica y la clase textural de muestras del sector Sierras de Tandil. Además, en la tabla también se indica la sección estratigráfica, la unidad litológica y el método utilizado. De forma análoga, la tabla 6.2 y la figura 6.2 corresponden al sector Sierras de Balcarce. La mayoría de las muestras analizadas 
presentaron un predominio de la fracción limo, seguida por arena; los porcentajes de arcilla, salvo en muestras de paleosuelos o del horizonte Bt del suelo actual, fueron generalmente menores al 10\%.

Las muestras de la Formación Las Ánimas (horizontes C) presentaron clases texturales que van desde Franco arenosa a Franco limosa. El valor promedio de cada fracción fue arena=43\%; limo=49,3; arcilla $=7,7 \%$. En el histograma de la figura $6.3 \mathrm{a}$ se indican los valores medios de las fracciones granulométricas determinadas mediante el método del pipeteo a intervalos de 1 phi. En la misma se observa que el valor más elevado corresponde a la fracción $3 \Phi-4 \Phi$ (arena muy fina), seguida por la fracción $4 \Phi-5 \Phi$ (limo grueso). El resto de las fracciones presentaron valores bajos, inferiores a 11\%. Estos resultados son consistentes con los obtenidos por Rabassa (1971, 1973) y por Zárate y Blasi (1991) en depósitos de loess del Pleistoceno tardío del Sudeste Bonaerense, cabe destacar que estos últimos indicaron que los mismos se habrían transportado principalmente por saltación modificada y por suspensión de corto plazo (Pye, 1987).

Se analizaron también algunas muestras extraídas del solum. La muestra TMI1 corresponde a la muestra del horizonte Ak del suelo actual del perfil PMI, la misma presenta incremento de la fracción limo en detrimento de la fracción arena, esto se vincula a procesos pedogenéticos. Cabe mencionar que dicha muestra posee clastos de basamento de tamaño arena media a muy gruesa, angulosos y subangulosos, como los que se muestran en la figura 6.4. Las muestras de la Formación Las Ánimas de la sección PRO incluyen los horizontes del suelo actual. La muestra del horizonte C, de textura Franco limosa presentó la menor cantidad de arcilla, en contraposición, la muestra del horizonte Bt, de textura arcillosa, registró el valor más elevado. Las muestras de los horizontes BC y A registraron porcentajes de arcilla intermedios. En el histograma de la figura $6.3 \mathrm{~b}$ se indican los porcentajes de las fracciones granulométricas determinadas mediante el método del pipeteo a intervalos de 1 phi y las curvas acumuladas de las cuatro muestras de la Formación Las Ánimas en la sección PRO. La muestra del horizonte $\mathrm{C}$ registró un valor máximo en la fracción limo grueso, seguido por la fracción arena muy fina. La muestra del horizonte $\mathrm{BC}$ registró, a diferencia de la anterior el valor máximo en la fracción $>9 \Phi$, seguida por limo grueso y arena muy fina, por lo tanto la muestra se puede considerar trimodal, donde el incremento en la porción más fina correspondería a arcilla pedogenética. La muestra del horizonte $\mathrm{Bt}$ registró el valor más elevado en la fracción $>9 \Phi$, esto se vincularía a procesos pedogenéticos, especialmente argiluviación. Las fracciones limo grueso y arena muy fina presentaron valores intermedios. El resto de las fracciones registraron valores bajos. Finalmente la muestra del horizonte A registró un valor elevado en la fracción $>9 \Phi$, seguido de las fracciones limo grueso y arena muy fina. Cabe destacar que en esta última se obtuvieron los valores más elevados de la fracción limo fino. La fracción arcilla corresponde a intervalos granulométricos mayores a $8 \Phi$; sin embargo la porción más 
gruesa de ésta $(8 \Phi-9 \Phi)$ registró valores por debajo del $10 \%$ en todas las muestras analizadas. En contraposición, la porción más fina $(>9 \Phi)$ registró valores más elevados, entre 12,7 y 46,5\%. Como se indica en la figura $6.3 \mathrm{~b}$, las curvas acumuladas presentaron incrementos en la fracción $>9 \Phi$; el de mayor magnitud corresponde a la muestra del horizonte Bt y el de menor magnitud a la muestra del horizonte $\mathrm{C}$. El incremento de la fracción $>9 \Phi$ correspondería principalmente a procesos pedogenéticos, como acumulación de arcilla iluvial (principalmente en el horizonte $\mathrm{Bt}$ ), y a neoformación de arcillas (principalmente en el horizonte A).

En las muestras de la Formación Vela se determinaron clases texturales Franco limosa, Franca y Franco arenosa. En el histograma de la figura 6.5a se indican los valores medios de las fracciones granulométricas determinadas mediante el método de la pipeta a intervalos de 1 phi para el sector Sierras de Tandil; en la misma se observa que el valor más elevado corresponde a la fracción $3 \Phi-4 \Phi$ (arena muy fina), seguida por las fracciones $4 \Phi-5 \Phi$ (limo grueso) y $6 \Phi-7 \Phi$ (limo mediano). El resto de las fracciones están por debajo de $10 \%$. En el histograma de la figura $6.5 \mathrm{~b}$ se indican los valores medios de las fracciones granulométricas determinadas mediante el método de la pipeta a intervalos de 1 phi, para el sector de Sierras de Balcarce, el cual presenta leves diferencias con el anterior, con un incremento de la

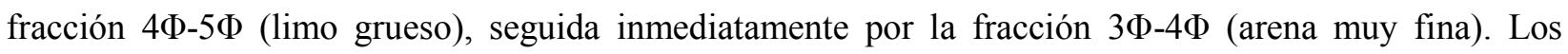
resultados obtenidos son similares a los obtenidos por Rabassa (1973) en las muestras de la Formación Vela. Cabe destacar que esta unidad presenta abundantes acumulaciones psefíticas conformando lentes, cuyos clastos corresponden a fragmentos de basamento, rocas sedimentarias (precámbricas a paleozoica) y/o carbonato de calcio (tosca).

En las muestras extraídas de la unidad litoestratigráfica U-SB3/4 (sector Sierras de Balcarce) los valores promedio de cada fracción fueron arena $=48,7 \%$; limo $=44,3$; arcilla $=7 \%$; las clases textural predominante es Franco arenosa, subordinadamente Franca (en la muestra del paleosuelo S-SB1) y Franco limosa en la muestra de la base del perfil. En el histograma de la figura 6.6 se indican los valores medios de las fracciones granulométricas determinadas mediante el método del pipeteo a intervalos de 1 phi. En la misma se observa que el valor más elevado corresponde a la fracción arena muy fina (3Ф-4Ф), que representa la mayor parte de la fracción arena. En las fracciones más gruesas se destaca la presencia de clastos angulosos que llegan hasta arena muy gruesa, incluso sábulo. Las fracciones limo grueso y limo mediano presentaron porcentajes intermedios. El resto de las fracciones registraron valores inferiores al $10 \%$.

Las muestras extraídas de la Formación Barker resultaron, en general, más resistentes a los procesos de desagregación. En algunos casos, a pesar de haber sido tratadas de forma similar al resto de las muestras (Analía Corrales, personal técnico IGS-CISAUA, com. pers.), no alcanzaron un grado de 
desagregación aceptable. Esto dio como resultado una sobrestimación de la fracción arena. En la figura 6.7 se muestran agregados tamaño arena gruesa formados por partículas finas correspondientes a la muestra TMI15. En la tabla 6.1 se indican en rojo las muestras con fracción arena sobrestimada. Se interpreta que este fenómeno estaría vinculado con un mayor grado de litificación, que se relacionaría en parte a la mayor antigüedad de la unidad. Para determinar los valores promedio de las fracciones se evitó utilizar aquellos resultados donde la fracción arena fue sobrestimada. En los histogramas de la figura 6.8 se indican los valores medios de las fracciones granulométricas determinadas mediante el método del pipeteo a intervalos de $1 \mathrm{phi}$, el de la figura 6.8a corresponde al sector Sierras de Tandil, el de la figura $6.8 \mathrm{~b}$ al sector sierras de Balcarce (sección PSM). Es notable la similitud entre ambos histogramas. Presentan dos valores modales, que corresponden a las fracciones $3 \Phi-4 \Phi$ (arena muy fina) y $4 \Phi-5 \Phi$ (limo grueso), seguidos por la fracción 5Ф-6Ф (limo mediano). El resto de las fracciones presentaron valores relativamente bajos $(<11 \%)$. Los resultados obtenidos presentan diferencias con los obtenidos por Rabassa $(1971,1973)$, quien indicó que el porcentaje de arena no supera el 15\%.

Finalmente la muestra de la matriz de los conglomerados de la unidad litoestratigráfica U-VC6 (clase textural Franco arcillo limosa), presentó un porcentaje de arcilla considerable y el porcentaje de arena más bajo de las muestras determinadas en esta tesis. Se interpreta que el elevado contenido de arcilla es resultado de procesos pedogenéticos. En el histograma de la figura 6.9 se indican los valores de las fracciones granulométricas determinadas mediante el método del trasvasado (a intervalos de dos $\Phi$ ). En este se observa la presencia de dos valores modales; los mismos corresponden a la fracción 4Ф-6Ф (limo grueso y mediano) y la fracción mayor a $8 \Phi$.

\subsubsection{Análisis granulométrico en el sector costero al norte de Mar del Plata}

En la tabla 6.3 y en la figura 6.10 se indican los porcentajes de las fracciones arena, limo y arcilla y la clase textural correspondiente a muestras del sector costero al norte de Mar del Plata. En la tabla se indica también la sección estratigráfica, la unidad litológica, la asociación de unidades a la que pertenecen las muestras y el método utilizado para la determinación granulométrica.

La mayoría de las muestras presentaron un predominio de la fracción limo, seguida por arena; los porcentajes de arcilla, salvo en muestras de paleosuelos y niveles gly, fueron bajos. La clase textural dominante (USDA) fue Franco limosas. La muestra TPD17 registró el mayor contenido de arena (54,2\%) (clase textural Franco arenosa). Por otro lado, la muestra con mayor contenido de arcilla corresponde a las muestra TGA12, del nivel hidromórfico U-GA5. Cabe destacar que la muestra TGA14, del mismo nivel 
hidromórfico, registró una textura no concordante con las observaciones de campo; esto se debería a una insuficiente dispersión física, así como a la floculación de las arcillas durante el análisis (Analía Corrales, com pers), esto último vinculado al elevado contenido de sales debido a que durante la pleamar la unidad se halla en contacto con agua de mar. Las muestras TPD14 y TPD18 también registraron porcentajes de arcilla relativamente elevados. La segunda fue extraída de la unidad basal de la sección PPD, identificada en el campo como un nivel de granulometría relativamente gruesa, con abundantes clastos psefíticos de arcilla. Se interpreta que la desagregación mecánica de éstos habría aportado cantidades significativas de arcilla, provocando la sobreestimación de ésta. En tanto la muestra TPD14, del nivel hidromórfico U-PD5, registró un contenido relativamente elevado de arcilla. El promedio de los resultados obtenidos indica que la fracción dominante es el limo (51,2\%), seguido de arena $(34,6 \%)$ y arcilla $(14,9 \%)$.

\subsection{Mineralogía}

\subsubsection{Observaciones en microscopio de luz transmitida}

Mediante microscopio de luz transmitida se observó la fracción arena de 22 muestras. Esto incluyó las fracciones 0,177-0,125 $\mathrm{mm}$ y 0,177-0,088 mm. Además se observaron concentrados magnéticos correspondientes a las mismas fracciones

Se determinó la presencia de las siguientes especies: plagioclasas, cuarzo, feldespato potásico, vidrio volcánico, litoclastos, hornblenda, clino y ortopiroxeno y minerales opacos. Se constató la presencia de las especies minerales indicadas por Teruggi (1957); Rabassa (1973); Teruggi et al. (1973); Zárate y Blasi (1991); entre otros.

En general los granos de las fracciones estudiadas presentan buen grado de redondeamiento (redondeados a subredondeados); a excepción del vidrio volcánico el cual es anguloso a subanguloso.

El vidrio volcánico es el componente que más varía en abundancia. En las muestras de la Formación Las Ánimas, así como en las unidades U-SB3/4 (Sierra Bachicha), la presencia de vidrio llegó a superar el 60\%; las fotografías de la figura 6.11a corresponden a la fracción 0,177-0,125 de la muestra TSB8, en la misma es posible observar la predominancia de vitroclastos. En contrapartida, en las muestras de la Formación Barker, la presencia de vidrio volcánico fue prácticamente nula. Otro componente de abundancia variable corresponde a los litoclastos volcánicos; en la mayoría de las muestras analizadas el contenido de éstos no superó el 25\%, sin embargo en las muestras de la Formación Barker alcanzararon 
incluso el $70 \%$ de la fracción 0,177-0,125 (Fig. 6.11b). Esto es concordante con lo observado por Rabassa (1973), quien indicó que en la Formación Barker predominan los litoclastos volcánicos y que prácticamente carece vidrio volcánico; asimismo indicó que el vidrio volcánico es un componente muy abundante en la Formación Las Ánimas. Los resultados obtenidos también concuerdan con los análisis realizados por Teruggi et al. (1973) en la zona de Sierra Bachicha, que determinaron elevados porcentajes de vidrio volcánico en el nivel 2, considerado equivalente a la unidad U-SB3 respectivamente. Estas consideraciones sustentan la idea surgida a partir de las observaciones realizadas durante el trabajo de campo, que sugieren que la unidad U-SB3/4 del perfil PSB corresponderían a una unidad litoestratigráfica diferente a la Formación Barker.

El análisis mineralógico efectuado por Teruggi et al. (1973) en los niveles considerados equivalentes a U-SB3/4 reflejan significativas diferencias con los resultados expuestos por Rabassa (1973) en cuanto a la mineralogía de la Formación Barker. Teruggi et al. (1973) indicaron que la fracción liviana (que supera el 96\%) de la fracción arena (nivel 2) presenta un porcentaje de trizas vítreas de 64\%, un predominio de plagioclasas sobre cuarzo y no hace referencia a los litoclastos; en contraposición, Rabassa (1973) indicó que la fracción arena de la Formación Barker presenta escaso a nulo vidrio volcánico, que el cuarzo predomina sobre la plagioclasa y que los litoclastos son el componente predominante. Cabe destacar que los trabajos de Rabassa (1973) y Teruggi et al. (1973) fueron publicados durante el mismo año; en Teruggi et al. (1973) se plantea la correlación tentativa de los niveles 2 y 1 con la Formación Barker, basándose en la posición estratigráfica y refiriéndose al trabajo de tesis de licenciatura de Rabassa (1971) donde no se expone un análisis detallado de la mineralogía de las unidades litoestratigráficas de las Sierras de Tandil.

Por otro lado, cabe aquí mencionar que Tapia (1937), mediante una perforación (a $45 \mathrm{~m}$ de profundidad) en las cercanías de Balcarce halló un fragmento fósil asignado a Ctenomys Chapadmalensis; dicho taxón da nombre a una biozona correspondiente al Piso Marplatense (Sanandresense) cuya edad estaría comprendida entre 2 y 2,4 Ma (Cione et al., 2007); en los sedimentos asignados a la Formación Barker en la sección PVC fueron exhumados restos de Actenomys y Lagostomopsis que corresponderían al Piso Chapadmalalense-Montehermosense, con edades superiores a 3,2 e inferiores a 6,8 Ma (Cione et al., 2007). En tanto se interpreta que la Formación Barker sería más antigua que la unidad litoestratigráfica U$\mathrm{SB} 3 / 4$.

Por otro lado cabe consignar que los concentrados magnéticos constan principalmente de litoclastos, predominantemente volcánicos, los cuales pueden alcanzar hasta un $90 \%$ de abundancia. Esto se debería principalmente a la presencia de inclusiones opacas (probablemente magnetita) en el interior de los mismos, como se muestra en la figura 6.11c. Asimismo, se han observado inclusiones de minerales 
opacos, aunque en menor proporción en granos de plagioclasa, cuarzo, vidrio volcánico presentes en los concentrados magnéticos. Los minerales opacos en el separado magnético en general fueron inferiores al 20\%. La presencia de inclusiones de opacos fue mencionada por otros autores. Rabassa (1973) indicó que los litoclastos de la Formación Barker corresponden principalmente a fragmentos de pasta volcánica, integrada por vidrio castaño, microfenocristales de plagioclasa y opacos en pequeños granos. Asimismo, Zárate y Blasi (1991) indicaron la presencia de inclusiones de minerales opacos en granos de hipersteno en muestras de loess del Pleistoceno tardío-Holoceno en el sector sureste de la provincia geológica de Tandilia.

\subsubsection{Difracción de Rayos X}

Los análisis mediante difracción de rayos $\mathrm{X}$ fueron realizados en 33 muestras. En las mismas se determinó la presencia de 9 especies minerales: cuarzo $(\mathrm{Q})$, plagioclasa $(\mathrm{Pl})$, feldespato potásico $(\mathrm{FK})$, calcita (Ca), piroxeno (diópsido) (D), anfibol (hornblenda) (Anf), magnetita (Mt), hematita (Ht) y goethita (Go). En la figura 6.12 se muestran tres difractogramas representativos. En la tabla 6.4 se indican las muestras analizadas, así como la intensidad del "pico" principal de cada especie mineral determinada.

En el histograma de la figura 6.13 se indican las intensidades promedio de las especies minerales identificadas. Las mayores intensidades promedio corresponden a los "picos" máximos de cuarzo (19,1 cuentas), plagioclasa (14,1 cuentas), feldespato potásico (9,3 cuentas) y calcita ( 8,7 cuentas). Cabe destacar que el cuarzo y la plagioclasa estuvieron presentes en todas las muestras analizadas, en cambio el feldespato potásico y la calcita se determinaron en el 97\% de las mismas.

Los clinopiroxenos presentaron una intensidad promedio de 4,6 cuentas, ligeramente mayor a la de los anfíboles (3,8 cuentas). Los primeros fueron determinados en el $94 \%$ de las muestras, en cambio los anfíboles en el $82 \%$.

En lo que respecta a los óxidos de hierro, el mineral que registró mayor intensidad promedio fue la magnetita (6,2 cuentas), que estuvo presente en el 97\% de las muestras. La hematita y la goethita registraron las intensidades más bajas, de 4,1 y 3,6 cuentas respectivamente. La hematita fue determinada en el $97 \%$ de las muestras, en cambio la goethita sólo en el $63 \%$.

Cabe destacar que piroxenos, anfíboles, hematita y goethita presentaron intensidades bajas, cercanas al ruido de medición. 


\subsubsection{Ensayo de Expansión Libre (Free Swell Test)}

Como se indicó en el capítulo 4, ensayos de expansión libre fueron realizados para obtener información acerca de la presencia y abundancia relativa de arcillas expandibles, del grupo de la esmectita. El ensayo fue practicado en 31 muestras. En la tabla 6.5 se indican las muestras analizadas, la unidad litológica, el tamiz utilizado y el porcentaje de expansión registrado.

El porcentaje de expansión promedio fue $22 \%$. Las muestras que registraron los valores más elevados corresponden a las muestras TGA12 del tope del nivel hidromórfico U-GA5 y TVC30, de la matriz de la unidad litoestratigráfica U-VC6. Se interpreta que estas muestras poseen cantidades significativas de esmectitas en la fracción arcilla. Otras muestras con expansiones relativamente elevadas corresponden a la muestra TPD14 de la unidad basal del perfil de Playa Dorada, a la muestra TRO2 del horizonte Bt del suelo actual en la sección de Ramos Otero y a la muestra TGA13 de la unidad hidromórfica U-GA5. La respuesta obtenida por esta vía indica la presencia de smectitas, aunque en abundancia menos significativa. El resto de las muestras presentaron valores de expansión inferiores a 30\%. Los valores más bajos fueron registrados en la muestra TCT3 de la Formación Las Ánimas y en la muestra TPD2 de la unidad cuspidal del perfil de Playa Dorada (asociación A1).

Cabe destacar que las muestras de la Formación Barker registraron una expansión promedio de $15 \%$, con valores mínimos de 6-8\%, y máximos de de $22-24 \%$, estas últimas correspondientes a niveles de paleosuelos conspicuos. Según estos datos, la presencia de arcillas del grupo de las esmectitas en la Formación Barker, sería escasa. Los resultados no son coincidentes con lo manifestado por Rabassa (1973), quien realizó análisis por difracción de rayos X de la fracción arcilla de la Formación Barker e indicó que el mineral de arcilla predominante correspondería a montmorillonita.

A partir de este análisis se comprueba que los minerales de arcilla predominantes no son expandibles. Teruggi (1957), Iñiguez y Scoppa (1972), Camilión (1993), entre otros, indicaron que la participación de caolinitas en sedimentos loessoides y suelos zonales de la región pampean es prácticamente despreciable, en tanto se constata lo expresado por Camilión (1993), quien indicó que el principal mineral de arcilla corresponde a illita. No obstante, algunas muestras presentaron porcentajes de expansión elevados, éstas corresponden a los niveles hidromórficos del sector costero y a la matriz arcillosa, con rasgos vérticos, del conglomerado U-VC6, se infiere que éstas muestras presentan cantidades significativas de arcilla del grupo de la esmectita. 


\subsection{Figuras del capítulo 6}

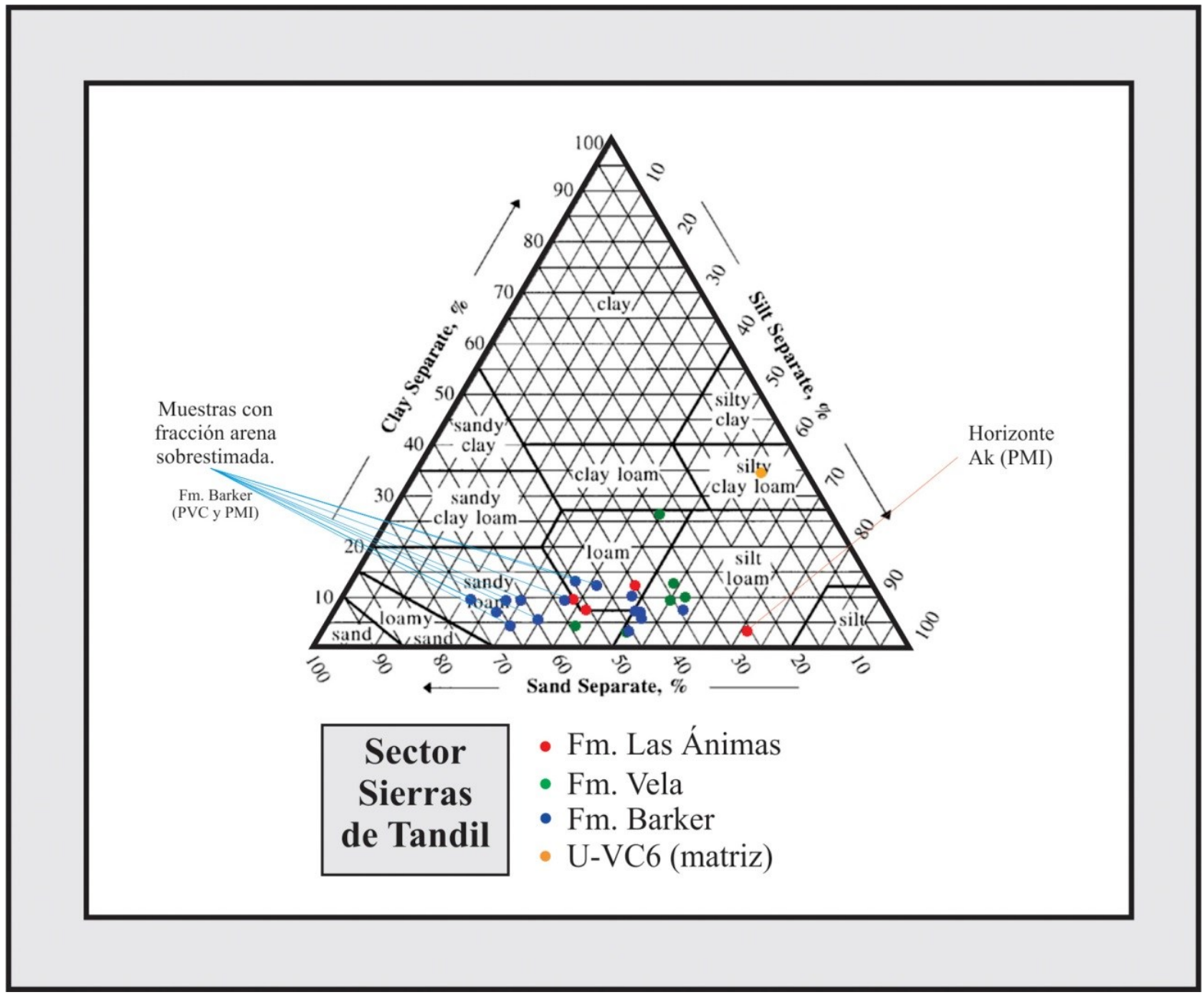

Figura 6.1. Triángulo textural (USDA) de muestras del sector Sierras de Tandil. Fuente: http://www.nrcs.usda.gov/ (Soil Texture Calculator). 


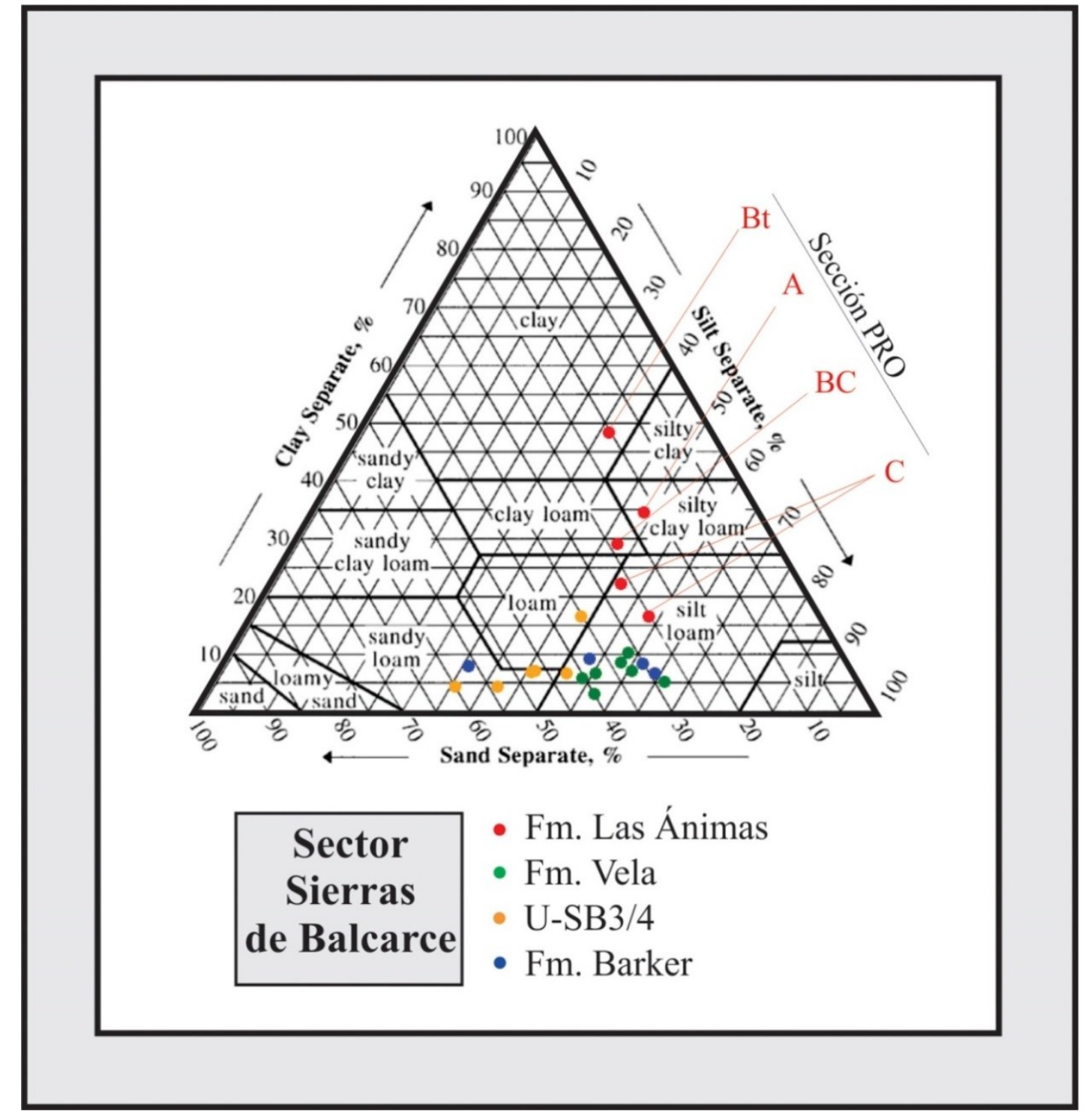

Figura 6.2. Triángulo textural (USDA) de muestras del sector Sierras de Tandil. Fuente: http://www.nrcs.usda.gov/ (Soil Texture Calculator). 


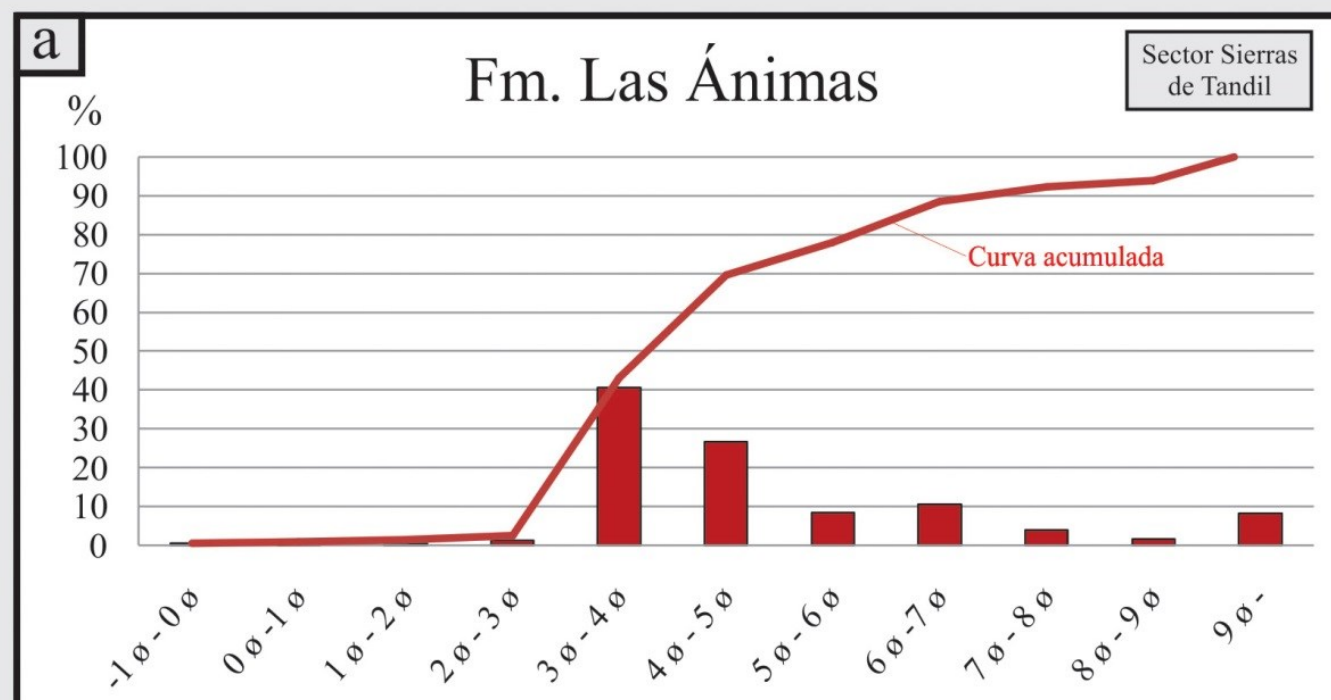

Fracciones granulométricas en escala phi

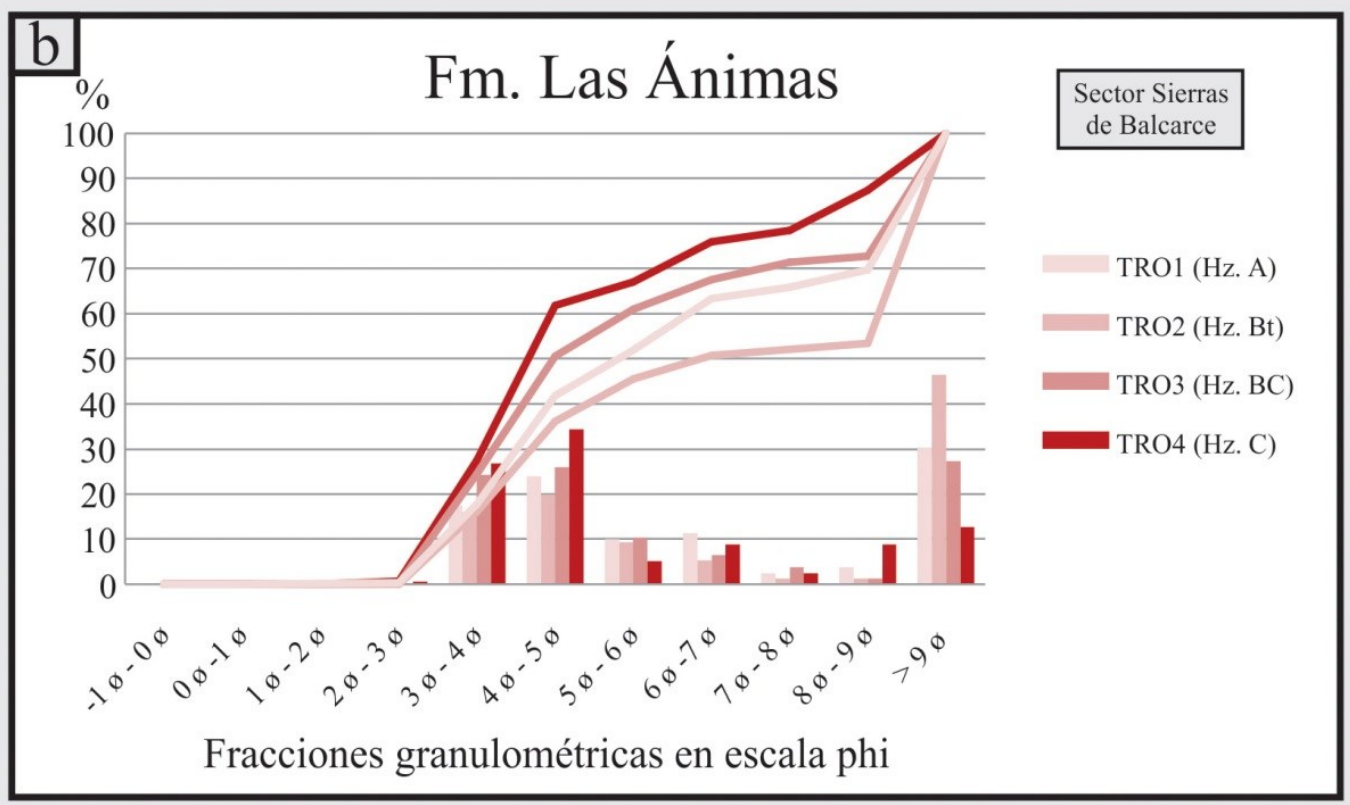

Figura 6.3. Histogramas de fracciones granulométricas a $1 \phi$ y curvas acumuladas para la Formación Las Ánimas; (a) en el sector Sierras de Tandil; (b) en la sección PRO (Sierras de Balcarce), donde se incluyen muestras del suelo actual. 


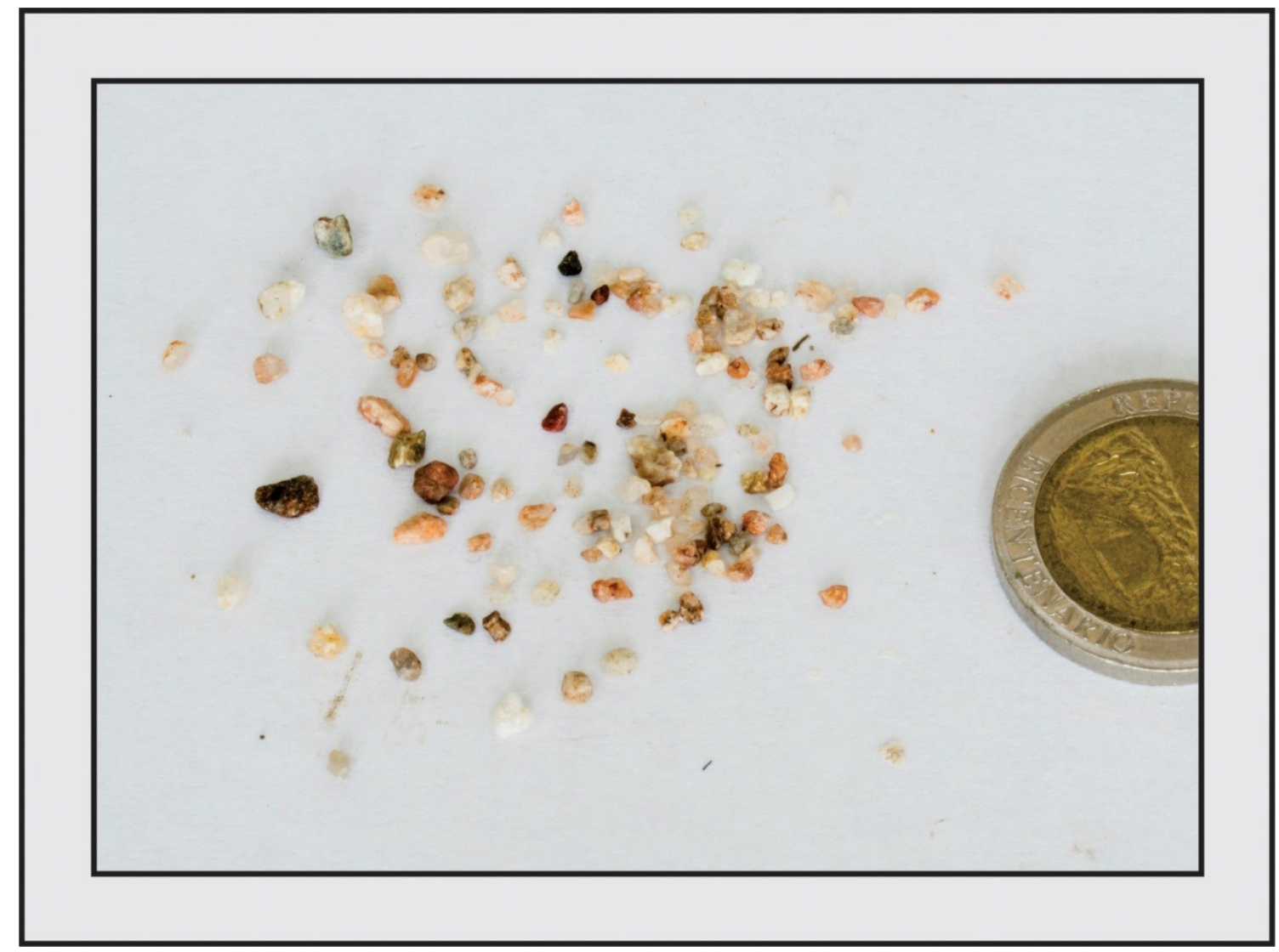

Figura 6.4. Clastos de clastos de tamaño arena media a muy gruesa, angulosos y subangulosos en la muestra del horizonte Ak en la sección de María Ignacia. 

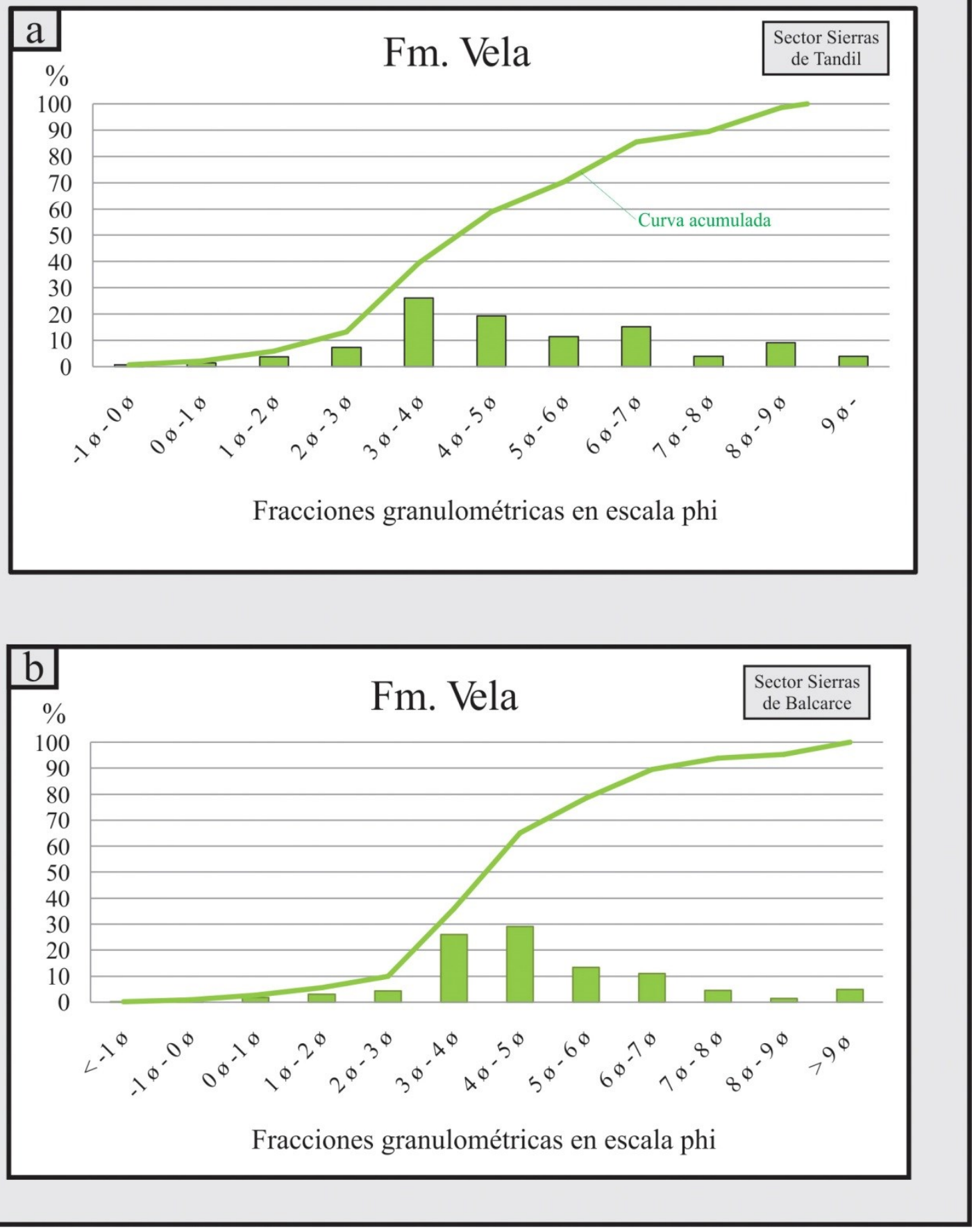

Figura 6.5. Histogramas de fracciones granulométricas a $1 \phi$ y curvas acumuladas para la Formación Vela; (a) en el sector Sierras de Tandil; (b) en el sector Sierras de Balcarce. 


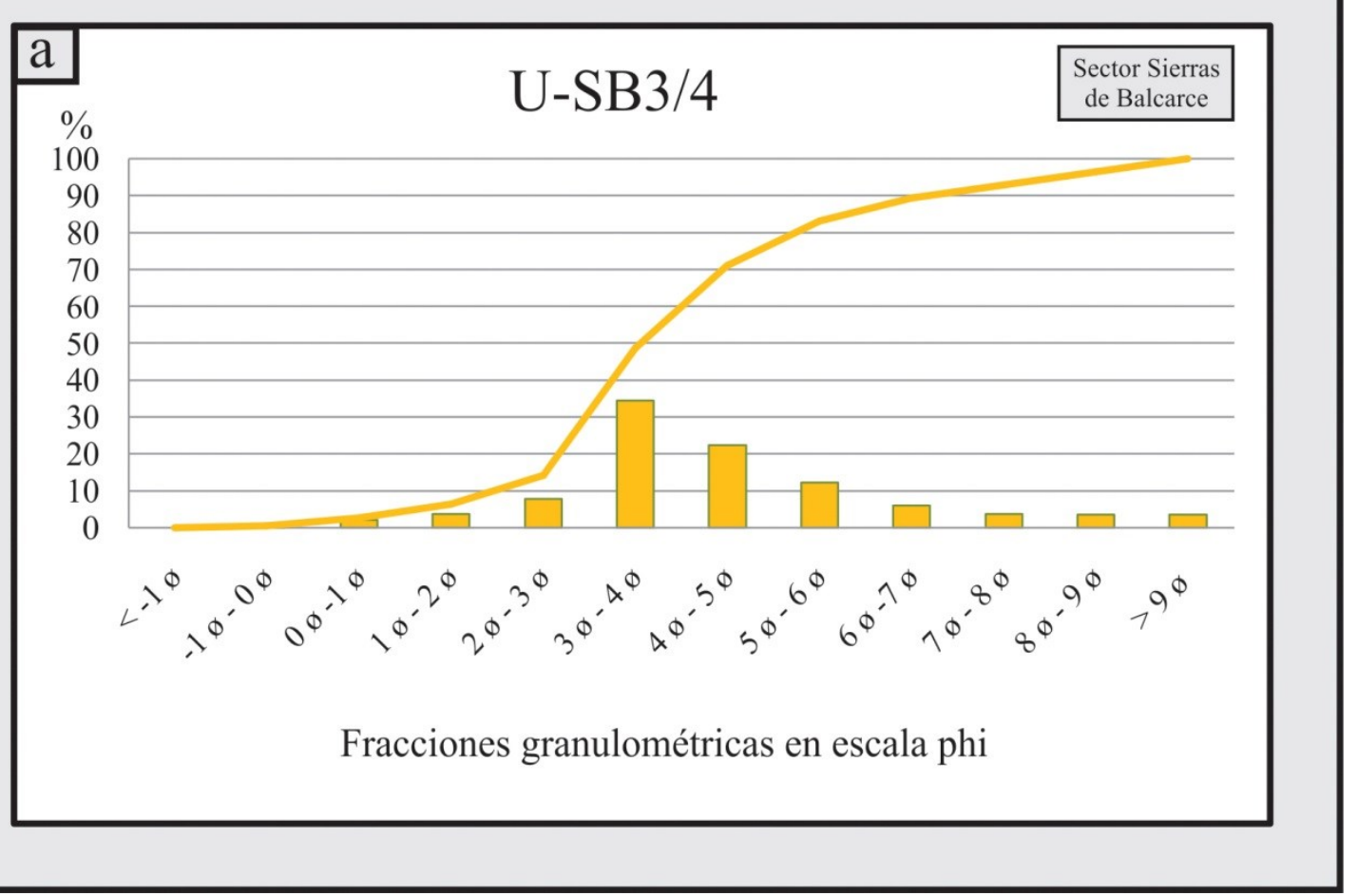

Figura 6.6. Histograma de fracciones granulométricas a $1 \phi$ y curva acumulada para la unidad litoestratigráfica U-SB3/4 (Sierras de Balcarce).

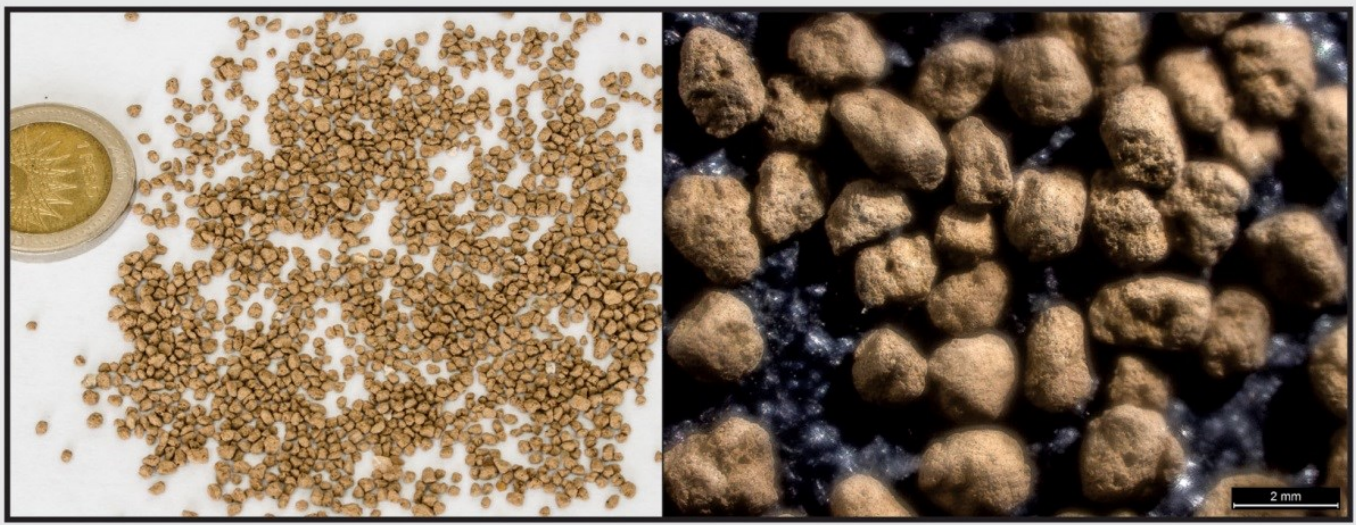

Figura 6.7. Agregados tamaño arena gruesa (Formación Barker). 


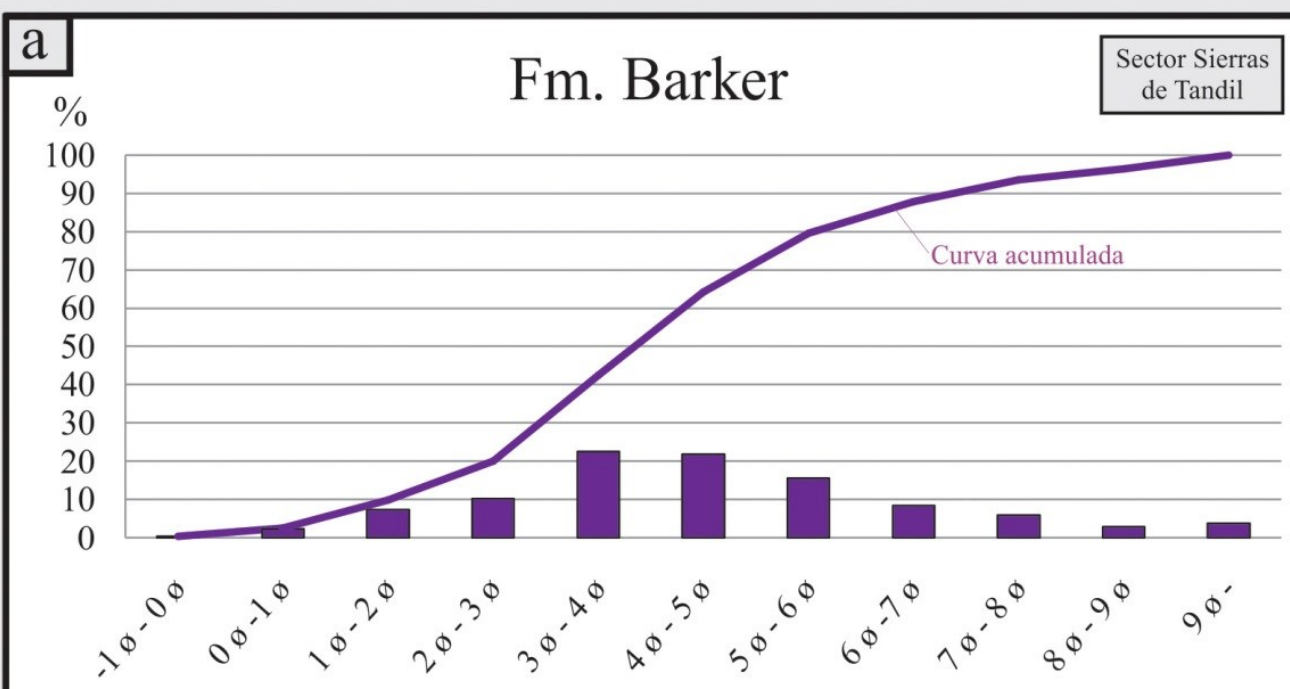

Fracciones granulométricas en escala phi

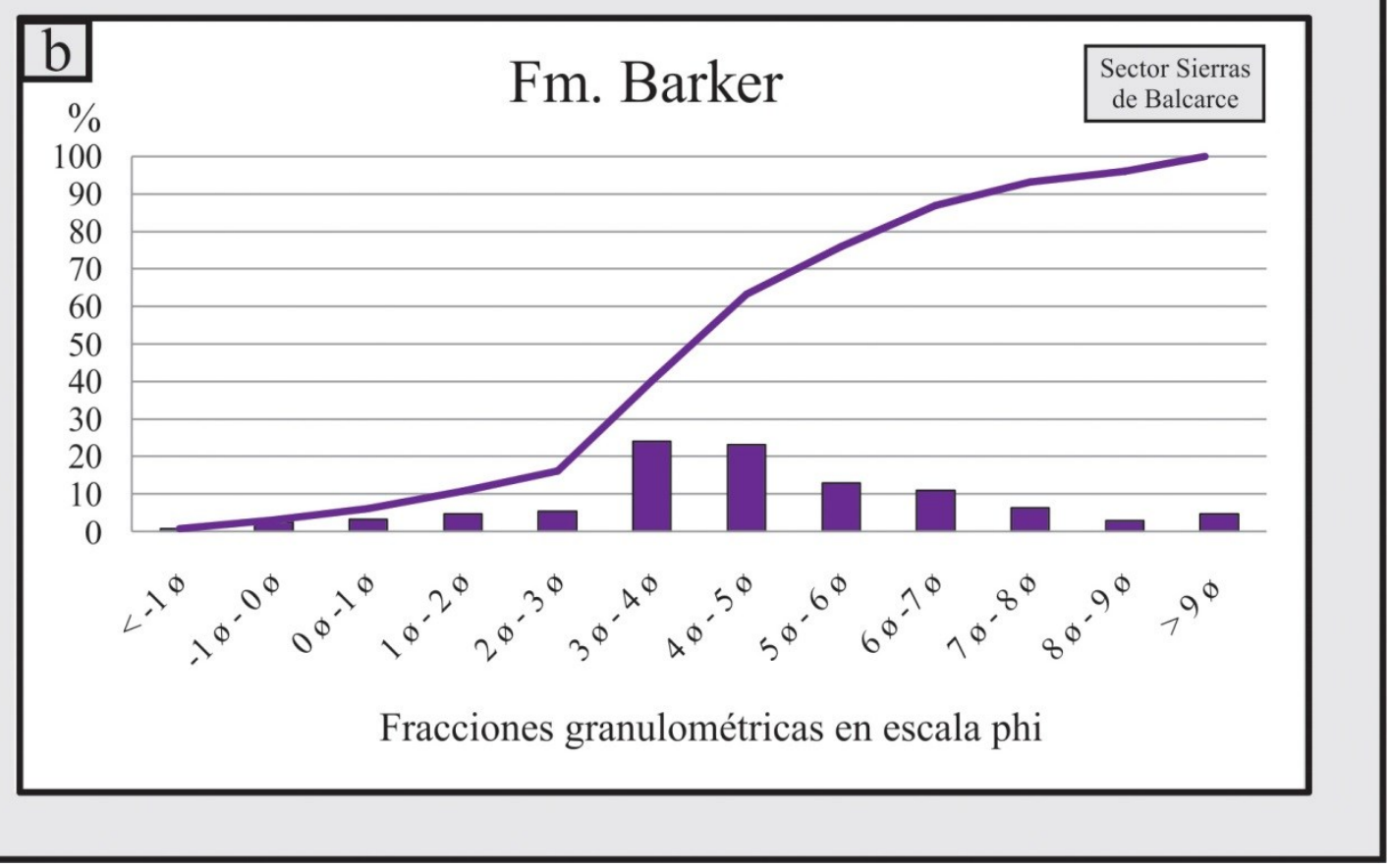

Figura 6.8. Histograma de fracciones granulométricas a $1 \phi$ y curva acumulada para la Formación Barker; (a) en el sector Sierras de Tandil; (b) en el sector Sierras de Balcarce. 


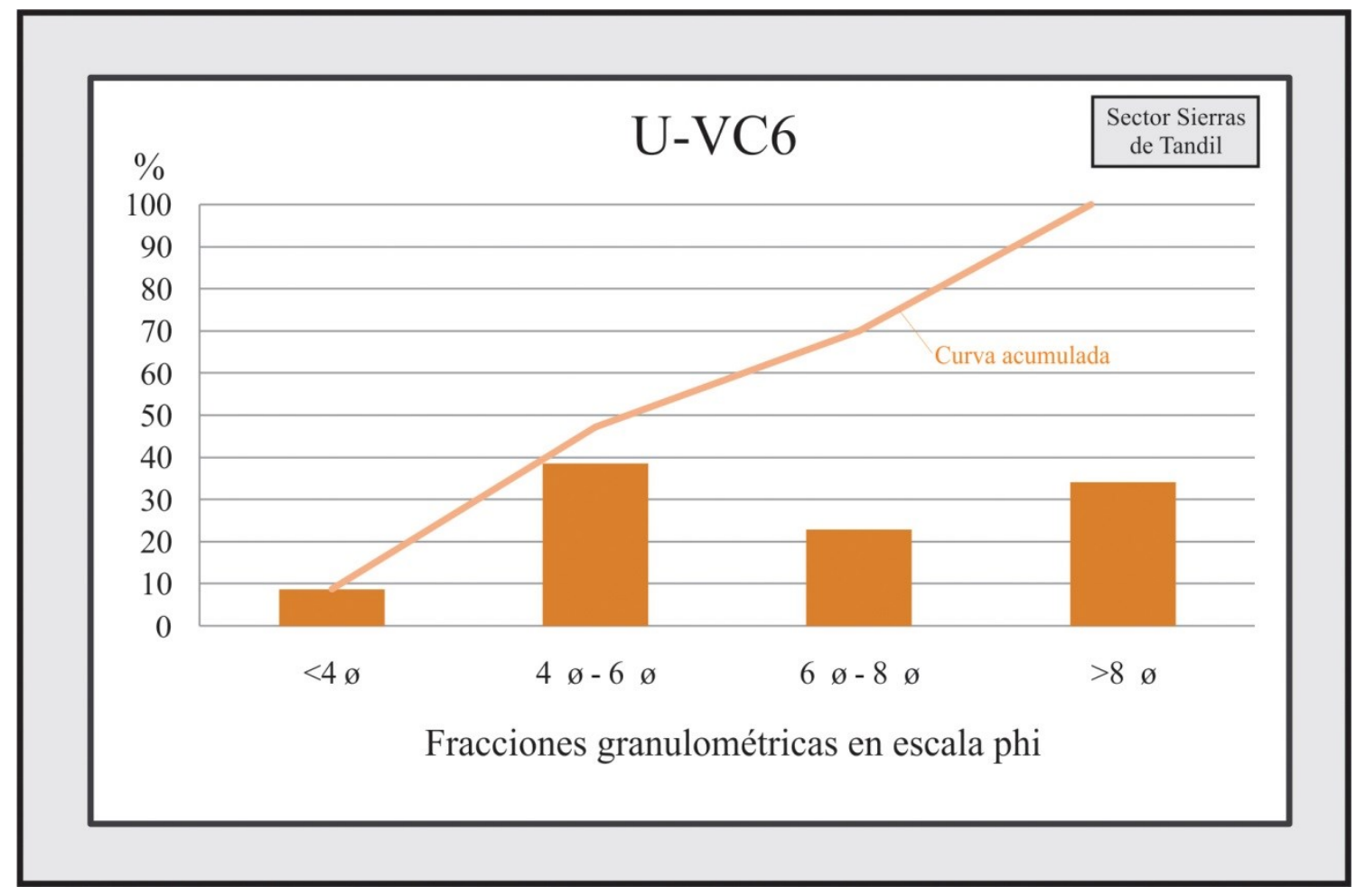

Figura 6.9. Histograma de fracciones granulométricas a $2 \phi$ y curvas acumulada para la unidad litoestratigráfica U-VC6 (Sierras de Tandil). 


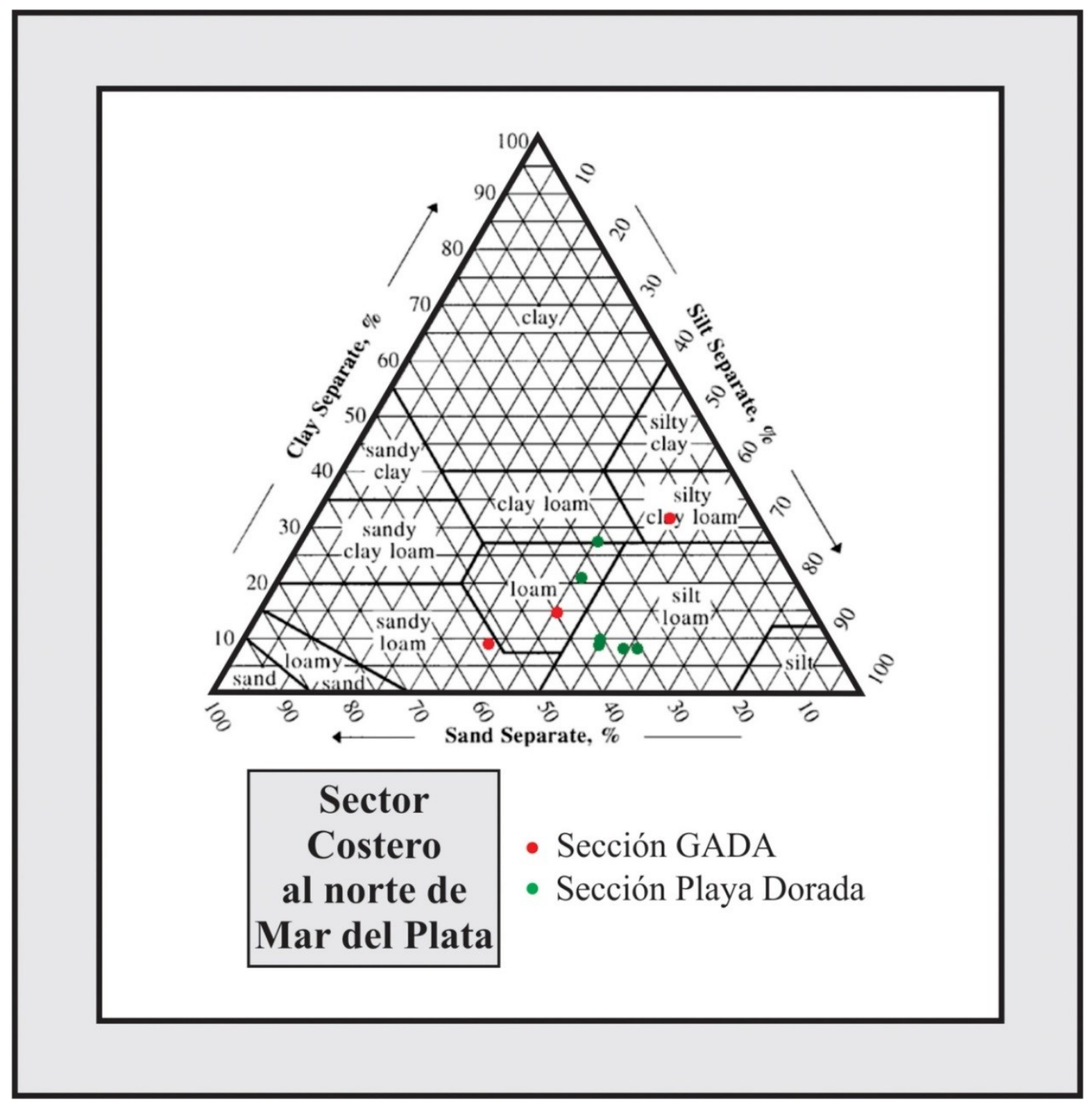

Figura 6.10. Triángulo textural (USDA) de muestras del sector costero al norte de Mar del Plata. Fuente: http://www.nrcs.usda.gov/ (Soil Texture Calculator). 


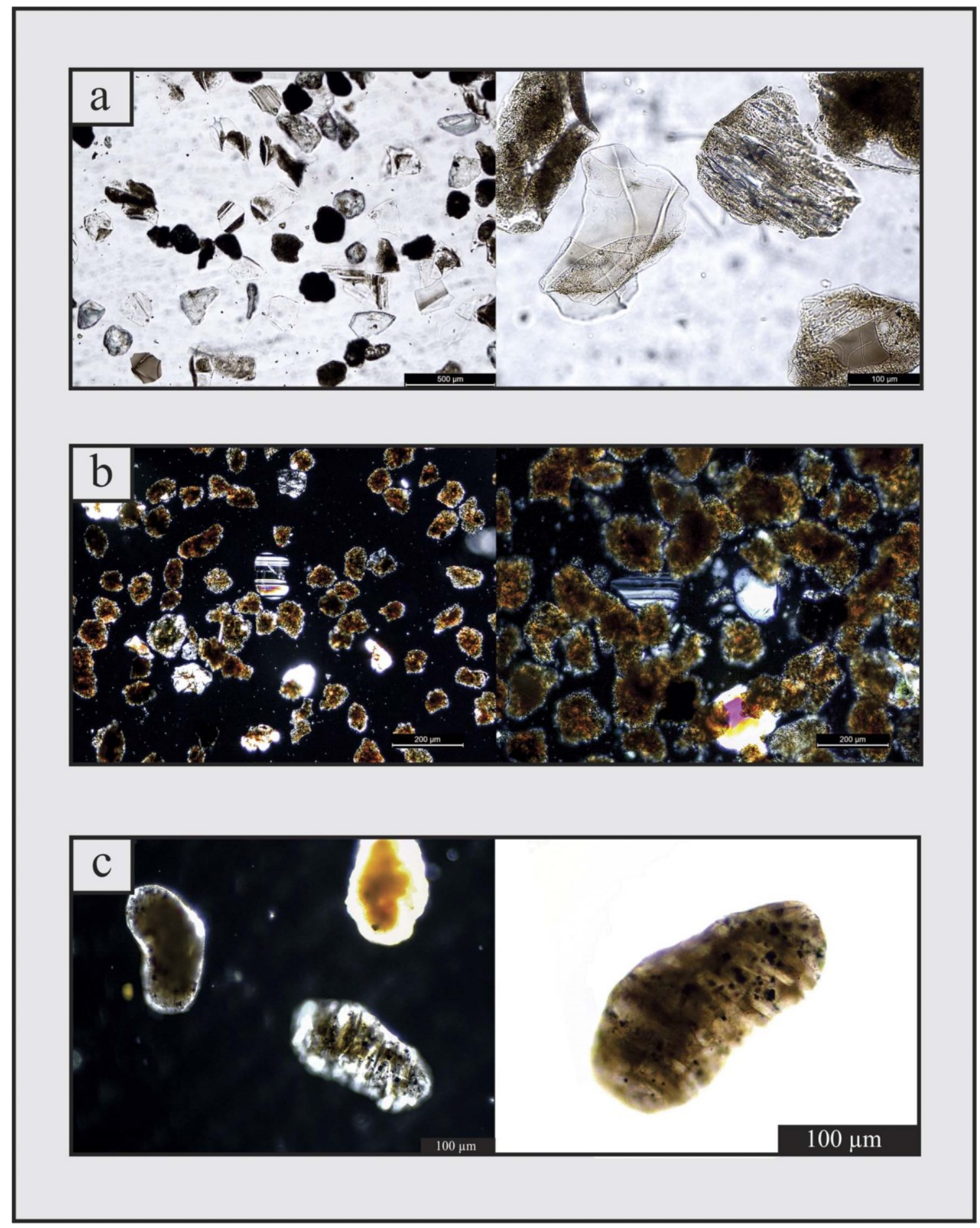

Figura 6.11. Fracción arena al microscopio de luz transmitida. a) Unidad litoestratigráfica U-SB3/4; b) Formación Barker; c) Litoclastos volcánicos con inclusiones opacas. 


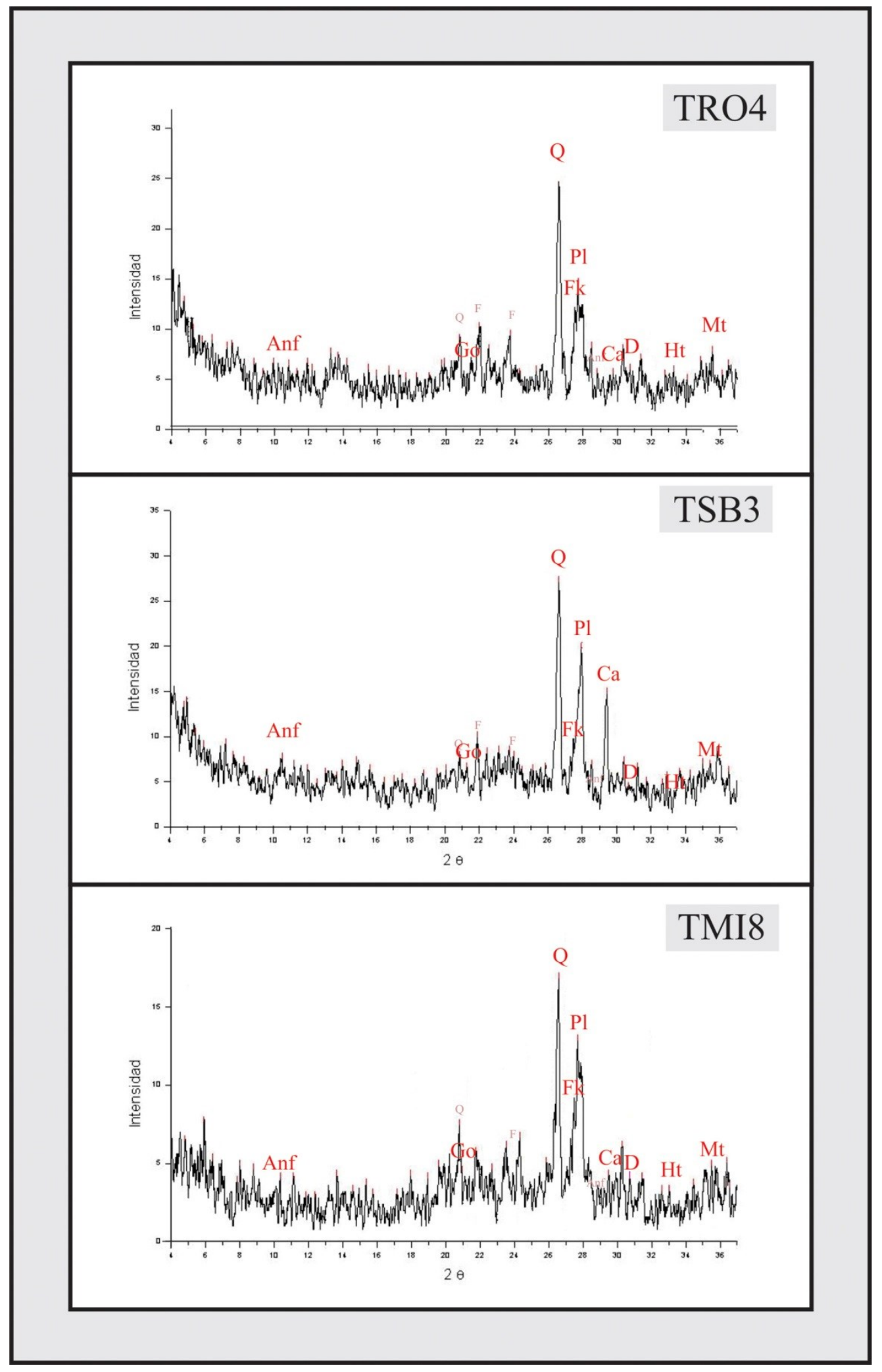

Figura 6.12. Difractogramas representativos de distintas muestras analizadas. $\mathrm{Q}=\mathrm{Cuarzo} ; \mathrm{Pl}=\mathrm{Plagioclasa}$; $\mathrm{Fk}=$ Feldespato potásico; $\mathrm{Ca}=$ Calcita; $\mathrm{D}=$ Piroxeno; $\mathrm{Anf}=\mathrm{Anfibol} ; \mathrm{Mt}=$ Magnetita; $\mathrm{Ht}=\mathrm{Hematita}$; $\mathrm{Go}=$ Goethita. 


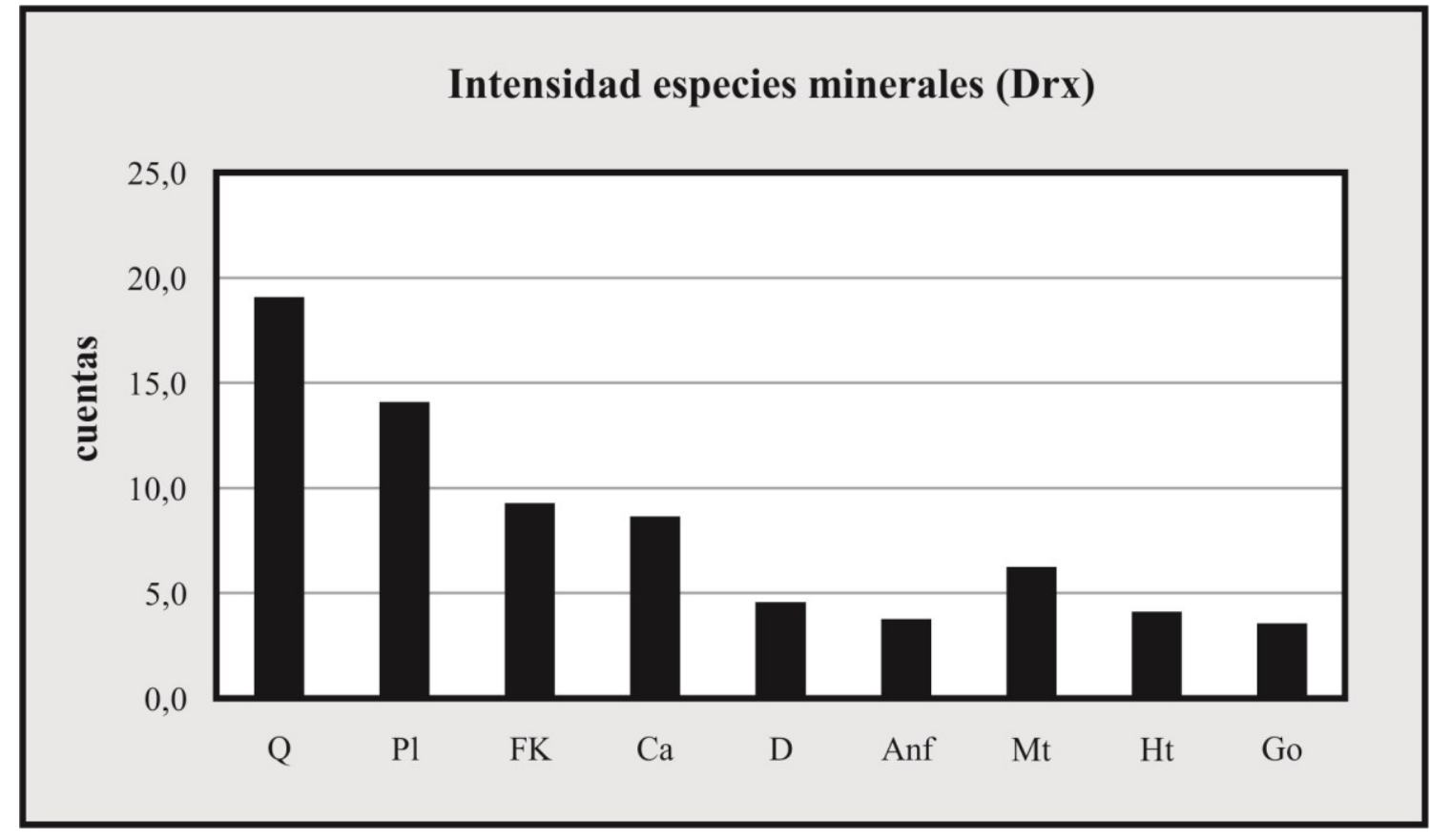

Figura 6.13. Intensidad promedio de las principales especies minerales identificadas por DRX. $\mathrm{Q}=$ Cuarzo; $\mathrm{Pl}=$ Plagioclasa; $\mathrm{Fk}=$ Feldespato potásico; $\mathrm{Ca}=$ Calcita; $\mathrm{D}=$ Piroxeno; $\mathrm{Anf}=\mathrm{Anfibol}$; $\mathrm{Mt}=$ Magnetita; $\mathrm{Ht}=$ Hematita; $\mathrm{Go}=$ Goethita. 


\subsection{Tablas del capítulo 6}

\begin{tabular}{|c|c|c|c|c|c|c|c|c|}
\hline Perfil & Muestra & Unidad & Formación & $\%$ Arena & \%Limo & $\%$ Arcilla & Textura - USDA & Método \\
\hline \multirow{7}{*}{ PVC } & TVC8 & U-VC2 & Vela & 36,6 & 54,5 & 8,9 & Franco limosa & Pipeteo \\
\hline & TVC15 & U-VC4 & \multirow{5}{*}{ Barker } & 50,6 & 36,7 & 12,8 & Franca & Pipeteo \\
\hline & TVC18 & $\mathrm{U}-\mathrm{VC5}$ & & 47,5 & 40,7 & 11,8 & Franca & Pipeteo \\
\hline & TVC20 & U-VC4 & & 70,1 & 20,8 & 9,1 & Franco arenosa & Pipeteo \\
\hline & TVC22 & $\mathrm{U}-\mathrm{VC} 4$ & & 54,5 & 36,7 & 8,9 & Franco arenosa & Pipeteo \\
\hline & TVC25 & U-VC5 & & 42,7 & 50,6 & 6,7 & Franco limosa & Pipeteo \\
\hline & TVC30 & U-VC6 & Villa Cacique & 8,7 & 57,2 & 34,1 & Franco arcillo limosa & Trasvasado \\
\hline \multirow{10}{*}{ PMI } & TMI1 & U-MI1 & Las Ánimas & 26,7 & 70,5 & 2,8 & Franco limosa & Pipeteo \\
\hline & TMI3 & U-MI2 & \multirow{4}{*}{ Vela } & 33,8 & 56,7 & 9,5 & Franco limosa & Pipeteo \\
\hline & TMI4 & U-MI2 & & 30,0 & 44,2 & 25,8 & Franca & Pipeteo \\
\hline & TMI5 & U-MI2 & & 55,1 & 40,9 & 4,0 & Franco arenosa & Pipeteo \\
\hline & TMI6 & U-MI2 & & 34,3 & 53,4 & 12,3 & Franco limosa & Pipeteo \\
\hline & TMI8 & U-MI3 & \multirow{5}{*}{ Barker } & 60,7 & 34,2 & 5,1 & Franco arenosa & Pipeteo \\
\hline & TMI10 & U-MI4 & & 66,9 & 26,5 & 6,6 & Franco arenosa & Pipeteo \\
\hline & TMI12 & U-MI4 & & 66,0 & 30,1 & 3,9 & Franco arenosa & Pipeteo \\
\hline & TMI15 & U-MI5 & & 64,2 & 26,8 & 8,9 & Franco arenosa & Pipeteo \\
\hline & TMI16 & U-MI5 & & 61,8 & 29,3 & 8,9 & Franco arenosa & Pipeteo \\
\hline \multirow{6}{*}{ PCF } & TCF12 & U-CF2 & Vela & 47,1 & 50,2 & 2,7 & Franco limosa & Pipeteo \\
\hline & TCF14 & U-CF3 & \multirow{5}{*}{ Barker } & 42,6 & 47,6 & 9,8 & Franca & Pipeteo \\
\hline & TCF16 & U-CF4 & & 46,6 & 50,6 & 2,8 & Franco limosa & Pipeteo \\
\hline & TCF19 & U-CF5 & & 43,5 & 49,6 & 6,9 & Franca & Pipeteo \\
\hline & TCF22 & U-CF5 & & 43,2 & 51,4 & 5,4 & Franco limosa & Pipeteo \\
\hline & TCF23 & U-CF5 & & 35,3 & 57,7 & 7,0 & Franco limosa & Pipeteo \\
\hline \multirow{3}{*}{ PCT } & TCT1 & U-CT1 & \multirow{3}{*}{ Las Ánimas } & $\overline{41,0}$ & $\overline{47,1}$ & 11,9 & Franca & Pipeteo \\
\hline & TCT2 & U-CT1 & & 52,8 & 38,1 & 9,1 & Franca arenosa & Pipeteo \\
\hline & ТСТ3 & U-CT1 & & 51,6 & 41,4 & 7,0 & Franca & Pipeteo \\
\hline
\end{tabular}

En rojo se resaltan aquellas muestras con fracción arena sobrestimada

Tabla 6.1. Análisis granulométrico de muestras del sector Sierras de Tandil. 


\begin{tabular}{|c|c|c|c|c|c|c|c|c|}
\hline Perfil & Muestra & Unidad & Formación & $\%$ Arena & \%Limo & $\%$ Arcilla & Textura - USDA & Método \\
\hline \multirow{8}{*}{ PSM } & TSM1 & U-SM1 & \multirow{4}{*}{ Vela } & 33,5 & 60,0 & 6,5 & Franco limosa & Pipeteo \\
\hline & TSM2 & U-SM1 & & 34,4 & 57,6 & 8,0 & Franco limosa & Pipeteo \\
\hline & TSM3 & U-SM1 & & 41,5 & 53,1 & 5,3 & Franco limosa & Pipeteo \\
\hline & TSM4 & U-SM1 & & 39,0 & 54,8 & 6,2 & Franco limosa & Pipeteo \\
\hline & TSM7 & U-SM2 & \multirow{4}{*}{ Barker } & 38,8 & 52,6 & 8,6 & Franco limosa & Pipeteo \\
\hline & TSM8 & U-SM3 & & 57,3 & 35,2 & 7,5 & Franco arenosa & Pipeteo \\
\hline & TSM9 & U-SM3 & & 30,2 & 63,6 & 6,1 & Franco limosa & Pipeteo \\
\hline & TSM10 & U-SM4 & & 31,3 & 60,9 & 7,8 & Franco limosa & Pipeteo \\
\hline \multirow{7}{*}{ PRO } & TRO1 & U-RO1 & \multirow{4}{*}{ Las Ánimas } & 17,9 & 48,0 & 34,1 & Franco arcilloso limosa & Pipeteo \\
\hline & TRO2 & U-RO1 & & 16,2 & 35,9 & 47,9 & Arcillosa & Pipeteo \\
\hline & TRO3 & U-RO1 & & 24,6 & 46,8 & 28,6 & Franco arcillosa & Pipeteo \\
\hline & TRO4 & U-RO1 & & 27,5 & 50,9 & 21,6 & Franco limosa & Pipeteo \\
\hline & TRO6 & U-RO2 & \multirow{3}{*}{ Vela } & 41,0 & 56,3 & 2,7 & Franco limosa & Pipeteo \\
\hline & TRO7 & U-RO2 & & 32,4 & 58,0 & 9,7 & Franco limosa & Pipeteo \\
\hline & TRO8 & U-RO2 & & 29,4 & 65,9 & 4,8 & Franco limosa & Pipeteo \\
\hline \multirow{7}{*}{ PSB } & TSB4 & U-SB3 & \multirow{7}{*}{$\begin{array}{c}\text { Sin } \\
\text { denominación } \\
\text { formal }\end{array}$} & 36,2 & 47,9 & 16,0 & Franca & Pipeteo \\
\hline & TSB5 & U-SB3 & & 47,9 & 45,6 & 6,5 & Franco arenosa & Pipeteo \\
\hline & TSB7 & U-SB3 & & 48,5 & 45,1 & 6,4 & Franco arenosa & Pipeteo \\
\hline & TSB9 & U-SB4 & & 48,9 & 44,7 & 6,4 & Franco arenosa & Pipeteo \\
\hline & TSB10 & U-SB4 & & 61,1 & 35,1 & 3,8 & Franco arenosa & Pipeteo \\
\hline & TSB11 & U-SB4 & & 54,7 & 41,5 & 3,8 & Franco arenosa & Pipeteo \\
\hline & TSB13 & U-SB4 & & 43,3 & 50,5 & 6,2 & Franco limosa & Pipeteo \\
\hline
\end{tabular}

Tabla 6.2. Análisis granulométrico de muestras del sector Sierras de Balcarce.

\begin{tabular}{|c|c|c|c|c|c|c|c|c|}
\hline Perfil & Muestra & Unidad & Asociación & \% Arena & \%Limo & \%Arcilla & Textura - USDA & Método \\
\hline \multirow{3}{*}{ PGA } & TGA12 & U-GA5 & A5 & 15,0 & 53,9 & 31,1 & Franco arcillo limosa & Trasvasado \\
& TGA14 & U-GA5 & A5 & 40,8 & 45,1 & 14,1 & Franca & Pipeteo \\
& TGA17 & U-GA6 & A5 & 54,2 & 37,3 & 8,5 & Franco arenosa & Pipeteo \\
\hline \multirow{6}{*}{ PPD } & TPD2 & U-PD1 & A1 & 37,2 & 54,5 & 8,3 & Franco limosa & Trasvasado \\
& TPD4 & U-PD2 & A2 & 36,6 & 54,0 & 9,4 & Franco limosa & Trasvasado \\
& TPD7 & U-PD3 & A4 & 33,7 & 58,6 & 7,7 & Franco limosa & Trasvasado \\
& TPD14 & U-PD5 & A5 & 33,9 & 45,6 & 20,5 & Franca & Trasvasado \\
& TPD18 & U-PD6 & A5 & 28,1 & 44.9 & 27,0 & Franco arcillosa & Trasvasado \\
& TPD20 & Ceniza & A1 & 31,7 & 60,7 & 7,6 & Franco limosa & Trasvasado \\
\hline
\end{tabular}

La muestra en rojo presentó la fracción arena sobrestimada

Tabla 6.3. Análisis granulométrico de muestras del sector costero al norte de Mar del Plata. 


\begin{tabular}{|c|c|c|c|c|c|c|c|c|c|c|}
\hline \multirow{2}{*}{ Muestra } & \multirow{2}{*}{ Unidad } & \multicolumn{9}{|c|}{ INTENSIDAD (cuentas) } \\
\hline & & $\mathbf{Q}$ & PI & FK & $\mathrm{Ca}$ & D & Anf & Mt & Ht & Go \\
\hline TVC12 & $\mathrm{U}-\mathrm{VC} 3$ & 24,9 & 20 & 7 & 6,8 & 5,5 & 7,2 & 7,5 & 5 & - \\
\hline TVC20 & U-VC4 & 15,4 & 16,1 & 8,8 & 6,1 & 6,3 & 5,8 & 8,8 & 5,7 & 8,4 \\
\hline TMI1 & U-MI1 & 24 & 14,8 & 7,5 & 5 & - & - & 6 & 4 & 6 \\
\hline TMI2 & U-MI2 & 7,5 & 9,2 & 9 & 35 & 2,5 & 3 & 4,7 & 4 & 2,5 \\
\hline TMI3 & U-MI2 & 12,5 & 13 & 10,5 & 4,9 & 2,6 & 2,5 & 4,2 & 2,9 & 4,1 \\
\hline TMI4 & U-MI2 & 9,5 & 9 & 5 & 21 & 3 & 3 & 5 & 2,8 & - \\
\hline TMI5 & U-MI2 & 14,9 & 8 & 7,5 & 5 & 3 & 2,5 & 6 & 2,7 & 4,5 \\
\hline TMI6 & U-MI2 & 8 & 7,5 & 6 & 23 & 4,2 & 3 & 5 & 2,5 & 2,3 \\
\hline TMI7 & U-MI3 & 18 & 13 & 7 & 5,4 & 4 & 4 & 6,8 & 3,8 & 5,2 \\
\hline TMI8 & U-MI3 & 18 & 14 & 10 & 4,8 & 4 & 4 & 5 & 4 & 6 \\
\hline TMI9 & U-MI3 & 16 & 12,5 & 12 & 4 & 4 & 3,8 & 7,5 & 3 & 5,1 \\
\hline TMI10 & U-MI4 & 19 & 12 & 7 & 4 & 3 & 3 & 5,2 & 3,5 & 6,8 \\
\hline TMI11 & U-MI4 & 12 & 9,5 & 5,5 & 5,5 & 5 & 4 & 5,5 & 3,5 & 5,5 \\
\hline TMI12 & U-MI4 & 12,5 & 11,8 & 12,5 & 6 & 3,8 & 3,6 & 5,8 & 2,5 & 5,5 \\
\hline TMI13 & U-MI4 & 14 & 12 & 8 & 5 & 3,8 & 2,5 & 6,5 & 3,8 & 6 \\
\hline TMI14 & U-MI5 & 13 & 8,8 & 12 & 6,2 & 3 & 2,5 & 5 & 2,5 & 5 \\
\hline TMI15 & U-MI5 & 14 & 10,8 & 10,2 & 4 & 3,9 & 4 & 5,5 & 4,2 & 5 \\
\hline TMI16 & U-MI6 & 7,2 & 9 & 10,1 & 4 & 4 & 4 & 5,8 & 4,6 & 5 \\
\hline TCF6 & U-CF2 & 26 & 20 & 8 & 8 & 5,1 & 5,2 & 8 & 6 & 7,5 \\
\hline TCF22 & U-CF1 & 19 & 21 & 14 & 8 & 5,8 & 5 & 8 & 4,5 & - \\
\hline TRO4 & U-RO1 & 25 & 15 & 12 & 5 & 5,4 & 5,8 & 8 & 5,2 & 7 \\
\hline TSB1 & U-SB1 & 30 & 12,5 & 12,3 & 5 & 5,8 & 7,5 & 7,5 & 4,9 & 6 \\
\hline TSB2 & U-SB2 & 25 & 15 & 10 & 16 & 12 & 7 & 7,5 & 5 & - \\
\hline TSB3 & U-SB2 & 28 & 20 & 8 & 14 & 4,8 & 7,5 & 7 & 6 & 6 \\
\hline TSB9 & U-SB4 & 18,5 & 21 & 14 & 8 & 8 & 7,5 & 7,5 & 5 & 8 \\
\hline TSB12 & U-SB4 & 25 & 17 & 8 & 10 & 5 & - & 8,5 & 5 & - \\
\hline TPD2 & U-PD1 & 28 & 15 & 13 & 11 & 7 & - & 8 & 7 & - \\
\hline TPD6 & U-PD3 & 24 & 27 & 9 & 11 & 5,5 & - & 6 & 4 & - \\
\hline TPD14 & U-PD5 & 24,5 & 17,5 & 8 & 4,8 & 4,8 & 5,5 & 7 & 5 & - \\
\hline TPD20 & U-PD1 & 25 & 8 & - & 6 & - & - & - & - & - \\
\hline TEC2 & U-EC2 & 29 & 16 & 13,5 & 17 & 5 & 5 & 5,5 & 3,5 & - \\
\hline TEC4 & U-EC3 & 22 & 14,5 & 11 & - & 5 & - & 6 & 4,8 & - \\
\hline TEC18 & U-EC6 & 20,5 & 14,8 & 10 & 6 & 6 & 6 & 5,9 & 4,8 & - \\
\hline
\end{tabular}

Tabla 6.4. Intensidad de las principales especies minerales identificadas por $D R X . Q=C u a r z o$; $\mathrm{Pl}=$ Plagioclasa; $\mathrm{Fk}=$ Feldespato potásico; $\mathrm{Ca}=$ Calcita; $\mathrm{D}=$ Piroxeno; $\mathrm{Anf}=\mathrm{Anfibol} ; \mathrm{Mt}=$ Magnetita; $\mathrm{Ht}=$ Hematita; $\mathrm{Go}=$ Goethita. 


\begin{tabular}{|c|c|c|c|c|}
\hline MUESTRA & UNIDAD & $\begin{array}{c}\text { Unidad litoestratigrá- } \\
\text { fica/asociación }\end{array}$ & $\begin{array}{c}\text { Tamiz } \\
\text { Pasante }\end{array}$ & EXPANSIÓN \\
\hline TVC24 & U-VC5 & Barker & 230 & $\mathbf{6 \%}$ \\
\hline TVC26 & U-VC5 & Barker & 230 & $\mathbf{1 1 \%}$ \\
\hline TVC30 & U-VC6 & U-VC6 & 80 & $\mathbf{6 7 \%}$ \\
\hline TMI1 & U-MI1 & Las Ánimas & 80 & $\mathbf{2 0 \%}$ \\
\hline TMI5 & U-MI2 & Vela & 80 & $\mathbf{1 8 \%}$ \\
\hline TMI8 & U-MI3 & Barker & 80 & $\mathbf{8 \%}$ \\
\hline TMI10 & U-MI4 & Barker & 80 & $\mathbf{2 2 \%}$ \\
\hline TMI12 & U-MI4 & Barker & 80 & $\mathbf{1 5 \%}$ \\
\hline TMI15 & U-MI5 & Barker & 80 & $\mathbf{2 1 \%}$ \\
\hline TMI16 & U-MI5 & Barker & 80 & $\mathbf{2 4 \%}$ \\
\hline CT1 & U-CT1 & Las Ánimas & 230 & $\mathbf{3 \%}$ \\
\hline TRO1 & U-RO1 & Las Ánimas & 230 & $\mathbf{1 2 \%}$ \\
\hline TRO2 & U-RO1 & Las Ánimas & 230 & $\mathbf{3 2 \%}$ \\
\hline TRO3 & U-RO1 & Las Ánimas & 230 & $\mathbf{2 5 \%}$ \\
\hline TRO4 & U-RO1 & Las Ánimas & 230 & $\mathbf{1 7 \%}$ \\
\hline TRO7 & U-RO2 & Vela & 120 & $\mathbf{1 1 \%}$ \\
\hline TSB4 & U-SB3 & U-SB3/4 & 120 & $\mathbf{2 3 \%}$ \\
\hline TSB5 & U-SB4 & U-SB3/4 & 120 & $\mathbf{1 6 \%}$ \\
\hline TGA12 & U-GA5 & A5 & 230 & $\mathbf{7 3 \%}$ \\
\hline TGA12 & U-GA5 & A5 & 40 & $\mathbf{4 7 \%}$ \\
\hline TGA13 & U-GA5 & A5 & 40 & $\mathbf{3 1 \%}$ \\
\hline TGA14 & U-GA5 & A5 & 120 & $\mathbf{2 5 \%}$ \\
\hline TGA15 & U-GA5 & A5 & 40 & $\mathbf{2 1 \%}$ \\
\hline TGA17 & U-GA6 & A5 & 230 & $\mathbf{1 0 \%}$ \\
\hline TGA19 & U-GA7 & A5 & 40 & $\mathbf{1 3 \%}$ \\
\hline TGA21 & U-GA7 & A5 & 40 & $\mathbf{2 3 \%}$ \\
\hline TPD2 & U-PD1 & A1 & 230 & $\mathbf{4 \%}$ \\
\hline TPD4 & U-PD2 & A2 & 230 & $\mathbf{1 4 \%}$ \\
\hline TPD7 & U-PD3 & A3 & 230 & $\mathbf{1 8 \%}$ \\
\hline TPD14 & U-PD5 & A5 & 230 & $\mathbf{3 8 \%}$ \\
\hline TPD18 & U-PD6 & A5 & 120 & $\mathbf{2 0 \%}$ \\
\hline & & & \\
\hline
\end{tabular}

Tabla 6.5. Porcentaje de expansión libre de las muestras analizadas. 


\section{CAPITULO 7. ANALISIS QUIMICO}

En este capítulo se exponen los resultados del análisis químico de las muestras de cada sección estratigráfica. Se indican los datos de pérdida por ignición a $550^{\circ} \mathrm{C}$ (PI550), los del contenido en carbonato de calcio $\left(\mathrm{CaCO}_{3}\right)$ y hierro total expresado como óxido $\left(\mathrm{Fe}_{2} \mathrm{O}_{3}\right)$. También se exponen los valores de hierro total normalizado en función del carbonato. Se infiere que la pérdida por ignición está controlada por el agua de composición de los minerales hidratados y por la materia orgánica.

\subsection{Análisis químico en el sector Sierras de Tandil}

\subsubsection{Química Sección Villa Cacique (PVC)}

En la figura 7.1 se muestran los valores de PI550 y $\mathrm{CaCO}_{3}$ de las muestras de la sección estratigráfica de Villa Cacique. Los valores son referidos a las unidades de la columna sedimentaria de la figura 5.5

La PI550 en las muestras de la sección PVC varió entre 2,5 y 6,9\%. En la Formación Las Animas el valor promedio de las muestras analizadas fue de 4,3\%. Los valores de PI550 se incrementan hacia el tope; los más bajos corresponden a las muestras TVC6 y TVC5 del horizonte C (2,9 y 2,7\% respectivamente) y los más elevados corresponden al solum, el valor más elevado de pérdida por ignición a $550^{\circ} \mathrm{C}$ correspondió a la muestra TVC1 del horizonte A del suelo actual. Se interpreta que el incremento de la PI550 en el solum se relaciona a la mayor proporción de materia orgánica, sobre todo en el horizonte A, y a un mayor contenido de agua de composición, vinculado a una mayor participación de minerales hidratados, principalmente arcillas (en los horizontes Bt y BC). Las muestras de la Formación Vela

registraron un valor promedio de PI550 más bajo (3,4\%) que las de la Formación Las Ánimas, esto se relaciona con la escasa presencia de arcillas. En contraposición, el valor promedio de PI550 de las muestras de la Formación Barker fue más elevado que las anteriores (4,8\%), esto se debería a la presencia de paleosuelos, en los cuales se incrementa la fracción arcilla. Las muestras de la matriz de la unidad UVC6 registraron el valor de PI550 promedio más elevado de la sección $(5,29 \%)$, esto se vincula con la mayor presencia de arcillas, especialmente expandibles, en este nivel. 
El porcentaje de $\mathrm{CaCO}_{3}$ varió entre 0,74 y 23,5\%, con un promedio de 3,25\%. Las muestras de las Formaciones Las Ánimas (2,4\%) y Barker (2,5\%) registraron los valores promedio más bajos. En la Formación Vela se registró un valor promedio de 3,2\%. El valor promedio más elevado corresponde a las muestras de la unidad U-VC6 $(13,1 \%)$, este valor se encuentra condicionado por el valor de la muestra de la base (TVC31), extraída de un sector fuertemente cementado por carbonatos.

En la sección de Villa Cacique se obtuvieron registros del contenido de $\mathrm{Fe}_{2} \mathrm{O}_{3}$ en muestras de la Formación Barker. A tales fines se analizaron muestras seleccionadas de distintas unidades, tales como las muestras TVC12 y TVC13 de la unidad U-VC3 y las muestras TVC15, TVC17, TVC18, TVC19, TVC20, TVC21 y TVC22 de la unidad U-VC4. Los valores variaron entre 5,43\% en la muestra TVC15, y 7,67\% en la muestra TVC13, con un promedio de 7,11\%.

\subsubsection{Química Sección María Ignacia (PMI)}

En la figura 7.2 se indican los valores de $\mathrm{PI} 550, \mathrm{CaCO}_{3}, \mathrm{Fe}_{2} \mathrm{O}_{3}$ y hierro total normalizado en función del carbonato de las muestras de la sección estratigráfica de María Ignacia. Los valores son referidos a las unidades de la columna sedimentaria de la figura 5.20.

La PI550 en las muestras de la sección PMI varió entre 2,9 y 10,7\%. El valor más elevado corresponde a la muestra del horizonte Ak del suelo actual. Las muestras de la Formación Vela registraron el valor promedio más bajo (3,6\%), esto se relacionaría a una menor presencia de arcillas que en la Formación Barker, con desarrollo de paleosuelos, donde la PI550 promedio fue 4,9\%.

El porcentaje de $\mathrm{CaCO}_{3}$ varió entre 1,8 y 37,8\%, con un promedio de $8,7 \%$. Se constató que las variaciones porcentuales entre las unidades analizadas fueron remarcables. El tope del perfil, muestra TMI1, presentó 5,9\% de $\mathrm{CaCO}_{3}$. La Formación Vela registró el promedio más elevado $(22,1 \%)$ de toda la sección y la Formación Barker el más bajo (2,63\%). El valor más elevado de la Formación Barker corresponde a la muestra TMI14 (4,41\%), extraída del tope del paleosuelo S-MI2.

El contenido de $\mathrm{Fe}_{2} \mathrm{O}_{3}$ varió entre 5,01 y 9,04\%, con un promedio de 7,02\%. La muestra TMI1 del tope del perfil (Formación Las Ánimas) registró un valor de 5,77\%, que normalizado por el carbonato ascendió a 6,11\%. Las muestras de la Formación Vela registraron un valor promedio de 5,84\%; al normalizar los valores por contenido de carbonatos, el promedio ascendió a 7,00\%. La Formación Barker registró el contenido de hierro más elevado de la sección, con un promedio de 7,95\%. Los valores más 
elevados corresponden a las muestras de los paleosuelos, donde el paleosuelo S-MI1 registró un valor promedio de $8,14 \%$ y el paleosuelo S-MI2 de $8,53 \%$.

En la figura 7.3a se observa el grafico PI550 vs. $\% \mathrm{Fe}_{2} \mathrm{O}_{3}$ y se indican las muestras de las formaciones Las Ánimas, Vela y Barker. El coeficiente de correlación entre ambos parámetros es bajo $(\mathrm{R}=0,1)$, sin embargo, si se exceptúa el valor de la muestra del horizonte Ak del suelo actual, que presenta un elevado valor de PI550, el coeficiente de correlación resulta positivo y muy fuerte $(0,83)$.

Se calculó también el coeficiente de correlación entre el $\mathrm{CaCO}_{3}$ y el $\mathrm{Fe}_{2} \mathrm{O}_{3}$ normalizado en función del carbonato, si bien este es positivo y bajo para todas las muestras del perfil, si se considera sólo las muestras de la Formación Barker este resulta muy fuerte y positivo $(0,80)$.

\subsubsection{Química Sección calle Fangio (PCF)}

En la figura 7.4 se muestran los valores de PI550, $\mathrm{CaCO}_{3}$, así como el hierro total $\left(\% \mathrm{Fe}_{2} \mathrm{O}_{3}\right)$ y normalizado en función del carbonato de las muestras de la sección estratigráfica de la calle Fangio. Los valores son referidos a las unidades de la columna sedimentaria de la figura 5.26.

La PI550 en las muestras de la sección PCF varió entre 1,8\% y 6,1\%. Las muestras de la Formación Las Ánimas registraron el valor promedio más elevado (4,5\%); los valores más bajos en esta unidad corresponden a las muestras de la base TCF7 y TCF6 (1,8 y 2,7\% respectivamente) (horizonte C), y los más elevados al solum, donde el más elevado de éstos corresponde a la muestra TCF2 del horizonte A2 del suelo actual (6,1\%). El incremento de la PI550 en el solum se relaciona a la mayor proporción de materia orgánica y probablemente a una mayor presencia de minerales hidratados. Las muestras de la Formación Vela registraron el valor promedio más bajo (3,76\%). Las muestras de la Formación Barker registraron un valor promedio de $3,9 \%$, con escasa variabilidad.

El porcentaje de $\mathrm{CaCO}_{3}$ varió entre 1,99 y 27,6\%, con un promedio de 6,6\%. Las muestras de la Formación Las Ánimas registraron el valor promedio más bajo (2,84\%), en tanto las de la Formación Barker el más elevado (9,6\%). Las muestras de la Formación Vela registraron un valor promedio de 5,2\%.

El contenido de $\mathrm{Fe}_{2} \mathrm{O}_{3}$ varió entre 4,97 y 7,8\%, con un promedio de 6,42\%. Las muestras de la Formación Las Ánimas registraron el valor promedio más bajo (5,8\%), sin incremento significativo al normalizar por el carbonato (5,9\%); en esta unidad el contenido de $\mathrm{Fe}_{2} \mathrm{O}_{3}$ disminuye levemente hacia el tope. Las muestras de la Formación Vela registraron un valor promedio de 6,65\%, que normalizado por contenido de carbonato ascendió a 7,11\%. La Formación Barker registró el contenido de hierro más 
elevado de la sección, con un promedio de $6,8 \%$, que asciende a 7,44\% al normalizarlo por el contenido de carbonato.

De forma similar a lo observado en la sección PMI, el coeficiente de correlación entre PI550 vs. $\% \mathrm{Fe}_{2} \mathrm{O}_{3}$ es bajo $(\mathrm{R}=-0,15)$, sin embargo, si se exceptúan los valores de las muestras que presentan mayor contenido de materia orgánica, vinculada al desarrollo del suelo actual (TCF1 a TCF5), el coeficiente de correlación resulta positivo y fuerte $(0,6)$.

Por otro lado, cabe destacar que el coeficiente de correlación entre el $\mathrm{CaCO}_{3}$ y $\mathrm{Fe}_{2} \mathrm{O}_{3}$ normalizado por carbonato es muy fuerte y positivo $(0,73)$.

\subsubsection{Química Sección Circuito Turístico (PCT)}

Todas las muestras extraídas de esta sección corresponden a la Formación Las Ánimas. La PI550 promedio fue 2,54\%, varió entre 2,28 (TCT4) y 3,3\% (TCT5). El porcentaje de $\mathrm{CaCO}_{3}$ promedio fue $2,47 \%$, varió entre 1,1 (TCT2) y 6,3\% (TCT5). En la tabla 7.1 se exponen los porcentajes de PI550 y $\mathrm{CaCO}_{3}$ de las muestras de la sección estratigráfica de la sección PCT.

\subsection{Análisis químico en el sector Sierras de Balcarce}

\subsubsection{Química Sección San Manuel (PSM)}

En la figura 7.5 se muestran los valores de pérdida por ignición a $550^{\circ} \mathrm{C}$ (PI550), carbonato de Calcio $\left(\% \mathrm{CaCO}_{3}\right)$, así como $\mathrm{Fe}_{2} \mathrm{O}_{3}$ de las muestras de la sección estratigráfica de San Manuel. Los mismos son referidos a las unidades de la columna sedimentaria de la figura 5.38.

La PI550 varió entre 3,31\% y 6,01\%. Las muestras de la Formación Vela registraron un valor promedio más bajo $(3,49 \%)$ que las muestras de la Formación Barker $(4,28 \%)$.

El porcentaje de $\mathrm{CaCO}_{3}$ varió entre 1,9 y 9,7\%. Las muestras de la Formación Vela registraron el valor promedio más elevado (4,86\%) en tanto las de la Formación Barker el más bajo (2,29\%).

El contenido de $\mathrm{Fe}_{2} \mathrm{O}_{3}$ varió entre 5,9 y 7,37\%, con un promedio de 6,66\%. Las muestras de la Formación Vela registraron un valor promedio de 6,44\%; normalizado por el contenido de carbonatos 
ascendió a 6,66\%. La Formación Barker registró el contenido de hierro más elevado de la sección, con un promedio de 6,89\%, y de 7,05\% normalizado por el porcentaje de carbonato. El coeficiente de correlación entre PI550 y \% $\mathrm{Fe}_{2} \mathrm{O}_{3}$ fue positivo y moderado $(0,4)$. El coeficiente de correlación entre el $\mathrm{CaCO}_{3}$ y $\mathrm{Fe}_{2} \mathrm{O}_{3}$ normalizado de las muestras de la Formación Barker fue muy fuerte y positivo $(0,99)$.

\subsubsection{Química Sección Ramos Otero (PRO)}

En la figura 7.6 se muestran los valores de PI550, $\mathrm{CaCO}_{3}$, así como el hierro total $\left(\% \mathrm{Fe}_{2} \mathrm{O}_{3}\right)$ y normalizado en función del carbonato de las muestras de la sección estratigráfica de Ramos Otero. Los valores son referidos a las unidades de la columna sedimentaria de la figura 5.42

La PI550 varió entre 2,72 y 8,1\%. Las muestras de la Formación Las Ánimas registraron el valor promedio más elevado $(5,26 \%)$, esto se debe principalmente a que las muestras extraídas de los horizontes del suelo actual presentan elevado contenido de materia orgánica y arcillas. Las muestras de la Formación Vela registraron un valor promedio más bajo $(2,85 \%)$.

El porcentaje de $\mathrm{CaCO}_{3}$ varió entre 1,6 y 21,4\%. Las muestras de la Formación Las Ánimas registraron el valor promedio más bajo $(2,12 \%)$ en tanto las de la Formación Vela el más elevado (12,3\%).

El contenido de $\mathrm{Fe}_{2} \mathrm{O}_{3}$ varió entre 5,3\% y 7,3\%; el primer valor corresponde a la muestra del horizonte A del suelo actual, el segundo al Bt. El promedio de la sección fue 5,98\%. Las muestras de la Formación Las Ánimas registraron un valor promedio levemente más elevado (6,29\%) que las de la Formación Vela (5,68\%). Los valores de $\mathrm{Fe}_{2} \mathrm{O}_{3}$ normalizados por el contenido de carbonatos ascendieron a 6,42 y $6,37 \%$ respectivamente.

El coeficiente de correlación entre PI550 y $\mathrm{Fe}_{2} \mathrm{O}_{3}$ es bajo $(\mathrm{R}=0,12)$, sin embargo, si se exceptúan los valores de la muestra del horizonte A del suelo actual, que presentan un valor elevado de PI550 vinculado al contenido de materia orgánica, el coeficiente de correlación resulta positivo y muy fuerte $(0,94)$.

\subsubsection{Química Sección Sierra Bachicha (PSB)}

En la figura 7.7 se muestran los valores de pérdida por ignición a $550^{\circ} \mathrm{C}$ (PI550), carbonato de Calcio $\left(\% \mathrm{CaCO}_{3}\right)$, así como el hierro total $\left(\% \mathrm{Fe}_{2} \mathrm{O}_{3}\right)$ y normalizado en función del carbonato de las 
muestras de la sección estratigráfica de Sierra Bachicha. Los valores son referidos a las unidades de la columna sedimentaria de la figura 5.48 .

La PI550 en las muestras de la sección PSB varió entre 2,3\% y 5,7\%. El promedio de la sección fue 3,5\%. La muestra de la Formación Las Ánimas registró un valor de 3,25\%. Las muestras de la Formación Vela registraron el valor promedio más bajo de la sección $(2,9 \%)$. En contraposición, las muestras de la unidad U-SB3 registraron el valor promedio más elevado (3,9\%); el valor más elevado de esta unidad corresponde a la muestra TSB4 del paleosuelo S-SB1 (5,7\%). Las muestras de la unidad USB4 registraron un promedio levemente menor $(3,5 \%)$, donde el valor más elevado $(4,5 \%)$ corresponde a la muestra TSB9 del paleosuelo S-SB2.

El porcentaje de $\mathrm{CaCO}_{3}$ varió entre 1,08 y $13,5 \%$, con un promedio de 4,2\%. La muestra de la Formación Las Ánimas registró un valor de 1,3\%. Las muestras de la Formación Vela registraron el valor promedio más elevado de la sección $(12,4 \%)$. Las muestras de las unidades U-SB3 y U-SB4 registraron valores promedio de 2,4 y $3,2 \%$ respectivamente.

El contenido de $\mathrm{Fe}_{2} \mathrm{O}_{3}$ varió entre 5,9 y 8,6\%, con un promedio de 6,7\%. La muestra de la Formación Las Ánimas registró un valor de 5,9\%, sin incremento significativo al normalizar por el carbonato $(6,01 \%)$. Las muestras de la Formación Vela registraron el valor promedio más bajo $(6,12 \%)$, que normalizado por el contenido de carbonatos, ascendió a 6,9\%. La unidad U-SB3 registró el contenido promedio de hierro más elevado de la sección (7,03\%), que asciende a 7,2\% al normalizarlo por el contenido de carbonato; el valor más elevado en esta unidad corresponde a la muestra del paleosuelo SSB1 (8,6\%). La unidad U-SB4 registró un contenido promedio de hierro de 6,7, que asciende a 6,9\% al normalizarlo por el contenido de carbonato; en esta unidad el valor más elevado corresponde a la muestra TSB9 del paleosuelo S-SB2 (7,73\%).

Se destaca que tanto PI550 como el contenido de $\mathrm{Fe}_{2} \mathrm{O}_{3}$ se incrementan en los niveles de paleosuelos; el coeficiente de correlación entre ambos parámetros es muy fuerte y positivo $(0,95)$. En la figura $7.3 \mathrm{~b}$ se muestra el gráfico PI550 vs. $\% \mathrm{Fe}_{2} \mathrm{O}_{3}$ y se indican las muestras de las Formaciones Las Ánimas y Vela y de la unidad litoestratigráfica U-SB3/4.

El coeficiente de correlación entre el $\mathrm{CaCO}_{3}$ y $\mathrm{Fe}_{2} \mathrm{O}_{3}$ normalizado por el carbonato resultó fuerte y positivo $(0,66)$. 


\subsubsection{Química Sección Cerro Quebracho (PCQ)}

Las muestras extraídas de esta sección corresponden a la Formación Vela. Los valores promedio de PI550 y $\% \mathrm{CaCO}_{3}$ fueron $4,7 \%$ y $36,2 \%$ respectivamente. En la tabla 7.2 se exponen los porcentajes de PI550 y $\mathrm{CaCO}_{3}$ de las muestras de la sección estratigráfica de la sección PCT.

\subsection{Análisis químico en el sector costero al norte de Mar del Plata}

\subsubsection{Química Sección GADA (PGA)}

En la figura 7.8 se muestran los valores de $\mathrm{PI} 550, \mathrm{CaCO}_{3}, \mathrm{Fe}_{2} \mathrm{O}_{3}$ y $\mathrm{Fe}_{2} \mathrm{O}_{3}$ normalizado en función del $\mathrm{CaCO}_{3}$ de las muestras de la sección estratigráfica GADA. Los valores son referidos a las unidades de la columna sedimentaria de la figura 5.54

El valor promedio de PI550 en las muestras de la sección PGA fue 4,3\%, varió entre 1,8 y 6\%. Los valores promedio más bajos se registraron en las muestras de la base de la unidad U-GA1 (2,1\%), hacia el tope de la misma unidad, donde se evidencian rasgos pedogenéticos actuales, ascienden a 5,1\%. La unidad U-GA2 registró un valor promedio de 4\%; los valores descienden hacia el tope de la unidad. Los registros de PI550 en las unidades U-GA3, U-GA4 y U-GA5 fueron relativamente constantes, con valores cercanos a 4,8\%. La muestra TGA17 del nivel arenoso U-GA6 presentó un valor relativamente menor $(3,5 \%)$. Las muestras no afectadas por carbonato de la unidad U-GA7 registraron un valor promedio de $4,6 \%$.

El contenido promedio de carbonato de calcio fue 9,9\%. Las mayores concentraciones de $\mathrm{CaCO}_{3}$ corresponden a la muestra TGA5, del tope de la unidad U-GA2 (53,9\%); a la muestra TGA16 del tope del nivel arenoso U-GA6 (42,8\%) y a la muestra TG18 del tope de la unidad basal (56,5\%). La parte central de la U-GA2 registró un valor relativamente elevado, como se indica en la figura. La muestra TGA9 registró un valor de 4\%. El resto de las muestras registraron valores inferiores a 3\%.

El contenido promedio de $\mathrm{Fe}_{2} \mathrm{O}_{3}$ fue 6,16\%, varió entre 4,6 y 7,3\%. La unidad con mayor contenido de $\mathrm{Fe}_{2} \mathrm{O}_{3}$ fue U-GA7, con un promedio de 6,7\%. La unidad con menor contenido de $\mathrm{Fe}_{2} \mathrm{O}_{3}$ fue U-GA2 (5,23\%). Cabe mencionar que la muestra con mayor contenido de $\mathrm{Fe}_{2} \mathrm{O}_{3}$ normalizado en función del $\mathrm{CaCO}_{3}$ corresponde a la costra calcárea del tope de dicha unidad. Así mismo las muestras TGA16, TGA6, TGA5, todas correspondientes a niveles con elevado $\mathrm{CaCO}_{3}$, registran valores de $\mathrm{Fe}_{2} \mathrm{O}_{3}$ 
normalizado relativamente elevados $\left(7,7,7,2\right.$ y 7,1\% respectivamente). El contenido promedio de $\mathrm{Fe}_{2} \mathrm{O}_{3}$ normalizado de las muestras que contienen porcentajes de $\mathrm{CaCO}_{3}$ mayores a $20 \%$ fue $8,2 \%$, y en las que presentaron menos de $20 \%$ de $\mathrm{CaCO}_{3}$ el promedio de $\mathrm{Fe}_{2} \mathrm{O}_{3}$ normalizado fue menor (6,5\%). El coeficiente de correlación entre $\mathrm{CaCO}_{3}$ y $\mathrm{Fe}_{2} \mathrm{O}_{3}$ normalizado resultó positivo y fuerte $(\mathrm{R}=0,67)$. Por otro lado, el coeficiente de correlación entre $\mathrm{Fe}_{2} \mathrm{O}_{3}$ y $\mathrm{PI} 550$ fue positivo y moderado $(\mathrm{R}=0,43)$.

\subsubsection{Química Sección Playa Dorada (PPD)}

En la figura 7.9 se indican los valores de PI550, $\mathrm{CaCO}_{3}, \mathrm{Fe}_{2} \mathrm{O}_{3}$ y $\mathrm{Fe}_{2} \mathrm{O}_{3}$ normalizado en función del $\mathrm{CaCO}_{3}$ de las muestras de la sección estratigráfica de Playa Dorada. Los valores son referidos a las unidades de la columna sedimentaria de la figura 5.60.

El valor promedio de PI550 en las muestras de la sección PPD fue 3,5\%. Los valores más elevados corresponden a las muestras TPD13 (5,5\%) (tope de la unidad hidromórfica U-PD5) y TPD6 $(5,3 \%)$ (paleosuelo con "calcreta reticulada" S-PD1) y los más bajos a las muestras TPD12 (4,86\%) y TPD10 (4,93\%). El valor promedio más elevado se registró en las muestras de la unidad U-PD6 (4,2\%); valores más bajos se registraron en las unidades U-PD4 y U-PD2 (ambas 2,4\%). E1 resto de las unidades registraron valores intermedios, cercanos a $3,8 \%$.

El contenido promedio de carbonato de calcio fue 4,1\%. La mayor concentración de $\mathrm{CaCO}_{3}$ corresponde a la muestra TPD6, del paleosuelo con "costra calcárea reticulada" del tope de la unidad UPD3 (13,3\%) y la menor concentración a la muestra TPD4 (1,4\%) y TPD20 (1,5\%), esta última corresponde al nivel de ceniza (no graficada en la figura). La unidad con mayor contenido promedio de $\mathrm{CaCO}_{3}$ fue la U-PD3 (7,8\%) y la de menor la U-PD2 (1,8\%). El resto de las unidades registraron valores intermedios, entre 2,9 (U-PD6) y 4,4\% (U-PD1).

El contenido promedio de $\mathrm{Fe}_{2} \mathrm{O}_{3}$ fue 5,7\%, varió entre 4,9\% (TPD12 y TPD10) y 6,6\% (TPD18). La unidad con mayor contenido de $\mathrm{Fe}_{2} \mathrm{O}_{3}$ fue U-PD6 (6,4\%) mientras que la de menor contenido fue UPD4 (4,9\%). El mayor contenido de $\mathrm{Fe}_{2} \mathrm{O}_{3}$ normalizado fue determinado en la muestra TPD6 del paleosuelo con costra calcárea reticulada (7\%). El coeficiente de correlación entre PI550 y $\mathrm{Fe}_{2} \mathrm{O}_{3}$ fue positivo y muy fuerte $(0,76)$. Cabe destacar que este asciende a 0,89 si consideramos al porcentaje de $\mathrm{Fe}_{2} \mathrm{O}_{3}$ normalizado por el $\mathrm{CaCO}_{3}$. Por otro lado, el coeficiente de correlación entre $\mathrm{CaCO}_{3}$ y $\mathrm{Fe}_{2} \mathrm{O}_{3}$ normalizado fue positivo y moderado $(0,42)$. 


\subsubsection{Química Sección El Casal (PEC)}

En la figura 7.10 se indican los valores de PI550, $\mathrm{CaCO}_{3}, \mathrm{Fe}_{2} \mathrm{O}_{3}$ y $\mathrm{Fe}_{2} \mathrm{O}_{3}$ normalizado por el $\mathrm{CaCO}_{3}$ de las muestras de la sección estratigráfica de Estancia El Casal. Los valores son referidos a las unidades de la columna sedimentaria de la figura 5.67.

El valor promedio de PI550 en las muestras de la sección PEC fue 4,04\%. El valor más bajo $(2,08 \%)$ corresponde a la muestra TEC2 del tope de la unidad U-EC2; los valores más elevados corresponden a las muestras de los paleosuelos del tope de las unidades U-EC5 y U-EC3, donde el valor más elevado corresponde a la muestra TEC9 (5,1\%). Las unidades U-EC3, U-EC5 y U-EC6 registraron los valores promedio más elevados $(4,45,4,35$ 4,34\% respectivamente). Los valores más bajos corresponden al promedio de las muestras de la unidad U-EC2 $(2,44 \%)$ y a la muestra de la unidad U-EC1 (2,64\%). La muestra de la unidad U-EC4 registró un valor intermedio $(3,99 \%)$.

El contenido promedio de carbonato de calcio fue 5,4\%. La mayor concentración de $\mathrm{CaCO}_{3}$ corresponde a las muestras TEC8 $(12,1 \%)$, TEC7 $(11,1 \%)$ y TEC13 $(10,7 \%)$. Los valores más bajos corresponden a las muestras TEC12 (2,44\%) y TEC6 (2,49\%). El resto de las muestras presentaron valores intermedios que oscilaron entre 2,9 (TEC3) y $6,1 \%$ (TEC2).

El contenido promedio de $\mathrm{Fe}_{2} \mathrm{O}_{3}$ fue 6,8\%, varió entre 5,35\% (TEC1) y 8,03\% (TEC13). El coeficiente de correlación entre PI550 y $\mathrm{Fe}_{2} \mathrm{O}_{3}$ fue positivo y muy fuerte $(0,93)$. El coeficiente de correlación entre $\mathrm{CaCO}_{3}$ y $\mathrm{Fe}_{2} \mathrm{O}_{3}$ normalizado fue positivo y fuerte $(0,60)$.

\subsubsection{Química Sección PSE}

Las muestras extraídas de esta sección corresponden al nivel de arenas de playa con contenido bioclástico de la base de unidad U-SE3 (nivel marino). Los valores promedio de $\mathrm{PI} 550$ y $\mathrm{CaCO}_{3}$ fueron $4,5 \%$ y $12 \%$ respectivamente. En la tabla 7.3 se exponen los porcentajes de PI550 y $\mathrm{CaCO}_{3}$ de las muestras de la sección estratigráfica de la sección PCT. 


\subsection{Caracterización química de las unidades litoestratigráficas del sector serrano.}

En base a las equivalencias establecidas, se calcularon los valores promedio de los parámetros químicos determinados, de las distintas unidades litoestratigráficas del sector serrano. En el histograma de la figura 7.11a se indican los valores promedio de agua de composición más materia orgánica (PI550), Carbonato de Calcio $\left(\mathrm{CaCO}_{3}\right)$ y Hierro total $\left(\mathrm{Fe}_{2} \mathrm{O}_{3}\right)$ de las formaciones Las Ánimas, Vela, la unidad litoestratigráfica U-SB3/4, la Formacion Barker y la unidad litoestratigráfica U-VC6.

El valor más elevado de PI550 corresponde a las muestras de la matriz de la unidad U-VC6 $(5,3 \%)$, esto se relacionaría con la elevada proporción de arcilla, predominantemente expandibles. Las unidades correspondientes a la Formación Las Ánimas registraron un valor promedio ligeramente menor $(5,1 \%)$, que se debería a la presencia de materia orgánica y arcillas de iluviación vinculadas al desarrollo del suelo actual; el promedio sin incluir los horizontes del solum desciende a 2,8\%. Otro conjunto de muestras con un valor promedio relativamente elevado corresponde a las unidades de la Formación Barker $(4,5 \%)$, esto se vincula principalmente a la presencia de paleosuelos en esta unidad. Las unidades de la Formación Vela y de la unidad litoestratigrafíca U-SB3/4 registraron los valores promedio más bajos (3,5 y $3,6 \%$ ), esto se vincula al predominio de texturas con escasa presencia de arcilla.

Los valores promedio más elevados de $\mathrm{CaCO}_{3}$ corresponden a la Formaciones Vela $(15,5 \%)$ y a la unidad litoestratigráfica U-VC6 (13,1\%). El promedio en la Formación Barker fue 4,4\%. La Formación

Las Ánimas y la unidad U-SB3/4 registraron los valores promedio más bajos (2,84 y 2,83 respectivamente).

Los contenidos promedio de $\mathrm{Fe}_{2} \mathrm{O}_{3}$ más elevados corresponden a la Formación Barker $(6,86 \%)$ y la unidad U-SB3/4 (6,85\%). Las muestras de la Formación Las Ánimas registraron un valor promedio de 5,94\%; las de la Formación Vela de 5,77\%.

\subsection{Caracterización química de las asociaciones de unidades del sector costero al norte de}

\section{Mar del Plata.}

En base a las equivalencias establecidas en el sector costero al norte de Mar del Plata, se calcularon los valores promedio de los parámetros químicos determinados, para las distintas asociaciones de unidades. Los mismos se indican en la figura 7.11b.

El valor promedio de PI550 más bajo corresponde a la asociación A2 (2,4\%) y el más elevado a la asociación A5 (4,37\%). Este patrón es evidentemente dependiente de la textura de los sedimento; la 
asociación A2 presenta en general texturas más gruesas, con baja participación de arcillas. El resto de las unidades presentaron valores intermedios.

Los valores promedio más elevados de $\mathrm{CaCO}_{3}$ corresponden a la asociación $\mathrm{A} 3$ (19,21\%), seguida por la asociación A5 (7,54\%). El resto de las asociaciones presentaron valores promedio por debajo del $4 \%$.

Los contenidos promedio de $\mathrm{Fe}_{2} \mathrm{O}_{3}$ más elevados corresponden a las unidades de las asociaciones A5 y A4 (6,18 y 6,35\% respectivamente). Las asociaciones A1, A2 y A3 presentaron valores similares, ligeramente por encima de 5,5\%.

\subsection{Consideraciones de Importancia}

Los valores de PI550 más elevados se presentaron en los horizontes del suelo actual, en los paleosuelos y en otros niveles con contenidos de arcilla relativamente elevados.

$\mathrm{El} \mathrm{CaCO}_{3}$ presentó gran variación (entre 0,7 y 54\%); las unidades con mayores porcentajes de $\mathrm{CaCO}_{3}$ correspondieron a la asociación A3 y a la Formación Vela. Ambas se caracterizaron por presentar abundante carbonato en la masa y por presentar una costra calcárea (Paleosuperficie Tandil) en el tope. Cabe resaltar aquí que en el capítulo 5 fue propuesta la equivalencia entre A3 y Vela; la elevada presencia de $\mathrm{CaCO}_{3}$ en ambas (Fig. 7.11) es sin duda un punto a destacar, puesto que corrobora dicha propuesta.

El contenido de $\mathrm{Fe}_{2} \mathrm{O}_{3}$ fue relativamente constante, varió entre 4,6 y 9\%, con un promedio de $6,5 \%$; en general las mayores concentraciones de $\mathrm{Fe}_{2} \mathrm{O}_{3}$ coincidieron con los valores de PI550 más elevados. En la mayoría de los perfiles se observó una correlación positiva, moderada a muy fuerte entre dichos parámetros. El coeficiente de correlación osciló entre 0,4 y 0,95 , con un promedio de 0,74 . Cabe destacar que este coeficiente disminuye al incluir muestras con elevada cantidad de materia orgánica; es decir que el incremento de $\mathrm{Fe}_{2} \mathrm{O}_{3}$ se produciría en los niveles con mayor contenido de agua de composición, atribuida principalmente a los minerales hidratados como las arcillas. Esto es un incremento de $\mathrm{Fe}_{2} \mathrm{O}_{3}$ en los horizontes $\mathrm{Bt}$, tanto de paleosuelos como del suelo actual, que podría interpretarse preliminarmente como un proceso de migración conjunta de arcillas y óxidos de hierro durante el proceso de argiluviación, o bien que los minerales de arcilla que se acumulan, presenten hierro en su composición, como es el caso de la illita, la cual presenta hierro ferroso (Murad y Wagner, 1994), sin embargo las

concentraciones de hierro en este mineral suelen ser bajas (hierro normativo 1,85\% según http://webmineral.com/); en tanto, es posible que el hierro se concentre por iluviación, conformando 
óxidos y/o hidróxidos. Cabe destacar la posibilidad de que las arcillas (y/o la materia orgánica) actúen como transportadores (carriers) de dichos óxi-hidróxidos de hierro.

Por otro lado, se registró la existencia de correlaciones positivas, moderadas a muy fuertes entre el contenido de $\mathrm{CaCO}_{3}$ y el contenido de $\mathrm{Fe}_{2} \mathrm{O}_{3}$ normalizado por el contenido de carbonato. Los coeficientes de correlación oscilaron entre 0,42 y 0,99 , con un promedio de 0,70 . Se interpreta que la presencia de carbonato de calcio habría generado la floculación de óxidos de hierro en estado coloidal, esto se debería a que la presencia de $\mathrm{CaCO}_{3}$ conduce a un incremento del $\mathrm{pH}$ hasta valores de 8,3, el cual es cercano al punto isoeléctrico (valor de $\mathrm{pH}$ en el cual el potencial electrocinético es cero) de óxidos de hierro como hematita, goethita y lepidocrocita, cuyos valores fluctúan entre 7,1 y 8,5 (van Schuylenborgh y Arens, 1950; Martínez Gasca et al., 1982). No se descartan procesos como la fijación de hierro mediante microorganismo o bien la presencia de carbonatos de hierro. Cabe destacar que algunos niveles con elevado $\mathrm{CaCO}_{3}$ no presentaron incremento relativo del $\mathrm{Fe}_{2} \mathrm{O}_{3}$, estos corresponden principalmente a la Formación Vela y a la asociación costera A3, se interpreta que en estas el carbonato de calcio habría sido posterior a la pedogénesis.

Los factores que conducen a incrementos de $\mathrm{Fe}_{2} \mathrm{O}_{3}$ serán tratados con mayor profundidad luego de efectuar el análisis de los parámetros magnéticos en el capítulo 9. 
7.7 Figuras del Capítulo 7

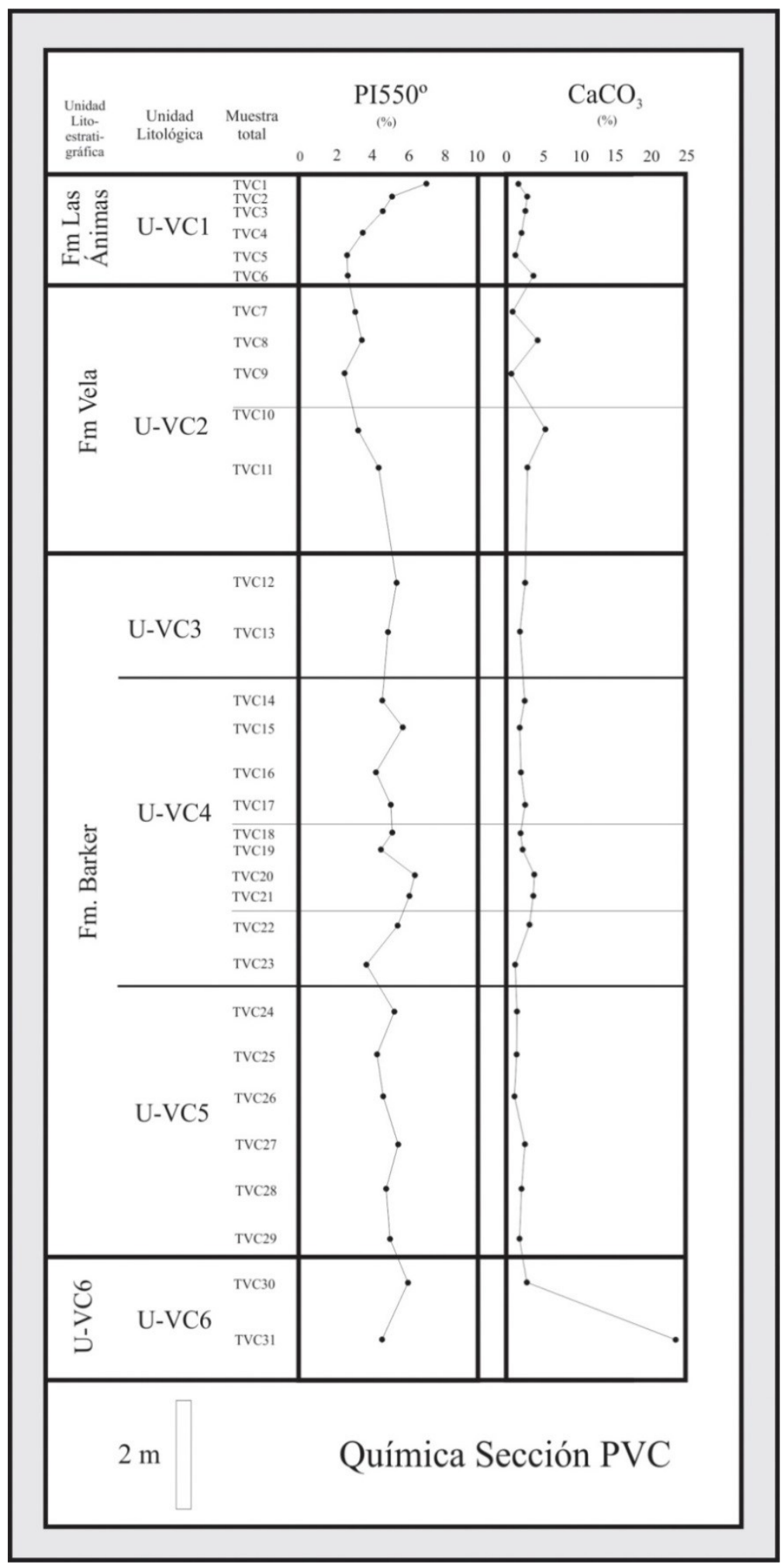

Figura 7.1. Valores de $\mathrm{PI} 550$ y $\mathrm{CaCO}_{3}$ de las muestras de la sección estratigráfica de Villa Cacique (PVC). 


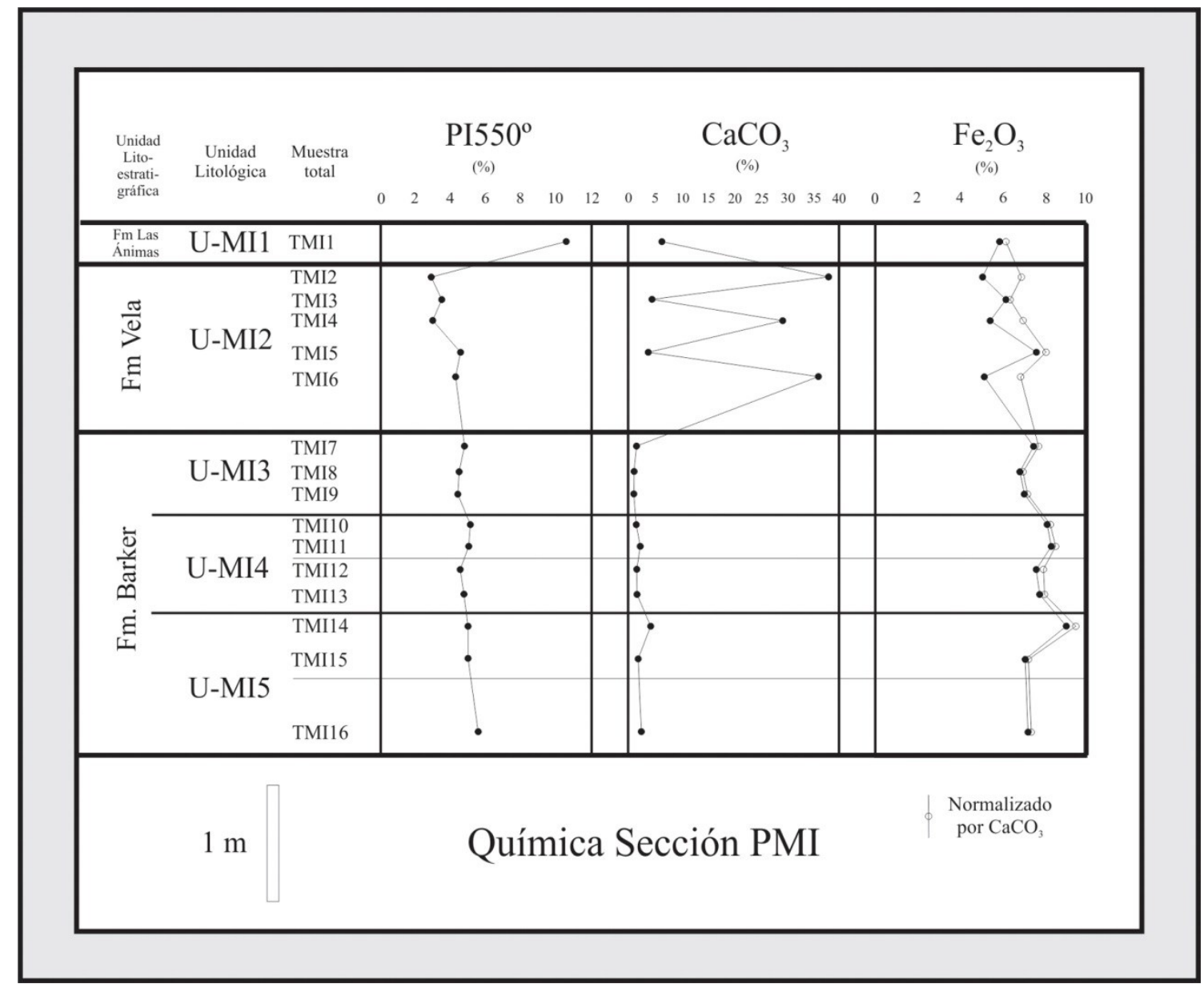

Figura 7.2. Valores de $\mathrm{PI} 550, \mathrm{CaCO}_{3}$ y $\mathrm{Fe}_{2} \mathrm{O}_{3}$ de las muestras de la sección estratigráfica de María Ignacia (PMI). 


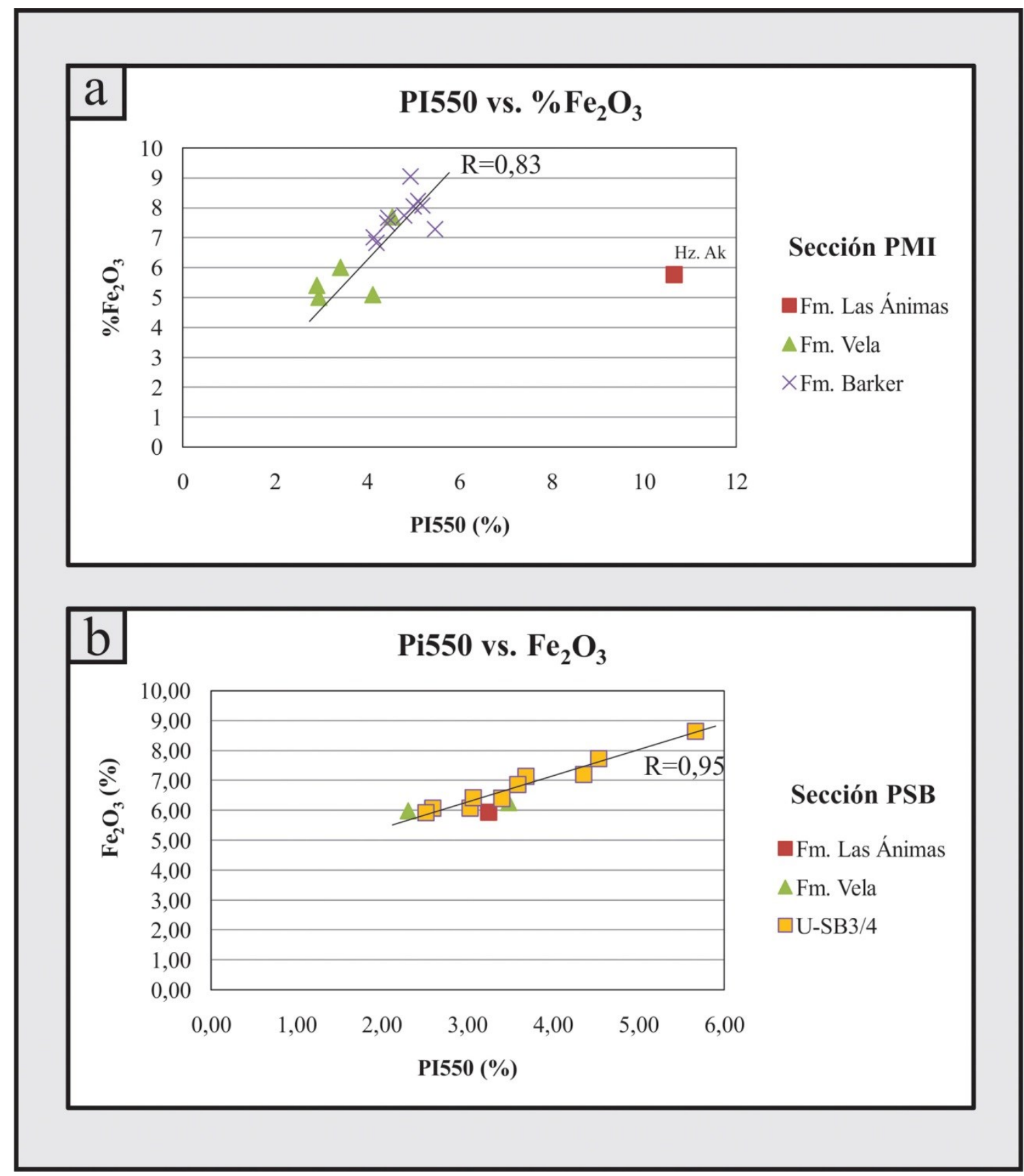

Figura 7.3. Gráficos PI550 vs. $\% \mathrm{Fe}_{2} \mathrm{O}_{3}$. a) Sección PMI; b) Sección PSB. 


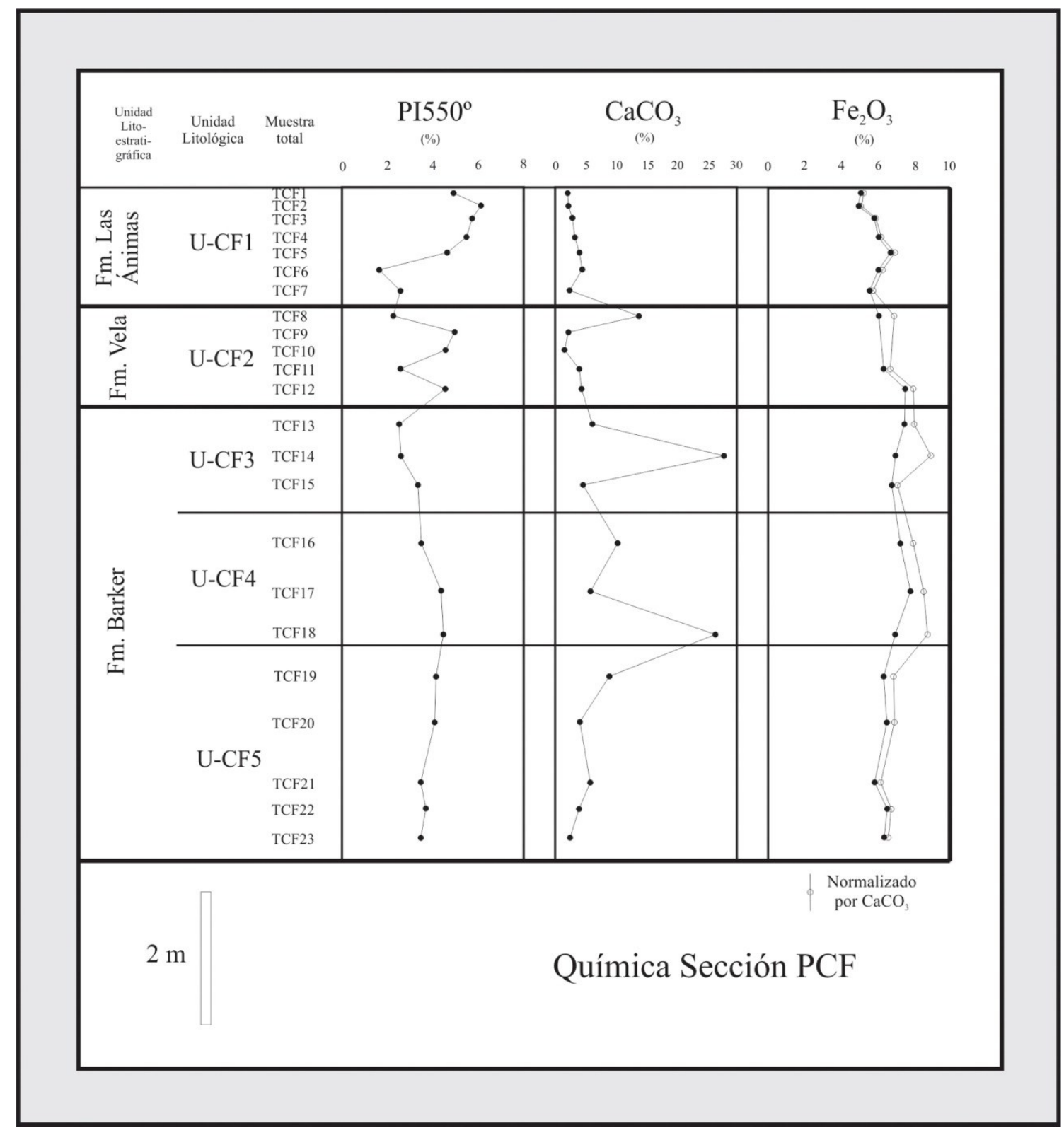

Figura 7.4. Valores de $\mathrm{PI} 550, \mathrm{CaCO}_{3}$ y $\mathrm{Fe}_{2} \mathrm{O}_{3}$ de las muestras de la sección estratigráfica de Calle Fangio (PCF). 


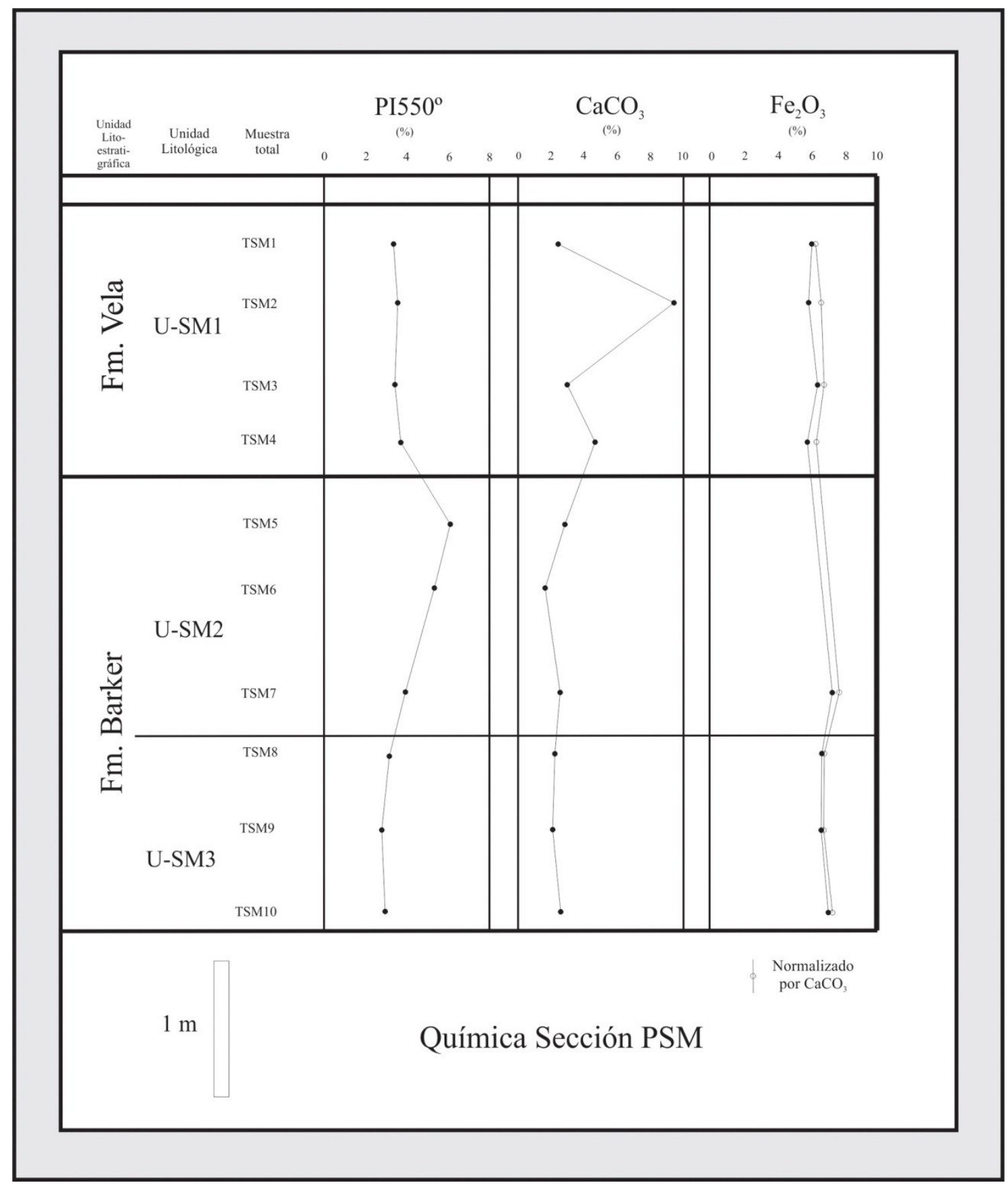

Figura 7.5. Valores de $\mathrm{PI} 550, \mathrm{CaCO}_{3}$ y $\mathrm{Fe}_{2} \mathrm{O}_{3}$ de muestras de la sección estratigráfica de San Manuel (PSM). 


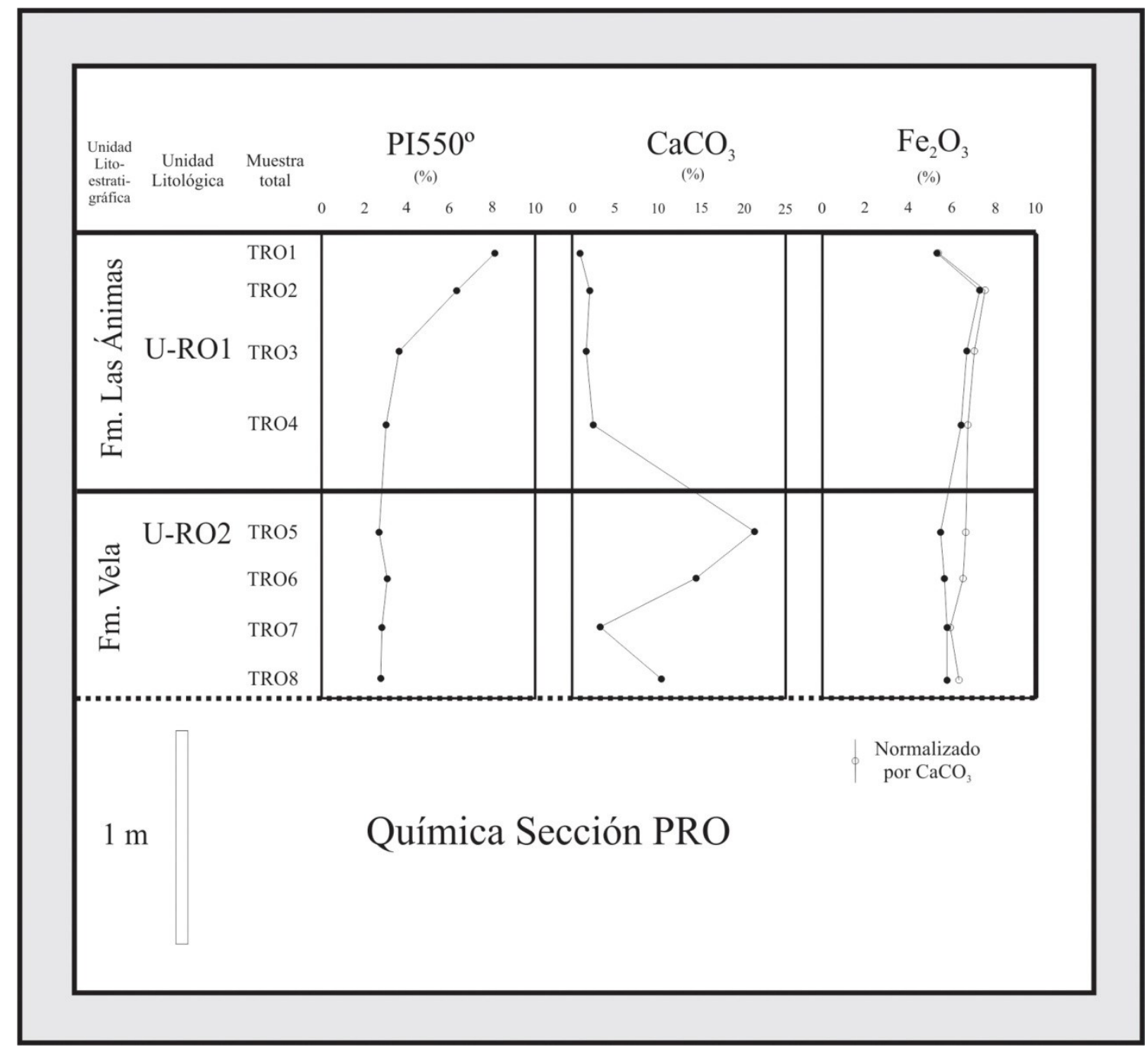

Figura 7.6. Valores de $\mathrm{PI} 550, \mathrm{CaCO}_{3}$ y $\mathrm{Fe}_{2} \mathrm{O}_{3}$ de muestras de la sección estratigráfica de Ramos Otero (PRO). 


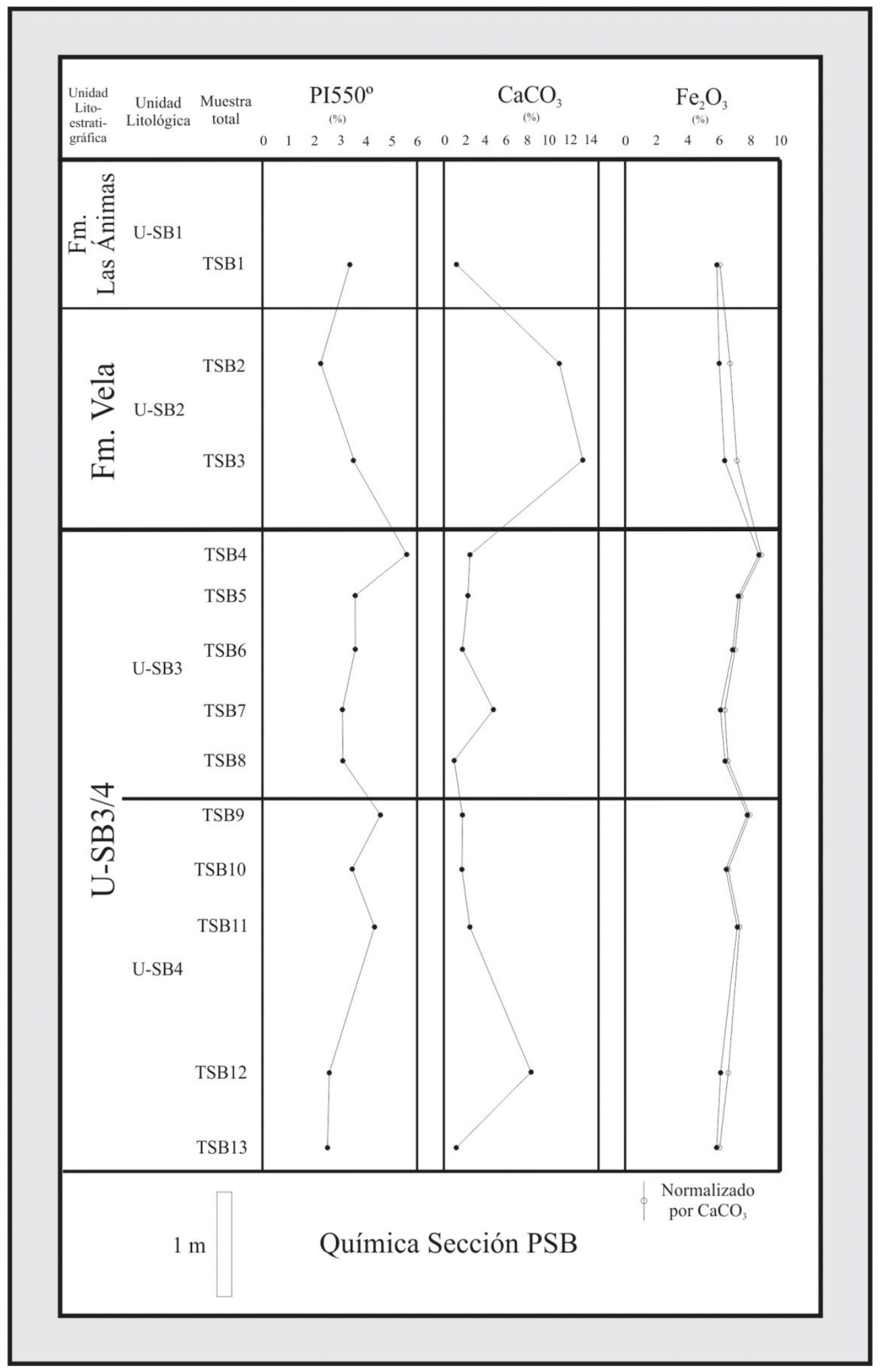

Figura 7.7. Valores de $\mathrm{PI} 550, \mathrm{CaCO}_{3}$ y $\mathrm{Fe}_{2} \mathrm{O}_{3}$ de muestras de la sección estratigráfica de Sierra Bachicha (PSB). 


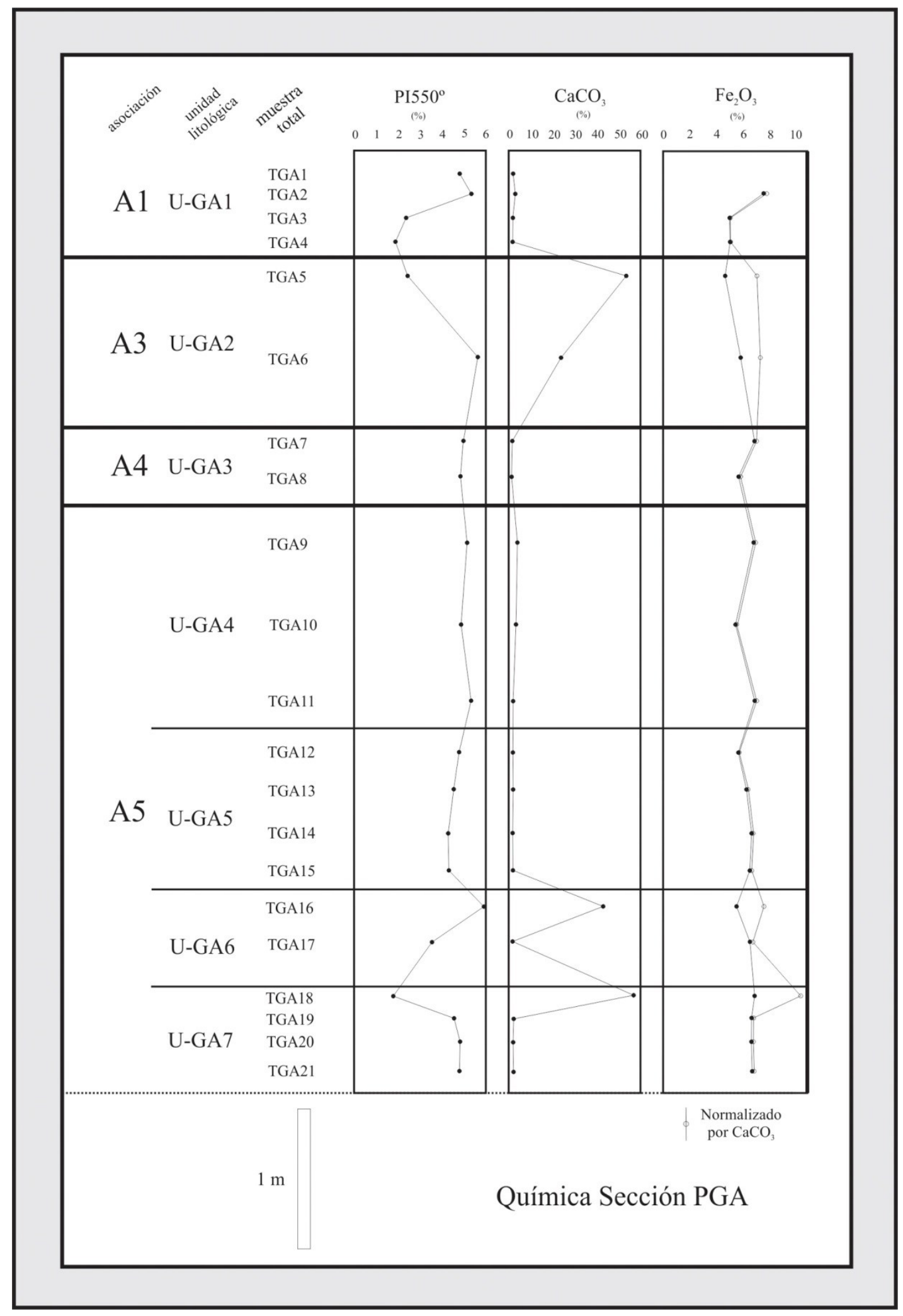

Figura 7.8. Valores de $\mathrm{PI} 550, \mathrm{CaCO}_{3}$ y $\mathrm{Fe}_{2} \mathrm{O}_{3}$ de muestras de la sección estratigráfica GADA (PGA). 


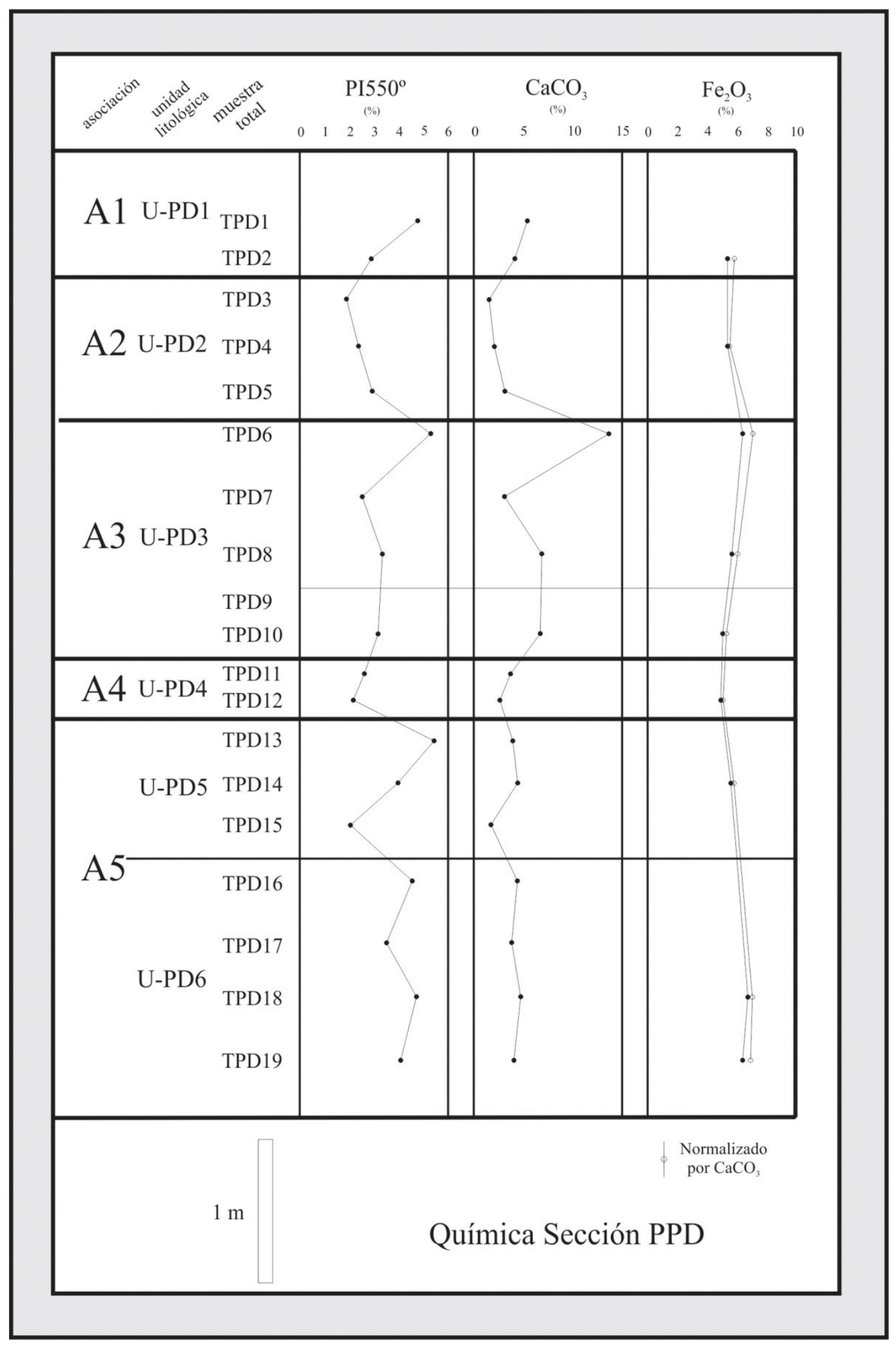

Figura 7.9. Valores de $\mathrm{PI} 550, \mathrm{CaCO}_{3}$ y $\mathrm{Fe}_{2} \mathrm{O}_{3}$ de muestras de la sección estratigráfica de Playa Dorada (PPD). 


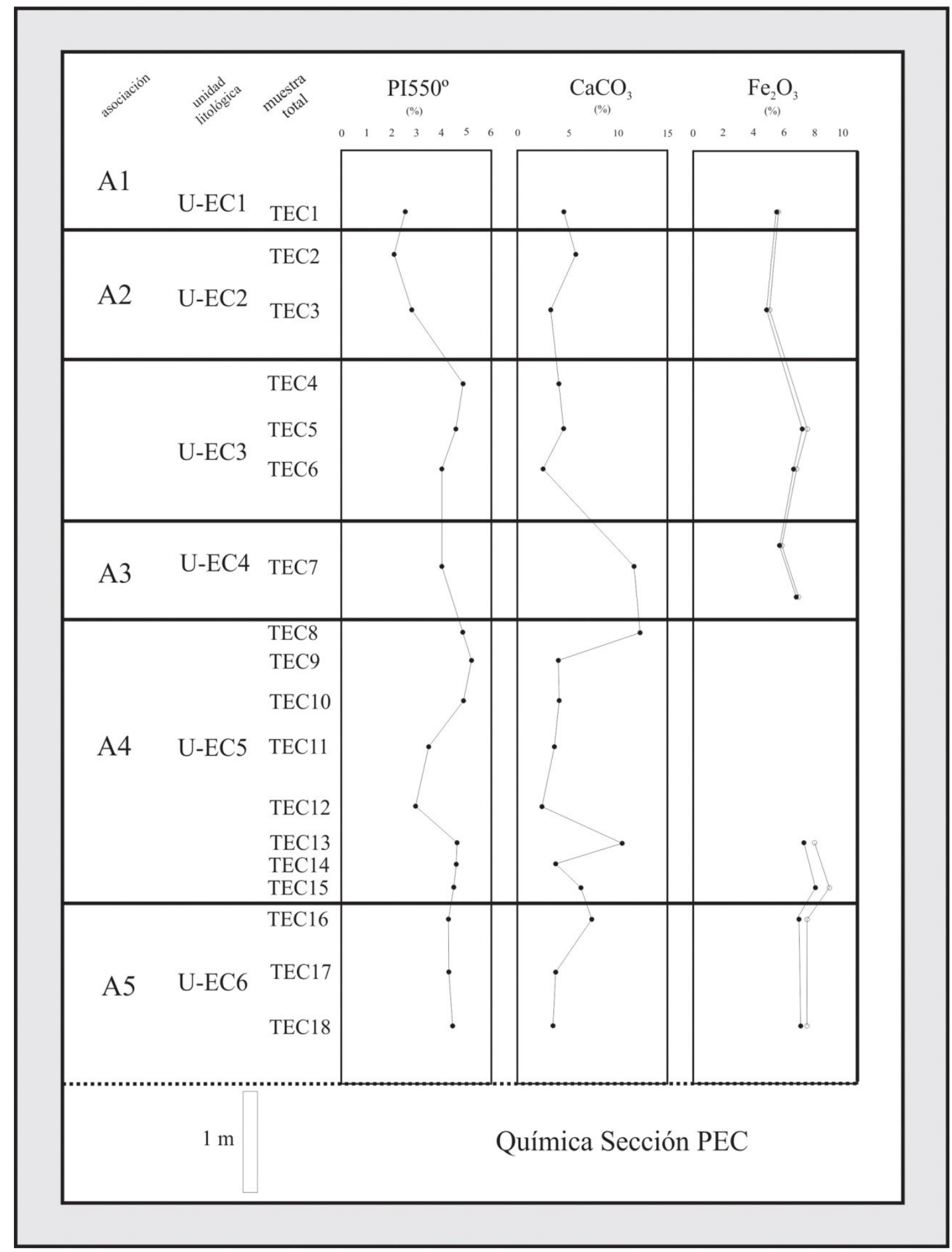

Figura 7.10. Valores de $\mathrm{PI} 550, \mathrm{CaCO}_{3}$ y $\mathrm{Fe}_{2} \mathrm{O}_{3}$ de muestras de la sección estratigráfica El Casal (PEC). 

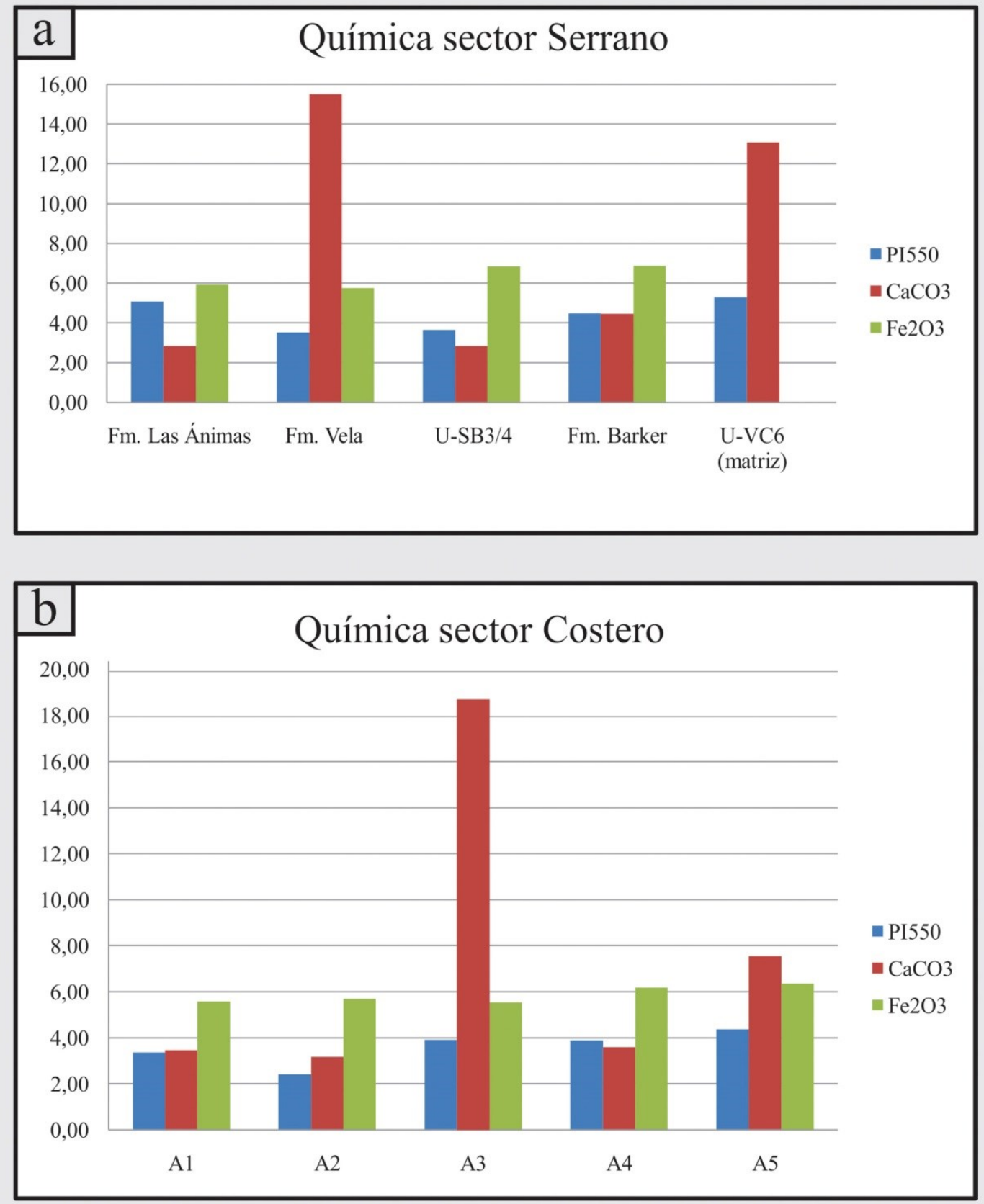

Figura 7.11. Valores promedio de $\mathrm{PI} 550, \mathrm{CaCO}_{3}$ y Fe ${ }_{2} \mathrm{O}_{3}$ de las unidades litoestratigráficas del sector serrano (a) y de las asociaciones del sector costero (b). 


\subsection{Tablas Capítulo 7}

\begin{tabular}{|c|c|c|}
\hline Muestra & PI550 & $\mathrm{CaCO}_{3}$ \\
\hline TCT1 & 2,46 & 1,39 \\
\hline TCT2 & 2,39 & 1,09 \\
\hline TCT3 & 2,30 & 1,12 \\
\hline TCT4 & 2,28 & 2,47 \\
\hline TCT5 & 3,30 & 6,29 \\
\hline & $\%$ & $\%$ \\
\cline { 2 - 3 }
\end{tabular}

Tabla 7.1. Valores de PI550 y $\mathrm{CaCO}_{3}$ de las muestras de la sección estratigráfica Circuito Turístico (PCT).

\begin{tabular}{|c|c|c|}
\hline Muestra & PI550 & $\mathrm{CaCO}_{3}$ \\
\hline TCQ1 & $\mathbf{5 , 5}$ & 30,7 \\
\hline TCQ2 & 3,9 & 41,8 \\
\hline & $\%$ & $\%$ \\
\hline
\end{tabular}

Tabla 7.2. Valores de PI550 y $\mathrm{CaCO}_{3}$ de las muestras de la sección estratigráfica Cerro Quebracho (PCQ).

\begin{tabular}{|c|c|c|}
\hline Muestra & PI550 & $\mathbf{C a C O}_{\mathbf{3}}$ \\
\hline TSE1 & 4,88 & 21,36 \\
\hline TSE2 & 4,04 & 2,72 \\
\hline \multirow{2}{*}{} & $\%$ & $\%$ \\
\cline { 2 - 3 }
\end{tabular}

Tabla 7.3. Valores de PI550 y $\mathrm{CaCO}_{3}$ de las muestras de la sección estratigráfica Santa Elena (PSE). 


\section{CAPITULO 8. PALEOMAGNETISMO Y MAGNETOESTRATIGRAFÍA}

En la primera parte de este capítulo se presentan los resultados obtenidos de las mediciones paleomagnéticas. Los perfiles paleomagnéticos se refieren a los paneles del capítulo 5. En las figuras correspondientes a cada perfil se indican los valores de intensidad, del magnetismo remanente natural $\left(\mathrm{J}^{\circ}\right)$ y a un campo pico desmagnetizante de $20 \mathrm{mT}\left(\mathrm{J}^{20}\right)$, los valores de declinación (D) e inclinación (I) de la magnetización remanente característica (MRC), así como la polaridad magnética y el nombre asignado a la magnetozona. Como fue dicho en el capítulo 4, las magnetozonas se designan con el prefijo M, seguido por guión, la sigla del perfil y el número de magnetozona, donde el número 1 corresponde a la magnetozona superior; por ejemplo M-CF2 designa a la magnetozona del perfil de Calle Fangio que se encuentra debajo de la magnetozona superior (M-CF1). Asimismo, las magnetozonas pueden abarcar distintas unidades litológicas o litoestratigráficas, dado que los contactos entre éstas involucran discontinuidades, que pueden significar hiatos temporales, cuya magnitud aún no se conoce con precisión, los análisis estadísticos se realizan teniendo en cuenta a cada unidad por separado. Tal criterio es a los fines de considerar las discontinuidades, que a nivel regional (antes de realizar la integración de todos los perfiles) pueden desempeñar un rol fundamental en la definición de la columna magnetoestratigráfica.

Hacia el final del presente capítulo se realizan correlaciones magnetoestratigráficas entre las distintas secciones. Las unidades establecidas se refieren a la escala internacional de los cambios de polaridad paleomagnética y se proponen edades mínimas y máximas.

\subsection{Paleomagnetismo en el sector Sierras de Tandil}

\subsubsection{Perfiles paleomagnéticos en la sección Villa Cacique (PVC).}

En la sección estratigráfica de Villa Cacique se construyeron cuatro perfiles paleomagnéticos (Fig. 8.1 y 8.2). La ubicación de los mismos respecto a las unidades litológicas se muestra en el panel de la figura 5.5. Se utilizaron datos de 126 muestras paleomagnéticas.

El perfil paleomagnético 1 (Fig. 8.1a) comprende los seis metros superiores del afloramiento de Villa Cacique, incluye las formaciones Las Ánimas y Vela. Las muestras obtenidas para la elaboración del 
resto de los perfiles paleomagnéticos corresponden a la Formación Barker Fig. 8.1b-c; Fig. 8.2). Debido a las características del material no fue posible extraer muestras paleomagnéticas de la unidad U-VC6.

En los perfiles paleomagnéticos de las figuras 8.1 y 8.2 se indican los valores de intensidad magnética tanto de la magnetización remanente natural $\left(\mathrm{J}^{\circ}\right)$ como a un campo pico de $20 \mathrm{mT}\left(\mathrm{J}^{20}\right)$, la declinación (D) y la inclinación magnética (I), y de magnetización remanente característica (MRC).

La intensidad del magnetismo remanente natural $\left(\mathrm{J}^{\mathrm{o}}\right)$ evidenció una gran variabilidad, osciló entre 4,5 y $683,1 \times 10^{-6} \mathrm{Am}^{2} / \mathrm{Kg}$. El valor medio de $\mathrm{J}^{\mathrm{o}}$ de las muestras de la Formación Las Ánimas fue el más elevado $\left(407,2 \times 10^{-6} \mathrm{Am}^{2} / \mathrm{Kg}\right)$; hacia el tope, los valores de $\mathrm{J}^{\mathrm{o}}$ fueron destacadamente más bajos. En contraposición, las muestras extraídas de la Formación Vela presentaron el valor medio más bajo $(75,1$ $\mathrm{x} 10^{-6} \mathrm{Am}^{2} / \mathrm{Kg}$ ). La Formación Barker presentó la mayor variación, pues los valores oscilaron entre 4,5 y $585,2 \times 10^{-6} \mathrm{Am}^{2} / \mathrm{Kg}$, el valor medio obtenido es de 93,3 $\times 10^{-6} \mathrm{Am}^{2} / \mathrm{Kg}$.

La intensidad magnética luego de aplicar un campo pico desmagnetizante de $20 \mathrm{mT}\left(\mathrm{J}^{20}\right)$ osciló entre 0,8 y $66,5 \times 10^{-6} \mathrm{Am}^{2} / \mathrm{Kg}$, con un valor medio de $14,5 \times 10^{-6} \mathrm{Am}^{2} / \mathrm{Kg}$. El valor promedio de la Formación Las Ánimas, al igual que $\mathrm{J}^{\mathrm{o}}$, fue el más elevado $\left(32,7 \times 10^{-6} \mathrm{Am}^{2} / \mathrm{Kg}\right)$, no obstante el comportamiento difiere de la medición a $\mathrm{J}^{\mathrm{o}}$. La Formación Vela registró un valor promedio de 15,2 ×10 $0^{-6}$ $\mathrm{Am}^{2} / \mathrm{Kg}$; se destaca que los valores más elevados de $\mathrm{J}^{20}$ corresponden a una crotovina circular, cuyo relleno se dispone en láminas paralelas. La $\mathrm{J}^{20}$ media de las muestras de la Formación Barker es la más baja $\left(13,1 \times 10^{-6} \mathrm{Am}^{2} / \mathrm{Kg}\right)$, con una variación elevada, entre 0,8 y $66,5 \times 10^{-6} \mathrm{Am}^{2} / \mathrm{Kg}$. El coeficiente de correlación entre la $\mathrm{J}^{\mathrm{o}}$ y la $\mathrm{J}^{20}$ fue de 0,33 , indicando una leve correlación positiva.

Las direcciones del MRC obtenidas, permitieron determinar distintas zonas de polaridad magnética, en tanto fue posible configurar la sección de Villa Cacique en distintas zonas de magnetopolaridad. En la Tabla 8.1 se indican las direcciones de D e I medias de las magnetozonas establecidas, así como los parámetros de concentración $\kappa$, el semiángulo de confianza $\alpha 95$ y las unidades litológicas y litoestratigráficas correspondientes. En las figuras 8.3 a 8.7 se indica mediante redes estereográficas, curvas de desmagnetización y diagramas de Zijderveld el comportamiento frente al "lavado" por CMA, de distintas muestras de las magnetozonas establecidas. La magnetozona M-VC1, de polaridad normal, se analizó en función de las tres unidades litolestratigráficas que abarca. En la figura 8.3a se exponen los diagramas de muestras de la Formación Las Ánimas. VC1 corresponde al horizonte A y VC5 al sector medio de la unidad. Los valores de D e I característicos de la muestra del horizonte A, así como su comportamiento frente a la desmagnetización, es diferente al resto de las muestras de la unidad; a campos bajos de 2,5 $\mathrm{mT}$ se eliminó una componente viscosa, a partir de dicho campo se desmagnetizó la componente principal $\left(\mathrm{D}=359,3^{\circ} ; \mathrm{I}=-63,2^{\circ}\right)$, que fue eliminada a un campo pico de $40 \mathrm{mT}$; luego presentó 
direcciones espúreas. La muestra VC5, a campos pico de baja intensidad presentó una componente secundaria de $\mathrm{D}=285,4^{\circ}$ e $\mathrm{I}=-0,3^{\circ}\left(\mathrm{MDA}=0,4^{\circ}\right)$ que fue eliminada entre 7,5 y $10 \mathrm{mT}$ de campo aplicado; a partir de $10 \mathrm{mT}$ de campo pico se desmagnetizó otra componente, de polaridad normal $\left(\mathrm{D}=292,2^{\circ}\right.$, I=$21,3^{\circ}$ ), con caída de la intensidad hacia el origen del sistema de Zijderveld. Las diferencias de comportamiento pueden vincularse a las observaciones de campo, que sugieren que los sedimentos de la parte superior de esta formación podrían corresponder a un evento depositacional posterior (discontinuidad litológica) enmascarado por pedogénis; no se descarta que las diferencias en la muestra del tope puedan deberse a una reorientación de las partículas con posterioridad a la depositación. Cabe resaltar que la posición del campo geomagnético actual para la localidad estudiada es $\mathrm{D}=354^{\circ} 14^{\prime} 57^{\prime \prime}$, I=$41^{\circ} 6^{\prime} 16^{\prime \prime}$, en tanto no se descarta que la orientación de las mismas se encuentre afectada por el campo magnético actual.

En la figura $8.3 \mathrm{~b}$ se presentan los gráficos de dos muestras representativas de la Formación Vela. En la muestra VC11, a partir de campos bajos $(2,5 \mathrm{mT})$ se desmagnetizó la componente principal $\left(\mathrm{D}=355,1^{\circ}, \mathrm{I}=-45,1^{\circ}\right)$, que fue eliminada a campos pico de $60 \mathrm{mT}$. Cabe destacar que esta componente se desmagnetizó apartándose del origen del sistema, en tanto se intuye la presencia de una componente, de elevada coercitividad, que no pudo ser lavada mediante la técnica empleada. La muestra VC17, a campos pico de baja intensidad presentó una componente secundaria de polaridad normal $\left(\mathrm{D}=6,2^{\mathrm{o}} ; \mathrm{I}=-32,4^{\mathrm{o}}\right.$; $\left.\mathrm{MDA}=2,5^{\circ}\right)$ que fue eliminada a un campo pico de $10 \mathrm{mT}$; luego se desmagnetizó la componente principal, de polaridad normal $\left(\mathrm{D}=357,2^{\circ}\right.$; $\mathrm{I}=-62,4$; MDA:6,4 $4^{\circ}$, la cual se dirigió al origen del sistema $\mathrm{y}$ fue eliminada tras aplicar un campo pico de $30 \mathrm{mT}$.

En el tope de la Formación Barker, se registraron direcciones de polaridad normal; en la figura 8.4a se observan las redes estereográficas, curvas de desmagnetización y diagramas de Zijderveld de dos muestras representativas de la unidad U-VC3. La muestra VC29, presentó una componente viscosa $\left(\mathrm{D}=29,9^{\circ} ; \mathrm{I}=-46,5^{\circ} ; \mathrm{MDA}=6,5\right)$ que fue eliminada a $5 \mathrm{mT}$ de campo pico; luego se desmagnetizó la componente principal $\left(\mathrm{D}=356,1^{\circ}, \mathrm{I}=-58^{\circ}\right)$, con caída de la intensidad hacia el centro del sistema del diagrama de Zijderveld; la misma fue eliminada a campos pico de $30 \mathrm{mT}$; a campos más elevados las direcciones fueron espúreas. La muestra VC36 presentó una componente de $\mathrm{D}=13,3^{\circ} ; \mathrm{I}=-35^{\circ}\left(\mathrm{MDA}=6,5^{\circ}\right)$ que fue eliminada a 7,5 $\mathrm{mT}$ de campo pico; luego se desmagnetizó la componente considerada principal $\left(\mathrm{D}=6,9^{\circ} ; \mathrm{I}=-46,5^{\circ}\right)$ que se dirigió al centro del sistema de Zijderveld y fue eliminada a campos pico de 40 mT. El resto de las magnetozonas corresponden a los sedimentos asignados a la Formación Barker. En la magnetozona M-VC2, a excepción de la muestra VC28 ( $\left.\mathrm{D}=325,7^{\circ} ; \mathrm{I}=-67^{\circ}\right)$, se evidenciaron polaridades anómalas (o bien oblicuas), esto es: declinaciones magnéticas que no se corresponden con las inclinaciones esperadas para el hemisferio sur; en la Fig. 8.4b se presentan los gráficos correspondientes a 
una muestra de esta magnetozona; la misma presentó una única componente (monocomponente) con valores de declinación que son afines a polaridad inversa $\left(\mathrm{D}=238,6^{\circ}\right)$ y valores de inclinación con afinidad a polaridad normal para el hemisferio sur $\left(\mathrm{I}=-63,7^{\circ}\right)$; ésta se desmagnetizó a partir de un campo pico de $5 \mathrm{mT}$ hacia el centro del sistema de Zijderveld; fue eliminada a un campo pico de $35 \mathrm{mT}$. Cabe resaltar que la muestra VC43, inclúida en la magnetozona M-VC2, es de polaridad claramente normal. Se desconocen con exactitud las causas que originan el comportamiento anómalo, dado que la magnetozona que le subyace es de polaridad inversa, es posible interpretar que podría estar vinculado al proceso de inversión del campo magnético terrestre. Las causas para este tipo de comportamiento serán analizadas con mayor profundidad hacia el final del presente capítulo.

La magnetozona M-VC3, de polaridad inversa, es coincidente con el paleosuelo del tope de la unidad U-VC4. En la figura 8.5 se observan estereogramas, curvas de desmagnetización y diagramas de Zijderveld de dos muestras representativas de dicha magnetozona. Ambas muestras presentaron comportamientos similares. La muestra VC48 exhibió dos componentes, una normal $\left(\mathrm{D}=4,1^{\mathrm{o}} ; \mathrm{I}=-20^{\mathrm{o}}\right.$; $\left.\operatorname{MDA}=3,9^{\circ}\right)$ que fue eliminada a campos bajos $(7,5 \mathrm{mT})$; y una inversa $\left(\mathrm{D}=195^{\circ}, \mathrm{I}=51,6^{\circ}\right)$, que fue eliminada al impartir un campo pico de $45 \mathrm{mT}$. La muestra VC80, presentó también una componente de polaridad normal $\left(\mathrm{D}=331,2^{\circ} ; \mathrm{I}=-20^{\circ} ; \mathrm{MDA}=3,9^{\circ}\right)$ que fue eliminada a campos bajos $(7,5 \mathrm{mT})$, luego fue desmagnetizada la componente considerada principal, de polaridad inversa $\left(D=176,7^{\circ} ; \mathrm{I}=53,8^{\circ}\right)$; eliminada al aplicar un campo pico de $40 \mathrm{mT}$. Cabe destacar que ambas muestras a pesar de corresponder a perfiles paleomagnéticos distintos ( 3 y 4) presentaron comportamiento análogos frente a la desmagnetización.

La magnetozona M-VC4, de polaridad normal abarca parte de dos unidades litológicas (U-VC4 y U-VC5). En la figura 8.6 se observan los gráficos de muestras representativas; dos extraídas de la unidad U-VC4 (Fig. 8.6a) y una de U-VC5 (Fig.8.6b). La muestra VC72, presentó una única componente ( $\mathrm{D}=5^{\circ}$; $\left.\mathrm{I}=-50,9^{\circ}\right)$, que se desmagnetizó desde el inicio del tratamiento y fue eliminada al aplicar un campo pico de $35 \mathrm{mT}$. La muestra VC85 también presentó una única componente de polaridad normal $\left(\mathrm{D}=330^{\circ}\right.$, I=$45,6^{\circ}$ ), que se desmagnetizó a partir de que se eliminó la componente viscosa (a $5 \mathrm{mT}$ de campo pico); a campos más elevados las direcciones son estables hasta que la caída de la intensidad de la remanencia alcanza el origen del sistema. Dicha componente principal se destruyó a un campo pico de $60 \mathrm{mT}$. La muestra VC101 presentó en cambio tres componentes; la primera $\left(\mathrm{D}=28,3^{\circ} ; \mathrm{I}=53,8^{\circ}, \mathrm{MDA}=0,8^{\circ}\right)$ fue eliminada a campos bajos; a partir de la aplicación de un campo pico de $5 \mathrm{mT}$ se desmagnetizó una componente de polaridad normal $\left(\mathrm{D}=1,2^{\circ} ; \mathrm{I}=-34^{\circ} ; \mathrm{MDA}=2^{\circ}\right)$, eliminada a un campo pico de $10 \mathrm{mT}$. A partir de ahí se desmagnetizó la componente principal, de polaridad normal ( $\mathrm{D}=346,9^{\circ} ; \mathrm{I}=-35,9^{\circ}$; $\mathrm{MDA}=3,1^{\circ}$ ), que se dirigió al centro del sistema y se eliminó al impartir un campo pico de $60 \mathrm{mT}$. 
En cuanto a las magnetozonas restantes, M-VC5 y M-VC7 son de polaridad inversa, mientras que M-VC6 es de polaridad normal; entre las magnetozonas M-VC6 y M-VC7, así como en la base del perfil, se registraron zonas de polaridad mixta; esto es, la existencia de muestras tanto normales, inversas como anómalas, sin mostrar un patrón vertical definido. Este comportamiento será analizado hacia el final del capítulo. Cabe destacar que las magnetozonas M-VC6 y M-VC7, de la base de Formación Barker, registraron los valores de $\kappa$ más bajos, así como los $\alpha 95$ más elevados de la sección; esto se vincularía principalmente a las características del depósito sedimentario, con gran proporción de clastos de tamaños superiores a $2 \mathrm{~mm}$. En la Fig. 8.7 se indica el comportamiento de muestras representativas de las magnetozonas M-VC5, M-VC6 y M-VC7. La muestra VC109 (Fig. 8.7a) presentó dos componentes; desde el inicio del tratamiento se desmagnetizó una componente viscosa, de polaridad normal $\left(\mathrm{D}=352,6^{\circ}\right.$; $\mathrm{I}=-35,6^{\circ} ; \mathrm{MDA}=3,2^{\circ}$ ) que fue eliminada a campos pico de 7,5 $\mathrm{mT}$; luego se desmagnetizó una componente inversa $\left(\mathrm{D}=166,8^{\circ} ; \mathrm{I}=-75,7^{\circ}\right)$, que se dirigió al centro del sistema de Zijderveld y es considerada como componente principal; la misma se eliminó al impartir un campo pico de $60 \mathrm{mT}$. La muestra VC112 (Fig. $8.7 b)$ presentó una única componente, de polaridad normal $\left(\mathrm{D}=339,4^{\circ} ; \mathrm{I}=-31,9^{\circ}\right)$, que fue eliminada a campos relativamente bajos (12,5 mT); cabe destacar que a dicho campo pico la muestra presentó un 10\% de su intensidad inicial; al continuar el tratamiento la muestra no varió en intensidad y presentó direcciones en torno a $\mathrm{D}=3,1^{\circ} ; \mathrm{I}=48,7^{\circ}$; a partir de un campo pico de $30 \mathrm{mT}$ presentó direcciones espúreas. En la muestra VC120 (Fig. 8.7c) se determinaron dos componentes. A campos (CMA) bajos se desmagnetizó una componente normal $\left(\mathrm{D}=7^{\circ} ; \mathrm{I}=-42,5^{\circ} ; \mathrm{MDA}=6,1^{\circ}\right)$ que fue eliminada a un campo pico de 7,5 mT; luego se desmagnetizó una componente considerada principal, de polaridad inversa $\left(\mathrm{D}=188,5^{\circ}\right.$; $\left.\mathrm{I}=51,9^{\circ}\right)$, con una caída de la intensidad hacia el origen del sistema a medida que se efectuó el proceso de "lavado" y que fue eliminada a un campo pico de $60 \mathrm{mT}$.

\subsubsection{Perfil paleomagnético en la Sección María Ignacia (PMI)}

En el panel de la figura 5.19 se indican las unidades muestreadas a los fines de realizar el perfil paleomagnético en la localidad de María Ignacia. Se utilizaron datos de 28 muestras paleomagnéticas.

El perfil paleomagnético comprende las unidades U-MI2 a U-MI5 (Fig. 8.8), la unidad superior no fue muestreada debido a que corresponde al horizonte A del suelo actual, con signos de removilización. Las muestras obtenidas de la unidad U-MI2 corresponden a la Formación Vela, mientras que las extraídas de las unidades U-MI3 a U-MI5 a la Formación Barker. En la figura 8.8 se indican los valores de intensidad magnética $\left(\mathrm{J}^{\mathrm{o}} \mathrm{y} \mathrm{J}^{20}\right)$, declinación (D) e inclinación (I) del MRC establecida. 
Las direcciones del magnetismo remanente característico (MRC) obtenidas de las muestras de la sección estratigráfica PMI permitieron establecer dos zonas de magnetopolaridad, una de polaridad normal correspondiente a las muestras extraídas de la Formación Vela y otra inversa correspondiente a Formación Barker.

La intensidad magnética del magnetismo remanente natural $\left(\mathrm{J}^{\circ}\right)$ osciló entre 16,9 y $120,5 \times 10^{-6}$ $\mathrm{Am}^{2} / \mathrm{Kg}$. El valor promedio de $\mathrm{J}^{\mathrm{o}}$ en la Formación Vela $\left(64,1 \times 10^{-6} \mathrm{Am}^{2} / \mathrm{Kg}\right)$ fue más elevado que el obtenido en la Formación Barker $\left(49,9 \times 10^{-6} \mathrm{Am}^{2} / \mathrm{Kg}\right)$; en contraposición la intensidad magnética promedio luego de aplicar un campo pico desmagnetizante de $20 \mathrm{mT}\left(\mathrm{J}^{20}\right)$, fue más elevada en la Formación Barker $\left(15,1 \times 10^{-6} \mathrm{Am}^{2} / \mathrm{Kg}\right)$ que en Vela $\left(6,9 \times 10^{-6} \mathrm{Am}^{2} / \mathrm{Kg}\right)$. Esto se relaciona a que varias muestras extraídas de la Formación Barker experimentan un incremento del módulo de la intensidad magnética durante los primeros pasos de desmagnetización. La variabilidad de los valores de intensidad son más elevados en la Formación Barker. El coeficiente de correlación entre $\mathrm{J}^{\mathrm{o}}$ y $\mathrm{J}^{20}$ fue positivo, moderado $(\mathrm{R}=0,29)$.

Como fue dicho anteriormente las direcciones del MRC obtenidas permitieron establecer dos zonas de magnetopolaridad, una de polaridad normal (M-MI1) correspondiente a las muestras extraídas de la Formación Vela y otra inversa (M-MI2) correspondiente a Formación Barker. Esta última fue analizada en función de las unidades litológicas que comprende.

En la tabla 8.2 se indican las direcciones (D e I) medias de cada magnetozona, así como los parámetros estadísticos $\kappa$ y $\alpha 95$. En las figura 8.9 y 8.10 se representan las redes estereográficas, curvas de desmagnetización y diagramas de Zijderveld de muestras paleomagnéticas representativas de cada magnetozona. La muestra MI3 (Fig. 8.9a) es un ejemplo de una muestra de baja coercitividad ("blanda”), presentó una componente de polaridad normal que comenzó a desmagnetizarse a partir de un campo pico de $5 \mathrm{mT}\left(\mathrm{D}=7,3^{\circ}\right.$; $\left.\mathrm{I}=-46^{\circ}\right)$; con disminución de la intensidad hacia el origen del sistema y fue eliminada tras aplicar un campo pico de 22,5 mT. La muestra MI7, de la misma magnetozona, presentó un comportamiento similar a la anterior; a partir de $5 \mathrm{mT}$ de campo pico aplicado comenzó a desmagnetizarse la componente primaria $\left(\mathrm{D}=342^{\circ} ; \mathrm{I}=-62,2^{\circ}\right)$ que fue eliminada a un campo pico de 20 mT. La muestra de la unidad superior de la Formación Barker (Fig. 8.9b) presentó a campos bajos una componente con $\mathrm{D}=76,8^{\circ}$ e $\mathrm{I}=-32,8^{\circ}\left(\mathrm{MDA}=1,8^{\circ}\right)$, que fue eliminada a un campo pico de $10 \mathrm{mT}$. A partir de ese campo comenzó a desmagnetizarse la componente considerada principal, de polaridad inversa $\left(\mathrm{D}=146^{\circ}\right.$; $\left.\mathrm{I}=51,6^{\circ}\right)$; la misma fue eliminada tras aplicar un campo pico de $30 \mathrm{mT}$. En la unidad del centro de la Formación Barker, la muestra MI14 (Fig. 8.10a), presentó una componente que se desmagnetizó entre 2,5 y $5 \mathrm{mT}$ de campo pico $\left(\mathrm{D}=62,4^{\circ}\right.$; $\mathrm{I}=-41,5^{\circ}$; $\left.\mathrm{MDA}=1,7^{\circ}\right)$; a partir de $10 \mathrm{mT}$ se desmagnetizó la componente principal, inversa $\left(\mathrm{D}=176^{\circ} ; \mathrm{I}=66,6^{\circ}\right)$. La muestra MI17, también de la unidad U-MI4, 
presentó una componente secundaria que fue eliminada a un campo pico de $10 \mathrm{mT}\left(\mathrm{D}=49,1^{\mathrm{o}} ; \mathrm{I}=-62,2^{\mathrm{o}}\right.$; $\mathrm{MDA}=4,6^{\circ}$ ), a dicho campo inició la desmagnetización de la componente que se considera principal, de polaridad inversa $\left(\mathrm{D}=176^{\circ} ; \mathrm{I}=66,6^{\circ}\right)$, que fue eliminada tras impartir un campo pico de $35 \mathrm{mT}$. Cabe destacar que esta componente se desmagnetizó con un leve apartamiento respecto al origen del sistema; se estable la existencia de una componente "dura" que no puede ser eliminada mediante la via empleada. En la unidad de la base, la muestra MI22 (Fig. 8.10b), presentó una componente que se desmagnetizó entre 2,5 y $10 \mathrm{mT}$ de campo pico $\left(\mathrm{D}=67,3^{\circ}\right.$; $\mathrm{I}=-41,5^{\circ}$; $\left.\mathrm{MDA}=2,8^{\circ}\right)$; luego comenzó a desmagnetizarse una componente inversa, considerada principal $\left(\mathrm{D}=168,2^{\circ} ; \mathrm{I}=49,6^{\circ}\right)$, con caída de la intensidad hacia el origen del sistema de Zijderveld. La muestra MI27, también de la unidad U-MI5, presentó una componente que se eliminó entre 2,5 y $10 \mathrm{mT}$ de campo pico $\left(\mathrm{D}=164,4^{\circ} ; \mathrm{I}=-19,8^{\circ} ; \mathrm{MDA}=0,2^{\circ}\right)$; a partir de $10 \mathrm{mT}$ se desmagnetizó la componente que se considera principal, de polaridad inversa $\left(\mathrm{D}=186,4^{\mathrm{o}} ; \mathrm{I}=56,8^{\circ}\right)$, la misma se eliminó a un campo pico de $65 \mathrm{mT}$.

\subsubsection{Perfiles paleomagnéticos de la sección Calle Fangio (PCF).}

Los tres perfies paleomagnéticos correspondientes a esta sección se indican en la figura 8.11. Para la elaboración de los mismos se utilizaron datos de 49 muestras (CF1 a CF49). Los perfiles 1 y 2 comprenden las unidades de las formaciones Las Ánimas y Vela. La parte inferior del perfil 1 afecta también a la Formación Barker. El perfil paleomagnético 3 comprende enteramente a la Formación Barker. Se determinaron tres zonas de magnetopolaridad, una normal que involucra a las formaciones Las Ánimas y Vela; una anómala y otra inversa, la primera en la parte superior de la Formación Barker, la inversa hacia la base de dicha unidad.

La intensidad magnética del magnetismo remanente natural $\left(\mathrm{J}^{\circ}\right)$ osciló entre 8,7 y 689,3 x10 6 $\mathrm{Am}^{2} / \mathrm{Kg}$. El valor medio de la Formación Las Ánimas $\left(43,7 \times 10^{-6} \mathrm{Am}^{2} / \mathrm{Kg}\right)$ fue el más bajo; en contraposición el valor promedio más elevado corresponde a las muestras de la Formación Barker (173,7 $\mathrm{x} 10^{-6} \mathrm{Am}^{2} / \mathrm{Kg}$ ), no obstante en la unidad superior de esta formación (U-CF3) se registró un promedio destacadamente más elevado $\left(426,8 \times 10^{-6} \mathrm{Am}^{2} / \mathrm{Kg}\right)$ que en la unidad basal (U-CF5) $\left(82,3 \times 10^{-6} \mathrm{Am}^{2} / \mathrm{Kg}\right)$; la unidad U-CF4 registró valores intermedios $\left(193,4 \times 10^{-6} \mathrm{Am}^{2} / \mathrm{Kg}\right)$.

La intensidad magnética luego de aplicar un campo pico desmagnetizante de $20 \mathrm{mT}\left(\mathrm{J}^{20}\right)$ osciló entre 0,8 y $66,5 \times 10^{-6} \mathrm{Am}^{2} / \mathrm{Kg}$. La Formación Las Ánimas, $\mathrm{J}^{20}$ promedio fue $14,4 \times 10^{-6} \mathrm{Am}^{2} / \mathrm{Kg}$. En la Formación Vela, $\mathrm{J}^{20}$ fue el más elevado $\left(16,8 \times 10^{-6} \mathrm{Am}^{2} / \mathrm{Kg}\right)$ y en Formación Barker el más bajo $(11,1$ 
$\mathrm{x} 10^{-6} \mathrm{Am}^{2} / \mathrm{Kg}$ ). En contraposición a lo ocurrido con $\mathrm{J}^{\mathrm{o}}$, la unidad inferior de la Formación Barker registró una $\mathrm{J}^{20}$ promedio más elevada $\left(14,1 \times 10^{-6} \mathrm{Am}^{2} / \mathrm{Kg}\right)$ que el resto de las unidades de dicha formación.

Las direcciones del magnetismo remanente característico (MRC) obtenidas de las muestras de la sección estratigráfica PCF permitieron establecer tres zonas de magnetopolaridad: M-CF1 de polaridad normal; M-CF2 de polaridad anómala y M-CF3 de polaridad inversa. La magnetozona M-CF1 afecta tanto a la Formación Las Ánimas como Vela, por ello se las analiza teniendo en cuenta ambas unidades. Con el mismo criterio M-CF2, con polaridad anómala, fue analizada en forma separada a partir de considerar los registros en unidades litológicas diferentes (U-CF3 y U-CF4). Como fue dicho, esto es a los fines de considerar las discontinuidades, que a nivel regional pueden desempeñar un rol fundamental en la definición de la columna magnetoestratigráfica.

En la tabla 8.3 se muestran las direcciones de D e I medias de cada magnetozona, así como los parámetros de concentración $\kappa$ y el semiángulo de confiaza $\alpha 95$. En las figuras 8.12 y 8.13 se presentan redes estereográficas, curvas de desmagnetización y diagramas de Zijderveld de muestras paleomagnéticas representativas de las magnetozonas de la sección PCF. La muestra de la Formación Las Ánimas (Fig. 8.12a), exhibió una componente normal a partir de campos pico de $5 \mathrm{mT}\left(\mathrm{D}=348,8^{\circ} ; \mathrm{I}=-47^{\circ}\right)$, la misma se desmagnetizó hacia el origen del sistema de Zijderveld y fue eliminada a un campo pico de $60 \mathrm{mT}$. La muestra de la Formación Vela (Fig. 8.12b) presentó una componente de polaridad normal $\left(\mathrm{D}=347,1^{\mathrm{o}}\right.$; $\mathrm{I}=$ $48^{\circ}$ ) que se considera principal y fue eliminada al aplicar un campo pico de $40 \mathrm{mT}$.

Todas las muestras de esta magnetozona anómala M-CF2 presentaron valores de declinación en el hemisferio norte y la mayoría de ellas valores positivos de inclinación, a exepción de la CF14, con una MRC claramente normal. Las muestras de las figuras $8.12 \mathrm{c} \mathrm{y} \mathrm{d}$ corresponden a esta magnetozona.mala. La muestra CF3 (Fig. 8.12c), presentó dos componentes; la primera se desmagnetizó entre 5 y $15 \mathrm{mT}$ de campo pico $\left(\mathrm{D}=38,3^{\circ} ; \mathrm{I}=7,3^{\circ} ; \mathrm{MDA}=0,7^{\circ}\right)$; a partir de $15 \mathrm{mT}$ se desmagnetiza la segunda $\left(\mathrm{D}=35,2^{\circ}\right.$; $\mathrm{I}=24,5^{\circ}$ ), con caída de la intensidad hacia el origen del sistema y es eliminada a $60 \mathrm{mT}$. La muestra CF12 (Fig. 8.12d), presentó también dos componentes, una, más débil, fue eliminada a 7,5 mT $\left(\mathrm{D}=26,1^{\circ}\right.$; $\mathrm{I}=-$ $\left.3,7^{\circ} ; \mathrm{MDA}=2,1^{\circ}\right)$; a partir de dicho campo se desmagnetizó otra componente $\left(\mathrm{D}=31,2^{\circ} ; \mathrm{I}=12,2^{\circ}\right.$; $\mathrm{MDA}=10,3^{\circ}$ ) que a campos bajos de $25 \mathrm{mT}$ perdió más del $90 \%$ de su intensidad inicial, luego presentó direcciones espúreas.

Las muestras de la figura 8.13 corresponden a la magnetozona inversa. La muestra CF19 presentó una componente inversa, de baja inclinación $\left(\mathrm{D}=210,8^{\mathrm{o}} ; \mathrm{I}=10,2^{\mathrm{o}} ; \mathrm{MDA}=3^{\circ}\right)$; que se desmagnetizó entre 2,5 y $15 \mathrm{mT}$ de campo pico; luego se desmagnetizó la componente que se considera principal $\left(\mathrm{D}=211,2^{\circ}\right.$; $\left.\mathrm{I}=32,5^{\circ} ; \mathrm{MDA}=11,9^{\circ}\right)$, con disminución de la intensidad hacia origen del sistema de coordenadas y fue 
eliminada al impartir un campo pico de $40 \mathrm{mT}$. En la muestra CF27 se identificó una componente normal $\left(\mathrm{D}=322,2^{\circ} ; \mathrm{I}=-33^{\mathrm{o}} ; \mathrm{MDA}=4,7^{\circ}\right)$ que se desmagnetizó entre 2,5 y 7,5 $\mathrm{mT}$ de campo pico; luego se desmagnetizó una componente inversa $\left(\mathrm{D}=171^{\circ} ; \mathrm{I}=38,4^{\circ} ; \mathrm{MDA}=4,5^{\circ}\right)$, a partir de $7,5 \mathrm{mT}$ se produce la caída de la intensidad hacia el origen del sistema.

\subsubsection{Perfil paleomagnético de la sección Circuito Turístico (PCT).}

El perfil paleomagnético se muestra en la figura 8.14. Se utilizaron datos de cuatro muestras paleomagnéticas extraídas de la unidad U-CT1 (Formación Las Ánimas).

La intensidad magnética del magnetismo remanente natural $\left(\mathrm{J}^{\circ}\right)$ promedio fue de $30,9 \times 10^{-6}$ $\mathrm{Am}^{2} / \mathrm{Kg}$; los valores decrecen hacia la parte superior del perfil. El valor medio de $\mathrm{J}^{20}$ fue $9,3 \times 10^{-6}$ $\mathrm{Am}^{2} / \mathrm{Kg}$, con una tendencia menos clara a disminuir los valores hacia el tope.

Las direcciones del magnetismo remanente característico (MRC) obtenidas permitieron establecer la zona M-CT1 de polaridad normal $\left(\mathrm{D}=329,5^{\circ} ; \mathrm{I}=-51,3^{\circ} ; \kappa=60,9 ; \alpha 95=2,3^{\circ}\right)$. En la figura 8.15 se muestra la red estereográfica, la curva de desmagnetización y el diagrama de Zijderveld de la muestra CT4. Dicha muestra presentó una única componente de polaridad normal $\left(\mathrm{D}=329,5^{\circ} ; \mathrm{I}=-51,3^{\circ}\right)$ que se desmagnetizó entre 2,5 y $40 \mathrm{mT}$ de campo pico aplicado.

\subsection{Perfiles paleomagnéticos del sector Sierras de Balcarce.}

\subsubsection{Perfiles paleomagnéticos de la sección San Manuel (PSM).}

En la sección estratigráfica de la localidad de San Manuel se realizaron dos perfiles paleomagnéticos, los mismos se representan en el panel de la figura 5.37. Para el establecimiento de la magnetoestratigrafía se utilizaron datos de 30 muestras paleomagnéticas (SM1 a SM30).

El perfil paleomagnético 1 comprende la unidad correspondiente a la Formación Vela; el perfil paleomagnético 2 comprende las unidades de la Formación Barker.

En la figura 8.16a-b se indican los valores de intensidad del $\mathrm{MRN}\left(\mathrm{J}^{\mathrm{o}}\right)$ y la obtenida luego del "lavado" a 20mT $\left(\mathrm{J}^{20}\right)$, la declinación (D) y la inclinación (I) del MRC del conjunto de muestras analizadas. 
La intensidad magnética del magnetismo remanente natural $\left(\mathrm{J}^{\circ}\right)$ osciló entre 16,1 y 343,4 x10 6 $\mathrm{Am}^{2} / \mathrm{Kg}$. El valor medio en la Formación Vela fue $132,4 \times 10^{-6} \mathrm{Am}^{2} / \mathrm{Kg}$, con tendencia al incremento hacia la parte superior. El valor promedio registrado en la Formación Barker fue $90,1 \times 10^{-6} \mathrm{Am}^{2} / \mathrm{Kg}$. Tanto el valor más elevado como el más bajo de la sección estratigráfica corresponden a la unidad U-SM3 (base de la Formación Barker). En la figura 8.16b, se observa que los valores de $\mathrm{J}^{\mathrm{o}}$ tienden a aumentar hacia el tope de la unidad U-SM2.

El valor medio de la intensidad magnética luego de aplicar un campo pico desmagnetizante de 20 $\mathrm{mT}\left(\mathrm{J}^{20}\right)$ osciló entre 2,8 y $183,2 \times 10^{-6} \mathrm{Am}^{2} / \mathrm{Kg}$. El valor medio de $\mathrm{J}^{20}$ de las muestras extraídas de la Formación Vela fue $10,9 \times 10^{-6} \mathrm{Am}^{2} / \mathrm{Kg}$. La $\mathrm{J}^{20}$ media de las muestras extraídas de la Formación Barker fue más elevada $\left(20,3 \times 10^{-6} \mathrm{Am}^{2} / \mathrm{Kg}\right)$. Cabe destacar que la muestra SM28, con elevados valores de intensidad fue obtenida de un sector con laminación paralela, con alternancia de finas capas (de hasta 2 $\mathrm{mm}$ ) de limo y de arcilla.

A partir de las direcciones del magnetismo remanente característico (MRC) obtenidas del análisis de las muestras de San Manuel se configuran tres zonas de polaridad magnética. Las direcciones de polaridad normal de la Formación Vela constituyen la magnetozona M-SM1. En la Formación Barker, se determinaron dos zonas de polaridad; una, en la parte superior, con predominio de muestras de polaridad anómala (M-SM2), aunque con tendencia mixta debido a la presencia de muestras de polaridad normal e inversa (Fig. 8.16b); otra de polaridad inversa (M-SM3) coincidente con la unidad U-SM3 de la base de la formación.

En la tabla 8.4 se muestran las direcciones de D e I medias de cada magnetozona, así como los parámetros de concentración $\kappa$ y el semiángulo de confiaza $\alpha 95$. La muestra de la magnetozona normal (Fig. 8.17a), presentó desde el inicio del proceso de desmagnetización una componente $\left(\mathrm{D}=1,7^{\circ} ; \mathrm{I}=5,7^{\circ}\right.$; $\mathrm{MDA}=1,4^{\circ}$ ) que fue eliminada al aplicar 7,5 $\mathrm{mT}$ de campo pico; a partir de dicho campo se desmagnetizó una componente de polaridad normal $\left(\mathrm{D}=339,3^{\circ} ; \mathrm{I}=-32,9^{\circ}\right)$ considerada primaria que fue eliminada a 80 mT. En el diagrama de Zijderveld se puede observar la estabilidad de las direcciones y la caída de la intensidad hacia el origen. La intensidad de la muestra SM13 (Fig. 8.17b), de la magnetozona anómala presentó un comportamiento similar a la anterior frente al "lavado" magnético; entre 2,5 y 7,5 mT $\left(\mathrm{D}=55,2^{\circ} ; \mathrm{I}=21^{\circ} ; \mathrm{MDA}=6,4^{\circ}\right)$ se desmagnetizó una componente "blanda"; a partir de $10 \mathrm{mT}$ de campo pico se desmagnetizó otra componente $\left(\mathrm{D}=81^{\mathrm{o}} ; \mathrm{I}=51,7^{\circ}\right)$, anómala, la intensidad cae hacia el origen del sistema y fue eliminada tras impartir un campo pico de $60 \mathrm{mT}$. Como fue dicho, cabe destacar que esta magnétozona tiende a mixta, esto en virtud de la presencia de muestras claramente inversas (SM11, 12, 16 y 20) y claramente normales (SM17 y 18). 
Finalmente, las muestras SM23 y SM28 corresponden a la magnetozona inversa (Fig. 8.17c). La muestra SM23 presentó una componente que se eliminó a un campo pico de 7,5 mT (D=341,2 $2^{\circ}$ I=12, $1^{\circ}$; $\left.\mathrm{MDA}=6,7^{\circ}\right)$; a diferencia de las muestras antes señaladas, esta componente de polaridad normal enmascara a una componente considerada principal, de polaridad inversa $\left(\mathrm{D}=180,4^{\circ} ; \mathrm{I}=55,2^{\circ}\right)$, que se desmagnetiza a partir de $10 \mathrm{mT}$ con una caída lineal hacia el origen, como se indica. La muestra SM28 representa el comportamiento monocomponente de magnetización $\left(\mathrm{D}=179,7^{\circ} ; \mathrm{I}=48,8^{\circ} ; \mathrm{MDA}=1,2^{\circ}\right)$, es de polaridad inversa (MRC) y desde los momento iniciales del tratamiento, que se efectuó a partir de 2,5 mT, la caída de la intensidad es lineal hacia el origen del sistema de coordenadas.

\subsubsection{Perfil paleomagnético de la Sección Ramos Otero (PRO).}

El perfil paleomagnético de la sección estratigráfica PRO se indica en el panel de la figura 5.41. Para la construcción del mismo se utilizaron datos de 14 muestras paleomagnéticas (RO1 a RO14).

El perfil paleomagnético comprende las unidades correspondientes a las formaciones Las Ánimas y Vela. En la figura 8.18 se indican los valores intensidad magnética $\left(\mathrm{J}^{\mathrm{o}} \mathrm{y} \mathrm{J}^{20}\right)$, declinación (D) e inclinación (I) del MRC.

La intensidad magnética del magnetismo remanente natural $\left(\mathrm{J}^{\circ}\right)$ osciló entre 23,3 y 71,5 x10 $0^{-6}$ $\mathrm{Am}^{2} / \mathrm{Kg}$. El valor medio de $\mathrm{J}^{\mathrm{o}}$ de las muestras obtenidas de la Formación Las Ánimas fue $48,1 \times 10^{-6}$ $\mathrm{Am}^{2} / \mathrm{Kg}$, el valor más bajo corresponde al tope del horizonte Bt y el más elevado al horizonte A; el resto de las muestras presentó valores relativamente constantes, levemente inferiores al promedio de la unidad. La Formación Vela registró un valor medio de $34,8 \times 10^{-6} \mathrm{Am}^{2} / \mathrm{Kg}$.

El valor medio de la intensidad magnética luego de aplicar un campo pico desmagnetizante de 20 $\mathrm{mT}\left(\mathrm{J}^{20}\right)$ osciló entre 4,1 y 29,5 $\times 10^{-6} \mathrm{Am}^{2} / \mathrm{Kg}$. El valor medio de $\mathrm{J}^{20}$ de las muestras extraídas de la

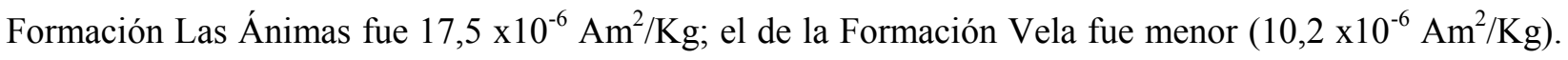
El coeficiente de correlación entre $\mathrm{J}^{\mathrm{o}}$ y $\mathrm{J}^{20}$ es muy fuerte y positivo $(0,98)$. La relación $\mathrm{J}^{\mathrm{o}} \mathrm{J}^{20}$ registró un valor medio de 3,3; la misma fue más baja en las muestras de la Formación Las Ánimas $(2,8)$ que en las de la Formación Vela $(3,7)$, esto se relaciona con una mayor resistencia a la desmagnetización en las muestras de Las Ánimas.

Todas las direcciones del magnetismo remanente característico (MRC) obtenidas en la sección PRO fueron de polaridad normal y se estableció la magnetozona M-RO. Las unidades litoestratigráficas se analizaron por separado a fin de considerar la discordancia. En la tabla 8.5 se muestran las direcciones de 
D e I medias; así como los parámetros de concentración $\kappa$ y el semiángulo de confiaza $\alpha 95$. En la figura 8.19 se presentan redes estereográficas, curvas de desmagnetización y diagramas de Zijderveld de dos muestras paleomagnéticas representativas; una de la Formación Las Ánimas; otra de Vela. La muestra de la Formación Las Ánimas (RO5) presentó una única componente de magnetización, de polaridad normal $\left(\mathrm{D}=2,5^{\circ} ; \mathrm{I}=-55,7^{\circ}\right)$. El proceso de "lavado" magnético se efectuó a partir de 2,5 mT mediante CMA, el 90 $\%$ de $\mathrm{J}^{\mathrm{o}}$ se eliminó a $60 \mathrm{mT}$ de campo aplicado. La muestra RO12, de la Formación Vela, presentó dos componentes de magnetización. Entre 2,5 y $10 \mathrm{mT}$ se desmagnetizó una componente de $\mathrm{D}=298,3^{\circ}$ e I=$49^{\circ}\left(\mathrm{MDA}=4,2^{\circ}\right)$; posteriormente, desde $10 \mathrm{mT}$ de campo pico aplicado se desmagnetizó la componente principal $\left(\mathrm{D}=338,9^{\circ}\right.$; $\left.\mathrm{I}=-66,8^{\circ}\right)$ que conserva menos del $10 \%$ de la intensidad inicial sin cambiar el signo de la magnetización a campos de $60 \mathrm{mT}$; un mayor apartamiento, aunque no muy significativo, se produce a 80 mT de campo aplicado, que estaría en relación con una posible destrucción de la señal.

\subsubsection{Perfiles paleomagnéticos de la sección Sierra Bachicha (PSB).}

Se realizaron cinco perfiles paleomagnéticos en la sección PSB, los mismos se indican en el panel del capítulo 5 (Fig. 5.47). Para la confección de los mismos se utilizaron datos de 80 muestras paleomagnéticas (SB1 a SB80).

El perfil paleomagnético 1 (Fig 8.20a) comprende la Formación Las Ánimas. El perfil paleomagnético 2 (Fig 8.20b) abarca la parte basal de la Formación Las Ánimas y la parte superior y media de la Formación Vela. El perfil 3 (Fig. 8.21) comprende el sector medio y basal de la Formación Vela y la unidad U-SB3. Finalmente los perfiles paleomagnéticos 4 y 5 (Fig. 8.22-23) abarcan las

unidades U-SB3 y U-SB4; cabe consignar que estas, por integrar una misma unidad litoestratigráfica (USB3/4), se analizan en conjunto.

En los perfiles paleomagnéticos de las figuras mencionadas se indican los valores intensidad magnética, declinación (D) e inclinación magnética (I) del MRC establecido.

La intensidad del magnetismo remanente natural osciló entre 3,21 y $164,5 \times 10^{-6} \mathrm{Am}^{2} / \mathrm{Kg}$. El valor medio de $\mathrm{J}^{\mathrm{o}}$ de las muestras de la Formación Las Ánimas fue $41,7 \times 10^{-6} \mathrm{Am}^{2} / \mathrm{Kg}$. En la Formación Vela se registró el valor promedio más elevado de la sección $\left(56 \times 10^{-6} \mathrm{Am}^{2} / \mathrm{Kg}\right)$. Los valores de $\mathrm{J}^{\mathrm{o}}$ de las muestras extraídas de U-SB3/4 exhibieron la mayor variabilidad; oscilaron entre 3,21 y $164,5 \times 10^{-6} \mathrm{Am}^{2} / \mathrm{Kg}$, con un promedio de $36,8 \times 10^{-6} \mathrm{Am}^{2} / \mathrm{Kg}$. 
El valor promedio de $\mathrm{J}^{20}$ de las muestras extraídas de la Formación Las Ánimas fue el más elevado de la sección estratigráfica $\left(14 \times 10^{-6} \mathrm{Am}^{2} / \mathrm{Kg}\right)$. El valor medio de $\mathrm{J}^{20}$ de las muestras extraídas de la Formación Vela fue 9,2 x10 $0^{-6} \mathrm{Am}^{2} / \mathrm{Kg}$. Finalmente, la $\mathrm{J}^{20}$ media de las muestras extraídas de U-SB3/4 registró el valor más bajo $\left(8,21 \times 10^{-6} \mathrm{Am}^{2} / \mathrm{Kg}\right)$, con importante variación (entre 0,7 y 58,5 x10 ${ }^{-6} \mathrm{Am}^{2} / \mathrm{Kg}$ ). El coeficiente $\mathrm{R}$ entre $\mathrm{J}^{\mathrm{o}}$ y $\mathrm{J}^{20}$ fue positivo y moderado $(0,31)$.

Las direcciones del magnetismo remanente característico (MRC) obtenidas, permitieron determinar cinco zonas de polaridad magnética. En el sector superior de la sección estratigráfica se determinó una zona de polaridad normal (M-SB1), que incluye a las formaciones Las Ánimas, Vela y la parte superior de la unidad U-SB3; el resto de U-SB3 presentó direcciones inversas (M-SB2). En la unidad U-SB4 se registraron dos zonas de polaridad normal (M-SB3 y M-SB5) y una de polaridad inversa (MSB4); en la parte superior de esta unidad en el perfil paleomagnético 5 (Fig. 8.23) se determinó una zona con polaridad mixta. En la tabla 8.6 se indican las direcciones de D e I medias de cada magnetozona, así como los parámetros $\kappa$ y $\alpha 95$. En la figura 8.24 y 8.25 se presentan redes estereográficas, curvas de desmagnetización y diagramas de Zijderveld de muestras representativas de cada magnetozona. Las muestras SB6, SB14 y SB30 (Fig. 8.24a) corresponden a la magnetozona M-SB1. SB6, de la Formación Las Ánimas, presentó dos componentes de magnetización, ambas de polaridad normal; la primera se desmagnetizó entre 2,5 y 17,5 mT de campo aplicado $\left(\mathrm{D}=8,3^{\circ} ; \mathrm{I}=-37^{\circ} ; \mathrm{MDA}=2,9^{\circ}\right)$; entre 17,5 y $60 \mathrm{mT}$ se desmagnetizó una componente considerada principal $\left(\mathrm{D}=354,3^{\circ} ; \mathrm{I}=-38,5\right)$, con caída de la intensidad hacia el origen del sistema ortogonal. La muestra SB14 de la Formación Vela presentó también dos componentes de magnetización; desde el inicio del "lavado" se demagnetizó una componente ubicada en el hemisferio norte de polaridad $\left(\mathrm{D}=54,6^{\circ} ; \mathrm{I}=-22,8^{\circ} ; \mathrm{MDA}=7,6^{\circ}\right)$ que fue eliminada a campos pico de 7,5 mT; a partir de dicho campo se desmagnetizó la componente considerada principal $\left(\mathrm{D}=6,9^{\circ} ; \mathrm{I}=-59^{\circ}\right)$ hacia el centro del sistema de Zijderveld y fue eliminada al aplicar un campo pico de $60 \mathrm{mT}$. La muestra SB30, del paleosuelo del tope de la unidad U-SB3 presentó direcciones y comportamientos frente al "lavado" similares a las muestras anteriores, con dos componentes, ambas de polaridad normal. Desde el inicio del proceso se desmagnetizó una componente de baja coercitividad ( $\left.D=334,3^{\circ} ; \mathrm{I}=-46^{\circ} ; \mathrm{MDA}=6,8^{\circ}\right)$, que fue eliminada a campos pico de $5 \mathrm{mT}$; a partir de dicho campo se desmagnetizó otra componente que fue eliminada a $30 \mathrm{mT}\left(\mathrm{D}=356,1^{\circ} ; \mathrm{I}=-52,3^{\circ}\right)$. La muestra SB58 (Fig. 8.24b), correspondiente a la magnetozona de polaridad inversa M-SB2, presentó una componente de baja coercitividad que fue eliminada a campos bajos de 7,5 $\mathrm{mT}\left(\mathrm{D}=330^{\circ} ; \mathrm{I}=2,4^{\circ} ; \mathrm{MDA}=9,4\right)$; a partir de dicho campo se desmagnetizó la componente principal $\left(\mathrm{D}=176^{\circ} ; \mathrm{I}=-42,1^{\circ}\right)$, con un decrecimiento lineal hacia el origen del sistema. La muestra SB70 (Fig. 8.25a), de la magnetozona M-SB3, presentó una única componente que se desmagnetizó a partir de un campo pico de $2,5 \mathrm{mT}\left(\mathrm{D}=346,7^{\circ} ; \mathrm{I}=-47,4^{\circ}\right)$; con caída de la intensidad hacia el origen y fue eliminada al impartir un campo pico de $30 \mathrm{mT}$; en los siguientes pasos las direcciones fueron espúreas. La muestra 
SB76 (Fig. 8.25b), de la magnetozona M-SB4, presentó una componente de polaridad normal $\left(\mathrm{D}=359,1^{\mathrm{o}}\right.$; $\mathrm{I}=-47,4^{\circ} ; \mathrm{MDA}=4,1^{\circ}$ ) desde el inicio de la desmagnetización hasta campos pico de $10 \mathrm{mT}$; a partir de este último se desmagnetizó una componente inversa, considerada como característica, con caída lineal de la intensidad hacia el centro del sistema; fue eliminada a campos pico de $50 \mathrm{mT}$. Finalmente, la muestra SB80 (Fig. 8.25c), de la magnetozona M-SB5, presentó una componente de baja coercitividad $\left(\mathrm{D}=24^{\circ}\right.$; $\mathrm{I}=$ 55,$\left.4 ; \mathrm{MDA}=0,5^{\circ}\right)$ que se desmagnetizó entre 2,5 y 7,5 $\mathrm{mT}$ de campo aplicado; a partir de 7,5 $\mathrm{mT}$ se desmagnetizó la componente considerada principal $\left(\mathrm{D}=19,5^{\circ} ; \mathrm{I}=-54^{\circ}\right)$, luego de impartir un campo pico de $20 \mathrm{mT}$, en los pasos siguientes presentó direcciones espúreas.

\subsubsection{Perfil paleomagnético de la sección Cerro Quebracho (PCQ).}

Se obtuvieron tres muestras paleomagnéticas de la sección estratigráfica de Cerro Quebracho. Todas corresponden a la Formación Vela, incluyendo la base, el sector medio y el techo de la unidad.

La intensidad magnética del magnetismo remanente natural $\left(\mathrm{J}^{\circ}\right)$ promedio fue de $49,7 \times 10^{-6}$

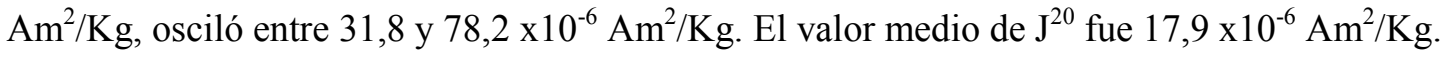

Las direcciones del magnetismo remanente característico (MRC) determinadas se ubican en el hemisferio norte (polaridad normal), constituyendo la magnetozona M-CQ de polaridad normal ( $\mathrm{D}=3,4^{\mathrm{o}}$; $\left.\mathrm{I}=-52^{\circ} ; \kappa=68,4 ; \alpha 95=2,07^{\circ}\right)$. En la figura 8.26 se muestra la red estereográfica, la curvas de desmagnetización y el diagrama de Zijderveld de la muestra CQ1. La misma presentó una única componente $\left(\mathrm{D}=342,7^{\circ} ; \mathrm{I}=-59,3^{\circ}\right)$, que se desmagnetizó a partir de un campo pico de $2,5 \mathrm{mT}$; la intensidad decreció hacia el origen del sistema de Zijderveld y fue eliminada tras aplicar un campo pico de $30 \mathrm{mT}$. 


\subsection{Perfiles paleomagnéticos del sector costero al norte de Mar del Plata.}

\subsubsection{Perfil paleomagnético de la sección GADA (PGA).}

En el perfil paleomagnético PGA (Fig. 8.27) se indican los valores de $\mathrm{J}^{\mathrm{o}}, \mathrm{J}^{20}$, D e I del MRC de las 31 muestras paleomagnéticas (GA1 a GA31) utilizadas para la confección de este perfil.

La intensidad magnética del magnetismo remanente natural $\left(\mathrm{J}^{\circ}\right)$ osciló entre 3,2 y 142,9 x10 $0^{-6}$ $\mathrm{Am}^{2} / \mathrm{Kg}$, siendo el promedio $38,1 \times 10^{-6} \mathrm{Am}^{2} / \mathrm{Kg}$. La unidad con valor promedio más elevado fue U-GA1 $\left(92,2 \times 10^{-6} \mathrm{Am}^{2} / \mathrm{Kg}\right)$; la de valor más bajo fue U-GA5 $\left(7,3 \times 10^{-6} \mathrm{Am}^{2} / \mathrm{Kg}\right)$. El resto de las unidades presentaron valores intermedios. Las muestras del paleosuelo S-GA2 registraron un promedio de 21,9 x10 ${ }^{6} \mathrm{Am}^{2} / \mathrm{Kg}$.

El valor medio de la intensidad magnética luego de aplicar un campo pico desmagnetizante de 20 $\mathrm{mT}\left(\mathrm{J}^{20}\right)$ osciló entre 0,2 y $56,9 \times 10^{-6} \mathrm{Am}^{2} / \mathrm{K}$, el promedio fue $8,5 \times 10^{-6} \mathrm{Am}^{2} / \mathrm{Kg}$. La unidad del tope del perfil (U-GA1) presentó el valor promedio más elevado $\left(30,1 \times 10^{-6} \mathrm{Am}^{2} / \mathrm{Kg}\right)$. La unidad hidromórfica UGA5 registró el valor promedio más bajo $\left(1,2 \times 10^{-6} \mathrm{Am}^{2} / \mathrm{Kg}\right)$. El resto de las unidades presentaron valores intermedios.

Las direcciones del magnetismo remanente característico (MRC) obtenidas permitieron configurar la sección PGA en dos zonas de polaridad magnética; una normal, otra inversa. La magnetozona normal (M-GA1) involucra a las unidades U-GA1 a U-GA5; la inversa (M-GA2) a las unidades U-GA6 y 7. Ambas magnetozonas fueron analizadas según las unidades litológicas que abarcan como se muestra en la tabla 8.7.

En la figura 8.28 se presentan redes estereográficas, curvas de desmagnetización y diagramas de Zijderveld de muestras representativas de cada magnetozona. La muestra GA11 de la magnetozona normal presentó una componente de baja coercitividad $\left(\mathrm{D}=37,2^{\circ} ; \mathrm{I}=-53,5^{\circ} ; \mathrm{MDA}=6,2^{\circ}\right)$ que fue eliminada a un campo pico de $5 \mathrm{mT}$; a partir de ahí comenzó la desmagnetización de la componente principal $\left(\mathrm{D}=2,5^{\circ} ; \mathrm{I}=-61,2^{\circ} ; \mathrm{MDA}=4^{\circ}\right)$ que evidenció un decrecimiento de la intensidad hacia el centro del sistema de Zijderveld y fue eliminada a $40 \mathrm{mT}$. La muestra GA26 de la magnetozona inversa, presentó desde el inicio del "lavado" una componente "blanda" que fue eliminada al aplicar un campo pico de $10 \mathrm{mT}$ $\left(\mathrm{D}=215,6^{\circ} ; \mathrm{I}=-23^{\circ} ; \mathrm{MDA}=2^{\circ}\right)$; luego se desmagnetizó una componente inversa estable $\left(\mathrm{D}=201^{\mathrm{o}} ; \mathrm{I}=29,7^{\mathrm{o}}\right.$; $\mathrm{MDA}=6,2^{\circ}$ ), ello se representa mediante el diagrama de Zijderveld. Cabe destacar que las muestras de la unidad U-GA6 (magnetozona inversa) registraron, como se verá más adelante, valores de susceptibilidad 
relativamente elevados, y de intensidad relativamente bajos; esto estaría indicando una menor orientación de las partículas magnéticas, que podría relacionarse con una merma de la intensidad del campo magnético terrestre durante el proceso de inversión, o bien, podría también estar condicionada por la granulometría del depósito, con abundante proporción de arena; aspectos que, sin lugar a dudas, son relevantes para encarar futuras investigaciones.

\subsubsection{Perfil paleomagnético de la sección Playa Dorada (PPD).}

En la figura 8.29 se indican los valores intensidad magnética $\left(\mathrm{J}^{\mathrm{o}} \mathrm{y} \mathrm{J}^{20}\right)$, D e I del MRC de muestras correspondientes a la sección geológica PPD. En el perfil paleomagnético se presentan datos de 39 muestras (PD1 a PD39); no obstante en el texto también se describen datos correspondientes a muestras de un nivel de ceniza volcánica (PD40 y PD41).

Los valores de intensidad magnética del magnetismo remanente natural $\left(\mathrm{J}^{\circ}\right)$ oscilaron entre 4,9 y

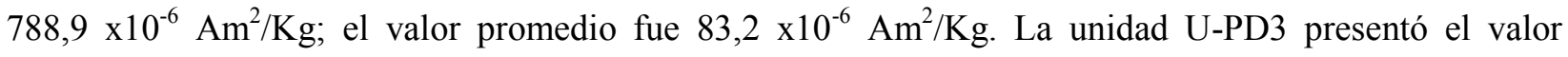
promedio más elevado $\left(140,9 \times 10^{-6} \mathrm{Am}^{2} / \mathrm{Kg}\right)$, donde los valores más elevados corresponden al tope. Los valores promedio más bajo de $\mathrm{J}^{\mathbf{o}}$ se registraron en el nivel de ceniza $\left(3,7 \times 10^{-6} \mathrm{Am}^{2} / \mathrm{Kg}\right)$ y en la unidad U$\mathrm{PD} 5\left(16,8 \times 10^{-6} \mathrm{Am}^{2} / \mathrm{Kg}\right)$. El resto de las unidades presentaron valores intermedios.

La intensidad $\mathrm{J}^{20}$ osciló entre 1,1 y $50,0 \times 10^{-6} \mathrm{Am}^{2} / \mathrm{Kg}$; el promedio fue $11,3 \times 10^{-6} \mathrm{Am}^{2} / \mathrm{Kg}$. Las unidades con los valores promedio más elevados se corresponden al tope del perfil (U-PD1 y U-PD2) (18,8 y $17,7 \times 10^{-6} \mathrm{Am}^{2} / \mathrm{Kg}$ respectivamente). Nuevamente, los valores promedio más bajos se registraron en el nivel de cenizas $\left(1 \times 10^{-6} \mathrm{Am}^{2} / \mathrm{Kg}\right)$ y en U-PD5 $\left(2 \times 10^{-6} \mathrm{Am}^{2} / \mathrm{Kg}\right)$. El resto de las unidades presentaron valores intermedios. Las intensidades $\mathrm{J}^{\mathrm{o}}$ y $\mathrm{J}^{20}$ presentaron patrones de variación similares.

A partir de las direcciones del magnetismo remanente característico (MRC) se determinó una magnetozona de polaridad normal (M-PD). Los valores de D e I medios, así como $\kappa$ y $\alpha 95$, fueron determinados para cada unidad; los mismos se indican en la tabla 8.8. En la figura 8.30 se presentan diagramas de dos muestras de la magnetozona. La muestra PD5, del tope del perfil, es de polaridad normal como se indica en la red estereográfica. Presentó dos componentes de magnetización con gran estabilidad en las direcciones. La componente secundaria se eliminó a 7,5 mT ( $\left.\mathrm{D}=348,2^{\circ} ; \mathrm{I}=-40,2^{\circ} ; \mathrm{MDA}=1,7^{\circ}\right)$; luego se desmagnetizó la componente considerada principal $\left(\mathrm{D}=344,5^{\circ} ; \mathrm{I}=-53,8^{\circ}\right.$; $\left.\mathrm{MDA}=2,5^{\circ}\right)$, con una caída lineal hacia el origen del sistema y fue eliminada tras impartir un campo pico de $80 \mathrm{mT}$. La muestra PD34, de la unidad basal, presentó una componente que se desmagnetizó desde el inicio del proceso hacia al origen del sistema de Zijderveld $\left(\mathrm{D}=355,5^{\circ} ; \mathrm{I}=-64,7^{\circ} ; \mathrm{MDA}=1,9^{\circ}\right)$, la misma fue eliminada al aplicar un 
campo pico de $20 \mathrm{mT}$; entre 20 y $30 \mathrm{mT}$ fue desmagnetizada otra componente $\left(\mathrm{D}=326,8^{\circ}\right.$; I=-51,2; $\mathrm{MDA}=5,1^{\circ}$ ) que se dirigió hacia el cuadrante SE del diagrama de Zijderveld; a partir de un campo pico de $40 \mathrm{mT}$ las direcciones obtenidas fueron espúreas.

En la figura 8.31 se presentan los gráficos correspondientes a las muestras PD40 y PD41 del nivel de ceniza; ambas presentaron componentes de magnetización que se "lavaron" a partir de campos bajos de 2,5 $\mathrm{mT}$ y se eliminaron tras aplicar campos pico de 15 y $10 \mathrm{mT}$ respectivamente; la dirección promedio fue $\mathrm{D}=62^{\circ}$ e $\mathrm{I}=-54^{\circ}\left(\mathrm{k}=100,45 ; \alpha_{95}=1,4^{\circ}\right)$.

Cabe destacar que las muestras PD10 y PD11 del paleosuelo con carbonatos reticulados (S-PD1), cuyos valores de $\mathrm{J}^{\mathrm{o}} \mathrm{y} \mathrm{J}^{20}$ registrados fueron lo máximos de la sección, presentaron direcciones de polaridad con un apartamiento significativo respecto de las demás muestras de la magnetozona; la dirección promedio de las muestras fue $\mathrm{D}=46,4^{\circ} ; \mathrm{I}=-15,1^{\circ}\left(\kappa=299,7 ; \alpha 95=0,47^{\circ}\right)$. En la figura 8.32 a se presentan los gráficos correspondientes a la muestra PD10. Presentó dos componentes de desmagnetización; la componente de menor coercitividad se desmagnetizó entre 2,5 y $15 \mathrm{mT}$ de campo pico $\left(\mathrm{D}=53,1^{\mathrm{o}}\right.$; I=1,4; $\mathrm{MDA}=0,7)$; a partir de $15 \mathrm{mT}$ se desmagnetizó la segunda componente $\left(\mathrm{D}=45^{\circ} ; \mathrm{I}=-12.1^{\mathrm{o}} ; \mathrm{MDA}=4,7^{\circ}\right)$ que presentó una caída lineal de la intensidad hasta $60 \mathrm{mT}$ de campo pico aplicado.

Asimismo, cabe destacar que en muestras de la unidad U-PD4 se detectó un apartamiento paulatino de los valores de declinación en sentido antihorario (Fig. 8.30); la muestra de la base de la unidad (PD26) registró una declinación de 309,3ㅜ la muestra PD25 presentó una declinación cercana al ecuador $\left(281^{\circ}\right)$ y finalmente la muestra PD24 registró un valor de declinación en el hemisferio sur $\left(215,3^{\circ}\right)$; las tres muestras presentaron valores negativos y elevados de inclinación. La dirección promedio de dichas muestras fue $\mathrm{D}=273,6^{\circ}$ e $\mathrm{I}=-83^{\circ}\left(\kappa=33,5 ; \alpha 95=4,27^{\circ}\right)$. La muestra PD24 de la figura $8.32 \mathrm{~b}$ presentó una componente viscosa que se eliminó a 2,5 mT , luego entre 2,5 mTy $10 \mathrm{mT}$ se desmagnetizó una componente inversa $\left(\mathrm{D}=190,6^{\circ} ; \mathrm{I}=23,4^{\circ} ; \mathrm{MDA}=5,3^{\circ}\right)$; a partir de $15 \mathrm{mT}$ de campo pico se desmagnetizó otra componente $\left(\mathrm{D}=215,3^{\circ} ; \mathrm{I}=-72,8^{\circ} ; \mathrm{MDA}=15,3^{\circ}\right)$.

\subsubsection{Perfil paleomagnético de la sección El Casal (PEC).}

El perfil paleomagnético se refiere al panel de la figura 5.62. Para su elaboración se utilizaron datos de 45 muestras paleomagnéticas (EC1 a EC45). En la Fig. 8.33 se indican los valores de intensidad magnética $\left(\mathrm{J}^{\mathrm{o}} \mathrm{y} \mathrm{J}^{20}\right)$, declinación (D) e inclinación (I) del MRC de las muestras de la sección PEC. 
Los valores de intensidad magnética del magnetismo remanente natural $\left(\mathrm{J}^{\mathrm{o}}\right)$ oscilaron entre 3 y

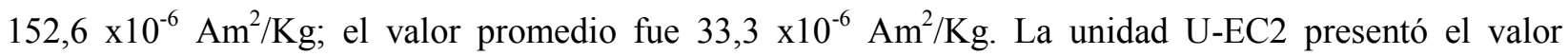
promedio más elevado ( $77 \times 10^{-6} \mathrm{Am}^{2} / \mathrm{Kg}$ ); las muestras EC4 y EC5 de esta unidad presentaron los valores más elevados de la sección. Los valores más bajos se registraron en las unidades con mayores evidencias pedogenéticas; la unidad U-EC5 registró un valor promedio de $11 \times 10^{-6} \mathrm{Am}^{2} / \mathrm{Kg}$ y la unidad U-EC3 de $19,2 \times 10^{-6} \mathrm{Am}^{2} / \mathrm{Kg}$. El resto de las unidades presentaron valores intermedios.

El valor medio de la intensidad magnética $\mathrm{J}^{20}$ osciló entre 0,7 y $21,2 \times 10^{-6} \mathrm{Am}^{2} / \mathrm{Kg}$, el promedio fue $6,9 \times 10^{-6} \mathrm{Am}^{2} / \mathrm{Kg}$. La unidad U-EC2 presentó el valor promedio más elevado $\left(16,8 \times 10^{-6} \mathrm{Am}^{2} / \mathrm{Kg}\right)$. Los valores promedio más bajos se registraron en las unidades con paleosuelos: U-EC3 (1,6 x10 $0^{-6}$ $\left.\mathrm{Am}^{2} / \mathrm{Kg}\right)$ y U-EC5 $\left(2,4 \times 10^{-6} \mathrm{Am}^{2} / \mathrm{Kg}\right)$. Los valores de $\mathrm{J}^{\mathbf{0}}$ y $\mathrm{J}^{20}$ presentan variaciones similares, con descenso de los valores en los paleosuelos; el coeficiente de correlación entre $\mathrm{J}^{\mathrm{o}} \mathrm{y} \mathrm{J}^{20}$ fue positivo y fuerte $(0,69)$.

Las direcciones del magnetismo remanente característico (MRC) obtenidas de la sección estratigráfica permitieron establecer una magnetozona de polaridad normal (M-EC); no obstante, cabe destacar que en dos sectores del perfil se detectaron muestras con componentes de magnetización inversa. Los valores de D e I medios, así como $\kappa$ y $\alpha 95$, fueron determinados para cada unidad, los mismos se indican en la tabla 8.9. En la figura 8.34 se presentan redes estereográficas, curvas de desmagnetización y diagramas de Zijderveld de las muestras analizadas. La muestra EC43, presentó una componente de magnetización, de polaridad normal $\left(\mathrm{D}=9,1^{\circ} ; \mathrm{I}=-65,7^{\circ} ; \mathrm{MDA}=2^{\circ}\right)$, que comenzó a desmagnetizarse a partir de campos pico de $5 \mathrm{mT}$ y un pérdida de más del $10 \%$ de la intensidad inicial a $40 \mathrm{mT}$ de campo pico aplicado; en el diagrama de Zijderveld se puede observar la estabilidad de las direcciones hacia el origen del sistema, al igual que en la red de la izquierda de la figura 8.34. En la misma figura se presentan muestras de los sectores con componentes de magnetización inversa. La muestra EC4 (unidad U-EC2) presentó una componente de polaridad inversa $\left(\mathrm{D}=216,3^{\circ} ; \mathrm{I}=36,5 ; \mathrm{MDA}=5^{\circ}\right)$ que se desmagnetizó desde la aplicación de un campo pico de 2,5 mT hasta su eliminación al impartir un campo pico de $15 \mathrm{mT}$; a partir de dicho campo la caída de la intensidad es asintótica y es cuando se desmagnetizó la otra componente de magnetización $\left(\mathrm{D}=308^{\circ} ; \mathrm{I}=-78,3^{\circ} ; \mathrm{MDA}=11,9^{\circ}\right)$, en el diagrama de la derecha se observa el cambio operado en las direcciones y la caída de la intensidad a campos alternos más elevados que $15 \mathrm{mT}$. Cabe pensar, que a valores de intensidad de la remanencia tan bajos como los que se obtienen a 40

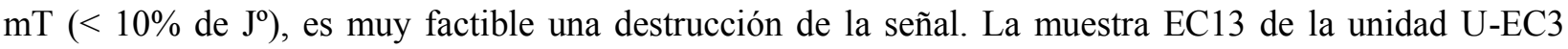
presentó dos componentes de magnetización; la primera, muy "blanda", se desmagnetizó desde el inicio del "lavado" hasta un campo pico de $5 \mathrm{mT}\left(\mathrm{D}=287,2^{\circ}\right.$; I=38,1; MDA=9,5 $)$; a partir de dicho campo se 
desmagnetiza la componente característica, inversa, que decrece en intensidad hacia el origen del sistema de Zijderveld ( $\mathrm{D}=239,9^{\circ} ; \mathrm{I}=24,2^{\circ}$; MDA=8, $6^{\circ}$ ).

Si bien las direcciones predominantes obtenidas son de polaridad normal y perfectamente asignables al cron Brunhes, cabe destacar la existencia de direcciones de polaridad inversa en los sectores superiores del perfil. En U-EC2 (muestras EC4 y EC5) con componentes de magnetización que se ubican en el hemisferio sur (promedio $\mathrm{D}=175,2^{\circ} ; \mathrm{I}=48,9$ ) y que llamativamente presentan valores elevados de $\mathrm{J}^{\mathrm{o}} \mathrm{y}$ $\mathrm{J}^{20}$. Del mismo modo la unidad U-EC3 presentó niveles con MRC en el hemisferio sur $\left(\mathrm{D}=239,9^{\circ}\right.$; $\left.\mathrm{I}=24,2^{\circ}\right)$, y también direcciones anómalas $\left(\mathrm{D}=56,2^{\circ} ; \mathrm{I}=24,2\right)$. Se considera relevante el estudio de estos fenómenos, pues los registros mencionados podrían estar vinculados a episodios de inversión del campo magnético terrestre durante el cron Brunhes. Esto será retomado más adelante.

\subsubsection{Perfil paleomagnético de la Sección Santa Elena (PSE).}

Se obtuvieron tres muestras paleomagnéticas de la sección estratigráfica PSE. Todas ellas corresponden a la parte basal de la unidad U-EC3 donde se hallaron sedimentos asociados a una ingresión/transgresión marina.

La intensidad magnética del magnetismo remanente natural $\left(\mathrm{J}^{\circ}\right)$ promedio fue de 27,3 $\times 10^{-6}$ $\mathrm{Am}^{2} / \mathrm{Kg}$, osciló entre 21,6 y 33,6 x10-6 $\mathrm{Am}^{2} / \mathrm{Kg}$. El valor medio de $\mathrm{J}^{20}$ fue $8,3 \times 10^{-6} \mathrm{Am}^{2} / \mathrm{Kg}$, varió entre 3,9 y $12,4 \times 10^{-6} \mathrm{Am}^{2} / \mathrm{Kg}$.

Las direcciones de polaridad magnética características de las tres muestras se ubicaron en el hemisferio norte. La dirección promedio fue $\mathrm{D}=356^{\circ} ; \mathrm{I}=-57,2^{\circ}\left(\kappa=57,3 ; \alpha 95=2,47^{\circ}\right)$. En la figura 8.35 se presenta la red estereográfica, la curva de desmagnetización y el diagrama de Zijderveld de la muestra SE3. Entre 2,5 y $20 \mathrm{mT}$ de campo pico aplicado fue determinada una componente de magnetización de polaridad normal $\left(\mathrm{D}=340,6^{\circ} ; \mathrm{I}=-53,6^{\circ} ; \mathrm{MDA}=4,2^{\circ}\right)$. Luego de aplicar un campo pico de $20 \mathrm{mT}$, en los pasos siguientes las direcciones obtenidas estuvieron en torno a $\mathrm{D}=125,4^{\circ}$ e $\mathrm{I}=-7,9^{\circ}$. La intensidad de la remanencia se mantuvo elevada, en torno al 58\% de la intensidad inicial, aún a un campo pico desmagnetizante de $60 \mathrm{mT}$; no se descarta la posibilidad de la existencia una componente de polaridad inversa, de alta coercitividad, que no pudo ser desmagnetizada por esta vía. En la red estereográfica como en el diagrama ortogonal se evidencia una inversión de las direcciones, por otra parte cabe consignar que el resto de las muestras presentaron comportamientos similares. Este aspecto podría vincularse a una inversión del campo magnético terrestre durante el cron Brunhes, que a juzgar por la posición 
estratigráfica y las características del sedimento (ingresion marína) podría corresponderse con el evento Blake (ca. $120 \mathrm{Ka})$.

\subsection{Consideraciones de importancia.}

La mayoría de las muestras presentaron las direcciones MRC a campos pico aplicados que oscilaron entre 5 y $30 \mathrm{mT}$. Asimismo, el comportamiento frente a la desmagnetización por CMA es consistente con minerales magnéticos de baja coercitividad, es decir ferrimagnéticos (e.g. titanomagnetita). En el próximo capítulo se analizarán exhaustivamente las características magnéticas de los sedimentos en estudio.

A partir de las magnetozonas establecidas y teniendo en cuenta las correlaciones litoestratigráficas realizadas en el capítulo 5, fue posible generar un esquema de correlaciones magnetoestratigráficas entre las secciones de cada sector, como así entre los distintos sectores.

\subsubsection{Magnetoestratigrafía en el sector Sierras de Tandil}

En la figura 8.36 se presenta un esquema de correlación magnetoestratigráfica para el sector Sierras de Tandil a partir de los datos paleomagnéticos obtenidos.

Las magnetozonas determinadas tanto en la Formación Las Ánimas como en la Formación Vela, en cada sección estratigráfica fueron de polaridad normal y se asignaron al cron Brunhes $(<0,78 \mathrm{Ma})$. En cambio, las magnetozonas determinadas en la Formación Barker resultaron de polaridad normal, inversa y anómala. En la unidad U-VC4 (Fm. Barker; sección PVC) fueron hallados restos óseos que corresponden al Piso Chapadmalalense-Montermosense (3,3/3,2 a 5,3/6,8 Ma), estos se tuvieron en cuenta en relación con las zonaciones de polaridad magnética establecidas en la Formación Barker (sección PVC). A partir de los datos paleomagnéticos y de la correlación estratigráfica regional, los sedimentos de la Formación Barker, en la localidad de Villa Cacique se asignan a los crones Gauss y Gilbert. El nivel portador de fósiles es coincidente con la magnetozona $\mathrm{M}-\mathrm{VC} 3$ de polaridad inversa. Si se considera cómo edad mínima al límite superior propuesto para el Piso Chapadmalalense (3,2/3,3 Ma), dicha magnetozona correspondería al sub-cron Mammot (3,207 - 3,330 Ma); en tanto la magnetozona normal M-VC4 correspondería a Gauss inferior (3,330 - 3,596 Ma) y las magnetozonas M-VC5 a M-VC7 al cron Gilbert (>3,596 Ma). Cabe destacar que por encima de la unidad portadora de fósiles se halló una unidad saltuaria (U-VC3), asignada a la Formación Barker, donde las direcciones magnéticas del sector superior de la 
misma fueron de polaridad normal (parte inferior de M-VC1) y podrían asignarse a Gauss medio (3,116 3,207 Ma). Se propone para la Formación Barker una edad más antigua que 3,1 Ma y para la unidad litoestratigráfica U-VC6 una edad superior a 3,6 Ma, probablemente mayor a 4,2 Ma.

La Formación Barker, en el resto de las secciones estratigráficas del sector Sierras de Tandil presentó, magnetozonas inversas y anómalas. En la sección PMI la magnetozoma M-MI2, de polaridad inversa, incluyó las tres unidades litológicas correspondientes a la Formación Barker; en la sección PCF, la magnetozona M-CF2, de polaridad anómala, incluyó las unidades U-CF3 y U-CF4 (del sector superior y medio), y la magnetozona M-CF3, de polaridad inversa, incluyó la unidad inferior (U-CF5). Caben al menos dos posibilidades en cuanto a la interpretación magnetoestratigráfica de las magnetozonas inversas. La edad mínima de las mismas correspondería al subcron Mammot (3,207 - 3,330 Ma), sin embargo cabe la posibilidad de que correspondan al cron Gilbert, probablemente a Gilbert superior (3,596 - 4,187 Ma).

\subsubsection{Magnetoestratigrafía en el sector Sierras de Balcarce}

En la figura 8.37 se muestra el esquema de correlación magnetoestratigráfica para el sector Sierras de Balcarce.

De manera análoga a lo descripto para el sector de Sierras de Tandil, las magnetozonas determinadas en las formaciones Las Ánimas y Formación Vela, en cada sección estratigráfica del sector Sierras de Balcarce, fueron de polaridad normal y se asignan al cron Brunhes $(<0,78 \mathrm{Ma})$.

En la sección PSB, en la unidad litoestratigráfica U-SB3/4 fueron determinadas zonas tanto de polaridad normal como inversa. En el paleosuelo del tope de la unidad U-SB3 fue determinado un cambio de polaridad; en la parte superior del paleosuelo se registraron direcciones normales (M-SB1), posiblemente relacionadas al cron Brunhes $(<0,781 \mathrm{Ma})$, y en la parte inferior, así como el resto de la unidad U-SB3, las direcciones de polaridad fueron inversas (M-SB2), indicando una edad más antigua que 0,781 Ma (límite Brunhes-Matuyama). En la unidad U-SB4 se determinaron tres zonas de magnetopolaridad; en el sector cuspidal se determinaron direcciones normales (M-SB3); en el sector central direcciones inversas (M-SB4); y en el sector basal direcciones normales (M-SB5). Una posible interpretación, teniendo en cuenta la edad mínima del depósito, sería vincular las magnetozonas M-SB2 a M-SB5 al cron Matuyama (0,781 - 2,581 Ma), donde la magnetozona M-SB2 correspondería a Matuyama superior (0,781 - 0,988 Ma), M-SB3 al subcron Jaramillo (0,988 - 1,072 Ma), M-SB4 a Matuyama medio (1,077 - 1,778 Ma) y la magnetozona M-SB5 de la base de la sección, a Olduvai (1,778 - 1,945 Ma). No se descartan edades más antiguas para este depósito; cabe la posibilidad de que la magnetozona M-SB3, 
dado su espesor, corresponda (o incluya) al sub-cron Olduvai; en tanto la magnetozona normal de la base, siguiendo este criterio, podría corresponderse con Gauss superior (2,581 - 3,032 Ma). La edad máxima para la unidad litoestratigráfica U-SB3/4, teniendo en cuenta las correlaciones establecidas, así como el registro fósil, sería 3,2 Ma.

Cabe destacar que el paleosuelo S-SB1, de destacada continuidad lateral, presentó direcciones de polaridad inversa en su sector medio e inferior. En base a las edades mínimas establecidas, las características litológicas y la posición estratigráfica, es posible relacionar este paleosuelo con otros paleosuelos con polaridad inversa, registrados cerca del tope de la Formación Ensenada (en sentido de Riggi et al., 1986) en canteras de La Plata (Bidegain, 1991) y Baradero (Nabel et al., 1993).

La unidad más antigua determinada en el sector de Sierras de Balcarce corresponde a las unidades U-SM3 y U-SM4 de la sección de San Manuel. Dichas unidades se asignaron a la Formación Barker y registrararon direcciones de polaridad anómala e inversa. Cabe destacar la similitud de esta sección con la sección PCF del sector Sierras de Tandil, ya sea en cuanto a las unidades litoestratigráficas presentes, como al patrón de polaridades magnéticas; de esta manera resulta posible correlacionar ambas secciones, y de la misma manera que en la sección PCF, se asigna la magnetozona inversa al subcron Mammot (3,207 - 3,330 Ma) o bien a Gilbert superior (3,596 - 4,187 Ma).

\subsubsection{Magnetoestratigrafía en el sector costero al norte de Mar del Plata.}

En la figura 8.38 se muestra el esquema de correlación magnetoestratigráfica para el sector costero al norte de Mar del Plata.

Las magnetozonas de polaridad normal de las distintas secciones estratigráficas se asignan al Cron Brunhes $(<0,781 \mathrm{Ma})$ y la magnetozona inversa de la base de la sección PGA se asigna al Cron Matuyama (0,781 - 2,581 Ma), específicamente a Matuyama superior (0,781 - 0,998 Ma); esto es consistente con lo determinado por Bidegain et al. (2005b) en los acantilados marinos entre el arroyo La Tapera (Mar del Plata) y Santa Elena (Santa Clara del Mar).

En lo que respecta a las magnetozonas de polaridad normal asignadas al cron Brunhes en las distintas secciones del sector costero cabe hacer algunas consideraciones de importancia:

En la base de la unidad U-PD1 (A1) fue encontrado un nivel de ceniza de donde se extrajeron las muestras PD40 y PD41, éstas registraron direcciones con significativo apartamiento hacia el Este respecto al dipolo de polaridad normal $\left(\mathrm{D}=62^{\circ}\right.$ e $\left.\mathrm{I}=-54^{\circ}\right)$; este dato es similar a lo observado por Corbella et al. 
(2000) en el nivel de cenizas de la localidad de Camet Norte (Cineritas Camet) a $3 \mathrm{Km}$ al NNE de Playa Dorada, donde se registró también un significativo apartamiento hacia el Este $\left(\mathrm{D}=83^{\circ}\right.$ e $\left.\mathrm{I}=-34^{\circ}\right)$. Esto corrobora la hipótesis esbozada en el capítulo 5, donde se planteó la equivalencia entre las cenizas de Camet Norte y las de Playa Dorada. En tanto, la edad de la asociación A1 se considera inferior a $21 \mathrm{Ka}$.

La asociación A5 contiene el cambio de polaridad mencionado, éste se asocia con el límite Brunhes-Matuyama (0,78 Ma) y fue hallado en el sector basal de la sección PGA; en el resto de las secciones estratigráficas donde fue muestreada la asociación A5, se registraron sólo direcciones normales (Brunhes); asimismo, la mayor parte de A5 registró polaridad normal (Brunhes). Cabe destacar que la magnetozona inversa incluye el paleosuelo S-GA2, de la base del acantilado; éste, dada su posición estratigráfica, así como la polaridad magnética, es posible vincularlo a paleosuelos con polaridad inversa registrados en canteras de La Plata (Bidegain, 1991) y Baradero (Nabel et al., 1993).

Finalmente, un aspecto importante en los perfiles del sector costero es la presencia de muestras paleomagnéticas en unidades asignadas al Cron Brunhes $(<0,78 \mathrm{Ma})$ que presentaron componentes inversas. Esto incluyó a las unidades litológicas U-EC2 (A2), U-EC3, U-SE3 y U-PD4 (A4). Los hallazgos, de importancia, motivan a la realización de futuras investigaciones que deberán incluir muestreos de detalle, a los fines de analizar el posible registro de excursiones paleomagnéticas en sedimentos loéssicos pampeanos, cuya mención en la literatura es hasta el momento escasa (Orgeira et al., 1988; Vizán et al., 2015). No obstante, si consideramos que estas zonas corresponden a eventos o excursiones paleomagnéticas, teniendo en cuenta la posición estratigráfica, se podría especular que las componentes inversas de las muestras de U-EC2 corresponderían a Laschamp (o bien Mono Lake), ambas

muy cercanas en el tiempo (39-41 y 32-34 Ka respectivamente); que las componentes inversas de las unidades U-EC3 (paleosuelo S-EC1) y U-SE3 (nivel marino), con idéntica posición estratigráfica y vinculadas a clima cálido y húmedo, corresponderían al evento Blake ( ca. $117 \mathrm{Ka})$ en coincidencia con el Estadio Isotópico 5e. Las componentes inversas de la unidad U-PD4 son más difíciles de asignar a excursiones o eventos paleomagnéticos. Considerando que la unidad U-PD4 forma parte de la asociación A4, donde es común la presencia de paleosuelos (Geosol Mar del Plata); se podría vincular al evento CR1 (ca. 315 - $325 \mathrm{Ka}$ ), coincidente en edad con el Estadio Isotópico 9.

\subsubsection{Magnetoestratigrafía en el sector Tandil-Balcarce-Mar del Plata.}

Una vez establecidas las correlaciones lito y magnetoestratigráficas para cada sector, es posible establecer un esquema que vincula el sector serrano (Tandil y Balcarce) con el sector costero. En la figura 
8.39 se muestra el esquema de correlación entre las unidades litoestratigráficas del sector serrano y las asociaciones de unidades establecidas en el sector costero; para la confección del mismo se exponen las columnas magnetoestratigráficas representativas; para el sector Sierras de Tandil la sección PVC, para el sector Sierras de Balcarce la sección PSB y para el sector costero las secciones PGA y PPD. Asimismo en la Tabla 8.10 se plasman las correlaciones establecidas y las edades propuestas para las distintas unidades de los sectores serranos y costeros.

En el capítulo 5 se esbozó que la Formación Las Ánimas sería equivalente con la asociación A1, esto fue manifestado en función de las características litológicas, sedimentarias y por la posición estratigráfica. Tanto en la Formación las Ánimas como en la asociación A1 se determinaron direcciones de polaridad normal que fueron asignadas al cron Brunhes $(<0,78 \mathrm{Ma})$. En la base de la asociación A1 del perfil PPD (unidad U-PD1) fue hallado un nivel de ceniza que dadas sus características paleomagnéticas, así como sus valores de susceptibilidad magnética (como se verá más adelante), es posible correlacionado con él descripto por Fasano et al. (1984), datado en $21 \mathrm{Ka}$ (Corbella et al., 2000). Cabe consignar que Gentile y Ribot (2001) analizaron y compararon, química, mineralógica y estratigráficamente el nivel de ceniza de Camet Norte con niveles de tefra hallados en la localidad de Tandil (en la Formación Las Ánimas) y Olavarría (en el miembro Guerrero de la Formación Luján) y destacaron que sendos niveles se encuentran en unidades litoestratigráficas correlacionables y que la composición química y mineralógica de los niveles analizados es similar; si bien dichos autores no indicaron si los niveles de tefra poseen una misma edad, las consideraciones realizadas refuerzan la idea de plantear una equivalencia entre asociación A1 y la Formación Las Ánimas. En función de la presencia del nivel cinerítico, se considera que el manto eólico (Las Ánimas-A1) posee una edad inferior a $21 \mathrm{Ka}$.

Siguiendo con el análisis de los depósitos de loess de la Formación Las Animas (y A1), cabe aquí realizar algunas consideraciones en cuanto a los valores de intensidad magnética registrados. Si bien, las direcciones paleomagnéticas obtenidas fueron en todos los casos de polaridad normal y a pesar de presentar características geológicas muy semejantes, se obtuvieron intensidades magnéticas contrastantes. En la mayoría de los perfiles las intensidades $\mathrm{J}^{\mathbf{0}}$ y $\mathrm{J}^{20}$ promedio variaron entre 31 y $92 \times 10^{-6} \mathrm{Am}^{2} / \mathrm{Kg}\left(\mathrm{J}^{\mathrm{o}}\right)$ y entre 9,3 y 30,1 x10 ${ }^{-6} \mathrm{Am}^{2} / \mathrm{Kg}\left(\mathrm{J}^{20}\right)$. No obstante, en la sección de Villa Cacique se obtuvieron valores destacadamente más elevados; cuyos promedios fueron $407 \times 10^{-6} \mathrm{Am}^{2} / \mathrm{Kg}\left(\mathrm{J}^{\circ}\right)$ y $33 \times 10^{-6} \mathrm{Am}^{2} / \mathrm{Kg}\left(\mathrm{J}^{20}\right)$. Si se tiene en cuenta el carácter episódico de la sedimentación del loess (Zárate y Blasi, 1991; Martínez, 2001; Dangavs, 2005, entre otros) es posible pensar que las diferencias de intensidad estén vinculadas a distintos eventos de depositación. Esto es, sin duda, un aspecto que merece ser analizado en detalle en futuras contribuciones. 
Por otro lado, cabe consignar que la asociación A3 y La Formación Vela fueron homologadas en base a sus similitudes litológicas, sedimentológicas y estratigráficas en capítulos precedentes. El hecho de que ambas posean registros de polaridad normal y hayan sido asignadas al Cron Brunhes corrobora la propuesta. Dado que estratigráficamente por encima de A3 se hallaron sedimentos vinculados al Estadio Isotópico 5 (117 a $130 \mathrm{Ka}$ ), es posible extrapolar esta edad a la Formación Vela, considerándola más antigua que dicho intervalo, y dado que se asigna al Cron Brunhes, la misma se habría depositado durante el Pleistoceno medio. Sin embargo es posible que la Formación Vela en el sector serrano incluya también sedimentos equivalentes a la asociación A2, que en posiciones topográficas elevadas podrían tener menores espesores o bien estar ausentes; en el primero de los casos, los mismos se encontrarían enmascarados por la costra calcárea del tope de la Formación Vela; en el segundo caso, dado que la asociación A2 suele presentar $\mathrm{CaCO}_{3}$, es posible que este evento de carbonatación se sume a la costra calcárea vinculada a la paleosuperficie Tandil. En este sentido, en cuanto a los ciclos de carbonatación que dieron origen a la calcreta de dicha paleosuperficie, surge que en el sector costero serían más antiguos que $120 \mathrm{Ka}$, donde probablemente el último evento de carbonatación correspondería al estadio isotópico 6 $(130-186 \mathrm{Ka})$; en tanto, en el sector serrano, la antigua superficie podría haber estado activa durante mucho más tiempo e incluya carbonatos más jóvenes, incluso en algunos sitios elevados (lomadas), la paleosuperficie Tandil coincide con superficie actual.

Siguiendo la cronología propuesta, cabe discutir que la asociación A4, la cual se encuentra afectada generalmente por pedogénesis, conformando el Geosol Mar del Plata, sería más antigua que lo planteado por Martínez (2001), quien vinculó el evento pedogenético al estadio isotópico 5. En tanto, dada la posición estratigráfica, la edad mínima para el evento pedogenético correspondería al estadio isotópico 7 (180 - $240 \mathrm{Ka})$. No obstante, no se descarta que, dado el importante desarrollo que adquiere en muchos casos el Geosol Mar del Plata, este podría corresponderse también al Estadio Isotópico 9 (300 - $360 \mathrm{Ka}$ ) o bien al 11 (398 - $410 \mathrm{Ka}$ ); según Droxler et al. (2003) el Estadio isotópico 11, en conjunto con el 9, corresponderían a un período inusualmente cálido, asimismo dichos autores destacaron que el 11 habría tenido características climáticas similares a las del Holoceno, o incluso más cálidas; además cabe considerar que Verzi et al. (2004) basandose en la presencia de Ctenomys Kraglievichi en sedimentos del Norte de Mar del Plata, Necochea y Bajo San Jose, que asignaron a la base del Piso Bonaerense, indicaron que estos corresponderían el estadio isotópico 11; cabe considerar que la sección estudiada por dichos autores en el Norte de Mar del Plata es coincidente con el paleosuelo de la Unidad 3 de Bidegain et al. (2005b), de polaridad normal (Brunhes), que correlacionaron con la Formación Buenos Aires; que sería equivalente a la asociación A4 del presente trabajo. 
En la asociación A5 en la sección GADA del sector costero, así como en la unidad U-SB3/4 del perfil de Sierra Bachicha se determinaron cambios de polaridad magnética que fueron asignados al límite Brunhes-Matuyama (0,78 Ma); esto permitió correlacionar ambas unidades. Asimismo cabe resaltar que en sendas secciones estratigráficas se hallaron paleosuelos con polaridad inversa, que fueron vinculados a otros paleosuelos con polaridad inversa, en el límite Brunhes-Matuyama, como los registrados en canteras cercanas a la ciudad de La Plata (Bidegain, 1991) y de Baradero (Nabel et al., 1993), en este último caso designado como Geosol Hisisa; en tanto es posible correlacionar dichos paleosuelos. Cabe destacar que en la unidad A5 del sector costero se registró una única magnetozona inversa en la base de la sección PGA que fue atribuida a Matuyama superior $(0,78-1,072 \mathrm{Ma})$; en tanto que la mayor parte de A5 resultó de polaridad Normal y se asignó al Cron Brunhes $(<0,781 \mathrm{Ma})$. En cambio, en la sección PSB, las edades de la unidad U-SB3/4 llegarían hasta el sub-cron Olduvai $(1,778$ - 1,945 Ma) y la parte asignada al cron Brunhes abarcaría sólo una pequeña parte, en el sector superior del paleosuelo S-SB1.

Cabe señalar que en el sector de Sierras de Tandil, así como en la sección San Manuel (oeste del sector Sierras de Balcarce) no fue posible determinar sedimentos asignables al cron Matuyama (0,781 2,581 Ma), así como de la parte basal de Brunhes y el tope de Gauss. Los sedimentos depositados durante el Cron Brunhes $(<0,78 \mathrm{Ma}$ ) (Formaciones Las Ánimas y Vela) se apoyan en discordancia erosiva sobre sedimentos a los que se les atribuye una edad superior a 3,1 Ma (Formación Barker y U-VC6); por lo tanto allí existiría un significativo hiatus, de al menos 2,6 Ma. Este es sin duda un aspecto importante a resaltar. Situaciones semejantes han sido registradas en la pampa interserrana, en el ámbito de Ventania y en la provincia de La Pampa (ver Folguera y Zárate, 2009 y trabajos allí citados), donde se hallan unidades miocenas y pliocenas, muy cerca de la superficie, en general cubiertas por un delgado manto del Pleistoceno tardío-Holoceno. En Folguera y Zárate (2009) se indica que la interrupción de la sedimentación mio-pliocena se debe al fin del espacio de acomodación en la cuenca. Los autores explicaron esto mediante dos alternativas; una, la colmatación de la cuenca; otra, el ascenso del area. En Folguera Telichevsky (2011), Folguera y Zárate (2011) y Folguera et al. (2015) se continúan los estudios al respecto, introduciendo conceptos vinculados a la Neotectónica y fundamentalmente, una perspectiva desde los controles sedimentológicos ejercidos por la dinámica andina. Se entiende que los análisis que se efectúan, y que incluyen las causas que generaron hiatus de magnitud en el registro sedimentario, son de fundamental importancia para el estudio estratigráfico de la región y darán respuestas a interrogantes fundamentales acerca de los controles en la sedimentación a gran escala y durante largos intervalos durante el Cenozoíco tardío.

Para finalizar el presente capítulo, un aspecto a resaltar es la presencia de zonas de magnetopolaridad anómalas y mixtas. En el presente trabajo, el hallazgo de las mismas estuvo 
practicamente restringido a los sedimentos de la Formación Barker (Gauss-Gilbert). Existen en el plano local, numerosos trabajos del paleomagnetismo referidos a sedimentos loessicos del Cenozoico tardío en los que se indican zonas de polaridad anómala (denominada muchas veces oblicua) y mixta (Nabel y Valencio, 1981; Valencio y Orgeira, 1983; Orgeira y Valencio, 1984; Bobbio et al., 1986; Bidegain, 1991, 1999; Nabel et al., 1993; Bidegain et al., 2007; 2011, entre otros). Incluso, en algunos de estos trabajos se registró un predominio de zonas con este comportamiento respecto a las de polaridad claramente normal o inversa (e.g. Orgeira y Valencio, 1984). Si bien en algunos de estos trabajos se esbozan hipótesis acerca de este fenómeno, las causas de su origen no son tratadas en profundidad. En Nabel y Valencio (1981) se indica que las "polaridades intermedias" (anómalas) son una característica del cron Matuyama. No obstante en Orgeira y Valencio (1984) este fenómeno es citado para los crones Gauss y Gilbert y en Bobbio et al. (1986) también para Brunhes. Nabel et al. (1993), en referencia a una zona de polaridad oblicua que incluyeron en Matuyama (base del perfil de Baradero), indicaron que este comportamiento se ha reiterado en secciones equivalentes de otros perfiles del area y sugirieron que es causa de un "acontecimiento de magnetización", es decir que se debería a características del campo geomagnético en el momento de fijación de la magnetización. Por otro lado, Bidegain et al. $(2007 ; 2011$ y otras publicaciones que involucran al primer autor) indicaron polaridad transicional para estos fenómenos, especialmente cuando se encuentran entre zonas de polaridad inversa y normal. En este sentido, en estudios recientes sobre la transición Brunhes-Matuyama en depósitos de loess de China (Yang et al, 2010; Wu et al. 2016) se registraron patrones similares a los que en este trabajo denominamos polaridad mixta. Por su parte, Laj et al. (1987), Yang et al. (2010), entre otros, indicaron que durante las transiciciones se producen repetidas alternancias de polaridad magnética, en eventos de corta duración. Esta explicación podría aplicarse a las zonas de polaridad mixtas de la sección Villa Cacique y Sierra Bachicha. No obstante, si se consideran las propuestas acerca de que las inversiones paleomagnéticas transcurren extremandamente rápido (Sagnotti et al. 2014, 2016), esta explicación quedaría practicamente invalidada dada la baja posibilidad de preservación de la inversión en función de las tasas de depositación, las cuales se suponen relativamente bajas (y probablemente discontinuas) para los sedimentos en cuestion. Una posible causa para la existencia de estas zonas podría deberse a errores introducidos durante el muestreo. No obstante, esta posibilidad queda descartada para este trabajo, pues las muestras anómalas se registraron en zonas específicas, y no distribuidas al azar. Asimismo, cabe destacar que en sedimetos con características litológicas muy semejantes y muestreados de forma idéntica, se registraron zonas de polaridades normales, inversas, anómalas y mixtas. Otro factor que se debe considerar es que el fenomeno podría deberse a excursiones del campo magnético terrestre. No obstante, esto sería poco probable en función de la corta duración de las excursiones paleomagnéticas, de las tasas de depositación relativamente bajas y del espesor $(>1 \mathrm{~m})$ de las zonas anómalas registradas en este trabajo. Asimismo, no 
se descarta que estos fenómenos estén relacionados a problemas de adquisición en función de las características del sedimento. No obstante, cabe considerar que sedimentos con características muy semejantes, y homogeneos desde el punto de vista magnético, como se verá en el capítulo 9, han registrado tanto polaridades anómalas como inversas (e.g. Fm. Barker en PCF y PSM).

El estudio del origen de las zonas mixtas y anómalas excede el objetivo de esta tesis y se considera que no es abarcable con las técnicas utilizadas y los datos disponibles, empero se entiende la relevancia del estudio de estos fenómenos, tan corrientes en sedimentos del Cenozoico tardío de la región pampeana. 


\subsection{Figuras del capítulo 8}
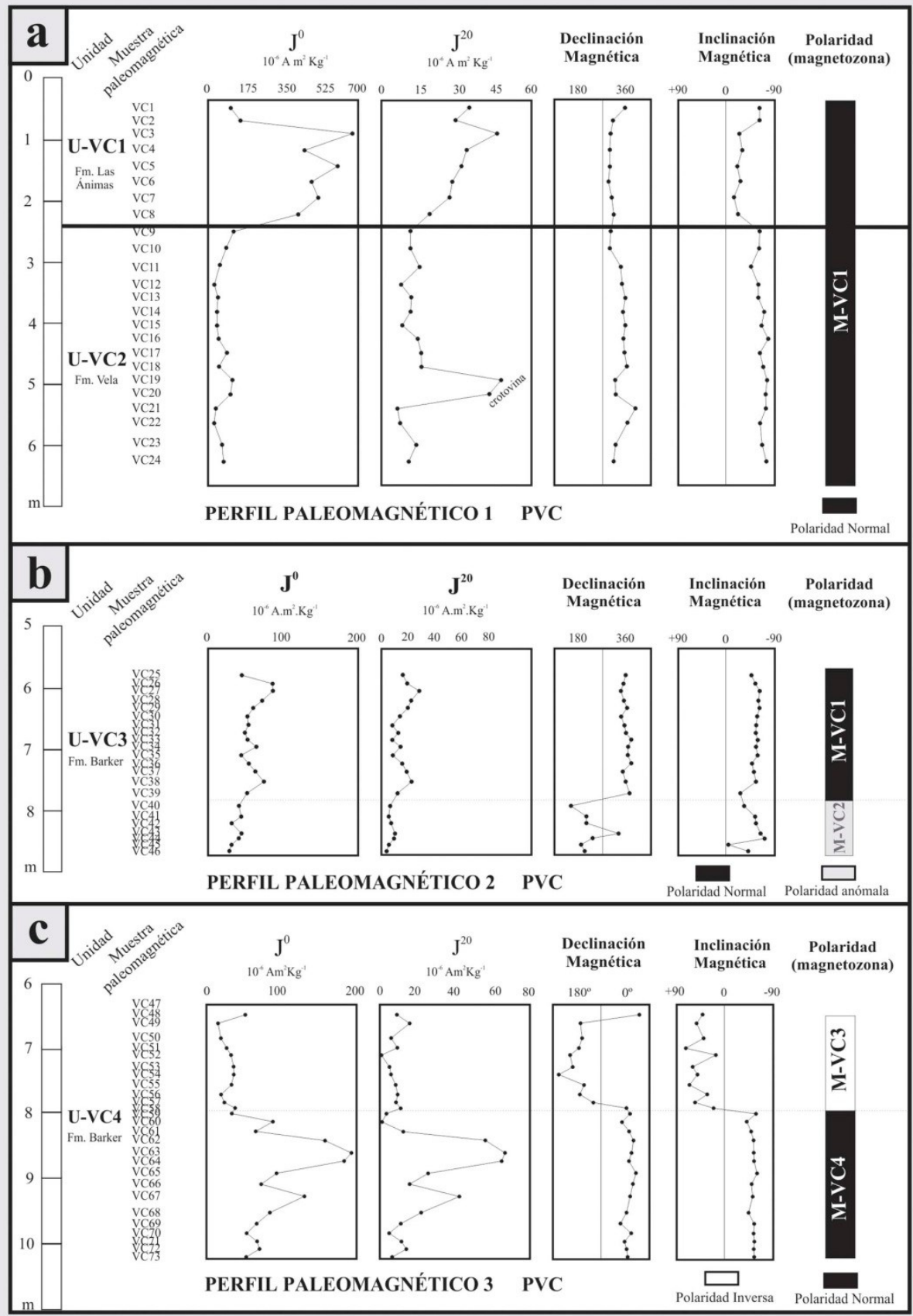

Figura 8.1. Perfiles paleomagnéticos de la sección de Villa Cacique (PVC). a) Perfil paleomagnético 1: b) Perfil paleomagnético 2; c) Perfil paleomagnético 3. 


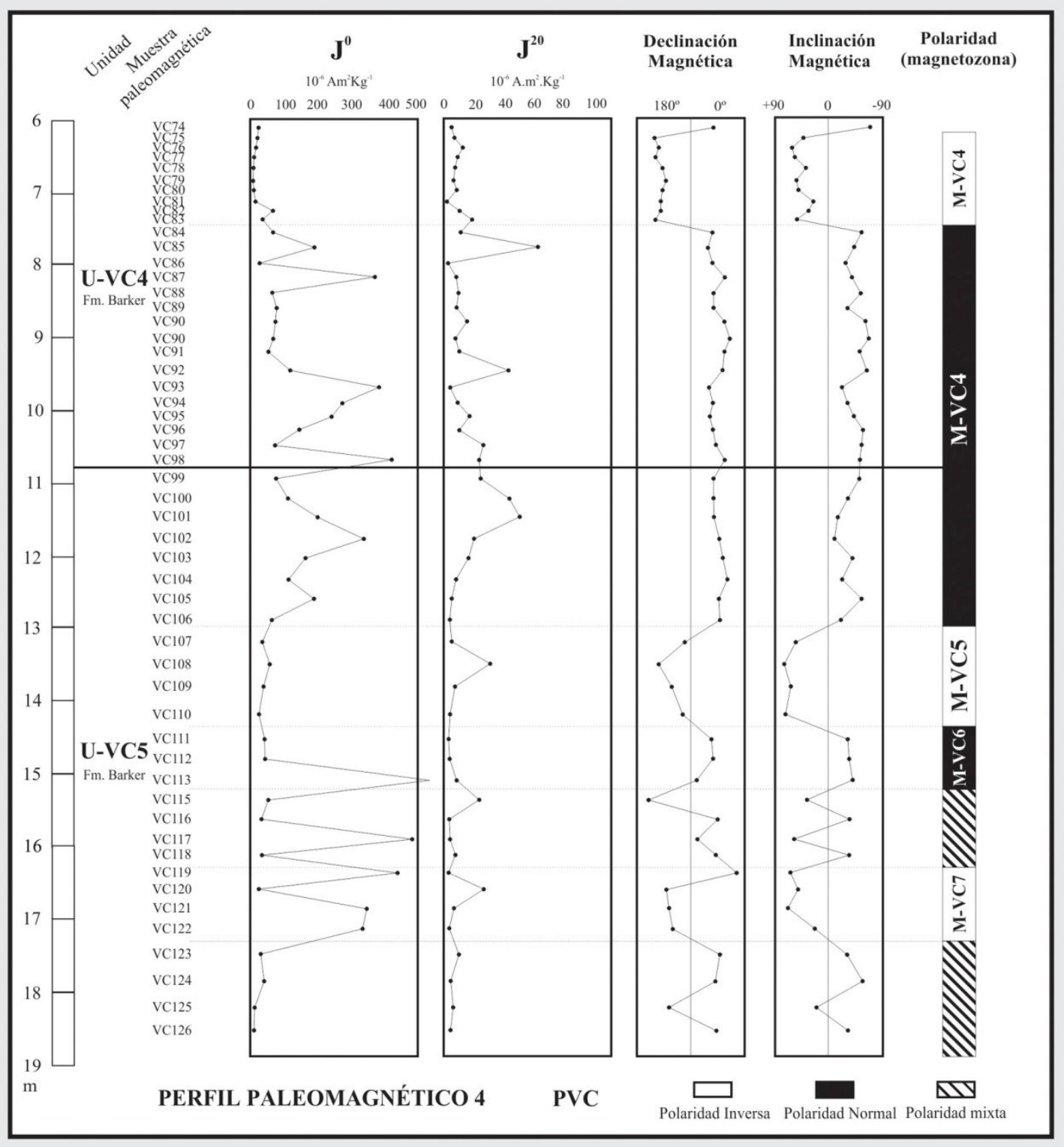

Figura 8.2. Perfil paleomagnético 4 de la sección de Villa Cacique (PVC). 


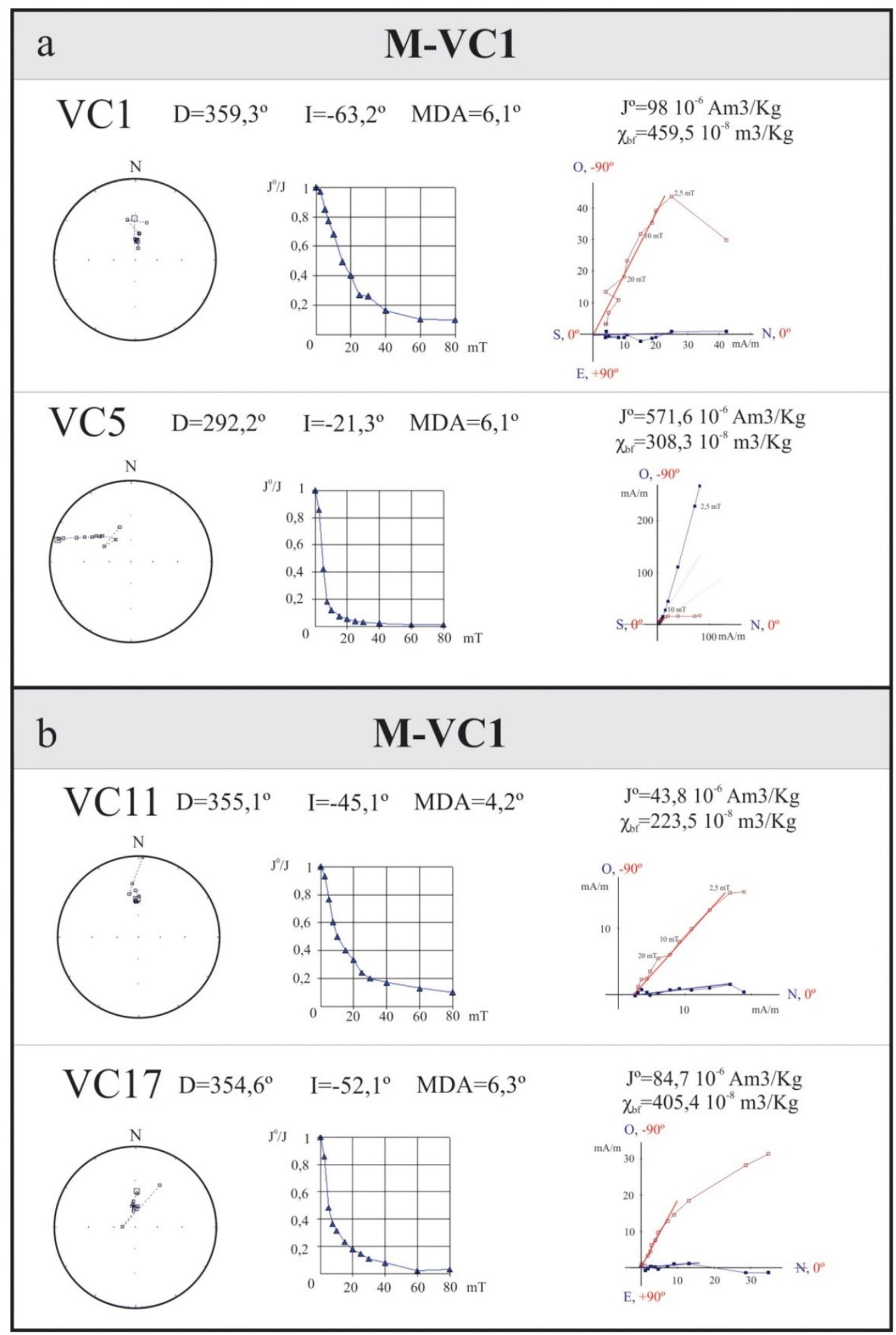

Figura 8.3. Estereogramas, curvas de desmagnetización y diagramas de Zijderveld de muestras de la magnetozona M-VC1. a) muestras de la Formación Las Ánimas; b) muestras de la Formación Vela. 


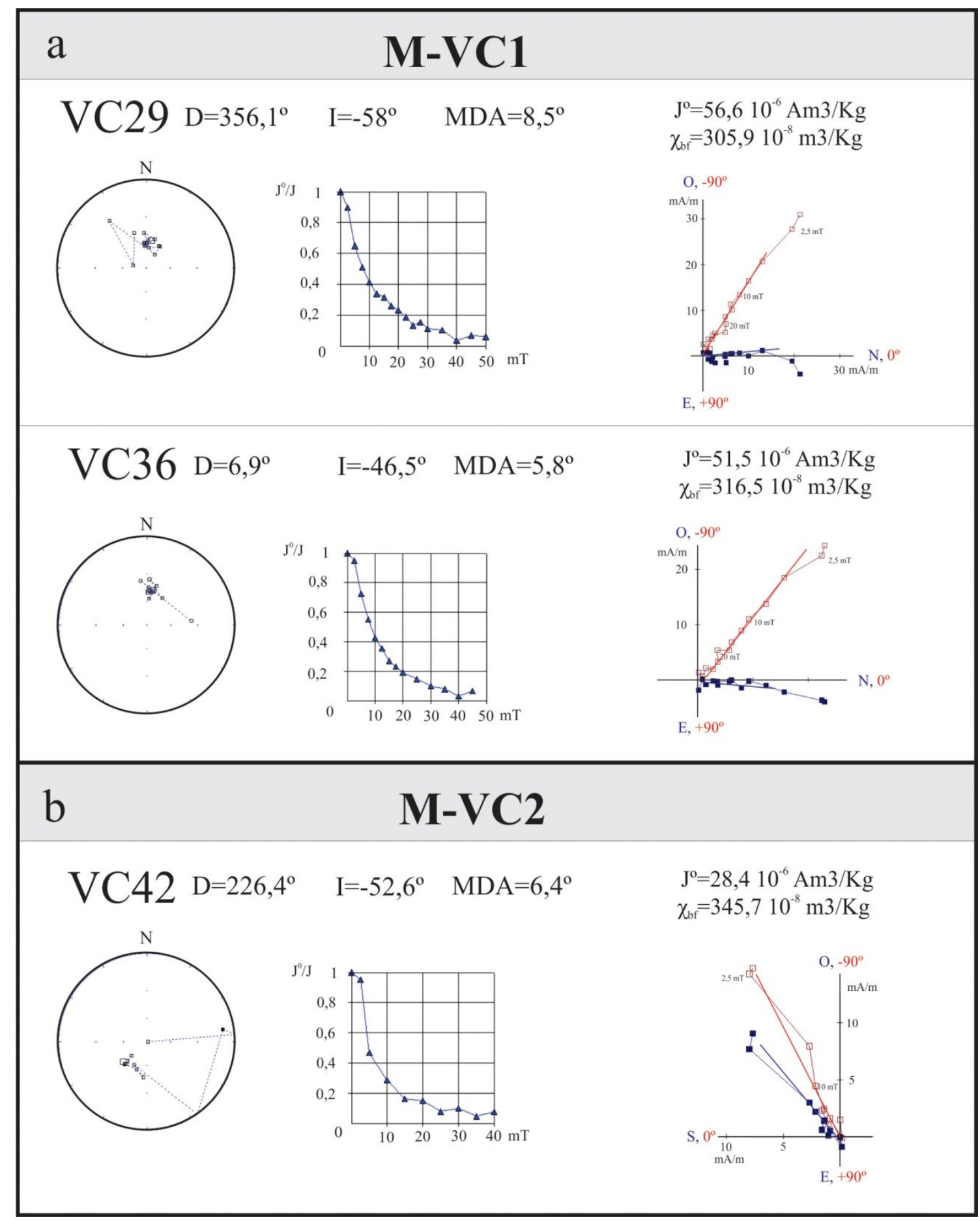

Figura 8.4. Estereogramas, curvas de desmagnetización y diagramas de Zijderveld de muestras de la unidad U-VC3 (Formación Barker). a) muestras de la magnetozona M-VC1; b) muestras de la magnetozona $\mathrm{M}-\mathrm{VC} 2$. 


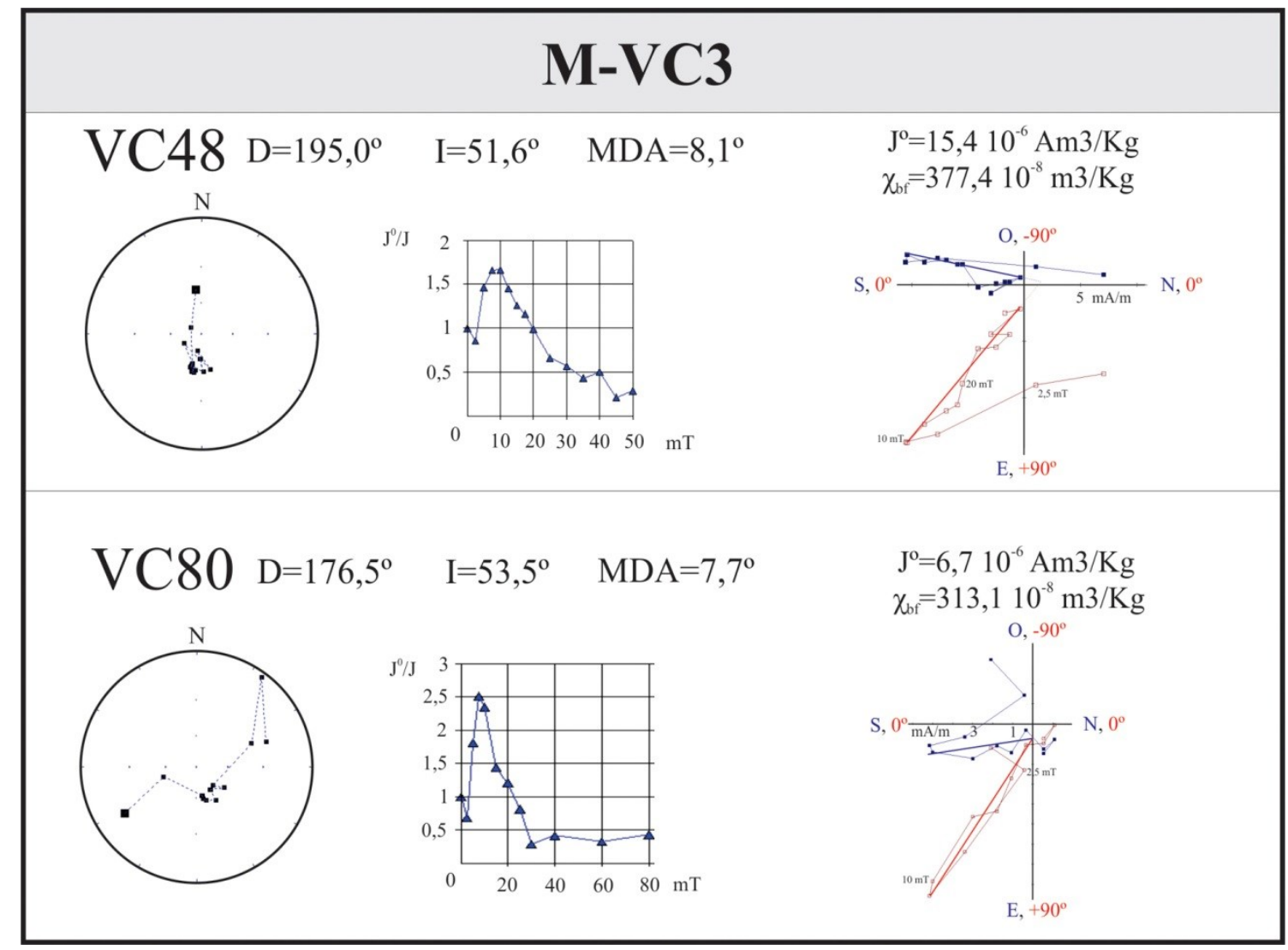

Figura 8.5. Estereogramas, curvas de desmagnetización y diagramas de Zijderveld de muestras de la magnetozona M-VC3. 


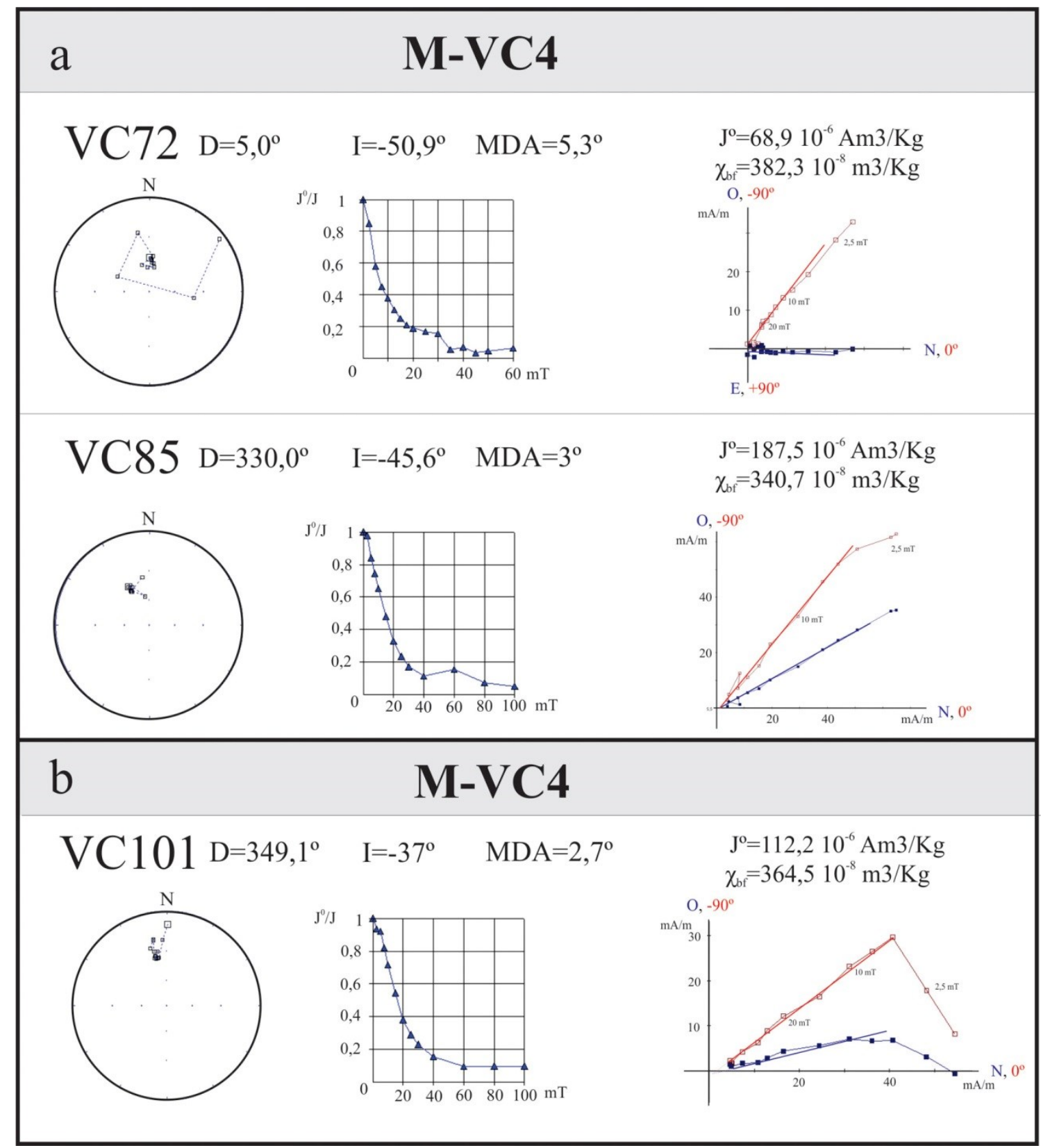

Figura 8.6. Estereogramas, curvas de desmagnetización y diagramas de Zijderveld de muestras de la magnetozona M-VC4. a) muestras de la unidad U-VC4; b) muestra de la unidad U-VC5. 


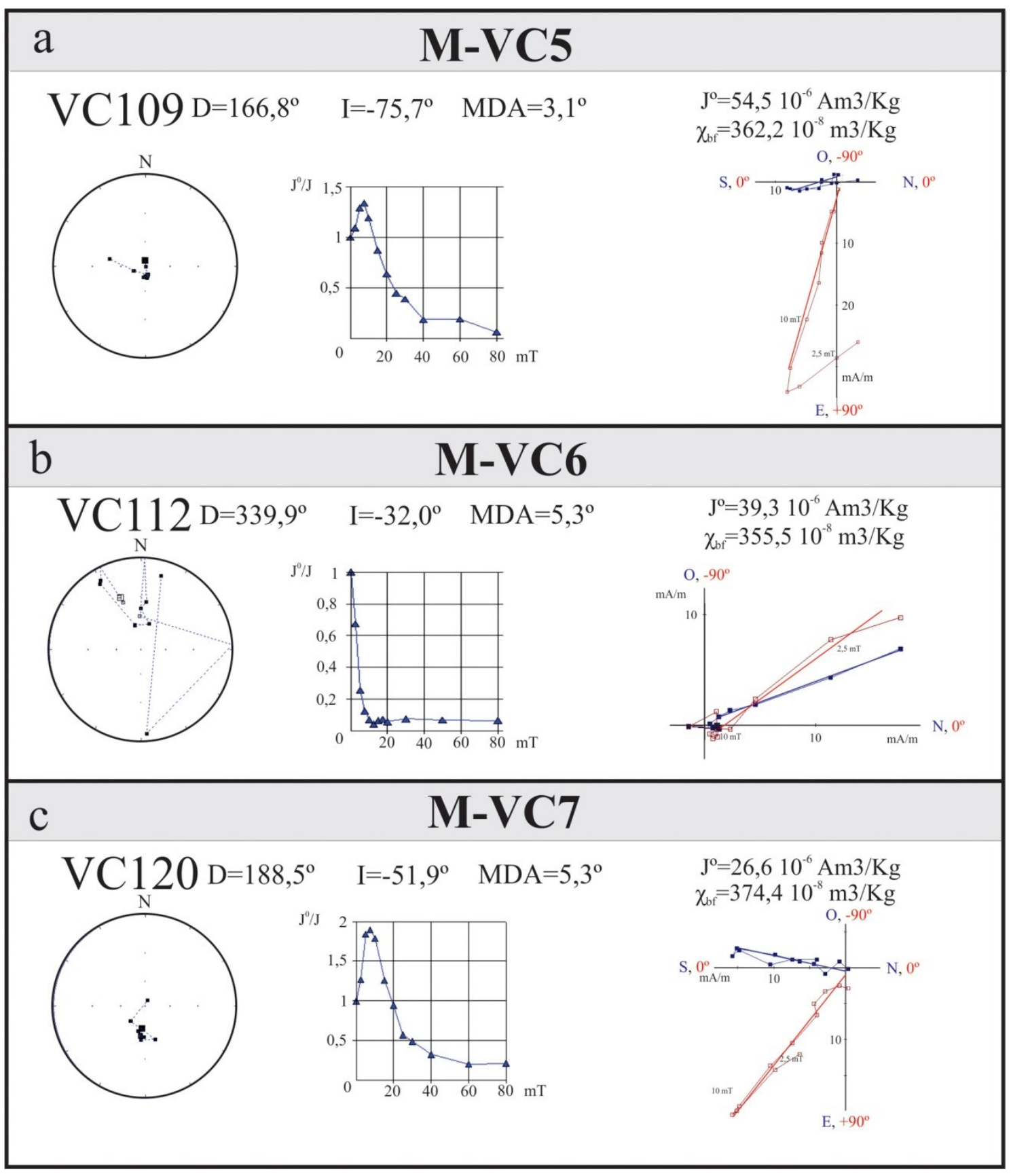

Figura 8.7. Estereogramas, curvas de desmagnetización y diagramas de Zijderveld de muestras de las magnetozonas de la base de la Formación Barker (sección PVC). a) muestra de magnetozona M-VC5; b) muestra de la magnetozona M-VC6; c) muestra de la magnetozona M-VC7. 


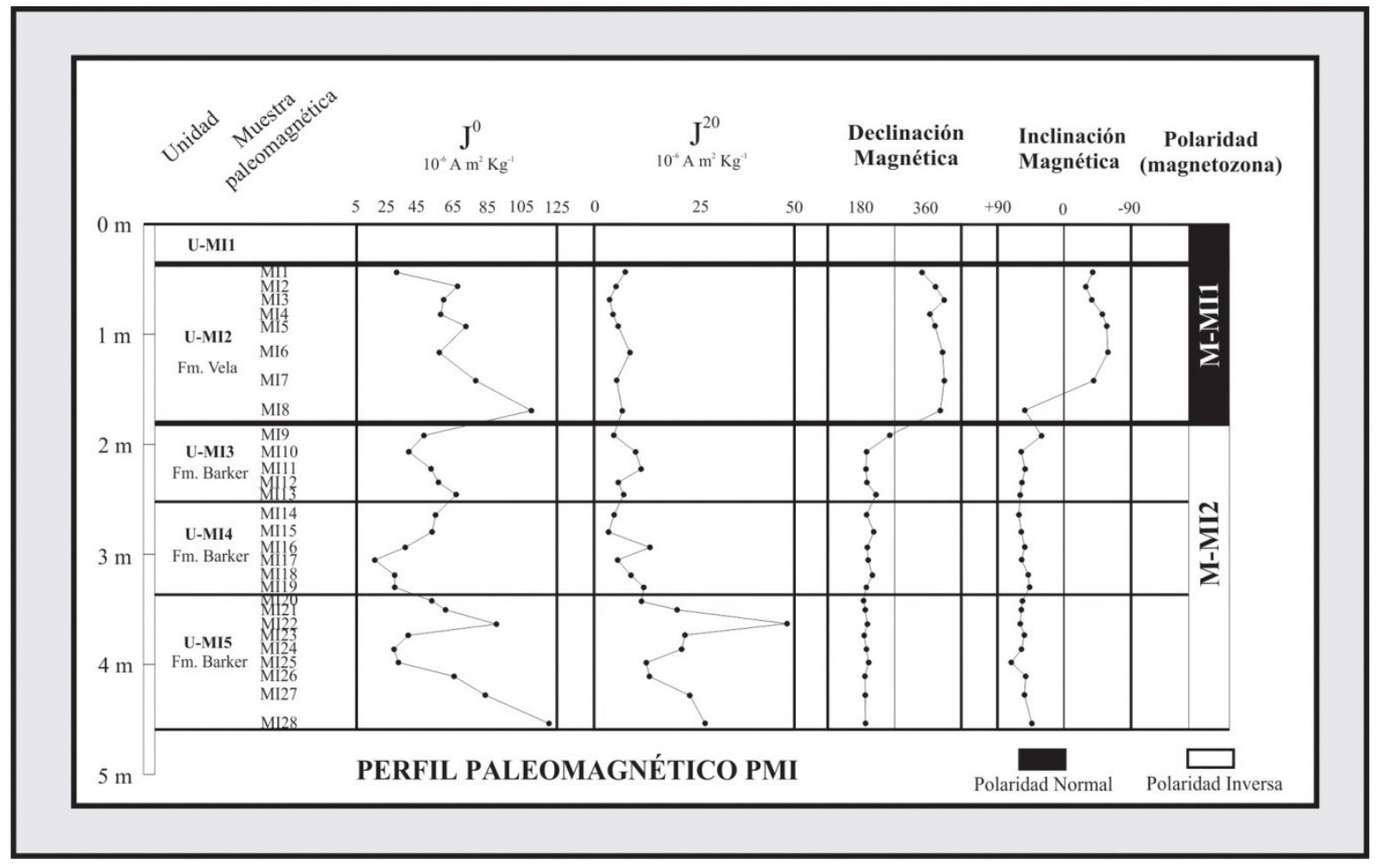

Figura 8.8. Perfil paleomagnético de la sección de María Ignacia (PVC). 


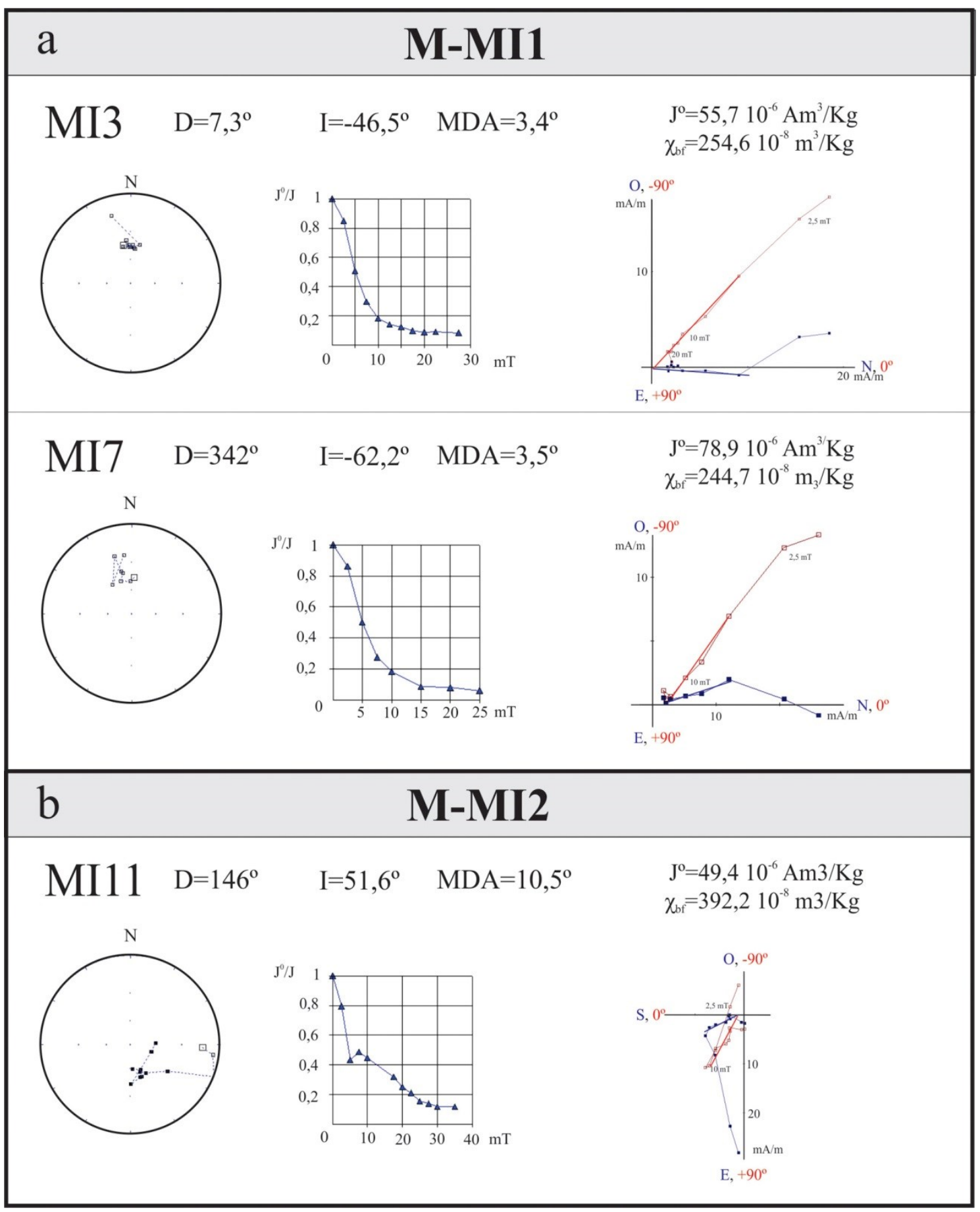

Figura 8.9. Estereogramas, curvas de desmagnetización y diagramas de Zijderveld de muestras del perfil paleomagnético de María Ignacia (PMI). a) muestras de la magnetozona M-MI1 (Fm. Vela); b) muestra de la magnetozona M-MI2 (unidad U-MI2, Fm. Barker). 


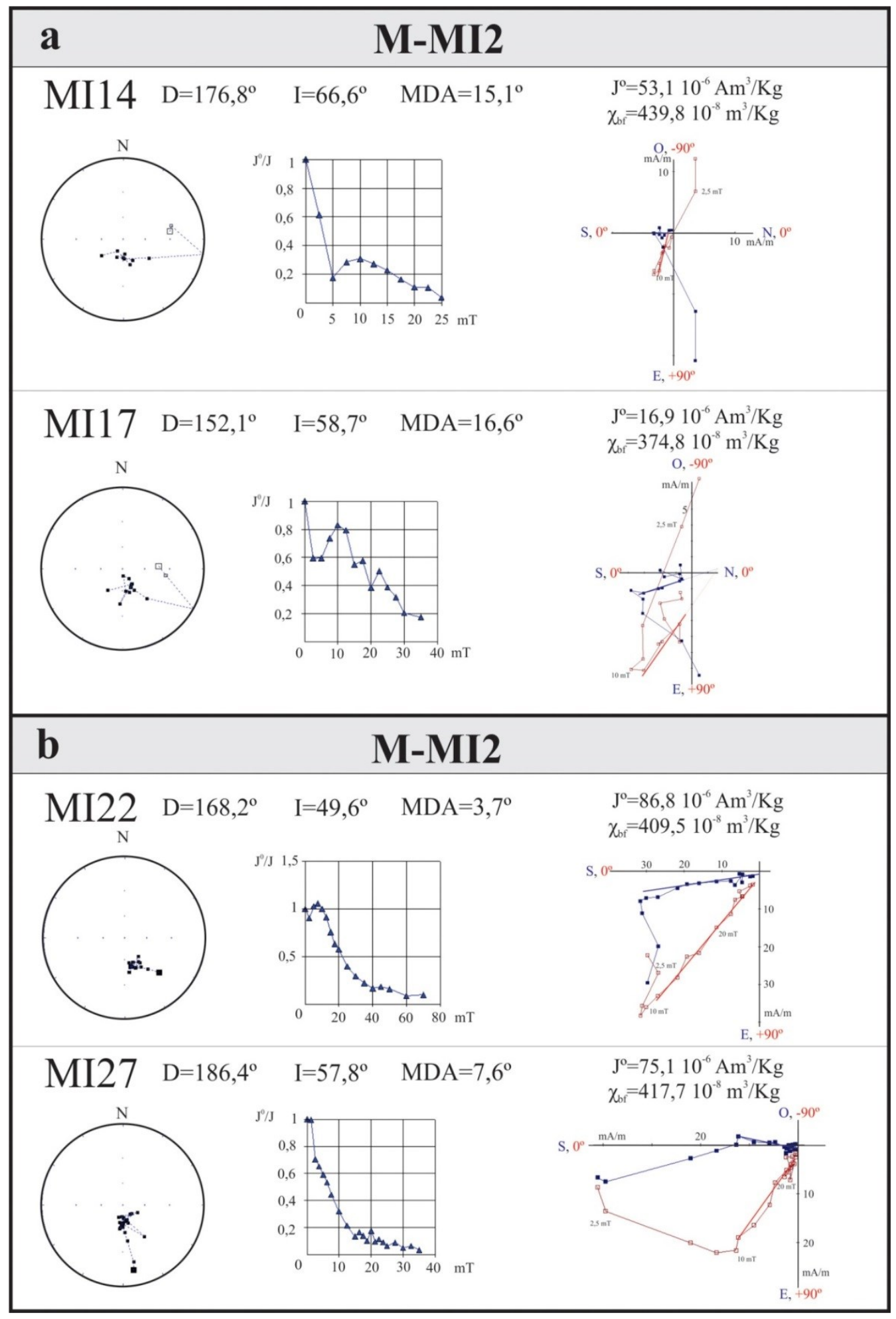

Figura 8.10. Estereogramas, curvas de desmagnetización y diagramas de Zijderveld de muestras de la magnetozona M-MI2 del perfil paleomagnético PMI. a) muestras de la unidad U-MI3, Fm. Barker; b) muestras de la unidad U-MI4, Fm. Barker. 


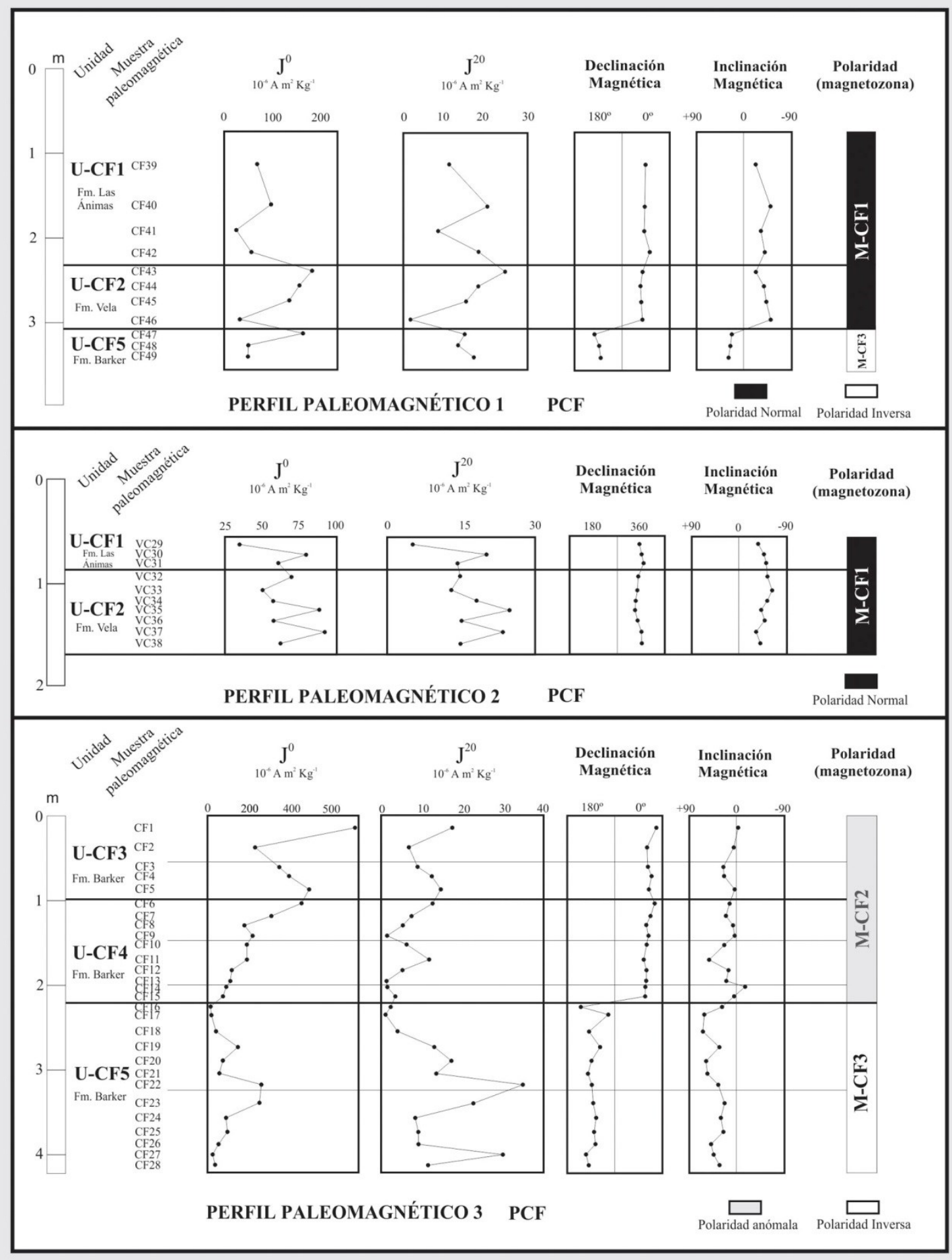

Figura 8.11. Perfiles paleomagnéticos de la sección Calle Fangio (PCF). 


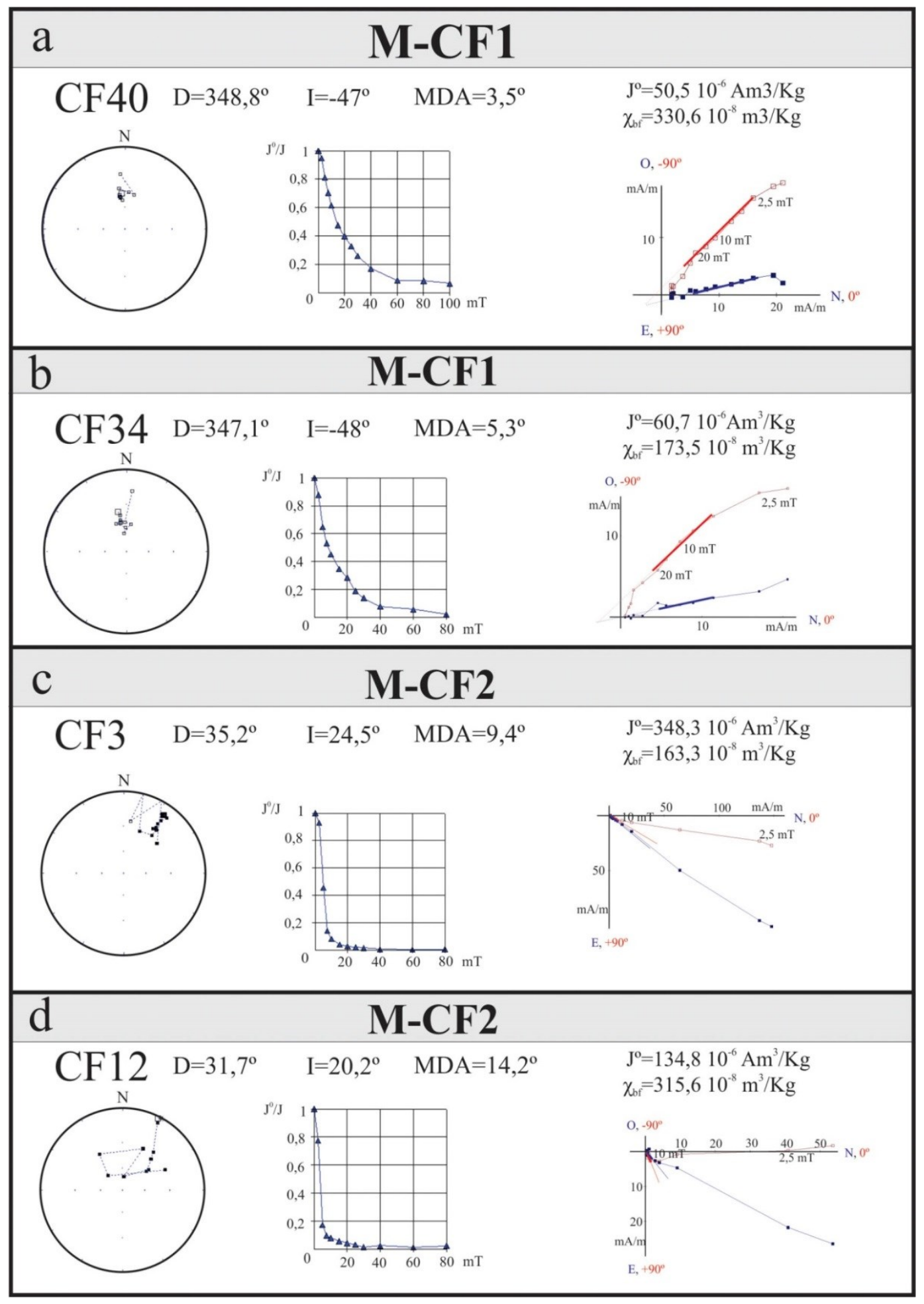

Figura 8.12. Estereogramas, curvas de desmagnetización y diagramas de Zijderveld de muestras de los perfiles paleomagnéticos de Calle Fangio (PCF). a) muestra de la Fm. Las Ánimas (M-CF1); b) muestra de la Fm. Vela (M-CF1); c) muestra de la unidad superior de la Fm. Barker (M-CF2); d) muestra de la unidad central de la Fm. Barker (Fm. Barker). 


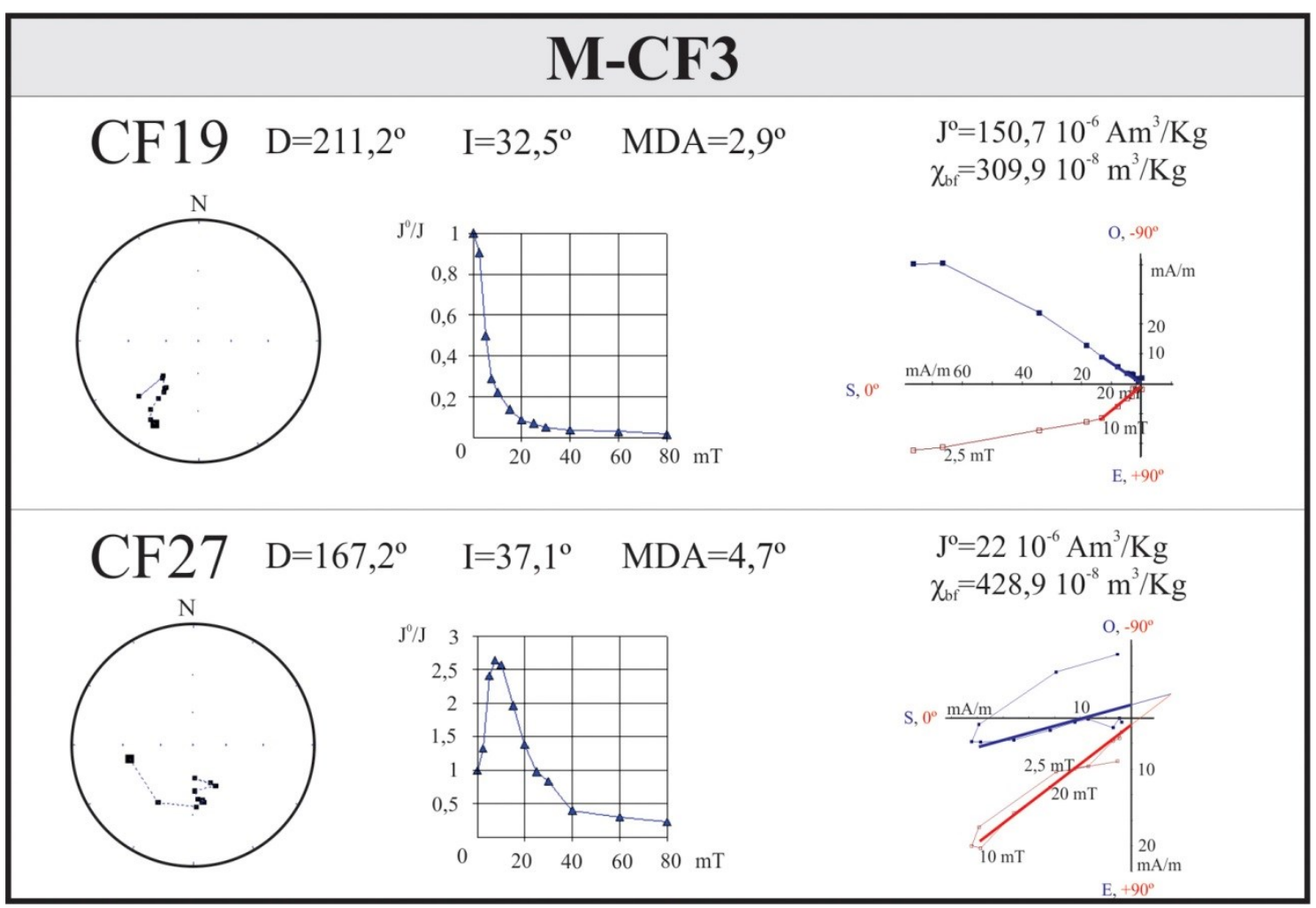

Figura 8.13. Estereogramas, curvas de desmagnetización y diagramas de Zijderveld de muestras de la magnetozona inversa de la sección PCF

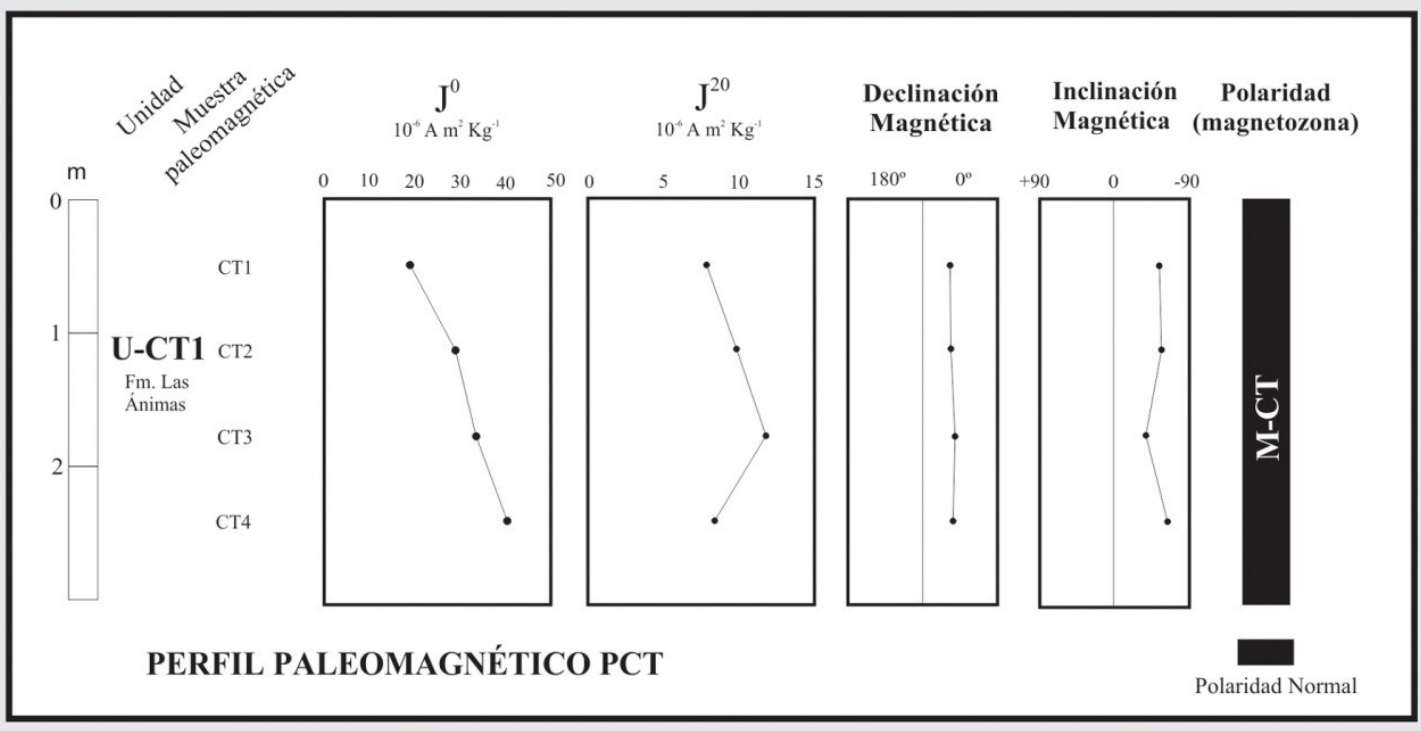

Figura 8.14. Perfil paleomagnético de la sección Circuito Turístico (PCT). 


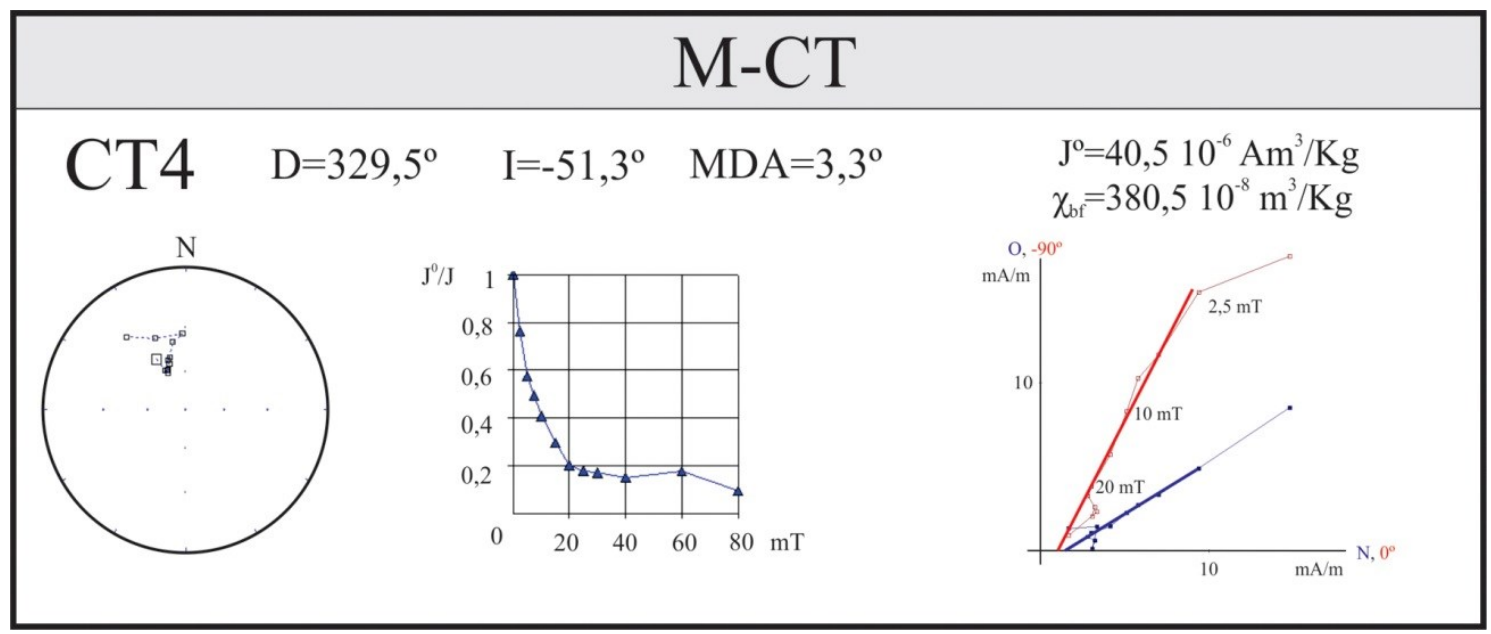

Figura 8.15. Estereogramas, curvas de desmagnetización y diagramas de Zijderveld de una muestra de la sección PCT (Fm. Las Ánimas). 


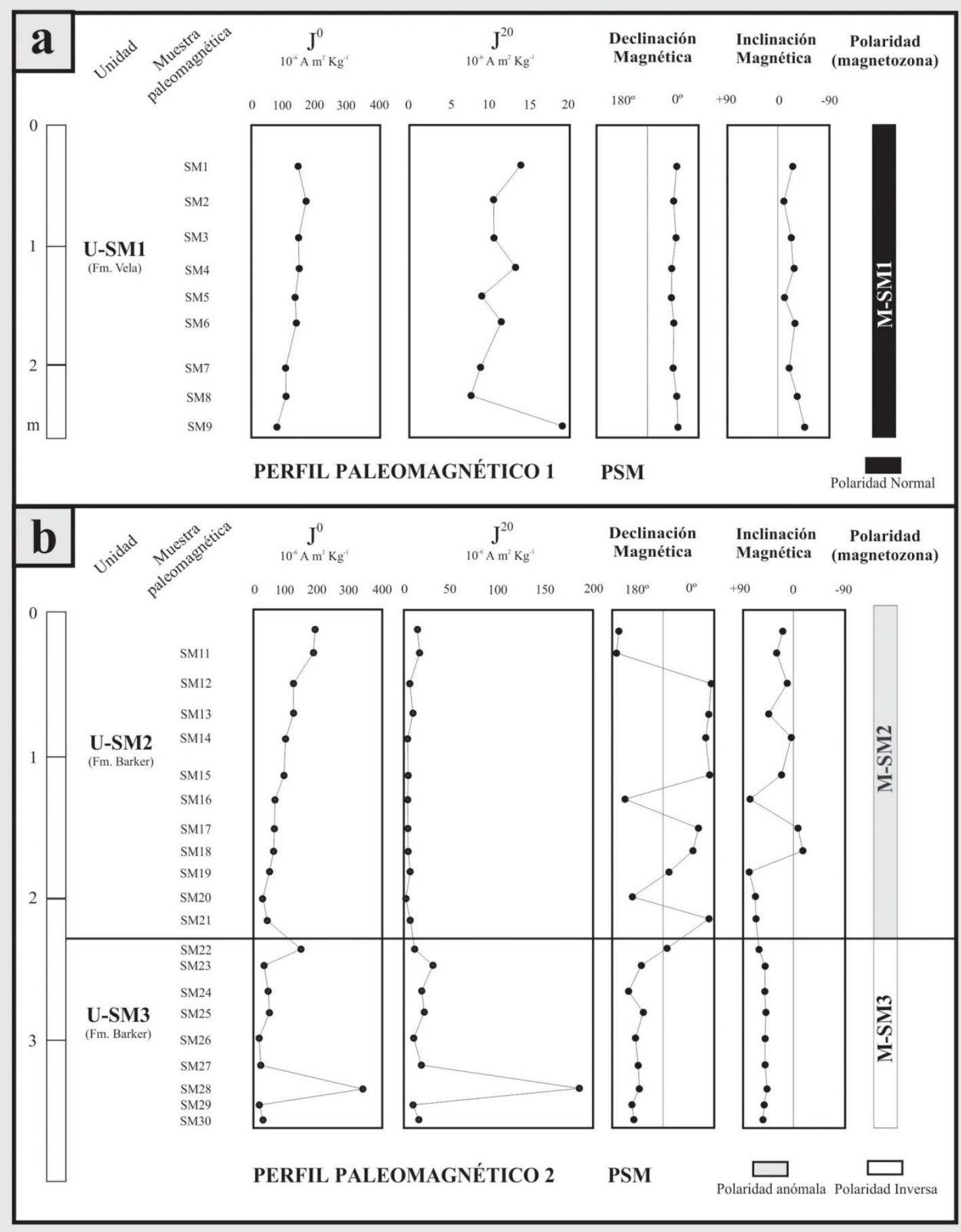

Figura 8.16. Perfiles paleomagnéticos de la sección de San Manuel (PSM). a) Perfil paleomagnético 1; b) Perfil paleomagnético 2. 


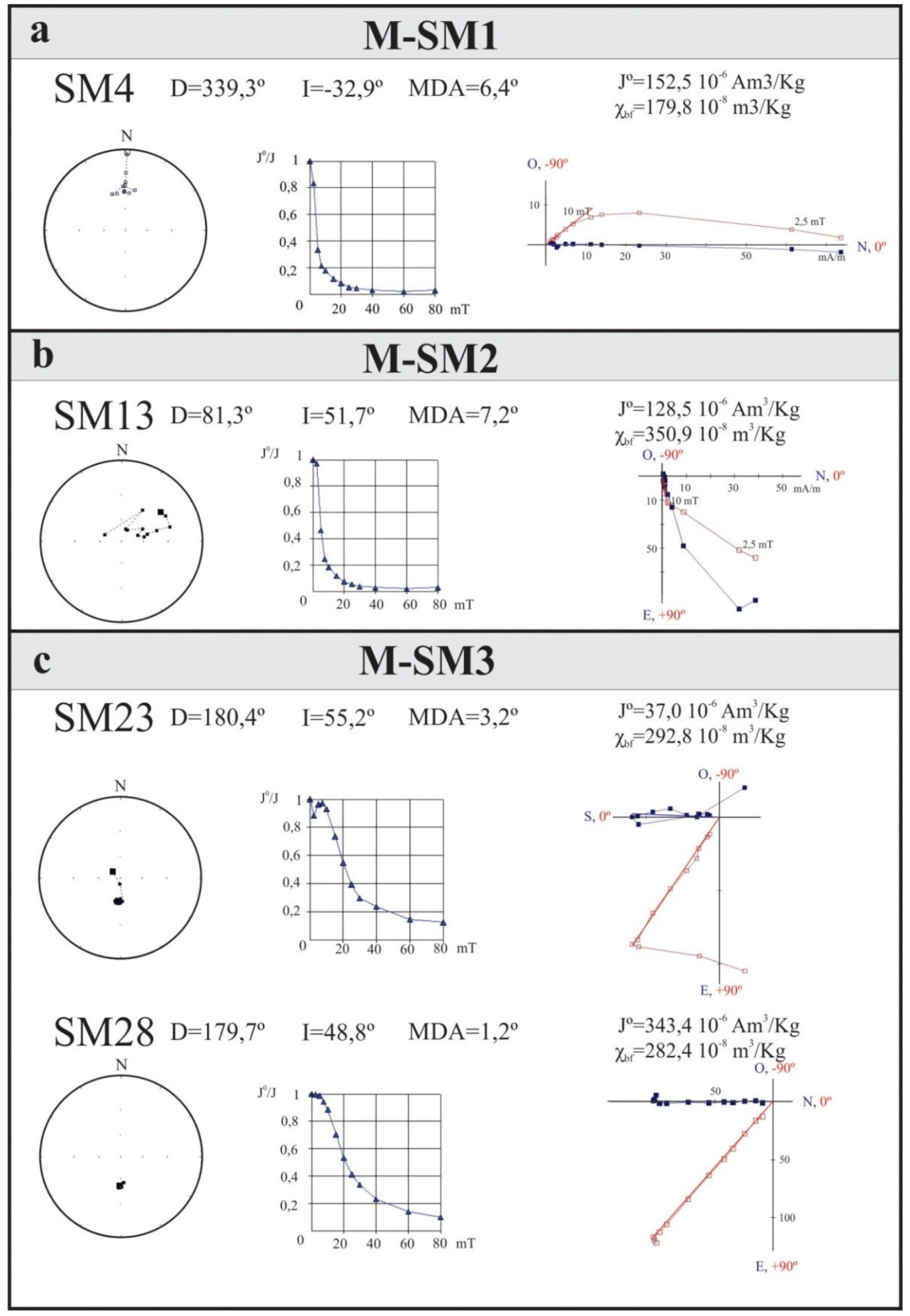

Figura 8.17. Estereogramas, curvas de desmagnetización y diagramas de Zijderveld de muestras de la sección San Manuel (PSM). a) Muestra de la magnetozona M-SM1 (Fm. Vela); b) Muestra de la magnetozona M-SM2 (Fm. Barker); c) muestras de la magnetozona M-SM3 (Fm. Barker). 


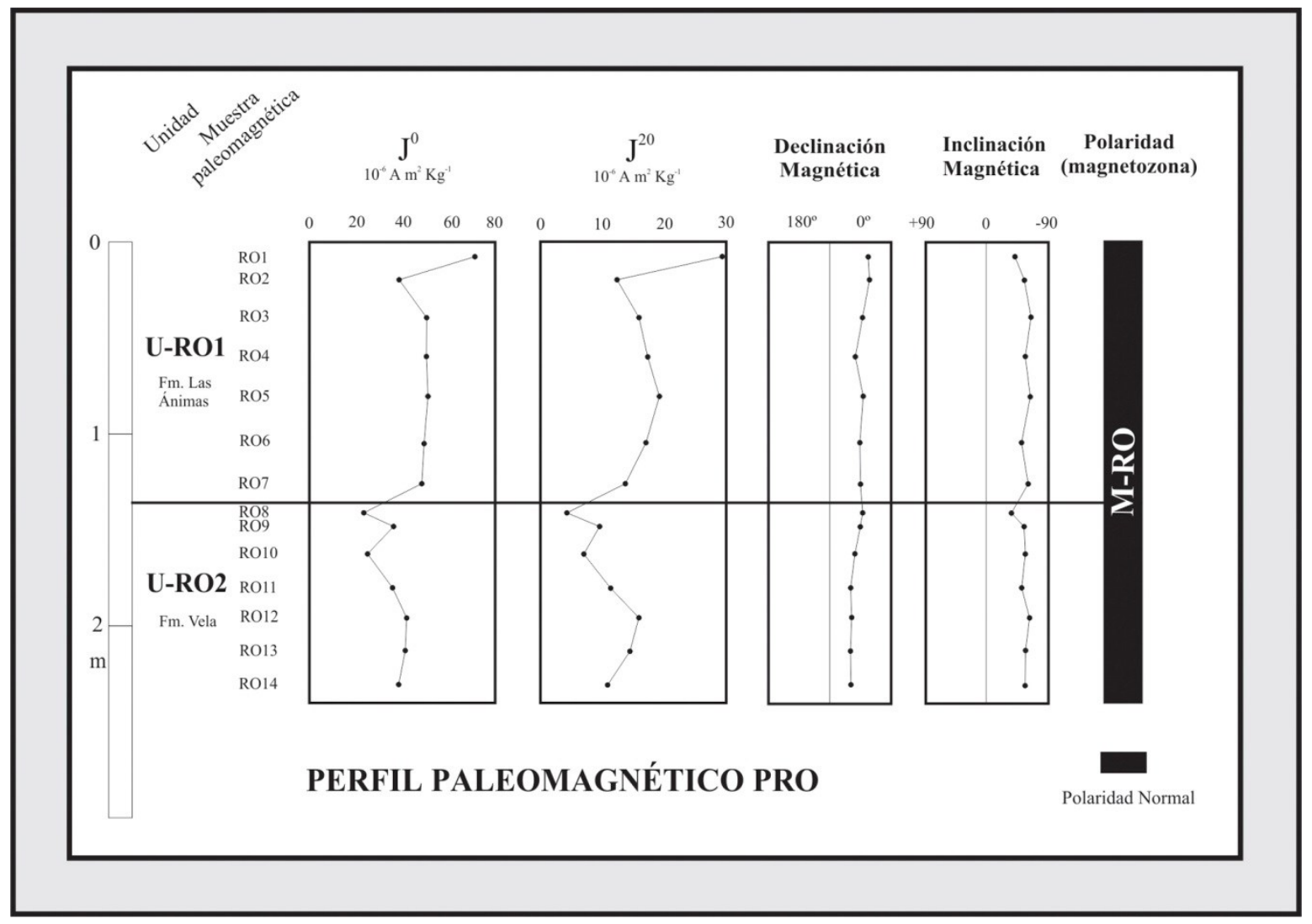

Figura 8.18. Perfil paleomagnético de la sección de Ramos Otero (PRO). 


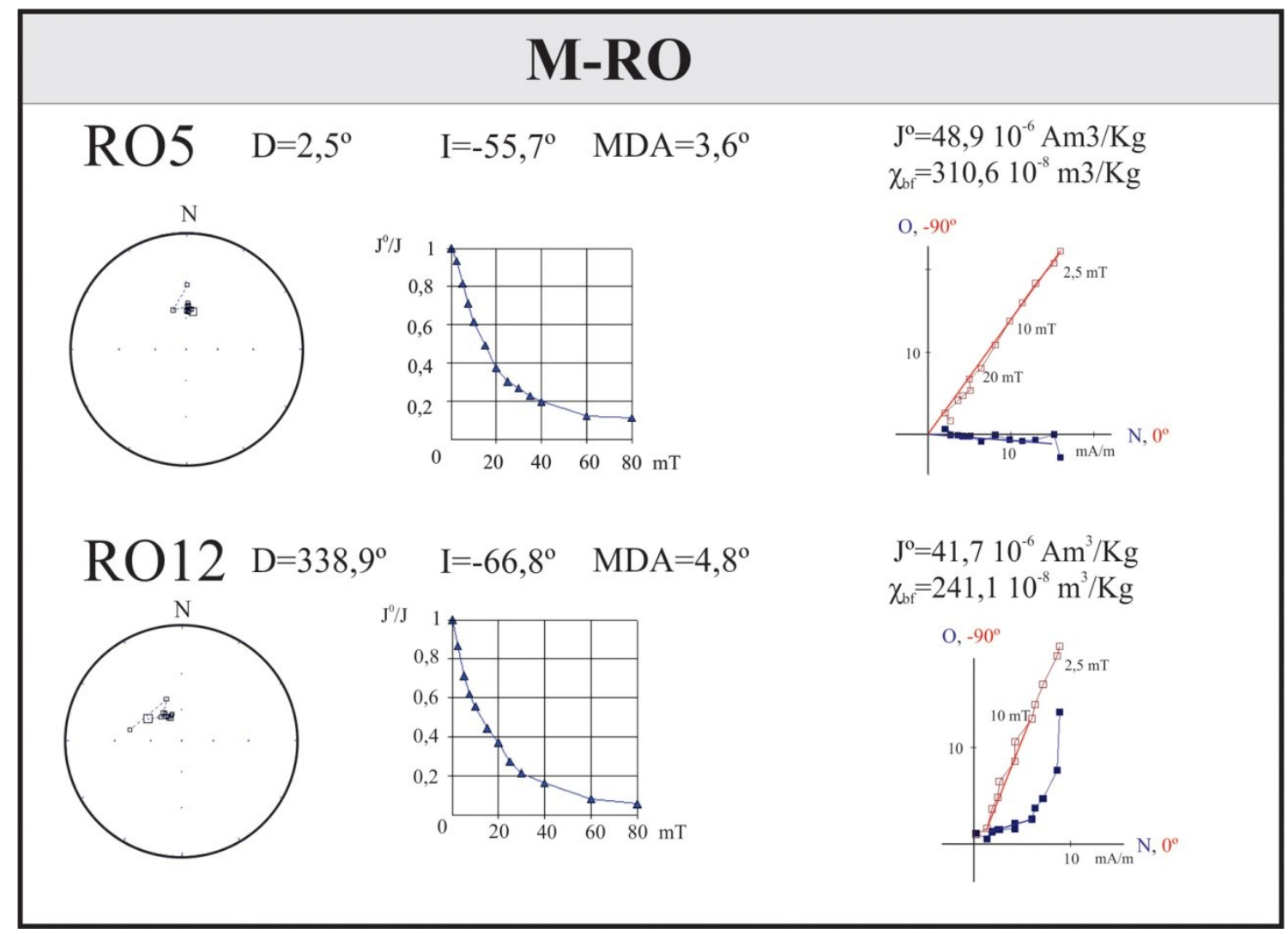

Figura 8.19. Estereogramas, curvas de desmagnetización y diagramas de Zijderveld de muestras paleomagneticas del perfil de Ramos Otero (PRO). 


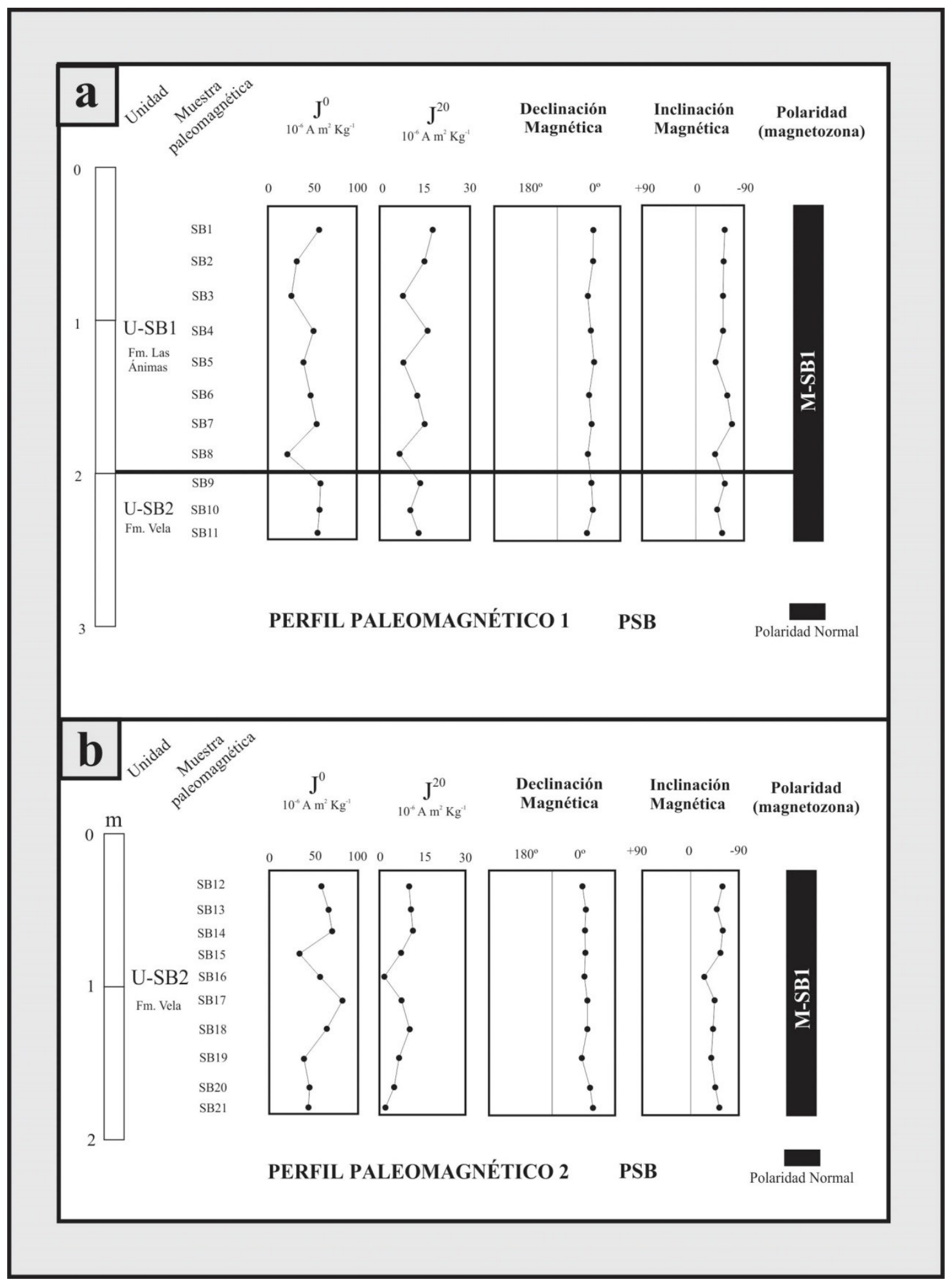

Figura 8.20. Perfiles paleomagnéticos de la sección de Sierra Bachicha (PSB). a) Perfil paleomagnético 1; b) Perfil paleomagnético 2 . 


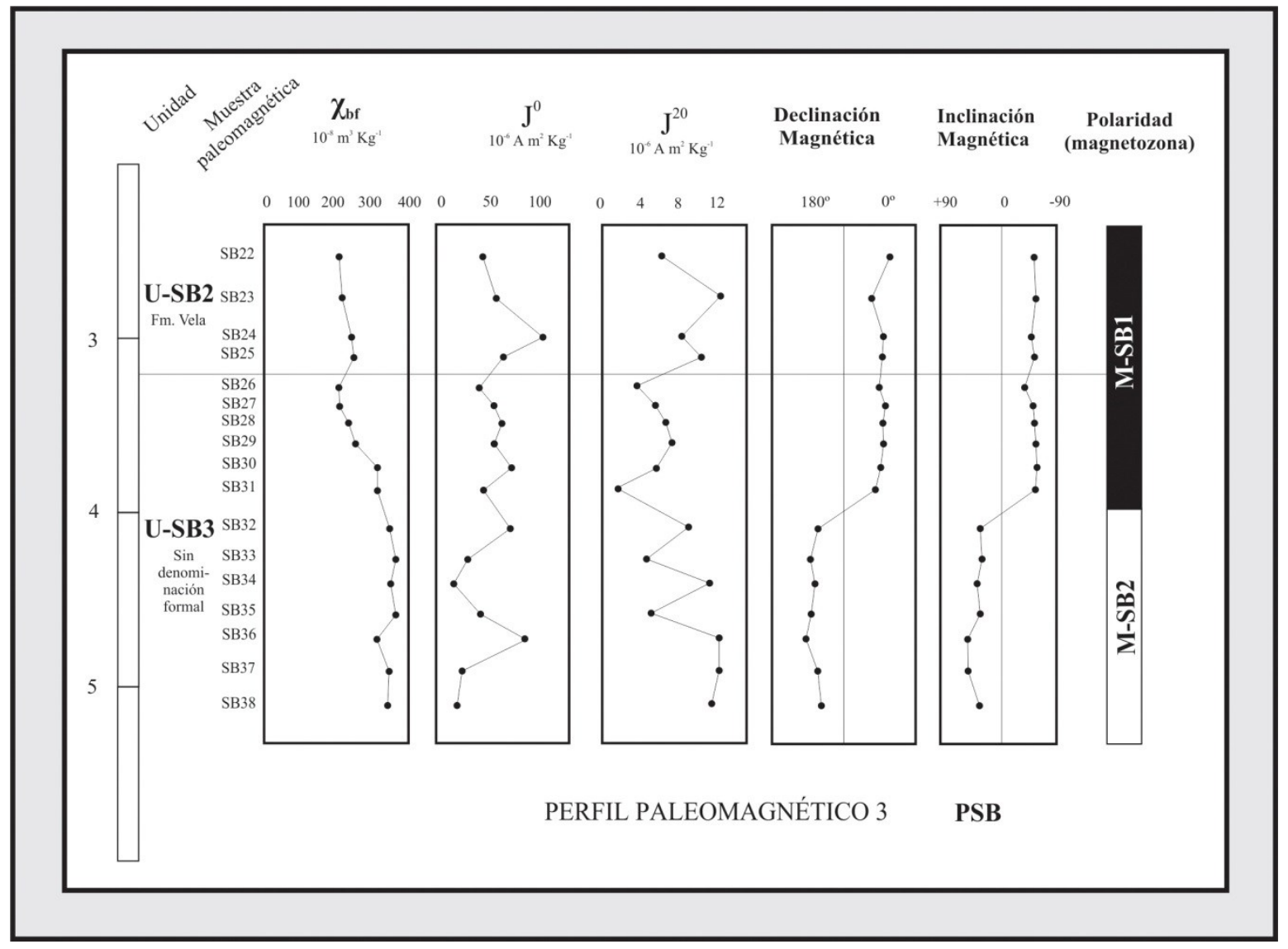

Figura 8.21. Perfil paleomagnético 3 de la sección de Sierra Bachicha (PSB). 


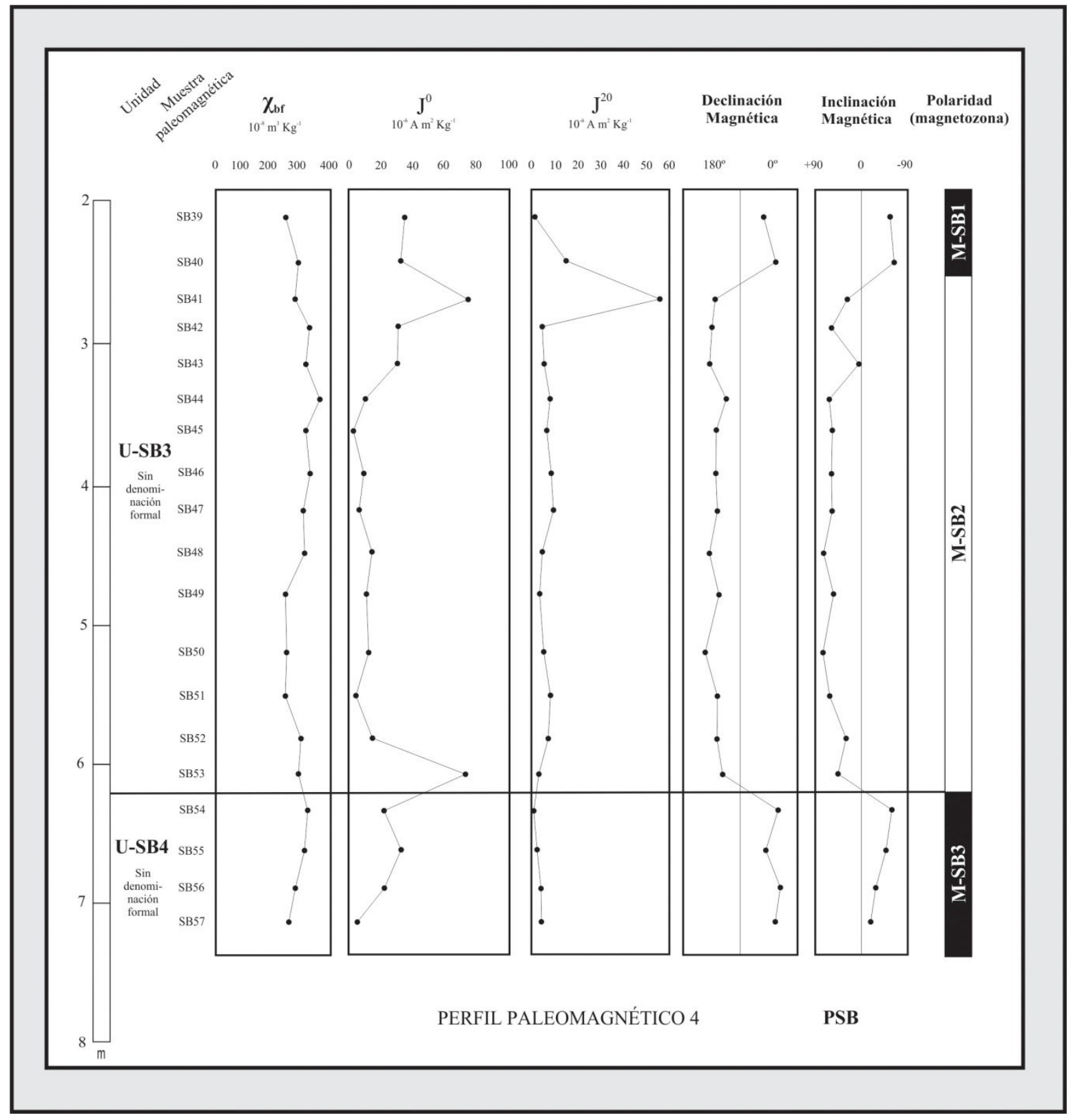

Figura 8.22. Perfil paleomagnético 4 de la sección de Sierra Bachicha (PSB). 


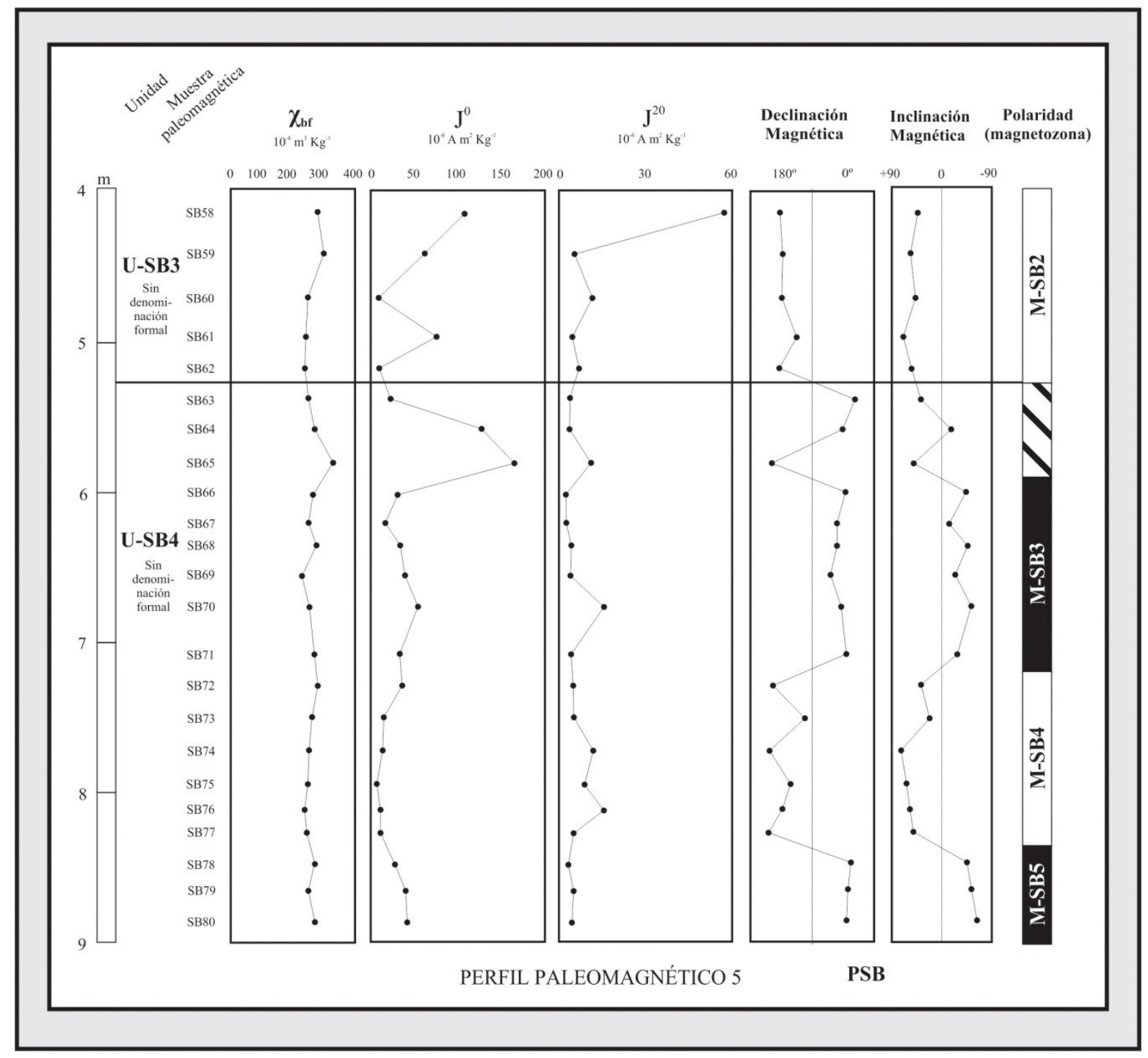

Figura 8.23. Perfil paleomagnético 5 de la sección de Sierra Bachicha (PSB). 


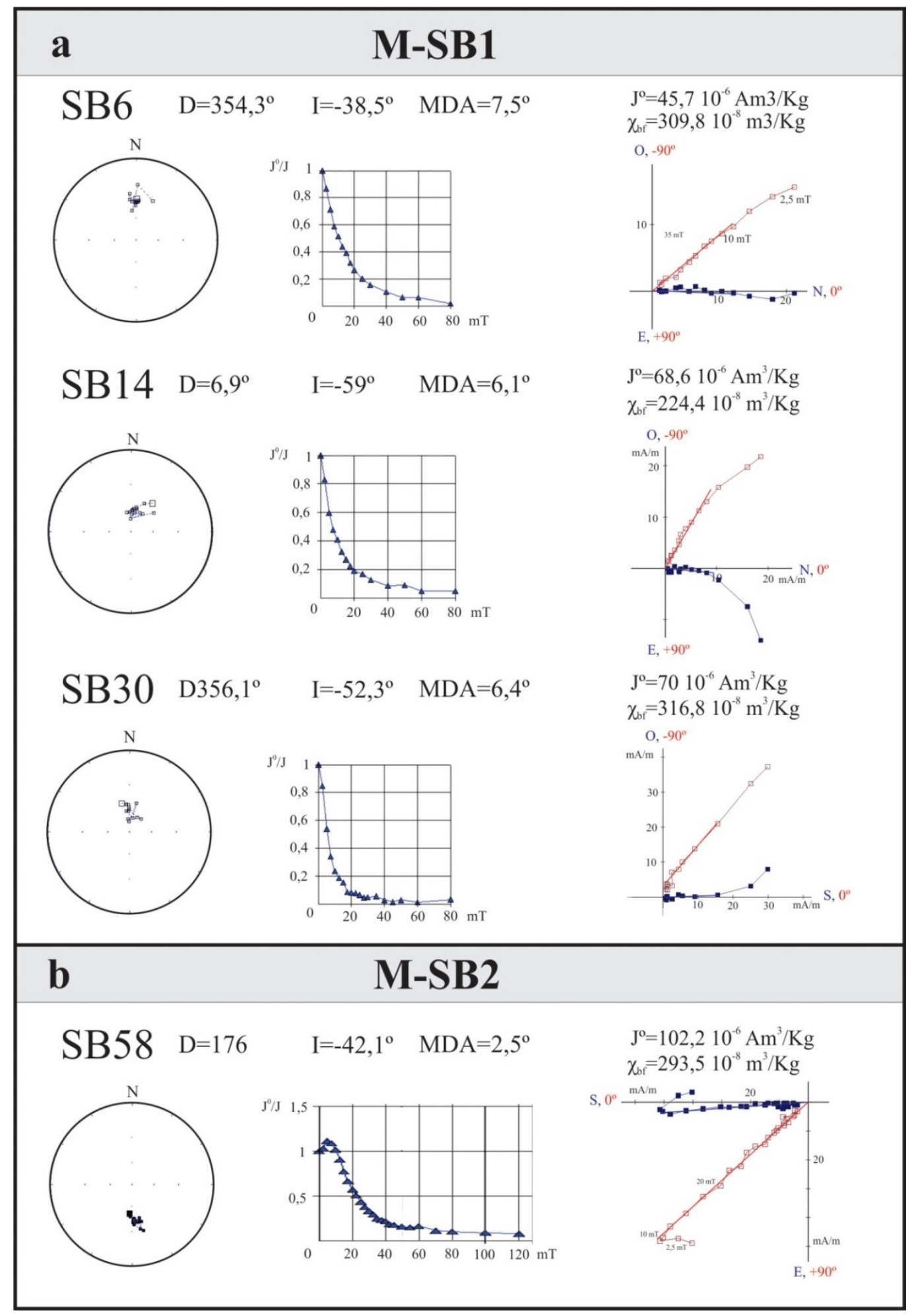

Figura 8.24. Estereogramas, curvas de desmagnetización y diagramas de Zijderveld de muestras paleomagnéticas de la sección Sierra Bachicha (PSB). a) Muestras de la magnetozona M-SB1; b) Muestra de la magnetozona M-SB2. 


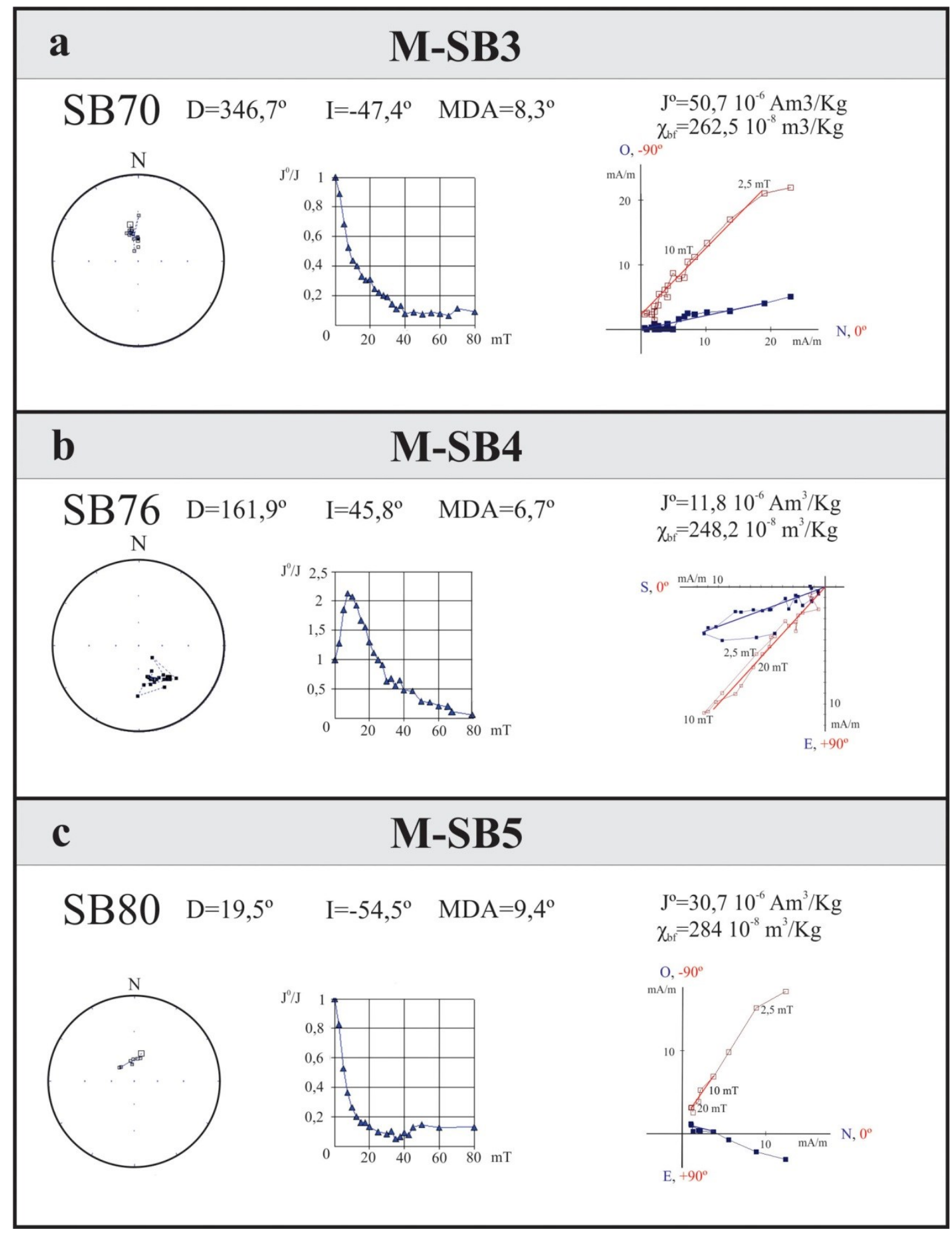

Figura 8.25. Estereogramas, curvas de desmagnetización y diagramas de Zijderveld de muestras paleomagnéticas de la sección Sierra Bachicha (PSB). a) Muestra de la magnetozona M-SB3; b) Muestra de la magnetozona M-SB4; c) Muestra de la magnetozona M-SB5. 


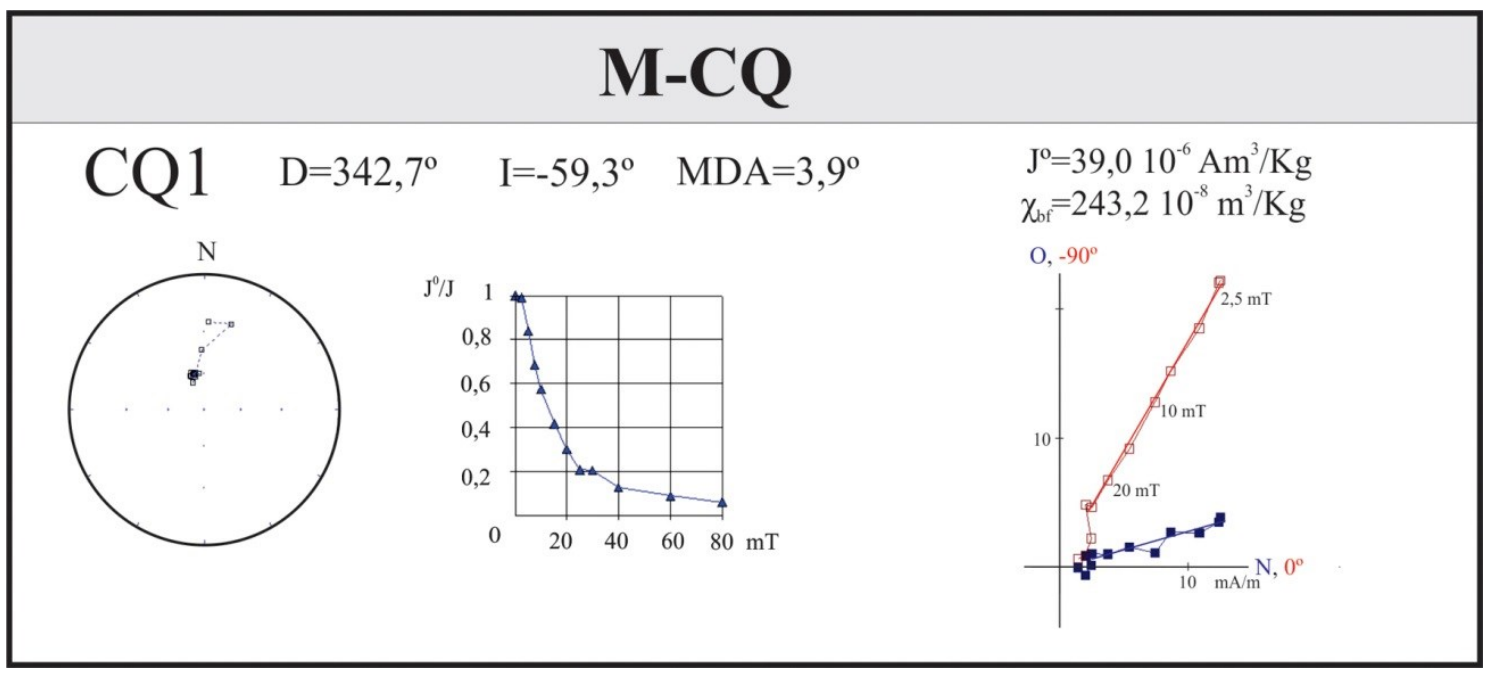

Figura 8.26. Estereograma, curva de desmagnetización y diagramas de Zijderveld de una muestra paleomagnéticas de la sección Cerro Quebracho (PCQ). 


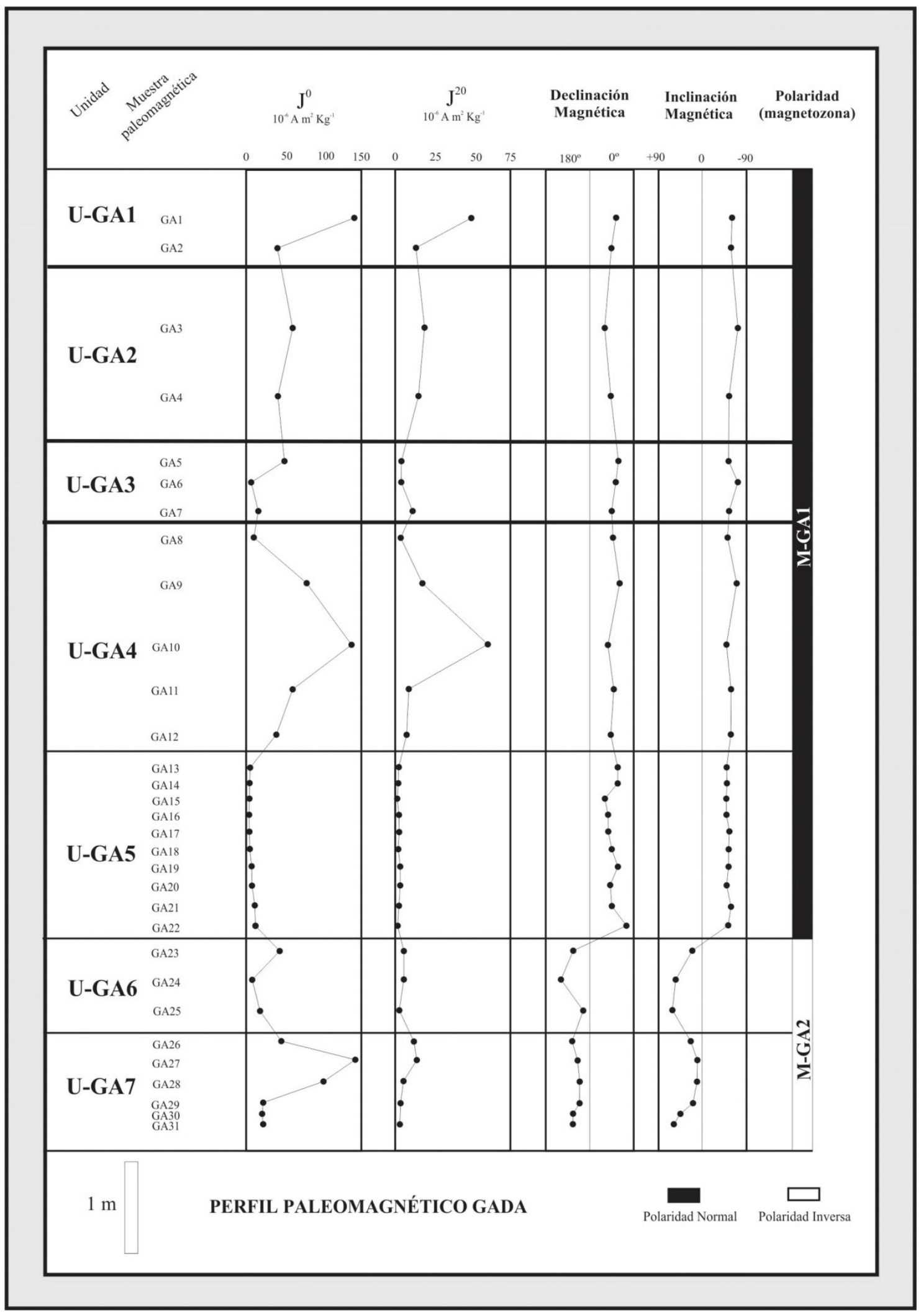

Figura 8.27. Perfil paleomagnético de la sección GADA (PGA). 


\section{M-GA1}

\section{GA $11 \mathrm{D}=2,5^{\circ} \quad \mathrm{I}=-61,2^{\circ} \quad \mathrm{MDA}^{\circ}=4^{\circ}$ \\ $\mathrm{J}^{\mathrm{0}}=54,910^{-6} \mathrm{Am}^{3} / \mathrm{Kg}$ $\chi_{\mathrm{bf}}=174,210^{-8} \mathrm{~m}^{3} / \mathrm{Kg}$}
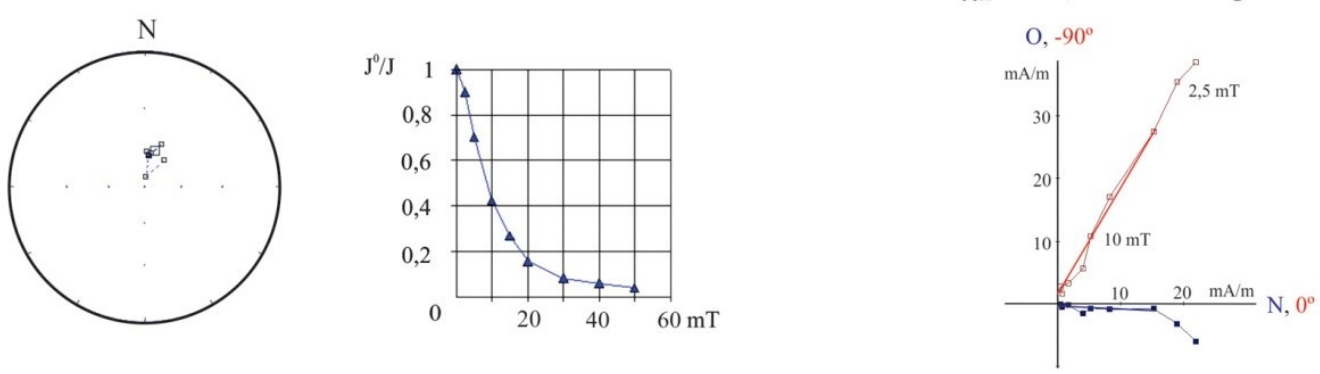

\section{M-GA2}

GA26 $\mathrm{D}=203,1^{\circ} \quad \mathrm{I}=-25^{\circ} \quad \mathrm{MDA}=6,2^{\circ}$

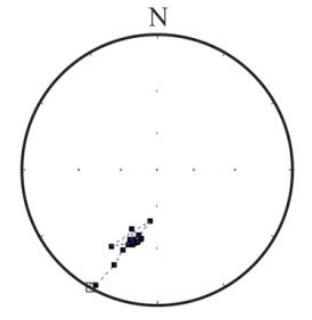

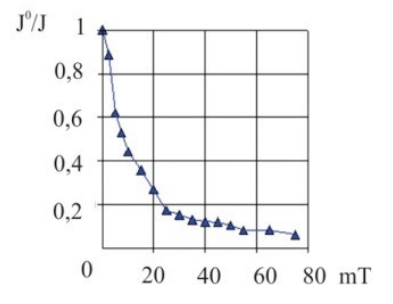

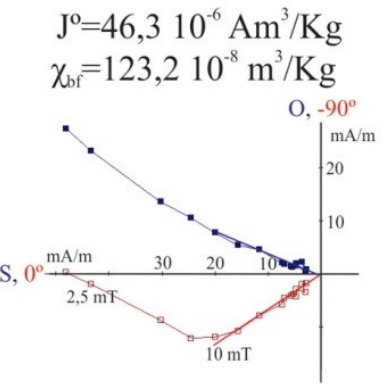

Figura 8.28. Estereogramas, curvas de desmagnetización y diagramas de Zijderveld de muestras del perfil paleomagnético PGA. 


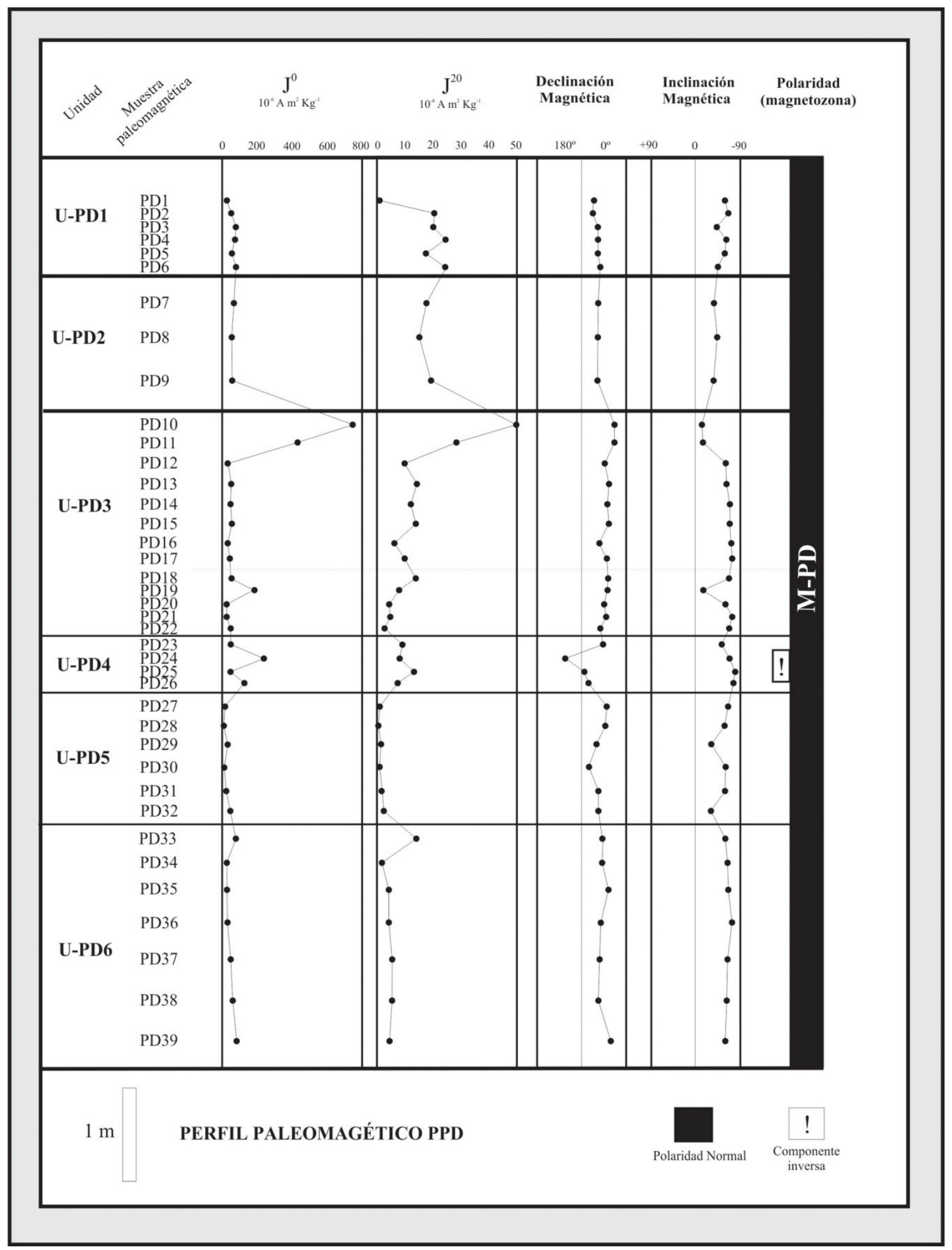

Figura 8.29. Perfil paleomagnético de la sección de Playa Dorada (PPD). 


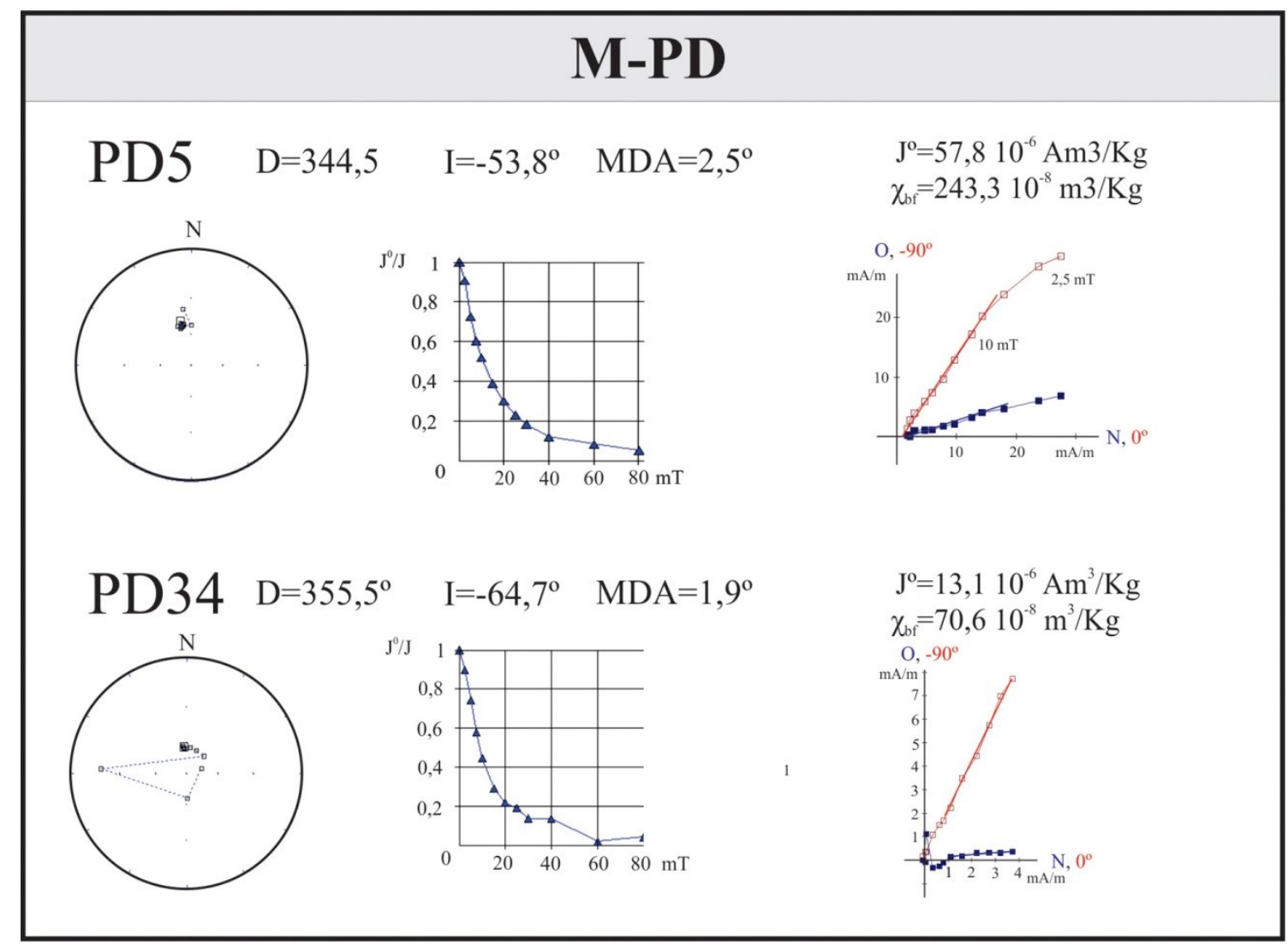

Figura 8.30. Estereogramas, curvas de desmagnetización y diagramas de Zijderveld de muestras de polaridad normal de la magnetozona M-PD. 


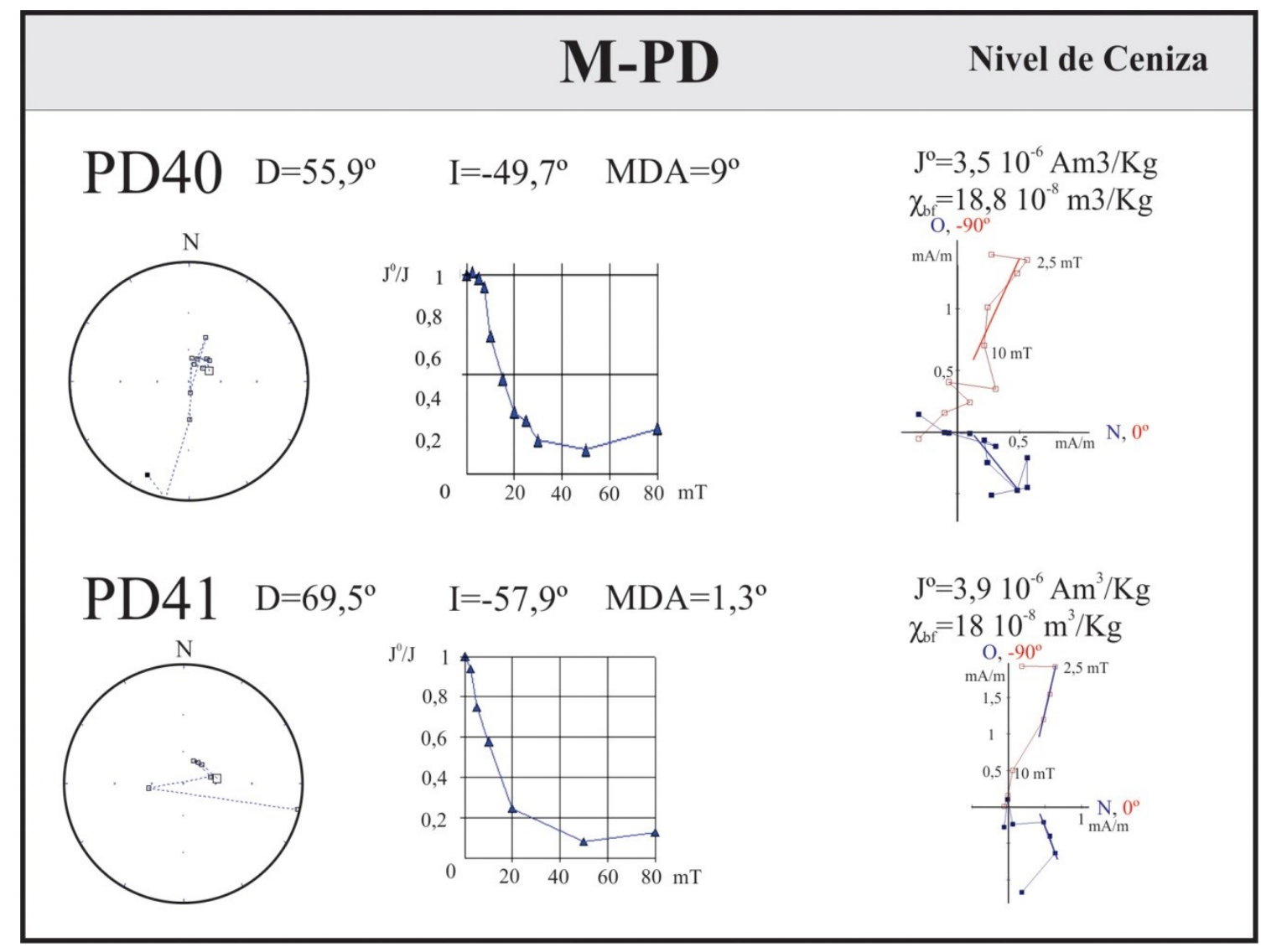

Figura 8.31. Estereogramas, curvas de desmagnetización y diagramas de Zijderveld de muestras del nivel de ceniza de la sección PPD. 


\section{M-PD}

a

$\mathrm{PD} 10 \mathrm{D}=45^{\circ} \quad \mathrm{I}=-12,1^{\circ} \quad \mathrm{MDA}=4,7^{\circ}$

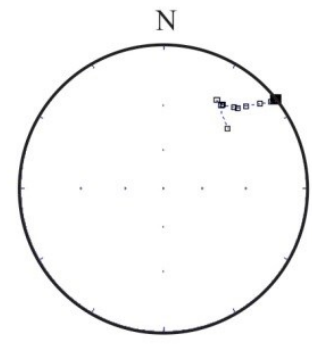

$\mathrm{J}^{0} / \mathrm{J}$

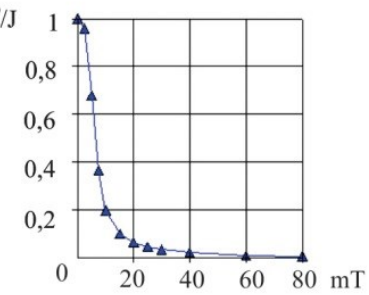

$\mathrm{J}^{\mathrm{o}}=788,9 \quad 10^{-6} \mathrm{Am} 3 / \mathrm{Kg}$ $\chi_{\mathrm{bf}}=266,310^{-8} \mathrm{~m} 3 / \mathrm{Kg}$

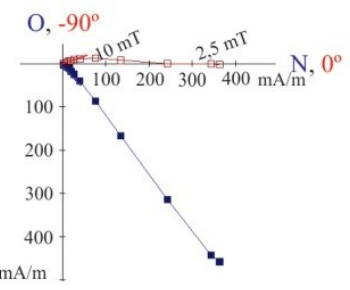

\section{b}

PD24 $\mathrm{D}=214,3^{\circ} \quad \mathrm{I}=-72,8^{\circ} \quad \mathrm{MDA}=15,3^{\circ}$

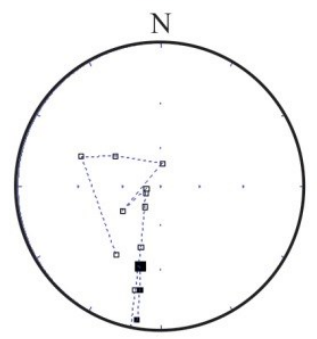

$\mathrm{J}^{0} / \mathrm{J}$

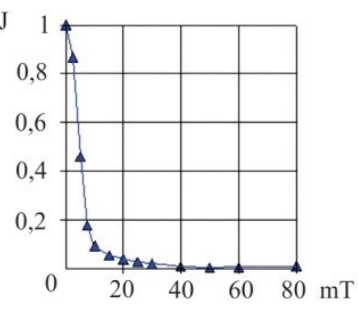

$\mathrm{J}^{\mathrm{o}}=231,210^{-6} \mathrm{Am}^{3} / \mathrm{Kg}$ $\chi_{\mathrm{bf}}=206,210^{-8} \mathrm{~m}^{3} / \mathrm{Kg}$

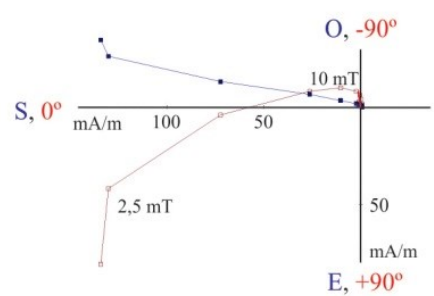

Figura 8.32. Estereogramas, curvas de desmagnetización y diagramas de Zijderveld de muestras paleomagnéticas de la sección PPD. a) Muestra del paleosuelo S-PD1; b) Muestra con componente de polaridad inversa de la unidad U-PD4. 


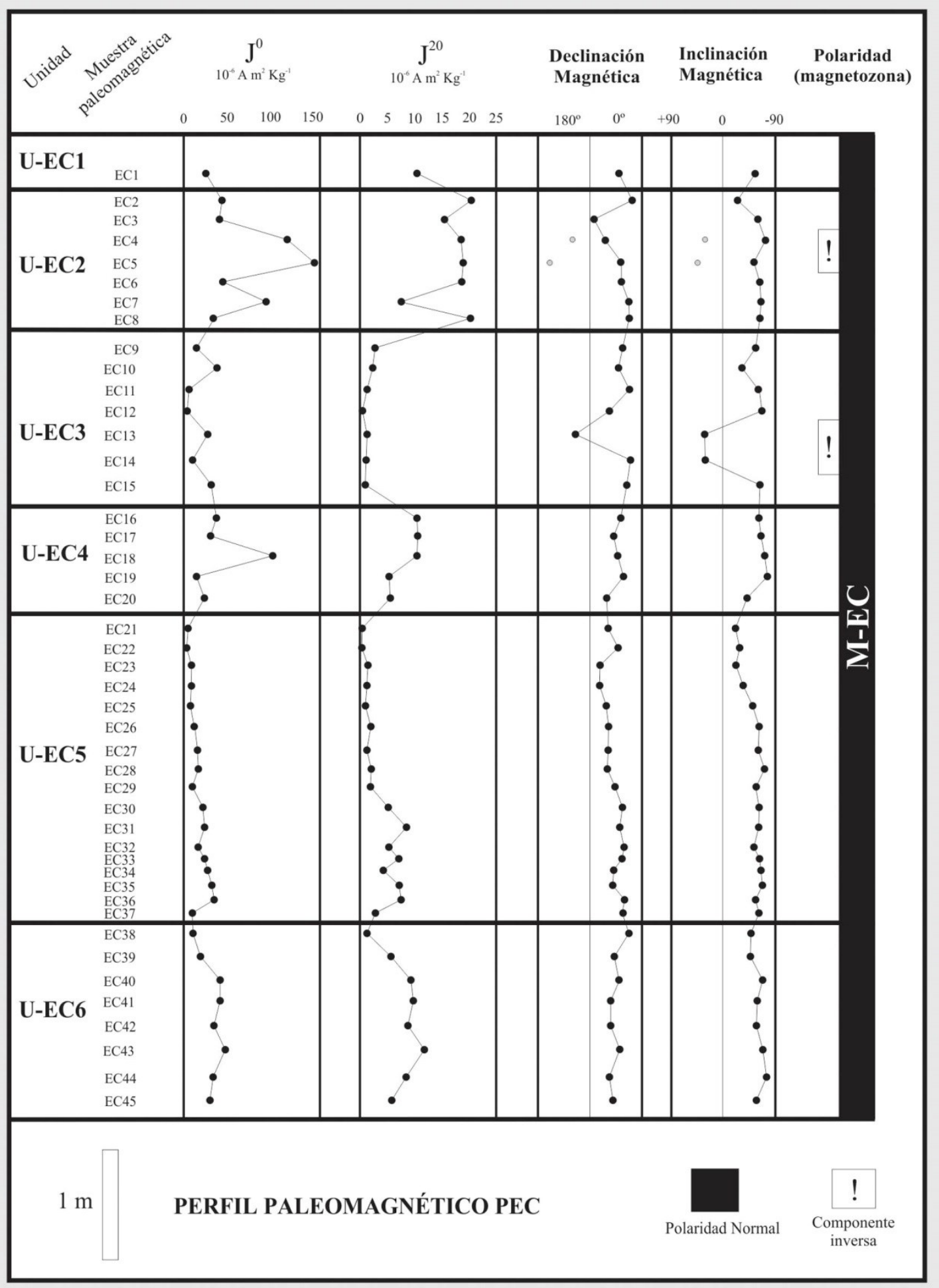

Figura 8.33. Perfil paleomagnético de la sección El Casal (PEC). 


\section{M-EC}

$\mathrm{EC} 43 \mathrm{D}=9,1^{\circ} \quad \mathrm{I}=-65,7^{\circ} \quad \mathrm{MDA}=2^{\circ}$
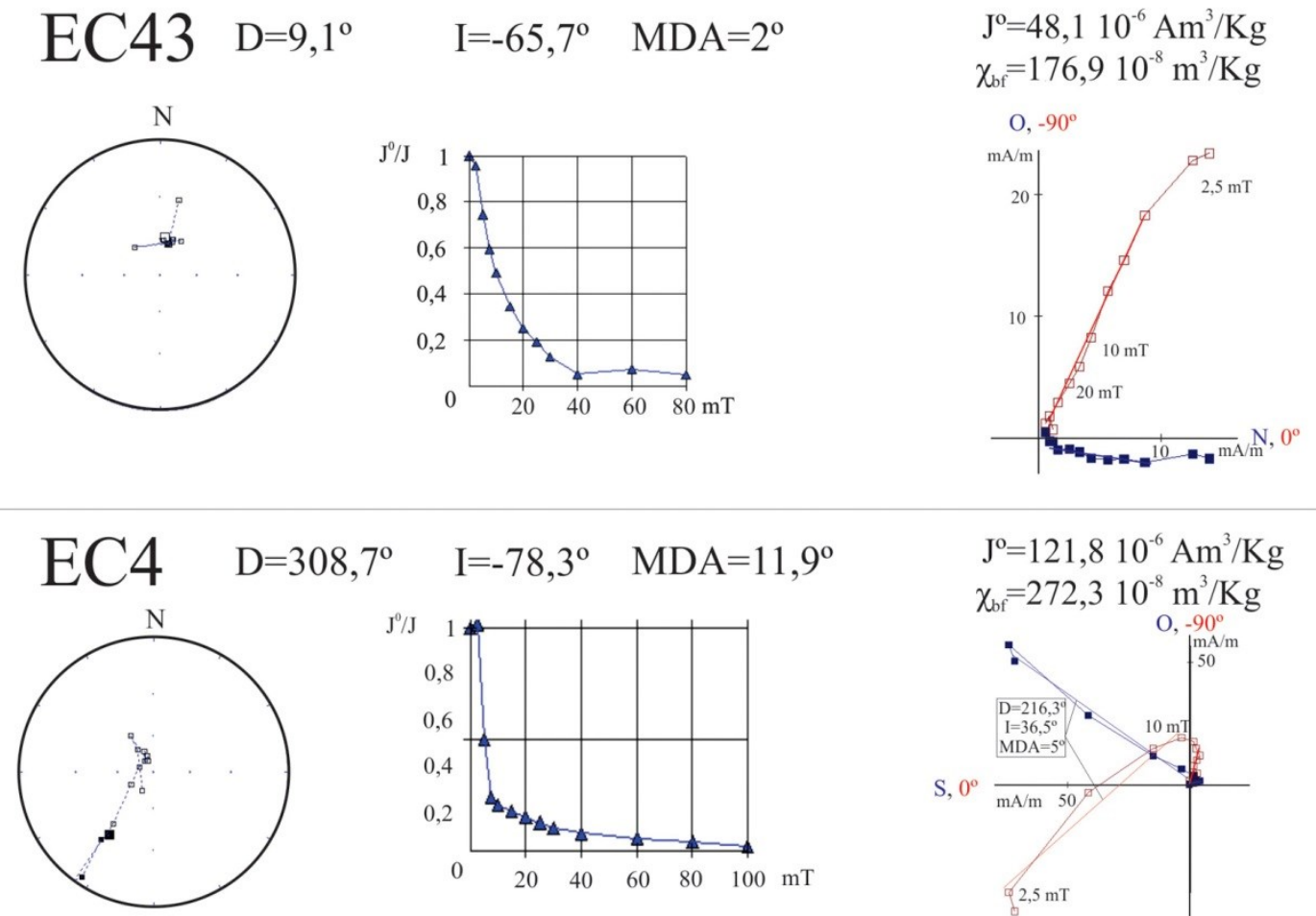

$\mathrm{J}^{\circ} / \mathrm{J}$
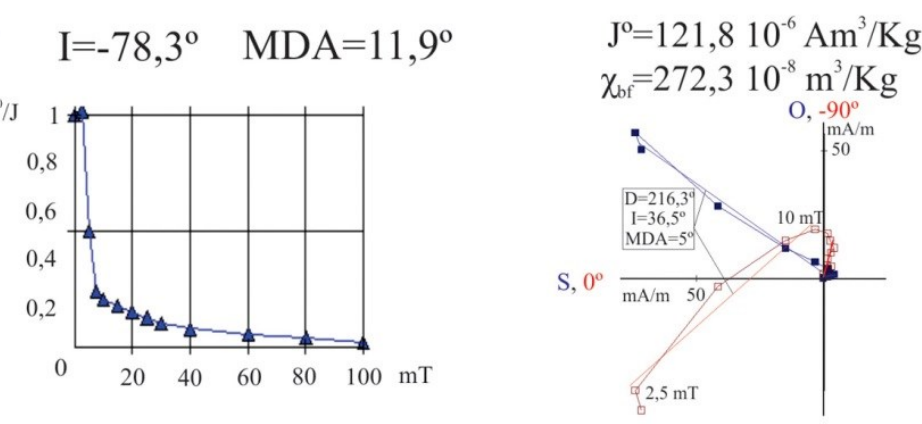

$\mathrm{EC} 13 \mathrm{D}=239,9^{\circ} \quad \mathrm{I}=24^{\circ} \quad \mathrm{MDA}=8,6^{\circ}$
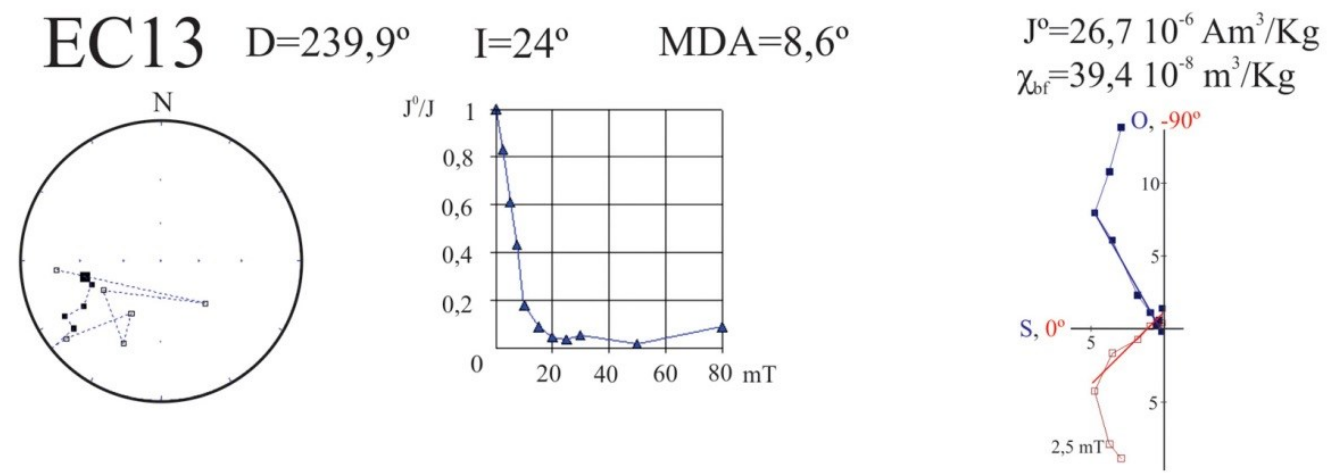

Figura 8.34. Estereogramas, curvas de desmagnetización y diagramas de Zijderveld de muestras del perfil paleomagnético de la sección El Casal (PEC). 


\section{Sección PSE}

SE3 $\mathrm{D}=340,6^{\circ} \quad \mathrm{I}=-53,6^{\circ} \quad \mathrm{MDA}^{\circ}=4,2^{\circ} \quad \begin{array}{r}\mathrm{J}^{\mathrm{o}}=21,610^{-6} \mathrm{Am} / \mathrm{Kg} \\ \chi_{\mathrm{bf}}=240,310^{-8} \mathrm{~m}^{3} / \mathrm{Kg}\end{array}$
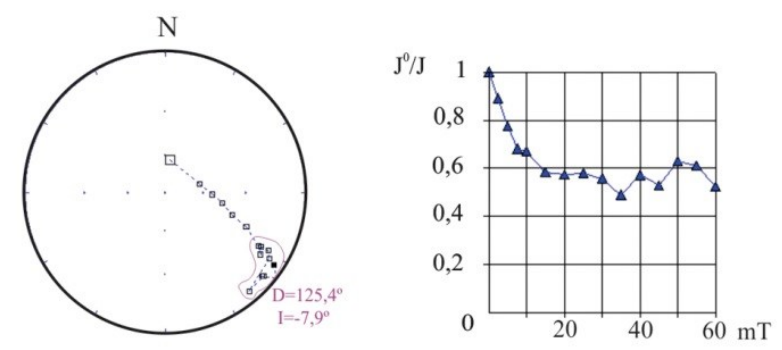

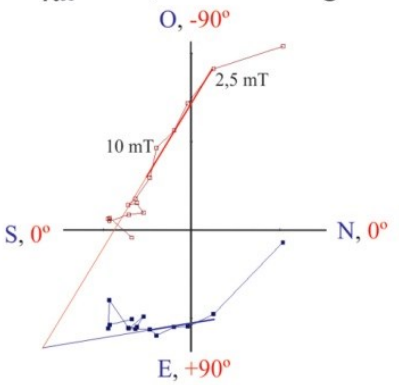

Figura 8.35. Estereogramas, curvas de desmagnetización y diagramas de Zijderveld de una muestra paleomagnética de la unidad U-SE3 de la sección Santa Elena (PSE). 


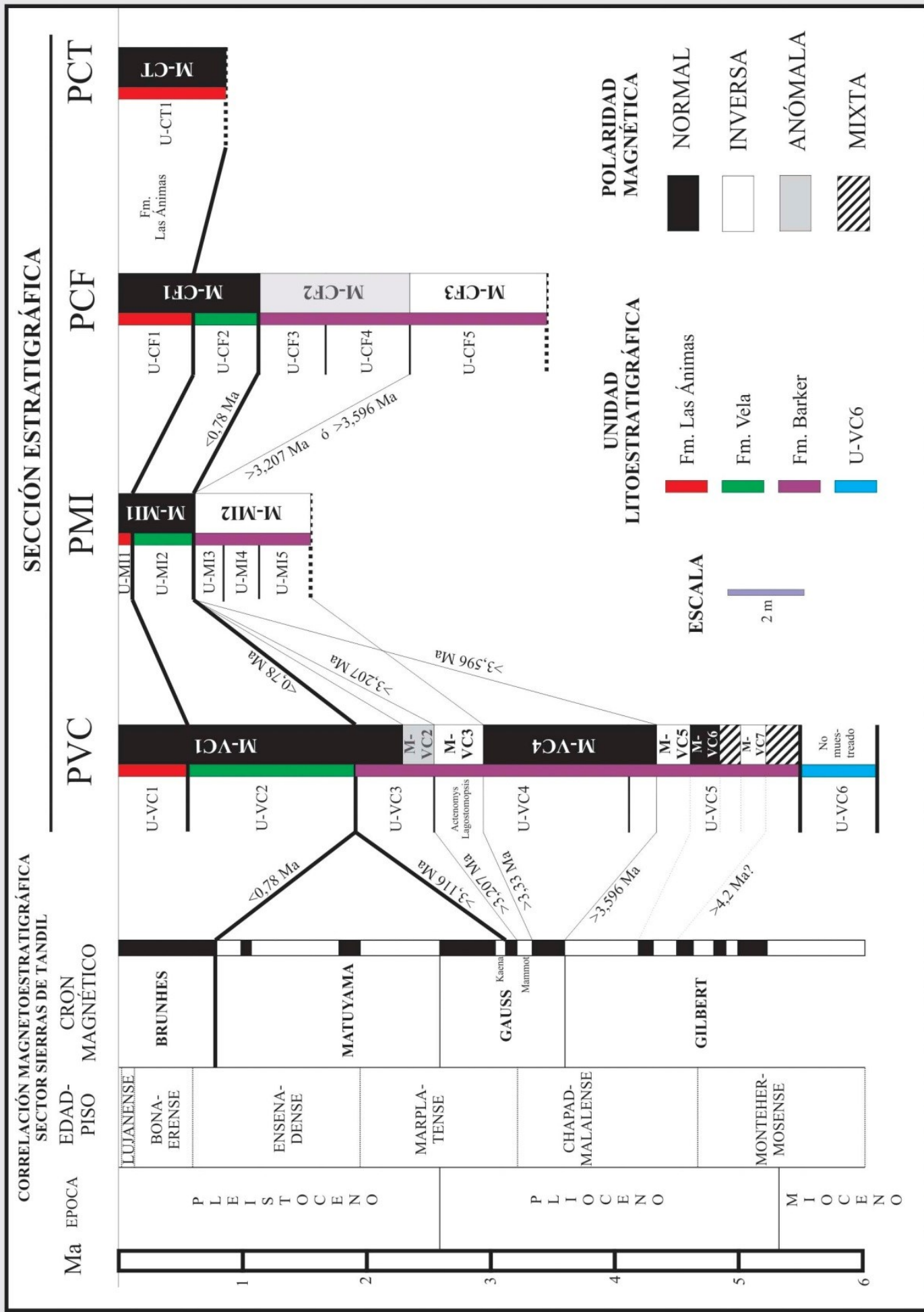

Figura 8.36. Correlación magnetoestratigráfica en el sector Sierras de Tandil. 


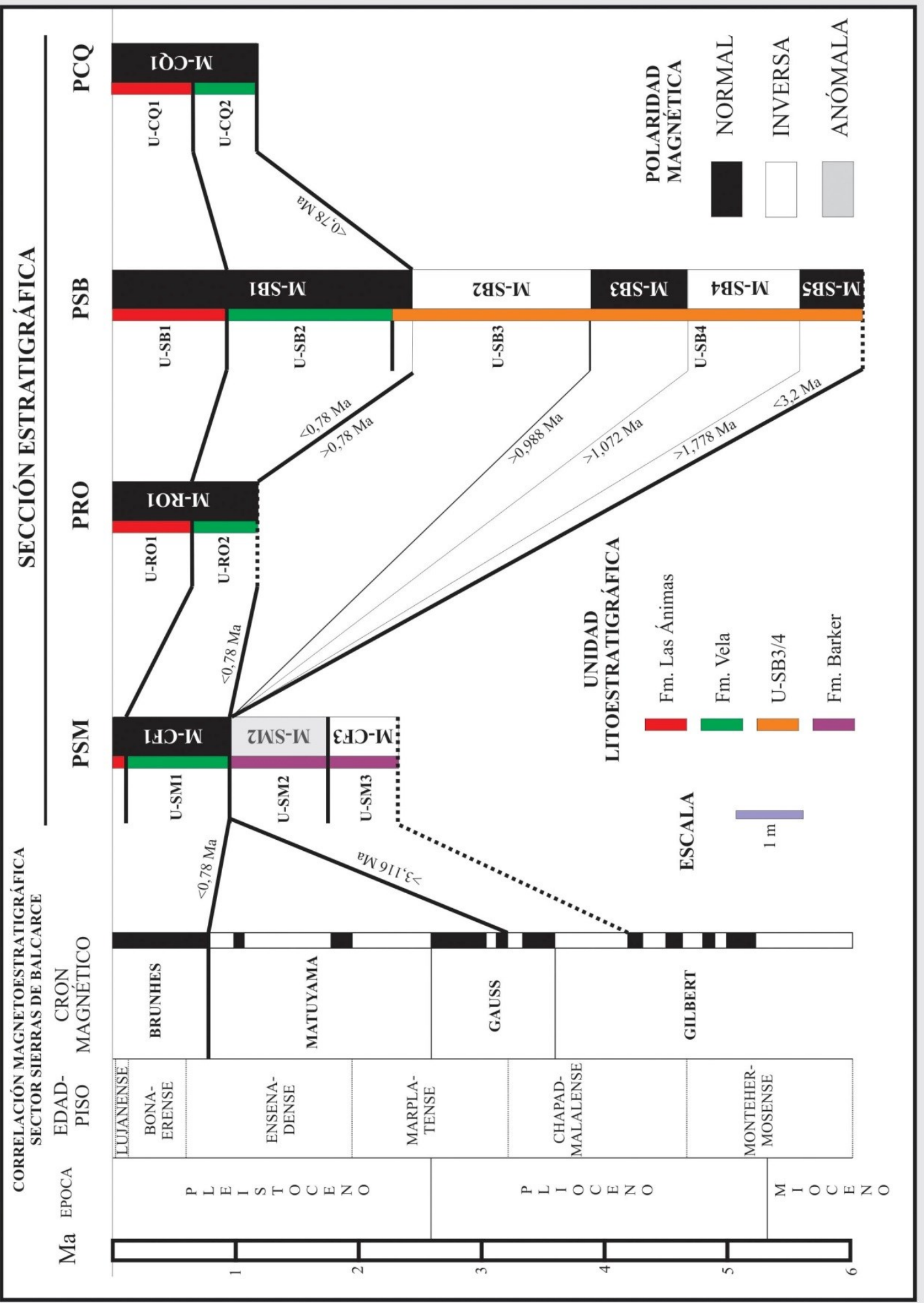

Figura 8.37. Correlación magnetoestratigráfica en el sector Sierras de Balcarce. 


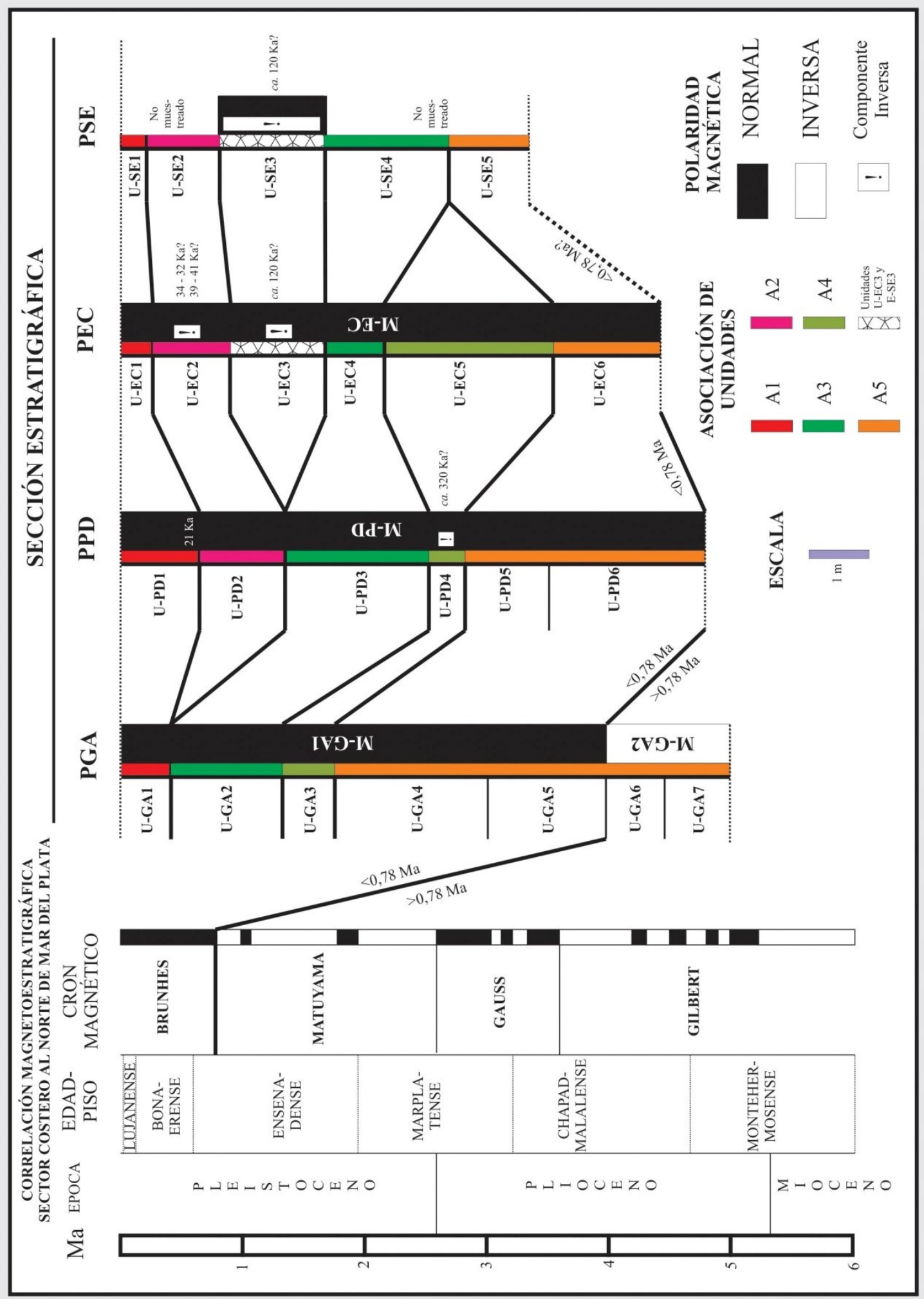

Figura 8.38. Correlación magnetoestratigráfica en el sector costero al norte de Mar del Plata. 


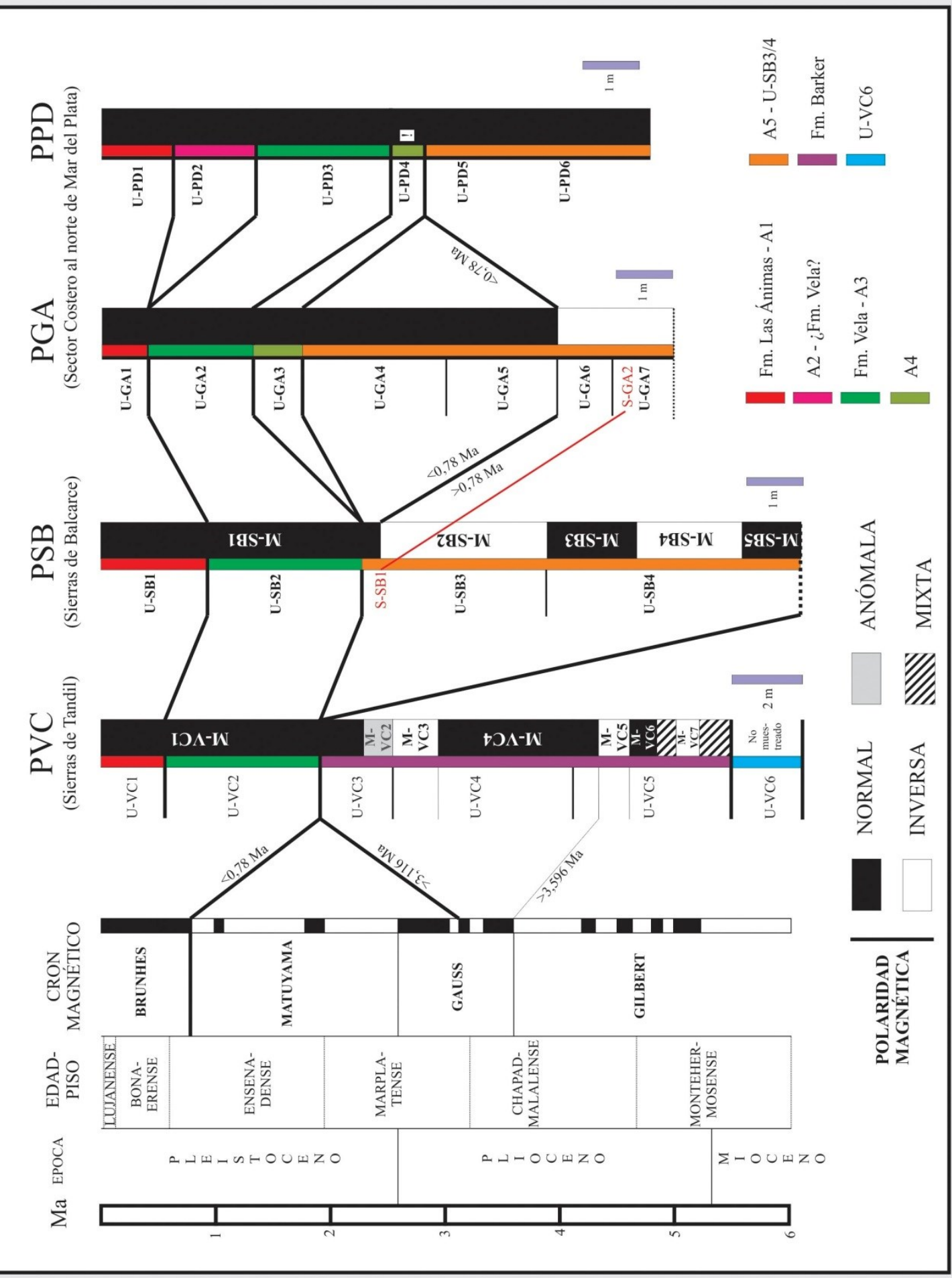

Figura 8.39. Correlación magnetoestratigráfica entre secciones de los sectores serranos (Tandil y Balcarce) y costero. 


\subsection{Tablas del capítulo 8.}

\begin{tabular}{|c|c|c|c|c|c|c|c|c|}
\hline MAGNETOZONA & UNIDAD & FORMACIÓN & D & I & к & $\alpha 95$ & n & POLARIDAD \\
\hline \multirow{3}{*}{ M-VC1 } & U-VC1 & Las Ánimas & 304,8 & $-37,0$ & 9,7 & 16,4 & 10 & \multirow{3}{*}{ Normal } \\
\hline & U-VC2 & Vela & 346,9 & $-66,0$ & 19,6 & 7,2 & 22 & \\
\hline & \multirow{2}{*}{ U-VC3 } & \multirow{8}{*}{ Barker } & 357,4 & $-52,6$ & 76,2 & 1,9 & 15 & \\
\hline M-VC2 & & & \begin{tabular}{|l|}
193,3 \\
\end{tabular} & $-55,3$ & 5,7 & 27,8 & 7 & Anómala \\
\hline M-VC3 & \multirow{2}{*}{ U-VC4 } & & 168,6 & 57,3 & 13,0 & 9,4 & 20 & Inversa \\
\hline \multirow{2}{*}{ M-VC4 } & & & 353,9 & $-52,7$ & 20,4 & 8,4 & 16 & \multirow{2}{*}{ Normal } \\
\hline & \multirow{4}{*}{ U-VC5 } & & 2,7 & $-34,7$ & 17,2 & 13,7 & 8 & \\
\hline M-VC5 & & & 228,4 & 72,4 & 27,9 & 5,2 & 4 & Inversa \\
\hline M-VC6 & & & \begin{tabular}{|l|}
328,2 \\
\end{tabular} & $-40,6$ & 12,4 & 36,7 & 3 & Normal \\
\hline M-VC7 & & & 236,5 & 77,3 & 4,1 & 52,1 & 4 & Inversa \\
\hline
\end{tabular}

Tabla 8.1. Magnetozonas, direcciones de D e I medias y parámetros estadísticos, en la sección de Villa Cacique (PVC).

\begin{tabular}{|c|c|c|c|c|c|c|c|c|}
\hline MAGNETOZONA & UNIDAD & FORMACIÓN & D & $\mathbf{I}$ & $\kappa$ & $\alpha 95$ & $\mathbf{n}$ & POLARIDAD \\
\hline M-MI1 & U-MI2 & Vela & 4,7 & $-49,0$ & 13,6 & 17,0 & 7 & Normal \\
\hline \multirow{3}{*}{ M-MI2 } & U-MI3 & \multirow{3}{*}{ Barker } & 147,2 & 54,9 & 36,2 & 4,0 & 6 & \multirow{3}{*}{ Inversa } \\
\hline & U-MI4 & & 175,2 & 55,9 & 36,2 & 4,0 & 12 & \\
\hline & U-MI5 & & 171,5 & 59,6 & 115,6 & 1,2 & 11 & \\
\hline
\end{tabular}

Tabla 8.2. Magnetozonas, direcciones de D e I medias y parámetros estadísticos, en la sección de María Ignacia (PMI).

\begin{tabular}{|c|c|c|c|c|c|c|c|c|}
\hline MAGNETOZONA & UNIDAD & FORMACIÓN & D & I & к & $\alpha 95$ & n & POLARIDAD \\
\hline \multirow{2}{*}{ M-CF1 } & U-CF1 & Las Ánimas & 357,7 & $-41,8$ & 30,1 & 4,8 & 7 & \multirow{2}{*}{ Normal } \\
\hline & U-CF2 & Vela & 346,1 & $-45,6$ & 37,8 & 3,8 & 11 & \\
\hline \multirow{2}{*}{ M-CF2 } & U-CF3 & \multirow{3}{*}{ Barker } & 42,3 & 11,0 & 22,5 & 6,4 & 5 & \multirow{2}{*}{ Anómala } \\
\hline & U-CF4 & & 34,0 & 18,5 & 12,3 & 14,4 & 10 & \\
\hline M-CF3 & U-CF5 & & 186,0 & 46,5 & 16,4 & 8,5 & 19 & Inversa \\
\hline
\end{tabular}

Tabla 8.3. Magnetozonas, direcciones de D e I medias y parámetros estadísticos, en la sección Calle Fangio (PCF). 


\begin{tabular}{|c|c|c|c|c|c|c|c|c|}
\hline MAGNETOZONA & UNIDAD & FORMACION & D & I & $\mathbf{\kappa}$ & $\alpha 95$ & $\mathbf{n}$ & POLARIDAD \\
\hline M-SM1 & U-SM1 & Vela & 6,1 & $-28,5$ & 44,1 & 3,2 & 10 & Normal \\
\hline M-SM2 & U-SM2 & \multirow{2}{*}{ Barker } & 77,9 & 34,8 & 3,2 & 29,3 & 12 & Anómala \\
\hline M-SM3 & U-SM3 & & 176,6 & 60,9 & 24,3 & 6,0 & 10 & Inversa \\
\hline
\end{tabular}

Tabla 8.4. Magnetozonas, direcciones de D e I medias y parámetros estadísticos, en la sección San Manuel (PSM).

\begin{tabular}{|c|c|c|c|c|c|c|c|c|}
\hline MAGNETOZONA & UNIDAD & FORMACIÓN & $\mathbf{D}$ & $\mathbf{I}$ & $\boldsymbol{\kappa}$ & $\boldsymbol{\alpha 9 5}$ & $\mathbf{n}$ & POLARIDAD \\
\hline \multirow{2}{*}{ M-RO } & U-RO1 & Las Ánimas & 6,6 & $-53,5$ & 52,9 & 2,7 & 7 & \multirow{2}{*}{ Normal } \\
\cline { 2 - 8 } & U-RO2 & Vela & 340,2 & $-53,0$ & 48,0 & 3,0 & 7 & \\
\hline
\end{tabular}

Tabla 8.5. Magnetozonas, direcciones de D e I medias y parámetros estadísticos, en la sección de Ramos Otero (PRO).

\begin{tabular}{|c|c|c|c|c|c|c|c|c|}
\hline MAGNETOZONA & UNIDAD & FORMACIÓN & D & I & n & к & $\alpha 95$ & POLARIDAD \\
\hline \multirow{3}{*}{ M-SB1 } & U-SB1 & Las Ánimas & 3,8 & -49 & 13 & 53,5 & 2,7 & \multirow{3}{*}{ Normal } \\
\hline & U-SB2 & Vela & 1,1 & $-47,4$ & 14 & 37,6 & 3,8 & \\
\hline & \multirow{2}{*}{ U-SB3 } & \multirow{5}{*}{$\begin{array}{l}\text { Sin nombre } \\
\text { formal }\end{array}$} & 358,3 & \begin{tabular}{l|l|}
$-55,9$ \\
\end{tabular} & 6 & 55,0 & 2,6 & \\
\hline M-SB2 & & & 189,3 & 53,0 & 26 & 17,1 & 7,1 & Inversa \\
\hline M-SB3 & \multirow{3}{*}{ U-SB4 } & & 358,0 & $-36,8$ & 10 & 11,8 & 14,7 & Normal \\
\hline M-SB4 & & & 175,2 & 49,1 & 5 & 9,6 & 26,0 & Inversa \\
\hline M-SB5 & & & 8,7 & $-50,5$ & 5 & 168,9 & 0,8 & Normal \\
\hline
\end{tabular}

Tabla 8.6. Magnetozonas, direcciones de D e I medias y parámetros estadísticos, en la sección de Sierra Bachicha (PSM).

\begin{tabular}{|c|c|c|c|c|c|c|c|c|}
\hline MAGNETOZONA & UNIDAD & ASOCIACIÓN & D & I & к & $\alpha 95$ & $\mathbf{n}$ & POLARIDAD \\
\hline \multirow{5}{*}{ M-GA1 } & U-GA1 & A1 & 3,3 & $-68,1$ & 144,7 & 0,7 & 2 & \multirow{5}{*}{ Normal } \\
\hline & U-GA2 & A3 & 344,7 & $-67,0$ & 23,8 & 6,0 & 2 & \\
\hline & U-GA3 & $\mathrm{A} 4$ & 18,5 & $-62,0$ & $-41,6$ & 3,4 & 3 & \\
\hline & U-GA4 & \multirow{4}{*}{ A5 } & 359,6 & $-58,3$ & 40,6 & 3,5 & 5 & \\
\hline & U-GA5 & & 4,9 & $-58,8$ & 24,1 & 6,0 & 10 & \\
\hline \multirow{2}{*}{ M-GA2 } & U-GA6 & & 200,5 & 48,5 & 5,5 & 29,1 & 3 & \multirow{2}{*}{ Inversa } \\
\hline & U-GA7 & & 227,2 & 30,8 & 8,1 & 19,4 & 6 & \\
\hline
\end{tabular}

Tabla 8.7. Magnetozonas, direcciones de D e I medias y parámetros estadísticos, en la sección GADA (PGA). 


\begin{tabular}{|c|c|c|c|c|c|c|c|c|}
\hline MAGNETOZONA & UNIDAD & ASOCIACIÓN & D & I & $\bar{\kappa}$ & $\alpha 95$ & $\mathbf{n}$ & POLARIDAD \\
\hline \multirow{6}{*}{ M-PD } & U-PD1 & A1 & \begin{tabular}{|l|}
339,6 \\
\end{tabular} & $\mid-51,9$ & \begin{tabular}{|l|}
55,5 \\
\end{tabular} & 2,6 & 6 & \multirow{6}{*}{ Normal } \\
\hline & U-PD2 & $\mathrm{A} 2$ & 347,3 & $-38,3$ & 510,1 & 0,3 & 3 & \\
\hline & U-PD3 & $\mathrm{A} 3$ & 20,7 & $-56,7$ & 11,3 & 12,9 & 13 & \\
\hline & U-PD4 & A4 & 321,2 & $-78,6$ & 12,2 & 27,4 & 4 & \\
\hline & U-PD5 & \multirow{2}{*}{ A5 } & 336,8 & $-52,7$ & 19,9 & 15,4 & 6 & \\
\hline & U-PD6 & & 0,8 & $-66,4$ & 86,4 & 1,6 & 7 & \\
\hline
\end{tabular}

Tabla 8.8. Magnetozonas, direcciones de D e I medias y parámetros estadísticos, en la sección Playa Dorada (PPD).

\begin{tabular}{|c|c|c|c|c|c|c|c|c|}
\hline MAGNETOZONA & UNIDAD & ASOCIACIÓN & D & I & к & $\alpha 95$ & $\mathbf{n}$ & POLARIDAD \\
\hline \multirow{6}{*}{ M-EC } & U-EC1 & A1 & 4,8 & $-65,5$ & - & - & 1 & \multirow{6}{*}{ Normal } \\
\hline & U-EC2 & A2 & 35,9 & \begin{tabular}{|c|}
$-63,3$ \\
\end{tabular} & 12,4 & 17,8 & 7 & \\
\hline & U-EC3 & - & 12,9 & $-49,1$ & 2,1 & 55,3 & 7 & \\
\hline & U-EC4 & A3 & 350,7 & $-65,0$ & 19,8 & 17,6 & 5 & \\
\hline & U-EC5 & A4 & 348,4 & $-56,0$ & 13,0 & 10,3 & 17 & \\
\hline & U-EC6 & A5 & 359,1 & $-60,2$ & 37,0 & 3,9 & 8 & \\
\hline
\end{tabular}

Tabla 8.9. Magnetozonas, direcciones de D e I medias y parámetros estadísticos, en la sección El Casal (PEC). 


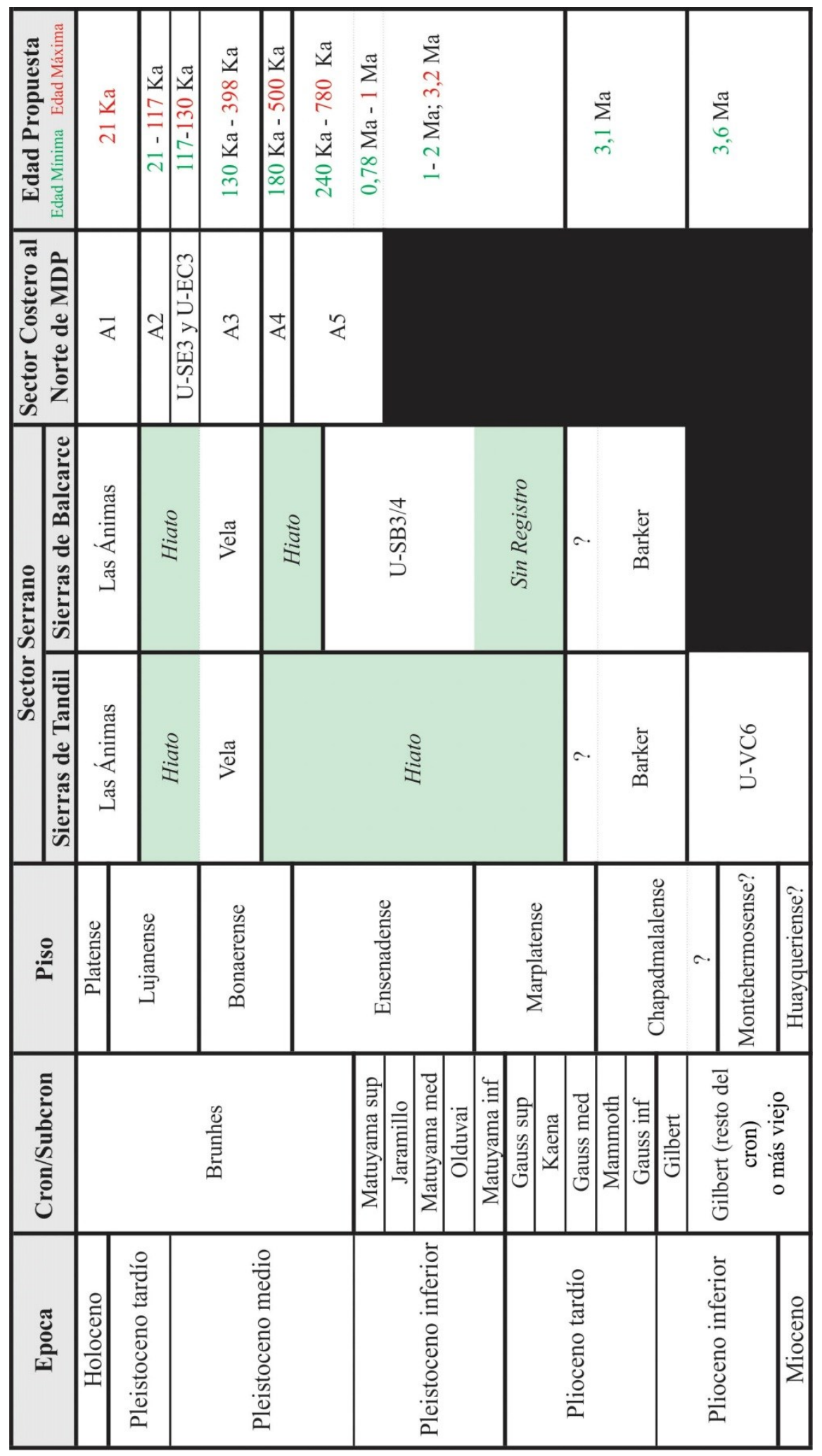

Tabla 8.10. Correlaciones establecidas y edades propuestas para las distintas unidades de los sectores serranos y costeros. 


\section{CAPITULO 9. PARÁMETROS MAGNÉTICOS Y MAGNETISMO DE ROCAS}

En este capítulo se analizan y discuten los resultados que derivan de la medición de los parámetros magnéticos en las muestras totales tomadas de las secciones estratigráficas. En la primera parte se describen los resultados obtenidos en cada sección estratigráfica. Posteriormente se realiza la caracterización magnética de los sedimentos del Cenozoico tardío del sector Tandil-Balcarce-Mar del Plata; esto incluye análisis acerca de la composición y tamaño de grano de los minerales que dominan la señal magnética. Hacia el final del capítulo también se analizan los resultados obtenidos del ciclo de histéresis, se relacionan los parámetros magnéticos con el contenido de hierro total y se realiza la caracterización magnética de las unidades litoestratigráficas del sector serrano y de las asociaciones de unidades del sector costero al norte de Mar del Plata. Finalmente se discuten los resultados obtenidos.

\subsection{Descripción de los parámetros magnéticos}

En este apartado se exponen sistemáticamente los valores de los parámetros magnéticos determinados en las distintas secciones estratigráficas. Estos incluyen a la susceptibilidad magnética $\left(\chi_{\mathrm{bf}}\right)$, factor susceptibilidad magnética dependiente de la frecuencia porcentual $\left(\chi_{\mathrm{d} \mathrm{f} \%}\right)$, magnetización remanente de saturación (MRIS), coercitividad de la remanencia $\left(\mathrm{H}_{\mathrm{cr}}\right)$, magnetización remanente anhistérica (MRA), susceptibilidad anhistérica $\left(\chi_{\mathrm{MRA}}\right)$, Coef S (-MRI $\left.-300 / \mathrm{MRIS}\right)$ y las relaciones interparamétricas $\chi_{\mathrm{MRA}} \chi_{\mathrm{bf}}$, $\chi_{\mathrm{MRA}} / \mathrm{MRIS}, \mathrm{MRA} / \chi_{\mathrm{bf}}, \mathrm{MRA} / \mathrm{MRIS}$ y MRIS/ $\chi_{\mathrm{bf}}$. Los parámetros extensivos también se presentan normalizados en función del porcentaje de $\mathrm{CaCO}_{3}$. Vale destacar que en todos los casos MRA y $\chi_{\text {MRA }}$ presentaron patrones de comportamiento idénticos, con coeficientes de correlación máximos y positivos $(\mathrm{R}=1)$; indicando que ambos son equivalentes. En tanto, para simplificar la lectura, se ha optado por describir solamente los valores de $\chi_{\text {MRA }}$. Con las relaciones interparamétricas que incluyen dichos parámetros sucede lo mismo; sólo serán descriptos los valores de $\chi_{\mathrm{MRA}} / \chi_{\mathrm{bf}} \mathrm{y} \chi_{\mathrm{MRA}} / \mathrm{MRIS}$. 


\subsubsection{Parámetros magnéticos en el sector Sierras de Tandil}

\section{Parámetros magnéticos en la sección Villa Cacique (PVC)}

En la figura 9.1 se presentan los parámetros magnéticos de la sección PVC. Los datos expuestos se refieren a la columna sedimentaria del capítulo 5 (Fig. 5.5); asimismo, se presentan los promedios de la sección (línea roja) y de cada unidad litoestratigráfica (línea verde).

La susceptibilidad promedio fue $345,1 \times 10^{-8} \mathrm{~m}^{3} / \mathrm{Kg}$; osciló entre 209,4 y $483,9 \times 10^{-8} \mathrm{~m}^{3} / \mathrm{Kg}$. El valor más elevado corresponde a la muestra del horizonte A del suelo actual; hacia la base los valores disminuyen gradualmente, en tanto las muestras del horizonte $\mathrm{C}$ presentaron los valores más bajos. Las muestras de la Formación Vela presentaron un valor promedio algo más bajo $\left(312,6 \times 10^{-8} \mathrm{~m}^{3} / \mathrm{Kg}\right)$, que normalizado en función del porcentaje de $\mathrm{CaCO}_{3}$ de la unidad se incrementó levemente $\left(322,7 \times 10^{-8}\right.$

$\mathrm{m}^{3} / \mathrm{Kg}$ ). Las muestras extraídas de la Formación Barker registraron el valor promedio más elevado (382,2 $\mathrm{x} 10^{-8} \mathrm{~m}^{3} / \mathrm{Kg}$ ), sin variabilidad importante. En esta unidad no se observó un patrón definido respecto al grado de pedogénesis. Las muestras del paleosuelo de la unidad U-VC3 presentaron un valor medio por debajo de la media de la unidad; el resto de los paleosuelos (S-VC2 y S-VC3) registraron valores cercanos al promedio de la formación, siendo el de S-VC3 ligeramente más elevado. Las muestras de la unidad litoestratigráfica U-VC6 registraron el valor promedio más bajo de la sección.

La $\chi_{\mathrm{df} \%}$ osciló entre 2,0 y 6,8\%. La Formación Las Ánimas registró la mayor variabilidad, los valores aumentan gradualmente desde la base (horizontes $\mathrm{C}$ ) hasta adquirir un máximo en el horizonte $\mathrm{A}$. Las muestras obtenidas de la Formación Vela y la unidad litoestratigráfica U-VC6 registraron los valores más bajos. En contraposición, las muestras de la Formación Barker registraron los valores más elevados, que oscilaron entre 4,4 y 6,8\%. En líneas generales, $\chi_{\mathrm{bf}} \mathrm{y} \chi_{\mathrm{df} \%}$ muestran un patrón semejante, con un coeficiente de correlación muy fuerte y positivo $(\mathrm{R}=0,73)$; este coeficiente es más elevado para la Formación Las Ánimas $(\mathrm{R}=0,94)$.

La magnetización remanente de saturación (MRIS) promedio fue $46,7 \times 10^{-3} \mathrm{~A} / \mathrm{m}^{2}$, varió entre 25,1 y $59,7 \times 10^{-3} \mathrm{~A} / \mathrm{m}^{2}$. Las formaciones Las Ánimas y Vela registraron idénticos valores de MRIS, sin embargo, en la Formación Las Ánimas se registró mayor variabilidad. Como se observa en la figura 9.1 el valor más elevado en la Formación Las Ánimas corresponde a la muestra TVC1 del horizonte A; por debajo de dicha muestra los valores disminuyen súbitamente, y se mantienen relativamente estables hasta la base de la unidad. La MRIS promedio de las muestras de la Formación Barker fue la más elevada; si bien no se registró un patrón definido en función del grado pedogenético, en el paleosuelo del tope de la 
formación los valores decrecen. La unidad U-VC6 registró el valor promedio más bajo, este asciende considerablemente tras normalizarlo por el porcentaje de $\mathrm{CaCO}_{3}\left(31,0 \times 10^{-3} \mathrm{~A} / \mathrm{m}^{2}\right)$.

La coercitividad de la remanencia $\left(\mathrm{H}_{\mathrm{cr}}\right)$ osciló entre 27 y 42,3 $\mathrm{mT}$, con un promedio de 32,2 $\mathrm{mT}$. En la Formación Las Ánimas se registró el valor promedio más elevado; asimismo, en el material parental del suelo actual se registraron los valores más elevados; hacia el tope los valores disminuyeron progresivamente, los más bajos corresponden a los horizonte A y Bt. La $\mathrm{H}_{\mathrm{cr}}$ promedio en la Formación Vela fue levemente más baja que la de la Formación Las Ánimas. La Formación Barker y la unidad litoestratigráfica U-VC6 registraron los valores más bajos; siendo levemente más bajos en U-VC6. En el histograma de la figura 9.2 se muestran la $\mathrm{H}_{\text {cr }}$ promedio de las cuatro unidades litoestratigráficas de la sección estratigráfica PVC. En la misma se observa que la $\mathrm{H}_{\mathrm{cr}}$ promedio es menor hacia las unidades litoestratigráficas más antiguas.

El Coef. S presentó escasa variación a lo largo del perfil, con un promedio de 0,95 , oscilando entre 0,92 y 0,98 .

La relación MRIS/ $\chi_{\text {bf }}$ registró un valor promedio de $13,3 \mathrm{kA} / \mathrm{m}$. Los valores promedio más elevados corresponden a la Formación Vela; los más bajos a las formaciones Barker y la unidad litoestratigráfica U-VC6. Las muestras de la Formación Las Ánimas registraron un promedio coincidente con la media de la sección, con valores más elevados en la base (horizontes C) y más bajos en el solum.

La $\chi_{\text {MRA }}$ se obtuvo en nueve muestras extraídas de la Formación Barker (TVC12, TVC13, TVC15, TVC16, TVC17, TVC18, TVC19, TVC20, TVC21, TVC22). El valor promedio $2485 \times 10^{-8} \mathrm{~m}^{3} / \mathrm{Kg}$. La relación $\chi_{\mathrm{MRA}} / \chi_{\mathrm{bf}}$ registró un promedio de 6,7 ; la relación $\chi_{\mathrm{MRA}} / \mathrm{MRIS}$ de $51,9 \times 10^{-5} \mathrm{~m} / \mathrm{A}$.

\section{Parámetros magnéticos en la sección María Ignacia (PMI)}

Los parámetros magnéticos de la sección PMI se presentan en la figura 9.3a y b. Los valores son referidos a las unidades litológicas de la columna sedimentaria (Fig. 5.19).

El promedio de los valores de $\chi_{\mathrm{bf}}$ de la sección estratigráfica PMI fue $381,7 \times 10^{-8} \mathrm{~m}^{3} / \mathrm{Kg}$, osciló entre 189,7 y 486,9 x10-8 $\mathrm{m}^{3} / \mathrm{Kg}$. La muestra TMI1 extraída de horizonte Ak del suelo actual registró un valor relativamente elevado. Las muestras extraídas de la Formación Vela presentaron los valores más bajos de la sección, tendencia que se mantiene aun luego de normalizar por el carbonato de calcio. Las muestras de la Formación Barker presentaron los valores más elevados; asimismo los más bajos de ésta se registraron en los niveles con menos pedogénesis (e.g. U-MI3) y los más elevados en muestras de 
paleosuelos (TMI10 y TMI15); los valores promedio de las muestras extraídas de los paleosuelos S-MI1 y S-MI2 estuvieron ligeramente por encima de la media de la formación, siendo más elevado en S-MI2 $\left(460,9 \times 10^{-8} \mathrm{~m}^{3} / \mathrm{Kg}\right)$ que en S-MI1 $\left(452,8 \times 10^{-8} \mathrm{~m}^{3} / \mathrm{Kg}\right)$.

La $\chi_{\mathrm{d} \mathrm{d} \%}$ promedio fue 5,3\%, osciló entre 1,6 y 7,3\%. La muestra del horizonte Ak (TMI1) registró un valor de 5,31\%. En la Formación Vela se registró el valor promedio más bajo de la sección; los valores más elevados en ésta corresponden a una capa con mayor contenido de arcilla. El promedio de la Formación Barker fue el más elevado; con valores más bajos en la unidad U-MI3 y más elevados en los paleosuelos S-MI1 $(6,7 \%)$ y S-MI2 (6,8\%). La tendencia en la Formación Barker es al incremento de los valores, tanto de $\chi_{\mathrm{bf}}$ como de $\chi_{\mathrm{dr} \%}$, en los paleosuelos.

La MRIS varió entre 26,9 y 61,1 x10 $0^{-3} \mathrm{~A} / \mathrm{m}^{2}$. La muestra TMI1 (horizonte Ak) presentó un valor relativamente elevado. La Formación Vela registró el valor promedio más bajo del perfil y la Formación Barker el más elevado. No se registró patrón definido respecto a la pedogénesis. La relación MRIS/ $\chi_{\mathrm{bf}}$ (Fig. 9.3b) varió entre 10,6 y 15,9 kA/m, con un promedio de 13,2 kA/m. Los valores promedio más elevados corresponden a la Formación Vela y los más bajos a la Formación Barker; en esta última los valores más bajos corresponden a los niveles con mayor evidencia de pedogénesis.

La coercitividad de la remanencia $\left(\mathrm{H}_{\mathrm{cr}}\right)$ (Fig. 9.3a) presentó escasa variación a lo largo del perfil. Los valores promedio más elevados corresponden a la Formación Vela mientras que los más bajos a la Formación Barker. El horizonte Ak del suelo actual presentó un valor relativamente elevado. Los valores medios de coercitividad en los paleosuelos de la Formación Barker fueron ligeramente más bajos que la media de la unidad (29,3 - 29,7 mT); en tanto, los sedimentos menos pedogenizados presentaron un valor promedio algo más elevado $(31,2 \mathrm{mT})$.

Los valores más elevados de $\chi_{\text {MRA }}$ corresponden a la Formación Barker; el más bajo de esta unidad corresponde a la muestra de la base de U-MI4, con escasos rasgos pedogenéticos y el más elevado a la muestra TMI15 (paleosuelo S-MI2). Los valores promedio obtenidos de muestras de los paleosuelos SMI1 y S-MI2 fueron 3054 y $3576 \times 10^{-8} \mathrm{~m}^{3} / \mathrm{Kg}$ respectivamente, esto representa un incremento respecto al promedio de las muestras de sectores con menos pedogénesis $\left(2856 \times 10^{-8} \mathrm{~m}^{3} / \mathrm{Kg}\right)$. Por otro lado, la Formación Vela registró el valor promedio más bajo, incluso luego de normalizar por el $\% \mathrm{CaCO}_{3}$. La muestra de la unidad U-MI1 (Hz. Ak) registró un valor relativamente elevado.

El Coeficiente S (Fig. 9.3b) experimentó escasa variación a lo largo de la sección estratigráfica PMI, con un promedio de 0,95. El valor promedio, tanto para la Formación Barker como Vela fue de 0,95. El Coef. S de la muestra del tope del perfil fue de 0,93. 
El valor promedio más elevados de $\chi_{\mathrm{MRA}} \chi_{\mathrm{bf}}$ corresponde a la Formación Barker, asimismo los valores más elevados en esta unidad corresponden a muestras de paleosuelos. En contraposición, en la Formación Vela se registró el valor promedio más bajo. La muestra de la unidad superior presentó un valor coincidente con el promedio de la sección. De manera similar, los valores de $\chi_{\text {MRA }}$ /MRIS resultaron más elevados en la Formación Barker, registrándose incrementos en los paleosuelos. El valor promedio más bajo corresponde a la Formación Vela y es intermedio en el horizonte "A" del suelo actual.

\section{Parámetros magnéticos en la sección Calle Fangio (PCF)}

Los parámetros magnéticos de las muestras de la sección PCF se indican en las figuras 9.4 y 9.5 . En las mismas, los valores son referidos a las unidades litológicas de la columna sedimentaria de la figura 5.25 .

El promedio de los valores de $\chi_{\mathrm{bf}}$ obtenidos en la sección estratigráfica PCF fue de $358,7 \times 10^{-8}$ $\mathrm{m}^{3} / \mathrm{Kg}$, osciló entre 221,2 y $479,5 \times 10^{-8} \mathrm{~m}^{3} / \mathrm{Kg}$. Las muestras extraídas de la Formación Las Ánimas registraron el valor promedio más elevado de la sección, los valores se incrementan gradualmente hacia el tope de la unidad; los más elevados corresponden a los horizontes A del suelo actual y los más bajos al horizonte C. La Formación Vela presentó el valor promedio más bajo, incluso tras normalizar por el $\mathrm{CaCO}_{3}$. El promedio más elevado corresponde a las muestras de la Formación Barker; donde el valor más elevado en esta unidad corresponde a la muestra TCF21 del paleosuelo de la base.

La $\chi_{\mathrm{d} \text { \% }}$ promedio obtenida en las muestras de PCF fue 4,3\%, osciló entre 1,5 y 7,6\%. Las muestras de la Formación Las Ánimas registraron el valor promedio más bajo, no obstante los valores más elevados en esta unidad corresponden a las muestras de los horizonte Bw. En la Formación Barker se obtuvo el valor promedio más elevado, asimismo en ésta el valor más elevado en el suelo S-CF1. En la Formación Vela se registraron valores intermedios.

En la figura 9.6 se muestra el gráfico $\chi_{\text {bf }}$ vs. $\chi_{d \mathrm{~d} \%}$. El coeficiente de correlación entre ambos fue bajo $(\mathrm{R}=-0,15)$, sin embargo para las muestras de la Formación Las Ánimas fue positivo y muy fuerte $(\mathrm{R}=0,81)$ y para las formaciones Vela y Barker fue de $-0,30$ y 0,52 respectivamente. Como se observa en la figura, las muestras de la Formación Las Ánimas con los valores más elevados, tanto de $\chi_{\mathrm{bf}}$ como $\chi_{\mathrm{dp} \%}$, corresponden a los horizontes A y Bw del suelo actual. Por otra parte se observa que las muestras del paleosuelo S-CF1 de la Formación Barker se apartan del resto de las de la misma unidad litoestratigráfica. 
La MRIS varió entre 27,6 y 54,6 x10 $0^{-3} \mathrm{Am}^{2} / \mathrm{Kg}$. Las muestras de la Formación Las Ánimas registraron el valor promedio más elevado del perfil. En contraposición, las de la Formación Vela registraron el valor promedio más bajo. En la Formación Barker se obtuvieron los valores más elevados en el paleosuelo de la base.

La coercitividad de la remanencia presentó un promedio de 34,6 mT. En la Formación Las Ánimas se registró el promedio más elevado mientras que el más bajo en la Formación Barker; la Formación Vela presentó un valor intermedio. Cabe destacar que los valores más elevados de este parámetro corresponden a los horizontes C de la Formación Las Ánimas (41,7 - 42,2 mT), en el solum los valores disminuyen. En el paleosuelo S-CF1 se registró un descenso de los valores respecto al promedio de la Formación Barker. Como se muestra en la figura 9.7, los valores de $\mathrm{H}_{\mathrm{cr}}$ presentaron una correlación negativa y muy fuerte con la $\chi_{\mathrm{d}+\%}(\mathrm{R}=-0,81)$, siendo de $-0,86$ para la Formación Barker; $-0,78$ para Las Ánimas y 0,29 para Vela. En la misma figura se observa que los valores más elevados de $\mathrm{H}_{\mathrm{cr}} \mathrm{y}$ los más bajos de $\chi_{\mathrm{d} r \%}$ corresponden a la Formación Las Ánimas, en esta, en el solum disminuye $\mathrm{H}_{\mathrm{cr}} \mathrm{y}$ aumenta $\chi_{\mathrm{dr} \%}$. La Formación Barker presentó los valores más bajos de $\mathrm{H}_{\mathrm{cr}} \mathrm{y}$ los más elevados de $\chi_{\mathrm{df} \%}$. Los valores del extremo inferior de la recta corresponden al paleosuelo S-CF1 y a las muestras TCF15 y TCF18, correspondientes a niveles de paleosuelos discontinuos.

En cuanto a $\chi_{\mathrm{MRA}}$, el promedio más elevado corresponde a la Formación Barker; no obstante, los valores más elevados de dicha unidad corresponden a la muestra TCF21 del paleosuelo de la base; el valor promedio en este palesuelo fue $3010 \times 10^{-8} \mathrm{~m}^{3} / \mathrm{Kg}$. En contraposición, la Formación Vela registró los valores más bajos, aún luego de normalizar por el $\% \mathrm{CaCO}_{3}$. Las muestras extraídas de la Formación Las Ánimas presentaron un promedio relativamente bajo, no obstante, el promedio de las muestras extraídas del material parental (horizontes C) fue el más bajo de la sección $\left(1150 \times 10^{-8} \mathrm{~m}^{3} / \mathrm{Kg}\right)$.

El Coeficiente S experimentó escasa variación, con un promedio de 0,95. El valor promedio, tanto para la Formación Barker como Vela fue de 0,95; para la Formación Las Ánimas fue 0,94.

El promedio más elevado de $\chi_{\mathrm{MRA}} \chi_{\mathrm{bf}}$ corresponde a la Formación Barker, asimismo este parámetro es más elevado en las muestras de paleosuelos. Los valores más bajos corresponden a la Formación Las Ánimas, donde el horizonte C del suelo actual registró los más bajos (promedio 3,4). La Formación Vela presentó valores intermedios. De manera similar, el valor promedio de $\chi_{\mathrm{MRA}} / \mathrm{MRIS}$ más elevado corresponde a la Formación Barker, con incremento en los niveles pedogenizados. Los valores más bajos corresponden a la Formación Las Ánimas, con valores incluso más bajos en el horizonte C. La Formación Vela presentó valores intermedios. 
Finalmente la relación MRIS/ $\chi_{\text {bf }}$ varió entre 10,3 y 14,6 kA/m, con un promedio de $12,4 \mathrm{kA} / \mathrm{m}$. Los valores promedio más elevados corresponden a la Formación Vela y los más bajos a las formaciones Barker y Vela. Este parámetro presenta valores mínimos en niveles con pedogénesis.

\section{Parámetros magnéticos en la sección Circuito Turístico (PCT)}

Se obtuvieron 5 muestras totales (TCT1 a TCT5) de la sección estratigráfica correspondiente al perfil circuito turístico (PCT). Los parámetros magnéticos determinadas en las mismas se presentan en la Tabla. 9.1.

La $\chi_{\text {bf }}$ promedio fue de $330,9 \times 10^{-8} \mathrm{~m}^{3} / \mathrm{Kg}$. La susceptibilidad magnética normalizada en función del porcentaje de $\mathrm{CaCO}_{3}$ fue $338,8 \times 10^{-8} \mathrm{~m}^{3} / \mathrm{Kg}$. El $\chi_{\mathrm{df} \%}$ promedio fue relativamente bajo, osciló entre 1,3 y 2,1\%. La MRIS varió entre 43,2 y 53,3 $\times 10^{-3} \mathrm{~A} / \mathrm{m}^{2}$, con un promedio de $49,3 \times 10^{-3} \mathrm{~A} / \mathrm{m}^{2}$. En tanto MRIS $_{\mathrm{CO} 3}$ promedio fue de $50,4 \times 10^{-3} \mathrm{~A} / \mathrm{m}^{2}$. La coercividad de la remanencia $\left(\mathrm{H}_{\mathrm{cr}}\right)$ promedio fue 41,3 $\mathrm{mT}$. La $\chi_{\text {MRA }}$ promedio fue $1173 \times 10^{-8} \mathrm{~m}^{3} / \mathrm{Kg}$. El Coef. S experimentó muy escasa variación con un valor promedio de 0,94 . El valor promedio de $\chi_{\text {MRA }} / \chi_{\text {bf }}$ fue de 3,5 y de $\chi_{\text {MRA }} /$ MRIS, $23,9 \times 10^{-5} \mathrm{~m} / \mathrm{A}$. Finalmente la relación MRIS/ $\chi_{\mathrm{bf}}$ promedio fue de $14,9 \mathrm{kA} / \mathrm{m}$, osciló entre 14,2 y $15,4 \mathrm{kA} / \mathrm{m}$.

\subsubsection{Parámetros magnéticos en el sector Sierras de Balcarce}

\section{Parámetros magnéticos en la sección San Manuel (PSM)}

En las figuras 9.8 y 9.9 se presentan los valores de los parámetros magnéticos y de las relaciones interparamétricas para la sección PSM, referidos a las unidades litológicas de la columna sedimentaria de la figura 5.38 .

El valor promedio de $\chi_{\text {bf }}$ fue $288,9 \times 10^{-8} \mathrm{~m}^{3} / \mathrm{Kg}$; varió entre 184,6 y $436,6 \times 10^{-8} \mathrm{~m}^{3} / \mathrm{Kg}$. Las muestras extraídas de la Formación Vela registraron los valores más bajos. Las muestras de la Formación Barker registraron los valores más elevados.

La $\chi_{\mathrm{df} \%}$ osciló entre 3,4 y 5,4\%. La Formación Vela registró valores más bajos que la Formación Barker. El coeficiente de correlación entre $\chi_{\mathrm{df} \%} \mathrm{y} \chi_{\mathrm{bf}}$ fue fuerte y positivo $(\mathrm{R}=0,65)$. 
La MRIS varió entre 22,8 y $53,7 \times 10^{-3} \mathrm{~A} / \mathrm{m}^{2}$. Presentó un patrón muy similar al de la susceptibilidad (Fig. 9.8); el coeficiente de correlación entre ambos parámetros fue muy fuerte y positivo $(\mathrm{R}=0,99)$. Las muestras de la Formación Vela registraron los valores más bajos y las de la Formación Barker los más elevados. A pesar de que el patrón de comportamiento de MRIS y $\chi_{\mathrm{bf}}$ es similar, cabe considerar a la relación MRIS/ $\chi_{\text {bf }}$ (Fig. 9.9), presentó valores más elevados en la Formación Vela y más bajos en la Formación Barker, en esta última con mayor variación.

La coercitividad de la remanencia $\left(\mathrm{H}_{\mathrm{cr}}\right)$ (Fig. 9.8) osciló entre 34,7 y 39,6 mT. El valor promedio más elevado de $\mathrm{H}_{\mathrm{cr}}$ corresponde a las muestras de la Formación Vela, con escasa variación de los valores. En la Formación Barker se registró una $\mathrm{H}_{\mathrm{cr}}$ media más baja; en esta unidad los valores disminuyen en la unidad U-SM2. La coercitividad de la remanencia presentó una correlación negativa muy fuerte tanto con la susceptibilidad $(\mathrm{R}=-0,98)$ como con la MIRS $(\mathrm{R}=-0,97)$.

Los valores de los parámetros MRA y $\chi_{\mathrm{MRA}}$ fueron determinados en la mayoría de las muestras de esta sección; no obstante, en las muestras TSM5 y 6 no fueron determinados debido a desperfectos en el equipo desmagnetizador al momento de la medición. Los valores promedio en la Formación Vela fueron destacadamente más bajos que los de la Formación Barker. Cabe destacar que la relación $\chi_{\mathrm{MRA}} / \mathrm{MRA}$ fue levemente más elevada en la Formación Barker que en la Formación Vela.

El Coef. S (Fig. 9.9) presentó escasa variación a lo largo del perfil, con un promedio de 0,95, osciló entre 0,92 y 0,98 .

Finalmente, el promedio más elevado de $\chi_{\mathrm{MRA}} \chi_{\mathrm{bf}}$ corresponde a la Formación Vela; el más bajo a la Formación Barker. De la misma manera, el promedio de $\chi_{\mathrm{MRA}} / \mathrm{MRIS}$ es más elevado en la Formación Vela y más bajo en la Formación Barker.

\section{Parámetros magnéticos en la sección Ramos Otero (PRO)}

En las figuras 9.10a y b se presentan los parámetros magnéticos de las muestras de la sección de Ramos Otero.

El promedio de los valores de susceptibilidad magnética $\left(\chi_{\mathrm{bf}}\right)$ de la sección estratigráfica PRO fue de $319,8 \times 10^{-8} \mathrm{~m}^{3} / \mathrm{Kg}$. Las muestras extraídas de la Formación Las Ánimas presentaron un valor promedio más elevado; como se muestra en la figura 9.10a, en esta unidad los valores se incrementan gradualmente desde la base hacia el tope. Las muestras de la Formación Vela presentaron la $\chi_{b f}$ más baja de la sección, las muestras del tope de Vela presentan un incremento significativo tras normalizar por el $\mathrm{CaCO}_{3}$. 
El factor $\chi_{\mathrm{df} \%}$ promedio fue 2,9\%; osciló entre 2,0 y 4,4\%. En la Formación Las Ánimas el promedio fue levemente más elevado que en Vela. En la Formación Las Ánimas se registró un incremento hacia el tope, coincidente con el de la susceptibilidad; el coeficiente de correlación entre $\chi_{\mathrm{bf}} \mathrm{y} \chi_{\mathrm{df}}$ fue muy fuerte y positivo $(\mathrm{R}=0,94)$. En la Formación Vela los valores son estables.

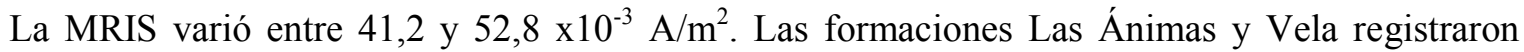
valores cercanos; sin embargo, la MRIS normalizada por el porcentaje de $\mathrm{CaCO}_{3}$ resultó más elevada en la Formación Vela (promedio 49,9 x10 $\left.0^{-3} \mathrm{~A} / \mathrm{m}^{2}\right)$ que en Las Ánimas $\left(44,7 \times 10^{-3} \mathrm{~A} / \mathrm{m}^{2}\right)$.

La relación MRIS $/ \chi_{\text {bf }}$ (Fig. 9.10b) varió entre 11 y 16,7 kA/m. Los valores promedio más elevados corresponden a la Formación Vela y los más bajos a la Formación Las Ánimas; en esta última, los valores disminuyen hacia el tope.

La coercitividad de la remanencia $\left(\mathrm{H}_{\mathrm{cr}}\right)$ (Fig. 9.10a) varió entre 35,2 y 45,5 mT. Los valores promedio más elevados corresponden a la Formación Vela, mientras que los más bajos a la Formación Las Ánimas. En esta última los valores decrecieron hacia el tope, en horizonte A del suelo actual (TRO1) se registró el valor más bajo de la sección. Cabe destacar que el patrón de variación de este parámetro es inverso al de la $\chi_{\mathrm{bf}}$ (normaliazada por $\mathrm{CaCO}_{3}$ ) y $\chi_{\mathrm{df} \%}$, el coeficiente de correlación de $\mathrm{H}_{\mathrm{cr}}$ con dichos parámetros fue muy fuerte y negativo (-0,93 y $-0,78$ respectivamente).

se consideran equivalentes. La Formación Las Ánimas presentó los valores más elevados de $\chi_{\text {MRA }}$; en esta unidad, los valores se incrementan hacia el tope, los valores máximos corresponden a la muestra TRO1 del horizonte A del suelo actual y los mínimos a la muestra TRO4 del horizonte C. La Formación Vela registró los valores promedio más bajos.

El Coeficiente S (Fig. 9.10b) experimentó escasa variación a lo largo de la sección, con un promedio de 0,93. Todas las muestras extraídas de la Formación Las Ánimas obtuvieron un valor de 0,95. Las muestras de la Formación Vela presentaron un promedio de 0,91.

Los valores promedio más elevados de $\chi_{\mathrm{MRA}} / \chi_{\mathrm{bf}} \mathrm{y} \mathrm{MRA} / \chi_{\mathrm{bf}}$ corresponden a la Formación Las Ánimas. La muestra TRO1 (horizonte A) registró los valores más elevados; que disminuyen gradualmente hacia el horizonte $\mathrm{C}$ (TRO4). La Formación Vela registró un promedio más bajo, con valores más estables. De manera similar, los promedios de $\chi_{\mathrm{MRA}} /$ MRIS y MRA/MRIS fueron más elevados en la Formación Las Ánimas, donde se registró un incremento hacia el tope. La Formación Vela registró valores más bajos y estables. 


\section{Parámetros magnéticos en la sección Sierra Bachicha (PSB)}

En las figuras 9.11 y 9.12 se indican los parámetros magnéticos de la sección PSB.

El promedio de los valores de susceptibilidad $\left(\chi_{\mathrm{bf}}\right)$ fue $330,6 \times 10^{-8} \mathrm{~m}^{3} / \mathrm{Kg}$; osciló entre $251,3 \mathrm{y}$ $394,9 \times 10^{-8} \mathrm{~m}^{3} / \mathrm{Kg}$. La muestra extraída de la Formación Las Ánimas registró un valor relativamente elevado. La Formación Vela presentó el valor promedio más bajo de la sección. Las unidades U-SB3 y USB4 presentaron una susceptibilidad promedio muy cercana (338 y $339,8 \times 10^{-8} \mathrm{~m}^{3} / \mathrm{Kg}$ respectivamente); el valor más bajo de U-SB3/4 corresponde a la muestra TSB4 del paleosuelo S-SB1 $\left(265,8 \times 10^{-8} \mathrm{~m}^{3} / \mathrm{Kg}\right)$. El paleosuelo S-SB2 (TSB9) también registró un valor levemente más bajo que la media de la unidad.

El factor $\left(\chi_{\mathrm{d} \mathrm{d} \%}\right)$ promedio fue 3,4\%; osciló entre 1,5 y 7,1\%. En las muestras de las formaciones Las Ánimas y Vela se registraron valores relativamente bajos. Las unidades U-SB3 y U-SB4 presentaron valores promedio muy cercanos (3,6 y 3,5\% respectivamente); el valor más elevado $(7,1 \%)$ se registró en la muestra del paleosuelo S-SB1; el paleosuelo S-SB2 presentó un valor ligeramente más elevado que la media de la unidad $(4,4 \%)$. Cabe destacar que en esta sección, a diferencia de las anteriores, el coeficiente de correlación entre $\chi_{\mathrm{df} \%}$ y $\chi_{\mathrm{bf}}$ fue negativo y moderado $(-0,44)$; la correlación negativa más fuerte corresponde a las muestras de la unidad U-SB3 $(-0,65)$.

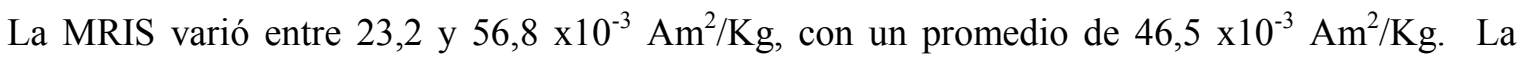
muestra de la Formación Las Ánimas registró un valor levemente más elevado que la media de la sección. Las muestras de la Formación Vela registraron el valor promedio más bajo; no obstante normalizado por el porcentaje de carbonatos ascendió a 46,4 $\times 10^{-3} \mathrm{Am}^{2} / \mathrm{Kg}$, coincidente con la media de la sección. Las unidades U-SB3 y U-SB4 registraron valores promedio muy cercanos $\left(47,3\right.$ y 47,4 x10 $0^{-3} \mathrm{Am}^{2} / \mathrm{Kg}$ respectivamente); el valor más bajo corresponde al paleosuelo S-SB1; el paleosuelo S-SB2 presentó un valor por debajo de la media de la unidad U-SB4.

La coercitividad de la remanencia presentó un promedio de 36,6 $\mathrm{mT}$. El valor de la muestra extraída de la Formación Las Ánimas fue muy cercano al promedio de la sección. La Formación Vela presentó el valor medio más elevado. Los valores promedio de las unidades U-SB3 y U-SB4 fueron respectivamente 36,3 y $35,5 \mathrm{mT}$; el valor más bajo corresponde al paleosuelo S-SB1; el paleosuelo S-SB2 presentó un valor por debajo de la media de la unidad U-SB4.

La muestra de la Formación Las Ánimas registró un valor de $\chi_{\text {MRA }}$ cercano a la media de la sección. Las muestras de la Formación Vela registraron el valor promedio más bajo. En la unidad litoestratigráfica U-SB3/4 el valor promedio fue el más elevado; en el paleosuelo del tope de la unidad U- 
SB3 se registran valores que superaron el valor promedio de la unidad; en cambio la muestra TSB9 del paleosuelo S-SB2 registró un valor por debajo del promedio.

El Coeficiente S (Fig. 9.12) experimentó escasa variación en las muestras de la sección estratigráfica, con un promedio de 0,94; varió entre 0,91 y 0,96. La muestra extraída de la Formación Las Ánimas registró un valor de 0,96. El valor promedio en la Formación Vela fue 0,93. El valor promedio tanto para U-SB3 como U-SB4 fue 0,94 .

El valor promedio de $\chi_{\text {MRA }} / \chi_{\text {bf }}$ fue 4,78 . El valor más elevado corresponde a la muestra TSB4 del paleosuelo S-SB1 y el valor más bajo a la muestra TSB7 (sin manifestaciones pedogenéticas). La muestra de la Formación Las Ánimas presentó un valor levemente menor que el promedio de la sección estratigráfica. Los valores medios obtenidos en La Formación Vela, así como en la unidad litoestratigráfica U-SB3/4, fueron levemente más elevados que la media de la sección. El valor promedio de $\chi_{\text {MRA }} /$ MRIS fue $36,4 \times 10^{-5} \mathrm{~m} / \mathrm{A}$. La muestra del paleosuelo S-SB1 registró los valores más elevados $\left(87,2 \times 10^{-5} \mathrm{~m} / \mathrm{A}\right)$, mientras que la TSB8, con escasas manifestaciones pedogenéticas, presentó el valor más bajo $\left(21,1 \times 10^{-5} \mathrm{~m} / \mathrm{A}\right)$. El valor de la muestra de la Formación Las Ánimas fue levemente menor que la media de la sección. El promedio en la Formación Vela fue levemente mayor que la media de la sección. El promedio de U-SB3/4 fue coincidente con la media de la sección.

Finalmente, la relación MRIS/ $\chi_{\text {bf }}$ varió entre 8,7 y 17,7 kA/m. La muestra de la Formación Las Ánimas presentó un valor relativamente bajo. La Formación Vela registró el valor promedio más elevado. El valor promedio registrado en las unidades U-SB3 y U-SB4 fue 13,9 y $14 \mathrm{kA} / \mathrm{m}$ respectivamente; sin embargo en ambas unidades se registró gran variación. El valor más bajo corresponde al paleosuelo SSB1; en el paleosuelo S-SB2 se registró un valor por debajo de la media de la unidad U-SB4.

\section{Parámetros magnéticos en la sección Cerro Quebracho (PCQ)}

En la tabla 9.2 se indican los valores de los parámetros magnéticos de las dos muestras extraídas de la sección PCQ.

La susceptibilidad promedio fue $144 \times 10^{-8} \mathrm{~m}^{3} / \mathrm{Kg}$ y normalizada en función del porcentaje de $\mathrm{CaCO}_{3} 196 \times 10^{-8} \mathrm{~m}^{3} / \mathrm{Kg}$. La $\chi_{\mathrm{df} \%}$ promedio fue de 2,9\%. La MRIS promedio fue $19,6 \times 10^{-3} \mathrm{~A} / \mathrm{m}^{2}$ y la MRIS $_{\mathrm{CO} 3}$ promedio fue $26,8 \times 10^{-3} \mathrm{~A} / \mathrm{m}^{2}$. La coercividad de la remanencia $\left(\mathrm{H}_{\mathrm{cr}}\right)$ promedio fue $39,7 \mathrm{mT}$. El Coef. S fue 0,93 para ambas muestras. Finalmente la relación MRIS $/ \chi_{\text {bf }}$ promedio fue de $13,6 \mathrm{kA} / \mathrm{m}$. 


\subsubsection{Parámetros magnéticos en el sector costero al norte de Mar del Plata}

\section{Parámetros magnéticos en la sección GADA (PGA)}

En las figuras 9.13 y 9.14 se presentan los valores de los parámetros magnéticos y relaciones interparamétricas para las muestras de la sección PGA; los mismos son referidos a la columna sedimentaria de la figura 5.54 .

El valor medio de $\chi_{\text {bf }}$ obtenido fue $182,5 \times 10^{-8} \mathrm{~m}^{3} / \mathrm{Kg}$. La unidad con promedio más elevado corresponde al tope del perfil (U-GA1) y el más bajo en la unidad hidromórfica U-GA5. El resto de las unidades registraron valores intermedios. En las unidades con paleosuelos (U-GA3 y U-GA7) se registraron valores más bajos que la media de la sección.

La $\chi_{\mathrm{d} \mathrm{f} \%}$ osciló entre 0,3 y 5,6\%; el promedio fue 2,5\%. La unidad de la base del perfil obtuvo el valor promedio más elevado. Los valores más bajos corresponden a la unidad hidromórfica U-GA5 y a la unidad loéssica U-GA1 del tope. El resto de las unidades registraron valores intermedios, que oscilaron entre 2,1 y $2,7 \%$. No se registró similitud entre el comportamiento de $\chi_{\mathrm{bf}}$ y $\chi_{\mathrm{df} \%}$, el coeficiente de correlación entre ambos parámetros fue bajo $(-0,05)$.

La MRIS varió entre 2,1 y 47,5 $\times 10^{-3} \mathrm{~A} / \mathrm{m}^{2}$. Los valores promedio más elevados fueron registrados en las unidades U-GA1, U-GA4 y U-GA6. Los valores más bajos corresponden a la unidad hidromórfica U-GA5 y a las unidades con paleosuelos (U-GA3 y U-GA7). El resto registró valores intermedios.

La coercitividad de la remanencia $\left(\mathrm{H}_{\mathrm{cr}}\right)$ promedio fue $37,7 \mathrm{mT}$, el valor más bajo corresponde a la muestra TGA20 del paleosuelo de la base y el más elevado a la muestra TGA10 del nivel hidromórfico. Los valores promedio más elevados corresponden a las unidades U-GA2 y U-GA5. Los valores promedio más bajos corresponden a la unidad U-GA4 y U-GA7. El resto de las unidades registraron valores intermedios.

Los valores promedio más elevados de $\chi_{\mathrm{MRA}}$ se registraron en la unidad del tope (U-GA1) y UGA4. Los valores más bajos corresponden a la unidad hidromórfica (U-GA5). El resto de las unidades registraron valores cercanos al promedio de la sección.

El Coef. S (Fig. 9.14) promedio fue 0,92. Es notorio un descenso de los valores hacia el tope de la unidad hidromórfica U-GA5, alcanzando un mínimo de 0,84 (TGA10); esta unidad presentó el valor 
promedio más bajo. Asimismo, se destaca un descenso de los valores hacia la base de la unidad U-GA7, donde el valor más bajo corresponde a la muestra TGA21, del paleosuelo S-GA2.

Las relaciones $\chi_{\mathrm{MRA}} / \chi_{\mathrm{bf}}$ y $\chi_{\mathrm{MRA}} /$ MRIS presentan comportamientos semejantes. Los valores de $\chi_{\mathrm{MRA}} / \chi_{\mathrm{bf}}$ más elevados corresponden a las unidades con paleosuelos; en tanto los más bajos a la unidad hidromórfica (U-GA5), a U-GA6 y la unidad loéssica del tope del perfil. Los valores promedio de $\chi_{\text {MRA }}$ MRIS más elevados corresponden a las unidades con paleosuelos y a U-GA4. Los valores promedio más bajos corresponden a la unidad hidromórfica y a la unidad U-GA1, del tope del perfil. El resto de las unidades registraron valores intermedios.

La relación MRIS/ $\chi_{\mathrm{bf}}$ promedio fue $12,9 \mathrm{kA} / \mathrm{m}$; el valor más bajo corresponde a la muestra TGA1 del tope del perfil y el más elevado a la muestra TGA6 de la unidad U-GA6, esta unidad presenta a su vez el valor promedio más elevado de la sección, seguida por la unidad U-GA2. El valor promedio más bajo se registró en la unidad hidromórfica. El resto de las unidades registraron valores cercanos a la media de la sección. Cabe destacar que las unidades con paleosuelos presentan valores menores a la media.

\section{Parámetros magnéticos en la sección Playa Dorada (PPD)}

En las figuras 9.15 y 9.16 se presentan los valores de los parámetros magnéticos y las relaciones interparamétricas de la sección PPD.

La $\chi_{\text {bf }}$ promedio de la sección fue $207,9 \times 10^{-8} \mathrm{~m}^{3} / \mathrm{Kg}$; varió entre 39,3 y $357,8 \times 10^{-8} \mathrm{~m}^{3} / \mathrm{Kg}$. Los valores promedio más elevados se registraron en las unidades del tope del perfil (U-PD1 y U-PD2) y en la unidad U-PD4. Los valores promedio más bajos corresponden a las unidades de la asociación A5, donde la unidad hidromórfica (U-PD5) presentó los valores más bajos. La unidad U-PD3 presentó un valor levemente mayor a la media de la sección. Por otra parte cabe destacar que la muestra TPD20, del nivel de ceniza (no graficada en la figura) registró muy baja susceptibilidad $\left(3,5 \times 10^{-8} \mathrm{~m}^{3} / \mathrm{Kg}\right)$.

El factor $\chi_{\mathrm{df} \%}$ osciló entre 0,7 y $4,7 \%$. El promedio fue bajo $(1,5 \%)$. El valor promedio más elevado corresponde a la unidad hidromórfica U-PD5, esto condicionado por el valor de la muestra TPD14. Los valores promedio más bajos corresponden a las unidades U-PD1 y U-PD4 (ambas 1,3\%). Este parámetro en la muestra del nivel de ceniza no pudo ser calculado debido a la baja concentración magnética. No se registró similitud entre las variaciones de $\chi_{\mathrm{d} \%} \mathrm{y}$ susceptibilidad; el coeficiente de correlación entre ambos fue muy bajo $(-0,02)$. 
El valor promedio de MRIS de la sección fue $28,2 \times 10^{-3} \mathrm{~A} / \mathrm{m}^{2}$. Varió entre 4,7 y $52,3 \times 10^{-3} \mathrm{~A} / \mathrm{m}^{2}$. El comportamiento de este parámetro es similar al de la susceptibilidad; el coeficiente de correlación entre ambos parámetros fue muy fuerte y positivo. Al igual que en la susceptibilidad los valores promedio más elevados corresponden a las unidades U-PD1, U-PD2 y U-PD4; y los más bajos corresponden a las unidades de la asociación A5. La muestra del nivel de ceniza registró un valor muy bajo $\left(0,5 \times 10^{-3} \mathrm{~A} / \mathrm{m}^{2}\right)$.

La coercitividad de la remanencia $\left(\mathrm{H}_{\mathrm{cr}}\right)$ promedio fue 42,5 mT; varió entre 29,1 y 63,9. El valor promedio más elevado de $\mathrm{H}_{\mathrm{cr}}$ corresponde a la unidad hidromórfica U-PD5; los más bajos a las unidades U-PD6 y U-PD4. El resto de las unidades registraron valores intermedios. La muestra del nivel de ceniza presentó una $\mathrm{H}_{\mathrm{cr}}$ de $33,2 \mathrm{mT}$.

La $\chi_{\text {MRA }}(y$ MRA) presentan un comportamiento similar al del resto de los parámetros de concentración. Las unidades con valores promedio de $\chi_{\text {MRA }}$ más elevados son U-PD4 y la U-PD2. Los valores promedio más bajos corresponden a las unidades de la asociación A5; especialmente al nivel hidromórfico (U-PD5). El resto de las unidades registraron valores intermedios. La muestra del nivel de ceniza registró el valor más bajo $\left(10,2 \times 10^{-8} \mathrm{~m}^{3} / \mathrm{Kg}\right)$.

El Coef. S (Fig. 9.16) presentó un promedio de 0,91. Varió entre 0,78 y 0,95. Es notorio un descenso de los valores en la unidad hidromórfica U-PD5 (promedio 0,80), a juzgar por esto y por el incremento en los valores de $\mathrm{H}_{\mathrm{cr}}$ se infiere una mayor contribución de minerales antiferromagnéticos, como hematita o goethita en esos niveles. El resto de las unidades presentaron valores promedio que variaron entre 0,92 y 0,94 .

La relación $\chi_{\text {MRA }} \chi_{\text {bf }}$ presentó los valores promedio más elevados en las unidades de la asociación A5 y la unidad U-PD4. La unidad U-PD1 presentó los valores promedio más bajo. El resto de las unidades registraron valores intermedios, cercanos al promedio de la sección. La muestra del nivel de ceniza, no representada en la figura, registró un valor de 2,9. .

El valor más elevados de la relación $\chi_{\mathrm{MRA}} /$ MRIS corresponde a la muestra TPD19 de la base del perfil y el más bajos a las muestra TPD3. Los valores promedio más elevados se registraron en las unidades de la asociación A5. El valor promedio más bajo corresponde a la unidad del tope. E1 resto de las unidades presentaron valores intermedios. La muestra del nivel de ceniza registró valores de 19,8 x10 $0^{-5}$ $\mathrm{m} / \mathrm{A}$.

La relación MRIS/ $\chi_{\text {bf }}$ promedio fue 13,2 kA/m; el valor más bajo corresponde a la muestra TPD16 y el más elevado a la muestra TPD4. La unidad U-PD2 registró el valor promedio más elevado; el más 
bajo en la unidad U-PD6. El resto de las unidades registraron valores cercanos a la media de la sección. La muestra TPD20 del nivel de ceniza registró un valor de $14,6 \mathrm{kA} / \mathrm{m}$.

\section{Parámetros magnéticos en la sección El Casal (PEC)}

En las figuras 9.17 y 9.18 se presentan los parámetros magnéticos de la sección PEC referidos a la columna sedimentaria de la figura 5.67.

El valor promedio de $\chi_{\mathrm{bf}}$ obtenido en la sección fue $147,6 \times 10^{-8} \mathrm{~m}^{3} / \mathrm{Kg}$. Varió entre 30,7 y 279,6 $\mathrm{x} 10^{-8} \mathrm{~m}^{3} / \mathrm{Kg}$. Las unidades con valores más elevados se corresponden con aquellas con menos evidencias de pedogénesis (U-EC1, U-EC2 y U-EC4); los valores promedio más bajos se corresponden con las unidades que presentan paleosuelos (U-EC3 y U-EC5).

La $\chi_{\mathrm{df} \%}$ osciló entre 0 y 5,2\%. El promedio fue 2,6\%. Las unidades U-EC6 y U-EC3 registraron los valores promedio más elevados. El valor promedio más bajo corresponde a la unidad U-EC2. El resto de las unidades registraron valores intermedios. No se observó relación entre el factor y la susceptibilidad, el coeficiente de correlación entre ambos parámetros resultó muy bajo $(\mathrm{R}=-0,05)$.

El valor promedio de MRIS obtenido en la sección fue $19,2 \times 10^{-3} \mathrm{~A} / \mathrm{m}^{2}$. El valor más elevado corresponde a la muestra de la unidad U-EC4. De la misma manera que la susceptibilidad, los valores más bajos corresponden a las unidades con paleosuelos, el coeficiente de correlación entre ambos parámetros fue muy fuerte y positivo $(\mathrm{R}=0,98)$.

La coercitividad de la remanencia $\left(\mathrm{H}_{\mathrm{cr}}\right)$ promedio fue $36,9 \mathrm{mT}$. Los valores más elevados se obtuvieron en la unidad U-EC2, U-EC4 y en muestras de paleosuelos (S-EC1 y S-EC2). Los valores más bajos corresponden a la unidad de la base del perfil (A5).

El valor promedio de $\chi_{\text {MRA }}$ fue $677 \times 10^{-8} \mathrm{~m}^{3} / \mathrm{kg}$. Los valores más elevados corresponden a U-EC1 y U-EC4. Los valores más bajos corresponden a paleosuelos. Este parámetro presenta comportamiento similar al resto de los parámetros de concentración ( $\chi_{\text {bf }} \mathrm{y}$ MRIS); los coeficientes de correlación fueron muy fuertes y positivos $(0,91$ y 0,87 respectivamente).

El Coef. S (Fig. 9.18) presentó un promedio de 0,91; varió entre 0,83 y 0,95. Los valores más bajos corresponden a paleosuelos (S-EC1 y S-EC2). El resto de las muestras del perfil presentan valores entre 0,92 y 0,95 . La unidad con el valor promedio más elevado fue U-EC6. 
La relación $\chi_{\mathrm{MRA}} / \chi_{\mathrm{bf}}$ registró un promedio de 4,6. Los valores más elevados corresponden a la UEC6 y al tope del paleosuelo de la unidad U-EC3. Los valores promedio más bajos se registraron en la unidad U-EC2 y en el paleosuelo del tope de U-SE5. El valor promedio del coeficientes $\chi_{\text {MrA }} /$ MRIS fue $38 \times 10^{-5} \mathrm{~m} / \mathrm{A}$. Los valores más elevados se registraron en la unidad U-EC6 y U-EC3. Los valores más bajos se registraron en muestras de las unidades U-EC2, U-EC4 y U-EC5.

Finalmente, la relación MRIS $/ \chi_{\text {bf }}$ promedio fue $12,1 \mathrm{kA} / \mathrm{m}$. Los valores más elevados corresponden a sectores con escasos signos de pedogénesis y los más bajos a paleosuelos.

\section{Parámetros magnéticos en la sección Santa Elena (PSE)}

Las muestras totales de la sección PSE corresponden a la unidad U-SE3 (nivel marino). En la tabla 9.3 se presentan los valores de $\chi_{\mathrm{bf}}, \chi_{\mathrm{df} \%}$, MRIS, $\mathrm{H}_{\mathrm{cr}}$, Coef. $\mathrm{S}$ y la relación interparamétrica MRIS/ $\chi_{\mathrm{bf}}$.

La susceptibilidad promedio fue $233 \times 10^{-8} \mathrm{~m}^{3} / \mathrm{Kg}$; normalizada en función del porcentaje de $\mathrm{CaCO}_{3}$ ascendió a $259,1 \times 10^{-8} \mathrm{~m}^{3} / \mathrm{Kg}$. La $\chi_{\mathrm{df} \%}$ promedio fue baja, de $1,2 \%$. La MRIS promedio fue 20,1

$\mathrm{x} 10^{-3} \mathrm{~A} / \mathrm{m}^{2}$ y la MRIS $\mathrm{CO}_{\mathrm{C} 3}$ promedio fue $22,3 \times 10^{-3} \mathrm{~A} / \mathrm{m}^{2}$. La coercividad de la remanencia $\left(\mathrm{H}_{\mathrm{cr}}\right)$ promedio fue 38,7 mT. El Coef. S promedio fue 0,88. Finalmente la relación MRIS $/ \chi_{\text {bf }}$ promedio fue de 8,6 kA/m.

\subsection{Caracterización magnética de los sedimentos del Cenozoico tardío del sector Tandil-}

\section{Balcarce-Mar del Plata}

En este apartado se analiza la composición magnética de los sedimentos estudiados en el presente trabajo.

\subsubsection{Mineralogía Magnética}

Como fue dicho en el capítulo 3, el diagrama $\mathrm{H}_{\mathrm{cr}}$ vs. SIRM/ $\chi_{\text {bf }}$ según Peters y Dekkers (2003) puede ser utilizado como indicador de la mineralogía magnética dominante. Los valores de coercitividad oscilaron entre 27 y $64 \mathrm{mT}$, con un promedio de $36,2 \mathrm{mT}$; asimismo los valores de $\mathrm{SIRM} / \chi_{\mathrm{bf}}$ variaron entre 8,6 y $17,7 \mathrm{kA} / \mathrm{m}$. En el diagrama de la figura 9.19a se observa que la mayoría de las muestras caen en el campo de la magnetita-titanomagnetita-maghemita; sin embargo, algunas se apartan levemente del mismo; 
éstas corresponden a muestras con valores más elevados $\mathrm{H}_{\mathrm{cr}}$, extraídas de niveles hidromórficos, con colores gley (2,5Y a 5Y), del sector costero (Fig. 9.19b); esto podría deberse a la presencia de especies antiferromagnéticas enmascaradas por la señal ferrimagnética.

La composición magnética determinada mediante el gráfico es consistente con los valores de Coeficiente $\mathrm{S}$ obtenidos, que variaron entre 0,78 y 0,98 , con un promedio de 0,93 ; éstos indican un dominio de especies ferrimagnéticas (e.g. magnetita). El diseño de las curvas de adquisición del Magnetismo Remanente Isotérmico (Fig. 9.20 a,b,c), con saturación alcanzada a campos aplicados cercanos $300 \mathrm{mT}$, es también consistente con el comportamiento de minerales ferrimagnéticos como la magnetita (Thompson, 1986; Thompson and Olfield, 1986).

\subsubsection{Tamaño de grano magnético}

Según King et al. (1982), el diagrama $\chi_{\mathrm{bf}}$ Vs. $\chi_{\mathrm{MRA}}$ es indicador de tamaño de grano magnético, especialmente para magnetita. El valor de $\chi_{\text {bf }}$ promedio de todas las muestras fue $280 \times 10^{-8} \mathrm{~m}^{3} / \mathrm{Kg}$, los valores más elevados corresponden a los sectores de Sierras de Tandil y Sierras de Balcarce, cuyos promedios fueron respectivamente 363 y $304 \times 10^{-8} \mathrm{~m}^{3} / \mathrm{Kg}$; el promedio de las muestras del sector costero al norte de Mar del Plata fue destacadamente menor $\left(179 \times 10^{-8} \mathrm{~m}^{3} / \mathrm{Kg}\right)$. El valor de $\chi_{\text {MRA }}$ promedio fue $1402 \times 10^{-8} \mathrm{~m}^{3} / \mathrm{Kg}$, los valores más elevados corresponden al sector de Sierras de Tandil (promedio 2542 $\mathrm{x} 10^{-8} \mathrm{~m}^{3} / \mathrm{Kg}$ ); los más bajos corresponden al sector costero al norte de Mar del Plata (promedio $719 \times 10^{-8}$ $\mathrm{m}^{3} / \mathrm{Kg}$ ); en el sector de Sierras de Balcarce se registraron valores intermedios (promedio $1506 \times 10^{-8}$ $\left.\mathrm{m}^{3} / \mathrm{Kg}\right)$. El coeficiente de correlación entre ambos parámetros fue muy fuerte y positivo $(\mathrm{R}=0,85)$. En la figura 9.21 se representan los valores de $\chi_{\mathrm{bf}} \mathrm{y} \chi_{\mathrm{MRA}}$ de las muestras de los distintos sectores y se indican las rectas para los tamaños de grano de 0,1; 0,2 y $1 \mu \mathrm{m}$ según King et al. (1982). Como se observa en la figura, los valores se ubican por arriba de la recta de $1 \mu \mathrm{m}$, indicando tamaños inferiores a dicho valor; si bien la mayoría de las muestras se ubica entre las rectas de 0,1 y $1 \mu \mathrm{m}$, existen diámetros inferiores a 0,1 $\mu \mathrm{m}$, especialmente en las muestras del sector serrano (Sierras de Tandil y Balcarce).

Otro gráfico de amplio uso para la determinación de tamaño de grano es SIRM vs. $\kappa_{\mathrm{bf}}$ de Thompson y Oldfield (1986). En la figura 9.22a se presenta dicho gráfico y se indican las muestras de los sectores de Tandil, Balcarce y costero. Según éste, los diámetros de las partículas magnéticas de las muestras analizadas se encuentran entre los 4 y $16 \mu \mathrm{m}$, es decir partículas principalmente de dominios Pseudo Simple (DPS) y secundariamente multidominio (MD). 
Los resultados obtenidos mediante los sistemas utilizados no son consistentes. Esta inconsistencia entre ambos métodos ya había sido marcada por otros autores que estudiaron sedimentos cuaternarios pampeanos (e.g. Chaparro, 2006; Bartel, 2009), quienes atribuyeron las diferencias a factores tales como a la interacción entre granos magnéticos, la presencia de fases "duras" (antiferromagnéticas), la calibración de los equipos, y a que dichos gráficos se calibraron utilizando muestras sintéticas de magnetita pura y de tamaños homogéneos.

Por otro lado, cabe destacar que la presencia de partículas con propiedades superparamagnéticas (SP), esto es, diámetros inferiores a $30 \mathrm{~nm}$ para magnetita, condiciona los valores de susceptibilidad magnética, provocando el incremento de la misma. El factor susceptibilidad dependiente de la frecuencia $\left(\chi_{\mathrm{df} \%}\right)$ presentó una gran variabilidad (0 a 7,6\%). El valor promedio de $\chi_{\mathrm{df} \%}$ fue 3,4\%; los valores promedio más elevados corresponden al sector de Sierras de Tandil (4,6\%) y los más bajos al sector costero al norte de Mar del Plata (2,1\%); en el sector de Sierras de Balcarce se registraron valores intermedios (3,5\%). Siguiendo a Dearing et al. (1996), los valores obtenidos indicarían una contribución de partículas SP moderada, sin embargo en varias muestras, generalmente correspondientes a niveles pedogenizados del sector serrano, se han alcanzado valores por encima del 6\%, donde la contribución de partículas SP sería considerable.

Cantidades considerables de partículas SP, como se ha dicho incrementa los valores de susceptibilidad; en tanto en el gráfico de Thompson y Oldfield (1986) la presencia de éstas sería estimada como un incremento en el tamaño de grano magnético, cuando en realidad sucedería lo contrario; esto es evidente en el caso de los paleosuelos y suelos actuales del sector serrano; en la figura 9.22a se observa que el paleosuelo S-SB1 (que presentó una $\chi_{\mathrm{d} \%}$ mayor a 7\%) se aparta hacia diámetros más gruesos en el diagrama. En la figura 9.22b se presentan en el diagrama de Thompson y Oldfield (1986) las muestras de la Formación Las Ánimas y se indican las muestras correspondientes al Solum y al material parental (horizontes C); como se indica en la figura, las muestras del Solum presentaron un valor promedio de $\chi_{\mathrm{d} \%} \%$ más elevado que las del material parental, con valores que llegan a superar el 6\%, sin embargo esto es apreciado en el diagrama como un incremento en el diámetro de partícula magnética. El gráfico de Thompson y Oldfiel (1986) sería útil cuando todos los granos de (titano)magnetita presentes se encuentren por encima de los $60 \mathrm{~nm}$; esto en función de que MRIS es cero a tamaños inferiores a $60 \mathrm{~nm}$, presenta un máximo entre 60 y $70 \mathrm{~nm}$ y disminuye gradualmente para tamaños superiores (ver figura 2.12, del capítulo Generalidades). En cambio la $\chi_{\mathrm{df}}$ se incrementa cuando la magnetita es más fina que $60 \mathrm{~nm}$ y se mantiene estable para partículas más gruesas que dicho valor (Maher, 1988). 
Cabe destacar que los valores de $\chi_{\mathrm{d} f \%}$, expresados en forma porcentual, son dependientes de la concentración de partículas magnéticas más gruesas que SP; es decir, iguales concentraciones de partículas SP pueden otorgar diferentes valores de $\chi_{\mathrm{d}}$ en función de la concentración magnética original. Cabe considerar como ejemplo que en la localidad loéssica clásica de Luochuan (China) fueron determinados valores promedio de $\chi_{\text {bf }}$ en el material parental de aproximadamente $80 \times 10^{-8} \mathrm{~m}^{3} / \mathrm{Kg}$ y en paleosuelos de aproximadamente $170 \times 10^{-8} \mathrm{~m}^{3} / \mathrm{Kg}$ (Lu et al., 1999; Blomedal y Liu, 2005; entre otros) con valores de $\chi_{\mathrm{d} \mathrm{f} \%}$ que pueden alcanzar el 10\% (Zhou et al., 1990; Blomedal y Liu, 2005; entre otros); en contraposición, en el material parental (Horizontes "C") de los suelos que se desarrollan en la Formación Las Ánimas el valor promedio de $\chi_{\mathrm{bf}}$ resultó muy superior al de loess de Luochuan $\left(331 \times 10^{-8} \mathrm{~m}^{3} / \mathrm{Kg}\right)$, y el valor promedio en el solum fue $420 \times 10^{-8} \mathrm{~m}^{3} / \mathrm{Kg}$, es decir que la $\chi_{\text {bf }}$ se incrementó en cantidades semejantes a la de los paleosuelos de la localidad China; sin embargo, los valores de $\chi_{\mathrm{df} \%}$ resultan aquí destacadamente más bajos, con un promedio de $4,2 \%$ en el solum y sin superar valores de $7 \%$. Esto indicaría que la concentración de partículas SP en ambas localidades es similar, a pesar de que los valores de $\chi_{\mathrm{d}+\%}$ son destacadamente más bajos en los suelos de la Formación Las Ánimas.

Las relaciones $\chi_{\text {MRA }} / \chi_{\mathrm{bf}} ; \chi_{\mathrm{MRA}} / \mathrm{MRIS}$ y MRIS $/ \chi_{\mathrm{bf}}$ son indicadoras de tamaño de grano magnético, especialmente cuando la mineralogía magnética es homogénea y corresponde a (titano)magnetita; tanto el incremento en los valores de $\chi_{\text {MRA }} \chi_{\text {bf }}$ como de $\chi_{\text {MRA }} /$ MRIS, indicarían una mayor presencia de partículas DS; un descenso en los valores de MRIS/ $\chi_{\mathrm{bf}}$ sería indicador de incremento de partículas en el límite DS-SP (Zhang et a.l, 2007). Tanto en los niveles de paleosuelos como en los horizontes del solum del suelo actual se registró un incremento de los valores de $\chi_{\mathrm{MRA}} / \chi_{\mathrm{bf}} \mathrm{y} \chi_{\mathrm{MRA}} / \mathrm{MRIS}$, así como una disminución de los valores de MRIS/ $\chi_{\text {bf; }}$, esto indicaría un incremento de la contribución de partículas DS y del límite DS-SP vinculada a la pedogénesis.

\subsubsection{Ciclos de histéresis}

Los ciclos de histéresis fueron realizados en 48 muestras seleccionadas; incluyen secciones estratigráficas de los sectores de Sierras de Tandil y Sierras de Balcarce. En la figura 9.24 se muestran cuatro ciclos de histéresis representativos, que incluyen muestras de la Formación Las Ánimas, de la Formación Vela, de la unidad litoestratigráfica U-SB3/4 y de la Formación Barker; los mismos se presentan tanto sin corregir como corregidos. Todas las muestras presentaron ciclos de histéresis similares, coincidentes con especies magnéticas de baja coercitividad. En la mayoría de las muestras se ha observado un estrechamiento hacia el sector central de las curvas; esto fue denominado "cintura de avispa" (del inglés “wasp waisted”) (Jackson et al., 1990; Roberts et al., 1995); según los autores esto podría deberse a 
una mezcla de minerales magnéticos con coercitividades marcadamente diferentes o bien a una amplia distribución de tamaños de grano de un mismo mineral. Las muestras analizadas podrían contener fases antiferromagnéticas enmascaradas por las ferromagnéticas, así como una amplia distribución de tamaños de grano; en tanto el diseño en "cintura de avispa" podría deberse a una combinación de las dos alternativas planteadas por los autores.

Los parámetros determinados mediante histéresis fueron Magnetización de Saturación $\left(\mathrm{M}_{\mathrm{s}}\right)$, Campo coercitivo o coercitividad $\left(\mathrm{H}_{\mathrm{c}}\right)$, Coercitividad de la remanencia $\left(\mathrm{H}_{\mathrm{cr}}\right)$ y Magnetización Remanente de Saturación $\left(\mathrm{M}_{\mathrm{rs}}\right)$, asimismo fueron calculados los cocientes $\mathrm{H}_{\mathrm{cr}} / \mathrm{H}_{\mathrm{c}}$ y $\mathrm{M}_{\mathrm{rs}} / \mathrm{M}_{\mathrm{s}}$ necesarios para confeccionar el diagrama de Day modificado por Dunlop (2002). En la tabla 9.4 se presentan los valores de $\mathrm{M}_{\mathrm{s}}, \mathrm{H}_{\mathrm{c}}, \mathrm{H}_{\mathrm{cr}}, \mathrm{M}_{\mathrm{rs}}, \mathrm{H}_{\mathrm{cr}} / \mathrm{H}_{\mathrm{c}} \mathrm{y} \mathrm{M}_{\mathrm{rs}} / \mathrm{M}_{\mathrm{s}}$.

El valor de $\mathrm{M}_{\mathrm{s}}$ promedio fue 83,3 x10 ${ }^{-3} \mathrm{Am}^{2} / \mathrm{Kg}$; con gran dispersión de los valores (entre 21,4 y $142 \times 10^{-3} \mathrm{Am}^{2} / \mathrm{Kg}$ ). El promedio de las muestras de la Formación Las Ánimas fue el más elevado (111,1 $\left.\mathrm{x} 10^{-3} \mathrm{Am}^{2} / \mathrm{Kg}\right)$, en cambio el de las muestras de la Formación Barker fue el más bajo (72,2 x10 $0^{-3}$ $\mathrm{Am}^{2} / \mathrm{Kg}$ ); el promedio de las muestras de la Formación Vela fue $91,9 \times 10^{-3} \mathrm{Am}^{2} / \mathrm{Kg}$ y el de la unidad litoestratigráfica U-SB3/4 fue $75,8 \times 10^{-3} \mathrm{Am}^{2} / \mathrm{Kg}$.

La coercitividad $\left(\mathrm{H}_{\mathrm{c}}\right)$ varió entre 2,6 y 12,5 $\mathrm{mT}$, con un promedio de 5,4 $\mathrm{mT}$. La unidad litoestratigráfica U-SB3/4 presentó el promedio más elevado de este parámetro $(6,9 \mathrm{mT})$, en contraposición la Formación Las Ánimas presentó el valor promedio más bajo (4,23 mT); los promedios de las formaciones Vela y Barker fueron 5,6 y 5,1 $\mathrm{mT}$ respectivamente.

La coercitividad de la remanencia $\left(\mathrm{H}_{\mathrm{cr}}\right)$ promedio fue 34,2 $\mathrm{mT}$; varió entre 26,6 y 49,5. El valor promedio más elevado fue registrado en la Formación Vela $(38,7 \mathrm{mT})$, mientras que el más bajo en la Formación Barker (29,6 mT); la Formación Las Ánimas registró un valor promedio de 34,6 mT y la unidad litoestratigráfica U-SB3/4 35,8 $\mathrm{mT}$. Este parámetro es equivalente al determinado mediante Magnetización Remanente Isotérmica (MRI); el coeficiente de correlación entre los valores determinados por ambas técnicas fue muy fuerte y positivo $(\mathrm{R}=0,88)$; en la figura 9.24 a se muestra el diagrama bivariante entre los valores de coercitividad de la remanencia determinada mediante ciclos de histéresis $\left[\mathrm{H}_{\mathrm{cr}}\right.$ (his) $]$ y la coercitividad de la remanencia determinada mediante Magnetización Remanente Isotérmica $\left[\mathrm{H}_{\mathrm{cr}}(\mathrm{MRI})\right]$.

La $\mathrm{M}_{\mathrm{rs}}$ promedio fue $14,9 \times 10^{-3} \mathrm{Am}^{2} / \mathrm{Kg}$; varió entre 1,2 y $26,3 \times 10^{-3} \mathrm{Am}^{2} / \mathrm{Kg}$. La unidad litoestratigráfica con mayor valor promedio corresponde a la Formación Las Ánimas $\left(17,7\right.$ x $10^{-3}$ $\mathrm{Am}^{2} / \mathrm{Kg}$ ); el resto de las unidades presentaron valores promedio cercanos, entre $14,4 \times 10^{-3} \mathrm{Am}^{2} / \mathrm{Kg}$ 
(Formación Vela) y $14 \times 10^{-3} \mathrm{Am}^{2} / \mathrm{Kg}$ (U-SB3/4). Este parámetro es equivalente a la Magnetización Remanente Isotermal de Saturación (MRIS) determinada mediante MRI; el coeficiente de correlación entre los valores determinados por ambas técnicas fue positivo débil $(0,14)$; en la figura $9.24 \mathrm{~b}$ se muestra el diagrama bivariante entre los valores de $\mathrm{M}_{\mathrm{rs}} \mathrm{y}$ MRIS; en la misma figura se observa que los valores determinados por histéresis $\left(\mathrm{M}_{\mathrm{rs}}\right)$ presentan una mayor dispersión. Dado que $\mathrm{M}_{\mathrm{rs}}$ es dependiente de la masa, se interpreta que estos resultados pueden ser en parte erróneos debido a la escasa cantidad de material utilizado, o bien que se vincule a una falla en la normalización en función de la masa (realizada en forma automática por el software del aparato). $\mathrm{M}_{\mathrm{s}}$ es también dependiente de la masa, en función de su elevada variabilidad de los valores se estima que presentaría el mismo tipo de error; no obstante se considera que este desaparecería al realizar la relación $\mathrm{M}_{\mathrm{rs}} / \mathrm{M}_{\mathrm{s}}$

El valor promedio de la relación $\mathrm{H}_{\mathrm{cr}} / \mathrm{H}_{\mathrm{c}}$ fue 7,3; el mayor valor promedio fue obtenido en las muestras de la Formación Las Ánimas $(8,9)$ y el menor en las muestras de las unidades U-SB3 y U-SB4 $(5,3)$; en las muestras de la Formación Vela se obtuvo un valor promedio de 8,29 y en las de la Formación Barker de 6,4.

El valor promedio de $\mathrm{M}_{\mathrm{rs}} / \mathrm{M}_{\mathrm{s}}$ fue 0,17; el valor promedio más elevado fue obtenido en las muestras de la Formación Barker $(0,19)$; el resto de las unidades litoestratigráficas presentaron valores promedio entre 0,16 y 0,17 .

En la figura 9.25 se indica el gráfico $\mathrm{H}_{\mathrm{cr}} / \mathrm{H}_{\mathrm{c}}$ vs. $\mathrm{M}_{\mathrm{rs}} / \mathrm{M}_{\mathrm{s}}$ (Day et al. 1977; Dunlop 2002); en el mismo se observa que la mayoría de las muestras se ubican en el campo de mezcla, entre partículas Dominio Simple y Superparamagnéticas (DS-SP). Esta mezcla de tamaños de grano magnética es consistente con el diseño de las curvas de histéresis en forma de "cintura de avispa".

\subsubsection{Relación entre los parámetros magnéticos y el contenido de Hierro}

En este apartado se relaciona el contenido de Hierro total $\left(\mathrm{Fe}_{2} \mathrm{O}_{3}\right)$ con los parámetros magnéticos.

En la figura 9.26 se presentan los gráficos $\mathrm{Fe}_{2} \mathrm{O}_{3}$ vs. los parámetros extensivos ( $\chi_{\mathrm{bf}}$; MRIS; $\chi_{\text {MRA }}$ ). Los coeficientes de correlación entre el porcentaje de $\mathrm{Fe}_{2} \mathrm{O}_{3}$ y los parámetros extensivos indicaron correlaciones positivas en todos los casos, aunque moderadas a débiles; la correlación más fuerte se obtuvo con $\chi_{\text {MRA }}(0,43)$; el coeficiente de correlación con la $\chi_{\text {bf }}$ fue 0,23 y con MRIS fue 0,14 . 
Las correlaciones relativamente débiles entre el contenido de Hierro y los parámetros extensivos se atribuyen a la presencia de minerales portadores de hierro que no contribuyen significativamente a la señal magnética (paramagnéticos y antiferromagnéticos); en base a los estudios mineralógicos realizados por otros autores, así como a las observaciones realizadas en este trabajo, se infiere que los minerales paramagnéticos que aportan hierro pueden corresponder a minerales de arcillas como illita y smectitas ricas en hierro (estas últimas, dominantemente en los niveles hidrómorficos del sector costero); y en menor medida minerales ferromagnesianos como anfíboles, piroxenos o biotita; asimismo no se descarta la presencia de óxidos de hierro paramagnéticos como lepidocrocita o akaganeita. Cabe destacar que la presencia de minerales antiferromagnéticos, especialmente hematita y en menor medida goethita, fue distinguida mediante los difractográmas de $\mathrm{Rx}$; estos minerales pueden aportar cantidades significativas de hierro, aunque su señal magnética puede estar oculta por la de la (titano)magnetita; en este sentido cabe consignar a modo de ejemplo que Bidegain et al. (2012) determinaron en sedimentos loessicos de la localidad de Marcos Paz, mediante el método de separación de fases magnéticas de Chaparro y Sinito (2004), contribuciones antiferromagnéticas (con coercitividades de la remanencia entre 285,3 y 386,6 mT) cuyos porcentajes oscilaron entre 7,7 y 18,8\%. En dichos sedimentos, el aporte a la coercitividad de la remanencia total (que varío entre 35,2 y $45,8 \mathrm{mT}$ ) fue muy baja a pesar de la elevada $\mathrm{H}_{\text {cr }}$ de estos minerales; el incremento de la $\mathrm{H}_{\mathrm{cr}}$ registrado varió entre 3,8 y $11,4 \mathrm{mT}$.

Las relaciones establecidas entre el contenido de $\mathrm{Fe}_{2} \mathrm{O}_{3}$ y los parámetros intensivos, dependientes del tamaño de grano de la (titano)magnetita $\left(\chi_{\mathrm{df} \%} ; \chi_{\text {MRA }} \chi_{\mathrm{bf}} ; \chi_{\mathrm{MRA}} / \mathrm{MRIS} ;\right.$ MRIS $\left./ \chi_{\mathrm{bf}}\right)$, muestran que el contenido de hierro total tiende a incrementarse donde el tamaño de grano magnético disminuye. En la figura 9.27 se indican los gráficos $\% \mathrm{Fe}_{2} \mathrm{O}_{3}$ vs. y $\mathrm{MRIS} / \chi_{\mathrm{bf}}$; los coeficientes de correlación fueron respectivamente 0,$59 ; 0,47 ; 0,52$ y $-0,31$. Este patrón es coincidente con el incremento relativo de $\% \mathrm{Fe}_{2} \mathrm{O}_{3}$ determinado en los horizontes $\mathrm{Bt}$, ya sean de suelos actuales como de paleosuelos, donde también, en líneas generales, se registraron los valores más elevados de $\chi_{\mathrm{df} \% ;} \chi_{\mathrm{MRA}} / \chi_{\mathrm{bf}} ; \chi_{\mathrm{MRA}} / \mathrm{MRIS}$ y más bajos de MRIS $/ \chi_{\text {bf. }}$ Esto se debería en parte a que algunos minerales de arcilla pueden presentar hierro en su composición, como es el ejemplo la illita, la cual presenta hierro ferroso (Murad y Wagner, 1994), sin embargo las concentraciones de hierro en este mineral suelen ser bajas (hierro normativo 1,85\%); en tanto es posible que el hierro (conformando óxidos) se concentre por iluviación, ya sea en forma independiente, o bien que las arcillas y/o la materia orgánica actúen como "transportadores" (del inglés carriers), siendo, el segundo de los casos similar al proceso denominado queluviación. Dadas las variaciones de los parámetros magnéticos en los horizontes Bt se infiere que iluviación de hierro es un proceso factible; y se estima que el mismo se incorporaría a los horizontes iluviales conformando diferentes minerales; según los casos la acumulación de hierro consistiría en especies ferrimagnéticas (magnetita y/o maghemita); 
óxidos de hierro antiferromagnéticos (hematita y/o goethita) y/o probablemente paramagnéticos (lepidocrocita y akaganeita).

\subsubsection{Caracterización magnética de las unidades litoestratigráficas del sector serrano}

En la Tabla 9.5 se indican los valores promedio de los parámetros magnéticos de las distintas unidades litoestratigráficas del sector serrano. Asimismo, según los casos se presentan los valores promedio de horizontes del suelo actual, de los paleosuelos y del material parental; los valores de los parámetros extensivos de las unidades con abundante $\mathrm{CaCO}_{3}$ se presentan también normalizados $\left(\mathrm{N} / \mathrm{CO}_{3}\right)$.

La Formación Las Ánimas (Pleistoceno tardío-Holoceno), de origen dominantemente eólico (loess) es la unidad más superficial y es modificada por el ciclo pedogenético actual. Esto último condiciona el registro de los parámetros magnéticos, los cuales evidenciaron una gran variabilidad. El valor de susceptibilidad promedio $\left(\chi_{\mathrm{bf}}\right)$ de las muestras extraídas de esta unidad fue $369 \times 10^{-8} \mathrm{~m}^{3} / \mathrm{Kg}$; el patrón de comportamiento de $\chi_{\mathrm{bf}}$ coincide con el modelo de "incremento magnético" (enhancement en inglés), donde los valores más bajos corresponden al material original, sin modificación pedogenética (horizontes "C") incrementándose gradualmente hacia la superficie, alcanzando valores máximos en los horizontes "A" e intermedios en horizontes "B". El factor susceptibilidad dependiente de la frecuencia $\left(\chi_{\mathrm{df} \%}\right)$ presentó en esta unidad un valor promedio de 2,9\%; el comportamiento fue similar al de la susceptibilidad, con correlaciones muy fuertes y positivas entre ambos parámetros, es decir valores más bajos a las muestras de los horizontes "C" y los más elevados a las de los horizontes "A" y "B"; esto se relaciona con un incremento de partículas SP en los horizontes del solum. El valor promedio de Magnetización Remanente Isotérmica de Saturación (MRIS) fue el más elevado de las unidades litoestratigráficas del sector serrano, si bien este parámetro presentó correlaciones fuertes y positivas con la $\chi_{\mathrm{bf}}$, la variabilidad fue menos significativa. En las muestras de los horizontes " $\mathrm{B}$ " $\mathrm{y}$ " $\mathrm{C}$ " los valores fueron más bajos que en los horizontes "A". El valor de Coercitividad de la Remanencia $\left(\mathrm{H}_{\mathrm{cr}}\right)$ promedio

en la Formación Las Ánimas fue el más elevado de las unidades del sector serrano; este parámetro presentó correlación muy fuerte y negativa tanto con la $\chi_{\mathrm{bf}}$ como con el $\chi_{\mathrm{df} \%}$, es decir su comportamiento fue inverso; los valores más elevados de este parámetro corresponden a los horizontes " $\mathrm{C}$ ” y los más bajos a los horizontes "A" y "B". La $\chi_{\text {MRA }}$ presentó correlaciones muy fuertes y positivas con la $\chi_{\mathrm{bf}} \mathrm{y}$ con el $\chi_{\mathrm{df} \%}$, una correlación moderada y positiva con MRIS y una correlación muy fuerte y negativa con la $\mathrm{H}_{\mathrm{cr}}$; los valores más bajos de $\chi_{\text {MRA }}$ corresponden a los horizontes "C" y los más elevados a los horizontes "A". El Coef. S presentó un valor promedio de 0,94 , sin variaciones significativas. La relación $\chi_{\mathrm{MRA}} / \chi_{\mathrm{bf}}$ así como $\chi_{\text {MRA }}$ /MRIS presentaron los valores promedio más bajos de las unidades litoestratigráficas del sector 
serrano. Los valores más bajos de $\chi_{\mathrm{MRA}} \chi_{\mathrm{bf}}$ corresponden a los horizontes "C" y se incrementaron progresivamente hacia la parte superior del suelo actual, registrando valores máximos en los horizontes "A"; esta relación presentó una correlación muy fuerte y positiva con el $\chi_{\mathrm{df} \%} \mathrm{y}$ muy fuerte y negativa con $\mathrm{H}_{\mathrm{cr}}$. Los valores más bajos de $\chi_{\mathrm{MRA}} / \mathrm{MRIS}$ corresponden a las muestras de los niveles sin modificación pedogenética (horizontes "C") y se incrementaron progresivamente hacia la parte superior del solum; los valores más elevados se registraron en los horizontes "A" y "B"; registró coeficientes de correlación muy fuertes y positivos con $\chi_{\mathrm{df} \%}$ y $\chi_{\mathrm{MRA}} / \chi_{\mathrm{bf}}$, y muy fuerte y negativo con $\mathrm{H}_{\mathrm{cr}}$. La relación MRIS/ $\chi_{\mathrm{bf}}$ presentó un valor promedio de $13,1 \mathrm{kA} / \mathrm{m}$; las muestras de los horizontes $\mathrm{C}$ presentaron los valores más elevados; en tanto los horizontes del solum presentaron los valores más bajos; este parámetro presentó correlación muy fuerte y positiva con $\mathrm{H}_{\mathrm{cr}} \mathrm{y}$ muy fuerte y negativa con $\chi_{\mathrm{MRA}} /$ MRIS.

La Formación Vela (Pleistoceno medio-tardío?), de origen dominantemente fluvial, presentó una susceptibilidad promedio relativamente baja; dado que la unidad presenta abundante contenido de $\mathrm{CaCO}_{3}$ (promedio 15,5\%) los valores de los parámetros de concentración se exponen también normalizados. El factor susceptibilidad dependiente de la frecuencia $\left(\chi_{\mathrm{df} \%}\right)$ promedio fue relativamente bajo, con escasa variación de los valores; el coeficiente de correlación entre $\chi_{\mathrm{bf}} \mathrm{y} \chi_{\mathrm{df} \%}$ fue débil a nulo. La MRIS promedio fue también relativamente baja, esta tendencia continuó incluso tras normalizar en función del carbonato de calcio; el coeficiente de correlación entre MRIS y $\chi_{\text {bf }}$ fue muy fuerte y positivo $(0,94)$. La coercitividad de la remanencia $\left(\mathrm{H}_{\mathrm{cr}}\right)$ promedio fue relativamente elevada, aunque levemente más baja que la registrada en la Formación Las Ánimas, y con escasa variabilidad de los valores. La $\chi_{\mathrm{MRA}}$, al igual que el resto de los parámetros extensivos presentó valores relativamente bajos, incluso luego de normalizar por el $\mathrm{CaCO}_{3}$. $\mathrm{El}$ Coef. S promedio fue 0,93 . Las relaciones $\chi_{\mathrm{MRA}} / \chi_{\mathrm{bf}} \mathrm{y} \chi_{\mathrm{MRA}} / \mathrm{MRIS}$ presentaron valores intermedios. La relación MRIS/ $\chi_{\mathrm{bf}}$ promedio fue la más elevada para las unidades litoestratigráficas del sector serrano.

La unidad litoestratigráfica U-SB3/4 (Sierra Bachicha), asignada al cron Matuyama, presentó una susceptibilidad $\left(\chi_{\mathrm{bf}}\right)$ promedio relativamente elevada; en los niveles correspondientes a paleosuelos se registraron los valores más bajos, alcanzando un valor mínimo de $265,8 \times 10^{-8} \mathrm{~m}^{3} / \mathrm{Kg}$ en el paleosuelo $\mathrm{S}$ SB1. El factor susceptibilidad dependiente de la frecuencia presentó un valor promedio de 3,5\%; en los paleosuelos se registraron los valores más elevados, el valor máximo de este parámetro $(7,1 \%)$ fue registrado en el paleosuelo S-SB1; la correlación entre $\chi_{\mathrm{bf}} \mathrm{y} \chi_{\mathrm{d} \mathrm{r} \%}$ fue fuerte y negativa. La MRIS, al igual que la susceptibilidad presentó en los niveles de paleosuelos los valores más bajos y en el material parental los más elevados. $\mathrm{La} \mathrm{H}_{\mathrm{cr}}$ presentó un descenso de los valores en los niveles de paleosuelos, el valor mínimo $(28,7 \mathrm{mT})$ fue registrado en el paleosuelo S-SB1; este parámetro presentó correlación muy fuerte y negativa con $\chi_{\mathrm{df} \%}$. La susceptibilidad anhistérica $\left(\chi_{\mathrm{MRA}}\right)$ no presento una relación clara con la $\chi_{\mathrm{bf}}$, esto se vincula a que el paleosuelo S-SB1 registró un incremento de $\chi_{\mathrm{MRA}}$ respecto al material parental. El 
Coef. S presentó un promedio de 0,94 . Las relaciones $\chi_{\mathrm{MRA}} / \chi_{\mathrm{bf}} \mathrm{y} \chi_{\mathrm{MRA}} / \mathrm{MRIS}$ presentaron incrementos en los paleosuelos, los valores más elevados fueron registrados en el paleosuelo S-SB1. La relación MRIS/ $\chi_{\mathrm{bf}}$ presentó los valores más bajos en los paleosuelos, donde el valor mínimo se obtuvo en el paleosuelo S$\operatorname{SB} 1(8,7 \mathrm{kA} / \mathrm{m})$.

La Formación Barker, asignada a los crones Gauss y Gilbert, registró el valor promedio de $\chi_{\mathrm{bf}}$ más elevado de las unidades litoestratigráficas del sector serrano; en líneas generales los valores de este parámetro fueron más elevados en los paleosuelos, los casos más conspicuos corresponden a los paleosuelos de las secciones de María Ignacia y Calle Fangio; en los paleosuelos de la sección PVC no se determinó un patrón definido. El factor $\chi_{\mathrm{d} \mathrm{r} \%}$ presentó el valor promedio más elevado de las unidades litoestratigraficas del sector serrano; a su vez, los valores más elevados corresponden a niveles de paleosuelos, en algunos de estos se registraron valores mayores a 7\%; el coeficiente de correlación entre $\chi_{\mathrm{df} \%} \mathrm{y} \chi_{\mathrm{bf}}$ fue fuerte y positivo. Los valores MRIS obtenidos en paleosuelos fueron en general levemente más elevados; este parámetro presentó una correlación muy fuerte y positiva con la susceptibilidad. La coercitividad de la remanencia $\left(\mathrm{H}_{\mathrm{cr}}\right)$ presentó un valor promedio relativamente bajo $(30,5 \mathrm{mT})$; los valores en las muestras de paleosuelos fueron menores a $30 \mathrm{mT}$, el valor más bajo registrado (27,8 $\mathrm{mT})$ corresponde al paleosuelo S-VC2; este parámetro registró correlaciones negativas, moderadas a fuertes

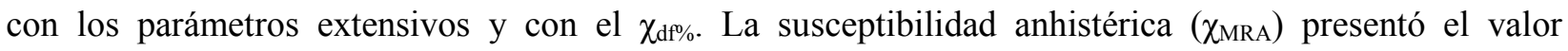
promedio más elevado del sector; con correlación positiva muy fuerte con $\chi_{\mathrm{bf}} \mathrm{y}$ MRIS; al igual que estos parámetros los valores más elevados corresponden a los paleosuelos, con valores que superan los 3000 $\mathrm{x} 10^{-8} \mathrm{~m}^{3} / \mathrm{Kg}$. El Coeficiente S. registró un valor promedio de 0,95 . Las relaciones $\chi_{\mathrm{MRA}} / \chi_{\mathrm{bf}} \mathrm{y} \chi_{\mathrm{MRA}} / \mathrm{MRIS}$ presentaron los valores promedio más elevados del sector serrano; los valores de ambos parámetros en los paleosuelos fueron más elevados. La relación MRIS/ $\chi_{\mathrm{bf}}$ promedio fue $12,5 \mathrm{kA} / \mathrm{m}$; en los paleosuelos se registraron los valores más bajos.

La unidad litoestratigráfica U-VC6 (Villa Cacique) presentó la susceptibilidad promedio más baja de las unidades litoestratigráficas del sector serrano, incluso luego de normalizar por contenido de $\mathrm{CaCO}_{3}$. El factor $\chi_{\mathrm{d}} \%$ promedio fue el más bajo $(2,6 \%)$. La MRIS fue la más baja del sector. La coercitividad de la remanencia promedio fue también la más baja $(27,6 \mathrm{mT})$. El Coef. S promedio fue 0,94. La relación MRIS $\chi_{\mathrm{bf}}$ promedio fue también la más baja de las unidades litoestratigráficas del sector serrano. 


\subsubsection{Caracterización magnética de las asociaciones de unidades del sector costero}

En la Tabla 9.5 se indican los valores promedio de los parámetros magnéticos de las asociaciones de unidades del sector costero al norte de Mar del Plata. Según los casos se presentan también los valores promedio de las muestras del solum, de los paleosuelos y del material parental; los parámetros extensivos de las unidades con abundante $\mathrm{CaCO}_{3}$ se presentan también normalizados $\left(\mathrm{N} / \mathrm{CO}_{3}\right)$.

Los sedimentos areno-limosos, de origen eólico de la asociación A1 presentaron la susceptibilidad $\left(\chi_{\mathrm{bf}}\right)$ promedio más elevada del sector costero; esta unidad se encuentra generalmente modificada por el desarrollo del suelo actual; sin embargo este se encontró generalmente disturbado por acción antrópica; sólo se extrajeron muestras del solum en el perfil PGA, donde el valor promedio de estas fue $390 \times 10^{-8}$ $\mathrm{m}^{3} / \mathrm{Kg}$, representando un incremento respecto a los horizontes C. El factor susceptibilidad dependiente de la frecuencia $\left(\chi_{\mathrm{df} \%}\right)$ promedio fue bajo; en las muestras del solum fue levemente más elevado que en el material parental. La MRIS presentó un comportamiento semejante al de la susceptibilidad, con un coeficiente de correlación muy fuerte y positivo. La coercitividad de la remanencia $\left(\mathrm{H}_{\mathrm{cr}}\right)$ promedio fue relativamente elevada; en las muestras del solum fue más baja que en el material parental. La $\chi_{\text {MrA }}$ presentó el valor promedio más elevado del sector costero; en los horizontes del solum fue más elevada que en los horizontes "C". El Coef. S promedio fue 0,94 , con escasa variación. Las relaciones $\chi_{\text {MRA }} \chi_{\text {bf }} \mathrm{y}$ $\chi_{\mathrm{MRA}} /$ MRIS presentaron los valores elevados en las muestras del solum. La relación MRIS/ $\chi_{\mathrm{bf}}$ disminuye hacia el solum.

La asociación A2 registró valores de susceptibilidad $\left(\chi_{\mathrm{bf}}\right)$ relativamente elevados; levemente más bajos que los del material parental de A1. El factor susceptibilidad dependiente de la frecuencia $\left(\chi_{\mathrm{df} \%}\right)$ promedio fue el más bajo de las asociaciones del sector costero; el coeficiente de correlación entre $\chi_{b f} \mathrm{y}$

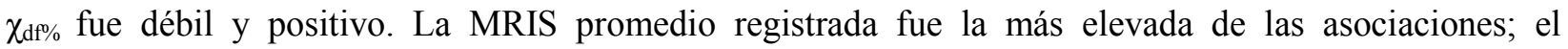
coeficiente de correlación de este parámetro con la susceptibilidad fue muy fuerte y positivo. La coercitividad de la remanencia $\left(\mathrm{H}_{\mathrm{cr}}\right)$ promedio fue la más elevada de las asociaciones. La $\chi_{\text {MRA }}$ presentó un valor promedio de $922,6 \times 10^{-8} \mathrm{~m}^{3} / \mathrm{Kg}$; este parámetro registró un coeficiente de correlación muy fuerte y positivo con la $\chi_{\mathrm{bf}} \mathrm{y}$ con MRIS. El Coef. S promedio fue 0,93 , con escasa variación. Las relaciones $\chi_{\mathrm{MRA}} / \chi_{\mathrm{bf}} \mathrm{y} \chi_{\mathrm{MRA}} / \mathrm{MRIS}$ presentaron los valores promedio más bajos de las asociaciones del sector costero. La relación $\mathrm{MRIS} / \chi_{\mathrm{bf}}$ promedio fue la más elevada de las asociaciones.

Cabe destacar que por debajo de las unidades de la asociación A2 en las secciones estratigráficas de El Casal y de Santa Elena fueron determinadas las unidades U-EC3 y U-SE3 respectivamente. Como fue dicho anteriormente, la U-EC3 corresponde a sedimentos fuertemente pedogenizados, donde se registraron valores relativamente bajos de los parámetros de concentración y valores relativamente 
elevados de coercitividad de la remanencia $\left(\mathrm{H}_{\mathrm{cr}}\right)$; las relaciones $\chi_{\mathrm{MRA}} / \chi_{\mathrm{bf}} \mathrm{y} \chi_{\mathrm{MRA}} / \mathrm{MRIS}$ presentaron valores relativamente elevadas y la MRIS/ $\chi_{\text {bf }}$ relativamente bajos. La unidad U-SE3, en cambio, corresponde a un nivel con arenas y valvas trituradas, vinculadas a una ingresión marina; la misma registró valores intermedios de los parámetros extensivos; valores bajos de factor $\chi_{\mathrm{d} \mathrm{f} \%}$, valores intermedios de $\mathrm{H}_{\mathrm{cr}}$, Coef. $\mathrm{S}$ relativamente bajos $(0,88)$ y los valores más bajos de la relación MRIS/ $\chi_{\text {bf }}$, estos últimos, en relación a la textura arenosa, se asocian a un mayor tamaño de partícula magnética, tal como se indica en el gráfico de Thompson y Oldfiel (1986) de la figura 9.22.

La asociación A3 (correlacionable con la Formación Vela) presentó gran concentración de $\mathrm{CaCO}_{3}$ $(19,1 \%)$, en tanto los parámetros extensivos se presentan también normalizados. Todos ellos presentaron valores relativamente elevados; cercanos a los registrados en el material parental de la asociación A1 y A2. El factor $\left(\chi_{\mathrm{df} \%}\right)$ promedio fue bajo $(1,6 \%)$. La coercitividad de la remanencia $\left(\mathrm{H}_{\mathrm{cr}}\right)$ promedio fue relativamente elevada. El Coef. S promedio fue 0,93 , con escasa variación. Las relaciones $\chi_{\mathrm{MrA}} / \chi_{\mathrm{bf}} \mathrm{y}$ $\chi_{\mathrm{MRA}} /$ MRIS presentaron valores intermedios. La relación MRIS $\chi_{\mathrm{bf}}$ promedio fue relativamente elevada.

La asociación A4, del Pleistoceno medio, se compone de sedimentos fluviales con desarrollo de paleosuelos; en tanto, se comparan los parámetros entre la zonas más pedogenizadas (horizontes "B", generalmente $\mathrm{Bt}$ ) y las zonas con menos signos pedogenéticos (material parental, horizontes “C”). Los parámetros de concentración presentaron comportamientos similares, sus valores promedio fueron relativamente bajos, con coeficientes de correlación muy fuertes y positivos. Los valores más bajos corresponden a los horizontes $\mathrm{Bt}$ y los más elevados al material parental. El factor susceptibilidad dependiente de la frecuencia $\left(\chi_{\mathrm{df} \%}\right)$ promedio fue bajo, en los horizontes " $\mathrm{C}$ " fue levemente más bajo que en los Bt. La coercitividad de la remanencia $\left(\mathrm{H}_{\mathrm{cr}}\right)$ promedio fue la más baja de las asociaciones del sector costero; está fue más baja en el material parental que en los horizontes "B". El Coef. S promedio fue 0,91; en los paleosuelos fue más bajo que en el material parental. Las relaciones $\chi_{\text {MRA }} / \chi_{\text {bf }}$ y $\chi_{\text {MRA }} /$ MRIS presentaron valores promedio más elevados del sector costero; en los niveles pedogenizados los valores de ambos parámetros fueron más elevados que en el material parental. La relación MRIS/ $\chi_{\text {bf }}$ promedio fue relativamente baja; el promedio en los niveles de paleosuelos fue menor que en el material original.

La asociación A5 se compone de alternancia de capas de color rojizo, con estructuras fluviales; y capas gley (hidromórficas) interpretadas como planicies aluviales y pequeños cuerpos límnicos; asimismo en la base del perfil PGA fue hallado un paleosuelo desarrollado sobre los sedimentos rojizos. Los valores de los parámetros de concentración fueron los más bajos, presentaron comportamientos semejantes, con coeficientes de correlación muy fuertes y positivos. Estos parámetros presentaron los valores más bajos en las capas gley; en el paleosuelo intermedios y en las capas rojizas los más elevados. El factor susceptibilidad dependiente de la frecuencia $\left(\chi_{\mathrm{d} \%}\right)$ promedio fue bajo, aunque más elevado que en resto de 
las asociaciones. En los niveles gley fue levemente más bajo que en las capas rojizas; en el paleosuelo se registraron los valores más elevados. La coercitividad de la remanencia $\left(\mathrm{H}_{\mathrm{cr}}\right)$ presentó en los niveles hidromórficos los valores más elevados, en los rojizos los más bajos. Cabe destacar que en el paleosuelo se registró el valor más bajo de $\mathrm{H}_{\mathrm{cr}}$ de la sección PGA $(31 \mathrm{mT})$, no obstante el valor promedio fue levemente más elevado que el de los niveles rojizos. El Coef. S promedio fue 0,91 ; en los niveles hidromórficos fue más bajo; en el paleosuelo más elevado. Las relaciones $\chi_{\mathrm{MRA}} / \chi_{\mathrm{bf}} \mathrm{y} \chi_{\mathrm{MRA}} / \mathrm{MRIS}$ presentaron comportamientos semejantes; en los niveles hidromóficos los valores de ambos parámetros fueron levemente más bajos; en las capas rojizas fueron más elevados, en el paleosuelo fueron aún más elevados. La relación MRIS/ $\chi_{\mathrm{bf}}$ promedio fue $12,6 \mathrm{kA} / \mathrm{m}$; el promedio en los niveles hidromórficos fue menor que en los materiales rojizos, en el paleosuelo se registraron los valores más bajos.

\subsection{Consideraciones de importancia}

El análisis de los parámetros magnéticos permitió determinar que la señal magnética de los sedimentos del Cenozoico tardío analizados corresponde a magnetita-titanomagnetita-maghemita. Esto es consistente con lo observado por otros autores en localidades loéssicas de la región pampeana, quienes propusieron que la composición magnética dominante corresponde principalmente a titanomagnetita, aunque próxima al extremo de la magnetita (Bidegain y Rico, 2004; Orgeira et al., 2008; Bartel, 2009; entre otros). Por otro lado, la presencia de maghemita fue propuesta por Bartel (2009) para los horizontes del solum de suelos en desarrollo sobre material loéssico de la provincia de la Pampa y sur de la provincia de Buenos Aires; esto vinculado principalmente a un descenso de los valores de la coercitividad de la remanencia $\left(\mathrm{H}_{\mathrm{cr}}\right)$ en los horizontes del solum y a un análisis de detalle de concentrados magnéticos mediante DRX; un patrón análogo, con disminución de los valores de $\mathrm{H}_{\mathrm{cr}}$ fue determinado en este trabajo en los suelos actuales y en los paleosuelos del sector serrano.

Los ciclos de histéresis mostraron un estrechamiento hacia el sector central de las curvas ("cintura de avispa") que puede estar ocasionado, entre otras razones, por una mezcla de minerales magnéticos con coercitividades marcadamente diferentes. En este sentido, la existencia de fases antiferromagnéticas (e.g. hematita), si bien no pudieron ser claramente identificadas mediante las técnicas magnéticas utilizadas, fueron inferidas a través de la combinación de las técnicas magnéticas con los análisis químicos y mineralógicos. El contenido de hierro total $\left(\mathrm{Fe}_{2} \mathrm{O}_{3}\right)$ presentó relativa homogeneidad, en contraposición los parámetros extensivos presentaron gran variabilidad; a juzgar por los valores relativamente bajos de estos últimos, así como los valores más bajos de Coef. $\mathrm{S}$ y los valores más elevados de coercitividad de la remanencia, correspondientes a los niveles hidromórficos (gley) de la asociación costera A5 y a los 
paleosuelos del sector costero, especialmente los de la asociación A4 y el paleosuelo S-EC1 de la sección PEC, se deduce que estos niveles (hidromórficos y paleosuelos del sector costero) presentan la mayor proporción de fases mineralógicas antiferromagnéticas. En cuanto al origen de los colores gley, que variaron entre distintos matices de amarillo, es posible vincularlo a la presencia de óxidos y oxihidróxidos de hierro (férrico), de comportamiento antiferromagnético y de coloraciones "ocres"; los mismos se presentarían dispersos en la masa del sedimento y/o recubriendo principalmente a los granos de cuarzo y plagioclasa.

Cabe destacar que los niveles con elevado contenido de $\mathrm{CaCO}_{3}$ que presentaron un incremento relativo de $\mathrm{Fe}_{2} \mathrm{O}_{3}$ no presentaron prácticamente diferencias en los parámetros magnéticos. No fue posible atribuir el incremento de $\mathrm{Fe}_{2} \mathrm{O}_{3}$ a la presencia de especies antiferromagnéticas, no obstante, a partir de los comportamientos observados, es posible que los minerales ricos en hierro que allí se concentraron, correspondan a especies paramagnéticas, del tipo lepidocrocita, akaganeita. Como se expresó anteriormente, la presencia de carbonato de calcio podría generar la floculación de estos óxidos de hierro en estado coloidal, haciendo que allí se concentren los óxidos que se movilizaban en suspensión a través de los poros del sedimento, e impidiendo su posterior movilización; esto se debería a que la presencia de $\mathrm{CaCO}_{3}$ genera valores de $\mathrm{pH}$ por encima de 7 , con valores cercanos al punto isoeléctrico de dichos óxidos (van Schuylenborgh y Arens, 1950; Martínez Gasca et al., 1982). No se descartan procesos como la fijación de hierro mediante microorganismo o bien la presencia de carbonatos de hierro.

El tamaño de grano magnético determinado según el diagrama de King et al. (1982) indicó tamaños inferiores a $1 \mu \mathrm{m}$, que serían coincidentes con minerales de dominio simple (DS); el diagrama de Thompson y Oldfield (1986) indicó tamaños de grano entre 4 y $16 \mu \mathrm{m}$, es decir dominios Pseudo Simple (DPS) y Multidominio (MD), no obstante este último gráfico se considera inadecuado cuando las muestras presentan partículas SP. Por otro lado, el diagrama de Dunlop (2002) indicó predominio de mezcla de partículas DS y superparamagnéticas (SP). Asimismo, cabe destacar que el diseño en "cintura de avispa" de las curvas de histéresis podría deberse también a una amplia distribución de tamaños de grano de un mismo mineral. En líneas generales, se podría establecer que el tamaño de grano magnético de los sedimentos estudiados sería dominantemente Dominio Simple y Dominio Pseudo Simple, con cantidades variables de partículas Superparamagnéticas y Multidominio. Cabe destacar que los tamaños de grano magnéticos determinados se corresponderían principalmente con las fracciones arcilla y limo muy fino. Sin embargo, en el análisis granulométrico (Capítulo 6) se registró un dominio de las fracciones limo grueso y arena muy fina $(31-125 \mu \mathrm{m})$, que si bien contienen granos magnéticos, estos no estarían aportando considerablemente a la señal magnética. 
En la Figura 9.21 (diagrama de King) fue posible observar que los tamaños de grano magnéticos más finos corresponden al sector de Sierras de Tandil y Balcarce; en tanto, los más gruesos al sector costero; este patrón es coincidente con la $\chi_{\mathrm{d} \% \text { } \%}$, cuyos valores más elevados corresponden al sector serrano y los más bajos al sector costero. Este comportamiento estaría vinculado, como se verá en el siguiente párrafo al desarrollo del suelo actual y a los paleosuelos.

En cuanto a los suelos y paleosuelos, fueron determinados dos patrones de comportamiento contrapuestos, vinculados principalmente a los valores de susceptibilidad. En los suelos actuales y la mayoría de los paleosuelos de la Formación Barker se registró un incremento de la señal magnética $\left(\chi_{\mathrm{bf}}\right)$ respecto del material parental; en cambio en los paleosuelos, tanto del perfil de Sierra Bachicha (S-SB1 y S-SB2) así como en los del sector costero, se registró un descenso de los valores.

Los suelos actuales muestreados se desarrollan modificando principalmente los sedimentos de la Formación Las Ánimas y su equivalente (A1) del sector costero. En éstos se observó que los parámetros extensivos (dominantemente $\chi_{\mathrm{bf}} \mathrm{y} \chi_{\mathrm{MRA}}$ ) incrementaron sus valores en el solum; el factor $\chi_{\mathrm{df} \%}$ registró también los valores más elevados en el solum, indicando una mayor contribución superparamagnética en dichos niveles; los valores de las relaciones interparamétricas $\chi_{\mathrm{MRA}} / \chi_{\mathrm{bf}} \mathrm{y} \chi_{\mathrm{MRA}} / \mathrm{MRIS}$, dependientes del tamaño de grano magnético, también registraron incrementos en el solum, esto se relacionaría con una mayor presencia de partículas DS. Por otro lado, se registró un descenso en el solum de los valores de $\mathrm{MIRS} / \chi_{\mathrm{bf}}$, esto podría relacionarse con la presencia de partículas de tamaños cercanos al límite SP-DS, éstas en virtud del descenso de los valores de $\mathrm{H}_{\text {cr }}$ podrían corresponder a maghemita (Avramov et al., 2006; Zhang et al., 2007; Torrent et al., 2006). En la mayoría de los paleosuelos de la Formación Barker el patrón de comportamiento fue similar al obtenido en el suelo actual; no obstante, en la Formación Barker el contraste entre los valores fue menor al determinado en los suelos actuales, esto se vincularía a tasas de depositación relativamente más bajas y a una mayor estabilidad climática, lo que habría permitido el desarrollo de suelos poligenéticos, compuestos y complejos. Esto es concordante con el estilo climático del intervalo temporal propuesto para la unidad (Plioceno) (ver Lisiecki and Raymo, 2005); ligado a esto cabe destacar que los valores medios de $\chi_{\mathrm{bf}} \mathrm{y}$ sobre todo $\chi_{\mathrm{MRA}}$ fueron los más elevados; sin embargo, MRIS presentó un valor medio levemente más bajo que el de la Formación Las Ánimas. Asimismo, $\chi_{\mathrm{df} \%}, \chi_{\mathrm{MRA}} / \chi_{\mathrm{bf}}$ y $\chi_{\mathrm{MRA}} / \mathrm{MRIS}$ presentaron valores medios más elevados que el resto de las unidades estudiadas y los valores de $\mathrm{H}_{\mathrm{cr}} \mathrm{y}$ MIRS/ $\chi_{\mathrm{bf}}$ fueron los más bajos, esto se vincula a una mayor contribución de partículas DS, SP y del límite DS-SP en la Formación Barker.

El fenómeno registrado se corresponde con el patrón de incremento de la susceptibilidad (“enhancement") y está ampliamente extendido en regiones loéssicas del mundo y fue ampliamente 
estudiado; la explicación más aceptada para este comportamiento es que el incremento de la señal se debe a la incorporación de partículas SP y DS de origen pedogenético (Maher, 1986; Evans y Heller, 1994). Sin embargo, los mecanismos que conllevan a la generación de magnetita fina y ultrafina son aún discutidos. La mayoría de los modelos coinciden en que en una etapa anterior a la neoformación partículas SP y DS se produciría mediante hidrólisis de los silicatos portadores de hierro (piroxenos, anfíboles, entre otros) la precipitación de óxi-hidróxidos de hierro de baja cristalinidad (e.g. ferrihidrita) (Cornell and Swertmann, 2003); que luego serían transformados en magnetita (o bien maghemita). Según Fisher (1988) la ferrihidrita puede ser fácilmente "reducida" en episodios anaeróbicos vinculados a la "respiración de la materia orgánica”, generando la precipitación de magnetita (Tamaura et al., 1983; Maher, 1998). Por otro lado Lovley et al. (1987) propusieron que el mecanismo estaría vinculado a acción bacterial (Magnetobacterium) en condiciones anaeróbicas, generando los denominados magnetozomas (trenes de magnetita ultrafina). Los mecanismos anteriores indican que condiciones anaeróbicas son necesarias, sin embargo Torrent et al. (2006) indicaron que no es necesaria la existencia de un ambiente reductor y que el mineral ferrimagnético producido sería maghemita, la cual antecede a la formación de hematita; los autores proponen las siguientes transformaciones: ferrihidrita $\rightarrow$ maghemita SP $\rightarrow$ maghemita DS $\rightarrow$ hematita. No obstante, en todos los casos se requiere que haya ciclos de humedecimiento-secado

Los paleosuelos desarrollados en la unidad U-SB3/4 del sector Sierras de Balcarce, así como en el sector costero, a diferencia de los anteriores, presentaron una disminución de los valores de susceptibilidad, y generalmente del resto de los parámetros extensivos (MRIS, $\chi_{\text {MRA }}$ ), respecto al material parental, así como un incremento en los valores de $\chi_{\mathrm{MRA}} / \chi_{\mathrm{bf}} \mathrm{y} \chi_{\mathrm{MRA}} / \mathrm{MRIS}$ y un descenso en los valores de MIRS $\chi_{\text {bf }}$; que puede estar indicando una mayor contribución de partículas DS y del límite DS-SP en los paleosuelos. La mayoría de los suelos que presentaron este tipo de comportamiento presentaron un

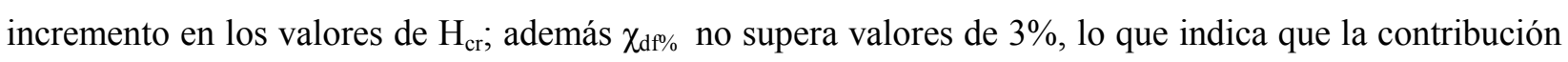
de partículas SP es baja. Algunos paleosuelos en los que se determinó un descenso de $\chi_{b f}$ presentaron comportamientos de $\mathrm{H}_{\mathrm{cr}} \mathrm{y} \chi_{\mathrm{dr} \%}$ diferentes; el paleosuelo del tope de unidad litoestratigráfica S-SB3/4 (S$\mathrm{SB} 1$; Sierra Bachicha), presentó valores de $\mathrm{H}_{\mathrm{cr}}$ más bajos que el material parental y registró un incremento considerable de $\chi_{\mathrm{df} \%}$ alcanzando un valor de 7,1\%; el paleosuelo S-GA2 de la A5 (GADA) no presentó prácticamente variación de $\mathrm{H}_{\mathrm{cr}} \mathrm{y}$ la $\chi_{\mathrm{d} \mathrm{f} \%}$ se incrementó superando un valor de $5 \%$. La disminución, pérdida o agotamiento del valor de susceptibilidad magnética en los suelos y paleosuelos es lo que conocemos como "depleción" o del inglés depletion. El fenómeno ha sido estudiado e interpretado en la región pampeana por distintos investigadores del paleomagnetismo. Bidegain et al. (2005a, 2007) y Nabel et al. (2000) relacionaron la ciclicidad de los valores a la alternancia de períodos más secos, glaciales (valores altos) y más húmedos, interglaciales (valores bajos). Orgeira y Compagnucci $(2006,2010)$ y Orgeira et al. 
(2011), en sus trabajos de suelos actuales lo relacionaron con el PWS (potencial de almacenamiento de agua en los suelos) o bien W (razón de humedad), y compararon distintos comportamientos de la región pampeana con datos de otras regiones loéssicas del mundo.

La variación de los valores de susceptibilidad respecto a la pedogénesis, se relacionaría al tiempo de permanencia del agua en el suelo; esto se vincula a la clase natural de drenaje (condicionada principalmente por la topografía y a la permeabilidad del material) y a las condiciones climáticas. En suelos con prolongada permanencia del agua, es decir con tendencia a las condiciones hidromórficas y con períodos anaeróbicos relativamente prolongados, se generarían procesos que conducen a la destrucción de la magnetita litogenética, mediante la oxidación, generalmente este proceso sería incompleto, resultando en una disminución del tamaño de la misma. Si bien la magnetita ha sido tradicionalmente considerada un resistato, en tanto más resistente a los procesos de meteorización, los registros de susceptibilidad en el par loess/paleosuelo, según los datos de los investigadores citados, demuestran que tal comportamiento de dicho mineral no explica la variación de la señal. Más aún, trabajos realizados en la región de La Plata por Bidegain y Rico (2004), indicaron claramente que los niveles con magnetita alterada (hidromórficos) presentan los valores más bajos de susceptibilidad, en tanto, los niveles con "buenos" cristales (octahédricos) de magnetita, sin rasgos pedogenéticos, presentan los valores más elevados.

Un aspecto a destacar corresponde al comportamiento de los parámetros magnéticos en los paleosuelos de la unidad litoetratigráfica U-SB3/4 (especialmente S-SB1) y el de la asociación A5 (SGA2), los cuales presentaron un comportamiento ambiguo, con descenso de la susceptibilidad pero con incremento del $\chi_{\mathrm{d} p \%}$ y disminución de la $\mathrm{H}_{\mathrm{cr}}$. Es posible explicar esto a través de una combinación de los dos patrones de comportamiento. En una primera etapa estos suelos se habrían desarrollado bajo condiciones de mayor humedad y permanencia de agua en el suelo, que habría generado la oxidación, "disolución" y consecuente reducción del tamaño de grano de la (titano)magnetita litogenética; posteriormente los suelos habrían continuado su desarrollo bajo condiciones de más sequedad, generándose la neoformación de partículas de maghemita (y/o magnetita) fina y ultrafina.

Cabe destacar, además que el contenido de $\mathrm{Fe}_{2} \mathrm{O}_{3}$ en los horizontes $\mathrm{Bt}$, tanto de suelos actuales como de paleosuelos, se incrementó en todos los casos respecto del material original, así como respecto al horizonte A en suelos actuales. El análisis de este fenómeno, teniendo en cuenta los parámetros magnéticos, permite esbozar algunas hipótesis. Se infiere que la iluviación de hierro es un proceso factible; se estima que el mismo se incorporaría a los horizontes iluviales conformando, según los casos, minerales diferentes. Una posibilidad podría deberse a que algunos minerales de arcilla presentan hierro en su composición, no obstante esto no explica la variación en el comportamiento de los parámetros magnéticos. En los suelos donde se da el patrón de incremento de la susceptibilidad magnética, la 
acumulación de hierro consistiría en especies ferrimagnéticas (magnetita y/o maghemita) y probablemente paramagnéticas (e.g. lepidocrocita). En cambio, donde se da el patrón de descenso de la susceptibilidad, con incremento de la coercitividad de la remanencia, la acumulación correspondería a óxidos y oxihidróxidos de hierro antiferromagnéticos y probablemente paramagnéticos.

Un aspecto interesante, es la comparación entre las variaciones de la susceptibilidad magnética con los valores de intensidad remanente de las muestras paleomagnéticas del capítulo 8. Cuando se da el patrón de incremento, los valores de intensidad magnética remanente $\left(\mathrm{J}^{\mathrm{o}}\right.$ y $\left.\mathrm{J}^{20}\right)$ de las muestras paleomagnéticas evidenciaron una mayor independencia respecto a los valores de susceptibilidad. En contraposición, en los perfiles donde se dio el patrón de depleción, la variación de la intensidad magnética (especialmente $\mathrm{J}^{20}$ ) fue similar a la de la susceptibilidad. Se deduce que la neoformación de magnetita (o bien maghemita) pedogenética, sin destrucción de la titano(magnetita) litogenética (portadora de la remanencia), no afectan considerablemente los valores de intensidad remanente. En cambio, mediante la oxidación de la (titano)magnétita litogenética se produciría un proceso de "desmagnetización química", que conduciría a la merma de la intensidad. 


\subsection{Figuras del Capítulo 9.}

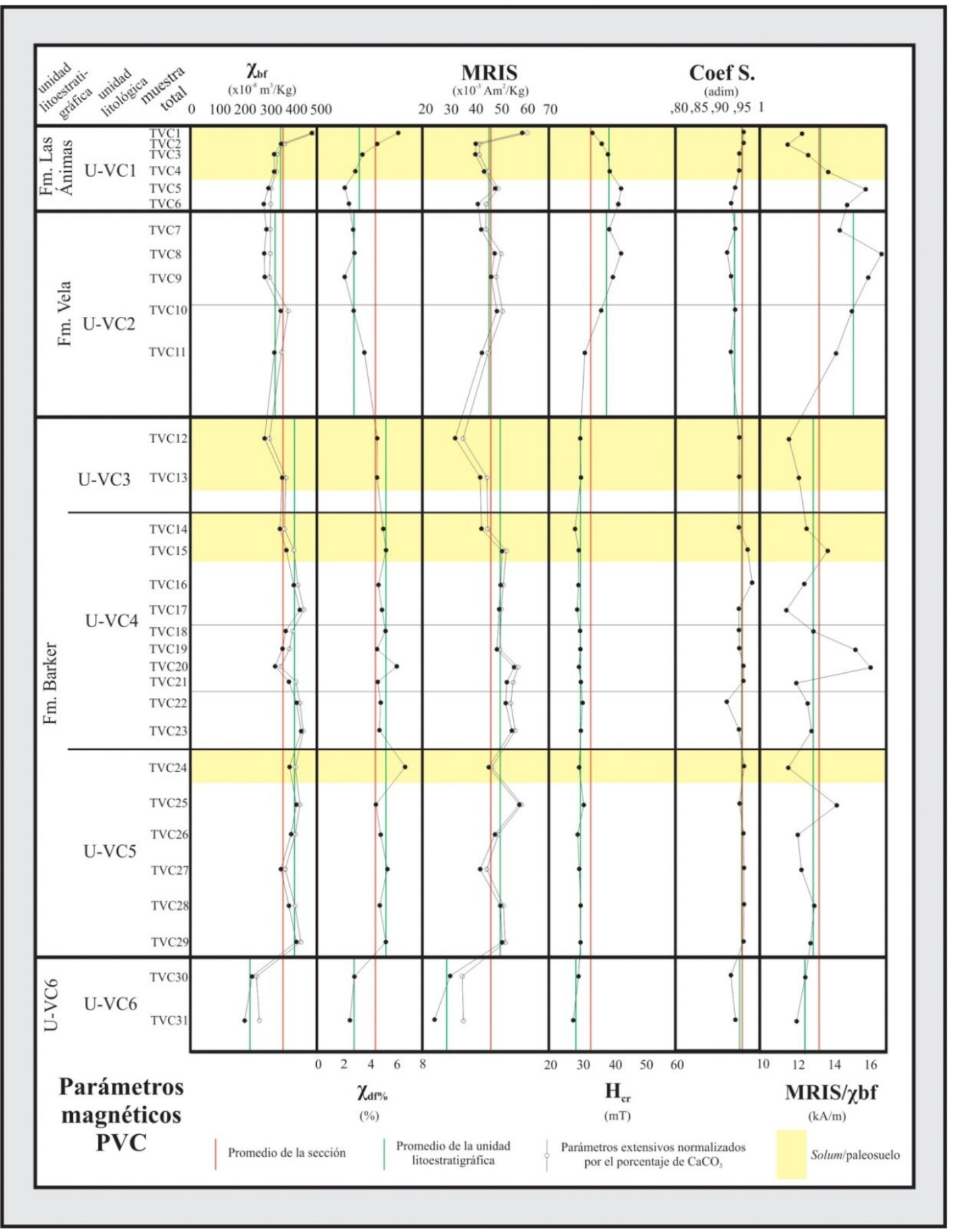

Figura 9.1. Parámetros magnéticos de la sección de Villa Cacique (PVC). Susceptibilidad magnética $\left(\chi_{\mathrm{bf}}\right)$, factor susceptibilidad dependiente de la frecuencia $\left(\chi_{\mathrm{d} \mathrm{d} \%}\right)$, magnetización remanente de saturación (MRIS), coercitividad de la remanencia $\left(\mathrm{H}_{\mathrm{cr}}\right)$, Coef. $\mathrm{S}\left(-\mathrm{MRI}_{-300} / \mathrm{MRIS}\right)$ y $\mathrm{MRIS} / \chi_{\mathrm{bf}}$. 


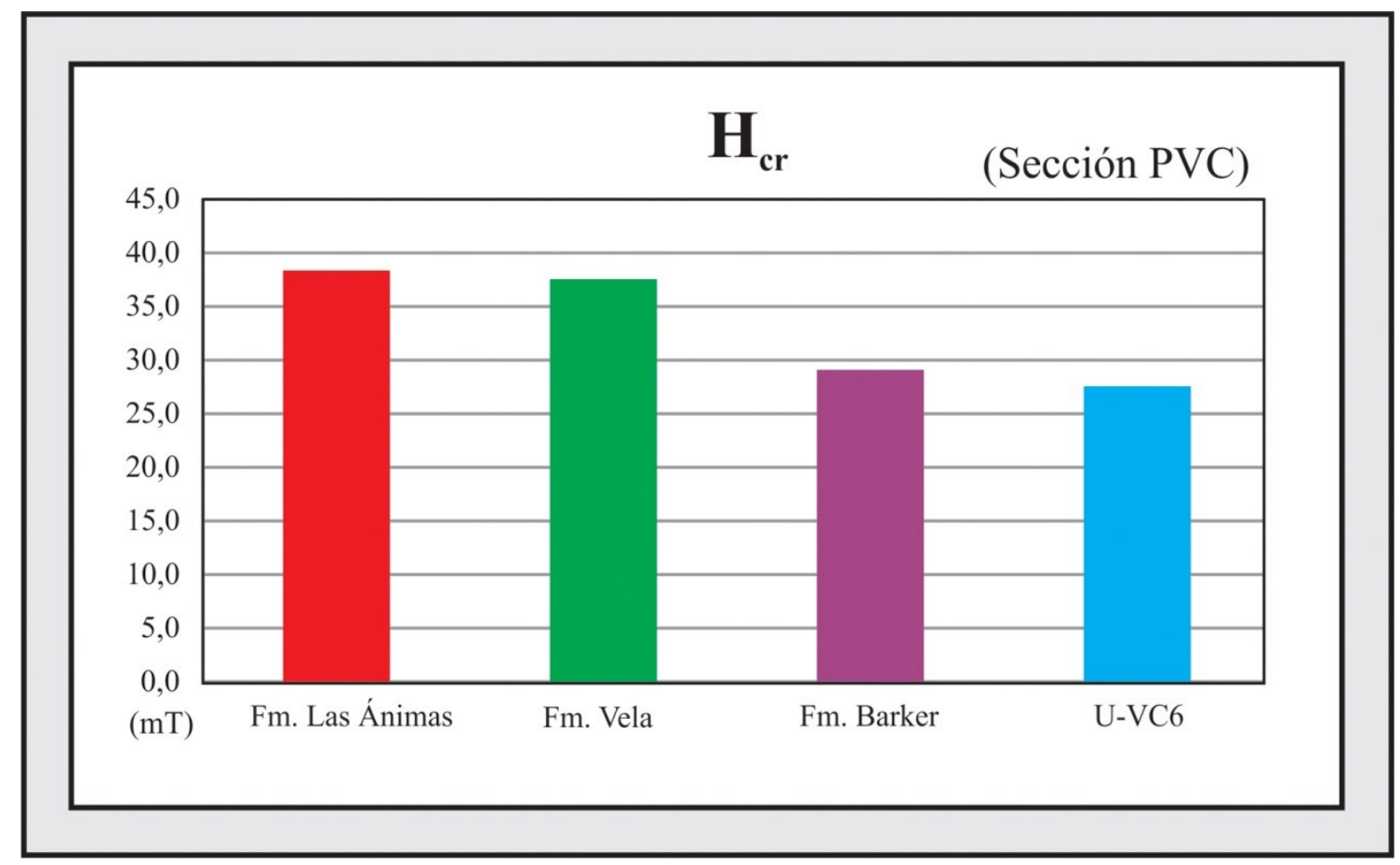

Figura 9.2. Valores de coercitividad de la remanencia $\left(\mathrm{H}_{\mathrm{cr}}\right)$ de las unidades litoestratigráficas de la sección PVC. 


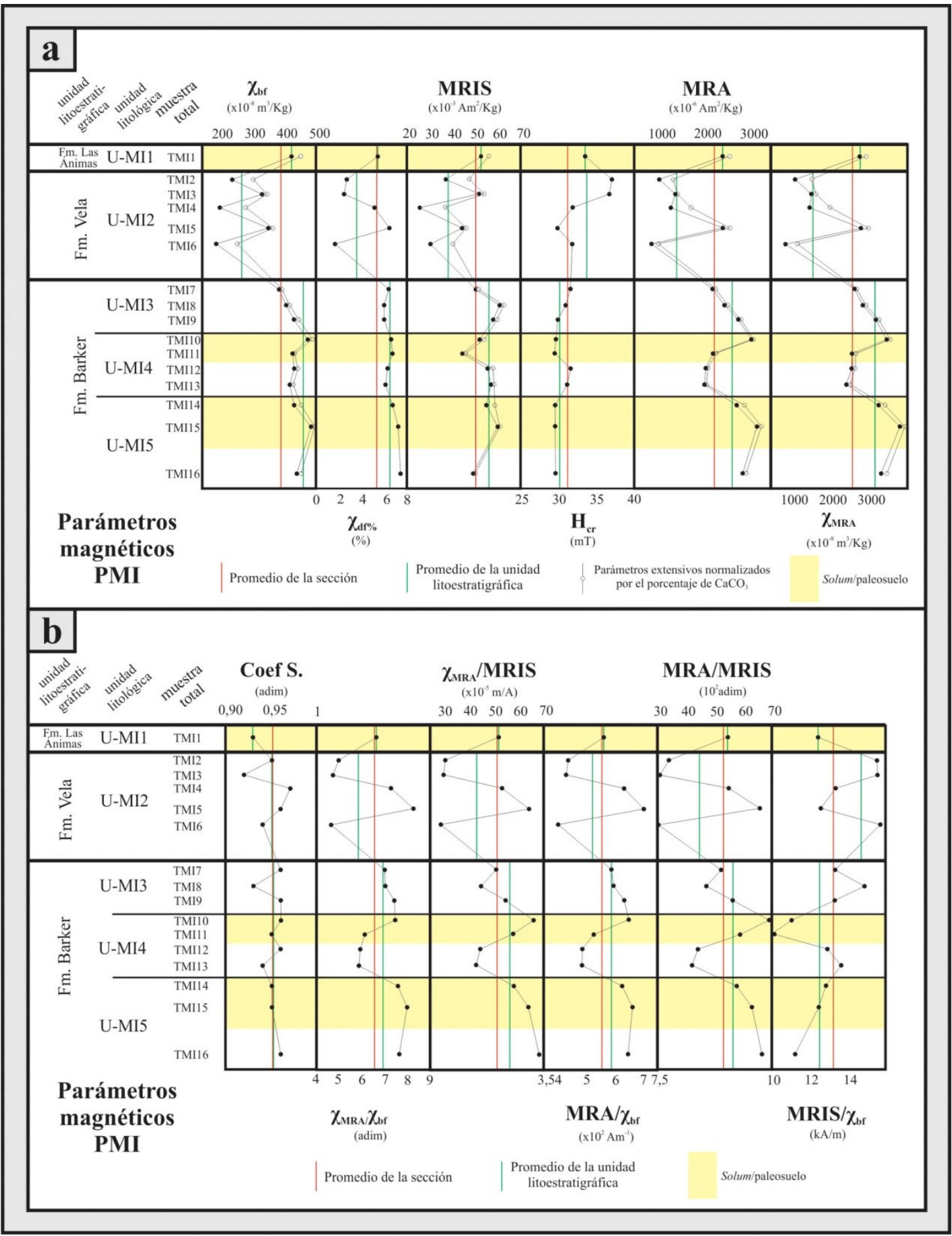

Figura 9.3. Parámetros magnéticos de la sección de María Ignacia (PMI). a) Susceptibilidad magnética $\left(\chi_{\mathrm{bf}}\right)$, factor susceptibilidad magnética dependiente de la frecuencia porcentual $\left(\chi_{\mathrm{df} \%}\right)$, magnetización remanente de saturación (MRIS), coercitividad de la remanencia $\left(\mathrm{H}_{\mathrm{cr}}\right)$, magnetización remanente anhistérica (MRA) y susceptibilidad anhistérica $\left(\chi_{\text {MRA }}\right)$. b) Coef. S (-MRI-300/MRIS) y las relaciones interparamétricas $\chi_{\mathrm{MRA}} / \chi_{\mathrm{bf}}, \chi_{\mathrm{MRA}} / \mathrm{MRIS}, \mathrm{MRA} / \chi_{\mathrm{bf}}, \mathrm{MRA} / \mathrm{MRIS}$ y MRIS$/ \chi_{\mathrm{bf}}$. 


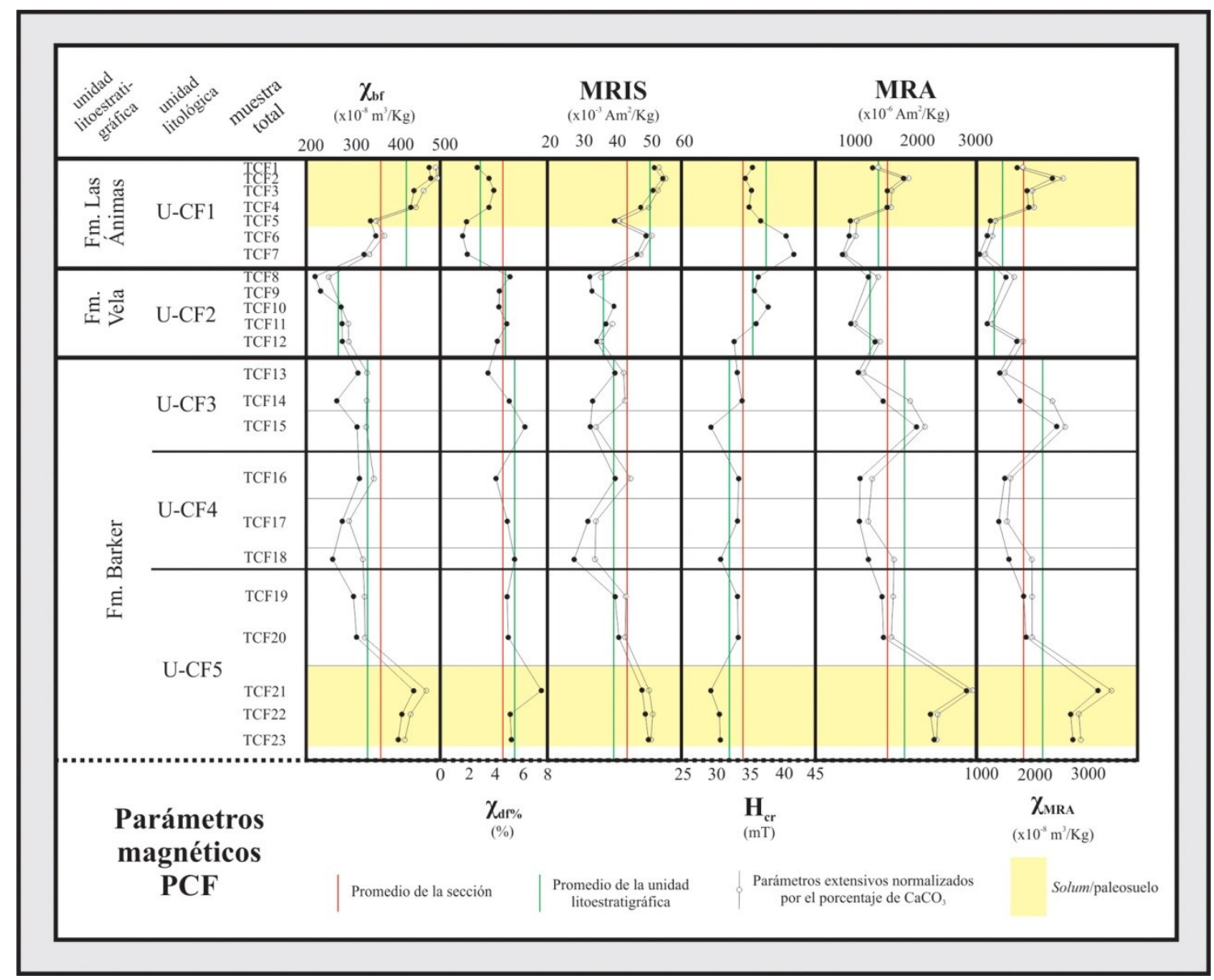

Figura 9.4. Parámetros magnéticos de la sección Calle Fangio (PCF). Susceptibilidad magnética $\left(\chi_{\mathrm{bf}}\right)$, factor susceptibilidad magnética dependiente de la frecuencia porcentual $\left(\chi_{\mathrm{dp} \%}\right)$, magnetización remanente de saturación (MRIS), coercitividad de la remanencia $\left(\mathrm{H}_{\mathrm{cr}}\right)$, magnetización remanente anhistérica (MRA) y susceptibilidad anhistérica $\left(\chi_{\text {MRA }}\right)$. 


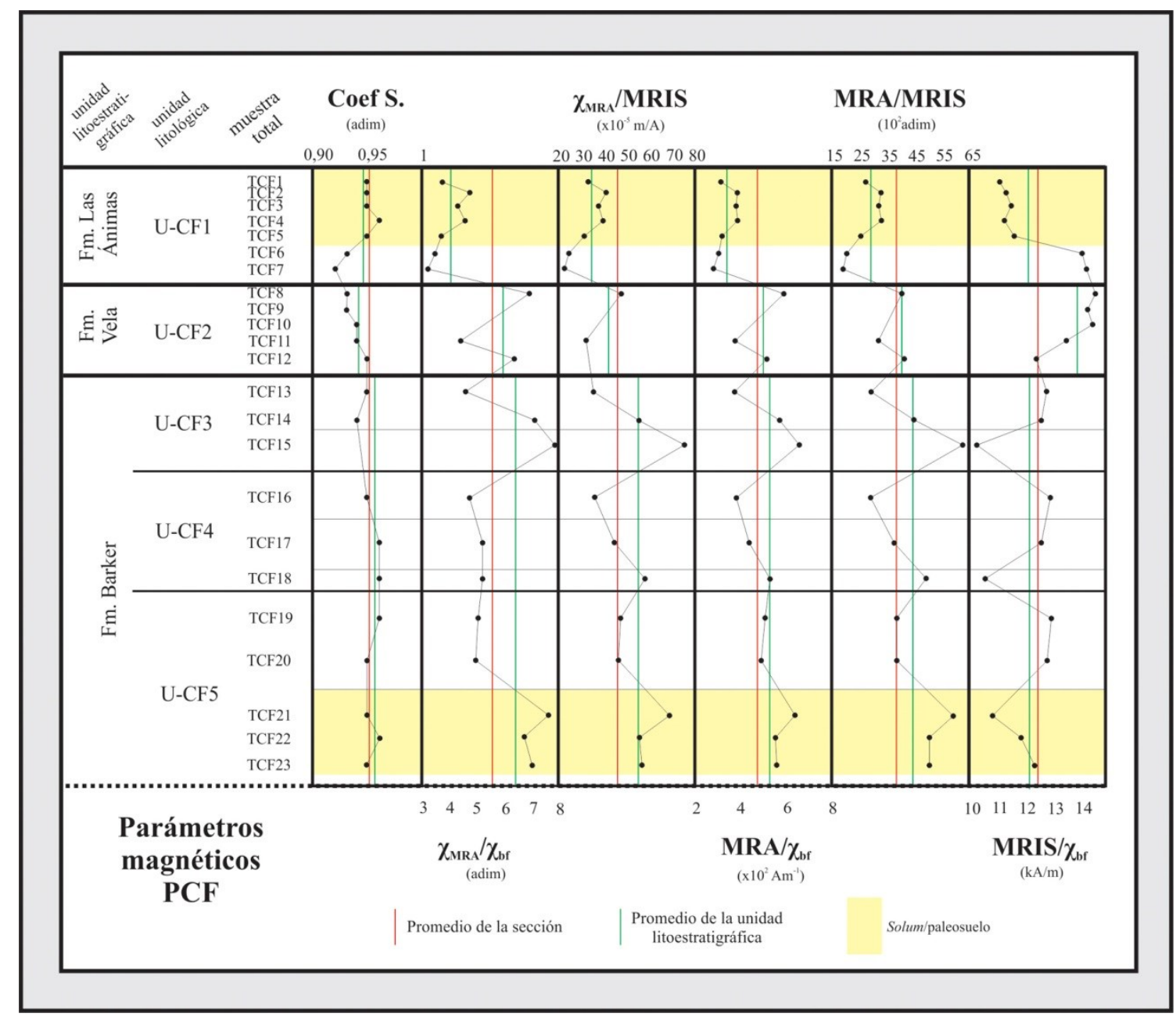

Figura 9.5. Parámetros magnéticos de la sección Calle Fangio (PCF). Coef. S (-MRI-300/MRIS) y las relaciones interparamétricas $\chi_{\mathrm{MRA}} / \chi_{\mathrm{bf}}, \chi_{\mathrm{MRA}} / \mathrm{MRIS}, \mathrm{MRA} / \chi_{\mathrm{bf}}, \mathrm{MRA} / \mathrm{MRIS}$ y MRIS $/ \chi_{\mathrm{bf}}$. 


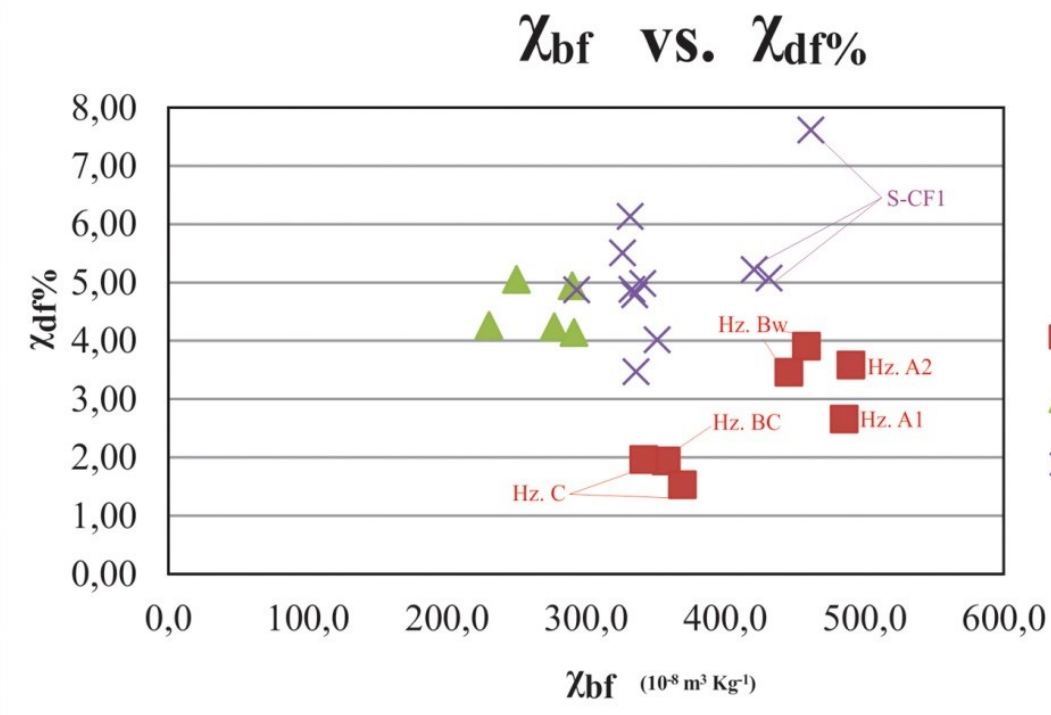

\section{Sección PCF}

Fm. Las Ánimas

$\triangle$ Fm. Vela

$\times$ Fm. Barker

Figura 9.6. Gráfico $\chi_{\mathrm{bf}}$ vs. $\chi_{\mathrm{df} \%}$ de las muestras totales de la sección PCF.

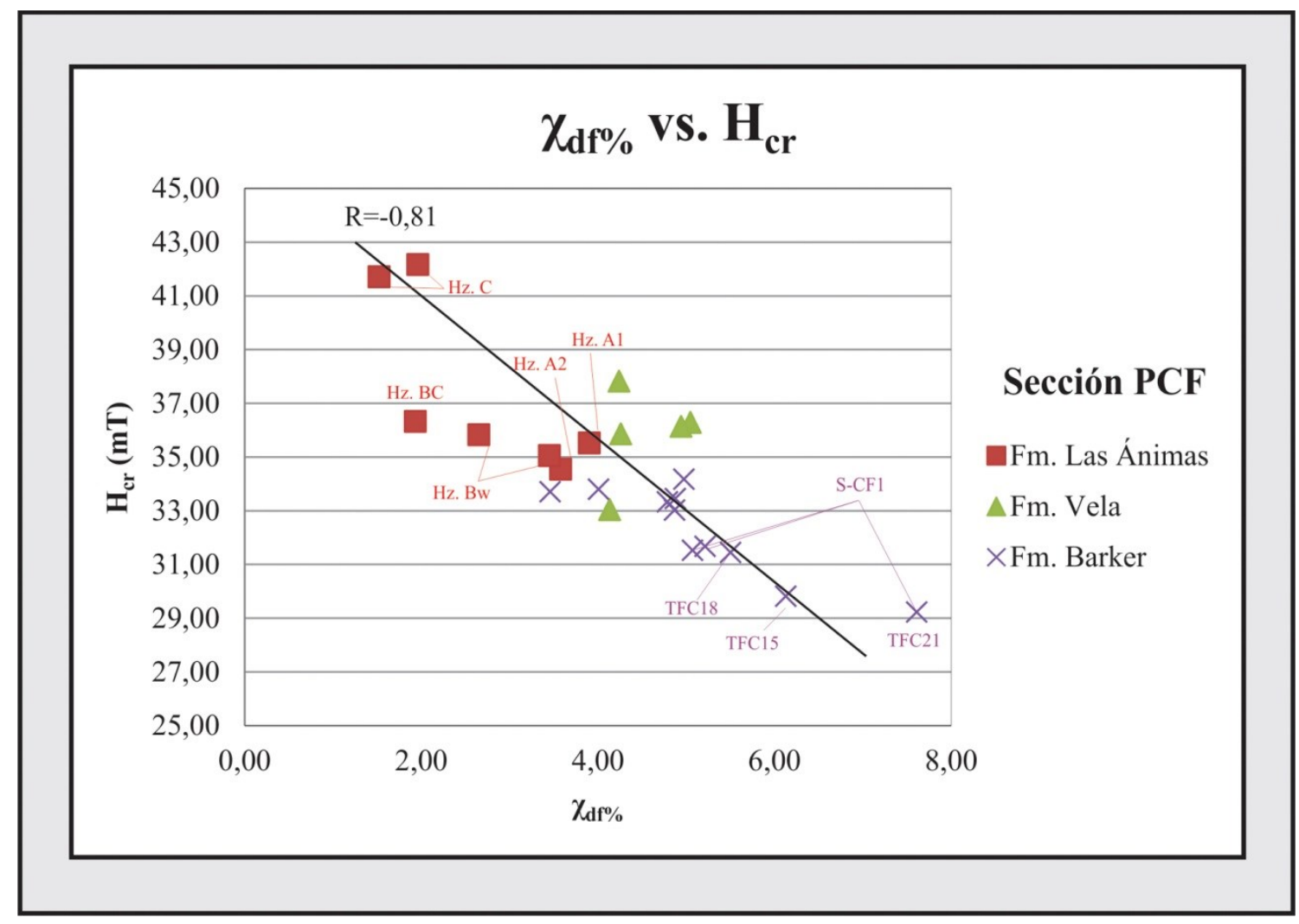

Figura 9.7. Gráfico $\chi_{\mathrm{df} \%} \mathrm{vs} . \mathrm{H}_{\mathrm{cr}}$ de las muestras totales de la sección PCF. 


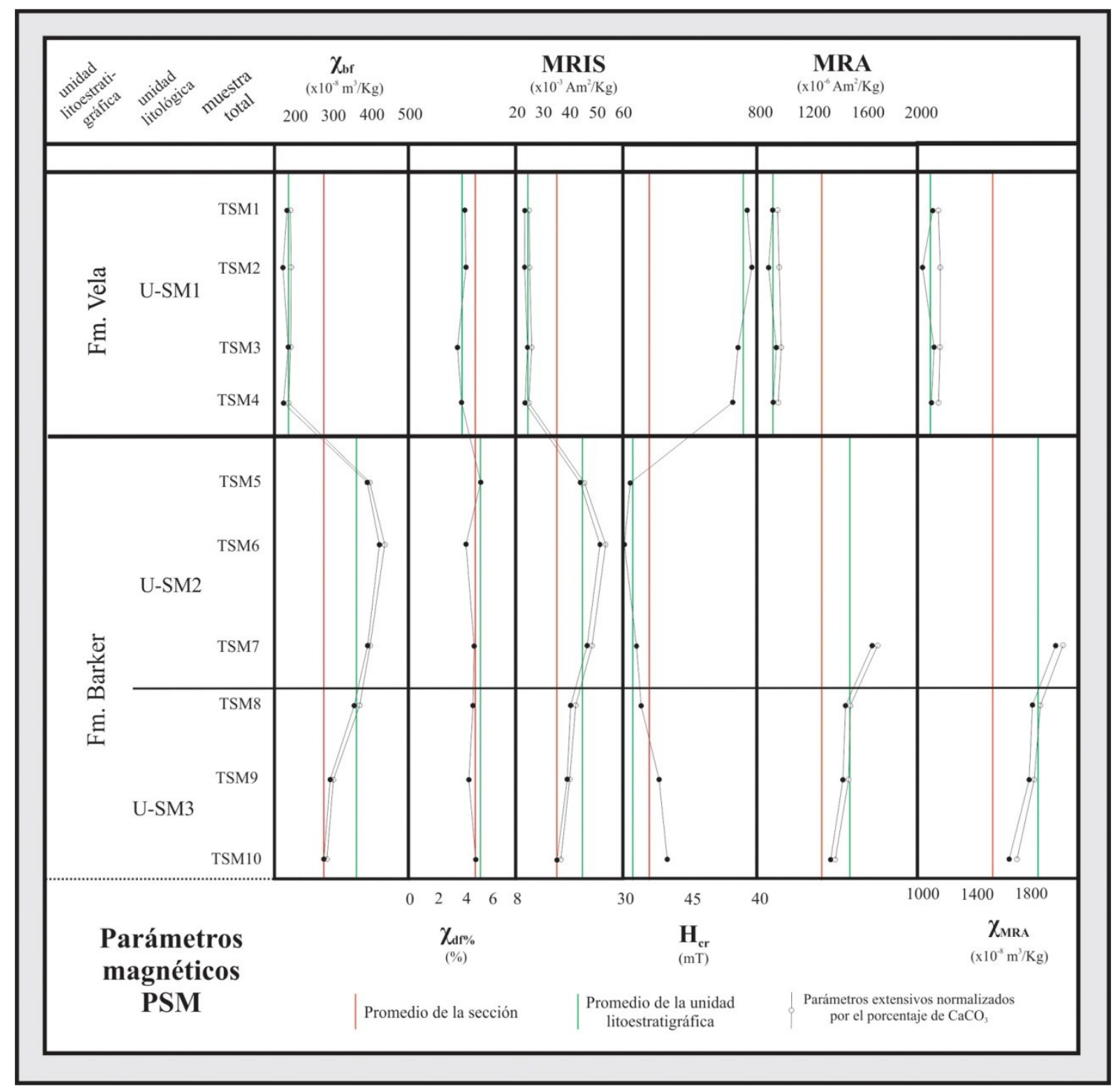

Figura 9.8. Parámetros magnéticos de la sección San Manuel (PSM). Susceptibilidad magnética $\left(\chi_{\mathrm{bf}}\right)$, factor susceptibilidad magnética dependiente de la frecuencia porcentual $\left(\chi_{\mathrm{d} \%}\right)$, magnetización remanente de saturación (MRIS), coercitividad de la remanencia $\left(\mathrm{H}_{\mathrm{cr}}\right)$, magnetización remanente anhistérica (MRA) y susceptibilidad anhistérica $\left(\chi_{\text {MRA }}\right)$. 


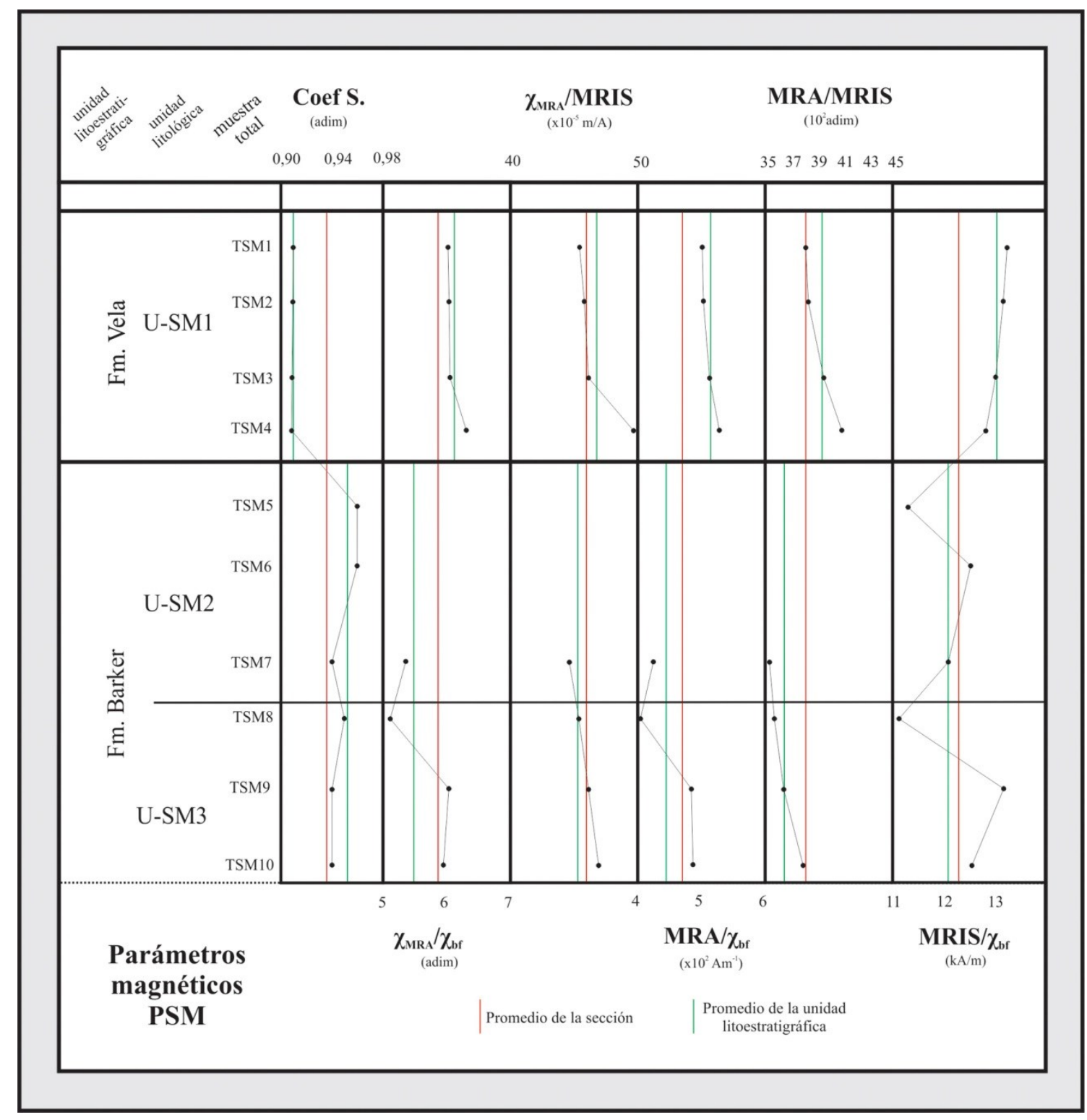

Figura 9.9. Parámetros magnéticos de la sección San Manuel (PSM). Coef. S (-MRI $300 / \mathrm{MRIS})$ y las relaciones interparamétricas $\chi_{\mathrm{MRA}} / \chi_{\mathrm{bf}}, \chi_{\mathrm{MRA}} / \mathrm{MRIS}, \mathrm{MRA} / \chi_{\mathrm{bf}}, \mathrm{MRA} / \mathrm{MRIS}$ y MRIS$/ \chi_{\mathrm{bf}}$. 


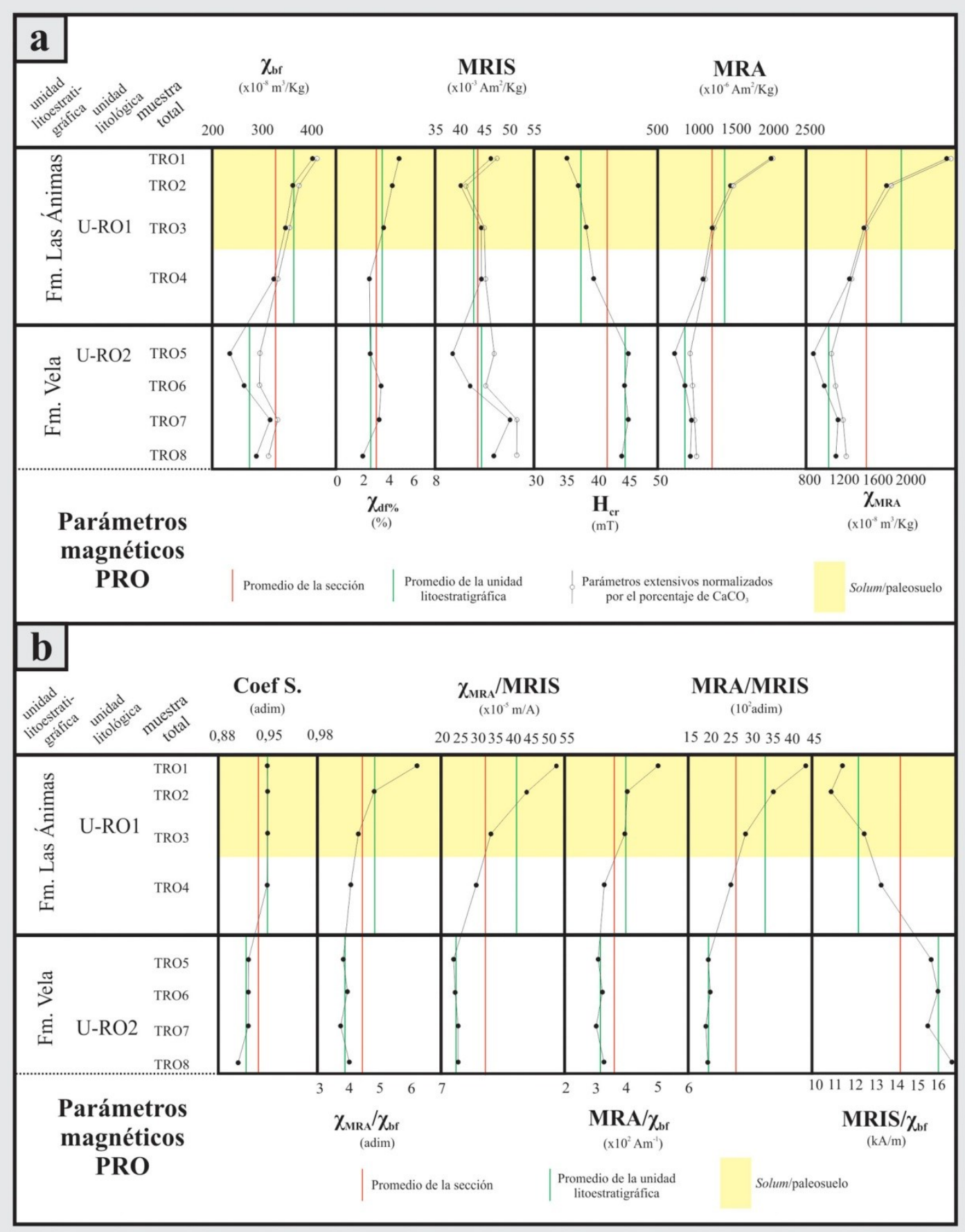

Figura 9.10. Parámetros magnéticos de la sección de Ramos Otero (PRO). a) Susceptibilidad magnética $\left(\chi_{\mathrm{bf}}\right)$, factor susceptibilidad magnética dependiente de la frecuencia porcentual $\left(\chi_{\mathrm{d} \%}\right)$, magnetización remanente de saturación (MRIS), coercitividad de la remanencia $\left(\mathrm{H}_{\mathrm{cr}}\right)$, magnetización remanente anhistérica (MRA) y susceptibilidad anhistérica $\left(\chi_{\text {MRA }}\right)$. b) Coef. S (-MRI $-300 /$ MRIS) y las relaciones interparamétricas $\chi_{\mathrm{MRA}} / \chi_{\mathrm{bf}}, \chi_{\mathrm{MRA}} / \mathrm{MRIS}, \mathrm{MRA} / \chi_{\mathrm{bf}}, \mathrm{MRA} / \mathrm{MRIS}$ y MRIS $/ \chi_{\mathrm{bf}}$. 


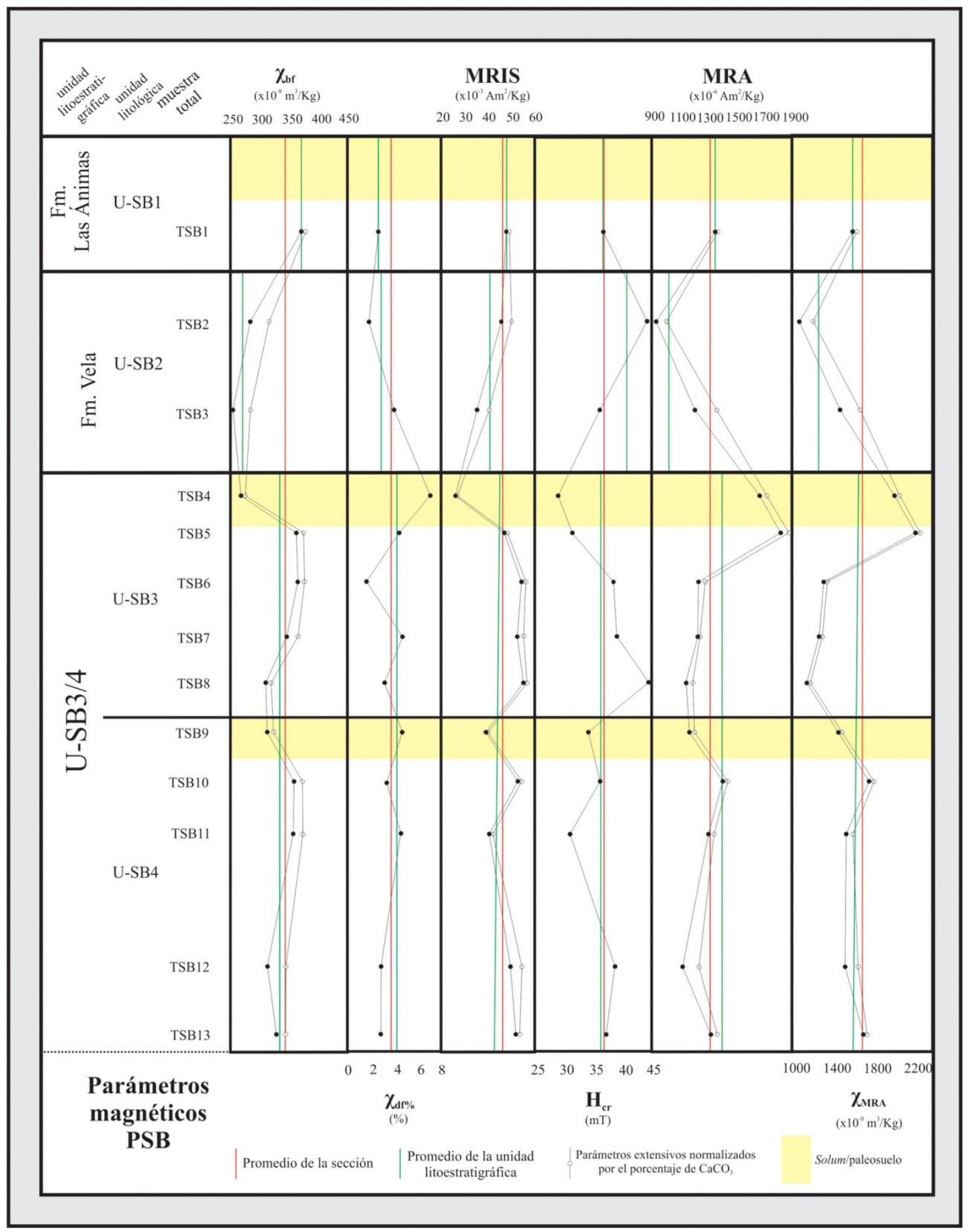

Figura 9.11. Parámetros magnéticos de la sección de Sierra Bachicha (PSB). Susceptibilidad magnética $\left(\chi_{\mathrm{bf}}\right)$, factor susceptibilidad magnética dependiente de la frecuencia porcentual $\left(\chi_{\mathrm{dr} \%}\right)$, magnetización remanente de saturación (MRIS), coercitividad de la remanencia $\left(\mathrm{H}_{\mathrm{cr}}\right)$, magnetización remanente anhistérica (MRA) y susceptibilidad anhistérica $\left(\chi_{\text {MRA }}\right)$. 


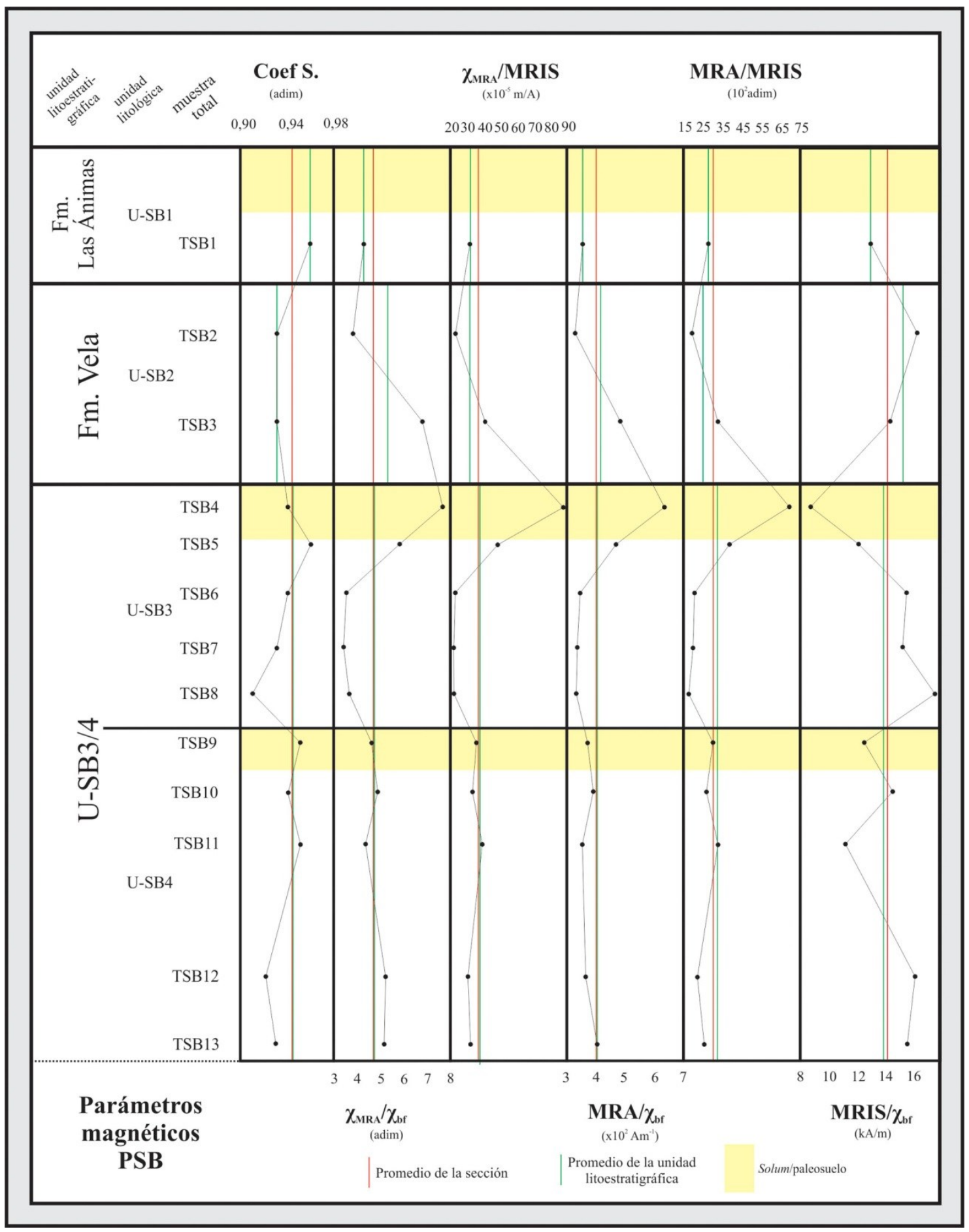

Figura 9.12. Parámetros magnéticos de la sección de Sierra Bachicha (PSB). Coef. S (-MRI $-300 / \mathrm{MRIS})$ y las relaciones interparamétricas $\chi_{\mathrm{MRA}} \chi_{\mathrm{bf}}, \chi_{\mathrm{MRA}} / \mathrm{MRIS}, \mathrm{MRA} / \chi_{\mathrm{bf}}, \mathrm{MRA} / \mathrm{MRIS}$ y MRIS$/ \chi_{\mathrm{bf}}$. 


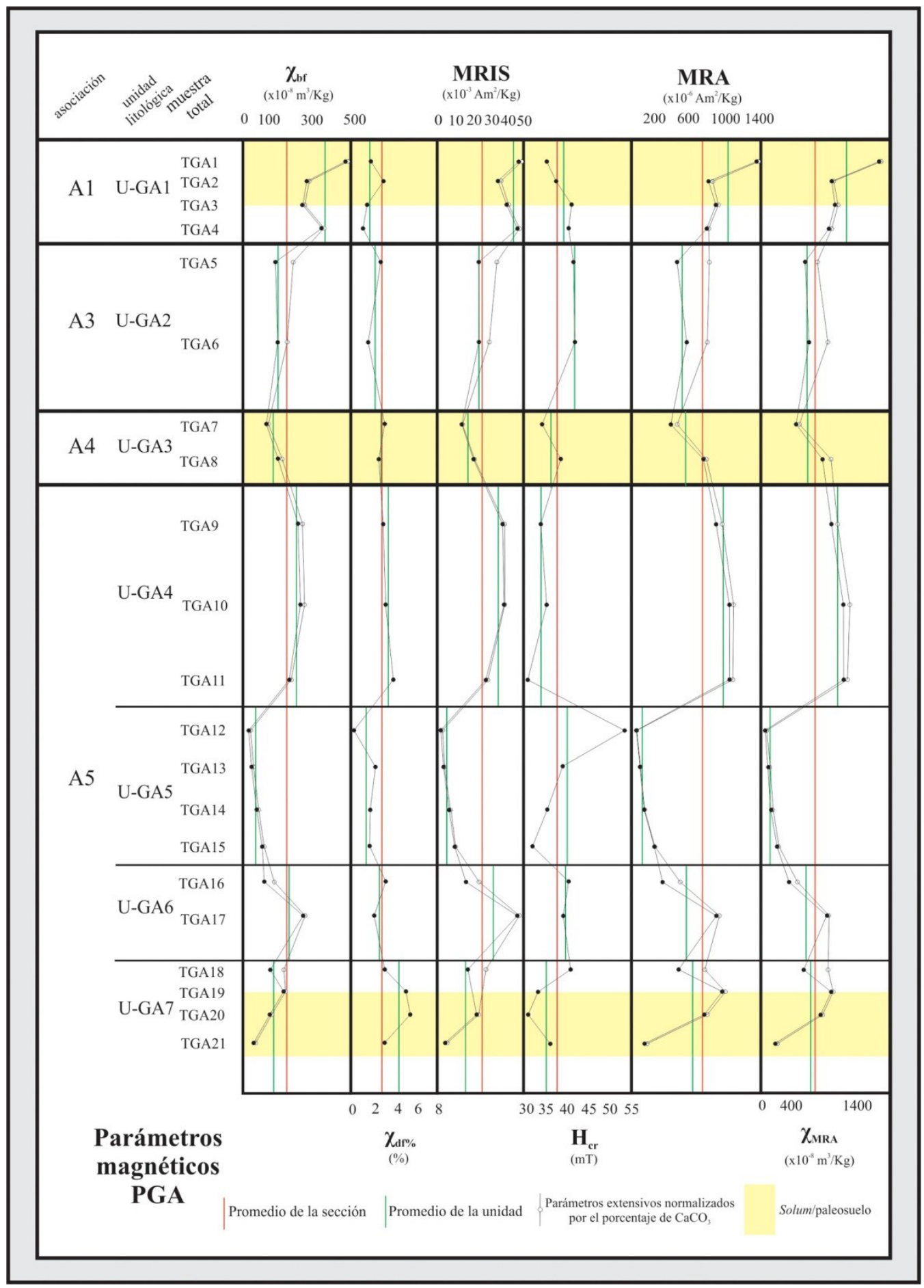

Figura 9.13. Parámetros magnéticos de la sección GADA (PGA). Susceptibilidad magnética $\left(\chi_{\mathrm{bf}}\right)$, factor susceptibilidad magnética dependiente de la frecuencia porcentual $\left(\chi_{\mathrm{d} \mathrm{f} \%}\right)$, magnetización remanente de saturación (MRIS), coercitividad de la remanencia $\left(\mathrm{H}_{\mathrm{cr}}\right)$, magnetización remanente anhistérica (MRA) y susceptibilidad anhistérica $\left(\chi_{\mathrm{MRA}}\right)$. 


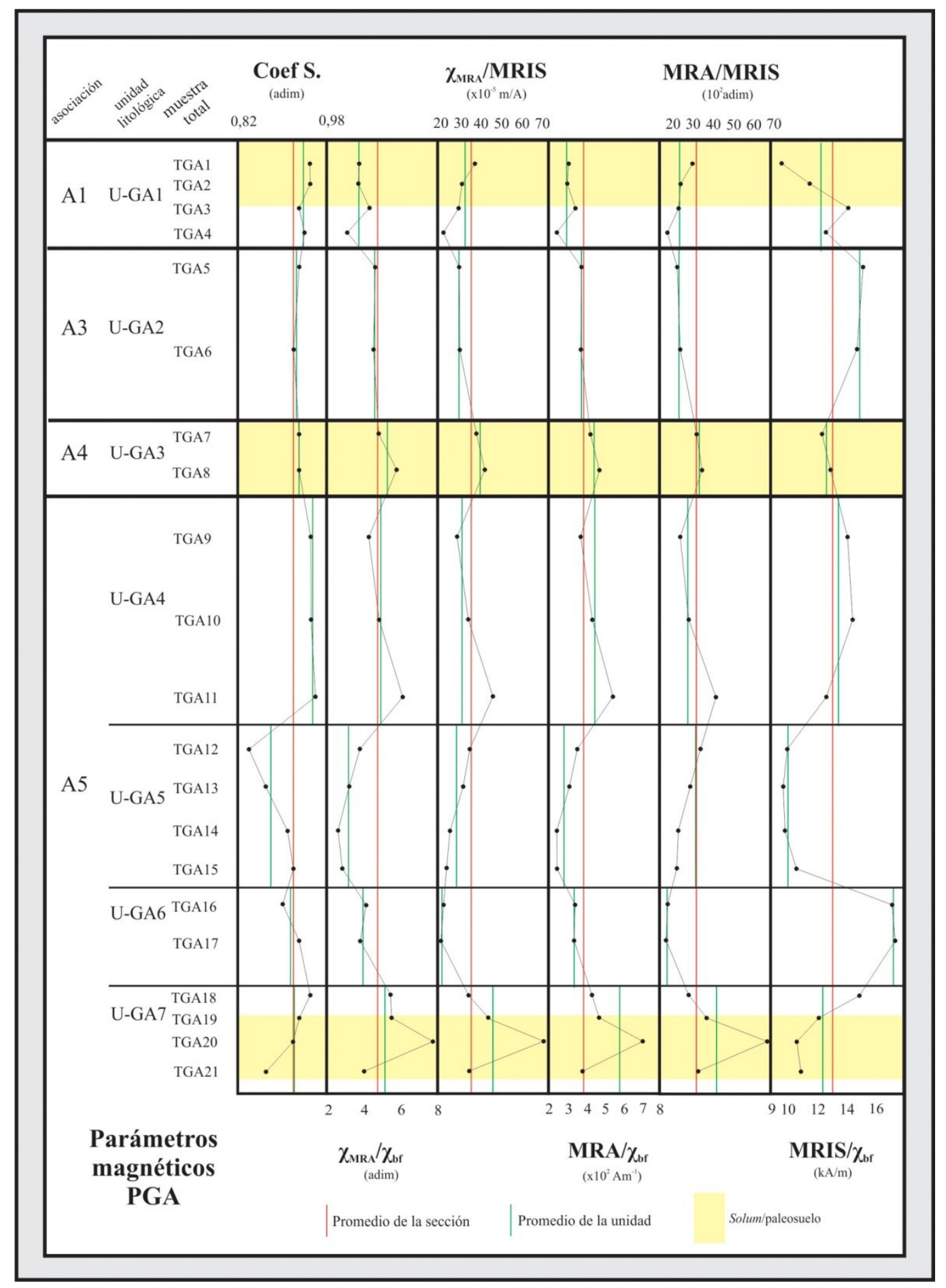

Figura 9.14. Parámetros magnéticos de la sección GADA (PGA). Coef. S (-MRI $\left.\mathrm{M}_{-30} / \mathrm{MRIS}\right)$ y las relaciones interparamétricas $\chi_{\mathrm{MRA}} / \chi_{\mathrm{bf}}, \chi_{\mathrm{MRA}} / \mathrm{MRIS}, \mathrm{MRA} / \chi_{\mathrm{bf}}, \mathrm{MRA} / \mathrm{MRIS}$ y MRIS$/ \chi_{\mathrm{bf}}$. 


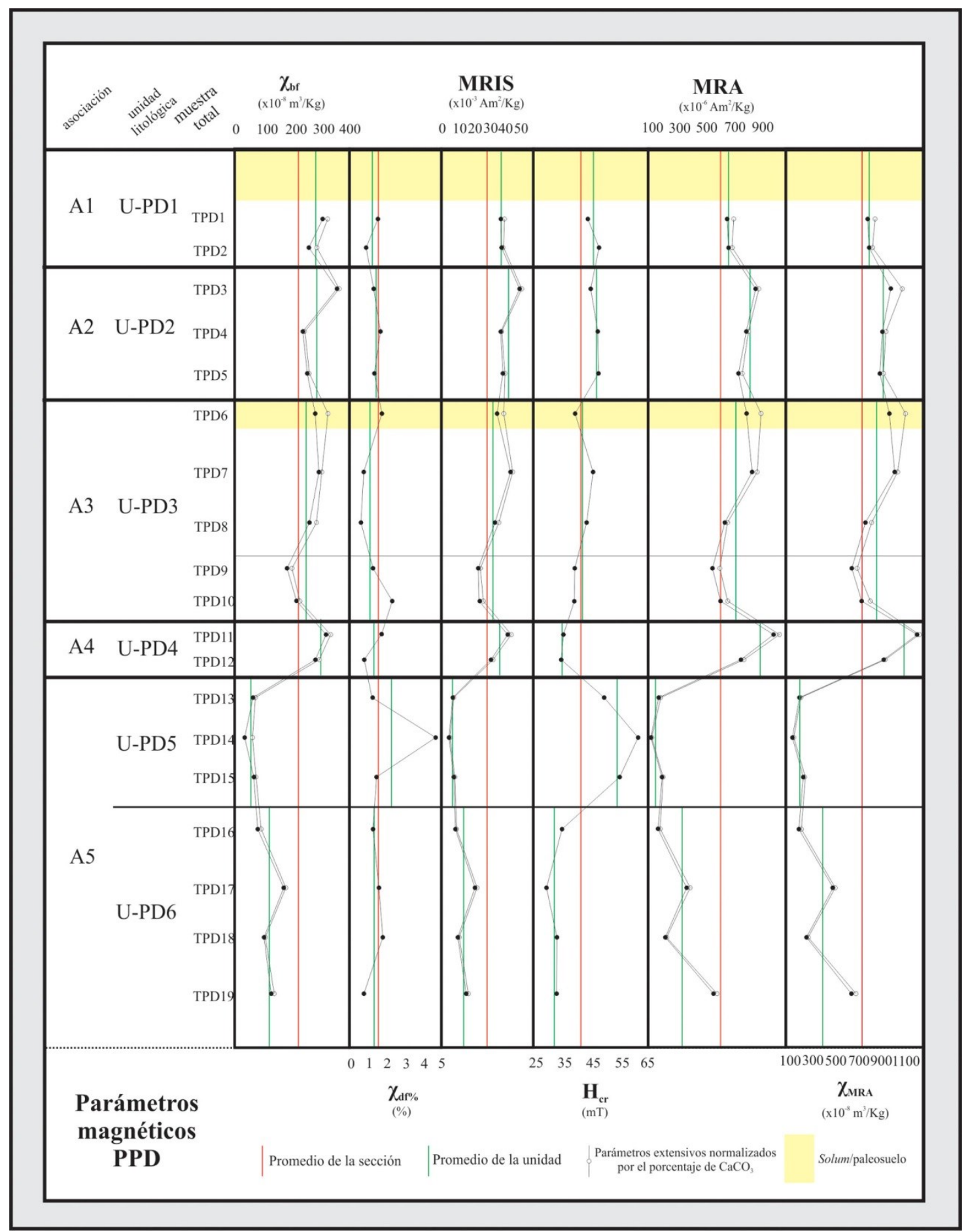

Figura 9.15. Parámetros magnéticos de la sección Playa Dorada (PPD). Susceptibilidad magnética $\left(\chi_{\mathrm{bf}}\right)$, factor susceptibilidad magnética dependiente de la frecuencia porcentual $\left(\chi_{\mathrm{df} \%}\right)$, magnetización remanente de saturación (MRIS), coercitividad de la remanencia $\left(\mathrm{H}_{\mathrm{cr}}\right)$, magnetización remanente anhistérica (MRA) y susceptibilidad anhistérica $\left(\chi_{\text {MRA }}\right)$. 


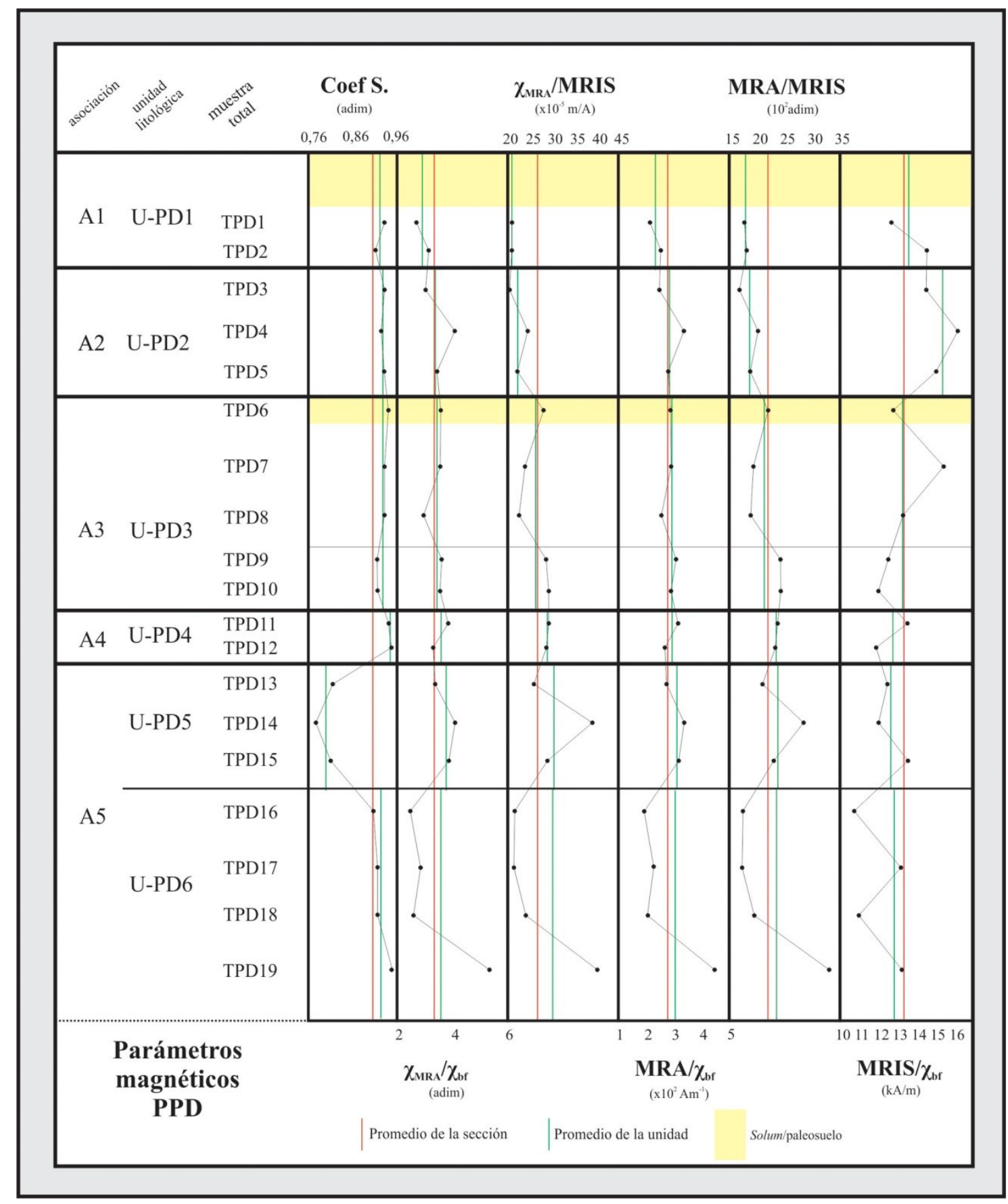

Figura 9.16. Parámetros magnéticos de la sección Playa Dorada (PPD). Coef. S (-MRI-300/MRIS) y las relaciones interparamétricas $\chi_{\mathrm{MRA}} / \chi_{\mathrm{bf}}, \chi_{\mathrm{MRA}} / \mathrm{MRIS}, \mathrm{MRA} / \chi_{\mathrm{bf}}, \mathrm{MRA} / \mathrm{MRIS}$ y MRIS $/ \chi_{\mathrm{bf}}$. 


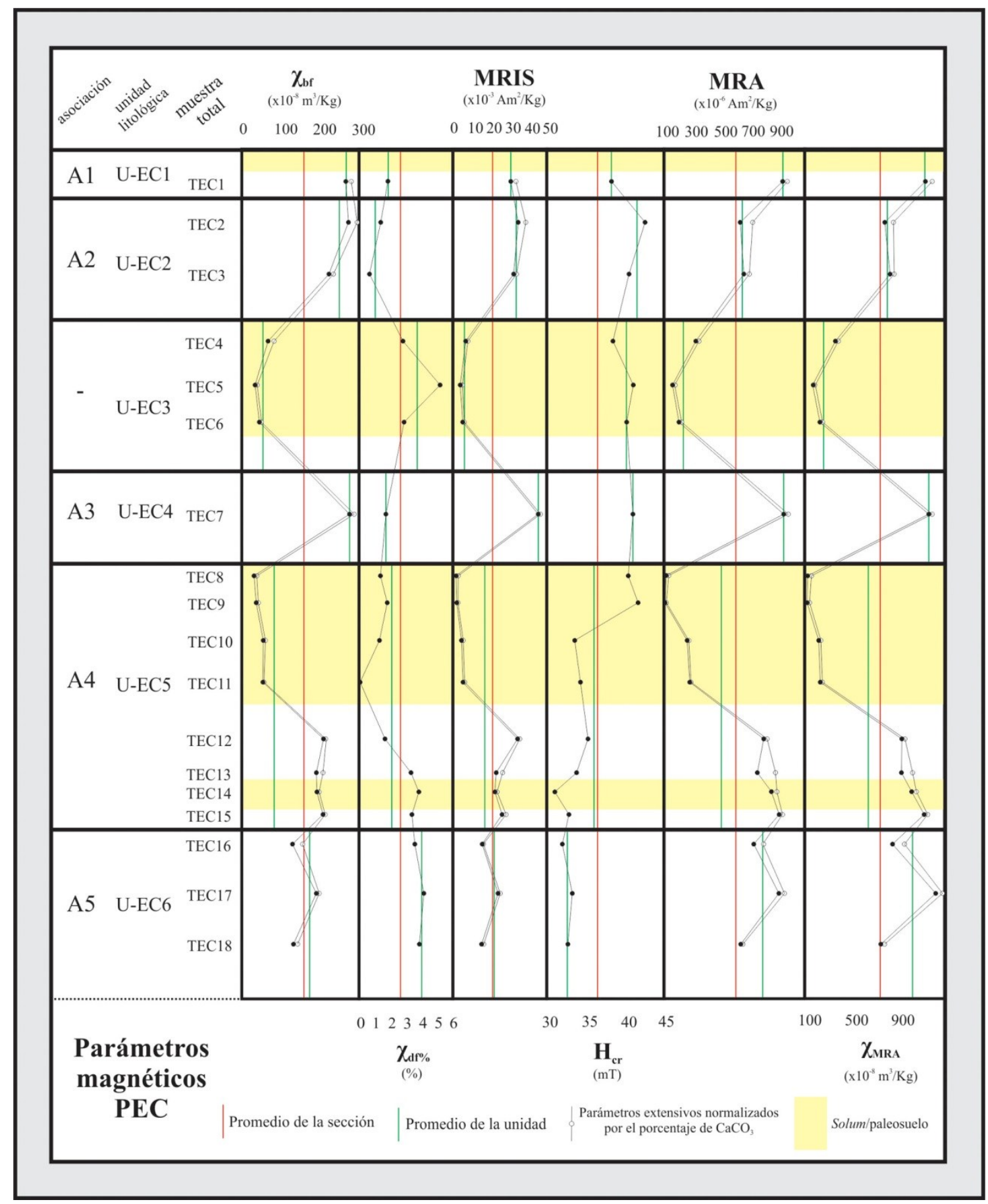

Figura 9.17. Parámetros magnéticos de la sección El Casal (PEC). Susceptibilidad magnética $\left(\chi_{\mathrm{bf}}\right)$, factor susceptibilidad magnética dependiente de la frecuencia porcentual $\left(\chi_{\mathrm{df} \%}\right)$, magnetización remanente de saturación (MRIS), coercitividad de la remanencia $\left(\mathrm{H}_{\mathrm{cr}}\right)$, magnetización remanente anhistérica (MRA) y susceptibilidad anhistérica $\left(\chi_{\mathrm{MRA}}\right)$. 


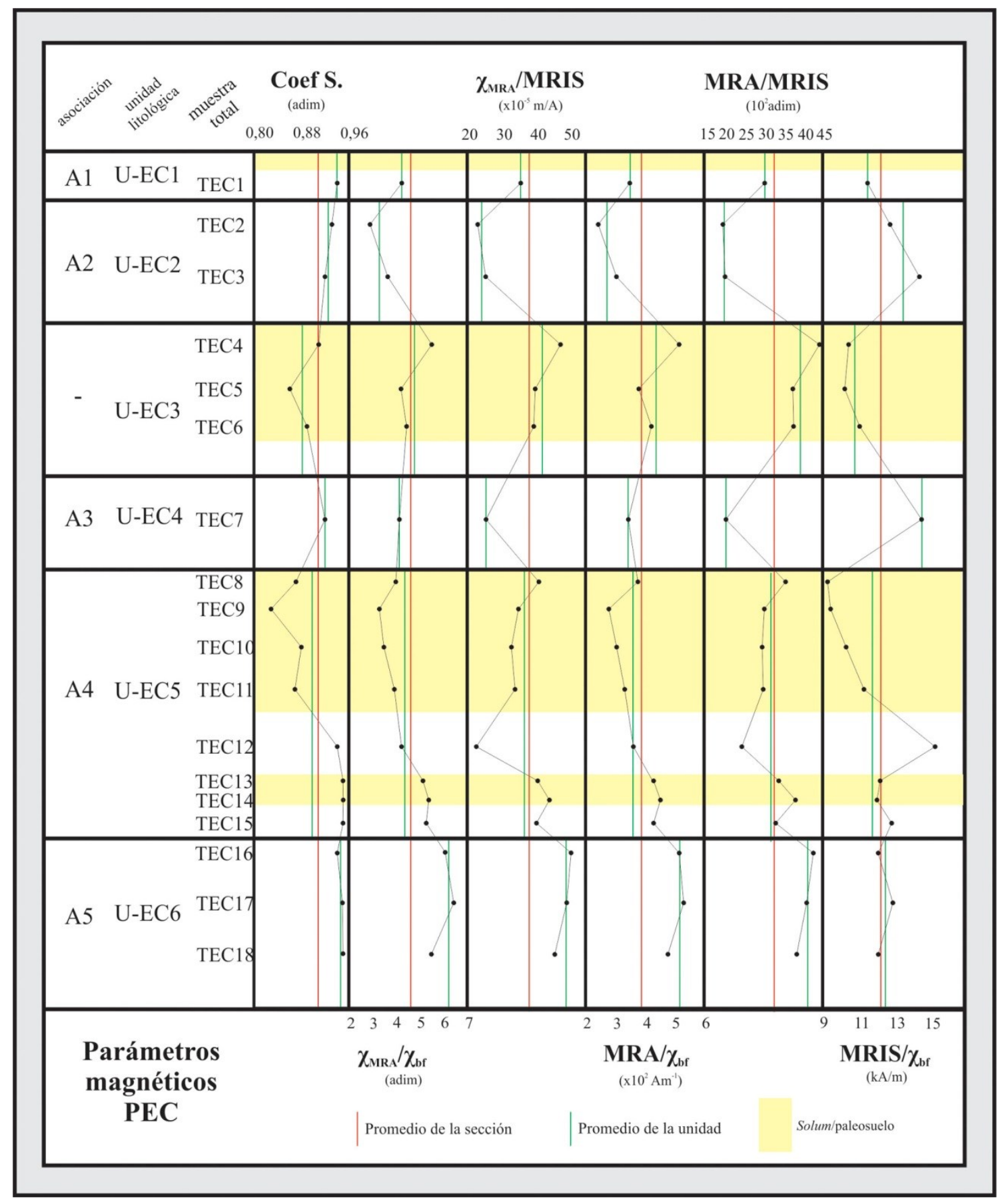

Figura 9.18. Parámetros magnéticos de la sección El Casal (PEC). Coef. S (-MRI-300/MRIS) y las relaciones interparamétricas $\chi_{\mathrm{MRA}} / \chi_{\mathrm{bf}}, \chi_{\mathrm{MRA}} / \mathrm{MRIS}, \mathrm{MRA} / \chi_{\mathrm{bf}}, \mathrm{MRA} / \mathrm{MRIS}$ y MRIS $/ \chi_{\mathrm{bf}}$. 

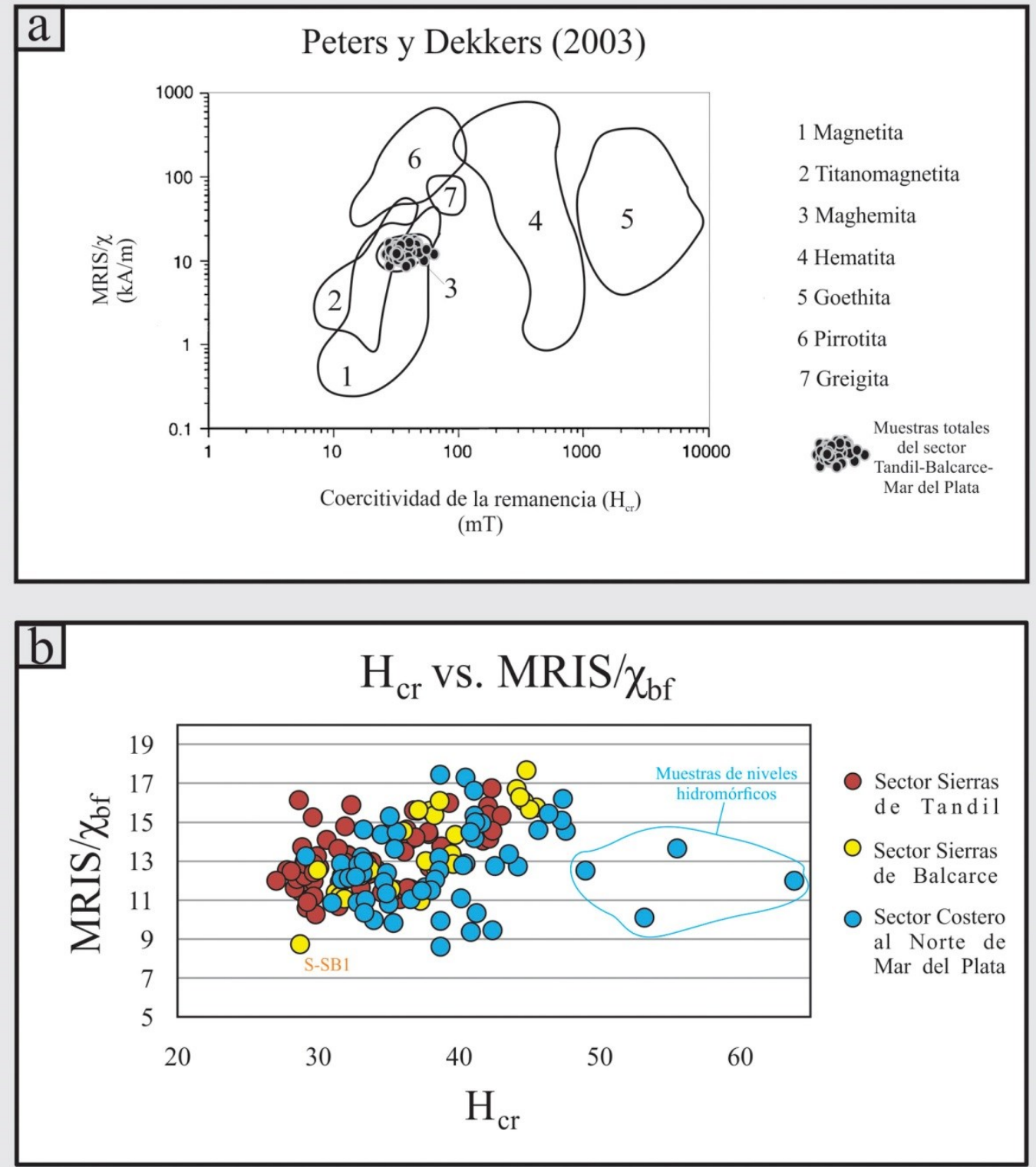

Figura 9.19. Diagramas $H_{c r}$ Vs. SIRM/ $\chi_{b f}$ a) Mineralogía magnética dominante según Peter y Dekkers (2003); b) Detalle del diagrama $\mathrm{H}_{\mathrm{cr}}$ Vs. SIRM $/ \chi_{\mathrm{bf}}$ 


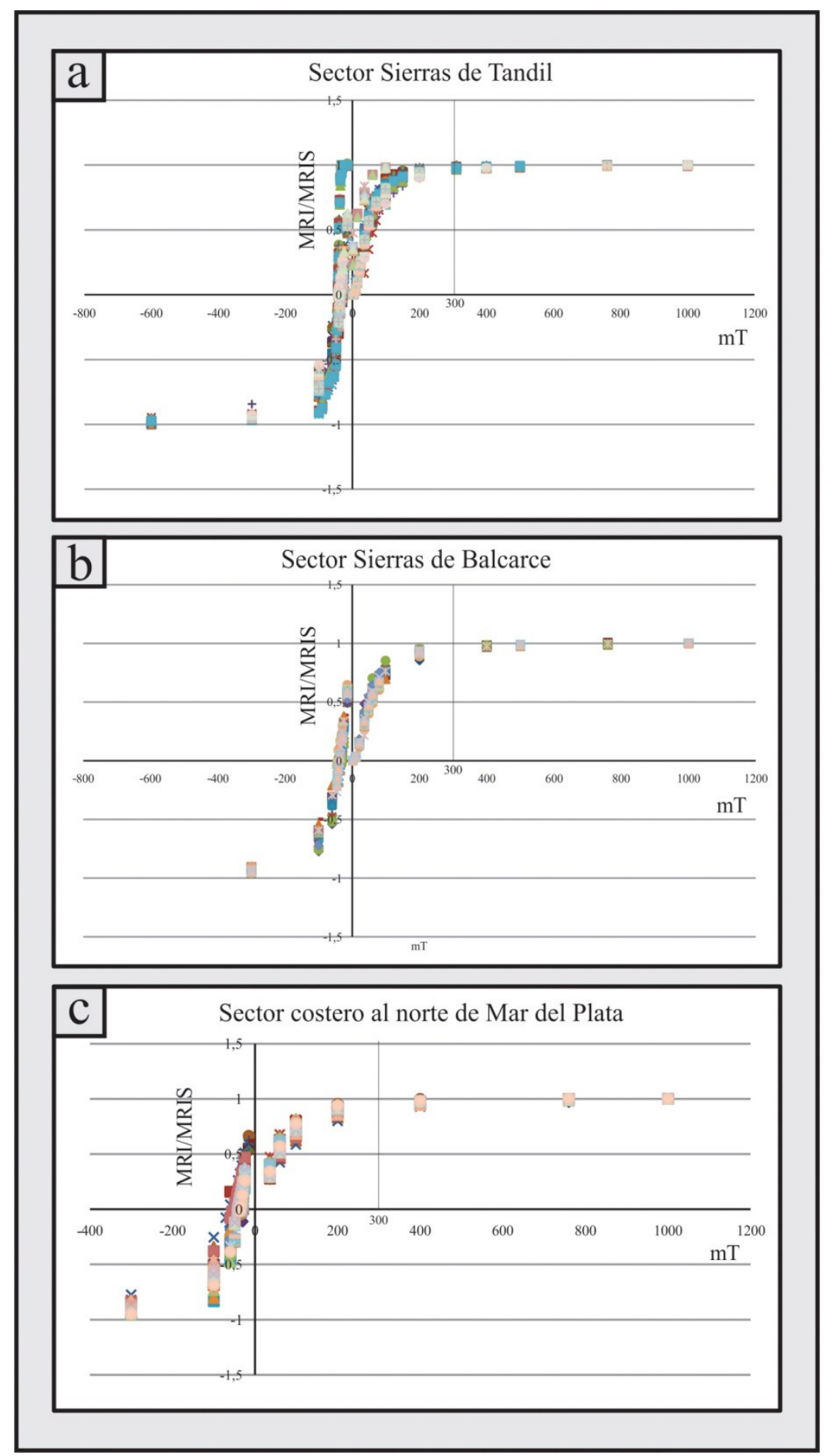

Figura 9.20. Curvas de adquisición de la Magnetización Remanente Isotermal y Back Field. a) sector Sierras de Tandil; b) sector Sierras de Balcarce; c) sector costero al norte de Mar del Plata. 


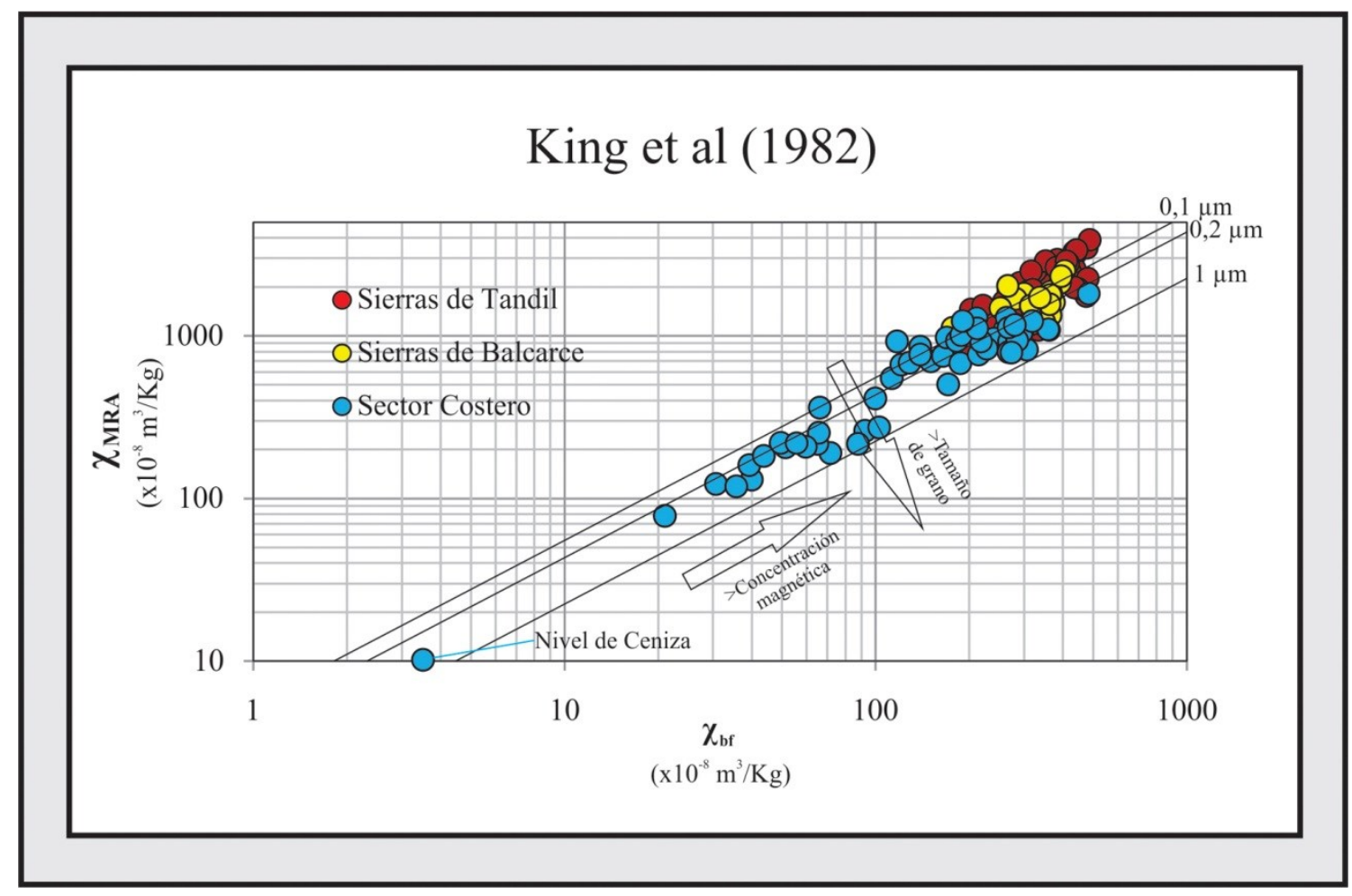

Figura 9.21. Diagrama $\chi_{\mathrm{bf}}$ Vs. $\chi_{\mathrm{MRA}}$ para la determinación de tamaño de grano magnético según King et al. (1982). 


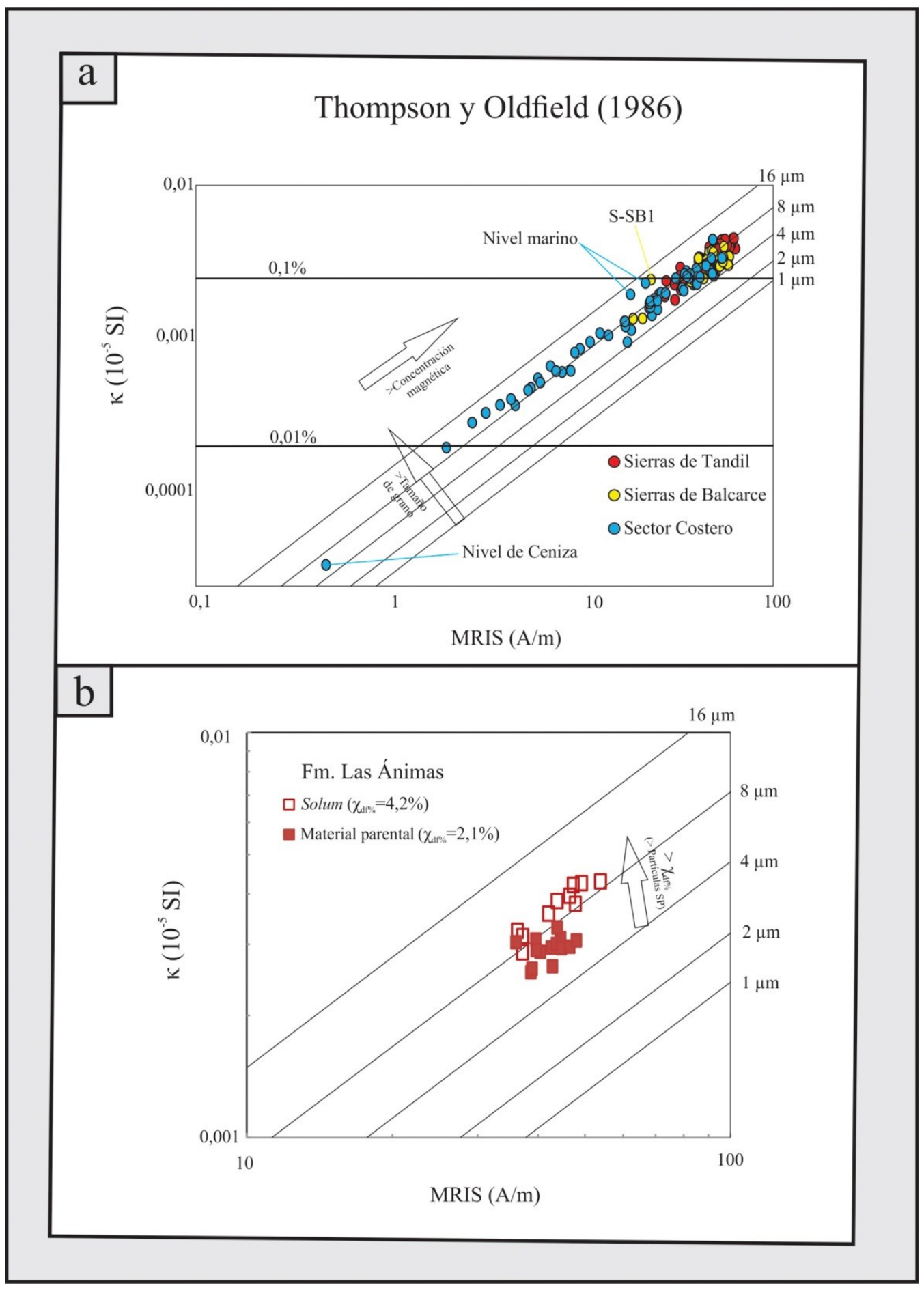

Figura 9.22. Diagramas SIRM vs. $\kappa_{\mathrm{bf}}$ para la determinación de tamaño de grano magnético según Thompson y Oldfield (1986). a) Todas las muestras analizadas; b) Muestras de la Formación Las Ánimas 


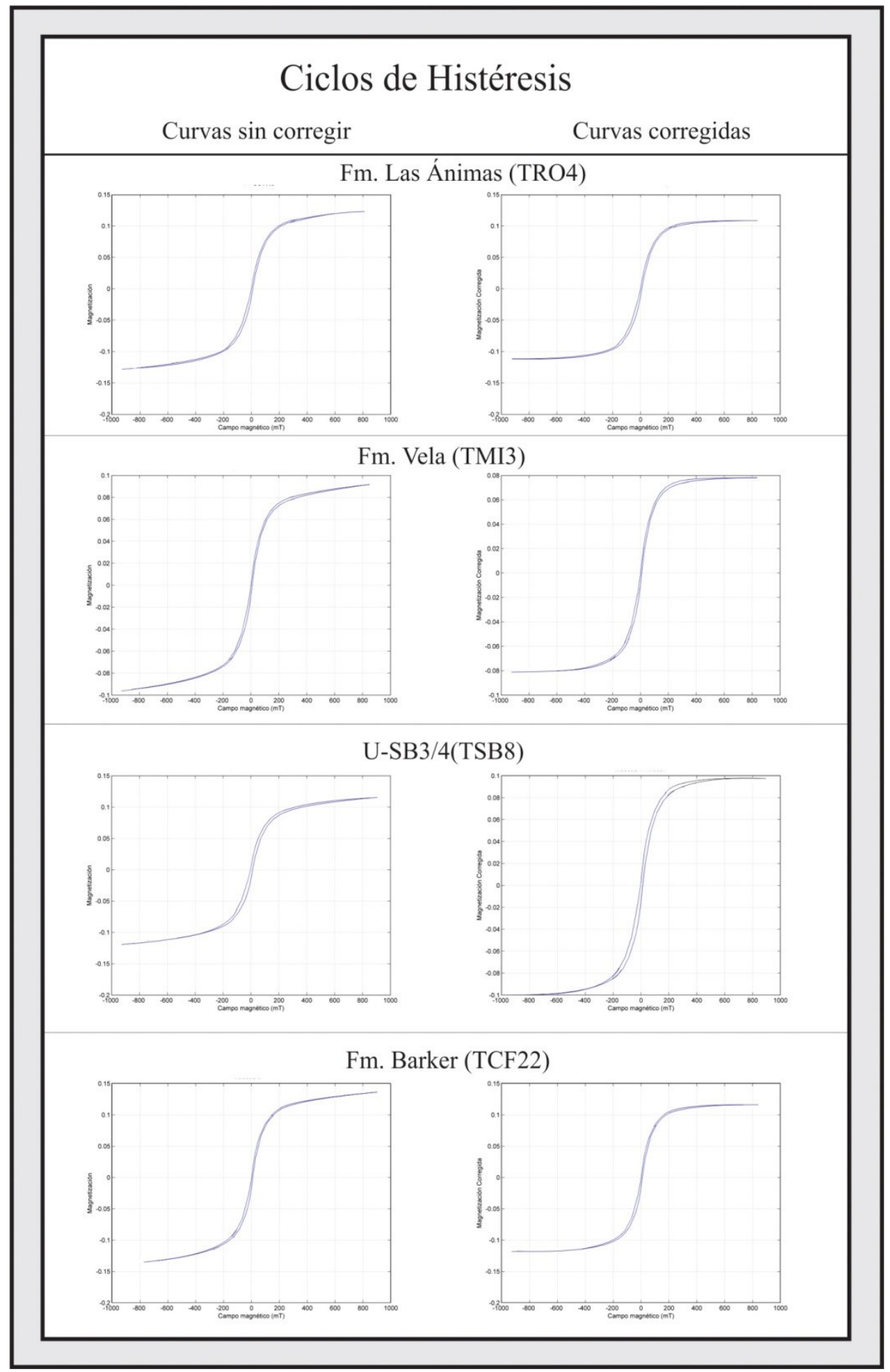

Figura 9.23. Ciclos de histéresis de muestras representativas de distintas unidades litoestratigráficas del Cenozoico tardío del sector serrano de Tandilia. 


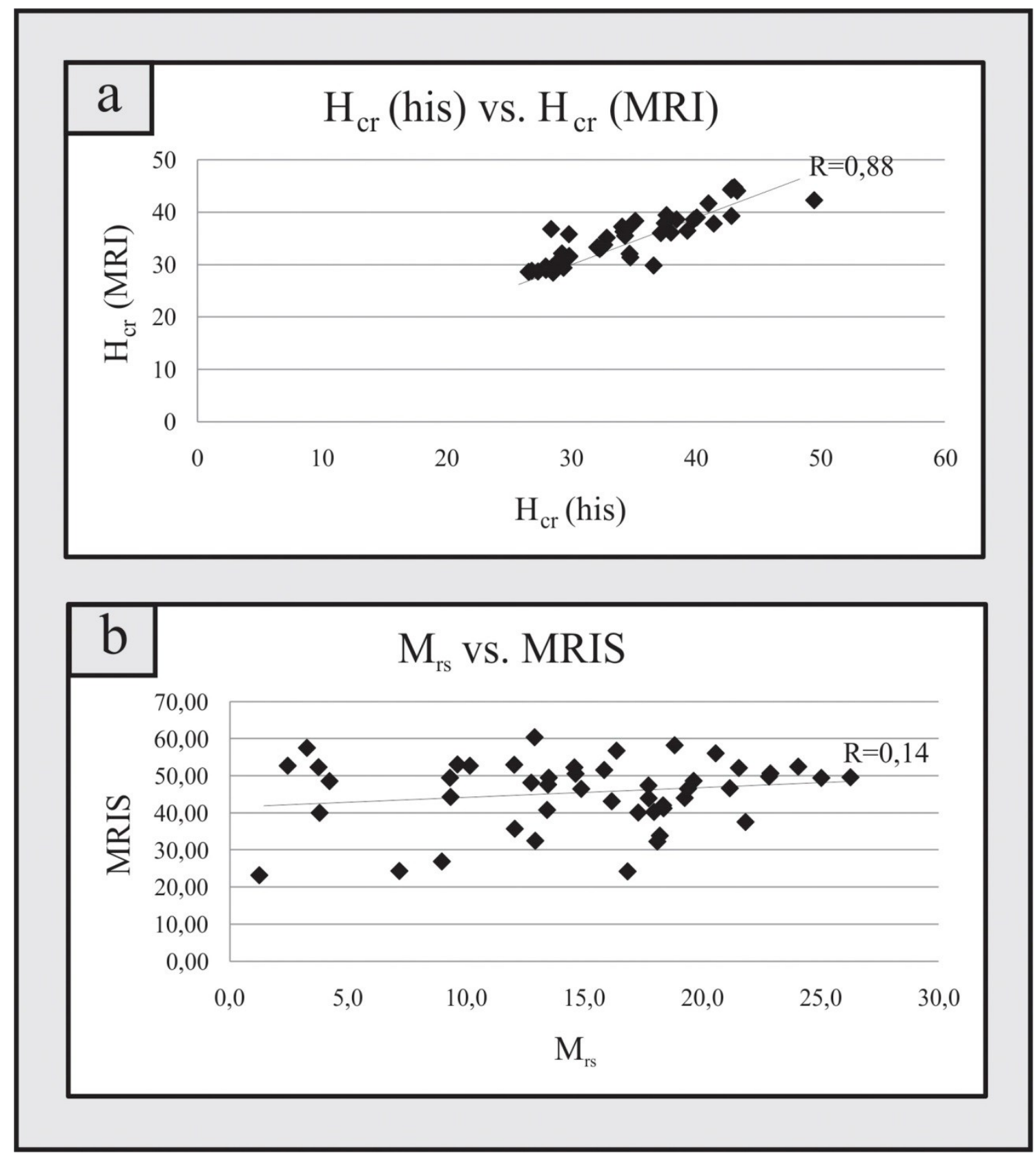

Figura 9.24. Diagramas bivariantes entre parámetros equivalentes determinados por ciclos de histéresis y Magnetización Remanente Isotérmica. a) $\mathrm{H}_{\mathrm{cr}}$ (his) vs. $\mathrm{H}_{\mathrm{cr}}$ (MRI); b) $\mathrm{M}_{\mathrm{rs}}$ Vs. MRIS 


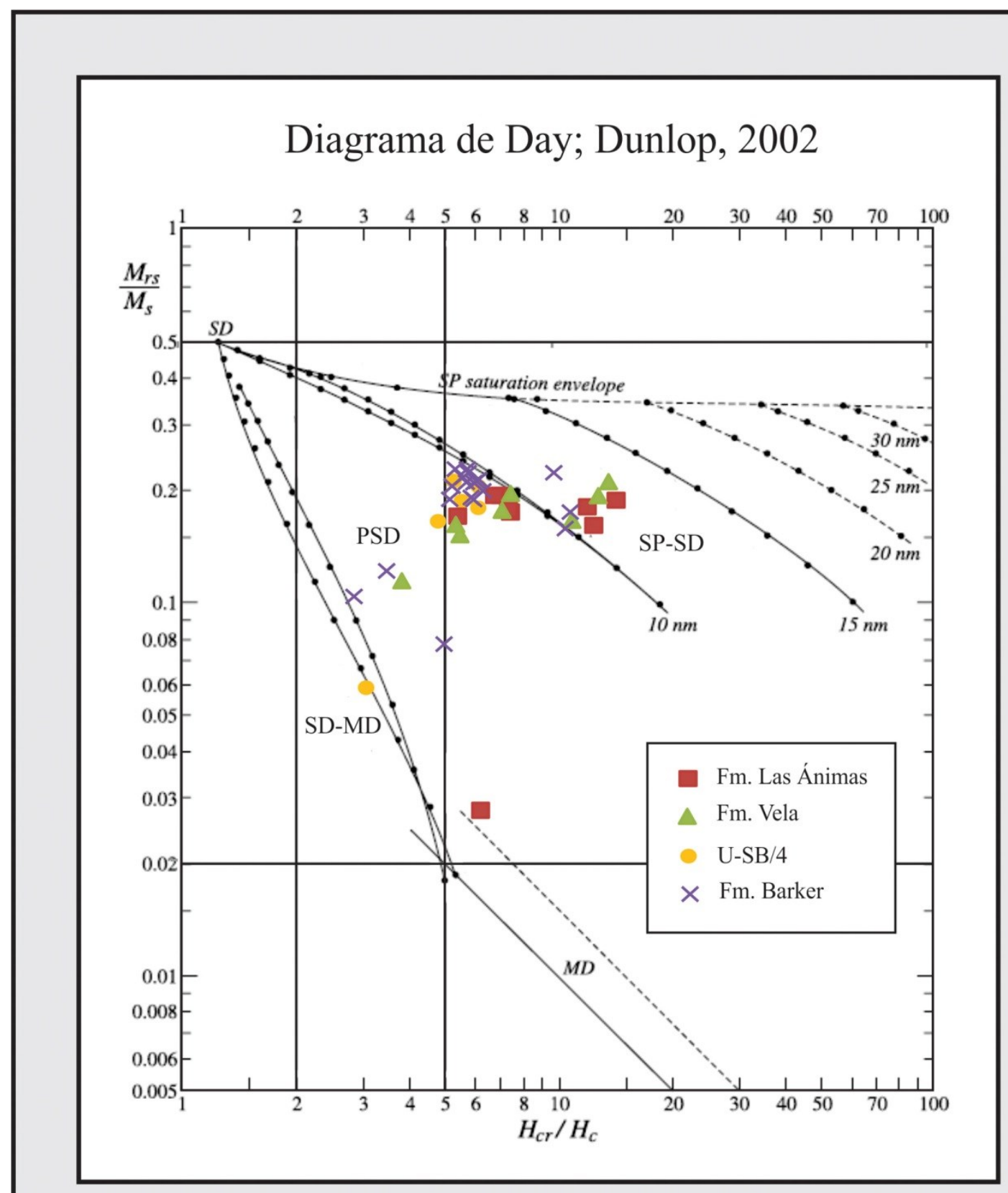

Figura

9.25. Diagrama $H_{\mathrm{cr}} / \mathrm{H}_{\mathrm{c}}$ vs. $\mathrm{M}_{\mathrm{rs}} / \mathrm{M}_{\mathrm{s}}$ de Day-Dunlop. 


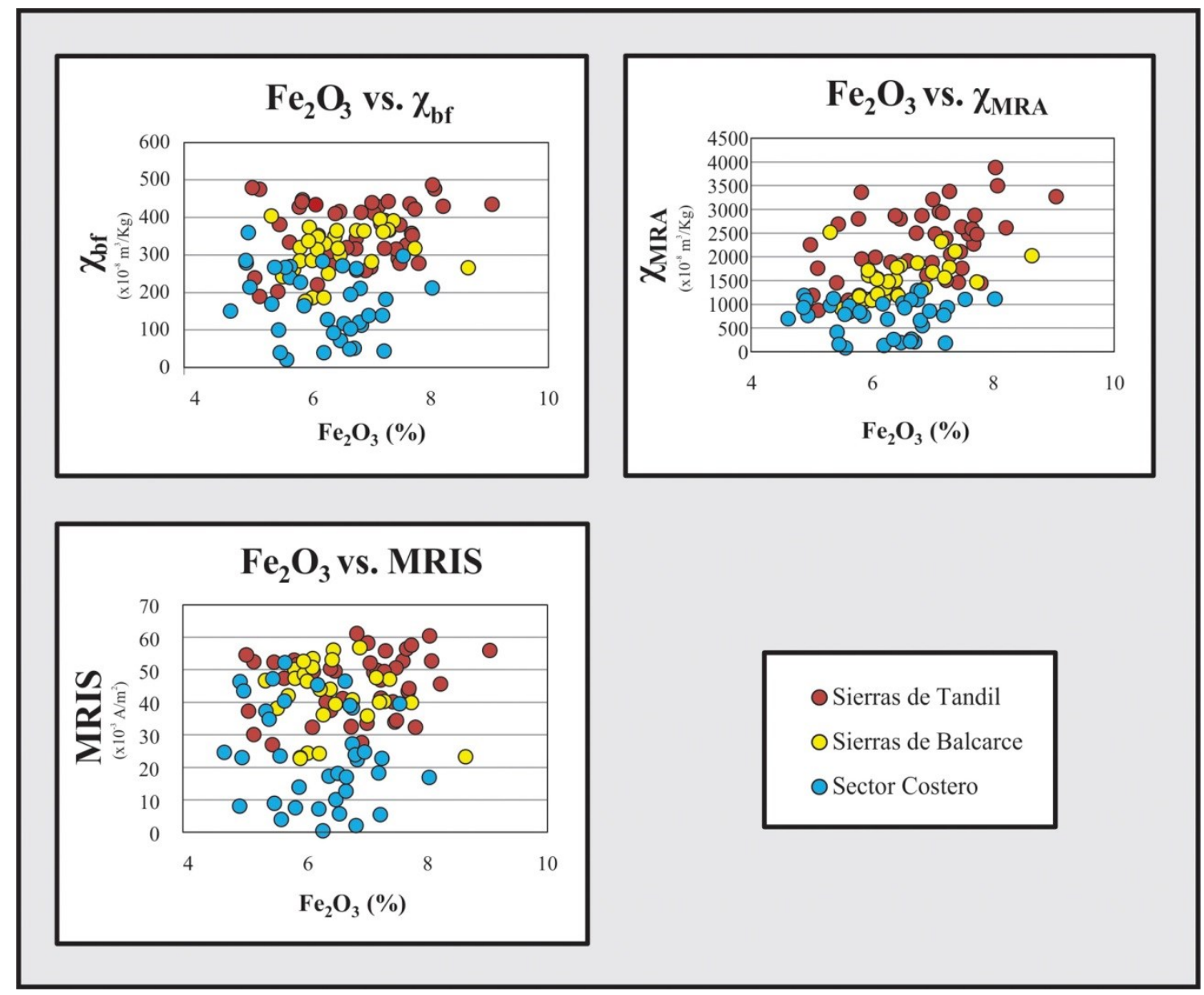

Figura 9.26. Diagramas de $\mathrm{Fe}_{2} \mathrm{O}_{3}$ vs. parámetros magnéticos extensivos ( $\chi_{\mathrm{bf}} ;$ MRIS; $\left.\chi_{\text {MRA }}\right)$. 


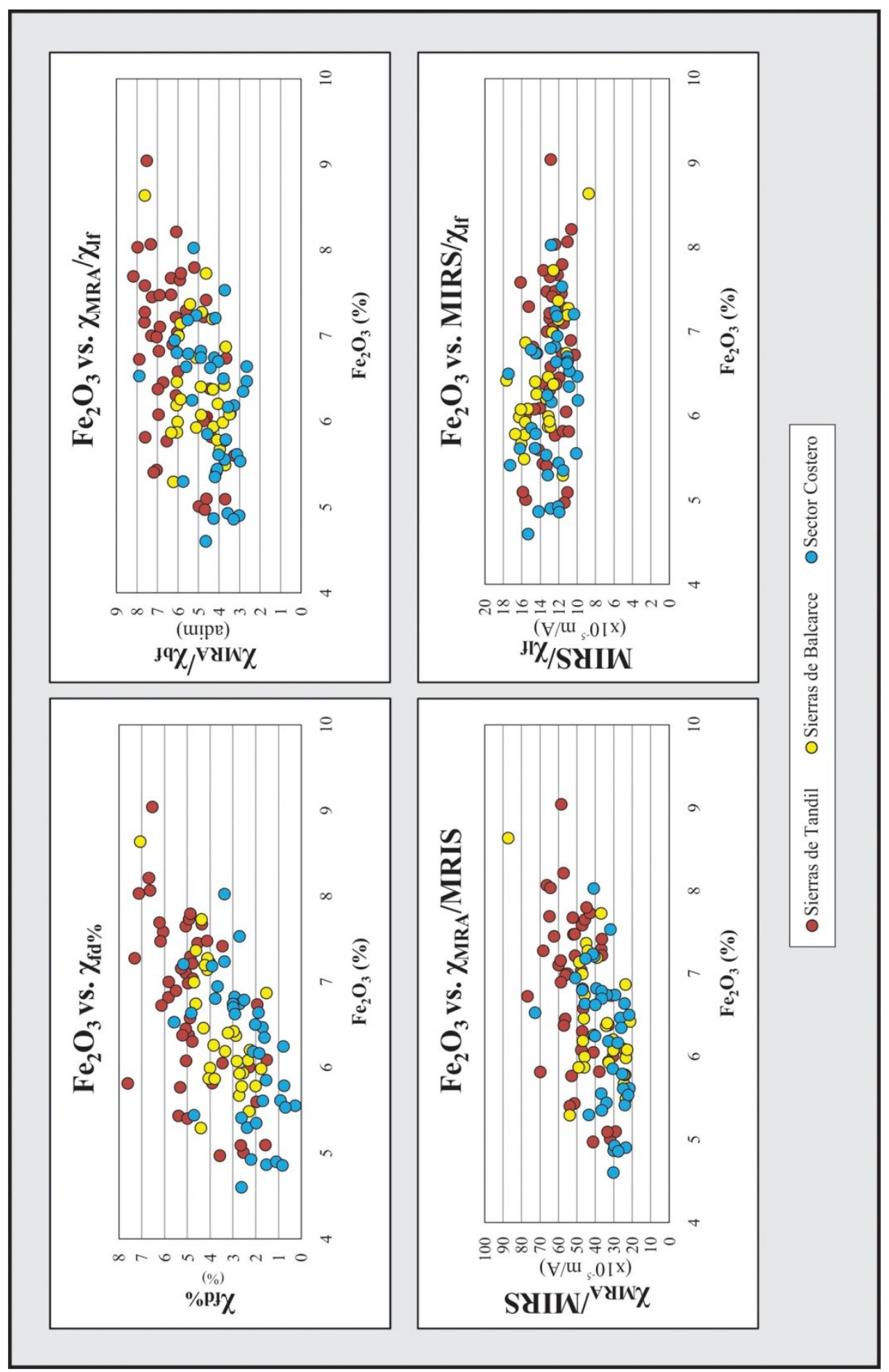

Figura 9.27. Diagramas de $\mathrm{Fe}_{2} \mathrm{O}_{3}$ vs. parámetros magnéticos intensivos $\left(\chi_{\mathrm{df} \%} ; \chi_{\mathrm{MRA}} / \chi_{\mathrm{bf}} ; \chi_{\mathrm{MRA}} / \mathrm{MRIS}\right.$; $\left.\operatorname{MRIS} / \chi_{\mathrm{bf}}\right)$. 


\subsection{Tablas del Capítulo 9.}

\section{Parámetros magnéticos sección PCT}

\begin{tabular}{|c|c|c|c|c|c|c|c|c|c|c|}
\hline Muestra & $\chi_{\text {bf }}$ & $\chi_{\text {bic03 }}$ & $\chi_{\text {df\% }}$ & MRIS & MRIS $_{\text {C03 }}$ & H $_{\text {cr }}$ & MRA & MRA $_{\text {C03 }}$ & $\chi_{\text {MRA }}$ & $\chi_{\text {MRAC03 }}$ \\
\hline TCT1 & 341,0 & 345,7 & 1,6 & 48,51 & 49,2 & 36,9 & 608,7 & 617,2 & 1245,22 & 1292,2 \\
\hline TCT2 & 333,5 & 337,1 & 1,7 & 49,63 & 50,2 & 42,1 & 575,8 & 582,1 & 1189,34 & 1221,9 \\
\hline TCT3 & 335,7 & 344,0 & 1,3 & 51,66 & 52,9 & 42,1 & 574,8 & 589,0 & 1196,07 & 1226,9 \\
\hline TCT4 & 347,8 & 351,7 & 1,5 & 53,32 & 53,9 & 43,0 & 570,0 & 576,4 & 1169,35 & 1195,6 \\
\hline TCT5 & 296,7 & 315,3 & 2,1 & 43,20 & 45,9 & 42,4 & 535,8 & 569,5 & 1065,05 & 1132,0 \\
\hline
\end{tabular}

\begin{tabular}{|c|c|c|c|c|c|c|}
\hline Muestra & Coef. S & $\chi$ MRA $/$ lf & $\chi_{\text {MRA }} /$ MRIS & MRA $/ \chi \mathbf{b f}$ & MRA/MRIS & MRIS/ $\chi_{\text {bf }}$ \\
\hline TCT1 & 0,95 & 3,65 & 25,7 & 1,79 & 12,5 & 14,2 \\
\hline TCT2 & 0,94 & 3,57 & 24,0 & 1,73 & 11,6 & 14,9 \\
\hline TCT3 & 0,94 & 3,56 & 23,2 & 1,71 & 11,1 & 15,4 \\
\hline TCT4 & 0,93 & 3,36 & 21,9 & 1,64 & 10,7 & 15,3 \\
\hline TCT5 & 0,93 & 3,59 & 24,7 & 1,81 & 12,4 & 14,6 \\
\hline & adim & adim & $10^{-5} \mathrm{~m} / \mathrm{A}$ & $10^{-2} \mathrm{~A} / \mathrm{m}$ & $10^{2}(\operatorname{adim})$ & $\mathrm{kA} / \mathrm{m}$ \\
\hline
\end{tabular}

Tabla 9.1. Parámetros magnéticos de la sección Circuito Turístico (PCT).

\section{Parámetros magnéticos sección PCQ}

\begin{tabular}{|c|c|c|c|c|c|c|c|c|}
\cline { 2 - 9 } \multicolumn{1}{c|}{} & $\chi_{\text {bf }}$ & $\chi_{\text {bfCO3 }}$ & $\chi_{\text {df\% }}$ & MRIS & MRIS $_{\text {CO3 }}$ & H $_{\text {cr }}$ & Coef. S & MRIS $\chi_{\text {bf }}$ \\
\hline TCQ1 & $\mathbf{1 4 4 , 2}$ & $\mathbf{1 8 8 , 5}$ & $\mathbf{3 , 0}$ & $\mathbf{1 8 , 6}$ & $\mathbf{2 4 , 2}$ & $\mathbf{3 9 , 6}$ & $\mathbf{0 , 9 3}$ & $\mathbf{1 2 , 9}$ \\
\hline TCQ2 & $\mathbf{1 4 3 , 9}$ & $\mathbf{2 0 3 , 9}$ & $\mathbf{2 , 9}$ & $\mathbf{2 0 , 7}$ & $\mathbf{2 9 , 3}$ & $\mathbf{3 9 , 7}$ & $\mathbf{0 , 9 3}$ & $\mathbf{1 4 , 4}$ \\
\hline
\end{tabular}

Tabla 9.2. Parámetros magnéticos de la sección Cerro Quebracho (PCQ). 


\begin{tabular}{|c|c|c|c|c|c|c|c|c|}
\hline \multicolumn{9}{|c|}{ Parámetros magnéticos Sección Santa Elena } \\
\hline & $\chi_{b f}$ & $\chi_{\mathrm{bfCO} 3}$ & $\chi_{d f \%}$ & MRIS & MRIS $_{\mathrm{CO} 3}$ & $\mathbf{H}_{\mathrm{cr}}$ & Coef. S & MRIS $/ \chi_{\mathrm{bf}}$ \\
\hline TSE1 & 212,9 & 258,4 & 1,3 & 18,3 & 22,2 & 38,7 & 0,87 & 8,61 \\
\hline TSE2 & 253,0 & 259,9 & 1,1 & 21,8 & 22,4 & 38,7 & 0,88 & 8,61 \\
\hline & \multicolumn{2}{|c|}{$10^{-8} \mathrm{~m}^{3} \mathrm{Kg}^{-1}$} & $\%$ & \multicolumn{2}{|c|}{$10^{-3} \mathrm{Am}^{2} \mathrm{Kg}^{-1}$} & $\mathrm{mT}$ & adim & $\mathrm{kA} / \mathrm{m}$ \\
\hline
\end{tabular}

Tabla 9.3. Parámetros magnéticos de la sección Santa Elena (PSE). 


\begin{tabular}{|c|c|c|c|c|c|c|c|c|}
\hline $\begin{array}{c}\text { Sección } \\
\text { Estratigráfica } \\
\end{array}$ & Muestra & \begin{tabular}{|c|}
$\begin{array}{c}\text { U. Litoestrati- } \\
\text { gráfica }\end{array}$ \\
\end{tabular} & \begin{tabular}{|c|} 
Ms \\
$\times 10^{\prime} \mathrm{Am}^{\prime} / \mathrm{Kg}_{8}$ \\
\end{tabular} & $\begin{array}{c}\mathrm{Hc} \\
\mathrm{mT}\end{array}$ & $\begin{array}{c}\text { Her } \\
\mathrm{mT}\end{array}$ & \begin{tabular}{|c|} 
Mrs \\
$\times 10^{-3} \mathrm{Am} / \mathrm{Kg}$ \\
\end{tabular} & \multicolumn{2}{|c|}{$\underset{\text { adimensional }}{\text { Her/He Mrs/Ms }}$} \\
\hline \multirow{10}{*}{ PVC } & TVC7 & \multirow{4}{*}{ Vela } & 87,6 & 3,7 & 41,4 & 16,2 & 11,3 & 0,18 \\
\hline & TVC8 & & 35,2 & 12,5 & 49,5 & 4,2 & 4,0 & 0,12 \\
\hline & TVC9 & & 103,1 & 5,8 & 42,9 & 19,4 & 7,3 & 0,19 \\
\hline & TVC10 & & 82,7 & 2,8 & 39,3 & 13,5 & 14,1 & 0,16 \\
\hline & TVC12 & \multirow{6}{*}{ Barker } & 86,9 & 4,5 & 28,4 & 18,2 & 6,3 & 0,21 \\
\hline & TVC15 & & 31,2 & 7,4 & 26,8 & 3,8 & 3,6 & 0,12 \\
\hline & TVC18 & & 103,2 & 2,8 & 28,0 & 22,8 & 10,1 & 0,22 \\
\hline & TVC20 & & 23,9 & 9,0 & 26,6 & 2,5 & 3,0 & 0,10 \\
\hline & TVC22 & & 103,7 & 4,7 & 28,8 & 21,6 & 6,2 & 0,21 \\
\hline & TVC26 & & 68,1 & 4,6 & 28,5 & 12,8 & 6,2 & 0,19 \\
\hline \multirow{10}{*}{ PMI } & TMI1 & Las Ánimas & 67,3 & 2,6 & 32,4 & 12,0 & 12,4 & 0,18 \\
\hline & TMI3 & \multirow{3}{*}{ Vela } & 88,6 & 5,0 & 28,4 & 14,6 & 5,7 & 0,16 \\
\hline & TMI4 & & 79,3 & 4,5 & 34,7 & 9,0 & 7,7 & 0,11 \\
\hline & TMI5 & & 53,3 & 6,6 & 36,6 & 9,3 & 5,5 & 0,18 \\
\hline & TMI7 & \multirow{6}{*}{ Barker } & 66,2 & 4,9 & 29,2 & 14,6 & 6,0 & 0,22 \\
\hline & TMI9 & & 83,2 & 4,8 & 28,7 & 18,8 & 5,9 & 0,23 \\
\hline & TMI10 & & 47,3 & 5,1 & 29,4 & 10,2 & 5,8 & 0,21 \\
\hline & TMI13 & & 42,7 & 6,8 & 34,7 & 3,3 & 5,1 & 0,08 \\
\hline & TMI15 & & 82,5 & 2,6 & 28,5 & 12,9 & 10,8 & 0,16 \\
\hline & TMI16 & & 45,8 & 5,2 & 27,9 & 9,3 & 5,4 & 0,20 \\
\hline \multirow{10}{*}{ PCF } & TCF1 & \multirow{4}{*}{ Las Ánimas } & 142,5 & 5,3 & 29,8 & 24,07 & 5,6 & 0,17 \\
\hline & TCF3 & & 99,4 & 2,7 & 34,3 & 15,85 & 12,9 & 0,16 \\
\hline & TCF5 & & 139,5 & 5,3 & 34,2 & 3,80 & 6,4 & 0,03 \\
\hline & TCF6 & & 134,3 & 2,8 & 41,0 & 25,04 & 14,8 & 0,19 \\
\hline & TCF11 & Vela & 104,3 & 2,9 & 38,0 & 21,83 & 13,3 & 0,21 \\
\hline & TCF15 & \multirow{5}{*}{ Barker } & 68,2 & 4,7 & 28,6 & 12,93 & 6,1 & 0,19 \\
\hline & TCF 16 & & 92,9 & 5,0 & 32,6 & 18,36 & 6,5 & 0,20 \\
\hline & TCF17 & & 85,3 & 5,1 & 32,3 & 18,10 & 6,4 & 0,21 \\
\hline & TCF 19 & & 83,0 & 5,4 & 32,1 & 17,29 & 5,9 & 0,21 \\
\hline & TCF22 & & 116,2 & 5,3 & 29,3 & 26,28 & 5,5 & 0,23 \\
\hline \multirow{4}{*}{ PSM } & TSM1 & \multirow{2}{*}{ Vela } & 47,7 & 7,60 & 40,08 & 7,179 & 5,3 & 0,15 \\
\hline & TSM3 & & 86,5 & 2,64 & 38,45 & 16,841 & 14,6 & 0,19 \\
\hline & TSM8 & \multirow{2}{*}{ Barker } & 77,6 & 2,67 & 29,83 & 13,434 & 11,2 & 0,17 \\
\hline & TSM10 & & 64,3 & 6,10 & 32,46 & 12,065 & 5,3 & 0,19 \\
\hline & TRO1 & & 110,2 & 4,5 & 32,8 & 21,17 & 7,3 & 0,19 \\
\hline & TRO2 & Las Ánimas & 103,6 & 4,4 & 34,1 & 17,96 & 7,7 & 0,17 \\
\hline DPO & TRO3 & Las Anımas & 92,3 & 5,0 & 35,1 & 17,73 & 7,0 & 0,19 \\
\hline PRO & TRO4 & & 109,4 & 4,9 & 37,6 & 19,26 & 7,6 & 0,18 \\
\hline & TRO6 & Vola & 114,3 & 6,8 & 42,9 & 18,35 & 6,3 & 0,16 \\
\hline & TRO8 & Vela & 92,4 & 7,8 & 43,3 & 17,73 & 5,6 & 0,19 \\
\hline & TSB01 & Las Ánimas & 112,46 & 4,81 & 34,83 & 19,64 & 7,2 & 0,17 \\
\hline & TSB02 & Vela & 83,81 & 7,84 & 42,82 & 14,88 & 5,5 & 0,18 \\
\hline & TSB04 & & 21,41 & 8,58 & 27,32 & 1,25 & 3,2 & 0,06 \\
\hline & TSB05 & & 75,72 & 4,70 & 29,83 & 13,47 & 6,3 & 0,18 \\
\hline PSB & TSB06 & & 88,39 & 6,54 & 37,51 & 16,37 & 5,7 & 0,19 \\
\hline & TSB08 & U-SB3/4 & 97,95 & 7,89 & 43,10 & 20,57 & 5,5 & 0,21 \\
\hline & TSB10 & & 58,91 & 7,50 & 37,19 & 9,64 & 5,0 & 0,16 \\
\hline & TSB12 & & 112,57 & 6,27 & 39,84 & 22,89 & 6,4 & 0,20 \\
\hline
\end{tabular}

Tabla 9.4. Parámetros de histéresis de las muestras analizadas. 


\begin{tabular}{|c|c|c|c|c|c|c|c|c|c|c|c|c|c|}
\hline 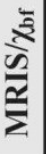 & 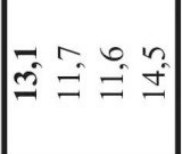 & $\stackrel{10}{ \pm}$ & 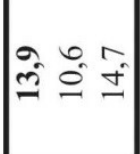 & $\stackrel{2}{\simeq}=\tilde{c}$ & בี & 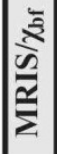 & 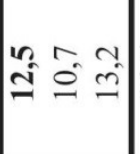 & $\mid \begin{array}{l}0 \\
\pm \\
\pm\end{array}$ & $\left|\begin{array}{ll}0 & 0 \\
= & \infty\end{array}\right|$ & É & $\stackrel{m}{=} \stackrel{2}{=}$ & 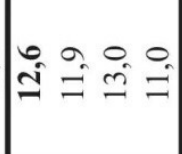 & 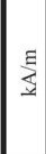 \\
\hline 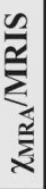 & 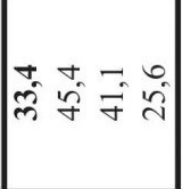 & $\begin{array}{c}m \\
\infty \\
\infty \\
m\end{array}$ & $\mid \begin{array}{lll}0 & 0 & n \\
m & 0 i & m \\
m & \delta & m\end{array}$ & $\left|\begin{array}{lll}\infty & 0 & 0 \\
i & 0 & 0 \\
n & 0 & n\end{array}\right|$ & ' ' & 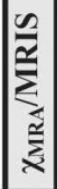 & $\begin{array}{lll}a & n & n \\
\infty & n & 0 \\
0\end{array}$ & जि & $|\hat{y} \cdot|$ & $\stackrel{\sim}{\stackrel{2}{\sim}}$ & 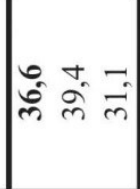 & 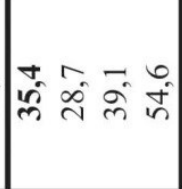 & $\begin{array}{ll}\frac{1}{ह} \\
\frac{\partial}{x}\end{array}$ \\
\hline 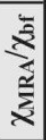 & 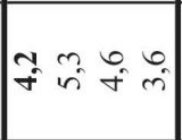 & 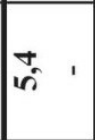 & 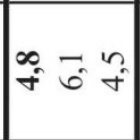 & $\mid \begin{array}{c}n \\
6\end{array}$ & ' ' & 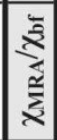 & $\begin{array}{lll}m & \hat{n} & n \\
m & m & m\end{array} \mid$ & m. & $\approx$ & $\begin{array}{lll}\infty & 1 \\
\infty & 1 & \end{array}$ & 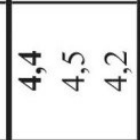 & 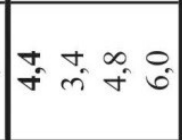 & 量 \\
\hline نे & 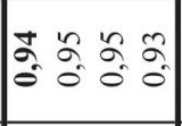 & है. & $\left|\begin{array}{lll}\pi & n & \ddots \\
\hat{\sigma} & 0 & \sigma\end{array}\right|$ & 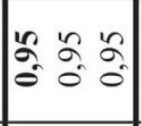 & है & 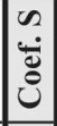 & $\left|\begin{array}{lll} \pm & n & \ddots \\
\hat{\sigma} & \hat{\sigma} & 0 \\
0 & 0 & 0\end{array}\right|$ & $\approx$ & $\left|\begin{array}{ll}2 & \infty \\
0 & \infty \\
0 & 0 \\
0 & 0\end{array}\right|$ & ڤू. & 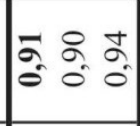 & 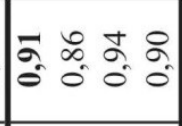 & 㝵 \\
\hline हूर & ప્డి & $\approx \tilde{\approx}$ & 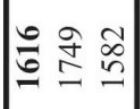 & 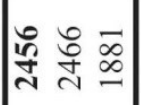 & ' ' & 产 & 월 & $\tilde{\Omega}$ & $\approx$ & $ळ$ రे & 00 in & $\overrightarrow{0} \stackrel{2}{\sim} \infty$ & 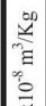 \\
\hline$\pm^{ \pm}$ & 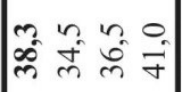 & $\vec{\infty} \quad$. & 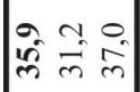 & 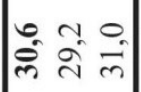 & : & $=$ & 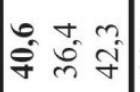 & fí & 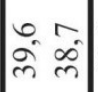 & $\vec{F}$ & 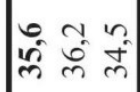 & 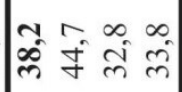 & 苯 \\
\hline$\cong$ & 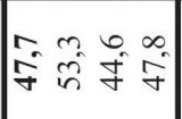 & 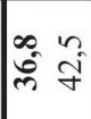 & $\mid \begin{array}{lll}\forall & n & m \\
\sigma & \bar{m} & \frac{1}{n}\end{array}$ & $\left|\begin{array}{lll}\forall & 0 & a \\
\tilde{F} & f & 0 \\
f & f\end{array}\right|$ & $\stackrel{2}{\pi} \frac{m}{m}$ & $\stackrel{\mathscr{z}}{\tilde{\Sigma}}$ & 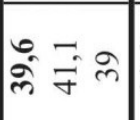 & ले & 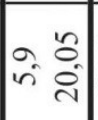 & 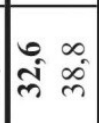 & $\begin{array}{lll}\partial & n & n \\
\partial & c & m\end{array}$ & $=\infty \stackrel{\tilde{\nu}}{0} \tilde{\sigma}$ & $\begin{array}{l}\infty \\
0 \\
0 \\
0\end{array}$ \\
\hline 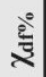 & 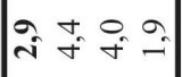 & $\stackrel{m}{m}$. & $\left|\begin{array}{lll}m & n & 0 \\
m & \text { in } & m\end{array}\right|$ & $\begin{array}{l}m \\
\text { in }\end{array}$ & $\begin{array}{ll}0 & 1 \\
\text { in } & 1\end{array}$ & $\frac{2}{3}$ & 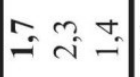 & 3 & $\hat{m}=1$ & $\stackrel{0}{0} 1$ & 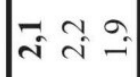 & $\mid \begin{array}{llll}0 & 9 & \infty & m \\
i & - & i & r\end{array}$ & $\therefore$ \\
\hline 3 & 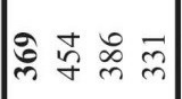 & กิ ลิ & ले ন̄ & 两 & สi & 3 & సె ڤે ৯े & $\stackrel{m}{\sim}$ & nn & సิ & $\ddot{n} \circlearrowright$ & 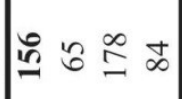 & है \\
\hline & 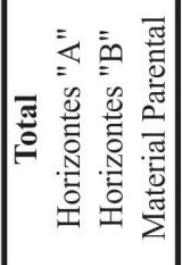 & 吾 & 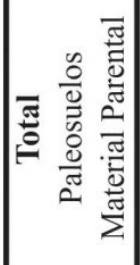 & 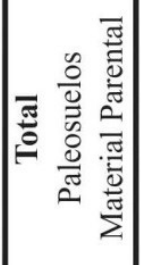 & 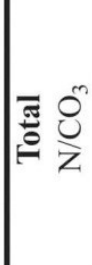 & & 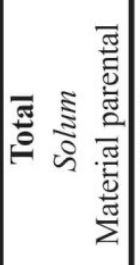 & है & 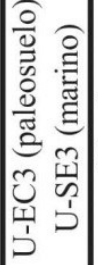 & 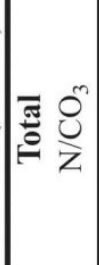 & 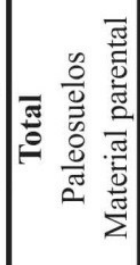 & 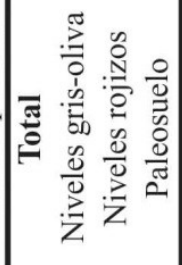 & \\
\hline 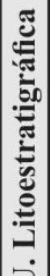 & 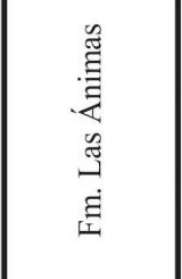 & $\frac{\pi}{2}$ & 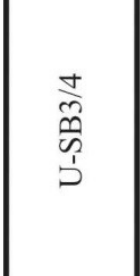 & 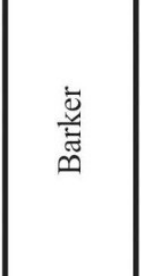 & $\begin{array}{l}0 \\
3 \\
\vdots \\
\vdots\end{array}$ & 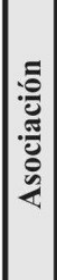 & Z & $\mid \frac{1}{2}$ & $\begin{array}{l}0 \\
5 \\
0 \\
0 \\
0 \\
0 \\
0 \\
01 \\
0\end{array}$ & 2 & ষ & 2 & \\
\hline \multicolumn{6}{|c|}{ 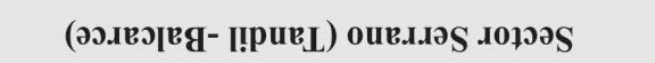 } & \multicolumn{8}{|c|}{ 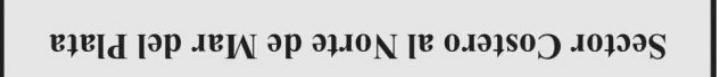 } \\
\hline
\end{tabular}

Tabla 9.5. Valores promedio de los parámetros magnéticos de las unidades litoestratigráficas del sector serrano y de las asociaciones del sector costero. 


\section{CAPÍTULO 10. AMBIENTES, EDADES, EQUIVALENCIAS Y CORRELACIONES DE LOS SEDIMENTOS DEL CENOZOICO TARDÍO DEL SECTOR TANDIL-BALCARCE-MAR DEL PLATA.}

Mediante los datos obtenidos es posible hacer inferencias acerca de las características de los distintos ambientes que dieron origen a las unidades estudiadas. Por un lado se analizan los procesos primarios, vinculados a la depositación del material y por otro, los procesos que afectaron a los sedimentos luego de la depositación.

Lo mencionado se vincula al marco cronológico; en tanto se expondrán aquí los crones y subcrones asignados, así como las edades propuestas para cada unidad y se elevará una propuesta de equivalencias y correlaciones con unidades lito, alo y bioestratigráficas propuestas por diversos autores, principalmente en el marco de la Provincia Geológica de Tandilia. En la Tabla 10.1 se indica el cron Magnético asignado a cada unidad; el Piso (Edad) para América del Sur según Cione y Tonni (2005); el subciclo de sedimentación para el Cenozoico tardío según Zárate (2005); las edades mínimas y máximas de las unidades de sedimentación; y finalmente las equivalencias y correlaciones establecidas.

La unidad superior de todos los perfiles corresponde a limos arenosos, bien seleccionados, sin estructura primaria identificable, de origen dominantemente eólico (loess); no obstante en la base suele presentar clastos de carbonato de calcio y laminación difusa, indicando acción hídrica encausada. El contacto con las unidades subyacentes es erosivo. En las secciones estratigráficas del sector serrano se apoya sobre una costra calcárea, sin embargo puede apoyarse sobre unidades más antiguas, incluso sobre el basamento (Complejo Buenos Aires). En el sector costero esta unidad fue definida como Asociación A1 y se apoya en la mayoría de los casos sobre la Asociación A2. En cuanto a la edad de la unidad; los resultados paleomagnéticos indicaron polaridad normal (Cron Brunhes; $<0,78 \mathrm{Ma}$ ); en función del nivel de cenizas hallado en el perfil de Playa Dorada correlacionado con el nivel de cenizas de Camet Norte, se estima una edad menor a $21 \mathrm{Ka}$; Piso dominantemente Lujanense y probablemente Platense. Esta unidad en el sector serrano fue designada como Formación Las Ánimas (Rabassa, 1971, 1973) y es equivalente al "Médano invasor" (Tapia, 1937), a la unidad litoestratigráfica 3 (Zárate y Mehl, 2010) del sector de la cuenca del arroyo Azul y a la Formación La Postrera (Fidalgo et al., 1986) en la cuenca del arroyo Tapalqué. Asimismo, sería equivalente al par E1-E3 de Tricart (1973) y a las Aloformaciones Médano Invasor y E1 de Martínez (2001) y se correlacionaría con el Post-Pampeano de Ameghino (1908). 
Los procesos post-depositacionales que afectan esta unidad se vinculan principalmente al desarrollo del suelo actual; los mismos corresponden generalmente a Argiudoles típicos, que representarían los suelos "zonales"; a Hapludoles típicos en zonas de pendientes pronunciadas; y Paleoudoles petrocálcicos cuando la unidad tiene poco espesor y se encuentra limitada por la costra calcárea. No se registró en ningún caso la presencia de rasgos de hidromorfismo. Como fue dicho, los procesos pedogenéticos actuantes condujeron a la neoformación de minerales magnéticos (probablemente maghemita) de tamaño fino y ultrafino; sin degradación de la magnétita detrítica. Cabe destacar que no se registraron niveles de paleosuelos en esta unidad. Zárate y Blasi (1993), indicaron que el manto eólico en el SE bonaerense se habría formado durante cuatro ciclos de sedimentación, vinculados a momentos de mayor aridez; posteriormente Martínez (2001) y Dangavs (2005) propusieron planteos análogos en la Cuenca del Salado; el primero propuso dos Aloformaciones (Médano Invasor y E1), cada una dividida en dos Alomiembros (Superior e Inferior); el segundo las denominó como Formación La Postrera I, II; II y IV. Según los autores, el carácter episódico de sedimentación es alternado por períodos de no depositación y pedogénesis; esto, vinculado a la ausencia de paleosuelos y al "buen grado" de desarrollo de los suelos "zonales", permite inferir que el mayor volumen sedimentario correspondería al primer ciclo de depositación (ocurrido según los autores durante el último máximo glaciar, ca. 18-20 Ka) y/o al segundo (del límite Pleistoceno-Holoceno, $c a$. 10-11 Ka); en tanto, los dos ciclos posteriores (Holoceno medio y Pequeña edad del Hielo) constituirían en las secciones estudiadas una fina capa que se adiciona al desarrollo del suelo actual, se estima que el desarrollo de los mismos involucra procesos originados durante el máximo térmico Holoceno u Hypsitermal (4 - 7 Ka).

Por otra parte, cabe destacar que en las zonas fluviales esta unidad es reemplazada lateralmente por lo que Rabassa $(1971,1973)$ denominó Formación Tandileufú, de origen fluvial, que según Martínez (2001) y Zárate y Mehl (2010) sería equivalente a la Formación Lujan de Fidalgo et al. (1986); a la Formación Lobería (Kraglievich, 1959) y la Aloformación Arroyo Lobería (Zárate, 1989).

En el sector serrano, la Formación Las Ánimas se apoya en discordancia sobre depósitos areno limosos y limo arenosos con laminación entrecruzada conspicua, que grada a laminar paralela; con presencia de importantes acumulaciones psefíticas, conformando lentes, y abundante carbonato de calcio disperso en la masa, cuya mayor concentración se halla hacia el tope de la unidad, donde conforma una costra calcárea en planchas, muy dura y de extensión regional que se correspondería con la Paleosuperficie Tandil (Teruggi et al., 1973). Esta unidad se interpreta como un depósito fluvial; en los perfiles analizados presentó polaridad normal y se asignó al Cron Brunhes $(<0,78 \mathrm{Ma})$. En el sector serrano de Tandilia se conoce con el nombre de Formación Vela (Rabassa (1971, 1973) y sería equivalente a la unidad litoestratigráfica 2 (Zárate y Mehl, 2010), descripta para la cuenca del arroyo Azul. 
El contacto con las unidades subyacentes es siempre discordante, erosivo, con incisiones profundas que indicarían una fuerte reactivación fluvial. Esta discordancia en el sector costero constituye la base de la asociación A3; que también presenta abundantes rasgos fluviales, tales como estratificación entrecruzada, acumulaciones psefíticas, además presenta abundante $\mathrm{CaCO}_{3}$ en la masa, en el tope conforma una duricostra en planchas y tabiques, que fue asociada a la Paleosuperficie Tandil. La Formación Vela y la asociación A3 se consideran equivalentes. Ambas presentaron una composición magnética semejante; caracterizada por una relativa homogeneidad; tanto los parámetros magnéticos extensivos como los intensivos presentaron escasa variación. La concentración de minerales magnéticos finos y ultrafinos es baja respecto al resto de las unidades analizadas; esto se debería al escaso grado de meteorización que presenta. Se vinculan a un sistema fluvial de energía relativamente alta, la cual se habría ido perdiendo gradualmente, culminando en un período estable, relativamente seco, dominado por el proceso de carbonatación. Cabe destacar que las características de la discordancia erosiva, con incisiones muy profundas son llamativas; se considera que la misma estaría ligada a un rápido descenso del nivel de base. Si bien los estudios sedimentológicos realizados en la región, referidos a depósitos más jóvenes que el límite Brunhes-Matuyama han versado principalmente sobre los controles climáticos en el estilo depositacional, cabe destacar que la presencia del potente conjunto conglomerádico en la base de la Formación Vela, en la sección de Villa Cacique, podría vincularse a efectos de un levantamiento cortical, en este sentido cabe mencionar que Zárate y Mehl (2010), indicaron que la distribución areal de la unidad litoestratigrafica 2 (correlacionable con la Fm. Vela) está controlada tectónicamente.

Por encima de A3, en el perfil de Santa Elena, en contacto erosivo, se hallaron depósitos vinculados a una ingresión marina (U-SE3) que se atribuyeron al "Belgranense", coincidente con el estadio isotópico 5 (117-130 Ka) y se correlacionarían con la Formación Pascua (Fidalgo et al., 1973). En función de lo expuesto se considera que A3 tendría una edad mayor a $130 \mathrm{Ka}$ y correspondería al Piso Bonaerense; en tanto las unidades de la asociación A2, limos arenosos con estratificación entrecruzada difusa, apoyadas generalmente por encima de A3, tendrían una edad entre 21 - $117 \mathrm{Ka}$, y correspondería al Piso Lujanense; cabe destacar que en la sección El Casal, en A2 se registraron componentes de magnetización inversa que podrían asignarse a los eventos Laschamp y/o Mono Lake (32-41 Ka); esta edad sería coincidente con el estadio isotópico 3; que habría sido algo más húmedo que los estadios 2 y 4 , sin embargo no se determinaron rasgos de clima húmedo; en cuanto a la composición magnética, la asociación A2 no presentó prácticamente diferencias con la asociación A3.

Cabe aclarar que los sedimentos de A2 no fueron determinados en el sector serrano, sin embargo no se descarta su presencia; se intuye que los mismos pueden encontrarse en algunos casos conformando 
un manto de poco espesor, que se incluiría a la costra calcárea regional o a la base de la Formación Las Ánimas.

El conjunto de unidades descriptas (A2 - A3) habría recibido en el sector costero al norte de Mar del Plata los nombres de Formación Santa Clara (Schnack et al. 1982); Miembro Superior de la Formación Santa Clara (Fasano, 1992); Aloformación Santa Clara (equivalente a la Aloformación El Hipódromo) (Martínez, 2001), cabe destacar que estas últimas fueron subdivididas en dos alomiembros (inferior y superior), probablemente equivalentes a A3 y A2 respectivamente. Los depósitos descriptos se correlacionarían con la parte Superior (de polaridad normal, sensu Orgeira, 1988 y Ruocco, 1989) de la Formación Arroyo Seco de Kraglievich (1959); con el Alomiembro Superior de la Aloformación Punta San Andrés (Zárate, 1989), con la Formación Buenos Aires (Riggi et al., 1986; Bidegain et al., 2005b); y con el Bonaerense (Ameghino, 1908).

La Asociación A4 tampoco fue determinada en el sector serrano. Esta se encuentra generalmente muy erosionada y conforma depósitos saltuarios. La misma corresponde a arenas limosas con estructuras que evidencian transporte fluvial y se encuentra muy modificada por procesos pedogenéticos. La polaridad magnética de la misma es dominantemente normal y se asignó al cron Brunhes $(<0,78 \mathrm{Ma})$; en la sección de Playa Dorada se determinaron componentes de magnetización inversas que fueron atribuidas al evento CR1 (315 - $325 \mathrm{Ka})$, coincidente con el estadio isotópico 9 (300 - $360 \mathrm{Ka})$; no obstante no se descartó que los paleosuelos se hayan desarrollado durante el estadio isotópico 7 (180-240 Ka) o bien el 11 (398 - $410 \mathrm{Ka}$ ). Dado que en esta unidad se han citado fósiles del Piso Bonaerense, se estima que la edad máxima sería $500 \mathrm{Ka}$. Los parámetros magnéticos presentaron un comportamiento vinculado a la pedogénesis opuesto al registrado en los suelos actuales, es decir que indicarían oxidación de los minerales magnéticos litogenéticos (titanomagnetita), sin neoformación de partículas magnéticas ultrafinas; esto se atribuye a condiciones humedad relativamente elevadas y prolongada permanencia del agua en el suelo, es decir con drenaje deficiente; si bien esto puede vincularse a climas húmedos, incluso más húmedos que el actual; la causa principal de la permanencia de agua en el suelo se relacionaría a la dinámica del sistema fluvial, durante la etapa de perdida de energía, ligada al ascenso del nivel del mar, y durante la etapa de mar alto.

Por otra parte cabe destacar que la única denominación clara que recibió este nivel estratigráfico (A4) corresponde a Martínez (2001) quien lo designó como Geosol Mar del Plata. Schnack et al. (1982) y Fasano (1992) habrían incluido esta unidad en la Formación Santa Clara y en el Miembro Superior de la Formación Santa Clara respectivamente. Por otra parte, Bidegain et al. (2005b) distinguieron este paleosuelo y lo incluyeron a la base de la Formación Buenos Aires. 
En algunos sectores la unidad A4 y en otros la A3 se apoyan en discordancia sobre la unidad designada como A5. Esta última está integrada por una sucesión de estratos tabulares, de colores rojizos y amarillentos (gley), que se vinculan a un ambiente fluvial de energía relativamente más baja que las unidades suprayacentes. Los niveles rojizos corresponderían a rellenos de canal, y los niveles gley a planicies de inundación y a pequeñas lagunas. El reemplazo de ambas facies se da tanto en sentido vertical como horizontal. Los datos obtenidos en estos niveles gley evidencian un fuerte proceso de destrucción de los minerales magnéticos litogenéticos (titanomagnetita) que habría generado la disminución de concentración de los mismos y la formación de fases antiferromagnéticas; en condiciones acuicas, propias de ese tipo de ambiente. Los colores gley, que variaron entre distintos matices de amarillo (2,5Y a 5Y), se vincularían a presencia de óxidos y oxhidróxidos de hierro (férrico), de comportamiento antiferromagnético y de coloraciones "ocres"; los mismos se presentarían dispersos en la masa del sedimento y/o recubriendo principalmente a los granos de cuarzo y plagioclasa. Asimismo, vinculado a los elevados porcentajes de expansión libre que presentaron estos niveles, no se descarta que la coloración podría vincularse también a la presencia de smectitas ricas en hierro (e.g. nontronita), que contienen cantidades variables de hierro férrico en su composición, y sus colores pueden ir del amarillo al verde (Komadel et al., 1990; Hradil et al., 2004; entre otros). Los niveles rojizos presentaron una mayor y mejor conservación de las (titano)magnetitas detríticas y menor presencia de fases antiferromagnéticas que los niveles gley; estos últimos presentaron menor concentración ferrimagnética y tamaños de grano magnéticos más pequeños que los depósitos fluviales suprayacentes; característica que estaría vinculada a la menor energía del ambiente.

La asociación A5 presentó direcciones de polaridad dominantemente normales que se asignaron al Cron Brunhes $(<0,781 \mathrm{Ma})$; no obstante en la base de de la misma, en el perfil en que presentó mayor espesor (PGA) se determinaron direcciones de polaridad inversa que se atribuyeron al Cron Matuyama, específicamente a Matuyama Superior (0,781 - 0,998 Ma). En función de que la edad mínima atribuida a la asociación A4 correspondería al estadio isotópico 7, la edad mínima para A5 sería el límite inferior de dicho estadio isotópico (240 Ka); dado que la fauna fósil reportada para esta unidad corresponde al Piso Ensenadense, la edad minina según este esquema sería ca 450-500 Ka (Cione et al., 2007). Esta unidad se correspondería al Miembro Inferior de la Formación Santa Clara (Fasano, 1991) y a la Formación Ensenada (Bidegain et al., 2005b). Asimismo se correlacionaría parcialmente con la parte inferior de la Formación Arroyo Seco y probablemente con la Formación Miramar (Kraglievich, 1959), con el alomiembro medio de la Aloformación Punta San Andrés (Zárate, 1989) y con el Ensenadense de Ameghino (1908). 
La unidad litoestratigráfica U-SB3/4, determinada en la sección de Sierra Bachicha, por debajo de la Formación Vela, se interpreta como una sucesión de depósitos coluviales distales, con abundante participación de material de composición alóctona (loessoide). Presenta niveles de paleosuelos que reflejan momentos de estabilidad entre distintos pulsos de sedimentación. La concentración magnética es relativamente elevada, sobre todo en el material parental; en los paleosuelos es notablemente menor. Se infiere que el paleosuelo del tope habría comenzado su desarrollo en condiciones de abundante humedad y con ciclos de larga permanencia de agua. En una primera etapa de la pedogénesis, se habría producido la destrucción parcial y reducción del tamaño de grano de las titanomagnetitas litogenéticas; posteriormente, las condiciones habrían cambiado a períodos más cortos de permanencia de agua en el suelo, permitiendo de ese modo la neoformación de partículas SP y DS, sin destrucción total de los minerales magnéticos previos. En este paleosuelo se determinó un cambio de polaridad magnética cuya edad mínima sería la del límite Brunhes-Matuyama (0,781 Ma), no obstante se interpreta que el material original del mismo se habría depositado durante polaridad inversa; el desarrollo del paleosuelo en parte habría sucedido durante un período con polaridad normal (Brunhes), afectando las direcciones de magnetización del sector superior del mismo. Asimismo en esta unidad se determinaron otros dos cambios de polaridad a los que se le atribuyeron edades mínimas de 1,072 Ma (límite Matuyama inferior-Jaramillo) y de 1,778 Ma (límite Matuyama medio-Olduvai); como se dijo anteriormente no se descarta que pueda alcanzar edades más antiguas. Esta unidad correspondería al Piso Ensenadense y probablemente al Marplatense $(<3,2 \mathrm{Ma})$.

En función de la edad mínima asignada, la parte superior de la unidad litoestratigráfica U-SB3/4 habría sido coetánea a la parte basal de la unidad A5, de polaridad inversa, del perfil GADA; en tanto sería correlacionable a las unidades equivalentes de esta última; asimismo U-SB3/4 se correlacionaría con la Formación Ensenada (Riggi et al., 1986); con la parte inferior de la Formación Arroyo Seco; con la Formación Miramar (Kraglievich, 1959); y con el alomiembro medio, y probablemente inferior, de la Aloformación Punta San Andrés (Zárate, 1989).

En la mayoría de los perfiles del sector de Sierras de Tandil y en la localidad de San Manuel (sector de Sierras de Balcarce), por debajo de la Formación Vela se presenta la Formación Barker (Rabassa, 1971, 1973). Esta corresponde principalmente a limos gruesos y arenas muy finas, con litificación parcial, con contenidos variables de arcilla; algunos niveles presentaron acumulaciones psefíticas y clastos, correspondientes a fragmentos de rocas (precámbricas y paleozoicas) y a limolitas retransportadas. Su coloración es más rojiza que las unidades descriptas anteriormente. Presenta estructuras sedimentarias difusas, generalmente estratificación entrecruzada y laminación paralela, que son consistentes con ambiente fluvial; no obstante, en el perfil de María Ignacia se reconoció una capa de limos masivos, probablemente vinculados a ambiente eólico. Los rasgos pedogenéticos son prácticamente 
constantes en toda la formación; no obstante se reconocieron niveles de paleosuelos conspicuos. Los resultados paleomagnéticos, conjuntamente con los restos fósiles hallados, permiten establecer una edad mínima entre 3,1 y 4,2 Ma, es decir Plioceno (Cron Gauss y Gilbert). Los parámetros magnéticos evidenciaron una mineralogía magnética muy homogénea. La concentración magnética en esta unidad es la más elevada de las unidades estudiadas; asimismo presentó la contribución de partículas magnéticas ultrafinas (SP) y finas (DS) más elevada. Cabe señalar, que si bien el aporte de tales partículas es mayor que en otras unidades formacionales, el incremento de las mismas es mayor en los paleosuelos y podría corresponder a maghemita pedogenética. Aspecto relevante que genera la diferencia de registro entre el sector serrano y el costero. No se registraron indicios de destrucción de la (titano)magnetita detrítica; esto indicaría que la permanencia del agua en el suelo no fue demasiado prolongada. La presencia constante de rasgos pedogenéticos, ligada a la presencia constante de partículas SP y DS, así como la homogeneidad de los parámetros magnéticos sugieren que la depositación habría sido relativamente lenta. El patrón de comportamiento de los parámetros magnéticos en los paleosuelos es consistente con el determinado en los suelos actuales de la región; esto podría indicar regímenes de humedad semejantes; se deduce que el clima durante la depositación de la Formación Barker habría sido más estable que el actual, consistente con el Plioceno; no se descarta que la temperatura media haya sido algo más elevada. Esta unidad se considera equivalente a la unidad Litoestratigráfica 1 (Zárate y Mehl, 2010) de la cuenca del arroyo Azul y a la “formación El Polvorín" (Poiré et al., 2005) en Sierras Bayas (Olavarría). Cabe consignar que en esta última, fueron citados restos fósiles asignados al Piso Chapadmalalense (De los Reyes et al., 2013; Zurita et al., 2014; Zamorano et al., 2014). Además, Gómez Samus et al. (2014) registraron direcciones de polaridad normal que asignaron al Cron Gauss, consistente con una edad Pliocena. La Formación Barker se correlacionaría con parte de la Formación Chapadmalal (Kraglievich, 1959); con la aloformación Playa los Lobos y probablemente la aloformación Playa San Carlos (Zárate, 1989); y con el Chapadmalense (Ameghino, 1908). Tanto el registro fosilífero como los estudios paleomagnéticos avalan estas correlaciones; en cuanto a esto último cabe resaltar que Orgeira y Valencio (1988) y Rico et al., (2015a) registraron direcciones normales e inversas que asignaron a los crones Gauss y Gilbert (Plioceno) en unidades asignadas a la Formación Chapadmalal, en acantilados marinos entre Mar del Plata y Miramar. No se descarta una posible correlación con la Formación Monte Hermoso (Fidalgo et al., 1975; Zavala, 1993), descripta para los acantilados marinos de la zona de Farola Monte Hermoso, en el sur de la provincia de Buenos Aires.

La unidad más antigua corresponde a la unidad litoestratigráfica U-VC6, determinada entre la Formación Barker y las rocas precámbricas de la Formación Loma Negra en el perfil de Villa Cacique; los contactos, superior e inferior, son mediante discordancia erosiva. Esta unidad corresponde a un conglomerado matriz sostén que grada a clasto sostén. Los clastos corresponden a fragmentos angulosos 
de sedimentitas precámbricas, y quizá cámbricas y ordovícicas, compuestos dominantemente por fragmentos de calizas y secundariamente cuarcitas. La matriz de esta unidad es de color rojizo, arcillo limosa, muy dura en seco, con abundantes Slickensides y agregados cuneiformes; los ensayos de expansión libre indicaron elevada expansión, sugiriendo que las arcillas corresponden a la familia de las smectitas. Los parámetros magnéticos indicaron que la (titano)magnetita dominaría la señal magnética; esto es consistente con los depósitos del Cenozoico tardío. La concentración magnética de esta unidad es la más baja del sector serrano, el análisis de los datos obtenidos indica la presencia de partículas DS, aunque escasa. Las concreciones de Carbonato de Calcio e impresiones radiculares son abundantes. Se interpreta que la unidad U-VC6 es un depósito de remoción en masa entremezclado con depósitos alóctonos (loessoides) que fueron afectados por pedogénesis. La edad mínima para la misma es de 3,6 Ma y la máxima estaría entre 10 y $12 \mathrm{Ma}$, coincidentemente con el inicio de la sedimentación del ciclo Cenozoico tardío, según Zárate (2005). Las correlaciones con otras unidades son tentativas. Martínez (2001) (en Sierras de Balcarce) y Poiré et al. (2013) (en Sierras Bayas) indicaron la presencia de niveles conglomerádicos apoyados sobre rocas precámbrica; debido a la posición estratigráfica, estos niveles podrían correlacionarse. Dado que el rango de edad planteado es amplio, la misma podría correlacionarse tanto con unidades del Plioceno como del Mioceno tardío. En el primero de los casos se correlacionaría con la parte inferior de la Formación Chapadmalal (Kraglievich, 1959), con la aloformación Playa San Carlos (Zárate, 1989). En este sentido, cabe mencionar que Rico et al. (2015), en la base del acantilado del balneario de San Eduardo del Mar determinaron un nivel arcilloso, rojizo y con abundantes Slickensides, con importantes similitudes con la matriz de la unidad U-VC6, que asignaron a la aloformación Playa San Carlos. Además, cabe la posibilidad de correlación con la Formación Monte Hermoso (Fidalgo et al., 1975; Zavala, 1993). Si consideramos una edad miocena, podrían correlacionarse con unidades atribuidas a esa edad, descriptas en la provincia de La Pampa (Fm. Cerro Azul; Llambías, 1975), en la zona de Ventania (Fm. Saldungaray; Pascual, 1961) y en la cuenca interserrana (Fm. Irene; Reig, 1957). 
10.1 Tabla del capítulo 10

\begin{tabular}{|c|c|c|c|c|c|c|c|c|c|c|c|}
\hline & & 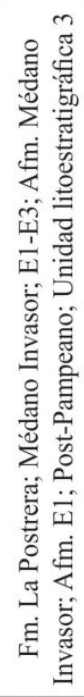 & 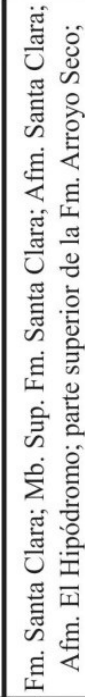 & 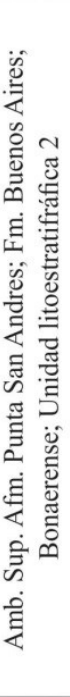 & 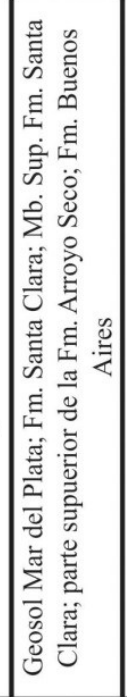 & & 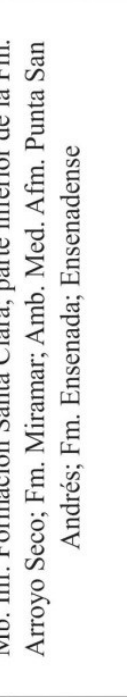 & $\sigma$ & 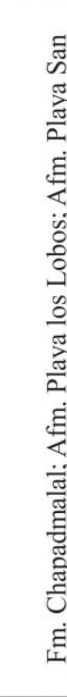 & 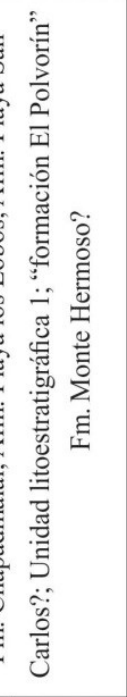 & 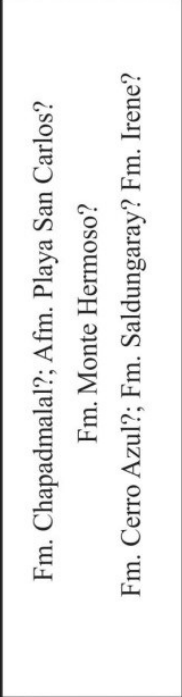 \\
\hline & & $\frac{\widetilde{\pi}}{\vec{N}}$ & 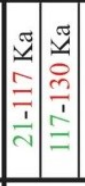 & 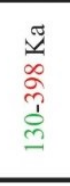 & 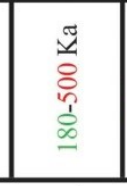 & 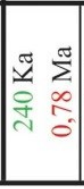 & $\begin{cases}\sum_{\infty}^{\pi} \sum_{\infty} & \sum^{\pi} \\
0 & 0 \\
0 & =\end{cases}$ & $\begin{array}{l}\sum_{n}^{\pi} \\
\text { N } \\
\text { n }\end{array}$ & $\underset{m}{\sum^{n}}$ & 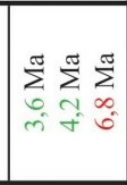 & 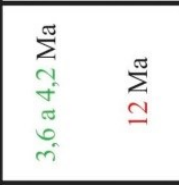 \\
\hline & & 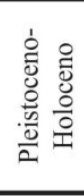 & & & 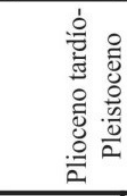 & & & & & 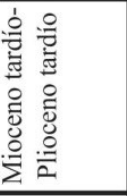 & 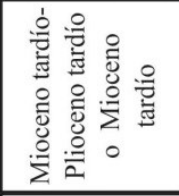 \\
\hline & & 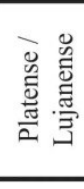 & 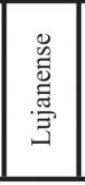 & & 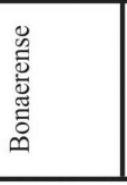 & & 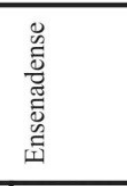 & $\begin{array}{l}\mathscr{D} \\
\stackrel{\vec{E}}{\Xi}\end{array}$ & & 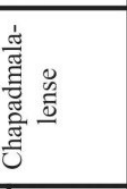 & 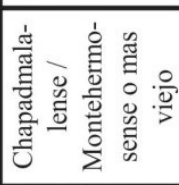 \\
\hline & & & & 造 & & & 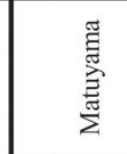 & & $\begin{array}{l}\text { 岁 } \\
\text { 胥 }\end{array}$ & $\begin{array}{l}\text { है } \\
\text { गे }\end{array}$ & 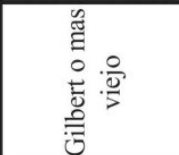 \\
\hline 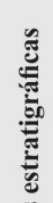 & 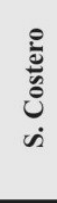 & Z & ₹| & 2 & \& & 2 & & & & a. & \\
\hline 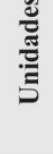 & 总 & 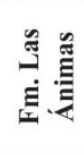 & a. & 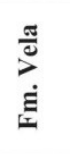 & & & $\begin{array}{l}\text { ले } \\
\text { की } \\
\text { की }\end{array}$ & & & 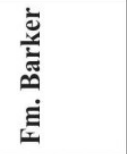 & נ) \\
\hline
\end{tabular}

Tabla 10.1. Cron Magnético, Piso para América del Sur, subciclo de sedimentación del Cenozoico tardío, edades mínimas y máximas de las unidades de sedimentación, equivalencias y correlaciones de las unidades litoestratigráficas del sector serrano y las asociaciones del sector costero. 


\section{CAPITULO 11. CONCLUSIONES}

Las sucesiones sedimentarias estudiadas son de origen dominantemente fluvial; no obstante, la influencia de depositación coluvial es importante en los sectores serranos. Sólo la unidad más reciente, afectada por el ciclo pedogenético actual presenta características de depósito eólico (loess).

Las fracciones granulométricas dominantes corresponden a limo grueso y arena muy fina. Seguidas en general por fracciones más finas. La presencia de clastos más gruesos es habitual en el sector serrano.

Los sectores de Sierras de Tandil y Sierras de Balcarce presentan similitudes estratigráficas. La mayoría de las unidades litológicas determinadas se corresponden con unidades litoestratigráficas propuestas por otros autores; se ha priorizado la utilización del esquema de Rabassa (1971, 1973), que si bien es el más completo para la zona serrana de Tandilia, se constató la presencia de otras unidades no contempladas en dicho esquema.

El esquema definido para el sector serrano consta de cinco unidades litoestratigráficas: Formación Las Ánimas; Formación Vela; Unidad litoestratigráfica U-SB3/4; Formación Barker; Unidad litoestratigráfica U-VC6, donde Las Ánimas es la más joven y la U-VC6 la más antigua. Las unidades USB3/4 y U-VC6 no se corresponden con ningún esquema precedente para la provincia Geológica de Tandilia.

Se hallaron restos fósiles con importancia bioestratigráfica hacia el techo de la Formación Barker, en su localidad tipo. Estos son los primeros hallazgos para dicha unidad en Sierras de Tandil. Los especímenes fueron identificados como Actenomys y Lagostomus (Lagostomopsis) y corresponden al Piso Chapadmalalense-Montehermosense (3,2-6,8 Ma).

En el sector costero al norte de Mar del Plata, si bien fue posible también vincular y correlacionar las unidades litológicas de las distintas secciones estratigráficas, la asignación de ellas a esquemas estratigráficos precedentes resultó dificultosa y ambigua; en tanto, las unidades correlacionadas fueron tratadas con nombres informales, denominadas asociaciones de unidades; este esquema constó de cinco asociaciones (A1 - A5), siendo A1 la más joven y A5 la más antigua; se distinguieron además dos depósitos ubicados temporalmente entre las asociaciones A2 y A3, con idéntica posición estratigráfica pero de composición litológica marcadamente diferente. Uno corresponde a sedimentos continentales fuertemente pedogenizados, el otro se vincula a una ingresión marina, que se atribuye al "Belgranense" 
(Estadío Isotópico 5e). Fue posible correlacionar la asociación A1 con la Formación Las Ánimas y la asociación A3 con la Formación Vela.

En cada sección estratigráfica analizada se determinaron zonas de magnetopolaridad, en función de las unidades litológicas correlacionadas, de los restos fósiles y de los antecedentes geológicos y paleontológicos de la zona. Las mismas fueron asignadas a crones (y subcrones) de la escala de inversiones de polaridad magnética. Los crones corresponden a Brunhes, Matuyama, Gauss y Gilbert.

El Cron Brunhes $(<0,781 \mathrm{Ma})$, de polaridad normal, fue el más extendido y fue determinado en todos los perfiles analizados. En el sector serrano se determinó para las formaciones Las Ánimas y Vela. Prácticamente todas las unidades del sector costero se depositaron durante este cron, sólo quedó excluida la parte inferior de la asociación A5 (Ensenadense) de la sección GADA, de polaridad inversa, asignada al cron Matuyama superior $(0,781-1,072 \mathrm{Ma})$.

En el tope de la unidad litoestratigráfica U-SB3/4 (Sierra Bachicha) se constató un paleosuelo donde se registró un cambio de polaridad; esto sugirió una edad superior al límite Brunhes-Matuyama $(0,781 \mathrm{Ma})$ para la mayor parte de la unidad. Se propone, en base a las correlaciones estratigráficas y a los antecedentes geológicos, una edad máxima para la unidad de 3,2 Ma.

Los crones Gauss (2,581 - 3,596 Ma) y Gilbert $(3,596$ - 6,033 Ma) fueron propuestos para la Formación Barker. Se establece que la edad de esta unidad es superior a 3,1 Ma.

La unidad más antigua corresponde a la unidad litoestratigráfica U-VC6. Esta unidad no pudo ser muestreada desde el punto de vista paleomagnético; no obstante, es posible proponer para la misma una edad mayor a 3,596 Ma e inferior a $12 \mathrm{Ma}$.

Las sucesiones sedimentarias del sector serrano abarcan lapsos mayores, que irían desde el Plioceno (o incluso Mioceno) hasta el Pleistoceno tardío-Holoceno, presentando hiatus significativos. El hiatus presente entre las formaciones Vela y Barker en Sierras de Tandil, abarcaría al menos 2,6 Ma. La interpretación de este lapso sin registro sedimentario surge del análisis de campo, las correlaciones lito y magnetoestratigráficas establecidas, de los fósiles y de los antecedentes geológicos y paleontológicos para la región. Éste es sin duda un aspecto importante a resaltar; motiva indudablemente la posibilidad de encarar futuras investigaciones vinculadas a la sedimentación neogena-cuaternaria de la región pampeana. Las mismas deberán involucrar enfoques desde la Neotectónica, la Sedimentología, la Geomorfología y la Geología del subsuelo. 
En el sector costero los espesores de las secciones fueron semejantes a los del serrano. Se determinaron edades más jóvenes, que irían desde el Pleistoceno inferior y medio hasta el Pleistoceno tardío-Holoceno, con una mayor continuidad en el registro. Si bien se evidencia la presencia de discordancias, éstas no representan hiatus tan significativos como los indicados para el sector serrano.

Un aspecto importante a resaltar es el hallazgo de tres zonas con polaridad inversa incluidas en depósitos asignados al cron Brunhes en el sector costero. Esto motiva a la realización de futuras investigaciones a los fines de analizar el posible registro de eventos/excursiones paleomagnéticas. Al momento se especula que las mismas podrían corresponder a Mono Lake-Laschamp (32 - $41 \mathrm{Ka})$, al evento Blake (110 - $125 \mathrm{Ka})$ y al evento CR1 (315 - $325 \mathrm{Ka})$.

Se determinó que la composición magnética dominante de los sedimentos estudiados corresponde a especies ferrimagnéticas, tales como magnetita-titanomagnetita-maghemita. Se advirtió la presencia de especies antiferromagnéticas (e.g. hematita), cuya señal magnética estaría enmascarada por fases ferrimagnéticas. Se dedujo que la presencia de especies antiferromagnéticas sería más abundante en niveles hidromórficos y en los paleosuelos del sector costero.

Según las técnicas utilizadas, el tamaño de grano magnético de los minerales que dominan la señal magnética sería principalmente dominio simple (DS) y dominio pseudo simple (DPS), con cantidades variables de partículas superparamagnéticas (SP) y multidominio (MD).

En todos los suelos y paleosuelos se detectó un incremento en minerales magnéticos finos DS y de la transición DS - SP. La contribución SP sería en general moderada a baja; sin embargo, en suelos y paleosuelos del sector serrano se advirtió un notable incremento de estas partículas. En los paleosuelos del sector costero, en general, no se detectaron incrementos significativos en la contribución SP.

El comportamiento de los parámetros magnéticos respecto a la pedogénesis presentó dos patrones contrapuestos, que se refieren principalmente a los valores de susceptibilidad magnética $\left(\chi_{\mathrm{bf}}\right)$. En el solum de los suelos actuales y en la mayoría de los paleosuelos de la Formación Barker los valores de $\chi_{b f}$ se incrementaron; en cambio en los paleosuelos del sector costero y de la unidad litoestratigráfica U-SB3/4 los valores disminuyeron.

Donde prevalece el patrón de incremento de la $\chi_{\mathrm{bf}}$, también se incrementó la susceptibilidad anhistérica $\left(\chi_{\mathrm{MRA}}\right)$ y en menor medida la magnetización remanente isotermal de saturación (MRIS). Se produjo un incremento de la $\chi_{\mathrm{df} \%}$ indicando mayor contribución de partículas SP, y se registró un descenso de los valores de $\mathrm{H}_{\mathrm{cr}}$, que podrían atribuirse a la neoformación de maghemita. Este proceso se vincula a la 
incorporación de partículas SP y DS de origen pedogenético, sin oxidación de la (titano)magnetita litogenética.

En los paleosuelos donde se registró un descenso de la $\chi_{\mathrm{bf}}$ éste fue acompañado en general por una caída de los valores de MRIS y generalmente de $\chi_{\text {MRA. }}$ En la mayoría de los paleosuelos del sector costero el $\chi_{\mathrm{d} \mathrm{r} \%}$ presentó valores bajos, sin variación significativa y la $\mathrm{H}_{\mathrm{cr}}$ se incrementó. Este patrón es el más reportado en paleosuelos de la región pampeana. Se relacionaría principalmente a la oxidación y “disolución" de la (titano)magnetita litogenética; generándose una reducción del tamaño de los granos y consecuentemente una pérdida de masa, que da como resultado un descenso en la concentración magnética.

Los comportamiento expuestos estarían en función del tiempo de permanencia del agua en el suelo; que se relaciona a la clase natural de drenaje (vinculada principalmente a la topografía y a la permeabilidad del material) y a las condiciones climáticas. En suelos con prolongada permanencia del agua, es decir con tendencia a las condiciones hidromórficas, se generarían procesos que conducen a la "destrucción" de la magnetita litogenética, mediante la oxidación de la misma. En tanto, en suelos con alternancia de ciclos húmedos y secos, de corta duración, y con predominio de condiciones aeróbicas, se produciría la neoformación de partículas de magnetita y/o maghemita, así como la conservación de la magnetita litogenética.

Cabe destacar que algunos paleosuelos, como el del tope de la unidad litoetratigráfica U-SB3/4 y el de la asociación A5, presentaron un comportamiento ambiguo, con descenso de la susceptibilidad pero con incremento del $\chi_{\mathrm{df} \%} \mathrm{y}$ disminución de la $\mathrm{H}_{\mathrm{cr}}$. Fue posible explicar esto a través de una combinación de los dos patrones de comportamiento. En una primera etapa estos suelos se habrían desarrollado bajo condiciones de mayor humedad y permanencia de agua en el suelo, que habría generado la oxidación, "disolución" y consecuente reducción del tamaño de grano de la (titano)magnetita litogenética; posteriormente los suelos habrían continuado su desarrollo bajo condiciones de más sequedad, generándose la neoformación de partículas de maghemita (y/o magnetita) fina y ultrafina.

Se determinó que el contenido de $\mathrm{Fe}_{2} \mathrm{O}_{3}$ en los horizontes $\mathrm{Bt}$, tanto de suelos actuales como de paleosuelos, se incrementó respecto del material original, así como respecto al horizonte A en suelos actuales. El análisis de este fenómeno, teniendo en cuenta los parámetros magnéticos, permitió esbozar algunas hipótesis. Se infiere que la iluviación de hierro es un proceso factible; se estima que el mismo se incorporaría a los horizontes iluviales conformando, según los casos, minerales diferentes. En parte podría deberse a que algunos minerales de arcilla presentan hierro en su composición. Asimismo, en los suelos donde se da el patrón de incremento de la susceptibilidad magnética, la acumulación de hierro consistiría 
en especies ferrimagnéticas (magnetita y/o maghemita) y probablemente paramagnéticas (e.g. lepidocrocita). En cambio, donde se da el patrón de descenso de la susceptibilidad, con incremento de la coercitividad de la remanencia, la acumulación correspondería a óxidos y oxihidróxidos de hierro antiferromagnéticos y probablemente paramagnéticos.

Fue corriente detectar que en niveles con elevado contenido de $\mathrm{CaCO}_{3}$ se produce un incremento relativo de $\mathrm{Fe}_{2} \mathrm{O}_{3}$, sin presentar prácticamente diferencias en los parámetros magnéticos. Se infiere que los minerales ricos en hierro que allí se concentraron corresponden a especies paramagnéticas, del tipo lepidocrocita, akaganeita. Se plantea que el mecanismo de concentración de tales óxidos se debería a que el carbonato de calcio podría generar la floculación de los mismos, cuando se movilizaban en suspensión coloidal a través de los poros del sedimento. Esto se debería a que la presencia de $\mathrm{CaCO}_{3}$ genera valores de $\mathrm{pH}$ por encima de 7 , con valores cercanos al punto isoeléctrico de dichos óxidos. 


\section{AGRADECIMIENTOS}

Muchísima gente contribuyó a hacer esto posible.

En primer lugar voy a agradecer a lo más importante: mi familia. Su apoyo fue constante desde que tengo memoria. Mi abrazo más especial es para mis viejos, sin su ayuda esto nunca hubiera sucedido.

Quiero continuar con Juan Carlos Bidegain, mi director, mi maestro. Por la confianza. Por la minuciosa corrección de los manuscritos. Por el apoyo incondicional y las buenas discusiones. Por enseñar a aprender.

A Yamile Rico, mi compañera de laboratorio y amiga. Por su contante estímulo, por las buenas charlas.

A Jorge Rabassa, co-director de las becas del CONICET. Por la revisión del manuscrito. Sus comentarios y sugerencias contribuyeron a mejorar la versión original.

A Martín Hurtado, co-director de la carrera de doctorado de la FCNyM. Por atender a mis consultas.

A los evaluadores de esta tesis: Marcelo Zárate, Ana Sinito y Luis Guarracino. Sus correcciones, comentarios y sugerencias han ayudado a mejorar sustancialmente la versión final.

A Sandra Jurado, por la buena compañía durante mis primeros tiempos en el LEMIT.

Al LEMIT y al Área de Paleomagnetismo, por las puertas abiertas y por permitir que allí dé mis primeros pasos en el camino de la investigación.

Sin financiamiento todo hubiera sido más difícil; es por ello que agradezco al CONICET, a la CIC y al LEMIT.

Agradezco a todos los que me acompañaron durante las tareas de campo; fundamentalmente a Leandro Remón, Yamile Rico, Numa Sosa, Leonardo Sierra y Juan Carlos Bidegain.

A la gente del IFAS de la Universidad del Centro, por permitir que allí realice gran parte del trabajo de laboratorio. Especialmente agradezco a Marcos Chaparro, Ana Sinito, Claudia Gogorza, Alicia Irurzun, Carolina Marié y Daniel Gargiulo. Entre ellos, un gran abrazo es para Daniel, quien que me 
brindó hospedaje, donde las charlas se extendieron a cenas y amistad; y no me olvido de Laura, su compañera, a quien también saludo y agradezco su hospitalidad.

A María Julia Orgeira quien me dio la posibilidad de realizar mediciones en los laboratorios de la UBA y además brindó importantes comentarios, consejos y bibliografía.

A la gente del Área de Química del LEMIT, quienes realizaron desinteresadamente las determinaciones químicas mediante fluorescencia. Gracias Silvia Zicarelli, Victor Parodi, Maxi y Maira.

Al Instituto de Geomorfología y Suelos por las determinaciones granulométricas. Destacó aquí a Analía Corrales y Ana Giorgis, quienes realizaron los ensayos.

Al Centro de Investigaciones Científicas por los difractogramas de rayos X.

A la gente del Área de Petrología y Mineralogía del LEMIT, por asesorarme durante mis observaciones en lupa y microscopio: Gracias Alejandro Ribot, Daniel Alves, Marcos Panei y Leandro Remón.

Al Museo Pachamama, especialmente a Pablo Straccia, por abrirnos las puertas del museo y permitir que nos alojemos en compañía de Gliptodontes y Macrauquenias.

A la Empresa LOMA NEGRA por las facilidades para el muestreo en Villa Cacique; el más grato reconocimiento es para Fabián Lastra y Miguel García; por la predisposición y buena onda.

A Pedro Maccario, por permitir que trabajemos en las canteras bajo su administración.

Agradezco también a Diego Verzi y Pablo Straccia quienes ayudaron en la identificación de los restos óseos.

A Jorge Genise por asesorarme con las trazas fósiles.

A los que me dan una mano con el inglés: Juan Carlos Bidegain, Beatriz Pión e Iván Tiemersma.

Y finalmente, debo agradecer, y muy profundamente, a Vale, mi compañera, por su apoyo constante, por su estímulo y por aguantarme en los momentos de alienación. 


\section{BIBLIOGRAFÍA}

\subsection{Artículos citados en el texto}

Almeida, F. (1971): Geochronological division of the Precambrian of South America. Revista Brasileira de Geociencias, 1: 3-21.

Ameghino, F. (1881): Mamíferos fósiles del terreno pampeano. En: Masson-Igon Hermanos (Eds): La antiguedad del hombre en el Plata. Buenos Aires-Paris (309pp).

Ameghino, F. (1889): Contribución al conocimiento de los mamíferos fósiles de la República Argentina. Academia Nacional de Ciencias de la República Argentina (Córdoba). Buenos Aires, 6:1-1027.

Ameghino, F. (1898): Sinópsis geologico-paleontológica. Segundo Censo Nacional de la República Argentina. Capítulo 1. Territorio. p111-255.

Ameghino, F. (1908): Las formaciones sedimentarias de la región litoral de Mar del Plata y Chadmalal. Anales del Museo Nacional de Buenos Aires. 10 (3):343-428.

ASTM standard D4546. (1997): Standard Test Methods for One Dimensional Swell or Collapse of Soils.ASTM standar Book 04.08.

Avramov, V., Jordanova, D., Hoffman, V., Roesler, W. (2006): The role of dust source area and pedogenesis in three loess-paleosol sections from north Bulgaria: a mineral magnetic study. Studia Geophysica et Geodaetica, 50: 259-282.

Banerjee SK y Hunt C (1993): Separation of local signals from the regional paleomonsoon record of the Chinese loess plateau: a rock-magnetic approach. Geophys Res Lett 20:843-846

Bartel, A.A. (2009): Caracterización magnética de una climosecuencia de suelos entre el sureste de la provincia de La Pampa y el litoral atlántico. Tesis Doctoral Universidad Nacional del Sur, Argentina, 325 pp.

Bartel, A., Bidegain, J.C., y Sinito, A.M. (2011): Magnetic parameter analysis of a climosequence of soils in the Southern Pampean Region, Argentina. Geofísica Internacional, 50: 9- 22 
Beilinson, E. (2009): Análisis de facies y paleoambiental de alta resolución de la Aloformación Punta San Andrés (Plio-Pleistoceno), provincia de Buenos Aires, Argentina. Latin American Journal of Sedimentology and Basin Analysis 16 : 57-74.

Beilinson, E. (2011): Estratigrafía secuencial de alta resolución y análisis arquitectural de cuerpos en sistemas fluviales de la Aloformación Punta San Andrés (Plio-Pleistoceno), Barrancas de Miramar a Mar del Plata. Tesis doctoral 1142, Universidad de La Plata (inédita), 320 p., La Plata.

Bidegain, J.C.(1991): Sedimentary development, magnetostratigraphy and sequence of events of the Late Cenozoic in Entre Rios and surrounding areas in Argentina.Doctoral Thesis, Stockholm University 345 p., Stockholm.

Bidegain, J. (1998): New evidence of the Brunhes/Matuyama polarity boundary in the Hernandez-Gorina quarries, nothwest of the city of La Plata, Buenos Aires Province, Argentina. Quaternary of South America and Antartic Peninsula, 11(12): 207-229

Bidegain, J.C. y Rico, Y. (2004): Mineralogía magnética y registros de susceptibilidad en sedimentos cuaternarios de polaridad normal (Brunhes) y reversa (Matuyama) de la cantera de Juárez, provincia de Buenos Aires. Revista de la Asociación Geológica Argentina, 59 (3): 451-461 (2004).

Bidegain, J.C. y Rico, Y. (2012): Magnetostratigraphy and magnetic parameters of a sedimentary sequence in Punta San Andrés, Buenos Aires, Argentina. Quaternary International, 253: 91-103.

Bidegain, J.C., Pavlicevic, R., Iasi, R. y Pérez, R.H., (1996): Susceptibilidad magnética y concentraciones de FeO en loess y paleosuelos cuaternarios, como indicadores de cambios paleoambientales y paleoclimàticos. Proc. XIII ${ }^{\circ}$ Congr. Geol. Argentino y III ${ }^{\circ}$ Congr. de Expl. de Hidrocarburos, II: 521-535, Buenos Aires.

Bidegain, J.C., van Velzen, A.J. y Rico, Y. (2001): Parámetros magnéticos en una secuencia de loess y paleosuelos del Cenozoico tardío en la Cantera de Gorina, La Plata: su relevancia en el estudio de los cambios paleoclimáticos y paleoambientales. Revista de la Asociación Geológica Argentina 56: 503-516.

Bidegain, J.C., Terminiello, L. Rico Y, Mercader, R.C. y Aragon, E. (2004): Mineralogía magnética en la transición Brunhes/Matuyama. Pleistoceno de la provincia de Buenos Aires. Rev. Asoc. Geol. Argent. v.59 n.2 Buenos Aires abr./jun. 2004

Bidegain, J.C., Evans, M.E. y van Velzen, A.J. (2005a): A magnetoclimatological investigation of Pampean Loess. Geophysics Journal international 160: 55-62. 
Bidegain, J.C., Osterrieth, M.L., Van Velzen, A., Rico, Y., (2005b): Geología y registros magnéticos entre arroyo La Tapera y Santa Clara del Mar, Mar del Plata. Revistade la Asociación Geológica Argentina 60 (3), 143-150. Buenos Aires.

Bidegain, J.C., van Velzen, A.J. y Rico, Y. (2007): The Brunhes/Matuyama boundary and magnetic parameters related to climatic changes in Quaternary sediments of Angentina. Journal of South American Earth Sciences 23: 17-29.

Bidegain, J.C., Rico Y., Bartel, A., Chaparro, M.A.E. y Jurado, S.S. (2009): Magnetic parameters reflecting pedogenesis in Pleistocene loess deposits of Argentina. Quaternary international 209: 175-186.

Bidegain, J.C., Jurado, S., Chaparro, M.A.E., Gómez Samus, M., Zicarelli, S. y Parodi, A.V. (2012): Magnetostratigrapgy and environmental magnetism in a Pleistocene sedimentary sequence, Marcos Paz, Argentina. Environmental Earth Sciences, 69: 749-763.

Bigazzi, G., F.P. Bonadonna, G. Leone \& G. Zanchetta.(1995): Primeros datos geoquímicos y geocronológicos a partir de algunas cineritas del área bonaerense. En: M.T. Alberdi, G. Leone \& E.P. Tonni (eds.), Evolución biológica y climática de la región pampeana durante los últimos cinco millones de años. Un ensayo de correlación con el Mediterráneo occidental, Museo Nacional de Ciencias Naturales, Monografías, CSIC, 12: 107-118

Blanchet, C., Thouveny, N., Vidal, L., Leduc, G., Tachikawa, K., Bard, E., Beaufort, L. (2007): Terrigenous input response to glacial/interglacial climatic variations over southern Baja California: a rock magnetic approach. Quat. Sci. Rev. 26, 3118-3133.

Blasi, A., Prieto, A., Fucks, E. y Figini, A. (2009): Análisis de las nomenclaturas y de los esquemas estratigráficos del Pleistoceno Tardío-Holoceno en la cuenca del río Luján, Buenos Aires, Argentina. Ameghiniana, 46: 373-390

Bloemendal J y Liu X (2005): Rock magnetism and geochemistry of two plio-pleistocene Chinese loess-paleosols sequences implications for quantitative paleoprecipitation reconstruction.Paleogeogr Palaoclimatol Paleoecol 226:149-166

Bobbio, M., Devincenzi, M, Orgeira, M. y Valencio D. (1986): La magnetoestratigrafía del Ensenadense y Bonaerense de la Ciudad de La Plata (excavación Nuevo Teatro Argentino): su significado geológico. Revista de la Asociación Geológica Argentina 41 (1-2): 7-21. 
Bogue, S.W. y Glen, J.M.G. (2010): Very rapid geomagnetic field change recorded by the partial remagnetization of a lava flow, Geophys. Res. Lett., 37.

Butler, R. F. (1992): Paleomagnetism: Magnetic Domains to Geologic Terranes. Boston, MA: Blackwell Science

Cabrera Á.L. (1976): Regiones fitogeográficas argentinas. En Kugler WF (Ed.) Enciclopedia argentina de agricultura y jardinería. Tomo 2. 2a edición. Acme. Buenos Aires. Argentina. Fascículo 1. pp. 1-85

Camilión, M.C. (1993): Clay mineral composition of pampean loess (Argentina). Quatarenary International. 17: 27-31.

Camps, P., Coe, R.S. y Prevot, M. (1999): Transitional geomagnetic impulse hypothesis: geomagnetic fact or rock-magnetic artifact?, J. geophys. Res., 104, 17 747-17 758

Chafetz, H.S., Akdim, B., Julia, R., Reid, A. (1998): Mn-and-Fe-rich black travertine shrubs: bacterially (and nannobacterially) induced precipitates. Journal of Sedimentary Petrology 68, 4042412

Chaparro, M.A.E. (2006): Estudio de parámetros magnéticos de distintos ambientes relativamente contaminados en Argentina y Antartida. Monografías del Instituto de Geofísica, UNAM, México. 107p.

Chaparro, M.A.E. y Sinito, A.M. (2004): An elternative experimental method to discrimínate magnetic phases using IRM acquisition curves and magnetic demagnetization by alterning field. Revista Brasileira de Geofísica, 22: 17-32.

Chlachula, J., Rutter, N.W. y Evans, M.E. (1997): A late Quaternary loess-paleosol record at Kurtak, southern Siberia.Canadian Journal of Earth Sciences 34: 679-686.

Cingolani, C. A. (2005): Unidades morfoestructurales (y estructuras menores) de la provincia de Buenos Aires. En: De barrio, R. E., Etcheverry, R. O., Caballé, M.F. y Llambías, E. (edit.): Geología y Recursos Minerales de la provincia de Buenos Aires. Relatorio del XVI Congreso Geológico Argentino, La Plata. Cap. II, pp. 21-30

Cingolani, C.A. (2010): The Tandilia System of Argentina as a southern extension of the Río de La Plata cratón: An overview. International Journal of Earth Science 100: 221-242.

Cionchi, J.L. (1997): Las reservas de aguas subterráneas disponibles en el Partido de General Pueyrredon (Provincia de Buenos Aires). Obras Sanitarias Mar del Plta SE, Informe OSSW-RH1/97. Mar del Plata, 15 pags. 
Cione, A.L. y Tonni, E.P. (1995): Chronostratigraphy and "Land mammal-ages": The Uquian problem. Journal of Paleontology 69: 135-159.

Cione, A. L. y Tonni, E.P. (2005): Bioestratigrafía basada en mamíferos del Cenozoico superior de la provincia de Buenos Aires, Argentina. $16^{\circ}$ Congreso Geológico Argentino, Relatorio 11: 183-200, La Plata.

Cione, A. L., Tonni, E.P. y San Cristóbal, J.O. (2002): Middle Pleistocene Marine Transgression in CentralEastern Argentina. Current Research in the Pleistocene 19:16-18.

Cione, A.L., Tonni, E.P., Bargo, S., Bond, M., Candela, A.M., Carlini, A.A., Deschamps, C.M., Dozo, M.T., Esteban, G. Goin, F.J. Montalvo, C.I., Nasif, N., Noriega, J.I., Ortiz Jaureguizar, E., Pascual, R., Prado, J.L. Reguero, M.A., Scillato-Yané, G.J., Soibelzon, L. Verzi, D.H., Vieytes, E.C., Vizcaíno, S.F. y. Vucetich, G.M. (2007): Mamíferos continentales del Mioceno tardío a la actualidad en la Argentina: cincuenta años de estudios. Ameghiniana Publicación Especial, 11: 257-278.

Clement, B.M., (2004): Dependence of the duration of geomagnetic polarity reversal on site latitude.Nature, 428(6983): 608-609.

Coe, R.S., Prevot, M. y Camps, P. (1995): New evidence for extraordinarily rapid change of the geomagnetic-field during a reversal, Nature, 374, 687-692.

Código Argentino de Estratigrafía. (1992): Asociación Geológica Argentina, Serie B(Didáctica y complementaria) 20, Corv64 pp.

Corbella, H., Nabel, P. y Martínez, G. (2000): Composición, edad y magnetoestratigrafía de las cineritas Camet en la costa atlántica bonaerense, Argentina. IX Congreso Geológico Chileno, Actas, 2-16-20, Puerto Varas.

Cornell R.M., Schwertmann U. (2003): The Iron Oxides, 2nd edn. Wiley-VCH

D’Orbigny, A. (1842): Voyage dans Ámérique Meridionalis.

Dalla Salda, L.H. e Iñiguez Rodríguez, A.M. (1979): La Tinta, Precámbrico y Paleozoico de Buenos Aires. $7^{\circ}$ Congreso Geológico Argentino, Actas 1: 539-550, Neuquén.

Dalla Salda, L, de Barrio, R.E., Echeveste, H.J. y Fernández, R.R. (2005): El basamento de las Sierras de Tandilia. En: R.E. de Barrio, R.O. Etcheverry, M.F. Caballé y E. Llambías (Editores), Geología y Recursos Minerales de la provincia de Buenos Aires. Relatorio del 16 Congreso Geológico Argentino:31-50. La Plata. 
Dangavs, N. (2005a): Los ambientes acuáticos de la provincia de Buenos Aires. En de Barrio, R., Etcheverry, R., Caballé, M. y Llambías, E. (eds.) $16^{\circ}$ Congreso Geológico Argentino, Relatorio 13: 219-236, La Plata.

Dangavs, N. (2005b): La Formación La Postrera I, II, III y IV de la Laguna Las Barrancas de Chascomús, provincia de Buenos Aires. $16^{\circ}$ Congreso Geológico Argentino, Actas 4: 115- 122, La Plata.

Dankers, P. H. M. (1978): Magnetic properties of dispersed natural iron-oxides of known grain-size, Ph.D. Dissertation, University of Utrecht.

Darwin, C. (1846): Geological observations on South America.Smith, Elder and Co.; 279p. London

Day, R., Fuller, M. y Schmidt, V. A., (1977): Hysteresis properties of titanomagnetites: grain-size and compositional dependence. Physics of the Earth and Planetary Interiors 13: 260-267. Amsterdam.

De los Reyes, M.; Poiré, D.G.; Soibelzon, L.; Zurita, A.E. \& Arouy, M.J. (2013): First evidence of scavenging in a Glyptodont (Mammalia, Glyptodontidae) from the Pliocene of the Pampean region (Argentina).Taphonomic and paleoecological remarks. Paleontologia electrónica, 16 (2)15A, 13

Demoulin, A.; Zárate, M.; Rabassa, J. (2005): Long-term landscape development: a perspective from the southern Buenos Aires ranges of east central Argentina. Journal of South American Earth Sciences, v. 19, p. 193 204, 2005.

Dearing, J.A., Dann, R.J.L., Hay, K., Lees, J.A., Loveland, P.J., band O’Grady, K., (1996): Frequency-dependent susceptibility measurements of environmental materials. Geophysical Journal International, 124: 228-240.

De Wall, H., Worm, H.U., (2000): A cautionary note on interpreting frequency-dependence of susceptibility solely in terms of superparamagnetism: University of Minnesota, Institute for Rock Magnetism Quarterly, 10(4), $1-6$

Doering, A. (1874): Molluscorum terrestrium et fluviatilium. Faunae Argentinae. EnumeratioSystematica, Period. Zool. Córdoba I: 121.

Doering, A. (1882): Geología. Informe oficial de la commission científica mixta agregada al estado mayor General de la expedición al Río Negro (Patagonia). Buenos Aires, 299-530.

Droxler, A.W, Alley, R. B., Howard, R.H., Poore, R.Z. y Burckle, L.H. (2003): Unique and exceptionally long interglacial marine isotope stage 11: window into earth warm future climate. En Droxler, A.W., Poore, R.Z. y Burckle, L.H. (eds.) Earth's climate and orbital eccentricity.The marine isotope stage 11 question.Americal Geophysical Union Geophysical Monograph 137, 240p. 
Dunlop, D. J.(2002): Theory and application of the Day plot (Mrs/Ms versus Hcr/Hc) Theoretical curves and tests using titanomagnetite data. Journal of Geophysical Research 107 (B3): 1029-2001.

Dunlop, D. J., and B. Carter-Stiglitz (2006): Day plots of mixtures of superparamagnetic, single-domain, pseudosingle-domain, and multidomain magnetites, J. Geophys.Res., 111, B12S09

Evans, M. E. y Heller, F. (1994): Magnetic enhancement and paleoclimate:study of a loess/paleosol couplet across the Loess Plateau of China. Geophys J Int 117:257-264

Evans, M.E. y F. Heller, F. (2003): Environmental Magnetism. Academic Press 2003, ISBN 0-12-243851-5, £45 hardback; $312 \mathrm{pp}$

Fasano, J. (1991): Geología y geomorfología, Región III, Faro Querandí - Mar de Cobo, provincia de Buenos Aires. Informe Final para la Evaluación del Recurso Hídrico Subterráneo de la Región Costanera Atlántica de la Provincia de Buenos Aires. Consejo Federal de Inversiones - Universidad Nacional de Mar del Plata, $118 \mathrm{p}$.

Fasano, J.L., Isla, F.I. y Schnack, E.J. (1984): Significado paleoambiental de los depósitos del Pleistoceno Tardío de Camet Norte (Partido de Mar Chiquita, Provincia de Buenos Aires. Revista de la Asociación Geológica Argentina 39: 244250

Fidalgo, F. (1990): La Formación La Postrera. Simposio Internacional sobre Loess. INQUA. Resúmenes Expandidos: 78-83. Mar del Plata

Fidalgo, F., De Francesco, F. y Colado, U. (1973): Geología superficial en las hojas Castelli, J. M. Cobo y Monasterio (Pcia. de Bs. As.). $5^{\circ}$ Congreso Geológico Argentino (Carlos Paz), Actas 4: 27-39

Fidalgo, F., De Francesco, F. y Pascual, R. (1975): Geolosgía superficial de la llanura bonaerense (Argentina). Geología de la Provincia de Buenos Aires. 6to Congreso Geológico Argentino, Relatorio: 103-138.

Fidalgo, F., R. O. Gentile y H. A. Correa (1986): Geología y Geomorfología en la cuenca del Arroyo Tapalqué. Comisión de Investigaciones Científicas de la Provincia de Buenos Aires. Informe 30:1-73

Fidalgo, F. y Gentile, R.O. (1995): La Formación Arroyo Seco en las barrancas ubicadas entre el arroyo Chapadamalal y Punta Hermengo (Prov.de Buenos Aires). $4^{\circ}$ Jornadas Geológicas y geofísicas Bonaerenses, 135-141, Junín

Fischer, W. R. (1988): Microbiological reactions of iron in soils. In: Stucki V et al. (ed) Iron in Soils and ClayMineals. Dorotrecht Reidel Publishing Company, 715-748 
Fisher, N. I., Lewis, T., y Embleton, B.J.J. (1987): Statistical Analysis of Spherical Data, Cambridge Univ. Press, Cambridge, 1-329, 1987.

Fidalgo, F. y Gentile, R.O. (1995): La Formación Arroyo Seco en las barrancas ubicadas entre el Arroyo Chapadmalal y Punta Hermengo (Prov. De Buenos Aires). 4tas. Jornadas Geológicas y Geofísicas Bonaerenses. 1: 135-141

Folguera, A. y Zárate, M. (2009): La sedimentación neógena continental en el sector extrandino de Argentina central. Revista de la Asociación Geológica Argentina 64 (4): 692-712.

Folguera Telichevsky, A. (2011): La reactivación neógena de la Pampa Central. Tesis Doctoral Universidad de Buenos Aires, Argentina, 192 pp.

Folguera, A. y Zárate, M.A. (2011): Neogene sedimentation in the Argentine foreland between $34^{\circ} 30$ 'S and $41^{\circ} \mathrm{S}$ and its relation to the Andes evolution. En J.A. Salfity y R. Marquillas (Eds.), Cenozoic Geology of the Central Andes of Argentina. SCS Publisher, Salta: 123-134.

Folguera, A., Zárate, M., Tedesco, A., Dávila, F. y Ramos, V.A. (2015): Evolution of the Neogene Andean foreland basins of the Southern Pampas and Northern Patagonia $\left(34^{\circ}-41^{\circ} \mathrm{S}\right)$, Argentina. Journal of South American Earth Sciences. 15p.

Folk RL, Ward WC. (1957): Brazos River bar: a study in the significance of grain size parameters. Journal of Sedimentary Petrology 27: 3-26

Frenguelli, J. (1921): Los terrenos de la costa atlántica en los alrededores de Miramar (Provincia de Buenos Aires). Boletín de la Academia Nacional de Ciencias de Córdoba, 24: 325-485.

Frenguelli, J. (1950): Rasgos generales de la morfología y la geología de la provincia de Buenos Aires. Laboratorio de Ensayo de Materiales e Investigaciones Tecnológicas, Serie 2, 33: 1-72.

Frenguelli, J. (1957): Neozoico en Geografía de la República Argentina, GAEA, Sociedad Argentina Estudios Gográficos 2(3): 1-218.

Frenguelli, J. y Outes, F.F. (1924): Posición estratigráfica y antigüedad relativa de los restos de industria humana hallados en Miramar. Physis 26: 277-304.

Galenhouse, J., (1971): Sedimentation analysis. In Carver, R. (Ed.), Procedures in sedimentary petrology: 65-94. Wiley- Interscience, New York. 
Gallet S., Jahn B.-m., Van Vliet Lanoe B., Dia A. and Rossello E. (1998): Loess geochemistry and its implications for particle origin and composition of the upper continental crust. Earth and Planetary Science Letters 156, 157- I77.

Gasparini, G., Rabassa, J., Soibelzon, E., Soibelzon, L., Tonni, E. (2012): Estratigrafía y paleontología del Cenozoico tardío de la región de Tandil, provincia de Buenos Aires. I Simposio del Mioceno-Pleistoceno del centro y norte de Argentina. Actas, 46-47.

Gentile, R.O. y Ribot, A.M. (2001): Niveles de tefras en sedimentos continentales del Pleistoceno TardíoHoloceno (provincia de Buenos Aires). Intersecciones en Antropología, 2: 47-59.

Glatzmaier, G y Roberts, P.H. (1995): A three-dimensional convective dynamo solution with rotating and finitely conducting inner core and mantle». Physics of the Earth and Planetary Interiors 91 (1-3): 63-75.

Godagnone, R.E., H. Bertola y M. Ancarola. (2002): Mapa de suelos de la Argentina. Instituto Geográfico Militar. Buenos Aires, Argentina.

Gómez Samus, M.L., Poiré, D.G., Bidegain J.C., Arrouy, J., De los Reyes, M., Canalicchio, J. M. (2014): Estudio paleomagnético preliminar en sedimentos de la Formación El Polvorín, Partido de Olavarria, Sistema de Tandilia. III Jornadas Paleontológicas del Centro. Actas, 15-16.

González Bonorino, F., (1965): Mineralogía de las fracciones arcilla y limo del Pampeano en el área de la ciudad de Buenos Aires y su significado estratigráfico y sedimentológico. Revista de la Asociación Geológica Argentina 20(1): 67-148

Gradstein, F.M, Ogg, J.G., Schmitz, M.D. (2012): The Geologic Time Scale 2012: Boston, USA, Elsevier.

Gubbins, D.y Herrero-Bervera, E. (2007): Encyclopedia of Geomagnetism and Paleomagnetism. Springer. pp. 159-161.

Heider, F., Zitelsberguer, A. y Fabian, K. (1996): Magnetic susceptibility and remanent voercive force in grown magnetite crista from o, $1 \mu \mathrm{m}$ to $6 \mathrm{~mm}$. Physiscs of the Earth and Planetary Interiors, 93, 239-256.

Heil, C., King, J., Zárate, M., Schultz, P.H., (2002): Paleomagnetic and environmental magnetic studies of Pampean loess deposits from Centinela del Mar, Argentina. EOS Transactions AGU (Fall Meet.Suppl.)83, 47.GP71A-0974.

Heller, F., Evans, M.E. (1995): Loess magnetism. Rev. Geophys. 33, 211-240.

Heller, F., Liu, T.S. (1984): Magnetism of Chinese loess deposits.Geophys. J. Roy. Astron. Soc. 77, 125-141. 
Heller F, Shen C.D y Beer J (1993): Quantitative estimates of pedogenic ferromagnetic mineral formation in Chinese loess and paleoclimatic implications. Earth Planetary Sci Lett 114: 385-390.

Hradil, D., Grygar, T., Hruskova, M., Pezdicka, P., Lang, K., Schneeweiss, O. y Chvatal, M. (2004): Green earth pigment from the Kadan region, Czech Republic: Use of rare fe-rich smectite. Clays and Clay Minerals, Vol. 52, No. 6, 767-778.

Hyodo, M., Biswas, D., Noda, T., Tomioka, N., Mishima, T., Itota, C. y Sato, H. (2006): Millennial- to submillennial-scale features of the MatuyamaBrunhes geomagnetic polarity transition from Osaka Bay, southwestern Japan, J. geophys. Res., 111.

Hurtado, M.A., Moscatelli, G.N. y Godgnone, R.E. (2005): Los suelos de la Provincia de Buenos Aires. En De Barrio, R. E., Etcheverry, R. O., Caballé, M. F. y Llambías, E. (eds.) Geología y recursos naturales de la Provincia de Buenos Aires. Relatorio del $16^{\circ}$ Congreso Geológico Argentino, 201-218, La Plata.

Jackson, M. J., Worm, H.-U. \& Banerjee, S. K. (1990): Fourier analysis of digital hysteresis data: rock magnetic applications. Physics of the Earth and Planetary Interiors, 65, 78-87

Instituto Nacional de Tecnología Agropecuaria (INTA). (1970): Carta de Suelos de la República Argentina, Hojas 3760-23, 3760-29 y 3760-30. Buenos Aires.

Instituto Nacional de Tecnología Agropecuaria (INTA). (1989): Mapa de suelos de la provincia de Buenos Aires. Instituto de Suelos. INTA. Buenos Aires. 525 pp.

Iñiguez Rodriguez, A. (1999): La Cobertura Sedimentaria de Tandilia. Cratón del Río de la Plata, SEGEMAR, Geología Argentina, Anales 29 (4):101-106, Buenos Aires, Argentina.

Iñiguez Rodriguez, A.M. y Scoppa, C.O. (1970): Los minerales de arcilla de los suelos «zonales» ubicados entre los ríos Paraná y Salado (provincia de Buenos Aires). Revista de Investigaciones Agropecuarias. INTA. VII: $1-41$.

Kageyama, A; Sato, T. (1995): Computer simulation of a magnetohydrodynamic dynamo. Physics of Plasmas 2 (5): 1421-1431.

King, J.W., Banerjee, S.K., Marvin, J., and Özdemir, Ö., (1982): A comparison of different magnetic methods for determining the relative grain size of magnetite in natural materials: some results from lake sediments. Earth Planet. Sci. Lett., 59:404-419. 
Kirschvink, J.L. (1980): The least-square line and plane and the analysis of paleomagnetic data, Geophys. J. R. Astron. Soc., 62, 699-718, 1980.

Komadel, P., Lear, RR., and Stucki, J.W. (1990): Reduction and reoxidation of nontronite: Extent of reduction and reaction rates. Clays and Clay Minerals, 38, 203-208.

Kostadinoff, J. (1985): Investigaciones sísmicas en la prolongación marina del Sistema deTandilia. Revista de la Asociación Geológica Argentina, 40 (3-4): 202 - 210.

Kraglievich, J.L. (1952): El perfil geológico de Chapadmalal y Miramar, Provincia de Buenos Aires. Revista Museo Municipal de Ciencias Naturales y Tradicional Mar del Plata 1: 8-37.

Kraglievich, J. L. (1953): La llanura bonaerense a través de un perfil geológico. Revista Mundo Atómico, 14: 8899.

Kraglievich, J.L. (1959): Contribuciones al conocimiento de la geología cuartaria en la Argentina. $4^{\circ}$ Nota acerca de la geología costera en la desembocadura del Arroyo Malacara (Provincia de Buenos Aires). Comunicaciones Museo Argentino de Ciencias Naturales Bernardino Rivadavia, Geología 1, 17: 3-9.

Kukla, G. J., F. Heller, X. M. Liu, T. C. Xu, T. S. Liu, y Z. S. An (1988): Pleistocene climates in China dated by magnetic susceptibility, Geology, 16, $811-814$

Kumari, M., Hirt, A.M.,Uebe, R., Schuler, D., Tompa, E., P osfai, M., Lorenz, W., Ahrentorp, F., Jonasson, C. y Johansson, C. (2015): Experimental mixtures of superparamagnetic and single-domain magnetite with respect to Day-Dunlop plots.Geochem.Geophys.Geosyst., 16, 1739-1752.

Laj, C., Guitton, S. y Kissel, C. (1987): Rapid changes and near-stationary of the geomagnetic field during a polarity reversal. Nature, 330: 145-148.

Lang, A. (1994): Infra-red stimulates luminescence dating of Holocene reworked silty sediments. Quaternary Geocrhonology Science Reviews, Vol 13: 525:528.

Liu Q, Banerjee, S.K; Jackson, M.J. (2004): Grain sizes of susceptibility and anhysteretic remanent magnetization carriers in Chinese loess/paleosol sequences.J Geophys Res 109.

Llambías, E. J. (1975): Geología de la provincia de La Pampa y su aspecto minero. Dirección de Minas de la provincia de La Pampa, Informe inédito, 38p. Santa Rosa.

Lovley, D.R., Stolz, J.F. y Nord, G.L. (1987): Anaerobic production of magnetite by a dissimilatory iron reducing microorganism. Nature 330:252-254 
Lowrie,W. y Kent, D.V. (2004): Geomagnetic polarity timescales and reversal frequency regimes, in Timescales of the Palaeomagnetic Field, pp. 117- 129, eds Channell, J.E.T., Kent, D.V., Lowrie, W. \& Meert, J., America Geophysical Union.

Lu, H., Liu, X, Zhang, F., An, Z., Dodson. J. (1999): Astronomical calibration of loess-paleosol deposits at Luochuan central Chinese loess plateau, Palaeogeogr. Palaeoclimatol.Palaeoecol.154 (1999) 237^246.

McElhinny, M. W. (1973): Palaeomagnetism and Plate Tectonics.(Cambridge Earth.Science Series).358 pp.

Maher, B.A. (1986): Characterization of soils by mineral magnetic measurements. Phys Earth Planetary Inter 42:76-92

Maher, B.A. (1988): Magnetic properties of some synthetic submicron magnetites. Geophysical Journal of the Royal Astronomical Society, 94: 83-96.

Maher, B.A. (1998): Magnetic properties of modern soils and Quaternary loessic paleosols: paleoclimatic implications. Palaeogeography, Palaeoclimatology, Paeleoecology 137: 25-54.

Maher, B. A. y Thompson, R. (1991): Mineral magnetic record of the Chinese loess and paleosols. Geology 19: 36.

Maher, B. A. y Thompson R. (1999): Palaeomonsoons I: the magnetic record of paleoclimate in the terrestrial loess and paleosol sequences. In: Maher BA, Thompson R (ed) Quaternary Climates, Environments and Magnetism. Cambridge University Press, Cambridge, 81-125

Maher BA, Alekseev A, Alekseeva T (2003): Magnetic mineralogy of soils across the Russian Steppe: climatic dependence of pedogenic magnetite formation. Palaeogeogr Palaeoclimatol Palaeocol 201:321-341

Marshall, L. (1985): Geochronology and Land-Mammal biochronology of the Transamerican Faunal Interchange. En: F.G. Stehli y S.D Webb (eds.), The Great American Biotic Interchange. Plenum Press, New York y London, pp. 49-85.

Marshall, L. G. y Pascual, R. (1978): Una escala temporal radiométrica preliminar de las edades -mamífero del Cenozoico medio y tardío sudamericano. Obra del cincuentenario de Museo de La Plata (5): 11-28.

Martínez Gasca, R., Cornejo, J. y de Arambarri, P. (1982): Estudio electroforético del punto isoelectrico de diversos oxidos de hierro. Anales de edafologia y agrobiologla, XLI(3-4) : 661-667p. 
Martínez G. A. (2001): Geomorfología y geología del Cenozoico superior de las cuencas de drenaje de los arroyos Los Cueros y Seco, vertiente nororiental de las Sierras Septentrionales, Provincia de Buenos Aires. Universidad Nacional del Sur. Tesis doctoral inédita.

Murad, E. y Wagner, U. (1994): The Mossbauer spectrum of illite Clay Minerals, v. 29, p. 1-10.

Nabel, P. (1993): The Brunhes-Matuyama Boundary in Pleistocene Sediments of Buenos Aires Province, Argentina.Quaternary International 17: 79-85.

Nabel, P. y Valencio, D. (1981): La magnetoestratigrafía del Ensenadense de la Ciudad de Buenos Aires: su significado geológico. Revista de la Asociación Geológica Argentina 36: 7-18.

Nabel P. y Morrás, H. (1996): Susceptibilidad magnética en suelos de la Pampa Ondulada, Prov. de Buenos Aires. $13^{\circ}$ Congreso Geológico Argentino, Actas 2: 541

Nabel, P., Camilion, C., Machado, G., Spiegelman, A. y Mormeneo, L., (1993): Magneto y litoestratigrafía de los sedimentos pampeanos en los alrededores de la Ciudad de Baradero, Provincia de Buenos Aires. Revista de la Asociación Geológica Argentina 48 (3-4): 193- 206

Nabel, P., Morrás, H., Petersen, N. y Zech, W. (1999): Correlation of magnetic and lithologic features from soils and Quaternary sediments from the undulating Pampa, Argentina. Journal of South American Earth Sciences 12 (3): 311-323

Nabel, P.E., Cione, A. y Tonni, E.P. (2000): Environmental changes in the Pampean area of Argentina at the Matuyama-Brunhes (C1r- C1n) Chrons boundary. Paleogeography, Paleoclimatology, Paleoecology 162: 403-412

Nágera, J. (1932): Primera carta geológica de Tandilia. Escala 1:500.000. Litografía Colombatti y Cía. Ltda., Buenos Aires.

Nágera, J. (1940): Historia física de la Provincia de Buenos Aires. 1-Tandilia. Universidad Nacional de La Plata, Facultad de Humanidades y Ciencias de la Educación, Biblioteca Humanidades (24). La Plata.

Oggs (2012): en Gradstein, F.M, Ogg, J.G., Schmitz, M.D. eds. The Geologic Time Scale 2012: Boston, USA, Elsevier.

Opdyke, N., and Channell, J.E.T. (1996): Magnetic Stratigraphy.International Geophysics Series 64.San Deigo, CA: Academic Press, 346 pp. 
Orgeira, M.J. (1987): Estudio paleomagnético de sedimentos del cenozoico tardío en la costa atlántica bonaerense. Revista de la Asociación Geológica Argentina 42: 362-376

Orgeira, M.J (1988): Estudio paleomagnético de sedimentos asignados al Cenozoico tardío aflorantes en la costa atlántica bonaerense. Rev. de la Asoc. Geol. Arg.; XLII, 3 y 4; 362-376

Orgeira, M.J. (1990): Paleomagnetism of late Cenozoic fossiliferous sediments from Barranca de Los Lobos (Buenos Aires Province, Argentina). The magnetic age of South American land mammal ages. Physics Earth Plan. Interiors; Vol 64 No 2-4 , pag:121-132.

Orgeira M.J. y D.A. Valencio (1984): Estudio paleomagnético de los sedimentos asignados al Cenozoico tardío aflorantes en la Barranca de los Lobos, Pcia. de Buenos Aires. IX Cong. Geol. Arg. Actas IV: 162-173.

Orgeira, M.J. y Compagnucci, R.. (2006): Correlation between paleosol-soil magnetic signal and climate. Earth, Planets and Space (EPS), Special Issue " Paleomagnetism and Tectonics in Latinamerica" 58 (10): 13731380 .

Orgeira, M.J. y R.H. Compagnucci (2010): Uso de la señal magnética de suelos y paleosuelos como función climática. RAGA 65 (4): 612-623.

Orgeira, M.J., Beraza, L.A., Vizán, H. y Bobbio, M.L. (1988): Evidencias de una excursión del campo magnético terrestre durante el Pleistoceno tardío. Revista de la Asociación Geológica Argentina, XLII: 265-268.

Orgeira, M.J., Walther, A.M., Vázquez, C.A., di Tommaso, I., Alonso, S., Sherwood, G., Hu Y. y Vilas, J.F.A. (1998): Mineral magnetic record of paleoclimate variation in loess and paleosol from the Buenos Aires Formation (Buenos Aires, Argentina). Journal of South American Earth Sciences 11: 561-570.

Orgeira, M. J., Walther, A.M, Tófalo, R.O., Vásquez, C.A., Lippai, H., y R. Compagnucci.(2001): Estratigrafía y magnetismo de rocas en un perfil cuaternario. Implicancias paleoambientales y paleoclimáticas. Ao. Tapalqué, Provincia de Buenos Aires. Revista de la Asociación Geológica Argentina 56 (3): 353-366.

Orgeira, M. J., Walther, A.M, Tófalo, R.O., Vásquez, C.A., Berquo, C., Dobois, F. y Böhnel. (2002): Magnetismo ambiental en un paleosuelo desarrollado en la Formación Luján (Luján, provincia de Buenos Aires). Comparación con otras áreas de la provincia; consideraciones paleoclimáticas. Rev. Asoc. Geol. Argent. v.57 n.4 Buenos Aires oct./dic. 2002

Orgeira , M.J.; C., Vásquez, R., Compagnucci, I., Raposo y F. Pereyra.(2009): Magnetismo de rocas en suelos actuales de la Pampa Ondulada provincia de Buenos Aires, Argentina. Vinculación del clima en el comportamiento magnético. Revista Mexicana de Cs. GeológicasV.26, núm,I pp. 65-78. 
Orgeira, M.J., Egli, R. and Compagnucci, R., (2011): A quantitative model of magnetic enhancement in loessic soils. 139 Chapter in Earth Magnetic Interior (IAGA special Sopron book series) Springer 25: 361-368

Pardiñas, U.F.J., E.P. Tonni \& A.J. Figini.(1998): Camet Norte: Diversidad Faunística Próxima al Último Máximo Glacial en el Sudeste de la Provincia de Buenos Aires, Argentina. X Congreso Latinoamericano de Geología y VI Congreso Nacional de Geología Económica, Actas 1: 257-262

Pascual, R. (1961): Un nuevo Cardiomynae (Rodentia, Caviidae) de la Formación Arroyo Chasicó (Plioceno inferior) de la Provincia de Buenos Aires. Ameghiniana 2: 61-71.

Pascual, R. (1966): Paleontografía Bonaerense. Comisión de Investigaciones Científicas de la Provincia de Buenos Aires, pp. 203.

Pascual, R., Ortega Hinojosa, E.J., Gondar, D. y Tonni, E.P.. (1966): Las edades del Cenozoico mamalífero de la Argentina, con especial atención a aquellas del territorio bonaerense. Anales de la Comisión de Investigaciones Científicas de la Provincia de Buenos Aires 6:165-193.

Peters, C. y Dekkers, M.J. (2003): Selected room temperature magnetic parameters as a function of mineralogy, concentration and grain size. Physics and Chemistry of the Earth 28 (2003) 659-667

Poiré, D.G.; Canessa, N.D.; Scillato-Yané, G.J.; Carlini, A.A.; Canalicchio, J.M. \& Tonni, E.P. (2005): La Formación El Polvorín: una nueva unidad del Neógeno de Sierras Bayas, Sistema de Tandilia, Argentina. XVI Congreso Geológico E.P. Argentino, Actas 1: 315-322.

Poiré D.G., de los Reyes, M., Arrouy, M.J. y Canalicchio, J.M. (2013): Estratigrafía del Neógeno intraserrano del Núcleo Central de las Sierras Bayas, extremo noroccidental del Sistema de Tandilia, Región Pampeana, Argentina. II Simposio del Mioceno-Pleistoceno del Centro y Norte de Argentina, Actas, 21-22.

Prevosti, F.J., E.P. Tonni \& J.C. Bidegain. (2009): Stratigraphic range of the large canids (Carnivora, Canidae) in South America, and its relevance to quaternary biostratigraphy. Quaternary International 210: 76-81.

Pye, K. (1987): Aerolian dust and dust deposits. Academic Press, 334 pp.

Rabassa, J. (1971): Geología Superficial en la hoja Sierras de Tandil (escala: 1:100.000), prov. de Buenos Aires. Trabajo de Licenciatura, Facultad de Ciencias Naturales y Museo (inédito)

Rabassa, J. (1973): Geología Superficial en la hoja "Sierras de Tandil", provincia de Buenos Aires. LEMIT, La Plata. Anales, Serie II, n. 240, p. 115-160, 1973 
Rabassa, J.; Zárate, M.A.; Camilión, M.C.; Patrigde, T.; Maud, R. (1995): Relieves relictuales de Tandilia y Ventania. IV Jornadas Geológicas Bonaerenses. Actas. p. 249-256

Rabassa, J., Zárate, M.A., Demoulin, A., Camilión, M.C., Patrigge, T., Maud, R. (1998): Superficies de erosion y morfogénesis de Tandilia y Ventania. V Jornadas Geológicas y Geofísicas Bonaerenses. Actas. Vol 1. p111-118

Rabassa, J., Coronato, A. y Salemme, M. (2005): Chronology of the Late Cenozoic Patagonian glaciations and their correlation with biostratigraphic units of the Pampeanregion (Argentina). Journal of South American Earth Sciences 20:81-104.

Ramos, V.A. (1999): Rasgos estructurales del territorio argentino. 1. Evolución Tectónica de la Argentina. En Caminos, R. (ed.), Geología Argentina, Anales 29, 24: 715-784. Instituto de Geología y Recursos Minerales, Subsecretaría de Minería. Buenos Aires.

Reig, O. (1957): Diagnosis previas sobre los marsupiales de la Formación Arroyo Chasicó, Ameghiniana 1(3): 27 31.

Rico, Y. y Bidegain, J.C. (2011): Parámetros magnéticos en la reconstrucción paleoclimática y paleoambiental de una secuencia del Cenozoico tardío, Punta San Andrés, acantilados de Chapadmalal, provincia de Buenos Aires. Latinmag Letters, Volume 1, Special Issue, D23, 1-6. Proceedings Tandil, Argentina

Rico, Y. y Bidegain, J.C. (2013a): Magnetostratigraohy and environmental magnetism in a sedimentary sequence of Miramar, Buenos Aires, Argentina. Quaternary International 317 53-63.

Rico, Y. y Bidegain, J.C. (2013b): Magnetoestratigrafía de los acantilados costeros ubicados al suroeste del río Quequén Grande, Necochea, provincia de Buenos Aires, Argentina. Resultados preliminares. Latinmag Letters, Volume 3, Special Issue. 1-9. Proceedings Montevideo, Uruguay.

Rico, Y., Gómez Samus, M.L., Bidegain, J.C. (2014a): Nuevos registros de polaridad magnética en el sector comprendido entre Chapalmalal y Necochea. III Jornadas Paleontológicas del Centro.

Rico, Y., Gómez Samus, M.L., Bidegain, J.C. (2014b): Magnetoestratigrafía y parámetros magnéticos en los acantilados de la costa bonaerense. Ciencia y Tecnología de los Materiales Revista del Laboratorio de Entrenamiento Multidisciplinario para la Investigación Tecnológica 4: 23-37

Riggi, J. C., Fidalgo, F., Martínez, O. y Porro, N., (1986): Geología de los "sedimentos pampeanos" en el partido de La Plata. Revista de la Asociación Geológica Argentina 41(3-4): 316-333. 
Roberts, A. P., Yulong Cui Y. y Verosub, K.L., (1995): Wasp-waisted histeresis loops: Mineral magnetic characteristics and discrimination of components in mixed magnetic systems. Journal of Geophysical Research 1000 (B9): 17909-17924. Washington

Ruiz de Galarreta, A. (2006): Geohidrología y balance hidrológico de la zona no saturada en la cuenca superior del arroyo Tandileofú, Provincia de Buenos Aires. Tesis doctoral. Facultad de Ciencias Naturales y Museo. Universidad Nacional de La Plata. 181 p. La Plata

Ruiz de Galarreta, A., Varni, M., Banda Noriega, R., Barranquero, R. (2007): Caracterización geohidrológica preliminar en la cuenca del Arroyo Langueyú, Partido de Tandil, Buenos Aires. Actas del V Congreso Argentino de Hidrogeología. p. 119-128. Paraná, Entre Ríos.

Rolleri, E.O., (1975): Provincias geológicas bonaerenses.En: Geología de la Provincia de Buenos Aires. $6^{\circ}$ Congreso Geológico Argentino, Relatorio: 29-54

Ruocco, M. (1989): A 3 Ma paleomagnetic record of coastal continental deposit in Argentina. Palaeogeography, Palaeoclimatology, Palaeoecology, 72, 105- 113.

Ruocco, M.I. (1990): Paleomagnetic analyses of continental deposits of the last 3 Ma from Argentina: Magnetostratigraphy and fine structures of reversals. Tesis doctoral, Department of Geology and Geochemistry, University of Stockholm, 100 p.

Sagnotti, L., Scardia, G., Giaccio, B., Liddicoat, J., Nomade, S., Renne, P.R., Sprain, C. (2014): Extremely rapid directional change during Matuyama-Brunhes geomagnetic polarity reversal. Geophys. J. Int. 199 (2): $1110-1124$.

Sagnotti, L, Giaccio, B, Liddicoat, J., Nomade, S., Renne, P.R., Scardia, G., Sprain, C. (2016): How fast was the Matuyama-Brunhes geomagnetic reversal? A new subcentennial record from the Sulmona Basin, central Italy. Geophys. J. Int. 204 (2): 798-812.

Sala, J. M. (1975): Recursos Hídricos. Relatorio Geología Provincia de Buenos Aires. VI Congreso Geológico Argentino. Pcia. de Bs. As. 178-193.

Sandgren, P. \& Snowball, I.F. (2001): Application of mineral magnetic techniques to paleolimnology. In: W.M. Last \& J.P. Smol (eds.) Tracking Environmental Changes in Lake Sediments: Physical and Chemical Techniques. Developments in Paleoenvironmental Research Book Series, Kluwer Academic Publishers, pp. 217-23 
Schnack, E.J., Fasano, J.L. e Isla, F.I. (1982): The evolution of Mar Chiquita lagoon, Province of Buenos Aires, Argentina. En: Colquehoun, D. J. (Ed.) Holocene Sea Level Fluctuations: Magnitudes and Causes. IGCP 61, 143 155, Columbia.

Schnack E.J., Isla F.I., De Francesco F.O., y Fucks E.E.(2005): Estratigrafía del Cuaternario marino tardío en la Provincia de Buenos Aires. En: De Barrio R.E., Etcheverry R.O., Caballé M.F., Llambías E. (editores) Geología y Recursos Minerales de la Provincia de Buenos Aires. Relatorio, XVI Congreso Geológico Argentino, La Plata, Argentina. Capítulo X: 159-182.

Schoeneberger, PJ; DA Wysocky; EC Benham y WD Broderson.(2000):. Libro de campaña para descripción y muestreo de suelos. Versión 1.1. Instituto de Suelos, Centro de Recursos Naturales, Instituto Nacional de Tecnología Agropecuaria, Argentina. Traducción en español del «Field Book for Describing and Sampling Soils», 1998. Centro Nacional de Relevamiento de Suelos, Servicio de Conservación de Recursos Naturales, Dto. de Agricultura EE.UU., Linconl, Nebraska 9 (10)p.

Schultz, P., Zárate, M., Hames, W., Camilion, C. y King, J. (1998): A 3.3 Ma impact in Argentina and possible consequences. Science 282: 2061-2063.

Schultz, P., Zárate, M., Hames, B., Koeberl, C., Bunch, T., Storzer, D., Renne, P.y Wittke, J. (2004): The Quaternary impact record from the Pampas, Argentina. Earth and Planetary Science Letters 219: 221-238.

Schultz, P.H., Zárate, M., Hames, W., Harris, S., Bunch, T., Koeberl, C., Renne, P. y Wittke, J. (2006): The record of Miocene impacts in the Argentine Pampas. Meteoritics \& Planetary Science 41 5: 749-771.

Schultz P.H. Harris, R. S. y Zárate. M.A. (2008): The Late Cenozoic Impact Glasses in the Argentine Pampean Sediments. 17 Congreso Geológico Argentino, Actas: 686.

Smith, J.P. (1985): Mineral magnetic studies on two Shropshire-Cheshire meres.Tesis Doctoral inédita.University of Liverpool.

Soibelzon, L. H., Isla, F. I. y Dondas, A. (2001): Primer registro de tres individuos asociados de Arctotherium latidens (Ursidae: Tremarctinae). Ameghiniana 38 (4)- Suplemento.

Soibelzon, E., Prevosti, F.J., Bidegain, J.C., Rico, Y., Verzi, D.H., Tonni, E.P., (2009): Correlation of late Cenozoic sequences of southeastern Buenos Aires province: biostratigraphy and magnetostratigraphy. Quat.Int. 210 (1e2), 51e56. 
Soibelzon, E., Tonni, E.P. y Bidegain, J.C. (2010): The Quaternary Outcrops of Punta Hermengo (Buenos Aires province, Argentina): magnetostratigraphi, biostratigraphi and the Loss of Paleontological Heritage. Geociences 27, 151-154.

Soil Survey Staff (2010): Keys to Soil Taxonomy. 11th Edition. USDA.Washington DC. 338 pp.

Spassov, S., Heller, F., Evans, M.E., Yue, L.P., Ding, Z.L. (2001): The Matuyama/Brunhes geomagnetic polarity transition at Lingtai and Baoji, Chinese Loess Plateau. Phys. Chem. Earth 26 (11-12), 899-904

Stratton Noller, J., Sowers, J.M., Lettis, W.R. (2000): Quaternary Geochronology.Methods and Applications.American Geophysical Union, Washington, DC.582 pp.

Sugiura, N. (1979): ARM, TRM and magnetic interactions: Concentration dependence. Earth and Planetary Science Letters 42, 451-455.

Tamaura, Y., Ito, K. y Katsura, T. (1983): Transformation of $\gamma$-FeO(OH) to Fe3O4 by adsorption of iron(II) ion on $\gamma-\mathrm{FeO}(\mathrm{OH})$. J Chem Soc Dalton Trans 2:189-194

Tapia, A. (1937): Datos geológicos de la provincia de Buenos Aires. Aguas minerales dela República Argentina, Comisión Climática y Aguas Subterráneas 2: 23-90.

Tarling, D.H., (1983): Palaeomagnetism.Principles and Applications in Geology, Geophysics and Archaeology. London: Chapman and Hall, 379 pp.

Tauxe, L. (2002): Paleomagnetic Principles and Practice. Dordrecht: Kluwer Academic Press.

Tauxe, L. (2010): Essentials of Paleomagnetism. University of California Press.ISBN 0-520-26031-7.

Teruggi, M.E. (1957): The nature and origin of Argentine loess. Journal of Sedimentary Petrology, 27: 322-332.

Teruggi, M.E. y Andreis, R.R. (1971): Composición, estabilidad mineral y acción climática en sedimentos argentinos. Revista Museo de La Plata, Geología 7(58): 175-206, La Plata.

Teruggi, M.E., Spalletti, L.A. y Dalla Salda, L.H. (1973): Paleosuelos en la Sierra Bachicha, Partido de Balcarce. Revista del Museo de La Plata, Sección Geología, VIII: 227-256.

Teruggi, M.E. y Kilmurray, J.O. (1975): Tandilia. En Relatorio Geología de la provincia de Buenos Aires, 6 Congreso Geológico Argentino, 55-77.

Teruggi, M.E., Andreis, R. H., Mazzoni, M. M., Dalla Salda, L. H. y Spalletti, L. A. (1974): Nuevos criterios para la estratigrafía del Cuaternario de las barrancas de Mar del Plata - Miramar. LEMIT, Serie 2, № 268., 
Thompson, R. y Oldfield, F. (1986): Environmental Magnetism. London: Allen and Unwin.

Tomassini, R.L., Montalvo, C.I., Deschamps, C.M., Manera, T. (2013): Biostratigraphy and biochronology of the Monte Hermoso Formation (early Pliocene) at its type locality, Buenos Aires Province, Argentina.Journal of South American Earth Sciences 48 31-42

Tonni, E. y Fidalgo, F. (1978): Consideraciones sobre cambios climáticos durante el Pleistoceno tardío-reciente en la provincia de Buenos Aires. Aspectos ecológicos y zoogeográficos relacionados. Ameghiniana 15: 235 253. Buenos Aires.

Tonni, E., Alberdi, M., Prado, J., Bargo, M. y Cione, A. (1992): Changes of mammal assemblenges in the pampean región (Argentina) and their relation with the Plio-Pleistocene boundary. Paleogeography, paleoclimatology, Paleoecology. 95:189-194.

Tonni, E. p., Cione, A. L. y Figini, A. J. (1999): Predominance of arid climates indicated by mammals in the pampas of Argentina during the Late Pleistocene and Holocene.Paleogeography, paleoclimatology, Paleoecology 147:257-281.

Tonni, E.P., Carbonari, J.E. y Huarte, R. (2010): Marine Sediments Attributed to Marine Isotope Stage 3 in the Southeastern Buenos Aires Province, Argentina. Geosciences. CRP 27.

Torrent. J., Barrón, V., Liu, Q. (2006): Magnetic enhancement is linked and precedes hematite formation in aerobic soil. Geophys Res Lett 33.

Torsvik, T.H., Briden, J.C., ySmethurst, M. A. (2000): Super-IAPD Interactive analysis of palaeomagnetic data. http://www.geodynamics.no/software.htm.

Tricart, J. L. F., (1973): Geomorfología de la Pampa Deprimida. Instituto Nacional de Tecnología Agropecuaria. Colección Científica 12: 1- 202, Buenos Aires.

van Schuylenborgh, J. y Arens, P.L. (1950): The electrokinetic behaviour of freshly prepared $\gamma$ - and $\alpha$-FeOOH. Recueil des Travaux Chimiques des Pays-Bas.Volume 69, Issue 12, pages 1557-1565.

Valencio, D. (1980): El magnetismo de las rocas. Editorial Eudeba, 351 p., Buenos Aires.

Valencio D.A. y M.J. Orgeira; (1983): La magnetoestratigrafía del Ensenadense y Bonaerense de la Ciudad de Buenos Aires: Parte II.Rev. Asoc. Geol. Arg. XXXVIII (1): 24-333

Valet, J.P., Fournier, A., Courtillot, V. y Herrero-Bervera, E. (2012): Dynamical similarity of geomagnetic field reversals, Nature, 490, 89-94. 
Vásquez, C.A.; A.M. Walther; M.J. Orgeira; I.M. Di Tommaso; H. Lippai; S. Alonso y J.F. Vilas.(1998): Magnetismo de rocas y su aplicación a paleosuelos: estudio piloto en una secuencia loess-paleosuelos de la región pampeana. Revista de la Asoc. Geol. Arg., 53 (1): 83-90.

Verzi, D., Deschamps, C.M. y Tonni, E.P.(2004): Biostratigraphic and Palaeoclimatic Meaning of the Middle Pleistocene South American Rodent Ctenomys kraglievichi (Caviomorpha, Octodontidae). Palaeogeography, Palaeoclimatology, Palaeoecology 212:315-29.

Verzi, D.H., Montalvo, C.I., (2008): The oldest South American Cricetidae (Rodentia) and Mustelidae (Carnivora): late Miocene faunal turnover in central Argentina and the Great American biotic interchange. Paleogeography, Paleoclimatology, Paleoecology 267, 284e291.

Vizán, H., Tófalo, R., Orgeira, M.J. y Panarello, H. (2015): El perfil Faro Claromecó: Dataciones y estudio paleomagnético en una sucesión pleistocena. VI Congreso Argentino de Cuaternario y Geomorfología, Ushuaia. Libro de resúmenes, 127-128.

Walden J., Oldfield F., Smith J.P. (1999): Environmental magnetism: a practical guide. Technical Guide, No 6. Quaternary Research Association, London.

Weldon, R.J., Thomas, W. M. y Boslough, M. B. y Ahrens, T. J. (1982): Shock-induced color changes in nontronite: Implications for the Martian fines. Journal of Geophysical Research B, 87 (B12).pp.

Yang, T., Hyodo, M., Yang, Z., Li, H. \& Maeda, M., (2010): Multiple rapid polarity swings during the MatuyamaBrunhes transition from two high-resolution loess-paleosol records, J. geophys. Res., 115.

Yrigoyen, M.R. (1975): Geología del subsuelo y plataforma continental. Geología de la provincia de Buenos Aires. $6^{\circ}$ Congreso Geológico Argentino, Relatorio: 139-168, Bahía Blanca.

Zamorano, M., De los Reyes, M., Poiré, D.G., Scillato-Yané, G.J. (2015): Primer registro fehaciente de Nopachtus coagmentatus (Xenarthra, Cingulata, Glyptodontidae) en la región Pampeana, Argentina. Contexto estratigráfico. Estudios Geológicos enero-junio 2015, 71(1), e027

Zárate, M.A. (1989): Estratigrafía y geología de los acantilados marinos comprendidos entre Playa San Carlos y Arroyo Chapadmalal. Universidad Nacional de lla Plta. Tesis Doctoral 220pp (Inédita).

Zárate, M.A. (2003): Loess of sourthern South America.Quaternary Science Reviews 22.1987-2006.

Zárate, M.A. (2005): El Cenozoico tardío continental de la provincia de Buenos Aires. Relatorio XVI Congreso Geológico Argentino, 139-149. 
Zárate, M.A. y Blasi, A. (1990): Consideraciones sobre el origen, procedencia y transporte del loess del sudoeste de la provincia de Buenos Aires. Simposio Internacional sobre el loess. 15-20p.

Zárate, M.A. y Blasi, A. (1991): Late Pleistocene and Holocene loess deposits of southeastern Buenos Aires province. Argentina. Geojournal 24.

Zárate, M.A. y Blasi, A. (1993): Late Pleistocene-Holocene eolian deposits of southern Buenos Aires Province. Argentina: a preliminary model. Quaternary International 17:15-30.

Zárate, M. A. and Flegenheimer, N. (1991): Geoarchaeology of Cerro La China locality (Buenos Aires, Argentina): Site 2 and Site 3. Geoarchaeology, 6 (3):273-294.

Zárate, M.A. y Mehl, A. (2010): Geología y geomorfología de la cuenca del arroyo del Azul, provincia de Buenos Aires, Argentina. Hacia la gestión integral de los recursos hídricos en zonas de llanura. I: 65-78.

Zárate, M.A. y Rabassa, J. (2005): Geomorfología de la provincia de Buenos Aires. Relatorio XVI Congreso Geológico Argentino, 139-149.

Zárate, M.A., Schultz, P.H., Blasi,A., Heil, C., King,J., Hames, W.. (2007): Geology and geochronology of type Chasicoan (late Miocene) mammal-bearing deposits of Buenos Aires (Argentina): Journal of South American Earth Sciences, 23, 81-90.

Zavala, C. (1993): Estratigrafía de la localidad de Farola Monte Hermoso (Plioceno inferior-medio), provincia de Buenos Aires. $12^{\circ}$ Congreso Geológico Argentino y $2^{\circ}$ Congreso de Exploración de Hidrocarburos 2:228235

Zhang, W., Yu, L, Lu, M., Zheng, M., Shi, Y. (2007): Magnetic properties and geochemistry of the Xiashu Loess in the present subtropical area of China, and their implications for pedogenic intensity. Earth and Planetary Science Letters 260 86-97

Zhou, L. P., Oldfield, F., Wintle, A. G., Robinson, S. G. y Wang, J. T. (1990): Partly pedogenic origin of magnetic variations in Chinese loess. Nature 346, 737-739.

Zinck, J.A. (2012): Geopedología. Elementos de geomorfología para estudios de suelos y riesgos naturales. Faculty of Geo-Information Science and Earth Ovservation, Netherlands, 123p.

Zurita, A.E.; Taglioretti, M.; De los Reyes, M.; Oliva, C. \& Scaglia, F. (2014): First Neogene skulls of Doedicurinae (Xenarthra, Glyptodontidae): morphology and phylogenetic implications. Historical Biology. 


\subsection{Difusión de los resultados}

Gómez Samus, M. (2012): Paleomagnetismo y registros de susceptibilidad magnética en una sucesión cuaternaria de María Ignacia, Partido de Tandil. Primera reunión de estudiantes de Paleontología (RADEP). Actas electrónicas. $1 \mathrm{p}$.

Gómez Samus, M. y Bidegain, J.C. (2012): Magnetoestratigrafía en sedimentos del Cenozoico tardío de la localidad de María Ignacia (Vela), Partido de Tandil, Provincia de Buenos Aires. V Congreso Argentino de Cuaternario y Geomorfología, Actas Trabajos Completos, 41- 50.

Gómez Samus, M.L. y Bidegain, J.C. (2013): Magnetoestratigrafía en sedimentos del Cenozoico tardío de Villa Cacique, partido de Benito Juarez. Provincia de Buenos Aires. LATINMAG LETTERS. 4p.

Gómez Samus, M. y Bidegain, J.C. (2014): Zonaciones de magnetopolaridad en sedimentos Cenozoicos de la Formación Barker, Sistema de Tandilia. XIX Congreso Geológico Argentino. Córdoba. 2p.

Gómez Samus, M.L. Straccia, P.C., Bidegain, J.C. Tassara, D.A. Sosa, N., Rico, Y., Scian, R.D. (2014): Paleomagnetismo, parámetros magnéticos y geoquímica en sedimentos del Pleistoceno del partido de Mar Chiquita y sector norte del partido de General Pueyrredón, provincia de Buenos Aires. III Jornadas Paleontológicas del Centro. Olavarría.Actas: 16-17.

Gómez Samus, M.L. y Bidegain, J.C. (2014): Magnetoestratigrafía de las Formaciones Vela y Barker, Tandil, Provincia de Buenos Aires. Revista de la Sociedad Geológica de España, 27: 29-38.

Gómez Samus, M.L., Rico, Y., Bidegain, J.C. (2014). Estratigrafía y magnetoestratigrafía de la cobertura neógeno-cuaternaria del sector central de Tandilia: Ciencia y Tecnología de los Materiales. Revista del Laboratorio de Entrenamiento Multidisciplinario para la Investigación Tecnológica. 4: 7-22.

Gómez Samus, M.L., Rico, Y., Bidegain, J.C. (2015): Estudio magnetoestratigráfico en sedimentos del Cenozoico tardío del partido de Balcarce, provincia de Buenos Aires. VI Congreso de Cuaternario y Geomorfología. Ushuaia, 8 al 12 de abril de 2015. Actas: 122-123.

Gómez Samus, M.L., Rico, Y., Bidegain, JC. (2015): Estratigrafía y edades de las unidades neógeno-cuaternarias del sector serrano de la provincia geológica de Tandilia. VI Jornadas Paleontológicas Regionales. Santa Clara del Mar, 26-27 de Junio 2015. 1p. 
Gómez Samus, M.L., Rico, Y., Bidegain, JC. (2015): Unidades de sedimentación neógeno-cuaternarias del sector serrano de la provincia geológica de Tandilia. III Simposio del Mioceno-Pleistoceno del centro y norte de Argentina. Actas: 21-22 .

Gómez Samus, M.L., Rico, Y., Bidegain, JC. (2015): Magnetoestratigrafía en sucesiones del Cenozoico tardío del area de Sierras de Balcarce, Tandilia. RAGA. Enviado.

Gómez Samus M., Rico, Y., Ziccarelli, S., Parodi, A.V. y Bidegain, J.C. (2015): Mineralogía magnética en sedimentos loessoides calcinados. Resultados preliminares. Geoacta. Enviado. 